

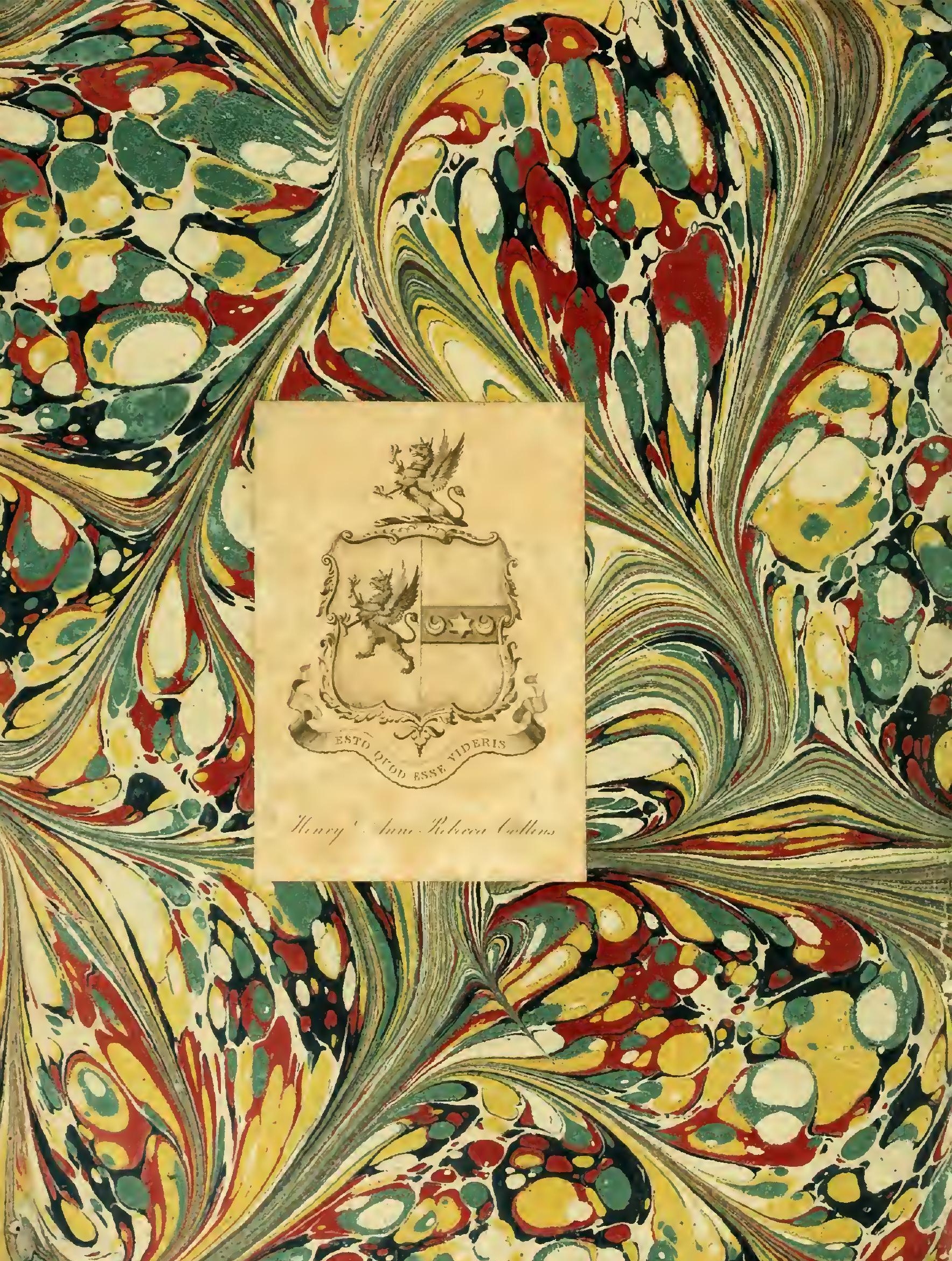


<smiles>C1C[Te]1</smiles>
$i z y-$ 


In Libraria GYLDENDALIA prodiit:

Zoologia danica s. animalium Daniac $\$$ Norvegiac rariorum ac minus notorum descriptiones $\$$ Historia. Auctt. O. F. Miuller, P. C. Abildgaard, M. Vahl, J. S. Holten, J. Rathke. IV volumina, cum CLX tabb. Hafniae 1 j88-1806. Fol. mai. charta belgica.

Venit 32 Rthl. arg. Sax. c. tab. nigris.

- 64 - - - color. 


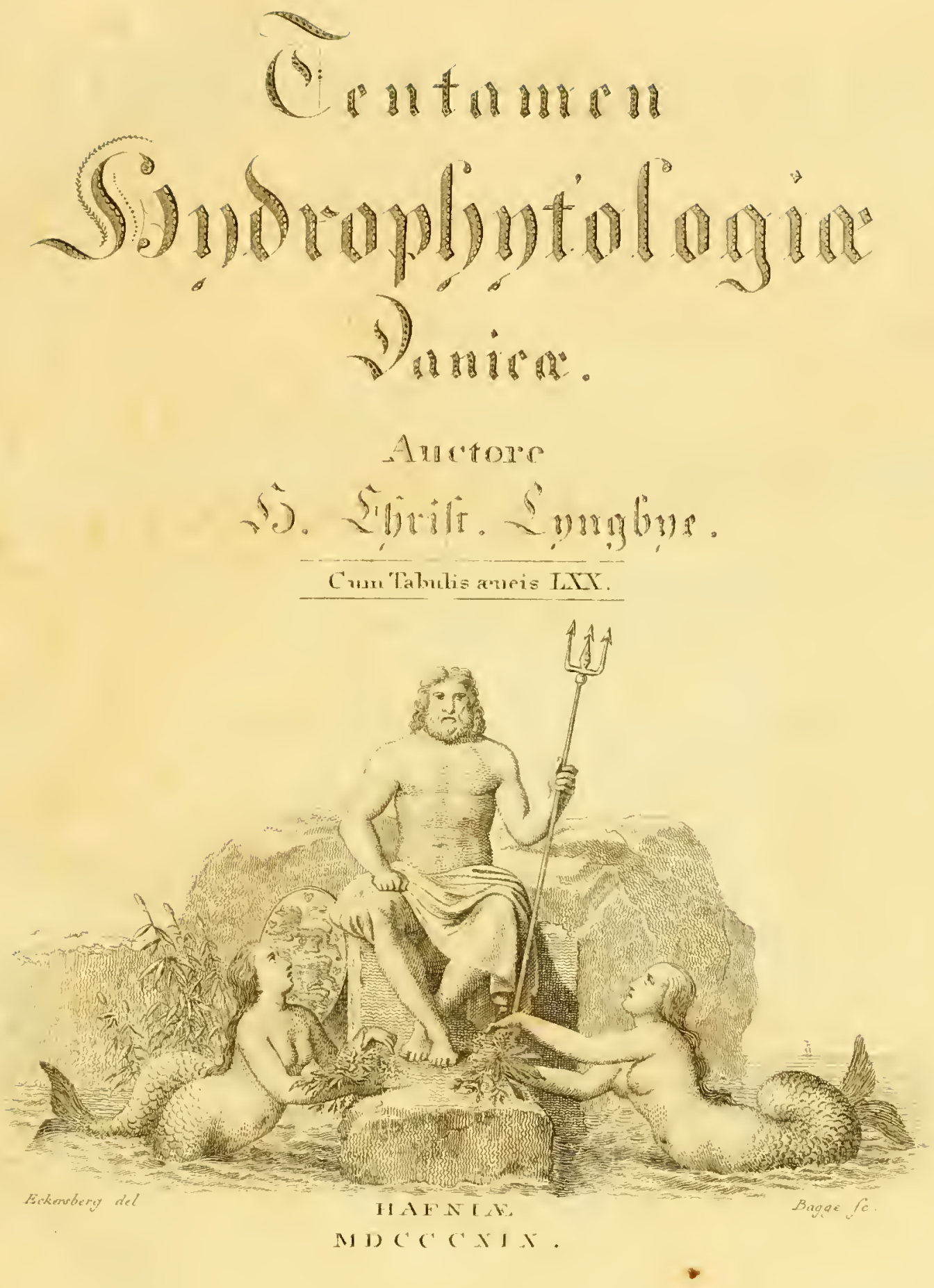





\section{T E N T A M E N}

\section{HYDROPHYTOLOGIAE}

\section{DANICAE}

CONTINENS

OMNIA HYDROPHYTA CRIPTOGAMA

DANIAE, HOLSATIAE, FAEROAE, ISLANDIAE, GROENLANDIAE

$$
\text { HUCUSQVE COGNITA, }
$$

SYSTEMATICE DISPOSITA, DESCRIPTA ET ICONIBUS ILLUSTRATA, ADJECTIS SLMUL SPECIEBUS NORVEGICIS.

OPUS, PRAEMIO AB INTERSITATE REgL haFNIENSI ORNATUM, ET SUMTU REgIO EDITUM.

A U C T O R E

HANS CHRISTIANO LYNGBYE,

CAND, S. S. MINIST. ET SOC. LITT. FIONENS. SOD.

CUM TABULIS AENEIS LXX.

H A F N I AE MDCCCXIX.

TIFIS SCHULTZIANIS.

IN COJLIIISSIS LLRRARLAE GYLDENDALIAE. 



\section{T E N T A M E N}

\section{HYDROPHYTOLOGIAE}

\section{DANICAE}

CONTINENS

OMNIA HYDROPHYTA CRYPTOGAMA

DANIAE, HOLSATIAE, FAEROAE, ISLANDIAE, GROENLANDIAE HUCUSQVE COGNITA,

SYSTEMATICE DISPOSITA, DESCRIPTA ET ICONIBUS ILLUSTRATA, ADJECTIS SIMUL SPECIEBUS NORVEGICIS.

OPUS, PRAEMIO AB UNIVERITATE REAL HAFNIENSI ORNATUM, ET SUMTU REgIO EDITUM.

A U C T O R E

HANS CHRISTIANO LYNGBYE, CAND, S, S. MINIST, ET GOC. HITT. FIONENS, SOD.

CUM" TABULIS AENEIS LXX.

H A F I AE MDCCCXIX.

TYYIS SCIIULTZIANIS.

IN COJLIISSIS LIBRARIAE GYLDENDALIAE. 



\title{
AUGUSTISSIMO GENEROSISSIMO
}

\section{PRINCIPI}

F R E D E R I C O SEX T O

\author{
REGI DANIAE \\ VANDALORUM GOTHORUM
}

D U C I SLESVICI

HOLSATIAE STORMARIAE DITHMARSIAE

LAUENBURGI OLDENBURGI.

DONINO CLFMENTISSIMO. 



\section{ReX AUGUSTISSIME!}

\section{DOMINE CLEMENTISSIME!}

Qvæ ad universam regni Tur felicitatem, salutem, sloriam faciunt, qvæe ad res patrias illustrandas et dilucidandas spectant, hæc omnia TIBI, optimo Patriæ patri, summæ semper fuerunt curæ et cordi, ut omnes venerabundi testantur, ut etiam factis TUIS satis et qvotidie probatur; qvare etiam, cum tot sustineas res, a tot tantisque negotiis animum semper vigilantem ad artes elegantiores advertens opera multa rei litterariæ honorifica, qvæ alias vix lucem vidissent, in orbis eruditi usum publici juris fieri jussisti; sic etiam factum est, id qvod silentio præterire mihi esset religio, ut, qvæ TUA est erga artes omnes humanas summa benevolentia et liberalitas, hoc qvalecunqve Tentamen de Hydrophytis Danicis in publicam lucem prodeat; sic etiam factum est, qvod lubenter fateor, ut 'TuIS 
beneficiis hæc cuncta debeantur. Cónfido iggitur, TE hoc opusculum, sacro 'Tuo nomini devotissime dedicatum, placidis manibus accepturum; perseqvitur autem particulam rei herbarie hactenus minus cultam, et dispositionem continet systcmaticam omnium Hydrophytorum, qvæ ad littora imperii Danici ad hoc usque tempus detecta fuerunt; hæe autem plantæ, licet nonnullæ earum parvæ sint ac tenues, formis tamen, quibus gaudent pulcherrimis, coloribus, qvibus nitent splendidissimis, structuris internis, non qvidem nisi ope microscopii rite discernendis, at non satis admirandis, ut usum earum oeconomicum taceam, sese commendant; videmus in his, naturam non solum in magnis, sed etiam in minimis observatu esse dignissimam, et hanc magnam rerum matrem in profundo maris pariter atqve in 
superficie terræ vim suam mirandam ostendere, qvin etiam in occultis thesauros suos pretiosissimos clanculum expandere.

Benigno igitur illo animo, qvo, imperantium optime, cives Tuos omnium ordinum excipis qvotidie, excipias precor hos marium fluviorumqve infantes, qvi aqvis emersi oculis TUIs angustissimis hic humillime sese subjiciunt, representare cupientes fratres suos atque sorores, qvos sub moderamine Neptuni ad littora TUI imperii habitantes Najades Nereidesqve omnes, fluviatiles atqive marinæ, gremiis alunt amiceqve tuentur. Haud qvidem ignorant, qvod vestimenta, qvibus simpliciter incedunt, splendore careant naturæ, vix ac ne vix qvidem imitabilis; nihilo tamen minus, cum ex domicilio Neptuni jam in TUUM translati sint, 
cum Cel. Hofmann Bangio iter in Norvegiam facere mili successerit, in qvo ipse littora hujus regui ad meridiem vergentia, imprimis inter oppida Arendal et Öster-Riisöer sita, me investigationum socio assumto, perlustravit, iisqve excursionibus Thalassiopliyta ibi obvia diligenter investigata sunt, et nomnulla etiam novæ species indagate. Hoc itinere peracto, cum domum reversum esset et descriptiones inceptas systematice dispositas peregissem, commentationem illam, cui inscribebatur Tentamen algologicum, unacum delineationibus ad Universitatem Hafniensem misi, ad praenium expositum, si fors ita tulerit, obtinendum concertaturus. Voti etiam compos fiebam; accidit enim, ut ad natales Regis nostri clementissimi ISI7 brabaum ex sententia reportarem. At enim vero, cum in Hydrophyta animus jam erat intentus, omnibus posthabitis, statui, xstate irruente iter algologicum ad insulas Feroenses suscipere; credidi enim ad littora liarum insularum, qvæ in vasto oceano tam solitarie et a patria tam remote sitæ sunt, Algas abundare et nonnullas forsan novas hujus tribus species ibi esse inveniendas; qvo ubi pervenissem, hanc meam conjecturam haud inanem fuisse inveni; magnæ enim 'Thalassiopliytorum cohortes rupibus adnascentes oculis objiciebantur, et præter majares Fucos, qrorum nonnulli in immensam molem in sinubus ibi excrescunt, plures Conferrarum species, ad littora Anglica recentiori tempore repertæe et jam ibi divulgatæ, profunda sinuum replere et latera rupium fluctibus agitatissima obducere et condecorare cernebantur; nonnulla etiam nova Hydrophyta, qvæ Viris celeberrimis et perspicacissimis $N$. Motorio et Landtio, qvi plantas Færoenses diligenter investigaverunt, utpote microscopica sese subduxerant, indagandi et delineandi ibi præbebatur copia. Isthinc Daniam tendens, qrum tempestatibus in portum Svinöer prope Lindesnas Norvegia navis depulsa esset, in plantas hujus ora, occasione per plures hebdomades oblata, inqvirere non omisi. 
Ex hoc itinere Hafniam reverso contigit, ut Rex noster clementissime permitteret, ut tentamen illud algologicum, qrod antea concinnaveram, unacum delineationibus Regio sumtu publici juris fieret; qram etiam summam ob gratiam illud opusculum novis speciebus seriori tempore inventis locupletavi, et ad opera algologica præstantissima, qvæ sedula interea versavi manu, diligenter correxi et emendavi, ut munificentia Regia, qrantum penes me fuit, haud indignum in lucem proderet. Præterea, qrod ad algas Groenlandicas attinet, clarissimorum Virorum O. Fabricii, Wormskioldii et Giesekii consului herbaria, ex quibus nonnullas hausi notitias, et unam alteramve speciem novam extricavi. Hæc est hujus opusculi historia, qram, levem qvidem per se, hunc in finem hic tetigi, ut sciant Lectores benevoli, qro factum sit, ut algas Faroenses, Groenlandicas et nomnullas Norvegicas attulerim; unde simul patet, qrod vix qvisqvam, qvi in liac sparta rite ornanda aliqvantum versatus est, facile infitias ibit, haud parum temporis ad hæc conamina conficienda exigi atqve postulari; neque enim una alterave hora diversæ hæ plantæ, diversis iisclemque dissitis atqve remotissimis in locis qværendæ, indagantur, examinantur, delineantur, describuntur, in ordinem rediguntur; qvæ omnia, licet cum periculo vitæ homini satis cauto non sint conjuncta (qrod Cel. O. F. Müllerus in præfatione Floræ Frederichsdalinæ præmissa perhibere videtur), freqventem tamen investigationem in vasto naturæ templo tam ad littora marium quam ad summitates rupium institutam, pedibus sæpe fatigantem, et examinationem iterum iterumqve sub lente domi repetitam, oculis liaud raro molestam, sæpissime reqvirunt. Qvare haud parum temporis ad hujusmodi molimina exigitur, qvid? qvod oleum et opera interdum perditur per frustaneas indagationes, dum in rebus tam tenuibus, qvæ non nisi ope microscopica rite discerni possunt, nubis pro Junone captatur haud raro. Qvæstio propo- 
sita præterea late patens, fuit explicatu eo difficilior, qro minus rite excultum fuit Algologixe Danicx territorium, qvoqve panciores in libris Botanicorum Danicorum species pro harum plantarum. ubertate publici juris hucusqve factæ fuerunt. Atqve ne sine causa hæc nugari existimer, annotare sufficiet, numerum Algarum Danicarum, hucusqre provulgatum, centesimum non multum excedere. In Flora Danica, ut ex seqventi conspectu apparebit, ir3 species et 13 Varietates continentur, et in operibus clarissimorum Virorum Schumacheri et Hornemanni pauca modo species exstant descriptx. Hinc etiam necesse fuit, ut multæ novæ descriptiones essent elaborandæ, atqve, qrastione academica ordinem systematicum postulante, cum filum systematis Ariadneum mihi defuit, nec in aliorum laboribus plane acqviescere potui, novum dispositionis genus vel novum systema, si ita dicere licet, esset condendum.

His igitur.allatis, ratio jam paucis reddenda est dispositionis illius systematicæ, qvæ in hoc opere usurpata peritorum judicio jam subjicitur. Ex Tabula synoptica, qra primas ordinis systematici lineas adumbrat, Lector benevolus uno qvasi obtutu intelliget ordinem, in qvem Hydrophyta Danica hic disposita occurrunt, et inde cuivis facile patebit, in dispositione me prius ad habitum externum, qram ad fructum respexisse. Primum qvidem opus aggredienti totum tentamen juxta fructum disponere animus fuit; sed Thalassiophyta continua sive Phycoidata, qvorm tamen fructus melins qvam ceterorum enucleatus dici potest, obstabant, qvo minus hoc propositum exegerim. Licet enim plura præclara opera ad harum plantarum fructum cognoscendum symbolas suas maxime æstimandas contulerint, omnia tamen huc spectantia nondum ita in liqvidum perducta sunt, ut is tanqvam frmo fundamento adificium systematis superstrui possit; e contrario plura dubia adhuc restant, et sine dubio etiamnum diu restabunt; qvare 
etiam non ita multo post animadvertebam, has plantas ex fructu solo in ordinem redigere esse difficillimum factu, et fere inutile conamen; scimnt enim omnes, qvibus Hydrophytorum cognitio curæ fuit, fructum in aliis noudum esse detectum, et igitur adhuc plane ignotum; qvibusnam igitur in locis tales plantæ steriles juxta fructum militarent, id nondum certo definiri posset, sed ad meras conjecturas, ex Anologia habitus exterioris sumtas, sed fallaces, esset refugiendum. Præierea fructus in aliis est rarissimus; hinc itaqve efficitur, ut, si ex fructu dispositio facta sit, tyro, cujus tamen in usum præprimis elaborata esset, parum inde ntilitatis caperet, cum inter plurima specimina lecta, interdum vix ac ne vix qvidem unicum fructiferum inveniret. Sunt porro nonnulla, neqve ita pauca numero ex Thalassiophytorum grege, qvæ duplici fructificatione gaudeant, partim capsulis externis instructa, partim seminibus nudis frondi vel apicibus ramulorum innatis; qvarum igitur inter Crytogamas ratio eadem est, ac Polygamiarum inter Phanerogamas. Utra harum igitur fructificationum fundamenti instar divisionis eligenda est? Fac capsulas; jam vero, si Algologo forte obvium fuerit exemplar seminibus nudis instructum, in eodem, qro antea, hæsitaret luto, nec multum ex tali dispositione proficeret. Deniqve, si Hydrophyta juxta fructum distribuuntur, haud raro accidit, ut ea, qvæ natura arcte conjunxit, procul disjungantur; sic, ut exemplum afferam, Furcellariam rotundam et lumbricalem tanta ad se invicem similitudine habitus exterioris accedere, ut vel difficillime a se discernantur, qvis negabit? Fructus autem omnino diversus; et item exemplum ab altera parte: Fructum Odonthalice dentatce et Gigartine subfuscre se invicem referre, qvis non videt? Habitu vero hæ plantæ adeo discrepant, ut utramqve ad idem genus referre, cuidam vix unqvam in mentem veniat. Q vid igitur in his faciendum? Si fructum ut fundamentum divisionis eligimus, contra naturam peccamus, si habitum, con- 
tra regulas artis delinqvimus; ut autem natura legibus humanis prævalet, sic etiam dispositio Hydrophytorum naturalis, ex habitu sumta, artificiosæ, ex fuctu sumtæ, me judice, anteponenda; atqve hxc qvidem dispositio naturalis non solum facilior mihi videtur, sed etiam utilior; qrando enim specimina, qvæ se invicem maxime referunt, juxta se ponuntur, eorum commutatio facillime prolibetur, et optime perspicitur, quibus in punctis conveniant, qvibus etiam discrepent. Inter auctores qvidem constat, qvod scio, ex flore et fructu sumendas esse notas illas, quibus divisio generum niti debet, characteristicas; sed simul me non fugit, hanc legem, ratione imprimis ad plantas plianerogamas liabita, latam esse, et absit, ut hanc Planerogamas disponendi methodum optimam negarem; nam qro penitior in plantæ naturam indolemqve intrat, ut eo constantior, sic et melior; sed dantur et aliæ plantas dividendi methodi, qrod conamina clarissimorum virorum et ante et post tempora illustrissimi Linnai incepta et instituta, nec plane irrita, satis comprobant; præterea regulæ, qvæ valent de Phanerogamis, qvippe qvarum fructus et fructificandi ratio evidenter ob oculos nobis versatur, exdem de Cryptogamis, qvarum fructus intimis sæpe recessibus absconditur, non semper, nec sine omni contradictione valere possunt. Atqve, si inter Cryptogamas ad Hydrophytorum tamiliam descendimus, ex iis, qra jam antea dixi, seqvitur, ut fructus eorum, qralem eum adhuc novimus imperfectum et dubiis vexatum, tanqvam fundamentum divisionis, difficillime aut plane non eligi possit ${ }^{\star}$ ), neqve inde sumi possint notx generum characteristicæ, siqvidem in aliis est incognitus, in aliis rarissimus, et iterum in aliis duplex, ut organa

") In a subject so intricate as this, it would be highly advisable that all prejudices, and all comparisons and ideas of analogy taken from plants growing on land, should be entirely laid aside. Goodenough and Woodward in Trausact. of the Linucan Soc. Vol. III. 1. 235. 
sexualia taceam, qvæ omnino latent; nulla enim ratione in dividendo ex partibus rerum difficillimis, vel incognitis vel inconspicuis characteres sumendi sunt, sed potius ex conspicuis et facile observandis; alias enim sine necessitate difficilior redditur scientia, qvin etiam ad metam minime perducit. Si igitur tales characteres, qvi ad objecta Hydrophytologica cognoscenda et discernenda idoneam, facilem et qvidem certam viam sternant, inveniri possunt, hi, etsi ex fructu non sumantur, difficilioribus sunt præferendi, inqve iisdem, si modo bono et certo fundamento nituntur, lubenter acqviescere possumus, usqve dum meliores inveniuntur. Constat enim, unumqrodqve systema naturæ, sive universale sive speciale, glossarii vice fungi debere, qrod lunnc in finem evolvimus, ut rem ignotam divisionis ope ibi inveniamus. Qvando igitur res, qvæ ad divisionem pertinent, certa ratione et summa diligentia, adeo ut analogia ubiqve servata sit, in ordinem, qvem elegimus, redactæ sunt, earumqve divisio characteribus conspicuis et constantibus nititur, is, qvi rem qværit, eam, si in dispositione descripta exstat, facile inveniat, necesse est, et ad certitudinem simul perveniat, oportet; is, qvi est omnis divisionis finis et meta. Qvibus etiam argumentis permotus, satius duxi utilitatem arti præferre, et ita credidi, characteribus primariis ex habitu exteriori sumtis, huic scientiæ faciliori reddendæ melius consultum iri, qram placitis eruditorum de fructu obtemperatis. Hæc vero omnia non ita sunt intelligenda, ac si fructificatio Hydrophytorum a me contemneretur aut neglecta jaceret; in fructu enim indagando et satis luculenter exponendo haud parum me posuisse operæ, ex delineationibus, in qvibus fructus ubiqve, ubi fieri poterat, apponitur, satis, ut spero, illucescet; sed id modo volo, ut fructificatio nondum rite cognita non primaria, sed modo secundaria divisio sisteretur. Scopus enim, ad qvem spectat hæc Hydrophytorum dispositio, in eo, ut jam tetigi, versatur, ut labor exemplar ignotum 
tyronibus obvium examinandi determinandiqve facilior reddatur, adeo ut distributionis ope certior fiat curiosus algarum rimator, utrum exemplar, qrod ei ad manus est, revera sit id, qrod hic descriptum reperiat, necne. Sic igitur factum est, ut, re bene pensitata, in his nostris Hydrophytis dispescendis ordinem naturalem, qvantum fieri potuit, servarem, ad fructum nilrilominus eâ, qvâ par erat, attentione ubiqve respiciens.

Ex operibus clarissimorum virorum Rothii, Stackhousii, Lamourouxii, Agardhii aliorumqve plura genera mutuatus sum, ad fontes, unde suni hausta, omnia referens, qvibus, ubi rei magis illustrandæ necessarium aut ntile videbatur, nonnulla nova addidi. In Synonymiis specierum earumqve descriptionibus elaborandis summam dedi operam, ut essent accuratæ, et inter prolixitatem. verbosiorem brevitatemqve obscuriorem mediam qrasi tenerent viam; descriptiones vero, ut bene intelligo, pro more nimis jejunx sunt atqve exsangves, cui jejunitati ut qvadantenus mederer, observationes nomnullas operi hic illic intexere placuit, in quibus, si qva notatu digna viderentur, paucis interdum exposui. Omnia vero ista genera, sub quibus Hydrophyta Danica apte comprehendi posse credidi, dilucide, ut opinor, a se invicem discriminata sunt in Sciagraphia, operi præmissa, cujus adminiculo omnes istas plantas ad suum qramqve genus referre, me qvidem proxenet?, non multis premetur difficultatibus. Onmia impedimenta, qræ in systemate condendo hic illic sese offerunt, de medio tollere, fieri non potest; nunqvam enim ad leges, qras humana mens excogitat, sese restringi patitur alma natura et polymorplia; sed libere, * ut magnus ipsius auctor, vim suam exserit, formas induens maxime multifarias, intellectumqve hominis limitati sæpe deludens; sic, nt exemplum afferam: Gigartina viridis, et Sytosiphon foeniculaceus, qros ad Pliycoidata continua merito amandavi, in summis ramulorum apicibus interdum genicula ostendunt; loc tamen non 
impedit, qro minus divisio persistat; nam a parte potiori fieri debet denominatio et item distributio. Natura nullum facit saltum, dixerunt veteres et in adagium abiit; harmonia qvidem etiam in operibus naturæ esse intelligitur, eaqve admiranda atqve divina; transitus sæpe dantur manifesti non solum inter ipsa regna naturæ, sed etiam inter qrasdam classes, genera et species; attamen non ubiqve transitus isti oculis observantium offeruntur; qvare etiam singulos in naturæ magna eaqve ut continua decantata catena indagare articulos, hoc opus, hic labor; qrorum veram concatenationem ut investigarent, plures sudarunt eruditi, at vota spemqve ipsorum nihilominus hucusqve fefellit eventus. Qvæ cum ita sint, delineationes, opera naturæ objecta repræsentantes, ubi verba ad rem, de qva agitur, exprimendam apta desiderantur, et ubi natura polymorpha systematicos in tricas conjicit aut ad incitas redigit, vicem verborum gerunt, defectuiqve systematis medentur; qvarum etiam ntilitatem ipse bene perspiciens non ita paucas cunctasque ad naturam diligentissime sub lente exaravi. Atqve hac occasione omittere non possum grates meas agere Viro excellentissimo Joh. Bülowio, Domino Sanderumgaard Fioniæ, cujus impensis exercitationes artis delineatoriæ in horto botanico Hafniensi instituuntur, qvibus elementa hujus artis edoceri cupiens subinde interfui. Illas vero delineationes sub mea ipsius inspectione æri ad amussim incidit O.O. Bagge, Chalcographus Hafniensis, non solum ob artem, qvam strenua nunc et felici manu exercet, sed etiam ob litteraś, quibus olim vacavit, laudatissimus; in qvibus æri incidendis, ut in Tabulis eodem ordine, qvo in opere occurrunt, aliæ alias, qvoad ejus fieri posset, exciperent, operam dedi; tali enim delineationum serie conspectum faciliorem reddi existimavi, earumqve plantarum affinitates et dissimilitudines melius ante oculos poni.

Haud raro accidit, ut litterarum rudes aliiqve interdum talia, qvæ circa plantas tam minutas et fere contemtas versantur, cona- 
mina demirentur, et de earum usu diligenter percunctantes sæpe idqve in tædium: Cui bono? qværant; qvare ntilitatem hujus scientix et pretium levi perstringere calamo a re non alienum videtur. Nil autem de pretio ejus absoluto dicam; suum enim qvamqve doctrinam in se habere pretium (siqvidem cognitio in universum est bonum qvid, homineque ratione prædito dignissima, qvæ qværatur), ideoqve imprimis colendam esse, per se patet; sed de pretio ejus relativo, qvatenus hæ plantæ aut in oeconomia naturæ salutares suas exserunt vires, aut in usum humanum suas habent utilitates, brevem mentionem injicere et necessarium et utile videtur. Constat igitur de rebus incognitis nos nullam certam nobis fingere posse notionem, nec ex iis ullam nobis capere posse utilitatem; si igitur res in natura obvias intelligere easdemqve in nostrum usum convertere cupimus, necesse est, ut ad eas cognoscendas et discernendas animum advertamus; sic etiam ex cognitione Hydrophytorum mere botanica pendent eorum utilitates intelligenda; atqve industriâ Botanicorum aliorumqve observatorum factum est, ut nonnullæ earum utilitatum haud amplius lateant; plures forsan postera dies docebit; qvarum qræ cognitæ sunt, nomnullas jam paucis eloqvar:

In oeconomia naturæ haud parvi sunt momenti; innumeris enim piscium insectorumqve, aqvas salsas æeque ac dulces inhabitantium, cohortibus domicilium prebent et tegumentum, ubi securam vitam degant et ovula sua excludenda deponant, atqve refugium iisdem præstant, qro'se contra hostium insidias ocyus convertant. De Fuco natante (Sargasso, ut in mappis geographicis antiqvioribus, qve Mare Atlanticum sistunt, dicitur) qvo forsan nulla planta in toto terrarum orbe copiosior, hæc secundum itinera Osbeckii et Kalmii affert Linnaus: ${ }^{\star}$ ) "Radicibus non hæret defixus

*) Amoen. Acad. Vol. 5. 1. 70. cfr. etiam Gmcl. Hist. Fuc. p. 94. 
in terra vel fundo, ut aliæ herbæ, sed in extrema superficie æqvoris, prati instar, natat et animalibus infra concursantibus alimento inservit; hoc ipso sedatur mare, et fluctibus suffocatis pacatum. evadit." - Animalibus autem non tantum aqraticis, sed qroqve domesticis alimento inserviunt; nam in Norvegia et insulis Færoensibus eqvi ovesqve, qvin etiam in graminum abundantia, ad littora sæpe festinare cernuntur, ut nonnullas, qvibus avide vescuntur et delectantur, sibi qværant algas; nam propter salem, qvem hæ plantæ in se multum fovent, a pecoribus amantur; et testante Lightfootio, pecora in insulis Hebridibus eodem esu tempore hyemali nutriuntur, qvin etiam cervi post tempestates littora petere visi sunt, hunc esum qværendi causa ${ }^{\star}$ ). - Præterea, qvemadmodum plantæ Phanerogamæ aëri athmosphærico purgando inserviunt, sic Algæ, teste saltem Cel. Pristleyo, idem efficiunt, gazim oxygenium, sub aqva soli expositæ, emittentes; atqve in eo sine dubio cansa qværenda est, cur aqvæ stagnantes, qvibus Confervæ innascuntur aut datâ operâ immittuntur, a corruptione maneant alienæ. - In locis humidis, qvæ exsiccantur, plures Confervarum species prima sunt vegetabilia, qvæ tempore vernali e gremio terræ eliciuntur, eaqve herbis majoribus, qvæ deinde paulatim proveniunt, viam idoneam sternunt, partim cum reliqviæ earum cæspitosæ solum terrestre obducentes herbis tenuibus infra pullulantibus tegumentum præbeant, partim cum dissolutæ in limum abeant, qvi terram fertiliorem reddit. - In aqvis dulcibus ad turfam producendam præprimis faciunt; qrare qro magis eâ foveantur homines, eo minus hæc plantæ contemni merentur. - Sunt etiam, qræ ad fundum maris paulatim elevandum vim habeant; sic Oscillatoria chthonoplastes insulam parvam, sabulo filis suis lubricis retento, temporis decursu formavit. ${ }^{\star \star}$ )

*) Lightf. Fl. scot. p. 906.

**) Hofmann Bung De usu Confervarum in oec. naturæ p. 17. 
Deniqve, si ad utilitates, qras Hydrophyta hominibus sine interventu præstant, respicimus, commoda, qvæ ex iis redundant, aut redundare possunt, certe plura et graviora dici merentur, qram qve vulgo putantur. Alimentum qvidem hominibus præstare possunt, idqve non solum in arctiori annona aut rei frumentariæ inopia haud spernendum, sed etiam pro vario hominum variorum gustu preparate in sat delicatum et jucundum vertuntur cibum. Sic Islandi non pauperiores tantum, sed qvoqve ditiores ferculis ex Ulva palnata et Laminaria esculenta aliisqve paratis mensas suas haud raro instruere solent. Færoenses costas Laminarice esculen$t a$, qvæ medullam caulis Brassica oleracea sapiunt, crudas coctasque comedentes gratum cibum predicant. Scoti Ulvam umbi. licalem et Lactucam pro suo more preparatas in deliciis habent. Lappi ultimam Thulen inliabitantes, ubi alius ipsis cibus deest, montes relinqvunt, orisqve vicinis petitis, Algis victitare dicuntur. Huc etiam referri possunt Nidi illi Indici esculenti, ex Thalassiophytis qvibusdam gelatinosis ab avibus constructi, qvibus nil in ventres divitum jucundius descendit; atqve haud scio, an Plutarchus, ubi de solertia animalium loqvitur, eosdem innuerit; dicit nempe: "Peculiariter Phycides ex alga veluti nidum qvendam construentes, eo suum foetum ab undis defendunt" $)$. Alium deinde et sine dubio præstantiorem usum in sale Alcalino, vulgo Kelp dicto, conficiendo Thalassiophyta præstare dicenda sunt; in insulis Orcadibus hunc in finem copiose leguntur, et reditus, qvi incolis inde obvenit, sat lucrificus esse perhibetur ${ }^{\star \star}$ ); bono etiam successu in insulis Færoensibus eodem modo adhibita fuerunt, et etiamnum.

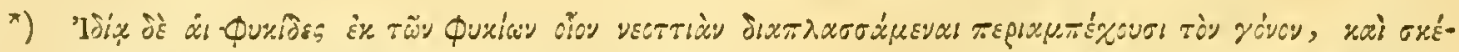

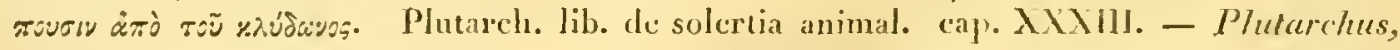
ut ex contextu patet, per $\phi$ uxides pisces qvosdam intellexit; sed nidi illi Indici ad Hirundine esculenta construi dicuntur.

*) Turn. Symops. Tons. I. p. 134. 
adhibere possunt, cum pluribus in locis copiosissime ibi adsunt. Agris præterea fertilioribus reddendis sterqvilinii loco ejusqve inopia commode inservire valent; sic in Norvegia, insulis Froensibus, Orcadibus alibiqve magnam ex is incolæ qvotannis capiunt utilitatem *). Neqve in Medicina Thalassiophytorum laudes desunt; Dioscorides ${ }^{\star \star}$ ) et post illum Plinius ${ }^{\star \star}$ ) nonnullis eorum, qvæ no-

*) Verba Stapelii huc aliqvatenus pertinentia hoc loco afferrc liceat: "Hanc algam (Fucum qvendam Tlicophrasti) rustici littoribus ejectam et æstate dispersam, ut fruifeces, rastcllis accumulant, et in campo expositam furcillis versant, qvoad probe siccata fuerit; deinde Irobe arefactum foeni instar in metas construnu, aut in focnilia vel palcaria inferunt; eaqve sunt, qvæ tum præparant pecorum boumve hybernæ stabulationi stramen1a. Ex eo gri line conficitur fimo, agros nimia defrugatione emaciatos et exhaustos stercorant, licto segetum proventu. Veneti is vitrea vasa, qvæ procul asportare volunt, involvere ae eircumtegere solent, ne mutuo collisu frangantur. Hac probe siccata agricolæ et qvi littora incolunt tomenti plumarum ac floccorum loco culcitras suas fulciunt, qvem usum apud antiquos ad fulciendos centones in castris habuit. l'itruv. Lib.10. c.2. Circum tabulata collocentur crates ex temuibus virgis creberrime textis, maximeque recentibus, percrudis, coriis duplicibus consutis, furctis algee aut paleis in aceto maceratis rircumtegutur machina tota. Ceterum alga dicitur ab algore aqvæx, sive qrod pedes alliget \&c." efr. Stapelii not. et comment. in Theopler. hist. plantar. Lib. 4. c. \% Amstelod. 1644. fol. p. 412. Hetuo antem, ne planta, gram Vir clarissimus innuit, nil aliud sit, quam Zostera marince.

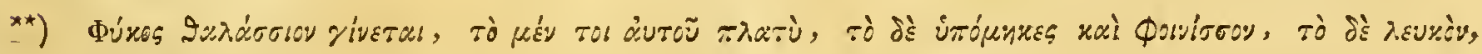

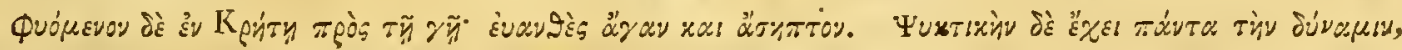

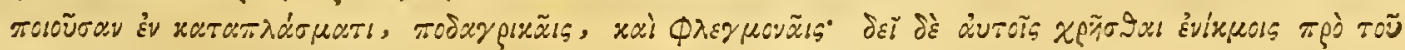

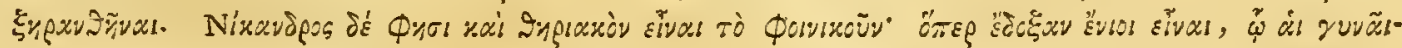

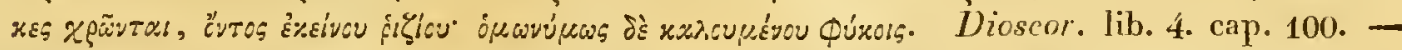
(E fuci marini generibus qvoddam latum, altcrum sublongius et rubens, tertinm candidum, mascens in Creta juxta terran; floridum valde, qvod unlla corruptionis labe polluitur. Omnia vim habent rèfrigeratoriam non podagra modo. sed etiam inflammation nibus, in cataplasnatis efficaciter ntilcm; verum is uti lsunidis convenit, priusqrava exarescant. Nicander puniceum asserit adversus serpentes valere: idipsumqve est, qvo existimavêre nonnulli colorcm suum mentiri mulieres, cum tamen radicula sit ejusdem nominis, qua sese fucant).

Prxeipue vero liberat co malo (prodagra) Phycos thalassion, id est Fucns marinus, Lactueæ similis, cfvi conchyliis substcrnitur; non podagræe nodo, sed omnibus articulorum morbis impositus, priusegram evarefiat. Tria autem genera cjus, latum et alterum longins, qvadantenus rubeus, tertium crispis foliis, qvo in Creta vestes tingunt; omnia 
stro tamen ævo vix certo definiri qveunt, efficncem in variis morbis attribuerunt medelam. Mucus ille, qvi in receptaculis Fuci vesiculosi adest, in glandibus scrophulosis corporis humani dispergendis salutarem qrandam vim habere dicitur*). Neqve in Technologia usus iis plantis derogatur; Chinenses et Japanenses, ut ex itinerariis Krusensternii et Langsdorfii discitur, ex Fuco qvodam, forsan tenace, vernicem suum splendidissimum parare sciunt, et aliam ejusdem tribus speciem glutinis loco adhibent; qremadmodum inter nostras Gastridium filiforme eadem causa nominari meretur; in arte deniqve tinctoria nonnullæ Algarum haud sunt sine pretio, eoqve nomine qvædam earum species jam a Theophrasto laudatur; dicit enim: Qvercus marina ad lanas inficiendas utilis est mulieribus $\left.{ }^{\star \star}\right)$; et nostro adhuc tempore Froenses Halidryn nodosam unacum aỉis herbis in pannis colore viridi inficiendis e re sua usurpant $^{\star \star \star}$ ); atqve hoc loco non omnino prætereundum est, qvædam Thalassiophyta ad colorem faciei mentiendum a mulieribus hic et illic adhiberi; qvare etiam Fucus, cujus hæc vis a priscis inde temporibus nota fuit, et plantam marinam et pigmentum, qro se fucant mulieres, denotat, a $\varphi^{\prime} \dot{y}$ ss, Alga, nomen trahens; Gmelinus nobis auctor est, puellas Kamtschatkicas his plantis faciem fricare, qræ inde ruberrima fit, itemqve foeminas ad maris Emropæi littora habitantes, pulchritudinisqve non minus studiosas, levidense idem artificium non ignorare. $\left.{ }^{\star \star \star}\right)$ Postremo, ut formas liarum plantarum pulcherrimas coloresqve nitidissimos, qvibus conspectis ad

ejusdem usus. Nicander ea et adversus serpentes in vino dedit. Plin. Hist. nat. Lib.26. cap. 8.

*) Rus.selins Dissertation concerning the use of Seawater p. 216. et Basteri Opusc. subsec. Tom. II. p. 121.

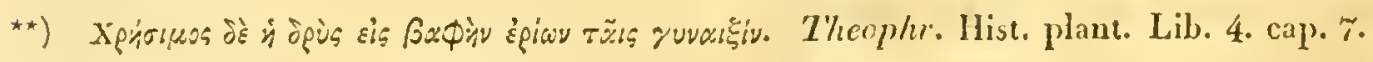

**) Landt Beskriv. over Fær. p. 227.

${ }_{* * * *)}$ Ginel. Hist. liuc. p. 5. 
admirationem Creatoris animus evehatur, oportet, taceam, Geognosir haud plane sunt inutilia; nonnullæ enim marinæ, qvæ in locis turfosis, non qvidem multum supra mare elevatis, sed ab eodem jam longissime remotis, repertæ sunt, conjecturis de successiva superficiei telluris formatione probabilibus dare possunt locum; ut enim $J$. C. Fabricius in turfosis Norvegicis prope Nidarosiam Zosteram marinam invenit ${ }^{\star}$, sic Humboldtius in turfosis $\mathrm{Li}$ num, prope Berolinum sitis, partem folii Laminarice saccharince indagavit, sartam tectam, prout in.littus maris Helgolandici nostro ævo ejicitur $\left.{ }^{\star \star}\right)$; qræ res in facto posita Geognosiæ saltem partiali lucem qvandam affundere posse videtur.

Hæc de Hydrophytorum utilitate disseruisse sufficiat; plura forsan commoda ex iis redundant; sed ex paucis illis, qvæ dicta sunt, satis intelligitur, istas plantas ob utilitates, qras et in oeconomia naturali consideratæ et in usum humanum conversæ præstant, dignissimas esse, in qvas inqviratur; atqve hæc qvidem consideratio in solatium cedit; nam, ut Phcedrus olim dixit, nisi utile est, qrod facimus, stulta est gloria. Spero etiam fore, ut alii, his consideratis, posthac huic scientiæ manus lubenter admoveant, neqve ob difficultates, qvæ occurrere possent, ab hoc studio alias jucundissimo retineri se patiantur, sed potius in ulteriora procedere studeant; et si cujus animus in hanc scientiam aliqvando intentus sit, ejusqve studiosus esse velit, is nec verbis Virgilianis: Projecta vilior alga; nec verbis vulgi: Cui bono? facile retinebitur; iis vero, qvæ jam facta sunt, minime contentus, in vastum illud regnum, qvod tanqvam novum oculis ejus expanditur, cupidus, opinor, ruet, in maribus fluviisqve miracula Dei lætus videbit, et multa adhuc restare facienda, multa expiscanda, extricanda, corrigenda animadvertet.

*) Reise nach Norweg. p. 269.

**) Bergmännisches Journ. Junii 1792. p. 551 . 
Qrod ad nomen Hydropleytologice, qrod huic libello inscripsi, attinet, metuo, ne in varias reprehensiones incurrat. Suspicor enim, alios id esse justo longius, ne dicam sesqvipedale, dicturos, alios, codem plantas aqvaticas phanerogamas, ut Hottoniam, Myrioplyyllum \&c. non esse exclusas; quibus respondebo, nomen Algologia, qvippe ex vocabulo latino et græco compositum, neqre omnibus numeris esse absolutum; et qroad alteram objectionem in titulo apposui vocabulum cryptogama, qvo Plianerogamæ excludantur; licet hæc præcautio non ita fuerit necessaria, siqvidem plantæ aqvaticæ Phanerogamæ aqvas qvidem amant, sed in aqvis generari proprie dici non possunt. Ilydrophyta igitur mihi sunt: Planter aqvatica cryptoganne, nunc frondosce aut filiformes, nunc gelatinosa. Ceterum vocabulum sponte se mihi obtulit; postea tamen idem duobus in locis ${ }^{\star}$, qrorum igitur auctoritate niti possum, jam usurpatum vidi.

Ad calcem libri adjeci conspectum algarum, in Flora Danica lnucusqve delineatarum, qrem, cum opus illud magnificum in magnam jam excreverit molem, haud supervacaneum duxi, nec Botanophilis fore ingratum speravi. Addidi etiam catalogum Auctorum, qvi de Algis scripserunt, qratenus mili noti sunt, neqve solum eorum, qui vasta volumina memoriæ prodiderunt, sed etian eorum, qui commentariola in diariis alicubi deposita composuerunt; ex eo igitur is, qvi in hac parte ulterius progredi cupit, eligat, qra sibi optime conducere opinabitur. Sic, qvi de Oscillatoria limosa et de ejns aliarumqve oscillationibus plura cupit, evolvat scripta Adansonii, De Saussure, Fontana, Hofmamn Bang, Sclierer, Senebier \&c., et qui de variis variorum de Nostoc communi sententiis plura desiderat, is scripta Carrodori, Reaumurii, Scetzen \&c. inspiciat. Sunt etiam in his libris haud pauca, qvæ ad

*) Groctl. gel. Anz. 1815. No. 64. p. 625. et Liljeblad Flora Srec. cd. II. 
harum plantarum physiologiam spectant, qvam, utpote altioris indaginis meisqve humeris imparem, plane omisi; qræ enim de obscura hac re ab eruditis jam excussa et in dissertationibus variis pertractata fuerunt, adhuc sufficere credidi.

Restat, ut pios gratosqve meos publice exprimam sensus in Viros excellentissimos, illustrissimos, celeberrimos, qvi in hoc opusculo edendo mihi benevolentissime adfuerunt; imprimis antem nominandus est Vir excellentissimus JOH. SIEG. ^ MÖSTING, eqves ordinis elephantini \&c. \&c., qvi insigni sua, qra me complexus est, indulgentia apud Regem nostrum augustissimum effecit, ut hoc opusculum in lucem proderet; Vir excellentissimus OVE MALLING, ordinis Dannebrogici magna cruce ornatus \& c., qvi pro suo in me favore limatissimum sum ad mea conamina commendanda calamum sumere haud fuit dedignatus; Cel. Prof. J. W. HORNEMANN, eqv. ord. Dannebr., cujus beneficio ad bibliothecam horti botanici Hafniensis, et item ad herbarium ipsius algarum ditissimum, et herbarium Cel. WORMSKIOLDII peregrinantis Groenlandicum aditus milhi patebat; Cel. HOFMANN BANG, eximius algologus, qvi mihi, liberorum ipsius præceptori, prima Algologiæ elementa præcepit, et ex suo herbario meas collectiones sæpe ditavit; Cel. Prof. JOH. COLSMANN, qvi editionem opusculi apud potentiores strenue commendavit; Summe Rev. OTTO FABRICIUS, Episc. et Dr. Theol. honor., eqv. ord. Dannebr., qvi algas suas Groenlandicas mihi percurrendas benevole permisit; idem debeo Cel. Prof. GIESEKE, commend. ord. Dannebr., qvi Hafniæ I817 aliqvantum temporis moratus algas suas in Groenlandia lectas mihi inspiciendas sponte porrexit.

Hæc sunt, qræ præfaminis loco liuic libello, cum jam in eo est, ut in publicum emittatur, præmittere voluerim; et nunc ad postremum opto, ut Botanicis haud displiceant mea in hac opella qraliacunqve conamina, qrorum me certe non pigeret, si qvandam 
rei obscuræe et difficili lucem affundere, aut firmiori cuidam fundamento parvam lianc rei herbariæ provinciam superstruere potuerint; deniqve si alios ad hanc partem ditandam luculentiusqve exponendam excitare, aut animos lectorum ad admirationem omnipotentis scientix, qræ miracula sua ubiqve, etiam in profundo maris, expandit, exhortari valuerint, ommes meos in hac palæstra labores abunde compensatos censebo. 


\section{TABULA SYNOPTICA}

C UM

S C I A G R A P H I A. 


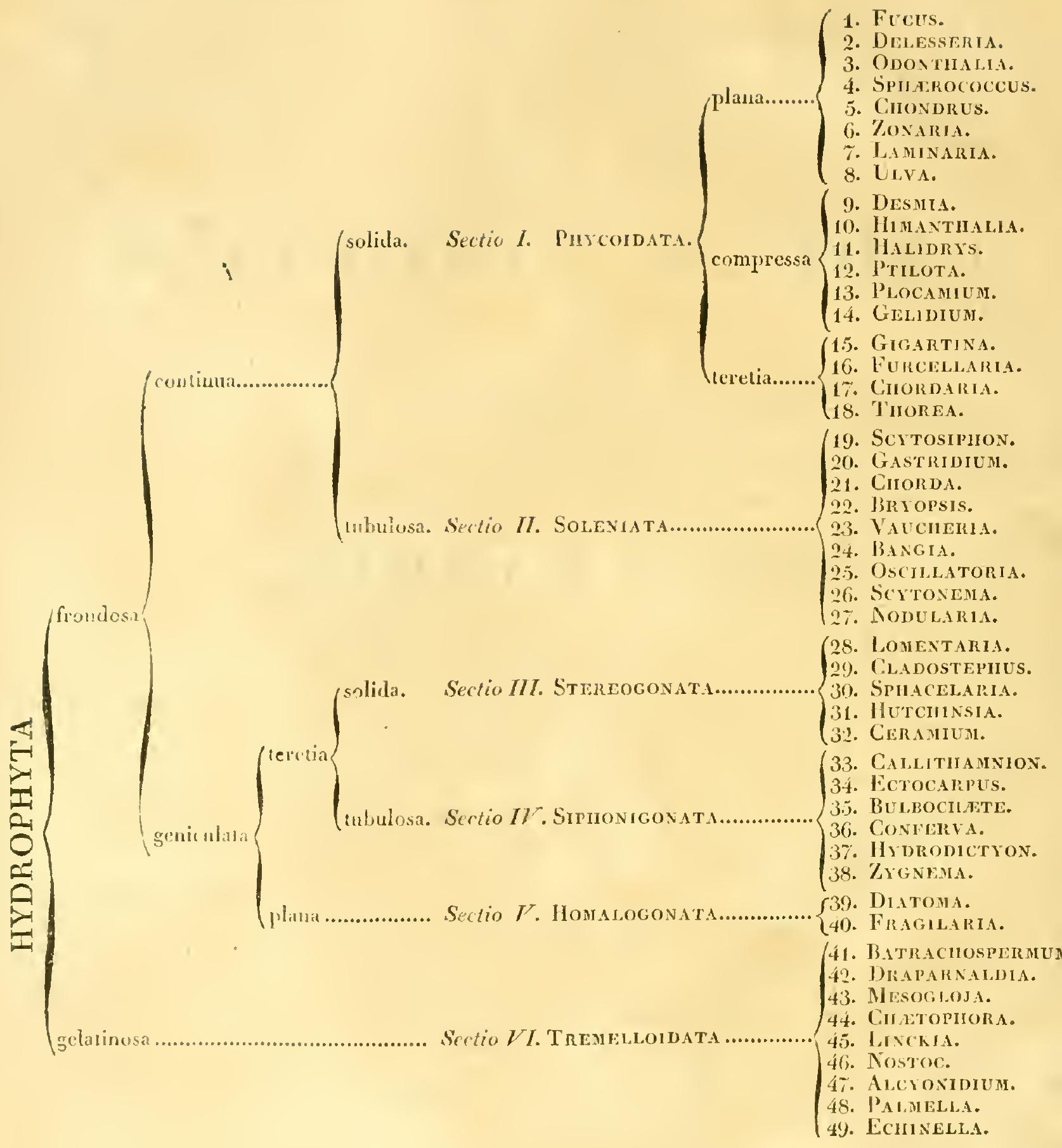




\section{SCIAGRAPHIA SIVE CONSPECTUS GENERUM.}

\section{SECTIO I.}

Phycoidata. ${ }^{\star}$ ) Frons plana, compressa vel teres, continua, solida.

* fronde plana.

1. Fucus (Lin.). Frons plana, dichotoma, olivacea. Fructus Receptacula terminalia, turgida, intus mucosa, tuberculis numcrosis sphæricis seminiferis fibrisque intertextis repleta.

2. Delesseria (Laur.). Frons plana, foliacea, menbranacca, costata, rosea. Fructus Scmina unda frondi immersa, vel Tubercula globosa, innata.

3. Odontilalia $\left(\operatorname{Lg} b_{0}\right)$. Frons plana, membranacea, subecostata, dentata, rubra. Fructus Siliqure axillares, lanceolatæ.

4. Sphserococcus (Stackh.). Frons plana, membranacea, ecostata, rubra. Fructus Tubercula globosa ad margiiem sessilia.

5. Chondrus (Stack\%.). Frons plana, dichotoma vel ramosa, rubra. Frnctus Tubercula hemisplerica, apicibus froudis innata.

6. Zonaria (Draparn.). Frons plana, orbicnlaris, adpressa. Semina nuda in lineas transversales concentricas disposita.

\%. Laminaria (Lam.). Frons plana, stipitata, olivacea, radice fibrosa. Semina nuda, frondi aticubi inumersa.

8. Ulva (Lim.). Frons plana, expansa. Semina nuda, substantiæ frondis hic illic immersa.

** fronde compressa.

9. Desmi $\left(L_{g} b_{3}\right)$. Frons compressa, ramosa. Fructus ignotus, vel forsan in fibris e substantia frondis exeumtibus qværendus.

10. Himanthalia $(L g b$. $)$. Frous compressa, dichotoma, ex basi cyathiformi erumpens. Tubercula numerosa, per totam frondem sparsa.

11. Halidrys (Stackh.). Frons compressa, ramosa. Receptacula turgida, intus mucosa, tuberculis sphæricis seminiferis repleta, lateralia vel terminalia.

12. Pтilota (Ag.). Frons compressa, ramosissina, supradecomposito-pinnata. Fructus Capsulæ quinquifidæ.

*) Ex Фंن́xos Fucus, et zidos species. 
13. Pi ocampur (Lam.). Fons compressa, disticla, ramosissima; ramulis ultimis pectinatosceundis. Fructus Capsula laterales, vel Semina muda, apicibus froudis immersa.

14. Gilnuvm (Lam.). Frons compressa rel angulata, ramosa. Fructus Tubercula globosa, terminalia.

\section{** fronde terete.}

15. Gigartina (Lama). Frons tcres, solida, ramosissima. Fructus Tubcrcula globosa, ad latera d'anulorum sessilia, externa, vel Scmina nula iuterua.

16. Furcelinkta (IJ eb. et Mohr.). Frons teres, solida, dichotoma, fastigiata. Fructus 'lubereula icrminalia subulata, vel lateralia spongiosa.

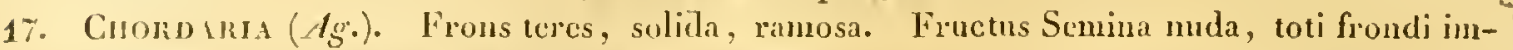
nucrsa, camelenque lanquam constituentia.

15. Tromes (bory.). Frons teres, solida, lubrica, ramosa, fibris articulatis mudigre obsessa. Fructus ignotus.

\section{S E C T I O II.}

\section{Soleniata. ${ }^{\star}$ ) Frons filiformis, tubulosa, continua.}

19. Scrtosipizox (Ag.). Frous teres, ıbulosa, continu, ramosa vel simplex, coriaccomcmbranacea, aqvalis. Fructus Sumina nuda, substanlia frondis innata, solitaria vel congesta.

20. Gastridiun (/ggb.). Frons teres, tubulosa, continna, ramosa rel simplex, gelatinosa, interdum articulato-coutracta. Functus Sendua nuda, substanias ramulorum immersa.

21. Cirorda (Stack/.). Frous teres, tubulosa, simplicissima. Fructus Scmina nuda, in muco frondem ambiente nidulantia.

22. Bкуорsis (tam.). Frons teres, tubulosa, subpinnatil. Granula minutissima in caule ct ramis nidulantia.

23. VAccueru (Deccund.). Fila capillaria, coutinua, plerumque ramosa, massâ granulosâ intus artspersa. Vesicula cxtcrnx, globosx.

24. BAxGa (L,gb.). Fila capillaria, coutinua. Gramula elliptico-cylindracea vel globosa intus congesla.

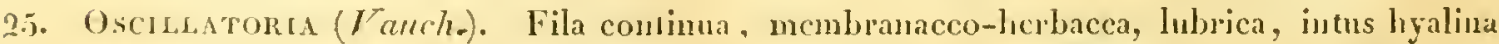
rel striis transversalibus parallelis dessis notata.

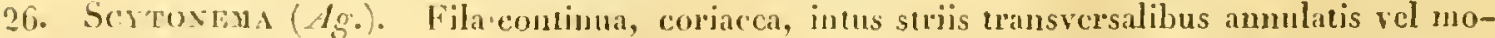
nilifinguilus nolata.

2\%. Nontudru (Link.). Fila contimua, simplicia, majuscula, extrusecus nodulosa. Seminit eylindsacco-ovata, in statu aduliori libera, tomm fili tubulun replentia.

* Ex swirivg tubulus. 


\section{S E C T I O III.}

\section{Stereogonata. ${ }^{\star}$ ). Frons filiformis, articulata, solida.}

28. Lonentaria $(\mathrm{Lg} b$.$) . Frons tercs, subgelatinosa, articulato-contracta, ramis oppositis$ vcrticillatisque instrncta.

29. Cladostepius $\left(A_{g}.\right)$. Frons teres, articulata, ramosa, setis ad genicula verticillatis obscssa.

30. Sphacelaria ( $\mathrm{Lg}_{\mathrm{g}}$.). Frons teres, articulata, ramosa, disticha. Semina nuda apicibus frondis splacelatis demum dehiscentibus inclusa; raro Capsulæ externæ.

31. Hutchinsia $\left(/ g_{*}\right)$. Frons teres, articulata, ramosa, rosea; articuli striis vel tubulis pluribus longitudinalibus notati. Fructus Capsula externa vel Tubercula apicibus ramulorum innata.

32. Ceranium (Roth.). Frons teres, articulata, dichotomo-ramosa, rosea; articuli reticulato-venosi vel subdiaphani. Fructus Capsulæ ramulis brevibus involucratæ.

\section{SE C T I O IV.}

\section{Siphonigonata. $\left.{ }^{\star}\right)$ Frons filiformis, articulata, tubulosa.}

33. Callitiannion $\left(L_{g} b_{3}\right)$. Frons teres, articulata, ramosissima, rosea; articuli uno tubulo latiori longitudinali notati. Fructus Capsulæ ad latera ramulorum subpedunculatæ.

34. Eстоcanpus $(L g b$.$) . Fila articulata, membranacea, ramosissima, fusca. Fructus Cap-$ sule ovate, siliqveformes vel racemose, ad latera ramulorum subpedunculatæ.

35. Bulbocı́te $(A g$.). Fila articulata, memlıranacea, ramosissima, viridia, setis bulbiferis ad summitates articulorum instructa. Fructus Capsulæ sessiles, laterales.

36. Conferva (Lin.). Fila articulata, membranacca, simplicia et ramosa, viridia. Granula in articulis hic illic sparsa.

37. Hydrodictyon (Roth.). Fila articulata, membranacea, in formam reticnli piscatorii connexa, viridia. Fructus Embryon, matri simile, in qrovis articulo invaginatum.

38. ZyGNema (Ag.). Fila articulata, membranacea, simplicia, viridia, denum per tubulos breves transversales conjugata. Fructus Semina solitaria, singulis articulis post copulationem inclusa.

\section{SECTIO V.}

\section{Homalogonata. ${ }^{\star \star}$ ) Frons filifornis, articulata, plana.}

39. Diatona (Decand.). Fila articulata, plana, simplicia, crystalliformia, immediate copulata, tandem articulis solutis angulo alternatim colærentibus.

40. Fragilaria $(l g b$.$) . Fila articulata, plana, simplicia, fragillima, articulis solutis an-$ gulo non alternatim colnarentibus.

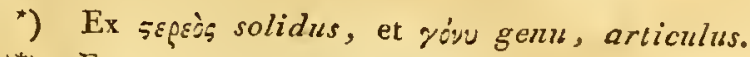

**) Ex rị̣iv tubulus, et góvu.

$\left.{ }^{\star \star *}\right)$ Ex ósaidos planus, el gówu. 


\section{S E C T I O VI.}

Tremelloidata.* ${ }^{\star}$ Frons vel Massa gelatinosa, solida.

41. Batracroserrmum (Roth.). Frons gelatinosa, articulata, ramosa; ramulis ad genicula verticillatis. Fructus Capsule globosx intra verticillos sitæ.

42. Draparatom (Bory.). Frons gelatinosa, articulata, ramosa; ramulis fasciculatis, penicilliformibus. Granula in articulis hic illic sparsa.

43. Mesoglosa (/g.). Frons gelatinosa, clongata, ramosa, filis ex communi frondis axe cxemntibus articulatis capsuliferis farcta.

44. Ch.tophora (Schrank.). Massa gelatinosa, clongata vel globosa, filis ramosis articulatis farcta.

45. Livска (Mich.). Massa gelatinosa, elongatia vel globosa, filis simplicilus rectis acminatis, articulatis vel subcontinuis farcta.

46. Nostroc (Purac.). Nassa gelatinosa, difformis vel globosa, filis simplicibus curvatis moniliformilus fanceta.

47. Arcrovionm (tam.). Massa gclatinosa, clongata, ramosa, olivacca, intus ccllulosa, capsulas solitirias granuliferas incluctus.

48. Pamplea ( / g b b.). Nassa gelatinosa, subliyalina, gramulis solitariis globosis farcta.

49. ECHNel.ta (Achar.). Massa subgclatinosa, granulis solitariis cuncatis clongatisque farcta.

*) Ex Tremella, ex reśsus, tremo, et sidos. 
T E N T A M N

HYDROPHYTOLOGIAE DANICAE. 
Multum allhuc restat operis, mulumqve restabit: nec ulli nato post mille sxecula precludetur occasio alig̣vid adhuc adjicicndi.

Seneca Epist. 64. 


\section{S E C T I O I.}

\section{PHYCOIDATA.}

Frons plana, compressa vel teres, continua, solida.

\section{F U C U S.}

Frons plana, dichotoma, nlivacea. Fructus Receptacula terminalia. turgida, intus mucosa, tuberculis numerosis sphrricis seminiferis fibrisque intertextis repleta.

1. $\boldsymbol{F}^{\prime}$. vesiculosus, fronde dichotoma, costata, integerrima; vesiculis binis Tab. 1. substantiæe frondis innatis; receptaculis tuberculiferis, turgidis, subellipticis.

F. vesiculosus Lin. - Huds. p. 576. - Lightt. p. 904. - Turn. Syn. n. 24. et Hist. T. 88. - Ner. Britt. Tab. 2. - Vell. Tab. 1. - Engl. Bot. T. 1066. - Fl. norv. I, p. 48.

- Esper. Tab. 12. 13. 83. 8. - - Dec. fl. franc. 2, p. 18. - Zoega 1. isl. - Mohr isl. p.226. - Landt. p. 238. - Olafs. it. isl. p. 442, - Siröm Söndm. n. 2. - Horn.

f. oec. p. 925. - Wahl. П. lapp. p. 490. - Ag. Syn. p.4. - Jürg. Alg. aqv. Dec. 2. 11. 1.

F. mamillaris Esp. T. I 8 .

F. quercus marina Gmel. p. 60.

F. divaricatus L. - Fl. norv. 2, p. 143. - Esp. T. 11.

Kyll. Virid. p. 46. n. 2. - Moris. 111. S. 15. Tab. 8. fig. in.

B) spiralis, fronde tenui evesiculosa, spiraliter torta, receptaculis subrotundis.

F. spiralis Lin. - Fl. dan. T. 286. - Fl. norv. 2, p. 64. - Donati p. 32. Tab. 4. Ner. Britt. T. 5. - Engl. Bot. T. 1685 - Sirom. Söndm. n. 3. - Dec. A. fr. 2, p. 19.

ү) inflatus, fronde apicem versus inflata, vesiculis longioribus.

F. inflatus Lin. - Fl. d. 'I' 1227. - Fl. norv. 2, p. 38. - Esp. T. 1o. - Kyll. Virid. p. 45. n. 3 .

d) acutus, fronde angusta, vesiculifera, apicibus productis Ianceolatis.

F. spiralis Esp. T. 14. 72. - Ner. Britt. T. 6.

६) subecostatus, fronde minuta, obsolete costata, tuberculis oppositis marginalibus.

F. vesicul. subecostatus Ag. Syn. p. 5.

F. balulicus Ag. Dec. n. 21, - Sr. Lot. T. 516. fig. a. b. c. e. 
Habitat $\alpha$ et $\beta$ ad littora Danix, Islandix, Færox, Groenlandixe et alibi sat freqvens; $\gamma$ et $\delta$ etian in sinu Othiniensi; $\varepsilon$ in freto Oresundico.

DESC. Radix callus expansus, ater. Frons plana, costata, duos at quatuor et ultra pedes longa, latitudine pollicari, per dielosomias pluries repetitas divisa; dichotomiarum anguli acuti; rami sulfastigiali; frondem totam percurrit costa compressa, supra subusque paululum elevata; frondis membrana immorse reperiuntur Vesicula splaxrica, flerumque line, ad costa latera opposite, extrinsecus glabre, intus care. Fiructus Receptaenla ad frondis apices sita, plerumqre urgida, interdum compressa, unum circitcr pollicem longa, solitaria vel bina, ovata vel elliptica, interdum c'marginatis; in his sita sunt tubercula poris mimutissimis pertusa, qroe scmina subrotunda, limbo pellucido cincta, fibris articulatis pellucidis inmixtis, includunt; in interiori receptaculorum parte adest massa gelatinosa seu mucus aquose pellueidus, fibris confervoidcis, Jichotomis articulatis, pellucidis, articulis dianetro 3 plo longioribus, intertextus. Hic mucus in exemplaribus vetustis interJum cvanescil, fibris solis remancntilus. Color intense olivacens, apicem versus dilutioi, Substantia coriacea, tenax. Perennis.

OBS. Ex poris devatis, per lotam frondem sparsis, fibre alba minutissima fasciculatim congeste sepe progredinntur, qre mieroscopio subjecta: Conferom omnino refermul sumt enim filiformes, geniculatie el sepe ramosx. Ilas fibras, $\mathrm{T} x$ in aliis speciehus, r. c. in f'uco cercenoidi, serrate, Laminaria bulbosa es esculenta, "tiam veperiuntur, Cel. Reaumurius (Nomoires de l'Academie royale des Scicuces 171?. 1. 26. s\%.) o Donatius (in historia waturali maris Adriatici 17.53. p. 32) ecuorgana l'ueormm sexualia olim lablouerunt, eosqve qrodammodo secutus est Ill. Linnceus, ot alii, fros inter recentinres J. WF. L. Luce (cfr. Annales Usteri Fase. XV. p. 39.) cidem opinioni addictus videtur; hxe vero cornm semtentia hodie non admiutur; uam ex foramiunlis tuberenlorum et froudis exeuntes procul dulio nil aliud sunt, qram prolongationes fibrarum, qre in inueo supra memorato versamur, alque igitur ex lextioni plante crescentia potius exuberare at originem ducere, qram pro staminibus habendx sunt; qvare ctian Cr.l. Stakthousius (Ner. brill. in profatione p. Xlli.) pro nuco casudato cas habuit, cumpre serutus est Cel. Rothius (Neuc Beits. P. 1. p. 36.), "t qvidesn rectius; in tota cmim hujus. ut multarum aliarun specicrum, fabsica interua tales filora articulata, nuco in-

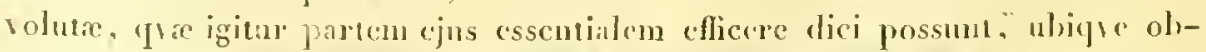
scrvantun: - Preterea iste umens in Medicina, observante Retsselio, fuit ad-

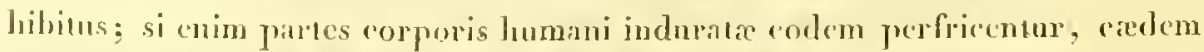
detumescere solemt (cfr. Hist. Turn. in annot. ad fue. resiculosum). - Deni-

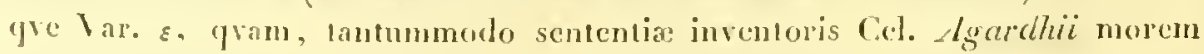
gerens. Ine retuli, nucialis est, dichotoma, vis lineans lata; forsinn melius ad genus spherecocei esset referenda. 
2. F. ceranoides, fronde subdichotoma, costata, integerrima, ramos laterales angustiores fructiferos emittente; rcceptaculis compressis, lineariacuminatis.

F. ceranoides. Linn. - Turn. Syn. 136. et Hist. .Tab. 89. - Ner. britt. T. 13. - Dec. A. fr. 2, p. זg. - Ag. Syn. p. 7.

$F$ distichus Esper. T. 159 .

Kylling Virid. p. 46. n. 7?

Habitat in mari Norvegico, Islandico, Groenlandico; etiam ad insulas Færoenses.

DESC. Radix callus exiguns nigricans. Frons plana costata vel alata, longitudine pedalis vel sesqripedalis, latitndine 3-4 linearis, subdichotoma; rami fastigiati, lineares. Stirps apicem versus ramos emittit laterales, horizontaliter patulos, altcrnos, qvi ad summitates plante breviores evadunt, bifurci aut palmati, segmentis tribus vel qratuor, et ultini vix linean lati; margo ubiqve integerrimus, Jeniter modulatus. Superficies, ut in Fuco resiculoso, poris exiguis fibras emittentibus sparsim pertusa. Frondem totam percurrit costa nigricans, penne passerinæ crassitic. Fruetus Receptaenla lineari-lanceolata, acuminata, compressa vel teretiuscula, poris minutissimis pertusa, gvibus immersa sunt tubercula sphærica, e fibris pellucitis articulatis constantia, immixtis seminibus subrotundis fuseis limbo pellucido cinctis; intus adest mucus argrose pellneidus fibris articulatis immixtis. Color olivaeeus, subdiaplamms. Substantia inter coriaccam et cartilagineam media, tennis. Perennis.

OBS. Antecedentem refert; facile vero dignoscitur partim substantia temuiori et resicnlarnm alssutia, prartim crescendi modo inter dichotomnm et pinnatum intermedio.

3. F. serratus, fronde dichotoma costata, margine serrato-dentata; re- Tab. 1. ceptaculis solitariis, planis, acutiusculis.

F. serratus Lin. - Turn. Syn. p. I10. et Hist. T. go. - Ner. Britt. T. I. - Vell. T. I.

- Engl. bot. 't. 1221. - Esper. T. 5. 6. - Zoega П. isl. n. 1. - Fl. norv. 1, p. 2s.

- Strön Söndm. n. r. - Schum. enum. 2, ए. 113. - Horn. 月. oec. p. 924. - Dec.

ก. fr. 2, p. 20. - Ag. Syn. p. 6.

Kyll. Virid. p. 46. n. I. - Moris. III. S. 15. Tab. 9. fig. r.

Habitat ad oras maritimas Daniae copiose, saxis adnascens, in profundo sinuum et in infimis littoribus ingentem attingit magnitudinem. Etiam in mari Groenlandico. Herb. Fabricii et Giesekii. - Ad insulas vero Færoenses non reperitur.

DESC. Radix callus crassus subconicus. Frons plana, solitaria, costata, longiundine a pedali ad orgyalem el ultri, imprimis in profundo sinum, excrescens; præterea dichotomiis sexies pluriesve repetilis divisa; furcarum anguli acuti; supcrficies poris, punetorum instix, exiguis, fibras fasciculatim con- 
gestas cmittentifus pertusa; frondem totam percurrit costa nigricans, elevata; margo ubiqve serratus vel serrato-dentatus, dentibus mann ad tres lincas longis et sursum spectuntibus. Fructus Recrptaculat plana terminalia mucosa poris minutissimic pertusa. sub qvibus litent Tubcrcula splaxica, immersa, paululum clevata, e tibris pelluejdis, ramosis, anticulatis constantia immixtis senninibus sulnotundis, limbo pellucido cinctis; in statu vero juniori senima adsune in apicibus fibrarum clavatis. Color olivaceus. Substintia coriaceocartilitgineit, lenta. Perennis.

Tab. 1. 4. F. distichus, fronde dichotoma, lincari, obsolete costata; receptaculis lanccolatis, acuminatis.

F. distichus Linu. Syst. - Turn. Hist. T. 4. - Ag. Syn. p. 7.

F. linearis [1. d. T. 35 r - Fl. norv. 2, p. 10 f. n. 835.

F. fliformis Gmel. p 72. T. 1. A. fig. I. - Esp. T. 152*

F. ceranoides Wallenb. n. 9.29

Habitat in fundo maris Islandici. Oeder. - Ad oras Norvegia. Vahl. - Ad insulas Færocnses, sed raro, ut ad rupes praruptas Norbes Eide prope Qvalböc.

DESC. Radix orbicularis, rupibus in summo refluxus limite agglutinata. Frons pendula, basi teres, mox compressa, evesiculosa, longitudine scmispithamæa, per dichotonias ter quatcrve repetitas divisa, linearis, unam lincam lati: nuargo integerrimus. Fructus Receptacula terminalia, turgida, lanceolita, mueosa; T'ubereulit in lis globosa, qre semina oblonga fusca, fibris immixtis, includunt. Color fusco-olivacens, exsiccate niger. Substantia coriacca vel cartilaginca, tentis. Perennis.

Tab. 1. 5. F. canaliculatns, fronde dichotona, canaliculata, ccostata ; receptaculis turgidis, obtusis, emarginatis vel bipartitis.

F. canaliculatus Lin. Sist. nat. - Gmel. T. 1. A. fig. 2. - Ner. Eritt. ed. 2. Tab. 19. Engl. B. T 823 - Vell. T. 1. - Turn. T. 3 - Dec. fl. fr. 2, p. 21. - Ag. Syn. p. 8 . F. excisus Lin. sp. pl. - Fl. d. T. 214. - Fl. no1v. 1. 1. gli. - Strüm Sündm. 11. 7. F. rolundus Esp. T. 17 .

Halitat ad oras Islandiæe König. Mohr. - Ad insulas Færoenses hic illic copiose.

DESC. Radiv cullus exiguns, subconicus. Fromdes angregata, palmam vel spithaman longa, lineam late, prorsus ceostata: hinc lrons siecata, rype ac madida canaliculoti, vel concavo-convexa; nargo integerrimus. Fructus licceptacula terminalia, oblonga, ungrem longa, duas lineas lata, apicc obtusa, bifida, vel cmarginata, intus muro arvose pellucido cum fibris articulatis repleta; Tubercula globosa e fibris compactis articulatis ramosis constuntia et 
scmina oblonga, fusca, oculo nudo visibilia includentia. Color fructiferæ olivaceus, sterilis nigresecns, exsiccate niger. Substantia coriacca lenta.

OBS. In exemplaribus aliqvantum temporis siccatis scmina, quæe dixi, si denuo madefacta lenti subjiciantur, in particulas minores dissolvi sæpius vidi; idem ctiam seminilus Halidr. nodosce accidit; cum vero hoc phænomenon in excmplaribus rcecntibus vix obscrvatur, denominationem vulgo receptam retinui, licet hxe semina codem etiam jure pro congerie seminum vel capsulis haberi posse non negem.

\section{D E L E S S E R I A.}

Frons plana, foliacea, membranacea, costata. Fructus Semina nuda frondi immersa, vel Tubercula glóbosa innala.

1. D. sangvinea; caule terete, ramoso; foliis petiolatis, oblongo-ovatis, Tab. 2. simplicibus, integerrimis; seminibus sparsis in processibus e caule foliaceis oblongis.

Fucus sangvineus Lin. - Fl. d. T. 349. - Fl. norv. 2, p. 9r. - Gmel. T. 24. fig. 2. Ner. britt. T. 7. - Engl. bot. T. 1041. - Turn. Syn. p. 7. et Hist. 'I. 36. - Zoega isl. - Landt. - Esper. T. 38. - Dec. I. fr. 2, p. 27. - Moris. Ill. S. 15. Tab. 8. Fig.6. Delesseria sangvinea Lam. Thal. - Ag. Syı. p. 21.

Habitat in profundo ostii sinus Othiniensis pulcherrima hæc species, stipiti Fuci vesiculosi adnascens; etiam ad ostium sinus Oxefiord Norvegix; in mari Islandico. Ad insulas Færoenses copiose.

DESC. Radix callus plerumqve subconicus. Frons palmam, raro pedem longa. Stipes brevis, pennam corvinam crassus, ramosus. Rami, pctiolorum instar, per folia transeuntes in costas ramosas parallelas mutantur et magis magisque attenuantur. Folia palmam fere longa pollicemqve lata, lanceolata, acuminata, integerrima, undulata. Fructus Semina nuda, subrotunda, foliolis e caule infra folium ortis immersa; reperiuntur etiam tubercula globosa acuta pedicellata seminifera e costa prodeuntia. Color amoenissime roseus, diaphanus. Substantia foliorum membranacea, tenerrima, caulis cartilaginea. Percmis.

2. D. sinuosa; caule terete ramoso; foliis subpetiolatis oblongis, sinuoso- Tab. 2. pinnatifidis; marginibus crenatis; seminibus margine immersis.

Fucus sinuosus Turn. Syn. p. 1. el Hist. T. 35. - Engl. Bol. T. 822. (insolitæ latitudinis).

- roseus Fl. d. T. 652 .

- crenatus Gmel. T. 24. fig. x.

- rubens Ner. britt. T. 7 .

- Palmella Var. Esp. T. 42. 
Ström Sündm. n. 9. et in Acl. Haf́́. 1o, p. 254. fig. 4. Delesseric sinuosa Lam. Thal. - Ag. Syn. p. 22.

B) quercifolia, frondis laciniis rotundatis, marginibus nudis. Fuc. sinuosus $\gamma$. Wahl. ก. lapp. p. 49 r.

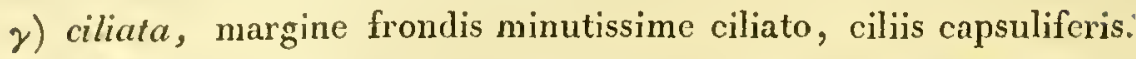
Habitat ad basin Fuci resiculosi aliorumqve parasitice ad oras Dania passim. Ad stipitem Laninarixe digitatæe ad littora Froensia copiose. B. ad Neoburgum Fionix. $\gamma$. ad littus Svinöer Norvegix legi.

DESC. Radix eallus exiguus. Frondes aggregate, pollicares ad scmipedales; folia unica, indivisa, elliptica, oblusiuscula, simnata, sinubus interdum tam profundis, ut frous pinnatifida evadat; sub lente pulcherrime reticulata vel punctata; nargo crenatus ct interdum, imprimis in Varictate $\gamma$, ciliis minutis oblongis cinctus; folium totum percurrit costa t'nuis, ahiis minoribus patulis et suboppositis instructa. Fruetus Semina nuda, in glomerulis oblongis juxta marginem folii dense clisposita vel Tuberenla spherica frondi immer'sa, vel processibus frondis ovatis e costa ortis insidcntia; interdum hae ublercula, qva semina minutissima fusca oblonga continem, in ciliis adsunt. - Color amocne roseus. Substantia membranacea, tencrrima. Perennis.

OBS. Precedentem refert; sed margine crenato ciliatoqve et fructificatione facile distingvitur.

Tab. 2. 3. D. alata, fronde lineari, subdichotoma; ramis alternatim pinnatis; seninibus nudis apici frondis immersis.

Fucus alatus Gmel. T. 25. fig. 1. - Fl. norv, 2, p. 9r. - Fl. d. T. 352. - Esp. T. 3. Ner. britt. T. 13. - T'urn. Syn. P. 144. et Hist. T. 160. - Engl. Jol. I. 1837. Zoega isl. - Ström in Acl. Halin. Vol. 10. p. 357. T. g. Fig. 8. - Dec. fl. fr. 2, p. 28. Delesscria alata, Lam. Tha!. - Ag. Syn. p. 22.

B) angustifolia, fronde subfiliformi, plana, costata, elongata.

Habitat parasitice in stipite Fuci vesiculosi, Laminaria digitatx \&c. arl Amagriam, in ostio sinus Othinicnsis; ad littora Frocnsia copiose; in fundo maris ante ostiun sinus Oxefiord Norvegia. Ad Söndmöer. In occano Islandico König, Zoega. - B. in mari Groenlandico. Herb. Fabricii.

DESC. Radix callus parvus di.pansus. Frondes aggregatar, qratuor circiter pulliees longa. Stipes compressus, penne passerina cressilic. Fo'ium mubranx instar costa annexum, alatum, lincare, lins lattudine. Cesta intcrdum proliferia. Frons plerungve prope ortum bifurea; rani distichi. dichotomi vel urichotomi, ad apices frondis copiosiores; margo integerrimus et planus. Fructus Semina nurla sparsa atrorubentia, partim in marulis oblongis ad apices foliorum sita, partim in foliolis costalibus proliferis, vix lincam 
longis posita; inveniuntur etiam Tubercula sphærica frondis costæ innata et semina minutissima oblonga iucludentia. Color amoene roseus. Substantia membranacea, tenerrima; costæ cartilaginea.

OBS. Varietas, qvam in lerbario Cel. O. Fabricii inveni, statura sua minori facile distingvitur. Primo intuitu Ceramï speciem ob tcnuitatem mentitur; sed diligentius iuspecta plana et costata conspicitur, ramis alternis, subremotis, distichis, patulis, apice subdentatis.

\section{O D N T HAL IA. *)}

Frons plana, membranacea, subecostata, dentata, rubra. Fructus Siliquæx axillares, lanceolata.

1. O. dentata.

Fucus dencacus Lin. - Fl. norv. 2, p. $9^{1}$ - Ner. britt. T. 15. - Turn. Syn. p. 149. et Hist. T. 13. - Engl. bor. T. 124r. - Moris. III. S. 15. Tab. 8. fig:5. - König Fl. IsL. - pinnatifidus Fl. d. T. 354 .

Delesseria dentata Lam. Thal. p. 36 .

Spharococcus dentatus Ag. Syn. p. 22.

Habitat in mari Islandico, Oeder. - Ad littus Norvegiæ meridionale; Prof. Smith in litteris. - In sinu prope Nidarosiam, Sommerfeldt. - Ad insulas Færoenses copiose.

DESC. Radix callus parvus expansus, subconicus. Frons solitaria, spithamæa vel pedalis, plana, duas circiter lineas lata. Costa obsoleta totam frondem percurrit, qra, si planta luci objiciatur, in conspectum venit. Ramuli alternatim pinnatifidi, lincares, infra margine integerrimi, deinde dentati et apice incisi, lacinulis 3 rel 4 brevilous acuminatis. Fructus Capsulæ vel potius Siliqure exignæ, qvæ vel frondis margini solitarie iusident, vel tanqvam panicula ad augulos congestæ sunt (hinc margines frondis tenuissime ciliatos dicit Königius), semina plurima subrotunda serie simplice vel duplici gerentes. Fructus alter, qri apud Turnerum depictus exstat Tab. 13. fig. g. sine dubio hetcrogeneum quid est. - Color obscure ruber, in juniori planta rosens. Substautia membranacca; tenuis. - Perennis. - Autumno cum fructu legi.

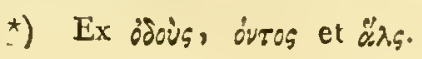




\section{S P H AE R O C O C C U S. *)}

Fron's plana, membranacea, ecostata, rubra. Fructus Tubercula globosa ad marginem sessilia.

'I'ab. 3. 1. S. membranifolius; stipite terete ramoso, apice expanso in folium subcuneiforme, bilobum dicholonumve; tuberculis globosis e caule pedunculatis.

S. membranifolius Ag. Syn. P. 2C.

F. membrafolius Esp. T'. I15. - Turn. Syn. p. 25. et Hist. T. 74. - Ner. brin. ed. 2. I. 20. - Lam. Diss. 'T. 2 r. lig. 3.

- rubens Fl. d. T. 827. - Molir Hist. nat. Isl. p. 217.

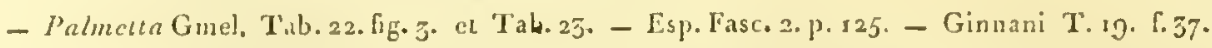

B) stellalus, foliorum apicibus tenuissime divisis, numerosissimis.

久) angustifolius, foliis angustis, sublinearibus, vage divisis, e margine prolileris.

Habitat ad litus Islandiæ, Molır. In sinubus Norvegiae passim, Mïller. Ad littora Danix, imprimis Fionize septentrionalis freqrens. Utramqve Varr. ibidem legi.

DESC. Radix callus parvus expansus, Fucis majoribus lapillibusfje agghlutinatus. lirons semipedalis. Stipes teres, filiformis, inferne simplex, superne vage ramosus. Rami subfastigrali. Folia plana, enervia, late cunciformia, biloha. dichotoma, pollicen fere longit et lata, margine integerrima, apicibus rotundata vel emarginata. Finctus Tubercula parva subglobosa, stipiti et ranis arl Jatera insidentia, pedmeutata, in qvibus scmina minutissima continentur, qvax, capsula fiacta, lanqvann fumulum viredescentcm cxhalasse vidi. Color in caule fuseo-niger, in froude mber, ad apicem sipperoseus. Substantia cautis cartilaginea, foliorm mombranneca. Perennis. Hyeme fert fructum.

OBS. In indice textus latinj Fl. d. T. 82\% locus natilis indicatur: "in sinulus "Norvegie passim," sed per crratum typographicum in textu ejus germanico

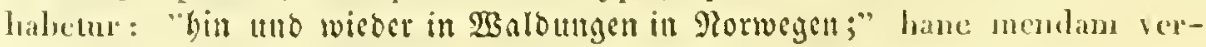
botenus sumens Cel. Espertes, in trinstersum mire abreptus est, cum (Iconcs

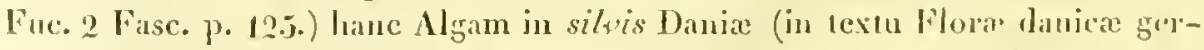
manieo dicitur Norvegie) eresecre aftrunat; codemqve indicio atel opiniontm suan de Fucis mandus, qvippe qui et in montibus terestubus, a mari procul remotis, provenire polleant, stabiliendan utitur: sed lowe ratiocinium, "1" pretitio principii, ex iis, prac attuli, facile labefactatur. - Idem etiam valet de amolatione in Biologia Trevirani 1'. 2. p. 139.

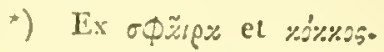


2. S. Brodici; stipite terete, ramoso; apice expanso in folium oblongum, Tab. 3. simples bifurcunre, e margine proliferum; tuberculis sphæricis, ad apices foliorum sessilibus rel brevissime pedicellatis.

Spharococcus Brodiai Ag. Syn. p. 27.

Fucus Brodiai Turn. Hist. T. 72. - Fl. daø. T. 1476.

- membranifolius Lam. Diss. Tab. 21. Gg. 1. 2 .

Delesseria Brodiai Lam. Thalass. p. 57.

B) concatenatus, foliis implicatis, lanceolatis, apice bifurcis, proliferis; rerrucis aggregatis, uræformibus, pedicellatis, frondis e margine ortis. Habitat ad oras Daniæ saxis adnascens, minus freqrenter. - T arietas ad littus Fioniæ septentrionalis hyeme et rere frequens.

DESC. Radir callus exiguus discoideus. Froudes aggregatæ, palmam et ultra longr. Sijpes tercs, inferne simplex, superne ramosus et compressus. Folium planum, ecostatum, elongato-cuneiforme, integerrimum. apice rotundatum, indivisum, vel bis terve dichotomum, ex apicibus prolifernm, folia alia minəra, apice sæpe bifurca emittens. Fructus Tubercula sphærica. capitulo aciculæ paulo minora, ad foliorum apices plerumqre sessilia, solitaria et gemina, apice folii acuminato fulta, interdum etiam ad basin foliorum glomeratim congesta, qræ intus e fibris constant excentricis, ramosis, articulatis, pellucidis. Color fusco-sangrineus, interdum apice foliorum virescens. Substantia caulis cartilaginea, foliorum membranacea, tenuis.

OBS. Tanta inter hanc et præcedentem interest affinitas, ut. fructu deficicnte, a se invicem difficillime discernantur. Inter fibras tuberculi, sæpins examinati, scmina, qræ depingenda curarit Cel. T'urnerus, nunqram, qrod ingenue fateor, indagare mihi snccessit; qvare fructum hujus Algæ venditatum semper mihi eqvidem fuisse suspectum non negabo: credidi enim. et etiamnum credo, tubercula illa laudata nil alind esse, qram parasiticum qrid, idemqre ad genus Chatophorce summo jure pertinere, atqve sub nomine Chotophorce membranifolii hanc speciem jamdndum delineavi ct descripsi; qrodsi vero hæc sententia assumatur, seqvitur, ut Sphceroc. Brodicei, qrippe synonymum omnino $S p h$. membranifolii, de civitate Algarum exterminetur. Auctoritate autem Ccl. Turneri, qvi primus hanc speciem in album retulit, cam retinui. - Varietas $\beta$ froñde gaudet maxime implicata, pedem unum alterumre, si extricetur, longa. Verrucæ, qras disi, pro fructu non sunt habendx, cum in iis nulla unqram conspiciuntur semina. Margini hujus globulum vidi insidentem, similem tuberculis $S_{p}$. Brodicei. Forsan hæc Yarietas propria species.

3. S. Pulmetta; stipite terete, simpliciusculo, apice expanso in folium subcuneiforme, palmatum; tuberculis hemisphæricis, in foliis imprimis ad marnem sessilibus. 
Fucus Palmete 'Turn. Syn. p. 2x, el Hist. T. 73. - Ner, britt. T. 16. - Engl. bot. T. Iта丿. - Esper. '1'. 40.

- Palmesa Far. $\beta$. Lam. Diss. T. 19. fig. 1. 2.4.

Strüm in Act. Hafn. 10, p. 255 . T. g. fig. 6.

G) bifidus, stipite in folium subcunciforme, simplex vel bifidum expanso. F. bifulus lluds. H. angl. p. $58 \mathrm{r}$.

Habitat ad oras Daniae non freqrenter; in fundo ostii sinus Othinicnsis, lapidibus agglutinatus; ibidem Var. B. a me lecta. $-\Lambda d$ oras sinus Oxefiord Norvegize a. sat freqrens.

DESC. Radix callus parvus discoidcus. Frondes aggregátar, 2 vel 3 pollices longic. Stipes plerumcye indivisus, raro bifidus, superne conpressus, platnus. Folium plannu, ecostatum, pollicem longum, multifidu-palmanum vel bifureum; nargo integerrimus; apiecs plerungve rotundati, interdum acutiusculi. Fructus Tubereula hemisphaxiea, in superficic frondis vel sapins in margine posita, qve semina ninuta splaxica mbra includun, fibris nullis immixtis. Color fusco-ruber, apice dilutior, suldiaphanus. Substantia canlis cartilaginca, folii nucmbrantece.

Tab. 4. 4. S. laciniatus; fronde plana, foliosa; foliis dilatatis, apice palmatis, obtusis, margine crenatis et interdum proliferis: tuberculis marginalibus subsessilibus.

Fucus laciniatus Turn. Syn. p. 16r. et Hist. Tab. 69. - Esper T. 1/go. - Engl. bol. T. rotis.

- miniatus Fl. d. T. 769 .

- ciliatus Gmel. p. 176. T. 2r. fig. 1.

- crispus Esp. 'T. 18.

- crispasus Net. Britr. T. 15.

Habitat in sinubus Norvegix, Miiller. Ad insulas Froenses copiose:

DESC. Radix callus expansus, discoideus. Frondes aggregatx, ecostate, e ccutro sxpe prodenntes, 3 ad 6 pollices longa. Stipes mullus. Folia hasi attenuata, deincle dilatata, pollicem fere lata, dichotoma vel potius palmata, apice rotundata et bifida; anguli foliorum rotundati. Margo planus, integerrimus, vel foliolis proliferis obsessus. Fructus Tubercula splicriea ad marginem subsessilia, semina minutissina, ovata, cupraa, nitida includentia. Color anoenc roseus. Substantia cartilaginco-uncmbranacca, infurne crassiuscula, tenax.

OBS. Citat Cel. Turnerus Fl. d. T. "69. arl Fucum rubentem T. sed ex mente Mertensii (2allg. Litt. 3cit. 1810. No. 18. ad 42.) ills tabula sistil l'uc. Lacinictum T., quod verosimile videtur.

'Tab. 4. 5. S.ciliatus; fronde plana, lanceolata, pimato-ramosa, superficie marginibusqgre ciliata; ciliis subulatis margine tuberculiferis. 
Sphrerococcus ciliatus Ag. Syrl. p. 28.

Fucus cilincus Turn. Syn. p. 169. et Hist. T. 70. - Fl. d. T. 353. - Fl. norv. 2, p. 96. Ner. Britt. T. 15. - Engl. bot. T. 1069. - Esp. T. 136. - Wulf. crypt. n. 4x. Horn. A. oec. p. 928 .

- holosetaceus. Gmel. p. 177. T. 21 fig. 2.

- ligulatus. Gmel. p. 178. T. 21. fig. 3.

Ulva ciliata Dec. f. fr. 2, p. 13.

B) fuscus, froude plana, lineari, ramosissima; ramis vage dichotomis, di- Tab. 4 . varicatis, margine ciliatis; ciliis teretibus, subulatis, tuberculiferis.

Habitat in mari Islandico, Oeder. - Ad littora Feroensia haud freqvens. B. ad littus Frederichshaab Groenlandia. Herb. O. Fabricii.

DESC. Radix callus parvus nigricans, interdum fibras teretes emittens. Frons plana, ecostata, longitudine palmaris, basi attenuata, mox latior, semipollicem latitudine æqvans, apicem versus attenuata, simplex vel in lacinias profunde fissa. Margo ciliatus; cilia compressa, patula, lineam longa, simplicinscula vel alternatim ramosa, deusa. Fruetus Tubercula splıærica, eiliis insidcntia, qribus semina minntissima, ovata, cupræa, nitida coutinentur. Color recentis dilnte roseus, siccatx intensior. Substantia membranacco-cartilaginca, lenta, tenax.

OBS. Ciliis proliferis se adglutinat corporibus hetcrogeneis. König. - Frons Varietatis membranacca, ecostata, semilincam lata, dcinde hic illic in lince latitndinem dilatata, apicem versus iterum attenuata, duos tresve pollices lon$\mathrm{ga}$, intricata; rami divaricati, apice ramulis abbreviatis approximatis subulatis diraricatis vel reflexis instructi; margo inferne integer, superne ciliis brevissimis tubereuliferis obsitus. Tuberenla globosa, interdnm rostrata, semina minutissima fusca includentia. Color fuscus, cxsiceate nigricans. Substantia membramacea, tenera. Vidi eqvidem specimina Fuci criniti $T$., qvæ in lanc Varietatem optime quadrare videbantur; attamcin sub Sphcerococco ciliato varictatis nomine eam melius militare posse credidi.

6. S. cristatus; fronde plana, subdiclıotoma palmatave; ramis alternis Tab. 4 . decurrentibus, sursum dilatatis, apice incisis; tuberculis globosis ad marginem sessilibus.

Splecrococcus cristatus Ag. Syn. pò. 29.

Fucus cristatus Herb. Linn. - Turn. Hist. T. 23. - Amoen. Acaủ. 7. p. 477.

- gigartinus Fl. d. T. 394. - Molr Hist. Isl. p. 247. - Fl. norv, n. 847.

B) angustatus, fronde lanccolata, elongata, acutiuscula. Habitat in Oceano Islandico, König. - Ad insulas Froenses in stipite Laminariæ digitatæ haud rarus. - $\beta$. in mari Grocnlandico, Herb. O. Fabricii. DESC. Radix callus cxiguus. Frond's aggrenatæ, sæpe imbricatæ, planæ, basi angustatæ, mox latiores, pollicem cireiter latæ longæqve, ramosæ; rami ap- 
provimati, decurentes, lineam lati, pluries altcrnatim divisi, apicibus bitrifidi; lacinia patentes, breves; angulis obtusis. Margo integerrimus. Fructus Tubereula globosa, oculo nudo visibilia, ad marginem sessilia, semina plurina angulata vel oblonga includentia. Color intense roseus. Substantia recontis rigida, cartilaginca, cxiccatx membranacca. Amnums. Nstatc cum fructu legi.

OBS. Wahlenberg in Fl. sua lapp. citat Fl. d. T. 394. ad suum F. corcineum $\beta$, pusillum; sed licet qradan similitudo interdum, at raro, inter las species observetur, Spharococcun cristatum tamen a Plocamio coccineo bene distincturu habeo; ille cnim ramulis illis secmudis pectinatis, qribus gaudet Ploc. coccineum, nunqvam instuctus reperitus; praterea statura sua minori, et fructu satis differt. Mcmoratu dignum etiam videtur, Janc Algam ab ipso Linnceo nusqvam descrijtam fuisse; exstant tanen, teste Turnero, in herbario ijsius, yrod in Anglia possidet Cel. Smith, qvaluor cjus specinima, omnia simulcum qvatuor Fuci alati, et uno Fuci sinuosi specinninibus, mi cidenqve charta atgglutinata, Titulo ab ipso Linnceo ad basin adscripto: I ucus cristatus, quod nomen ad hane speciem denominandam ideo retinuit T'urnems. Asservatur autem laac Alga in herbario Mertensii sub nomine $F$. cristulati, ut ca denominatione a Fuco cristato $\gamma$ articulato Turn. Tab. 23. fig. h. rite distingratur. De Fuco autem gisartino Kïnigit Fl. d. T. 394. in Fl. Island. ad fincm itineris Olafsen ct Povelsen lixe habctur amotatio:

"Fincus gigartinus Fl. d. T. 394; Frondes dichotonne, bijollicares, ultimx "ramificationes multifidx; lacinic lıx ultimx minimx lanceolat $x$ suls apice "intumescunt in tuberculum globosum, gro increscente, ipse apex ant re"primitur, aut plane evanescit; in utrogre casu tubserculurn videtur pedun"cnlatum, et in priori lacinia apex eristam tubereulun subjacenten refert; "hine descriprtio Limmana intellectu difficillima. Suspicor ceterum nomen "Königii ]’acedenti specici in Syst.nat. Limmano appositun, huic subjun"gendum fuisse." Hac Zoega.

Tab. 5. 7. S. mamillosus; fronde dichotoma, costata, supra canaliculata; ramis clilatatis, integris, utrinqve mamilloso-tuberculiferis.

Splererococcus mamillosus $\Lambda \mathrm{g} . \mathrm{S}_{\mathrm{j} n}$. p. 25.

Fucus mamillosis Esper. T. 122. - Turn. Syn. 11. 13. et Hist. T. 21 S. - Engl. Bot. T. 1051.

- spermoplorus Fl. norv. 2, p. 26. n. 414? (sec. Wahlenb.)

- alveolatus Esp. T. 7o.

- ceranoides V"ar. d. Gmel. p. Ir5.

- coronipifolius; Künig, Zocga, Molir, Honker.

Habitat ad littus Svinöer Norvegia prope Lindesnxs; ad insulas Faroenses copiose.

DESC. Radix callus exiguus. Frondes aggregatx, costæexpertes, ab una frondis parte plus minus canaliculatx, palmam et ultril longre, per dichotonias ter qra- 
terve repetitas divisæ; anguli dichotomiarum rotundati; ramuli ad basin lineam fere lati, sed statim magis magisqve dilatantu'; apices rotundati, interdum emarginati, mamillis sive rameutis brevibus clavatis tam in margine qvam in utraque folii pagina obsessi, qui tamen iu junioribus et in is, qva maxime aggregata erescunt, sxpe absunt. Fructus Semina minutissima ovata vel pyriformia in mamillis sive tuberculis breviter pedicellatis inclusa. Color violaceus, apice ruber. Substantia cartilaginea, superue membranacea, rigida, lenta. Peremis.

OBS. Ex mente TI ahlenbergii Fucum spermophorum Gunn.' ut synonymum hic adposui; neqve tamen me fugit, Cel. Turnerum plantam Gunneri ad summ Fucum spermophorum allegare; cum vero ista alga extra Occanum Iudicum, Ceilonam allueute, noudum, qvantum scimus, inverita fuit, vix maris Nordlandici accola labenda est. Ceterum criteriis brevibus, qvæaffert Königius, permotus, Fucum coronipifolium Köng luc etiam pertinere credo.

\section{CHONDRUS. *)}

Frons plana, dichotoma vel ramosa, rubra. Tubercula hemisphærica, apicibus frondis innata.

1. Ch. crispus; fronde dichotoma, crispa, ecostata; ramis dilatatis, inte- $-\mathrm{Tab} . \$ 5$ gris; tuberculis solitariis, apici frondis immersis, hine concavis.

Fucus crispus Lin. - Fl. norv. 2, p. gr. n. 748. - Turn. Syn. n. 42. et Hist. T. 216. et 217. - Olafs. ir. isl. p. 445. - Koenig. - Horn. 月. occ. p. 928.

- polymorphus Lam. Diss. Tab. 4. fig. 8. Tab. 5. fig. ro. II.

- ceranoides Gmel. Tab. 7. fig. I. - Esp. 'I. 98. fig. 1. 2. 3. - Schum. Enum. 2, p. 112.

Spharococcus crispus Ag. Syn. p. 24.

Ulva crispa Dec. 月. fr. 2, p. 13.

B) stellatus, submembranaceus, ramis dilatatis, apice in lacinias numerosissimas, breviusculas divisis.

Fucus stellatus, Ner. Britt. T. 12:

y) cequalis, cartilagineus, ramis omnibus æqvalibus, linearibus; laciniis Tab. obtusis.

Fucus crispatus Fl. d. T. 826 .

- crispus Ner. Britt. T. 12. - Esp. T. 144. A.

- polymorphus Lam. Diss. Tab. 6. fig. 12. Tab. 8. fig. 16. T. 9. f. 22.

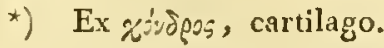


d) filiformis, cartilagineus, ramis sublinearibus, planis, laciniis elongatiu= sculis acutis.

Fuc. fliformis Huds. p. 585.

- seranoides Gm. p. 115. Tab. 7. 6g. 3.

£) pumilus, cartilagincus, ramis compressis, dilatatis, dichotomo-palmatis, divaricatis; tuberculis hemisphæricis apici laciniarum innatis.

Fuc. pumilus Fl. d. T. 1066.

- pusillus Esp. T. 142.

ל) incurvatus, cartilagineus, ramis infmis simplicibus; appendiculatis; secundis, deinde dichotomis, compressis, angustis; laciniis multifidis, elongatis, acutis, apice ad unam partem omnibus incurvatis.

ท) zuncincutus, cartilagineus, linearis, ramis angustis, apicibus ad instar cornuum arietis utrinqre reflexis.

Habitat $\alpha$. ad littora Froconsia lrand frequens. Varietates, excepta $\varepsilon$, qvam in scopulis maris Nordlandici legit Cel. Vahlius, ad oram Fionix septentrionalem ad unam omnes legi.

DESC. Radix callus exiguus. Frons plerumqve solitaria, plana, in o crispo-undulata, encrvis, palmari ad spithameam longitudine, basi attenuata, cum ad pollicarem supra basin altitudinem pervenerit, dichotoma, et deinde per 6 vel 8 dichotomias, intcrvallo inter singulas pollieari vel semipollieari, divisa; anguli dichotoniarum nunc acuti, nunc rotundati. Rami basi attenuati, sursum paulo dilatati; latitudo corum diversa, inferne plerumqve lincaris, superne bilinearis, sæpe vcro latior. Margo integerrimus. Fructus Tubercula solitaria in apice ramulorum disposita ab una pagina convexa, alb alcera concara, lucem versus imprimis manifesta, in quibus seinina ninutissima ovata contincnzur. Color fusco-rubcr. Substantia cartilaginea, lenta, tenax. Peremis. Vere cun frucu legi.

OBS. Summo jure Proteus hace alga salutari potest, qrod ex Varictatibus nulcis allatis facile pateı. - Var. $\zeta$ pedalem et ulıra longitudinem assergitur, linean modo lata. - Var. $\forall$ non nisi in palmarem longitudincm cxcresecns, crassa, vix lineam lata, per apices suos utrinque reflexos aliis Phycoidatis inlıxet.

2. Ch. norvegicus; fronde plana, dichotoma, ccostata; ramis linearibus integerrimis, apice rotundatis; tuberculis hemisplnæricis frondi insidentibus.

Fucus norvegicus Fl. norv. 2, p. 122. Tab. 5. fig. 4. - Esp. T. 153. fig. 1. 3. 4. - Tura. Syn. p. 222. et Hist. T. 4I. - Engl. bot. T. 1080. - Ner. brist. ed, 2. T. 18.

- polymorplus I'ar. Lam. Diss. T. 8. fig. I9.

Sphocrococcus norvegicus Ag. Syn. p. 24 . 


\section{Hąbitat in oceano Norvegico, Gunnerus.}

DESC. Radix callus tenuis. Stipes brevis', infra teres, mox compressus, planus. Frondes aggregatæ, eucrves, tres cireiter pollices longæ, lineam latæ, per dichotomias pluries repetitas divisæ; anguli acuti. Rami patentes, plerumqve spiraliter contorti, apice rotundati vel bifidi. Margo integerrimus. Fructus Tubercula hemisphærica utriqve frondis paginæ insidentia et e fibris articulatis constautia. Color sangvineus, superne roseus. Substantia cartilaginea, lenta, tenax.

OBS. Plantam Gunneri esse eandem, qvam descripsit Turnerus, non certo constat. Sunt, qvi credant, Fuc. norv. Gumn. esse modo Chondri crispi Varietatem, cui tamen opinioni, speciminibus utrinsque collatis, haud assentior.

3. Ch. Bangii; fronde plana, ramosa; ramis sublanceolatis; margine Tab. 3 . crispo-lacinulatis; lacinulis obtusis, furcatis; tuberculis subglobosis, frondi innatis.

Fucus Bangii Fl. d. T. 1477 .

Sphorococcus Bangii Ag. Syzr. p. 24.

B) tenuior; fronde angustissima, hic illic dilatata; margine crispo-lacinulata.

Habitat ad littus Hofinansgave Fioniz, ubi Cel. Hofmann Bang, cujus fert nomen, laanc pulchram speciem primus detexit. Etiam ad littus Abelöe prope Fioniam. - Varietatem ad oram Hofmansgave legi.

DESC. Radix exiguus concolor. Frons solitaria duos tuesve pollices longa, semiliueam ad unam lata. ecostata, plaua, vage ramosa, sinuato-flexuosa, implicata, stipite nullo vel perbrevi instructa. Folia vel potius rami lineares, hic illic dilatati, patuli, curvati, sine ordine dispositi, nunc dissiti nunc approximati, aliisqve ejusdem latitudiris et divisionis obsessi. Margo ubiqve lacinulatus, ubi vero frons in folium nembranaceum paulo dilatatur, ibi margo sæpe crenulatus. Lacinula brevissimæ, vix semilineam longæ, raro simplices, acutx, sxpissime apice obtusæ, et bi-vel trifurcatæ, fursis utrinqve falcis instar reflexis, ut plurimum alternatim secunda, e margine frondis convexo progredientes, et tunc alter frondis margo coneavus, integer permanet. Fructus Tubercula subglobosa, 4-granulata in substantia frondis remote et inordinate sparsa, paululum clevata, fuseo-rubra. Color intense rosens, ad basin et in medio interdum virescens. Substantia frondis angustatæ cartilaginea, dilatatæ membranacea, rigida, tcnax. Siceitate non mutatur. Perennis. Hycme inprimis reperitur.

OBS. Phycoidatis majoribus adıascens; inter rejectamenta maris radicibus Zosterce marina haud raro implicitus. Ob frondis qvalemcunque crassitiem ct rigidi- 
tatem charte non adheret. Fructus rarissimus et in unico specimine hactenus olsscrvatus.

4. Ch. rubens; fronde plana, obsolete costata, prolifera; foliis ellipticis, simplicilus bifurcisqre; tuberculis hemisphæricis rugosis, frondi insidentibus.

Fucus rubens Lin. - Turn. Syn. p. 216. et Hist. T.42. - Engl. bot. T. 1053. - Ner. britl. ed. 2. T, 19.

- epiplizllus Fl. d. T. 708.

- prolifer Lightf. 2, T. 30. - Esp. T. 129. - Dec. 月. fr. 2, p. 29.

- laciniatus Gmel. p. เ\$2. T. 22. fig. 2.

- Lanceolatres Retz. Prodr. n. 1707?

Sphocrococcus rubens Ag. Syn. p. 23.

Strǜn Sündin. n. ic. et in Act. Hafur. Vol, ro, p. 255. Tab, \&. f. fig. 5.

Habitat in sinubus Norvegia, Oeder. - Ad oras Islandize. - In mari Norregico ad Söndmöcr, Ström. - Ad oram septentrionalem Sellandiæ, Dr. Schout.

DESC. Radix callus expansus, temuis. Frons palmaris vel spithamæa. Sripcs teres, lincam unam alteranve longus, superne compressus. Folia sesyripollicem circiter longa, et duplicis formx, partim elliptica et sinplicia, partim apicen versus dilatata et bifurca; anguli et acuti et obtusi; alia folia prolifera e superficie frondis oriuntur, plermunge solitaria, ceteris similia. Margo planus integerrimus. Mediam fronden percurrit costa obsoleta, fronde crassior, in foliis primariis luci objectis inprimis manifesta, ceterum in substantia frondis scusin sensimqve evanesceus. Fructus 'Tubereula hemisphærica, extrinsecus rugulosa, superficiei frondis immersa, qva scmina minutissina oblonga includunt; oriuntur ctiam c fronde foliola peltata, granulis exiguis immersis, qræ an ad fructum pertineant, incertum. Color ruber. Substanstantia submembranacea, tenuis. Perennis.

5. Ch. laceratus; fronde plana, subdichotoma, venosa; foliis sublinearibus, apice rotundatis, margine crispo-lacinulatis; tuberculis hemispharicis immersis, seminibusqre nudis.

Fucus laceratus Gmel. Tab. 21. fig. 4. - Ner. britr. T.13. - Engl. bot. T. 1067. - Turn. Syn. P. 154, el Hist. T. 68. - Dec. 月. fr. 2, p. 28.

- crispacus Limn. Syst. nat. - Fl. norv. 2, p. 32 . n. 4\%7. - Esp. T. go.

Habitat in oceano Norvegico, Gunnerus.

DESC. Radix callus exignus. Frondes solitarix vel aggregatx, non costatx, scd venis aliqvot, sub lente et oculo nudo conspicuis, instructe, palman circiter longre, duas tresve lineas latæ. Folia per 5 vel 6 dichotomias divisa, ct ad apices laciniis brevibus ohsita; apiecs rotundati; nargo undulatus, raro integer, sxpissine crispo-lacinulatus; lacinula exiguac ovata. Fructus Tubcrcula he- 
misphærica, margini frondis imprimis immersa vel in laciniis disposita, semina plurima subrotunda intense rubra includentia; reperiuntur etiam semina muda, qvæ in maculas oblongas vel rotundas per ramos supcriores congestæ sunt. Color ruber, diaphanus, apice rosens. Substantia membranacca, tenerrima et ob tenuitatem folia nunqvam non lacerata, unde nomcn.

\section{Z O N A R I .}

Frons plana, orbicularis, adpressa. Semina nuda in lineas transversales concentricas disposita.

\section{Z. deusta.}

Zonaria deusta Ag. Syn. p. $4^{0}$.

Fucus. Fl. d. T. $4^{20}$. (excl. syn. Imperati).

- fungularis, coriaceus frondibus semicircularibus imbricatim sessilibus, subvillosis, fuscis, lasciis ochraceis el striis concentricis. Oed. Enum. n. 176. - Zoega ad finem itin. isl. Olafsen et Povelsen. - Mohr isl. p. 248. - C. Bauh. Pinax p. 364. - Moris. III. p. 645 .

- fungularis Gunn. 2, p. ro7. n. 852. Fungis affinis.

Habitat in mari Islandico, König, Zoega, Mohr, Hooker. - Ad rupes maxitimas insularum exteriorum ante ostium sinus Oxefiord prope Arendal Norvegiæ legi, paulo infra superficiem aqva marinæ.

DESC. Frondes aggregatx, imbricatæ, suborbiculatæ, adpressæ sive rupibus per totam frondem affixæ, dianetro fere semipollicari, vix semilineam crassæ, tenues, lineis transversalibus concentricis notatæ, glabræ, haud vero villosæ. Ciolor fusco-rubcr, extremitate dilutior, exsiccatæ nigricans. Substantia coriacea, rigida, exsiccatæ fragilis. Chartæ non adhæret. - Estate legi.

OBS. Sub lente contextus cellulosus e fibris dense compactis longitudinalibus parallclis, vel moneculis aggregatis constare cernebatur. Propria species unacum Fl.d. T. 420, minime vero basis Himanthalice lorece, ut nonnulli crediderunt, hæc placenta salntanda cst. Saxis Danix marinis aggutinatam, chartamqve, cui imponebatur, colore amoene roseo obducere, at semper minorem, et sine striis, eandem inveni. A Chatophora pellita, de qvâ infra, sublente diversissima, licet habitu externo similis. Incertus an digna, cujns nucntionem facerem, esset, auctoritate Cel. Agardhii hic locum ei assiguavi. 


\section{LAMINARIA.}

Frons plana, stipitata, olivacea, radice fibrosa. Semina uuda frondi alicubi immetsa,

1. L. digilala; stipite terete, apice expanso in folium unicum, ovale, subcordatum, integerrimum, in laminas plures ensiformes profunde fissum.

Laminaria digilaza Lam. Thal. p. 22. - Ag. Syn. p. I8.

Fucus digitatus Lin. Syst. nat. - H. d. T. 392. - Esp. T. 48. 49. - Ner. britt. T.3. Turn.Syn. p. 207. et Hist. T. 162. - Zoega. - Mohr. - Lands. - Nov. act. sor. oce. dan. x, P. 516. 'I'. 4 .

- hyperboress Fl. norv. n. 6r. Tab. 3. - Amoen. Acad. 7, p. 477.

- bifurcatus Fl. norv. 1, p. 96. n. 312. - Act. Nideros. 4, P. S6. T. 6. fig. 2. - Amoen. Acal. $7,5.477$.

Ulva digitaza Dec. ก. fr. 2, p. 16.

Phycodendron v. Fucus Arbor Olafs. it. isl. p. 443.

Fucres Ström Söndm. n. 14. et in Act. Hafn, 10, p. 250. T. f. Fig. r.

Habitat in fundo sinuum Færöcnsium profunditate plurium orgyiarum, superficiem maris, aqra decrescente, sylvæ instar, attingens; etiam ad oras Ditnire, ut in fundo ostii sinus Othiniensis.

DESC. Radix in fibras divisa plurimas, radiatim dispositas, ramosas, apieibusque ineurvis saxa, quibus innaseuntur, tenaeiter prehendentes. Planta maxime gregarix. Stipes pedalis, ercetus, indivisus, solidus, pemam anserinam ad digitum crassus; ad insulas autem Froconses gigantens, 3 nluas longus, brachiumqge fere humanum ad infimam partem crassus. Folium nnicum, planum, subrotundun vel flabelliforme, prorsus cuerve, longitudi$n \mathrm{em}$ hominis interdun bis terve superans, et in lanellas vel lacinias plurimas ensiformes, integerrimas, acuminatas fissum. Fruetus ignotus. Color olivaceus. Substantia stipitis lignosa, intıs mucosa, fulii cartilaginea, lenta. Perennis.

OBS. Folium in aqva dulci immersun visci pellueidi plurimum effundit, exsiceatumqve pulvere tenuissino albo, qri saecharum sapit, hic illie obductum reperitur, ommino ad instar Laminarice saccharinae. - In slipite hujus Algx maximo ad littora Færoensia et Norvegiea latc erescunt et liabitant Delesseria sanguinea, simuosa, alata; Ulva palmata; Plocamium coccineum; Ptilota plumosa; Callithemenion Rothii, roseum \&c. - Deniyve non est eclandum, in Aet. Nidros. 5. Procm. p. 1?, haxe juxlat annotationcm ipsius Rev. Gunneri, tune vita defuncti, afferri: "Fucus bifurcetus Act. Nidros. Tab. "6. fig. 2. cst Var. insolita Fuci digitati L."

2. L. bulbosa; stipite plano marginibus undulatis, apice expanso in folium unicum integerrimum, in laminas plures ensiformes profunde fissum; seminibus margini stipitis undulato immersis. 
Laminaria bulbosa Lam. Thal. p. 22. - Ag. Syn. p. 18.

Fucus bulbosus Esper. T. 123. - Engl. bot. T. 1760. - Turn, Syn. p. 212. es Hist. T. 163.

- polyscides Ner. britt. T. 4. - Landt. descript. Færoens.

- palmalus Ginel. T. 30 .

Ulva bulbosa Dec. 月. fr. 2, p. 16.

\section{Habitat ad insulas Færoenses, Landt.}

DESC. Radix tuberiformis, globosa, magnitudine pyri, qvin capitis infantis; intus cava, extrinsecus fibris densc obsila horizontalibus, lineam nnam alteramve longis, qvibus planta rupibns tenacissime adhæret. Stipes planus, coriacens, semel tortus, longitudine semipedali, marginibus inferne insigniter undulatis fimbriatisqve. Folium planum, prorsus enerve, peripheria oblongum vel cordito-rotundatum, in laminas 6 ad 20 simplices integerrimas fissnm. Superficies lavis; in plante tamen junioris superficie adsmnt pori minutissimi, e quibus progrediuntur fibræ alba fasciculatim congestæ. Fructus semina nnda in margine stipitis undulato, interdum in ipso stipite foliiqve basi posita, oblonga, pellucida, fibris albis simplicibus copiose interjectis. Color intense olivaceo-viridis, nitens, opacns, exsiccatæ nigricans. Substantia radicis et stipitis coriacea, folii cartilaginea, lenta, tenax. Pereunis.

OBS. Giganteam vel arboream hanc speciem appellarunt antiquiores Algologi; nec mirnm; superat enim magnitudinc Lam. digitatam, saccharinam et qvæ sunt cetera insignis amplitudinis Thalassiopliyta, ad nostra litlora obvia; et affrmant Cell. Lightf foot et Stackhouse in tantam molem excrescere plantam, nt qvandoqve vix humeris sit sustinenda. - Praterea auctoritate Rev. Landtii, qvi ad insulas Frroenses hanc speciem se invenisse testatur, in ca alleganda nixus sum. Ipse eam ibi non vidi; sed incolæ harum insularum de radicibus Fuci, globulos magnos referentibns, qvi tempore hycmali in littora ejiciebantur, narrarunt; et cum hæc alga ad oras Scotiæ provenit, assertio illorum verosimilis est; qvare nullus dubito, qvin inter nostras sit annumeranda; sed Fucus bifurcatus Gunn. testimonio ipsius Rev. viri, qvod ad præcedentem spcciem nuper citavi, ad Laminariam digitatam pertinere censendus est.

3. L. succharina; stipite terete, apice expanso in folium lineari-lanceo- Tab. 5 . latum, irtegerrimum, indivisum; seminibus sparsis hic illic folio innatis.

Laminaria saccharina Lam. Thal. p. 22. - Ag. Syn. p. 17.

Fucus saccharinus Lin. - Turn. Syn. n. 37. et Hist. T. 163. - Gmel. T. 28. fig. 1, Esp. T. 24. 56. - Fl. norv. 1, 52. - Olafsen it. isl. p. 443. - Hornemann A. oec. p. 927. - Sirö̀m Söndm. n. 12. - Zoega.

Ulva saccharina Dec. I. fr. 2, p. 15 .

- longissina f. norv, 2, p. 128. Tab. 7. fig. 2.

Kyll. Virid. p. 46. n. 1.

B) bullata, fronde bullata, marginibus undulatis. 
Fucus saccharinus Fl. d. T. 116. - Esp. T. 57. - Ner. britt. T. 9. - Engl. bot. T. 1376. - Gmel. T. 27.

Ulva lalissima Lin. Syst. nat. p. 719.

Ulva mesenteriformis Roth. Cath. bot, r, p. 210.

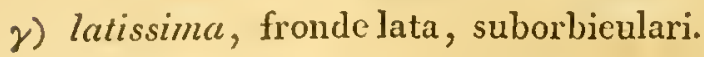

Ulva maxima $\mathrm{Fl}$, norv. 2, p. 127. T. 7. fig. 5.

Habitat $\alpha$. et $\beta$. ad littus Neobnrgi Fionix; in fundo ostii sinus Othiniensis; ad insulas Færoenses; ad Islandiam, Hooker; $\gamma$. in Occano norvegico, Gunnerus; etiam in profundo ostii sinus Othiniensis.

DESC. Radix ut pracedentis. Frondes gregarix. Stipes pedalis, erectus, pennx olorinx crassitic, teres. Folium unicum planum simplex ensiforme prorsus enerve, ab uno ad octo pedes longum, et ab uno ad octo polliees latum; basis folii lcviter cordata vel rotundata; margo integcrimus, plerumqve undulatus: apex acutus, interdum rotundatus. livuctus macula longitudinales in meelio frondis disposite, folium duplo crassius reddentes, qva, si microscopio subjiciunur, e seminibns minutis oblongis fuscis constare reperiuntur. Color olivaceus; soli diu objectx, albescit. Substantia cartilaginea, junioris membranacca. Stipes perennis, folium annumun.

OBS. Pulvis ille albus, qro folium exsiccatum, si aqva pura sal marinus non satis expurgatus fucrit, olducitur, et qvi saccharum sapit, hic, teste Gmelino, non nisi sal marinus est in substantia frondis eflorescens; si enin quadan copia sumitur, puìgantem habet effectum, sale fibras intestinales vellicante. Ceterum 1 on hanc speciem, sed Ulvam palmatam ct edulem (Fucum palm. et edul. Turn.) csse veram Algan sacchariferam Borrichii (Aet. med. et plilos. Hafn. Vol. 1. p. 119. et Vol. 4. p. 159.) satis docuit Moler in Ilist. nat. Island. et Stephensen in Nov. Act. soc. reg. dan. oce. Vol. 1. p. 491. sq.; unde Linnceus lhanc minus recte saccharinan appellavit. - Denique teste Turnero, qvi herbatrium Linnaei consuluie, scimus, Ulvam latissimam L. nil alind esse qram frustulum hujus speciei Var. Jullata. Ista Virrietas bullata, qva ael insulas Froenses freqvens occurrit, costi longitudinali instrueti sirpenumcro videtur; bullie enim ntrinqve adsunt, protuberationes in utraque fulii parte eflicientes, qra siccitx collabuntur, el partim concarx partim convera cradunt hinc minga folii siecati rugositas oritur: in medio vero, ubi plerumere mullic fucrunt bulls, plana folii prars costan Iongitudinalem mentiurs - Praterea stipitem perennem, folium anmum divimus; hoc ex observationilus Dilloynii, 'Tuneri aliorumque ita intelligendum est: Ex apiec stipitis normu qrotannis oriur folium, a qro vetustum, munere suo perfunctum, sensim sensimqve propellitur; vetustum tamen non prius decidit, qran novum in magnam jan cxereverit molem; qvo facto, axtate confectum frustratim delabiur. Iline fit, ut folium, qrod ipse observavi, e duabus interdun partibus constarc vidcatur, qrarun inferior, ut junior, substantian liabet supc- 
riori tenuiorem. Iden crescendi modus in Laminaria Agaro observatus dicitur.

4. L. Phyllitis; stipite compresso, apice expanso in folium unicum, lineari-lanccolatum, utrinqve acuminatum, integerrimum.

Laminaria Phyllitis Lam. Thalass. p. 22. - Ag. Syn. p. rg.

Fucus Phollitis Esper. T. 149. - Ner. britt. T. 9. - Turn. Syn. p. 193. et Hist. T. 164. - Engl. bot. T. 1331.

Cilva phyllitis Decand. A. fr. 2, p. 15.

Habitat ad insulas exteriores ante ostium sinus Oxefiord Norvegix, aliis Phycoidatis innascens, at raro.

DESC. Radix fibris 4 vel 5 simplicibus, abbreviatis, vix lineam longis instructa.

Frondes subaggregatx. Stipes pemnam passerinam crassus, basi teretinseulus, dein scusim magis magisqve compressus. Folium plannm, simplex, longitudine palmari, latitudine ungviculari, prorsus enerve, sub lente reticulata. Margo integerrimus, leniter undulatns. Fructus ignotus. Color fusco-flavus, exsiccatæ virescens. Substantia folii membranacea, tenerrima, stipitis cartilaginea. Amnua. - Exsiccata chartæ adhæret. - Forsan modo Varietas præccdentis.

5. L. esculenta; stipite terete, pinnis onusto, folium ensiforme integerrimum percurrente; seminibus pinnis immersis.

Laminaria esculenta Lam. Thalass. p. 22. - Ag. Syn. p. 16.

Fucus esculentus Linn. - Lightf. 2, T. 28. - Turn. Syn. p. roł. et Hist. T. 1r7. Fl. d. T. 417. - Engl. bot T. 1759. - Esper. T. 126 - Ner. britt. ed. 2. T. 20. - Stephensen in Nov. Act. soc. oec. dan. 1, p. 5 เn. T. 2. - Act. Hafn. Vol. in, p. 252. T. $f$. Fig. 2. - Olafs. it. Isl. p. 443. - Zoega. - Mohr. - Landr. Ström Söndm. n. 13. - Horn. 月. oec. p. $9^{27}$.

- fimbriatis Gmel. p. 200. T. 29. fig. x.

- pinnacus Fl. norv. n. 313. - Act. Nidros. 4, p. 84. Tab. 8. fig. r.

Habitat in mari Islandico et Norvegico; ad insulas Færoenses copiose, ubi rupibus præruptis in superficie maris adnascens summæe fluctuum vehementiæe exponitur.

DESC. Radix e fibris plurimis constans, teretibus ramosisqve. Frondes gregarix. Stipes simplex, inferne tcres, deinde apice compressus, pennam corvinam et srepe digitum crassus, et spithamam vel nltra longus. Folium simplex, unam ad 10 nlnas longum, et latitudine duos ad octo pollices æqvans, ad apicun vi fluctuum ob tencritatem semper laccratum, attenuatum. Margo intcgerrimus, leniter undulatus. Superficies punctis cxiguis, fibras albas fasciculatas emittentibus, pertusa. Pinmæ, qra stipitcm vestiunt, planæ, avenix, distichæe sparsa, approximatæ, cunciformes, pollicari ad semipeda- 
lem longitudine. Fructus Semina exigua, pinnis inmersa. Color olivaceoviridis, diaphanus; cocte (costa enim comeditur) viridis. Substantia stipitis cartilaginea, folii membranacea, tenerrima. Perennis.

6. L. Agarum; stipite terete, expanso in folium unicum, elliptico-sub-' rotundum, foraminibus pertusum, seminibus nudis in maculas per totam frondem sparsas dispositis.

Laminaria Agarum Lam. Thalass. p. 22. - Ag. Syn. p. 17.

Facus Agarum Gmel. p. 210. T. 52. - Turn. Hist. 'T. 75. - Fl. d. T. 1542.

- Clathrus Esp. T. 128.

Habitat in sinu Hudsonis Groenlandia, unde Cel. Wormskiold plura et qvidem pulchra specimina apportavit.

DESC. Radiv'fibrosa, filrris plurimis, ramosis, incurvis instructa. Stipes teres, pollicem ad pedem longus, penux passerinx et haud raro digiti hunnani crassitie, intus interdun cavus, mediam frondem costx instar perenrens, nervos nullos laterales cmittens. Foliun unicum, simplex, oblongum, pedem unum alterumve longum et latiudinis paulo minoris, ubique tanqvam cribrum foraminilus crebris pertusum; foramina $2 \mathrm{vel} 3$ lincas circiter in cliametro habentia, orlbicularia et sæpe angulata. Margo a Gmelino dentatus describitur, est autem, si frons illisa permanserit, omnino integerrimus, uudulatus. Fructus Semina cxigna, subrotunda, fusca, in maculas spher ricas congesta per totam frondem ubiffec sparsas. Color flarescenti-fuseus, crsiecatæ nigricans. Substantia stipitis lignosa, folii nembranaceo-coriacea. Peremis.

OBS. Frons perforata huic specici essentialis nota; semper enim, qrin etiam in prima plantx infantia, adsunt foramina, unde patet, ea e casu aliqro fortuito non oriri, sed revera ex ipsa stirpis indole pendere. Similia foramina in fronde Ulice reticulatce Forsk. e mari rubro allatie, observantur; ct inter plantas phancroganas exstat Dracontium pertusum foliis collem ferc molo perforatis. Cuínam vero fini a natura comparatis sint, id altioris, est indaginis, et tridem dictu difficillinum.

\section{U L V A .}

Frons plana, expansa.| Semina nuda, substantixe frondis hic illic immersa.

1. U.palmata; fronde palmata, integerrima; scgmentis oblongis, simpliciusculis; seminibus nudis per totam frondem sparsis.

Ulva palmatr Dec. A. fr. 2, p. 12. - With. 4. p. 125.

Halymenia palmata Ag. Syu. p. 35 . 
Fucus palmatus Lin. - Turn. Syn. n. 33. et Hist. T. r15. - Light. Tab. 27. - Engl. bot. T. 1306. - Ner. britt. ed. 2. 'I'. 19 - Fl. norv. 2, p. 6ig. - Olafs. it. isl. p. 444. 342. - König n, 20. - Landt. - Nov. Acl. soc. reg. oec. dan. I, p. 492. T. I.

- ovinus Gunn. Act. Nidros. 4, p. 85. T. 9. - Fl. norr. 1, p. 96. - Mohr Hist. isle p. 245 . - Horn. A. oec. p. 926 .

- caprinus FI. d. T. 1128. - Esp. p. 146. T. 74.

- bullatus Fl. d. T. $77^{\circ}$.

- rubens Esper. T. 75 .

Alga saccharifera Olai Borrichii, cfr. Barthol. Act. med. et phil. Hafn. r6zr. Vol. r, p. 119. et 1676. Vol. 4. pag. I59. cum icone.

B) marginifera, fronde oblonga, subsimplici, marginibus proliferis.

Ulva caprina Fl. norv. 2, p. 126. Tab. 6. fig. 4. - Nov. act. soc. reg. oec. dan. 1, p. 513. Tab. 3.

भ) laciniata, fronde tenuiter laciniata, foliolis sublinearibus.

Ulva delicatula Gunn. Fl. norv. 'T. 8 .

Fucus delicatulus FI. dan. T. rigo.

d) simplex, fronde cuneiformi, indivisa, membranacea:

Halymenia palmaia \& simplex Ag. Syn. p. 36 .

Habitat in mari Norvegico prope Laurvig, Miüller. - In oceano Islandico copiose; ad insulas Færoenses copiosissime, tam lapidibus ad superficiem maris agglutinata, qram stipiti Laminariæ digitatæ aliarunqve parasitice insidens.

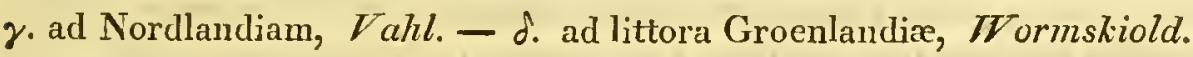

DESC. Radix callus cxiguus discoideus. Frondes maxime gregarix, basi angustx, mox latior's; ; foliuin planum, ecostatum, spithamam circiter longum pollicemqve latum, bifurcum vel palmatum, segmentis tribus pluribusve instructum; margo integerrimus, interdun proliferus. Fructus Semina ubiqre per frondem sparsa, in maculas informes disposita, rubescentia, minutissina, qræ in utraqve frondis pagina parvas efficiunt prominentias. Color purpureo-ruber. Substantia membranacea, tcnuis, exsiccatæ flaccida, Annua.

OBS. Odorem gratum, adinstar Thece, spirat tam recens, qram imprimis siccata. Contendit etiam Dom. Stephensen in tractatu suo de Fucis Islandicis esculentis radicen esse fibrosam et repentem, (cfi. Act. soc. rcg. occ. dan. Vol. 1, p. 499.) qvod tamen non observavi. - Var. marginifera fronde gaudet pollicari vel bipollicari, rotundata, crispa, atrorubente, non saccharifera. Notatu dignum etiam hoc loco videtur, hanc algam omnium qrarumqve primam ab antiquissimis Islandiæ scriptoribus commcmorari, candemyrc sub nomine Scul (Söl) inde a medio circiter seculi X. cognitam, ct ab initio secnli XII, ceu alimentum ad homines in arctiori amona substentandos haud contcmuendum, usurpatam fuisse. Sic ejus mentio injicitur in Saga Islandica 
Egilli, Scallagrimi filii, qvi sceulo X. vixisse perhibetur. Scilice cum Egillus, vir in Islandia potens, ob mortem filii dilcetissimi, fluctibus obruti, prematutam gravi tristitia aflectus, incelia vitam sibi funirc constituissct, ideo'Jve in cubieulum, nullo admisso, se inclusissct, filia ejus amantissima bol ad littus collegit, ct patris januam pulsans, ut se intromittercl, orando instabat. Compos voti facta alio lecto recubabat, et patris genii remula simulabar, se cjus excmplo vitam sibi qroqve conseisecre velle, eoqve nomine multum laudis a pratre reprortabat. 'Tum Egillus: Qvid rei est, filia, qvod mandueas? Cui illa: Söl mando, et malum mili inde augeri arbitrol. 'Tum ille: Num Sïl, inqvit, homini noxia sunt? Filia multun nocere allitmans qvarit, an jpse gustare velit. At ille parum referre cercele se respondit. Filia non ita mulıo post potım poposcit, cui et poculım aquâ. "ut simulahatum, plenun traditum est. T'un Egillus: Esum luujus alga sitis contatanr. At filia: $\backslash$ isne ipse bibcre? Egillus autem, poculo accepto, multum hausit; qvo facto, filia ei divit: Seducti sumus; nam pro aqva lac nobis datum est. Sic callido filix strategcmate patce a malo sno moricudi consilio revocitus, cum deinde alium etiam cibun capere non recusasset, aliffrot annis in vita permansit. Ex hac narratione patet, hane algam ab antirvissino tempore Islaudis fuisse cognitam, liect nondun usurpatam. Sed ex antiqvissina Islandorum lege, qva: Graggaas dicitur, at ab, initio seculi XII. conscripta fuit, satis luculcutco evinciur, candém algain, tanqvam cibum ntagni cestimatum, ab co inele tempore usurpatam fuisse; siquidem ejus taxatio in ea lege exacte constituitur. Eandemqve unacum aliis Thalassioplytis seriori ctian tempore tam in Islan-, dia, qvam in insulis Freconsibus alibiçve alimentum in cibariorum inopia hominibus haud incptum prxstare, satis constat; in cujus rei fidem excmplum a Bjarnone Pauli petitum afferre' placet; dicit nempe vir ille laudatus: "Solâ illâ alga (Ulva palmata) et alato arboreo eduli finco (Laminaria esculenta) paupereulam mendicam atrocia tempestatum astugve maris $\mathrm{cum}$ infantulo lactente in sinulo qvorlam scopelis septo interclusam triun hebdomadarum spatio crulis, ut in littus ejicicbantur, se et infantem sustentasse, a viro seniore fide digno, qvi matrem cum infante postea vidit, relatum aceepio" (cfr. ejus Specimen observationum circa plant. mar. Islant. el speciatim Alga sacchariferæ originem partes et usus Hafı. 1749. p. 21. et 26.)

2. $U$. edulis; fronde cuneiformi, integerrima, apice rotundata, basi attenuata; seminibus ubiqve per frondem sparsis.

Ulva edulis Decand. П. fr. 2, P. 12.

Fucus e'dulis Ner. brit. T. 12. - Engl. bot. T. 1307. - Turn. Syu. p. 18o. et Hisl. T. 114. - Witlı, britı. 4, p. ro1.

- dulcis Gmel. p. 189. T. 26.

- Lactuca Esper. 'T. 64.

- carnosus Esper. T. $7^{6}$.

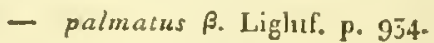


Habitat in oceano Islandico, Esper ad Tab. 64.

DESC. Radix ut pracedentis. Frondes aggregatæ. Stipes basi teres, pennæ corvina crassitie, sed mox compressus. Folium ecostatum, simplex, qratuor ad octo pollices longum. Mlargo integerrimus, planus, non proliferus. Fructus Semiua exigua, sphærica, coccinca, in maculas informes congesta, et substantix frondis inter epidermides immersa. Color intense sangrincus, subopacus. Substantia carmosa vel coriacea, crassiuscula.

3. U. rubescens; fronde lanceolata, vel subcuneiformi, apice lobata, inTab. 7. tegra; seminibus majusculis, solitariis, frondi immersis.

Habitat in profundo maris ante ostium sinus Oxefiord Norvegiæ, Fuco vesiculoso et aliis raro innascens.

DESC. Radix callus parvus nigricans. Stipes nullus. Folium planum, encrve, basi attematum, 2 ad 3 pollices longum, et semipollicem et ultra latum, ut plurinum lanceolatum, interdum cuneiformc et apice lobato-incisum, margine integerrimum. Fructus Semina majuscula, ovata vel rotunda, fusca, froudi solitarie et inordinate inmersa. Color fuscus, rubro tinctus. Substantia membranacea, sub lente punctis longitudinaliter dispositis seminibusqve majoribus iutermixtis, pulchre notata.

4. U. sobolifera; fronde plana, palmato-laciniata, margine prolifera; laciniis sursum dilatatis, summis apice multifido-incisis.

Fucus soboliferus Fl. d. T. 1065. - Turn. Hist. T. 45. - Wahlenb. П. lapp. n. 949. Halymenia sobolifera Ag. Syn. p. 36.

Habitat in mari Finmarkia, $V_{a} h l$. - In sinu maris prope Nidarosiam; $\Lambda$ micus Sommer feldt in litteris.

DESC. Rarlix callus exiguns. Stipes brevissimus, teretiusculus, mox compressus. Frons palmam circiter longa, ramosa, pluries bifurca vel palmata. Folia apicem versus dilatata, et subcuneiformia, extrema apice dentata; dentibus plurimis brevibus, subsetaccis. Margo integerrimus, sæpe proliferus. Color rosens. Substantia membranacea, sub lente reticulata, maculis subrotmidis ornata.

OBS. Ne ulterioris confusionis ansa detur, hoc de citatione F/orce danicce Tab. 1065 monendum esse censeo. In dispositione Tabularum Fl.d. 1065. et 1066. menda irrejserat respectu textus, qvi diagnoses continet; ideoqve Cell. Roth, T'rentepohl, I'urner, Wahlenberg, Agardh, qvibus omnibus exemplaria vetustiora Floræ Danicæ sine dubio ad manus fuerunt, Tabulam 1065. ad Fucum pumilum. FI. d. et Tab. 1066. ad Fucum soboliferum citant; et qridem recte, sigviden Tabula diagnosibus in vetustioribus exemplaribus ita bene respondent. Rothius primus hujus mendre fecit mentionem in Cat. bot. 2, p. 
160; coqve nutu permotus Col. Vahlius numeros Tabularum istarum in veros conmutaudos curasse censendus est; in exemplaribus cnim hodieruis unlla est umeuda, scel numcri Tabutarun textui benc respondent; qrate cham egro, ritis muneris, qvi lıodic in Tabulis insculpti exstaut, in iislcm citandis usus, Tabulam 1065. ad Uleam sobolifercm et Tab. 1060. ad Chondrum crispum $V_{a r}$ pumilum adposui. - Ceterum laxe alga cst dubia species, ab Algologis

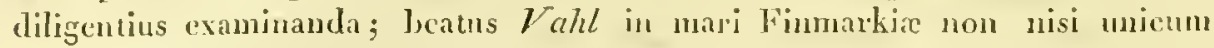
ejus excmplar, in herbario ipsius non amplius superstes, se legisse testatur, cujus deliucatio eum in figuram Turneri non optime fradrat, diagnosin cjus, que in Elore daniece labenu, corollarii loco adjicere lubet. En illan:

"Fucus soboliferus, fromdibus membranaccis dichotomis dilatatis integer-

"rimis serratisque apice bifidis: lacinis diraricatis, inleriorilus apl"pendiculatis." l'rahl.

5. U. Fascia; fronde simplici, lineari, utrinqve attenuata, undulata, integra, exstipitata.

Fucus Fascia Fl. d. T. 768. - Turn. Syn. n. 55. - Roth. Car. 2, p. 16 r.

Laminaria Fascia Ag. Syn. p. 19.

Tab. 5. B) tenuior, fronde simplici, lineari, tenerrima.

Habitat ad rupes maritimas Norvegia prope Cluristiansand, Mlilller. - Ad littus Ebeltoft Jutlandire, Hornemann. - Ad munimentum Trekroner prope Hafniam copiose, Marchio de Bonnay et Prof. Puerari. - Varietas ante ostium sinus Oxefiord Norvegia, Zosteræe marina insidens.

DESC. Radix perpusilla. Frondes ex eadem basi plurime, simplices, planx, palmari vel spithamxa longitudine, basi attenuata, deinde scusin sensingqe ad unius alteriusve linex latiudinem dilatate, pulcherrime undulater, vel spiraliter contortx, apice itcrum attenuate, obtusiuseula. Margo integerrimus. Fructus non observatus. Color fusco-ruber, exsiceata nigricans. Substantia inter coriaceam et membrinacean media, tenax, tenera.

OBS. Varietatem attuli non solum oly staturam miunrem, scd imprimis ob texturam iuternam, qva sub lente granulis longitudinaliter dispositis notata conspicitur; iltera vero punctis mimutissimis prexdita est.

6. U. umbilicalis; fronde plana, imbricatim gregaria, sub-orbiculari, umbilicata, sessili, longitudinaliter plicata.

Ulva umbilicalis Limn. - Gunn. A. norv. n. 959. - Roth. Gat. 3. P. 325. - Wulf. cryp. n. 12. - Horn. 月. oec. p. 92.4 - VYahlen. A. lapp. n. 96\%. - Dill. T. 8. fig.

3. - Dec. Il. fr. 2, p. 9 .

Fucus Tremella umbilicalis Gmel. p. 219 .

Ulz'a purpurea \%. umbilicalis Ag. Syn. p. 42. 
Habitat ad insulas Færoenses saxis in summo refluxus limite ubiqve et copiosissime adnascens. - Ad Islandiam, Köenig, Zoega, Mohr, Hook̉er.

DESC. Radix exigua, scutata, subtus ad centrum fronclis plerunnve sita. Frond.s maxime gregarix, imbriratx, palmam circiter longx, et suborbiculares, papyri crassitudine, longitudinaliter plicatæ, plicis peripheriam versus dilatatis, margine simuoso-lobatx. Frnetus non observatus. Color flavescentifuscus, exsiceate rubescens. Substantia membranacea, lenta, tennis, flaccida. Anmua.

OBS. Sub lente membrana pmetis minutissimis confertissimis repleta cernitur; qvæ tamen pro fructu vix sunt labenda. Scopulos, qribus copiose adnascitur, densis suis membrauis, lubricos ingredientibus reddit.

7. U. purpurea; fronde plana, solitaria, oblongo-lanceolata; margine integro, undulato.

Ulva purpuren Roth. Cat. hot. I, p. 2og. 'Tab. 6. fig. I. - Dec. A. fr. 2, p. 9. - Ag. Syn. p. 42. - Jürg. Alg. Dec. ı. n. 2.

Ulva umbilicalis $\beta$. purpurea Wahl. ח. lapp. n. 967.

B) elongata, fronde minori, lanccolata, acuminata.

Habitat ad rupes ante ostium sinus Oxefiord Norregix. - In sinu Frederitiæ Jutlandia, Prof. Hornemunn. - Varietas ad saxa maritima prope Qvalböe Færoæ, copiose.

DESC. Padix perpusilla, scutata, vix manifesta. - Frons solitaria, plana, basi parum contracta, non tamen attemiata, sed rotundata, deinde oblongo-Janceolata, pedem et ultra longa, duos tresve pollices lata, margine undulata. Fructus (?) granula densa minutissina oblonga vel angulata sulstantix frondis immersa et majora qram in precedente specie. Color pallide purpureus, cxsiccatix purpureo-violacens. Substantia mombranacea, tenax, pellucida. Amua. Estate. Cliarta lase adhreret.

OBS. Varictas spillanam vel infra longa, semipollicem lata, gregaria, de scopulis in summo refluxus limite pendet.

8. U. miniata; fronde plana, solitaria, oblonga, gelatinosa. Ulva purpurea $\beta$ miniata Ag. Syn. p. 42.

Habitat ad littus Groenlandixe; Wormskiold.

DESC. Radix uon visa. Frons pedem et ultra longa, palmam et ultra lata, solitaria, undulata; sub lente granulis exiguis, oblongis, dense confertis oruata. Color puniccus, vel amoene roseus. Substantia membranacea, tencrrima, gelatinosa.

OBS. Ob substantiam lubricam et granula interna majora a præcedentc distincta videcur. 
9. U. plicala; frondibus basi comatis, imbricatis, plicatis, ovatis, obtusis.

Ulva plicaca Fl. d. T. 829. - Ström Söudm. Ulva n. 4. et Acr. Hafn. Vol. I0, p. 257. T'ab. g. fig. 9. - Mohr hist. isl. p. 249. - Kotli. Cat. bot. 1, p. 208.

Lichen marinus Tabern. eicon. p. 817. - Bryon Lacluca folio Lobel. ic. 2, p. 247.

Muscus marinus alter Mathiol. epit, p. 872 . c. icone.

Habitat ad rupes maris Norvegici et nominatim ad insulam Erknöe prope Söıdmöer, Str̈̈̈n. - Ad Islandiam, Mlohr. - Ad insulas Froenses.

DESC. Radix scutata crassa rupibus declivibus adnata. Frondes aggregata, basi in umm corpus connata, contracta et umbilicata, dense imbricata, expansa, plane sed plicatx, diversa magnitudinis, tres polliees ad predem longae, pepyri crassitic, nunc rotundae, nunc ovate vel clongata, apicc olntusa, plerumgve laccrie. Fructus ignofus. Color saturate viridlis, flaro tinctus. Substantia membranacea, valida, minus diaphana, rigieliuseula, exsiccata rigida. Charte nou idlaaret.

OBS. Hanc Algan, ab intiquissinis Botmicis jam observatam el descriptam, in mari Norvegico primus decxit Rer. Ström, qvi ean scopulis abruptis in ipsil aqva superficie vel paule suprat candem scssilem vel potins prendentem el gridem imbricatam invenit. Ob fluctus vchencutes, il quibus semper vexatur, superiores membrane laccrate et perforate apparent. Suspicatur Cel. Strüm, cam bonun pecoribus pabulum possc presiare.

10. U. Lactuca; frondibus aggregatis, oblongis, planis, subundulatis, basi attenuatis, sursum dilatatis, laciniatis.

Ulva lactuca Lin. - Roth. Cat. bor. צ, p. 206. - Wulf. crypt. n. 4. - Decand. A. fr. 2, p. 9. - Engrl. bot. T. 1551. - Lam. Thal. p. 6q. - A p. Disp. 1. 24. et Syn. P. 40. - Wahl. 月. Lapp. p. 968. - Ström Söndu Ulva n. 3.

Kyll. Viricl. p. זo6. n. 7 .

ß) contorta, fronde basi attenuata, spiraliter contorta, crassa, deinde in plures lacinias dilatatas profunde fissa.

Habitat ad littora Daniae lapidibus conchisqre sat freqvens, etian libere fluctuans. B. ad insulas Fieroenses prope Thorshavn Fuco resiculoso aliisque aduascens.

DESC. Radis parva scutata. Fronde's "x una basi plurimx et distincte, non comratx, debiles, llaceidx, duas tesu pollices ad peden longar, pollicen ad palmam lata, planae. Margo sulundulatus, crispus, lacindatus. Granula mimuta frondi immersit. Coler late viridis, senio flavescens, exsiecatx pallide viridis. Substantia membranacea, tennissima, papyri crassitudinc, absque visciditate lavis. Amma. Nistate. Clarta non adlaxet.

OBS. Varicias solitaria, ob basin spiraliter contortam, rolustiorem crassiorempre insignis, spithanam longitudine plerumqve allingit. 
11. U. plantaginifolia; frondibus aggregatis, basi attenuatis, lanceTab. 6 . latis, obtusis, margine subcrenatis, planis.

Ulva plantaginifolia Wulf, cryt. n. 3.

- plantaginer Rotl. Cat. bot. 2, p. 243. Cat. 3, p. 326.

Laminaria plantaginea Ag. Syn. P. 20.

Dillen. T. 9. f. 4 .

B) tentior, fronde lineari lanceolata, obtusa, denticulata.

Tab. 6 .

Habitat in foliis Zostere marinæe in profundo ostii sinus Othiniensis eopiosissime, Ilofmann Bang; ad ostium sinus Oxefiord Norvegiae. - Varietatem ad littus Fioniae septentrionale legi.

DESC. Rarlix parva scutata nigricans. Frondes ex eadem basi plurimx, ad basin attenuatx, planx, tres ad octo pollices longæ, et ungvem fere latx, papyri crassitic, flaccidre et fluctuantes, elongato-ovatæ vel lanceolatx, apice obtusæ vel rotundatæ. Margo plerumqve iuteger, interdum crcuatus. Substantia frondis, sub lente visa, pulchre reticulata, e fibris constans longitudinalibus, subparallelis, ab aliis transversalibus in subqvadrata ubiqve sectis. Fructus Semina nuda minutissima globosa fusca solitaria substantia frondis sinc ordine sparsimqve immersa. Color flavo-virielis, sæpins olivaceus. Substantia mcmbranacea, lenta, flaccida, minus diaphana, omnis nitoris expers. Annua. Vere. Chartx laxe adharet.

OBS. Odorem spirat singnlarem, gramincum. Semper, qvod notatu dignum, in Zostera marina parasitica. Frons adulta ob Flustras minutas sordesere marinas, ei agglutinatas, sæpe scabriuscula. - Varictas est forsan planta in statu juniori; assecla cum eâ Conferva fucicola non raro conjungitur : margo frondis fibris pcllucidis geniculatis, qvæ tamcn in $\alpha$. absunt, obsessus; hinc denticulatus apparet.

12. U. dichotoma, fronde plana, subreqvali, dichotoma.

Ulvia dichotoma Huds. p. 568. - With. 4. p. 121. - Light. p. 975. T. 34. - Engl. bot. T. 774. - Dec. ff fr. 2, p. rt.

Fucus canaliculatus Esp. T. 73. sec. Mertens.

Habitat ad littus Bergense Norvegiae; Dom. Krïger. - Ad littus meridionale Norvegiae; Prof. C. Smith.

DESC. Radix parva scutata. Frondes cxspitosæ, planæ, basi attcnuate, palmam et ultra longa, per dichotomias, intervallo inter singulas circiter ungviculari, octies pluriesve repetitas divisæ. Anguli dichotomiarum rotundati. Frons pretcrca ubique subæqvalis, lineam lata, intcrdum vero ad latitudinem semipollicarcm accerlens. Fructus Semina minutissina fusca in qvadratis frondis sparsim disposita. Color viridis, vel fusco-olivaceus. Substantia membranacea, tenuis, sublenta; microscopio subjecta pulchre reticulata ap- 
paret, c fibris longitudinalibus, qve ab aliis transversalibus sectie qvadrata vel reetangula formant, comprasita. Anum. Estate. Chartæ non adhæret.

13. U. Linza; frondibus aggregatis, lanecolatis, integerrimis, utrinqve attenuatis, planis, margine flexuosis.

Ulva Linza Fl. d. T. 889. - Roth. Cat. bot. 3, p. 330. - Wulf. crypt. 1. 7. - Lam. Thal. p. $65 .-\Lambda g$. Syn. p. $4^{\circ}$.

- Lanceolata, Auctornm?

Habitat ad littora Danize passim, Miuller. $-\Lambda \mathrm{d}$ oram Fioniae septentrionalem. Ad littus Sellandixe prope Hafniam. - Ad insulas Froenses hie illic copiose.

DESC. Radix perpusilla, scutala, savis scopulisqve adnata. Frondes cxspitosoaggregatx, distinctx, papyro subtiliores, basi attennate, filifurmes, deinde in ung is latitudincm et ultra exereseentes, palman ad pedem longa, simplicissima, lanceolatx, apicem versus attenuatx. Margo utergve molulatus, sinuosus, in stau juniori planus. Fructus ignotus. Color viridis. Sulsstautia mombranacea, tencrima, fliccida, lavis, subdiaphana. Amua. Esstate. Chartæ laxe adlaxret.

Tab. 6. 14. U.terrestris; frondibus aggregatis, ovatis, confertis, tenuibus, decumbentibus, plicato-crispis.

Ulva terrestris Roth. Cat, bot. I, p. 21 r. - Wulf. crypt. 1, 14. - Wahlenb. v. 969. Jürg. Alg. Dec. 4. n. 3. - Dillen. Tab. 10. fig. 12.

- lacluca $\gamma$. Huds. P. 567.

- crispa Lightf. p. 972. - Ag. Syn. p. 43. (excl. syn. F. dan.)

Kylling Virid. p. 105. n. 6.

Habitat in tectis stramineis Jutlandix vulgaris. Prof. Hornemann. - In insulis Færoensibus in terrestribus umbrosis humidis, et ad rupes marinas paulo supra littora, aëri marino exposita. - Etian in Groenlandia; Wormskiold.

DESC. Radix propria mulla. Frondes expitosæ, aggregatx, imbricatx, decumbentes, arleo ut stratis suis densis magna tereni soli spatia tapetis viridis instar instcrnant; praterea diverse figura et magnitudinis, ungren ad polliccm longa, rage distente "t lobata, mungram plane, sed senper rugosx, rugis elevatis. Fructus incognitus. Color suturate viridis, exsiceatie olivaceo-vircscens. Substantiit membranacea, tencrrima, subliyalina, lubricitatis cxpers. Amnua. Vere et iestate. Churta non adlæxet.

15. U. furfuracea; frondibus aggregatis, ovato-subrotundis, confertis, tenuissimis, adscendentibus, sinuoso-lobatis, margine inflexis.

Ulva furfuracea Fl. d. T'. 1489. - Ag. Syn. p. 43. 
Habitat ad parietes ligneos umbrosos, et saxa terræ contigua, prædii Hofmansgave Fioniæ.

DESC. Radix nulla. Frondcs cæspitosæ, aggregatæ, unam altcramve lineam longæ, erectæ, lincam latæ, ovatæ. sinuosæ, apice rotundatæ. Margo intcgerrinus, inflexus. Fructus nondum observatus. Color et Substantia ut præcedentis, sed tenuiores. Annua. Vere et æstate reperitur. Chartæ non adliæret.

OBS. Frons hujus, ut precedentis, sub lente visa non reticulata, sed e punctis minutissimis, rectangulatis, in lineas parallelas transversales et longitudinales densissime dispositis constat; inter hæc puncta granula nonnulla majora, saturatius colorata, fusca aliqrando observari, qva sine dubio sunt semina vel corpuscula reproductiva. Puncta ista, qræ disi, rectangulata, undiqve frondi inınersa, qvæqve plerumqve qvaterna in conspectum veniunt, a Cel. Agardhio per semina definiuntur; illi vcro definitioni, qvæe minus apta videtur, haud plane assentior; eâ enim assumtâ, seqvitur, ut tota frons inde a prima infantia pro mera stminum congerie esset habenda; id vero vulgari naturx agendi rationi repugnat, qræ, cum planta ad maturitatem qvandam pervenerit, semina primum parit atqve producit; eodem etiam jurc totam frondem Delesserice sinuosce aliorumque, qræ sub lente visa hujusmodi punctis coustarc ceruitur, pro congeris seminum haberc possimus; illæ vero planta manifesta et longe alius indolis gerunt semina; huc etiam accedit, qvod character, qrem generi Ulve constituit Cel. Agardhits, non semper est universalis, id est, non in omnes hujus generis species qvadrare videtur. Hinc igitur factum est, ut alium huic generi characterem qvalemcunqve conficere atcre proponere coactus fuerino. - Deniqve hoc etiam loco moneri potest, quod Cel. Linkio nounnllis Ulvee speciebus (illis sine dubio, in qvarum substantia puncta qraterna sub lente adsunt) novum T'etrasporce nomen proponere placuit, ut tali denominatione a cetcris, hoc charactere destitutis, separarentur. (cfr. Schrad. Diar. bot. pro 1809. p. 9.)

\section{D E S M I A.**)}

Frons compressa, ramosa. Fructus ignotus, vel forsan in filis e substantia frondis exeuntibus qværendus.

1. D. ligulata; caule compresso, avenio, bipinnato; foliis pinnatis, di- Tab. \%: stichis, planis, oppositis, lanceolatis, margine serratis fibrosisqre.

*) Ex $\delta \varepsilon \sigma \mu \grave{s}$, vinculum, ligula. 
Fucus ligulatus Light. 2, p. 949. T. 29. - Turn. Syn. p. 99. et Hist. Tab. 98. - Engl. 33ot. T. 1636 - Nero britt. ed. 2. Tab. 20. - Dec. A. Ir. 2, p. 3\% - 1. dan. 'I'. 1592.

- herlaceus Huds. p. 582.

J.aminaria ligulata Ag. Syn. Introd. p. XIII.

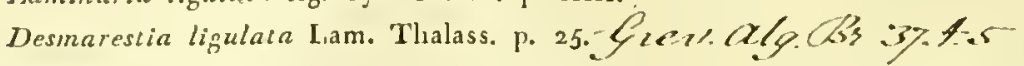

Habitat ad littora Freroensia haud freqvens, ut in sinu Qvalböe Suderöe, et ad littus Mölen prope Eide Österöe.

DESC. Radix callus subeonieus, parvus, magnitudine semen Vicice Craccee acyrans, eoneolor. Frons solitaria, pedem ad tres ulnas longa, disticha, bivel tripinnata. Caulis ad basin attenuatus, compressus, pennæ passerinæ crassitie, mox planus, ita tamen ut medio semper sit erassior, quare subecostatus videtur, duas lineas fere latus, apieem versus acmminatus, et per totam longitudinem ramis pinnatus. Rami ad basin renotiores et longiores, apieem versus densiores et breviores, intervallo inter singulos bilincari, patuli, plani, ejusdemqve fere, qva eaulis, latitudinis, distichi, e margine canlis utroqre opposite oriundi, ad basin ct apiees altenuati. Folia opposita, disticha, ad basin attenuata vel pedunculata, lanecolata, lineam latitudine seqvantia, acuminata, costa evanescente ad basin interdum notata, aliisqge minoribus codem modo obsessa, margine serrata, et sub lente ex singulis serraturis fibras emittentia simplices et rumosas, artienlatas, articulis diametrum longitudine æqvantibus. Caulis et rami preterea inter longiores breviorilons ramis foliisque obsessi. Fructus ignotus, vel forsan in fibris, qvas memoravi, qværendus. Color eanlis fuscus; ramorum foliorumqve flavescenti-viridis; exsiccatione non mutatur. Substantia eaulis cartilaginea, tenax, foliorum membranacea, tencra, exsiccatæ flaccida. Ammua. Estate legi. Chartæ non alharet.

Tab. 44. 2. D. aculeata; fronde compressa, ramosissina; ramis linearibus spiB. 1. nosis; spinis marginalibus, subulatis, erectis.

Fucus aculentus Herb. Lin. - Turn. Syn, n. 48, et Hist. T. 187. - Fl. đ. T. 355. Ner. britt. T. 8. - Decand. fl. fr. 2, p. 34.

- mrescoides Lin. - Gnel. T. 12. - Esper. T. 59. - Gunn. Fl. norv. n. 1071. König, Mohr, Hooker.

- concortus Esp. T. 亿3.

- virgatus Fl. norv. 1, p. 45. - Act. Nidros. 4, p. 83. Tab. 7.

- ussieoides Oeder Enum. n. 113.

Sporochnus aculeaius Ag. Syn. p. 10.

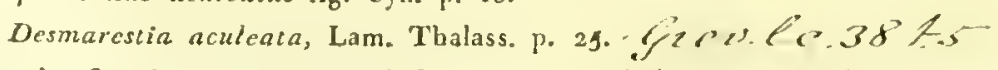

Habitat in fundo ostii sinus Othiniensis. Ad rupes maritimas ante ostium sinus Oxefiord Norvegiæe. Ad insulas Færoenses copiose. Ad Bornholmiam, Herb. Hofman Bangii. Ad Islandiam König, Zoega, Mohr. - Ad Groenlandiam, Wormskiold. 
DESC. Radix callus explanatus, saxis et aliis Phycoidatis majoribus agglutinatus. Frons compressa, lucem rersus costa obsoleta longitudinaliter percursa, pedali ad bipedalen et ultra longitudine, ad basin scmilineam vel lineam lata, apicem versus sensim sensimqve attenuata, alternatim triplicato-ramosissima. Ilami basi patentes, alterni, compressi, distichi, eadem fere longitudine ac ramus primarius. Ramuli pollicari ad tripollicarem longitudine, qvo magis ad apicem appropinqvant, eo breviores, alterni, interdum alternatim secuudi. Rami ramuliqve aculeis vel spinis subulatis erectis adpressis, brevibus, lineam circiter longis, intervallo inter singulas fere bilineari, tenuissimis, acutis, utrinqve obsessi. Fructus ignotus. Color olivaceo-viridis, exsiccatæ nigricans. Suhstantia cartilaginea, lenta, tenax. Perennis.

OBS. Qvotqvot specimina ex profundo ostii sinus Othiniensis vidi, hæc habitu flaccidiori, ramulis plerumqve alternatim secundis, spinis vix nisi sub lente conspicuis, apice geniculatis, et colore virescente a Norvegicis et F'ceroensibus aliqvantulum differunt; hæ vero differentiæ, statui plantæ juniori sine dubio attribuendæ, ad Varietatcm distingrendam vix sufficiunt.

3. D. Hornemanni; fronde compressa, ecostata, a basi usque ramosa, Tab. 7. decomposito-pinnata; pinnis suboppositis, acutiusculis:

Fucus Hornemanni Gölı. gel. Anz. 8815. No. 64.

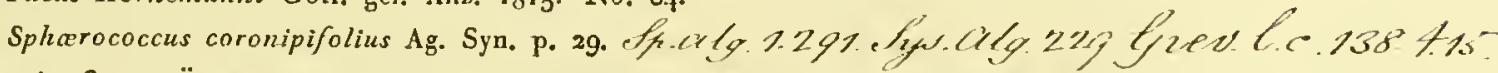

Habitat in freto Öresundico, ubi ad oram Helsingoræ hane speciem elegantem et quidem rarissimam Cel. Furskaal olim legisse fertur.

DESC. Radix non visa. Frons compressa, enervis, aliqrot pollices longa, vix semilincam lata, angustissima, et sensim magis magisqve attenuata, ita tamen, ut ramus primarius scmper sit ramulis latior. Rami ad basin vagi, patuli, divaricati. Ramuli distichi, conpressi, pimmati, paralleli; pinnæ distichæ, suboppositx, breves, omnes ejusdem fere longitudinis, subulatæ, sub lente dentatæ, acutiusculæ. Fructus ignotus. Color flavicans, rubro aliqvo tinctus. Substantia exsiccatæ cornea, fragilis.

OBS. Hanc speciem, inter collectanea Forskacliana sine nomine, sed cum loco natali indieato inventam, Cel. Mertensius, Professor Brcmensis, Algarumqve, si qvis, peritissimus, Fucum Hornemanni salutavit. Refert qvidem Fucum cartilagineum Turn., sed toto habitu minori et tenuiori, forma non pyramidali, ramis (si alias ab unico specimine certum qvid concludere licet) a basi usqve incipientibus, et pimis suboppositis acutisqve ab illo et Fuco coronipifolio satis distingvi posse videtur. 


\section{H I M A N T H A L I A . *)}

Frons compressa, dicholoma, ex basi cyahiformi erumpens. Tubercula numerosa, per colarn floudem sparsa.

Tab. 8. 1. H. lorea.

Fucus loreus Herb. Lin. - Fl. d. T. 7ro. - Turn. Syn. n. 45. el Hist. T. 196. - Ner. britt. T. 10. - Engl. bot. T. 569. - Esper. T. 19. 39. - Fl. norr. 2, P. 125. Zoega. - Mohr Hist. nat. Isl. p. 24 1. - Dec. A. fr. 2, p. $23 .-$ Ag. Syn. p. 8. Lam. Thalass. p. 19 .

- clongalus Lin. - Gmel. p. 103.

Ulva pruniformis Fl, norv. 2, p. 89. Tab. 2. S. 6. 7. el Tab. 9. fig. 4. 5. - König, Zoega, Mohr.

Habitat in fundo littoris ad insulas exteriores Islandia, Mo/tr. - Ad insulas Færoenses copiose, non solum in fundo, sed etiam in summo refluxus linite.

- In littus Cimbriac occidentale circa Nyemindegab haud raro ejicitur; Prof. Hornemann.

DESC. Radix omnino singularis et pararloxa, e placenta constans cyathiformi vel pezizaformi, concava, pollicem circiter lata, orbiculari, peltata, crassa, infra breviter stipitata. In statu juniori globum cerasi vel proui magnitudine: format olivaceum, intus cavum et äere solo sepletum, ad latera fibris pellucidis dichotomis articulatis intermixtis, articulis diametro 4-6plo longioribus, interdum, imprimis in infintia, succo aq̣ose pellueido rel aq̣rî̀ meraề salsầ plenum. Ille globus, cum ad pruni inagnitudinem excreverit, medio collabitur, ct ex centro ejus umbilicali, antea convexo, munc concavo progrediuntur tres vel quatuor frondes loriformes, compresse, per duas vel plures dichotomias divisa, duos pcdes ad duas orgyas longre, tres fere lineas latx, valde lnbrice, subrqvales, apice parum acuminatx. Fruetus Tubereulu sphærica, poro deliscentia, substantiæ totins frondis innata, unmerosissima, procminentia, in qvibus semina majuscula, pyriformia, fusca, unacum fibris pellucidis articulatis muco immixtis inchuduntur. Color fusco-olivacens, exsiccatæ nigricans. Substantia coriacea, lubrica, exsiccatie rigilla, fragilis. Amnuus. Estate.

OBS. Ad insulas Færoenses biorgyalem siepe attingit longitudinem, superficiemqve maris frondibus suis fluitantibus interdum totam obducit. Totam, qvam dixi, frondem per receptaculum definit Cel. Agardhius, qve quidem definitio beme defendi potest; receptam tamen denominationcm retinui.

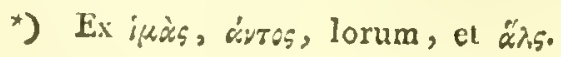




\section{H A L I D R Y S. *)}

Frons compressa, ramosa. Receptacula turgida, intus mucosa, tuberculis sphæricis seminiferis repleta, lateralia vel ternsinalia.

1. II. nodosa; fronde subdichotoma, vesiculis innatis hic illic inflata; Tab. 8: receptaculis pedumculatis, subglobosis, lateralibus.

Fucus nodostus Lin. - Fl. dan. T. 146. - Fl. norv. 1, p. 83. - Esp. T. 7. 6o. - Gmel. T. 1. B. fig. 1. - Ner britt. T. 10. - Engl. bot. T. 570. - Turn. Syn. p. 252. et Hist. T. 91. - Horn. П. оec. p. 925. - Dec. A. fr. 2, p. 22. - Lam. Tlıalass. p. ig. - Ag. Syn. p. 3.

- Siröm Söndm. n. 4. - Kyll. Virid. p. $4^{6 .}$ n. 6.

B) minor, receptaculis ovatis, pedunculo vix latioribus.

Habitat ad oras Daniæ raro; ad littora Norvegiæ, Færoæ copiose; etiam in mari Islandico et Groenlandico. - Varietatem ad littus Hofmansgave Fionia legit Hofmann Bang. - a. ad littus Frederichshavn Cimbria, copiosissime; Hornemann.

DESC. Radix callus majusculns, conicus. Frondes aggregate, compressæ, distichre, ceostata, duos pedes ad orgyam usqve longæ, tres circiter lineas latæ, et ubiqve æuvales, nisi qrod hic illic in vesiculas ellipticas sint inflatæ, unde stirpi facies nodosa, per duas vel tres dichotomias divisie. Rami lateraIcs, patuli, ad basin attenuati, margine minutissime denticulati. Frucus Receptacnla spharica, lateralia, plerumqre solitaria, et glandis fere magnitudine, pedunculata, et poris minutissimis pertusa, qvibus insunt Tubercula, qvæ fibris brevibus articulatis constant, seminibus immixtis oratis, fuscis, limbo pellucido cinctis. In mcdia receptaculorum parte mucus cum fibris adest, ut in Finco vesiculoso. Color alivaceus, exsiccatre niger. Substantia coriacea, lenta, tenax.

OBS. De seminibus, qva post exsiccationem in minores particulas dissolvuntm, (cfr. Tab. 8. B. 4.) vide qra ad Fucum canaliculatum antea annotavi.

2. H. siliquosa; fronde ramosa; ramis alternis distichis; vesiculis arti- Tab. \& culatis rostratis; receptaculis pedunculatis, lanceolatis, terminalibus.

Fucus siliqvosus Lin. - Fl. d. T. 106. - Fl. norv. 1, p. 83. - Esper. T.8. - Ner. britt. T. 5. - Engl. bot. T. 474. - Turn. Syn. p. 6o. et Hist. T. 59. - Wahl. A. lapp. p. 499. - Wulf. crypt. n. 14. - Dec. A. fr. 2, p. 19. - Ag. Syn. p. 2. - Jürg. Alg.

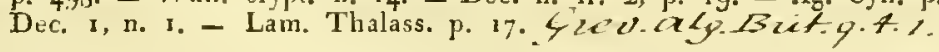

- König 月. isl. - Kyll. Virid. p. 46. n. 5. - Ström Söndm. n. 5.

B) denudata; fronde elongata, ubiqve foliosa, vesiculis nullis.

Habitat in mari Daniam alluente, copiose. - Varietas ad littus Fioniæ septentrionale, Hofmann Bang.

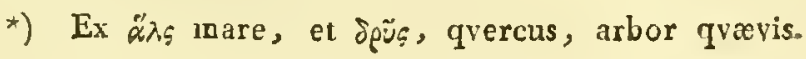


DESC. Radix callus expansus, conicus, ater. Frondes aggregatx; caulis unum ad 4 perles longus, et in profundo ostii sinus Othiniensis orgyalem et ultra attingens longitudinem, lineam latus, Ieniter flexnosus, glaberrinus; rani sparsi, distichi, patuli, caulem referentes. Vesiculæ ad latera caulis ramorumpre sitx, altcrux, siliquæformes, compressæ vel teretcs, petiolata, rostratx, extrinsecus sulcis qvinis ad octonos transversaliter notate, et, fibris nomnullis exceptis, intus cavæ. Folia, qva in junioribus plantis adsunt, plana, lincaria, duos circiter pollices longa, lineam fere lata. Fructus Receptacula ad ramorum cauliseve apices sita, lineari-lanceolatx, polliecm fere longa lineamqve lata, breviter pedunculata, poris minutissimis pertusa, sub qvibus latent Tubercula spharica, qva semina oblonga vel angulata fusca cum fibris ramosis articulatis includunt. Color olivaceus, exsiceate ater. Substantia coriacea, leuta, siceatæ rigida fragilisl, sub lente punctata.

OBS. Differentiam, qve inter vesiculas ct receptacula interest, Cel. IVahlenberg in Flora lapp. per siliqvas articulatas ct tuberculifcras distinxit.

\section{XIl. P T I L O T A. *)}

Frons compressa, ramosissima, supradecomposilo-pinnala. Fruclus Capsulæ quinquifidx.

Tab. 9.

1. P. plumosa.

Ptilota plumosa Ag. Syn. p. 39 .

Fucus plumosus Linn. - Fl. d. T. 350. - Fl. norv. 2, p. 9I. - Esp. T. 45. - Turn. Syn. p. 296 . el Hist. T. 6o. - Dec. A. Fr. 2, p. 31.

- pectinatus Fl. norv. 2, p. 122. Tab. 2. fig. 8. - Esper. T. 47.

- ptilotus Fl. norv. 2, p. 135. T. 2. fig. 15. - Esp. T. 46.

- Ström in Acl. Hafn. Vol. 10, p. 256. Tab. g. Fig. 7.

Ceramium plumosum Roth. Cat. bot. 3, p. 133. - Ag. Disp. p. 17.

Plocamium plumosum, Lam. Thalass. P. 50.

B) asplenivides, pinnis profunde serratis.

Ptilota plumosa ß. asplenioides Ag. Syn. p. 39.

Fucus asplenioides Turn. T. 62 ?

Habitat pulcherrima hae Alga in fundo maris Islandici, Oeder. - In oceano Norvegico, Gunnerus. - Ad insulas Færoenses in stipite I aminariæ digitatæe copiose; etiam ad Groenlandiam. - Varietas ad Færoas et Groenlandiann.

DESC. Rodix callus exiguus, nigricans. Frons compressa, ecostata, palmam ad pedem longa, semilineam lata, disticha; rami inordinate sparsi, distichi, elongati, pattuli, aliisqve minoribus et angustioribus obsessi; totam frondem.

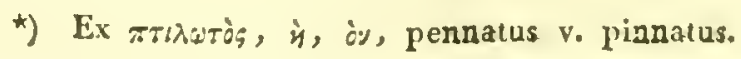


obsident pinnæ divarieatæ, unam alteramve lineam longx, 'approximatæ, oppositæ, ipsæ aliis minoribus simplicibus similiter pinnatæ, unde frons pulcherrime plumosa apparet. Hæ pinnæ unacun apice ramorum sub lente reticnlatæ, vel subarticulatæ. Fructus Capsulæ inter pinnulas vel in earum apicibus sitx, peduneulatx, apice in qvatuor vel sex lacinias longinsculas, qvibus semina majuscula, fusca involucrantur, fissæ. Color ruber, exsiccatæ intensior. Snbstantia cartilaginea, mollis, tenera.

OBS. Varietas, qvam ad insulas Færoenses lectam exemplo Cel. Agardhii attuli, ad Fucum asplenioidem Turneri proxime accedit: pimis gaudet non pectinato-plumosis, scd modo serratis, et capsulis, qræ ant pinnis alternatim oppositæ sıut, ant in apice pinnularum sitæ; laciniæ involucrantes sæpe absunt, qvo fit, ut semina nuda sime involucro globulum fuscum in apice peduneuli situm constituentia conspiciantur, id qrod in Fucum asplenioidem 'Turn., qui in mari Kamschatkam et insulas Knrilas alluente alias prọenit, etiam bene quadrat.

\section{P L O C A M I U M. *)}

Frons compressa, disticha, ramosissima ; ramulis ultimis pectinato-secundis. Fructus Eapsulae laterales vel Semina nuda apicibus frondis immersa.

1. P. coccineum.

Fucus coccineus Turn. Syn. p..2gr, et Hist. T. 59. - Ner. britt. ic. frontisp. - Witl. 4. p. 19. - Engl, bot. T. 1242. - Fl. d. Tab. 1593. - C. Smith in Topogr. statist. Saml. 1817. P. 2. p. 248.

- Plocrmium Gmel. T. 16. fig. 1. - Esper. T. 2. - Dec. fl. fr. 2, p. 3r. - Jürg. Alg. Dec. 4, n. 2.

- cartilagineus Oed. Enum. pl. n. 15r.

Cernmium Plocamium Roth. Cat. bot. 3, p. 107.

Plocanium vulgare Lam. Thalass. p. 50.

Delesseria coccinea $\Lambda \mathrm{g}$. Syn. Introd. p. XIV.

B) subtilis, fronde tenuiori.

Habitat elegantissima hæc Alga ad insulas Færoenses copiose; varietas ibidem; a. etiam ad littus Molde Norvegia; Prof. C. Snith.

DESC. Radix callus exiguus, secundum Turnerum fibrosa. Frons compressa, filiformis, longitudine circiter semipedalis, semilineam lata, flexuosa; rami distichi, patentes, ter quaterve alternatim pinnati. Ramuli snmmi subulati, leviter incurvi, aliis brevioribus secundis ad interiorem partem pectinatim ob-

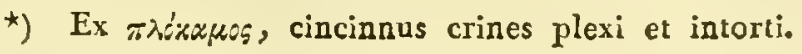


scssi. Fructus Capsulx globosæ, oculo nudo visibiles, ad latera ramorum sessiles, seminum minutissimorum congericm iucludentes; ctiam semina unda in. ramulis ultimis secuudis, tune sqrarrosis, simplici vel duplici sexie disposita. Color coccincus vel intensc roseus. Substantia cartilaginca, nembranacca, tencrima.

\section{GE L I D I U M.}

Frons compressa vel angulata, ramosa. Fructus Tubercula globosa, Icrminalia.

Tab. 9. 1. G. pinnatifidum; fronde compressa, ramosa; ramis subalternis, decomposito-pinnatifidis; ramulis obtusis callosis.

Fucus pinnatifidus Huds. p 58x. - With. 4, p. 106. - Esper T. 132. - Ner. britt. T. 11. - Dec. A. fr. 2, p. 3o. - Turn. Syn. 1).267. et Hist. T. 20. - Eng!. bot. T. 1202. - FI. d. T. 1478 .

- corymbifer Wulf. crypt. aquat. n. 32.

- corymbiferus Esp. T. 94.

- Oederi Fl. norv. n. soy?

Chondria pinnatifida Ag. Syn. P. 35.

B) angustum, fronde teretiuscula, ramis teretibus, sursum incrassatis, subsimplicilous.

Fucus pinnatifidus $\gamma$. Turn.

- pinnatifidus Gmel. Tab. 16. fig. 3.

- Fl. dan. T. 276. (cum Chacophora marina parasitica.)

Habitat ad oram Fionize septentrionalem, Fuco vesiculoso et saxis adnascens: Ante ostium sinus Oxefiord Norvegix. - In scopulis sinus prope Stavanger copiose; Oeder.

DESC. Radix callus explanatus, fibris brcvibus interdum instructa. Frondes aggregate, pralmar's, compresser, lineam fere lata, crassx. Caulis interdun dichotomus. Ramus primarius pimatifidus; rami similiter piunatifidi, distichi, patuli, subalterui; rani (sive pinne) breves, obtusi, simplies, interdum divisi; apiecs roumdati. Fruclus Scmina muda ovata fusca apicibus ramulorum innita; etiam Capsula oratx, sessiles, diaphanx; ille vero, qvas vidi, scminilus ceriust orbatx. Color sordide luteus, rubro tinctus, subdiaphanus. Substantia cartilaginca, succosa.

OBS. Sapror hujus Algx interdum est mordax, piperalus; ct Varictas acrem et ingratum semper spirat odorem, qvo facile se manifestat, atque ab aliis discerni potest; est autem Varictas minor, pollicem unum altcrumve longa, teretiuscnla, pennam passerinam fure crassa, ramis incrassatis et magis irregularitcr dispositis. 
2. G.gigartinum; fronde compressa, vage dichotoma; ramulis subulatis, subdistichis, tuberculiferis.

Fucus gigartinus Lin. - Turn. Syn. p. 280. et Hist. T. 28. - Engl. bot. T. 908. Dec. R. fr. 2. p. 33. - With. 4, p. Im.

- pistillatus Gmel. p. 159. T. 18. fig. I. - Lam. Diss. T. 27.

- Oederi Esp. T. 135.

Ceramium gigartinum Roth. Cat. bot. 5, p. $x$ og.

Gigartina pistillata Lam. Thalass. p. 49.

Habitat ad littus Norvegiae; Esper.

DESC. Radix callus tenuis. Frondes aggregatæ, compressæ vel planæ, interdum terctiusculæ, palmam circiter longæ, Jineam latæ; caulis ter pluricsve vage dichotomus, angulis patulis; ramuli subulati, subdistichi, alterni et oppositi, horizontales, lineares, subsimplices, acuminati, tuberculo sæpe terminati. Fructus Tubercula globosa sessilia capite ácicula paulo majora, ramulorum apici et lateri insidentia, solitaria vel bina, qvibus congeries seminum minutissimorum continctur. Color violacens vel chalybxus. Substantia cartilaginea, lenta.

OBS. Hanc algam a Cel. Vahlio acceptam cum loco natali littoris Norvegix ad Esperum (cfr. ejusd. Icon. Fasc. V. p. 52.) misit Wildenowius. Suspicatur autem Turnerus id loci natalis indicium ex errore factum esse, dubitans, hanc speciem ad littus Norvegix provenire. Utrum igitur inter nostras referenda sit, an excludenda, postera dies docebit.

3. G. pygmoum; fronde angulata, filiformi, rage ramosa, apice incrassata, tuberculifera.

Fucus pyginceus Lightf. p. 964. Tab. 52? - With. 4, p. 100. - Turn, Syn, p. 258. $\mathbf{n}_{\text {? }}$ 47. et Hist. T. 204. - Ag. Disp. n. 30.

- pumilus Esper. T. 116?

- claz'atus Konig, Zoega, Mohr, Hooker?

Lichen confinis Fl. d. T. 879. fig. 2. - Ach. Prod. p. 208.

Stereacaulon confine Acl. Meth. Lich. p. 317.

Gigartinn pygmoce Lain. Thalass. p. 49.

Lichina pygmaea Ag. Syn. p. 9.

Habitat ad saxa maritima littoris Hindsholm Fioniæe paululum supra maris superficiem, ubi ab undis identidem irrigatur. - Ad Hirtsholm prope Frederichshavn Cimbrix; Hornemann. - Ante ostium śinus Oxefiord Norvegix. Ad insulas Færoenses.

DESC. Radix placentula minutissima, saxis agglutinata. Frondes aggregatr, cxspitosx, lineam unam altcramve longx, raro longiores, solidx, ramosæ. Caulis tcretiusculus, angulatus, vix compressus. Rami divaricati, curvati, 
apicem versus densi, nec raro palmati, aliisqve brevioribus obsessi; ramuli ad apices imprimis al, globulos finctiferos, ilsi collocutos, incrassati; caulis ramique setil porcina paulo crassiores. liructus Tubereula globosal, fuscoflavicautia, subpcllucidir, semine Papareris somniferi minurit, in apicibus ramulorum disposita, yva semina mimutissima ovata fusca filoris plurinis ramosis immivtis includere dicuntur. Color irrigata fusco-virielis, siccatie niger. Substantia cartilaginca, exsiccalic rigiela fragilis. Percunis.

\section{GIGARTINA. *) \\ Frons teres, ramosissima. Frucue 'l'ubcrcula glohosa, ad latera ramulormm scssilia, exıerna, vel Semina nuda interna. \\ * Sructu externo.}

Tab. 60 .

1. G. plicuta; fronde filiformi, ramosissima; ramis vagis, implicatis, conA. 1. fertissimis; tuberculis lateralibus, verrucosis.

Gigariina plicala Lam. Thalass. P. 48.

Fucus plicalus Turn. Syn. n. 6o. et Hist. T. 180. - Gmel. p. 142. T. 14. fig. 2. With. 4, p. 144. - Engl. hot. Tab. so89. - Ner. britt. T. 7. - Dec. A. fr. 2, p. 37"?

- Plukenet. phyt. T. Is4, fig. 2.

- rlbus Fl. d. T. ¿ng.

Sphrerncoccus plicatus Ag. Syn p. "3-

Ceramium plicatum Roth. Cat. bot. 2, p. 163.

E) simplicior; dichotoma, fastigiala.

久) tenuior; pollicaris, dichotoma, insigniter erecta, apice bifurca; ramis divergentibus, capillaceis, nitidis, diaphanis.

Habitat ad oras Daniæe sat freqvens. Varictates ad oram Fionix scptentrionalem. In mari Islandico; König. - Ad insulas Faroenses, rarius.

DESC. Radix callus eviguns, nigricans, sixis adlivus. Frons teres, filiformis, aepratis. Inngifudine palmari el ulura, sctam porcinan crissitic superans, diaplatar, statim a batsi usque implicato-ramosissima. Rami divaricati, sicpe secundi, patuli, incurvi, lue illue reflexi, nunc approximati, unne dissiti, aliisfre minoribus cadem ratione itcrun iterumeve dispositis obsessi : ramuli ad summitates tenuiores, sape secundi, Jue illue divergentes. Fructus Tu-

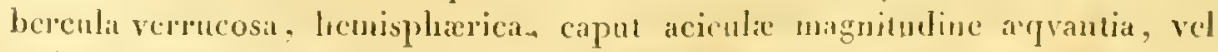
codern paulo minora, ad latcra ranulorum sita; scminat vero in is nunqram vidi. Color rariat: cxcmplaria rensta ad hasin intcrelun fusco-rublua juniora nune rubentia, vel rosca, nunc alba, plerumpre diaphaua, nitida. Sub-

*) Ex rigxpтo\%, drupa, qvoniau tuberculis interdın est limbus pellucidus. 
stantia cornea, rigida, tenax; basis et rami crassiores fragiles. Percunis. Vere cum fructu, sic dieto, imprimis legitur.

OBS. Varictas $\gamma$, qvam ad omne anni tempus eandem legi, vix status plantæ juvenilis.

2. G. Griffitshice; fronde filiformi, subdichotoma, fastigiata; tubercu- Tab. 11. lis ]àteralibus oblongis amplectentibus.

Fucus Griffitshice Turn. Hist. T. 37. - Ner. britt. ed. 2. T. 19.

Habitat ad littus Fionix septentrionale; Hofmann Bang.

DESC. Radix eallus exiguus. Frons teres, pollicen unum alterumve longa, setam porcinam crassa, per dichotomias divisa, ramis summis vagis sccundis patulis. Fructus Tnbercula oblonga, rubra, frondem amplectentia, qvibus semina ovata minntissima continentur. Color dilute ruber, subdiaphanus. Substantia cornea, tenax.

OBS. In honorem Dominæ Griffitshioe, felicissimæ Algarum in Anglia indagatricis, hanc speciem Cel. T'urnerus appellavit.

3. G. confervoides; fronde filiformi, ramosa ; ramis elongatis, simpliciusculis; ramulis setaceis, sparsis, utrinqve attenuatis; tuberculis ubiqve per frondem sessilibus.

Gigartina confervoides Lam. Thal p. 48 .

Fucus confervoides Linn. - Turn. Syn. p. 328 . et Hist. T. 84. - With. 4, p. 14. -

Engl. Bor. T. 1668. - Fl. norv. 2, p. 92. - Wulf, crypt. n. 20. - Esp. T. 68. - Dec.

f. Ir. 2, p. 36 .

- scorpioides Fl d. T. 887 ?

- longissimus Gmel. p. 134. T. 15. - Esp. T. 20?

- elongatus Fl. norv. 2, p. 143. n. 1095.

- vernucosus Ner. britr. T. 8.

- uniformis Esper. T. 108 ?

- acerosis Esp. T. ro3.

Spharococcus confervoides Ag. Syn. p. 33 .

B) procerrima; ramis in longum protensis, subsimplicibus, subnudis.

Fucus procerrimus Esp. T. 92.

- longissimus Wulf. crypt. n 24. - Ner. britt. T. 16.

Ceramium longissimum Roth. Cat. bot. 3, p. 16 .

2) plicata, ramis triplicato-ramosis, setaceis.

Fucus plicaus Esper. T. 37.

Habitat ad oras Daniæ raro; ad littus Hindsholm Fioniæ, Hofmann Bang. - $\beta$. in rupibus maritimis Islandiæ. - $\gamma$. e mari balthico accepit Esper. 
DESC. Radix callus exiguus. Frondes aggregate, terctes, fliformes, flexuosa, longitudine semipedali et ultra, pennan passerinam crassa, insigniter attenuator; rani elongiti, patentes. sparsi, sxpe subsecundi, interdum remoti; ramuli sxpe alternatim subsccundi, patuli, subsimplices, tres lincas et ultra longi. Fructus Tubercula sessilia, hemisplharica, capite ateicula minora, ratmis ad latera copiose iusidontia, "t semium ninutissimorum congeric fareta. Color dilute ruber, fisco vel viridi tinctus, diajhanus. Substantia cartilaginea, mollis, flexilis; exsiecatæ cornea. Perennis. Autumno fert fiuctum.

4. G. viridis; fronde filiformi, supradecomposito-pinnata; ramis ḷamu= lisqve oppositis; tuberculis hemisphrericis sessilibus.

Fucus viridis Fl. d. T. 886. - Esp. T. 114. - Ner. britt. T. 17. - 'Turn. Syn. p. 397. et Hist. T. 97. - Engl. bot. T. 1669. - Wec. H. fr, a p. 35.

Desmarestia viridis Lam. That. p. 25.

Chordaria viridis Ag. Syn. p. I4.

Habitat in sinu Dröbachiensi Norvegiae raro, AFüller. - In profundo'ostii sinus Othiniensis, Ilofmann Bang. - Ante, ostium sinus Oxefiord Norvegia, et ad insulas Freroenses copiose.

DESC. Radix callis parrus conicus. Frondes aggregatr, teretes, filiformes, solidæ, pedem circiter longx, pennæ passerinæ ad basin erassitic; ramus primarins ramulis oppositis obsessus. Raunli patentes, eapillacei, scusin scnsimqre attenuati, omnes oppositi, aliisqve minoribus itcrum itcrumeqe oppositis, apice hrand raro articulatis, instructi. Fructus Tubereula hemispherica sessilia per frondem (hand freqventer) sparsa. Color recentis fusco-aurantiacus; plantâ vero brevi tempore äeri athmospharico cxpositâ, color cito in æruginosum abit. Substantia cartilaginca, riggidluscula, inَ aqva dulci diu scrvatx lubrica; siccata flaccida. Annua. Vere et estate legi.

OBS. Fructum adposui juxta observationcm Cel. Mertensii, qui talcm in exenplari Kamschatkensi detexit. (Vide 2fag. $\mathfrak{E}$ itt. 3cit., pro anno 1810. No. 244 .

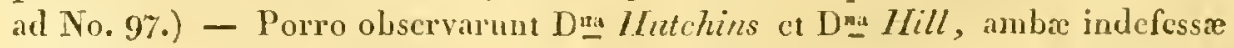
algarum in Auglia indagatrices, hanc algan nonuullas alias temuioris substantiæ (ex. gr. Fucum kaliformem, clavellosum, ovalcm, Ccramium virgatum Totl.) ei in aqra appositas destrucndi habere facultaten! idque Phrnomenon deinde repeticrunt Turnerus, Mertensius, Lamourouxius; illam autem vim ci non scinper incsse pro certo scio; nan Cerania varia rubri coloris (v, c. Ceramium diaphanum, rubrum \&c.) dc industria pluribus dicbus in aqqva dulci unacum Gigartina viridi asservata u!llame onnino subierunt mutationem. Cetcrum de olsservationis veritate non dubitans suspicor modo, hane algam primum xtate provectiori hane dissolvcndi habere vim; ea enim est ratio Gestridii filiformis, qua xate senili alias Algas tenues. in aqvit dulci ci intmistas, facile nec ita multo post una secum penitus decomponit. 
** fructu interno.

5. G. lycopodioides; fronde subsimplice, setis densis undiqve obtecta; seminibusqve in apice setarum nudis.

Fucus lycopodioides Lin. - Fl. norv. 2, p. 80. - With. 4, p. 107. - Turn. Syn. p. 343. et Hist. Tab. 12. - Engl. bot. T. 1 165 . - Ag. Dis p. p. 16.

Conferva squarrosa Fl. d. T. 357 - Fl. norv. 2, p. 105.

Furcellaria lycopodioides Ag. Syn. p. II.

Habitat ad rupes maris Islandici; Oeder. - Ad Finmarkiam et Islandiam; Gunnerus. - Ad insulas Færoenses; Landt.

DESC. Radix callus tenuis. Frondes aggregatæ, pedem unum alterumve longæ; pennam passerinam crass ad pollicem supra basin ortis instructæ. Caulis ad basin nudus, sed cum ad pollicem cireiter supra basin pervenerit, setis densis cooperta. Scta imbricatæ, inarticulatæ, setam porcinam crassæ, tres ad qvatuor lineas longæ; sqvarrosa vel patentes, interdum aliis minoribus pinnatim instructæ. Fructus Semina nuda, fusca, apici setarum intumescenti immersa. Color obscure rufo-fuscus. Substautia cartilaginea, flexilis, exsiccate rigida. Pcrennis.

6. G. pinastroides; fronde filiformi, ramosissima; ramis apice involu= tis; ramulis subsimplicibus, subulatis, sparsis, summis secundis.

Fucus pinastroides Gmel. p. 127. T. I1. fig. I. - Turn. Syn. p. 346. et Hist. Tab. II. Ner. britt. T. 13. - Engl. bot. Tab. 1042.

- incurvus Huds. p. 590. - With. 4, p. 115.

Ceramium incurvum Dec. A. fr. 2, p. 43.

Rytiplulaca pinastroides Ag. Syn. Introd. p. XXV.

Habitat ad insulas Færoenses, ut in sinı prope Thorshavn, at raro.

DESC. Radix callus parmus nigricaus. Frons palmam ad spithamam et ultua longa, filiformis, pennam corvinam crassa, inferne nuda, deinde ramulis plurimis subulatis, erectis, densissimis, setam porcinam crassis, aliisqve eadem ratione disposilis obsessa. Rami sparsi, sæpe recurvi, apicibus involutis. Ramuli summi ejusdem crassitudinis, subsimplices, subulati, undiqve imbricati. Fructus Scmina nuda, globosa, limbo pellucido cincta, summis ramulis innata; præterea secundum Turnerum Capsulæ sphæricæ bicvi pedunculo fultæ, in ramulorum parte superiori sitæ, semina pyriformia includentes. Color obscure ruber, exsiccatæ nigricans. Substantia cartilaginea, tenax, exsiccate rigida, fragilis. Annua. Aestate legi.

7. G. lubrica; fronde filiformi, subgelatinosa, vage ramosa, inferne Tab. 12. nuda, superne ramosissima; ramulis summis brevibus, subulatis; seminibus nudis, in ramulis mamillæformibus nidulantibus. 
Hahitat ad rupes exteriores ante ostium sinus Oxefiord Norvegia, inter Phycoidata, e fundo protracta, sed raro; Hofinunn Bang et ego.

DESC. Radix callus exiguus, planus, nigrieans. Frons tercs, solida, dimidiam lineam erassa, longitndine tripollicaris. Canlis rage dichotomus, flexnosus, inferne ad pollicem et ultra snpra basin plerumpre nudus, deinde ramis ejusdem, qvâ caulis, crassitici, brevibus, patulis instructus. Ramuli ramosi, qvo magis ad ipicen appropinqvant, eo densiores, hineam fere lonsi, sululati. Frucus Semina globosa minntissima atrorubeutia cluplici seric in mamillis rel capsulis oblongo-lanceolatis, obsolete geniculatis, sparsin vel subvertieillatim e ramulis summis exemutibus disposita. Color dilute rosens, sul)diaphanus. Substantia cartilaginca, subgelatinosa, flaccida; canlis cxsiccati cornca. Chartæarete adhæret.

8. G. purpurascens; fronde filiformi, ramosissima; ramulis setaceis, sparsis ; tuberculis sphæricis, solitariis, ramulis innatis.

Gigartina purpurascens Lam. Thalass. p. 48 .

Fucus purpurascens Turn. Syn. p. "57. et Hist. Tab. 9. - Velley Tab. 2. - With. 4. p. 115. - Engl. bot. Tab. 1243. - Decand. A. fr. 2, p. 36.0 - Ner. britt. cd. 2. I'. 18.

- corallinus Fl. d. T. 70g.

- capillaceus Esp. T. 35.

- acicularis Esper. Tab. 9 r.

Splocrococcus purpurascens Ag. Syn. p. 3 r.

B) cirrhosa, ramulorum apicibus spiraliter cirrhorum instar tortis.

Tab. 12. r) rostrata, fronde tenerrima rubra; ramulis summis subdichotomis, tuberculiferis, rostratis; rostris curvatis, simplicibus vel bi-trifidis.

'Tab. 12. d) virescens, fronde viridi, tuberculis roseis.

Habitat ad littora Danixe sat frequens. - Ad rupes Norvegix, Miiller. Ad Frederichsharn Cimbrix cum fructu legit Prof. Hornemann. - $\beta$. ad littus Hindsholm Fionia, Hofmann Bang. - $\gamma$. in herbario Rev. O. Fabricii Groenlandico observavi. - $\delta$. ad littus Svinöer prope Lindesnæes Norregiæe lcgi.

DESC. Radix sentata, interdum fibras decumbentes et erectas emittens. Frons sxje pedalis. Ramns primarins pennæ corvinæ crassitic, carnosus, ramis obsessus. Rami secundarii crecto-patentes, minoribus instructi; ramuli setacei, tres ad sex lincas longi, plerumgre simplices, attentati. Fructus T'nbercula sphrerica intense rosea, capilis acicula magnitudine, duo ad quatuor simplici seric in codem ramulo nidulimtia, quibus semina minutissima ovata rubra includuntur. Color dilute ruber diaplanus. Substantia carnosa, mollis, cartilaginea; cxsiccatione constringitur. Aumua. Estate et autumuo cum fructu legi. 
9. G. subfuscu; fronde filiformi, ramosissima; ramis alternis subulatis, Tab. 10 patentibus; ramulis penicillatis fasciculatis; tuberculis geminis apici ramulo- et $\mathbf{1 1}$. rum innatis vel capsulis externis pedunculatis.

Gigartina subfusca Lam. Thalass. P. 49.

Fucns subfuscus, Woodw. in Linn. Trans. 1, Tab. 12. - With. 4. p. 115. - Esper Tab. Ij7. - Tuun. Syn. P. 350. es Hist. T. 10. - Engl. bot. T. 1164 . - Fl. dan. T. 1543. Ner. britt. ed. 2. T. rg. - Jürg. Alg. Dec. 5. n. 2.

- setaccus Wull. crypt. n. 40.

- variabilis Gooder. et Woodw. in Lin. Trans. 3, p. 220.

Ceramium cortuosum Ducluz. Essai p. 73.

Spherococcus subfuscils Ag. Syn. p. 32.

Kyll. Virid. p. 106. n. 5 .

B) racemosa; fronde filiformi, robustiori, nigrescente; ramulis brevibus, penicillatis; penicillis densis lateralibus racemosis; granulis internis fuscis rotundis solitariis in apice ramulorum.

r) tenuior; fronde ramosissima; ramis divaricatis subrecurvis spinæformibus rigidıs; verrucis ad latera ramulorum sitis.

Spherococcus subfuscus $\beta$. tenuior Ag. Syn. p. 32 .

d) flaccida; fronde ramosissima; ramis in penicillum fasciculatum vel corymboso-fastigiatmm aggregatis, flaccidis, apice fibrillosis; tuberculis duplici serie in summis ramulis imnatis.

Habitat ad littora Daniæ; ad oram Fionia septentrionalem sat freqrens. B. ad insulas Færoenses et ad littus Svinöer Norvegiæ. $-\gamma$. ad littus Oxefiord Norvegiæ, et 'Torbæk Sellandia. - $\delta$. ad littıs Fioniæ tempore vernali copiose.

DESC. Radix placentula exigua, nigricans, Fuco vcsiculoso saxisqve adnascens. Frondes aggregatæ, terctes, filiformcs, palmari vel spithamra longitudine, ramosissime. Ramus primarius pemam passerinam crassus, teres, solidus, alternation pinnato-ramosus. Rami utrinqve erecto-patentes, inferne nudi, sècl mox apicem versus alternatim ramosi. Ramuli setacei, in penicillum fascicnlatum aggregati, apice iuterdum obsolete gcniculati, et fibrillosi. Fibrillæ tenuissimæ, lineam unam alteramve longæ, densissime congestæ, sub lente dichotomæ, geniculate, pellucidæ, articulis diametro 6-10plo longioribus, geniculis apicem versus ob tenuitatem evanescentibus. Fructus Tubercula globosa fusca, oculo nudo vix conspicua, apicibas ranulorum intumescentibus iunata, simplici vel duplici serie congesta, limbo pellucido cincta, qvex, qvando vel maturescunt vel diffringuntur, in semina 4 vcl 5 angulata dissol- 
vuntur; reperiuntur ctiam laand raro Capsulæ solitarix, ovatx, latcrales, brevi pedunculo fultx, quibus scmina 3 ad 7 ovata, fusca, muco pellucido immixta nidulantur. Color rubro-fuscescens, exsiccatæ nigricans. Substantia cartilaginea, tencra. Percmnis.

OBS. Capsnlas in paniculam pedunculatam ternas vel quiuas congestas, qras dclincandas curavit T'urnertes, in speciminibus ad nostra littora obviis non observavi. Ceterum hae species habitn, externo insignitcr difere; quare ctiam plures Varietates altuli. - Varictatem $\delta$. prino vere, nam A prili furt fructum, abundanter legi; ccteris anni temporibus fere evancscit; color cjus tempore hyenali in canle atroruleseens, in ramulis roseus, sed tempore vernali, qro florescit, in dilute fuscum abit, et ramuli tune magis prolongantur; anua est. - Verrucx, quas in Varietatc $\beta$. e Norregia vidi, nulla scmina continent; nam puncta illa nigra, qva in iis dissectis obscrvavi, (vide Tab. 11. B. 2.) potius pro massa intcrna hic illic unagis condensata, qvamı pro scminibus sumenda sunt.

Tab. 11. 10. G. Fabriciana; fronde filiformi, tenerrima, ramosa; ramis inferioribus remotis; ramulis summis abbreviatis, insigniter divaricatis.

Habitat in mari Groenlandiæ; Herb. Rev, O. Fabricii.

DESC. Radix non visa. Frons teres, solida, pollicem unum alterumve longa, infra setam porcinam crassa, apicem versus sensim sensinqye attennata, ramosa: rami altcrni, inferiores remoti, superiores densiores; ramuli sunmi brevissimi, alterni et secundi, divaricati, spinæformes. I'ructus non observatus. Color intense roseus. Substantia cartilaginea, mollis, flaccida; sub lente pulchre reticulata, inarticulata. Clartæ laxe adhæret.

OBS. Hanc Algam clegantcm, qvam in llerbario nominato siccatam obscrvavi, nomini indagatoris Sumnc Rev. O. F'abricii, qvi eam, dum in Groculandia ab anno 1768 ad 1773 muneri ccelesiastico in Colonia Fredericlsslaab pracfuit, unacum pluribus aliis legit, ea, qra par cst, observantia dedicavi, IIabitu cxtcrno ad C'eramium $W^{\top}$ ulfenii Roth, aliqvantum accedit, sed structura interna inarticulata ab eo satis distingvitur.

\section{FUR CELLARIA.}

Frons teres, dichotoma, Fastigiata. Fructus Tubercula terminalia subulata, vel lateralia spongiosa,

Tab. 40. 1. F. lumbricalis; fronde filiformi dichotoma; angulis dichotomiarum A.1-4. acutis; apicibus obtusis; tuberculis siliqvaeformibus in apicibus frondis. Furcellaria lumbricalis Ag. Syn. p. 10. 
Fucus lumbricalis Gmel. p. 108. Tab. 6. fig. 2 - Velley T. 4. - Turn. Syn. p. 317. et List. T. 6. - Engl. bot. T. 824. - Dec. A. fr. 2, p. 22. - Jürg. Alg. Dec. 4. n. I.

- furcellahus Linn. - Fl d. T. 419. et Tab. 1544. b. (ubi fructus sistitur). - Fl. norv. 2, p 78. - Esper. T. 41. - Sclum. enum. 2, p.112. - Ström. Sondm. n. 6. - Kyll. Vinid. p. 46. n. 8. - Moris. Hist. Oxon. III. S. 15. Tab. 9. Gg. 4.

B) fastigiata; apicibus compressis, ovato-lanccolatis, abbreviatis, acutis; diaphanis.

Fucus fastigiatus Linn. - Fl. d. T. 3.93. - With. 4, p. tro. - Turn. Hist. T. 6. fig. b. (optima) - Gmel. T. 6. fig. 1. - Ner. britt. T. 14. - Esp. T. 16. - Schum. enum. 2, p. 112. - Decand. il. fr. 2, p. 35 .

Habitat ad littora Dania freqvens. Varietatem, in Figuram Turneri optime qvadrantem, ad oram Fionia septentrionalem legi. - Ad insulas Færoenses raro.

DESC. Radix fibrosa. Frons palnam rel spithamam longa, teres, xqratis, pennam passeriuam crassa, per dichotomias sexies pluriesve repetitas divisa; rami subfastigiati; apices steriles, bifurci, obtusinsculi, pallide rubentes. Fruetus Tubercula siliquraformia, vel potius Semina nuda, fusca, oblonga, qrae in apicibus frondis intumescentibus, transversaliter sectis, juxta peripheriam ordine disposita, sub leute in conspectum veniunt. Color fuscoolivaceus, in statu juniori sæpe flavo-viridis, exsiecatæ nigerrimus. Substantia cartilaginca, tenax. Peremnis. Hycme cum fructu legi.

OBS. In hac Alga, cum diu in littus siccum ejecta et pluriâ freqventi humectata fucrit, Sphaerice species globosa, nigcrrima, intus cava, et granulis minutissimis nigris conferta, ramulis densissime insidens haud raro conspicitur.

2. F. rotunda; fronde fliformi, dicliotoma, angulis dichotomiarum obtusiusculis; apicibus acuminatis ; tuberculis lateralibus, amplectentibus, spongiosis.

Fucus rotundus Gmel. p I10. Tab. 6. fig. 5. - With. 4, p. 110. - Turn. Syn. p. 509. et Hist. T.5. - Engl. bot. T. 1738. - Fl. dan. T. 1544. a. - Ag. Disp. P. 14. Jürg. Alg. Dec. 5. n. 1 .

- caprinus Fl. norv. 1, p. 96. n. 3tr. - Act. Nidros. 4, p. 82. Tab. 5. fig. 4. 5.

- adiacus Ner. britt. 'T. 14.

- fastigiatus Ner. britt. T. 6.

- furcellatus Mohr Hist. nat. Isl. p. 242. (excl. syn. Fl. dan.)

Chardaria rotunda Ag. Syn. P. 12.

Habitat ad oram Fionize septentrionalem, at raro cum fructu. - Ad littus Islandix, Mohr.

DESC. Radix explanata, solida. Frons palmam et ultra longa, pennam passcrinam crassa, inferue simplex, deinde per dichotomias sexics pluricsse repetitas divisa; rami fastigiati; anguli divaricati, paulnlum rotundati. Fructus 
Tubercula spongiosa oblonga lateri frondis affixa rel amplectentia (sed quoad superficiem cpidermide frondis nou tcria), que scmina plurima subrotunda, limbo pellucido cincta includunt. fihris prellucidis articulatis excentricis intermistis. Secundum figuram Fl. dau. semina in congeries roseas stellatin dispositas aggregata sunt. Color fusco olivaccus, luecen versus diaphanus. Sulstantia cartilaginea, sub lente intus punctata, exsiccate cornea. Peremis. Hyeme ct vere venditatum fert fructurn.

OBS. Inter hauc et antecedenten qroad hahitum externum maxima interest aftinitas: fructifera quidem exemplaria fucile dignossuntur, stcrilia vero, frac

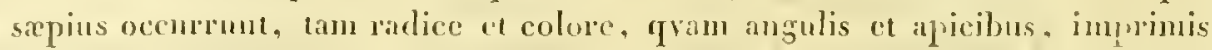
antem structura interiori, qre in Fure. rotunda sub, lente junctitia apparet, discerni possmnt. Fructus, qrem anctoritate Cel. 'Lurneri huic attribui specici, semper mihi copvidem fuit aliqvantulum suspectus; u, si hatritus cxtermens non obstaret, cx observatione Cel. Agardhii, qram non possum nom approbare, ad seqvens genus melius forsan esset referendia.

\section{CHORDARIA. *)}

Frons teres. Semina nuda toti fromdi inmersa, eandemque tanquam constiluentia.

Tab. 13. 1. Ch. scorpioides; fronde terete, vage et alternatim ramosa, seminibusqve nudis in tota frondis substantia densissime nidulantibus.

Fucus scorpioides Fl. d. T. 14.9.

Habitat in fundo maris ad oram Fionize septentrionalem sat vulgaris, imprimis ad littus preedii Hofmansgare.

DLSC. Radiccm non certe novi, parram puto lapidibns adnascontem. Frons solitaria, solida, teres, pedali et ultra longituline, basi atconata, pennxe passcrine crassitie, dcinde scnsim pennan corvinan crassitic arpans, ad altitudinem pollicis supra basin indivisus, dein ramos ragos cmittens. qvorum infimi eadem fere sunt longitudine, qva sanns primarins, ceteri breviores. Rami teretes, horizontaditer patuli, nunc currati, nunc reflexi, sed rarius adpressi, plermagre alewui, sed ctian sceundi, aliisque minoribus, iterum simili ratione divisis, obsessi, apicem versus attenuati, apice olutuso. interdum medio depresso. Fructus Semina uuda, exigua, ovata, flavescentia, linbo pellucido cineta, tela celluloste froudis ubiq̣e innata. Somed ctiam exemplar legi, eni insidebant Tubercula scutedliformia, pisi fere magnitudine, sed substantia corum interna erat eadcon, ac totins frondis. Color fu-

”) Ex zópòn, chorda, fides; cfr. Link, in Sclirad. Journ. 180g. p. 8. 
sco-viridis, interdum sordide flavescens, in apice rarissime pellncido-rubesccns; exsiccate uigcrinus. Substantia coriacca, rigidiuscula, Ieuta; exsiccatæ rigida, fragilis.

OBS. Opiuioni Cel. Agardhii, qui hanc speciem pro Halidry nodosa habet. minime subscribo; longe melius, si pro distincta spccie non haberetur, ad Halidryn siliquosan referri posset, a qua tamen et habitu et substantia satis differt. Si in locis terrestribus inveniretur. facile pro Rhizomorpher specie: qram siccata refert, haheretur; sed sat copiose et indubitate ad littora Fionix profundiora provenit.

2. Cl. fugelliformis; fronde terete, ramosa; ramis subdistichis, elonga- Tab. 13. tis, simpliciusculis; seminibus cuneatis frondi immersis.

Chordaria flagelliformis Ag. Syn. p. 12. yeev: Calg. Bbs 44. A. .

Gigartina flagelliformis Lam. Thal. p. 48.

Fucus flagelliformis, Fl. d. T. 650. - Turn. Syn. p. 335. et Hist. T. 85. - Eugl. bot.

T. 1222. - Ag. Dec. 3, n, 22.

Conferva dichotoma Fl. d. T. $558 .-$ Mohr. isl. p. 249.

Ceramium longissimam Schunı, enum. 2, p. ir.

Habitat in mari Islandico, Oeder, Mohr, Hooker. - In oceano Norvegico, Müller. - Ad insulas Færoenses. - Ad oram Fioniæ septentrionalem à tumno sat freqvens, lapidibus et saxis adnascens.

DESC. Radix callns perpusillus. Frons plerumqve solitaria, teres, filiformis, pedem et uhra longa, pemam passerinam crassa, ubiqve aqvalis. Rami distichi, sparsi, approximati, simplices, raro una vice dirisi, elongati, basi erectopatentes, apicibus truncati vel obtusiuserli. Fructus Semina exeentrica, dense aggregata, cuneata, articulata, e qribus tota stirps sub lente constare cernitur. Color fusco-olivaccus, exsiccatæ nigricans. Substantia subcartilaginca, lubrica. Anmua.

OBS. Planta aliquot dies in açva dulci servata admodum lubrica fit, et semina, qvæ imprimis extremam frondis peripherix partcm obsident, spoute sua libera cvadunt, in aqra solitarie fluitantia, coqve modo planta panlatim dissolvitur. Fila confervoidea, qra, teste Cel. Agardhio, frondem hujns speciei obrestircut, numqram in hac, at sipe in aliis speciebus, ut in Ulva plantaginifolia, Scytosiphone tomentoso, foeniculaceo aliisqve obscrvavi.

3. Ch.multifida; fronde tercte, filiformi, dichotona; fibris ramosis, monilifornibus, e centro communi totins frondis exeuntibus.

Rivularin multifida Web. et Mohr. it. p. 193. Tab. 3. fig. a. U. c. - Rotb. Cat. bot. 3 , p. 335 .

Clectophora rubra Ag. Disp. p. 42. et Syn. p. ז27.

Ulva rubra Huds. p. 571. - With. 4, p. 126. 
Habitat ad littus Grenaac Cimbrix, Prof. ILornemann. - Ad littus IIofmansgave Fionixe nonnullis annis astate frequens, saxis adnascens.

DESC. Radix callus pusillus, subconicus, lapidibus agghlutinatus. Frondes gregaria, leretes, filiformes, spithamara ad pedalem Iongitudine, pemas passerina crassitic, flexuose, huc illuc llnctuantes, molles, lubrica, dichotumar. intricata, uhigre aqvales, apice obtusiuscula. Fructus fibre minutissima, pellucida, geniculate, dichotome vel ramosx, e centro vel axe communi frondis undigre et ubiqte progredientes, eamqre totam constitnentes. Color atro-ruber, exsiccate nigricans. Substantii subcoriacea, admedum lubrica, tenax. Anmia. Aug. el Sept. eam legi. Charte arcte allharet.

OBS. Congeriem verninm nigrescentum intrientam in aqva libre fluctuans admodum refert. In aqva dulci aliqgantum temporis servata ol, fibras e fronde sensim sensimqve cxeuntes planta quoad peripheriam praulatim diminuitur, et ad postremum, ad modum precedentis speciei, onuino dissolvitur.

4. Ch.tuberculosa; fronde terete, vage dichotomo-ramosa, ubiqve tuberculosa; tuberculis verrucosis toti frondi insidentibus.

Coramium tuberculosum Fl. dan. '1'. 15,6. (excll. synom.)

Chaclophara nodilosa Ag. Syn. p. 127 .

Mabitat ad oram Fionixe septentrionalem non freqvens; ad littus Hindsholın Fionixe Fuco vesiculoso copiose aduascens, passim.

DESC. Radix callus parus. Fronles aggregate, teretes, solicla, palnam ct ulura langx, pennamyıc passerinam crasse, vage ramose, intcrdum dichotomx, apicem versus paulo attenuate: rami patuli, altcrui, raro genini vel oppositi, apice obtusinsculi. Supcrficies tolius frondis a basi ad apiecm usfre unberenlis rerrucosis densis ovatis vel oblongis paululum elevalis olivaccis vel nigricantibus, semina l'apaveris somniferi minoribus, undique cl ubiqve obsessa. Fruetus Fibre minutissime, e quavis verruca excentrice exenutes, pyriformes, aleo ut apicem versus sint cuneata, ab altera vero parte acuminatre, simplices et rlichotome, et 'fre in apjicibus fibrarum contincutur gramula fusca, laxe sine dubio censenda sunt semina sive corpuscnla reproducti1a. Color fusco-viridis, raro olivaccus, exsiecate nigerrimus. Substantia coriacea sublenta mullis, in statu vero juniori ob verrucas interdum scalniuscuia. Anuma. Nistatc legi.

Tab. 13. 5. Ch. rhizodes; fronde terete, filifornt, dichotoma; tuberculis verrucosis, remotiusculis, frondem nodulorm adinstar amplectentibus.

Habitat ad littora Daniae raro; ad mumimentum 'Trekroner prope Hafniam.

DESC. Radicem non vidi, pracedentis similem puto. Frons solitarit, teres, Gliformis, sp̧ithaman longa, setam porcinan crassa, dichotoma, apicenn versus panlo attennata. Anguli dichotomiarum acuti. Ramuli erecti, flaccidi. 
Fructus Tubercula verrucosa, non ubiqve, sed modo hic illic, intervallo inter singula semilineari, frondem amplectentia, unde frondi facies nodulosa. In his tuberculis diffractis sub lente conspiciuntur fibræ excentrice exeuntes, apice cuneate, simplices. Color olivaceus, interdum rubescens, exsiccate nigricans. Substantia coriacca, lenta, flaccida.

6. Ch. paradoxa; fronde subterete, filiformi, dichotoma; ramulis api- Tab. 14. cem versus paululum attenuatis, fibrisqve moniliformibus verticillatim obsessis.

Scytosiphon paradoxus Fl. d. 'Tab. 1595. fig. 2.

Chordaria rhizodes $\beta$. paradoxa Ag. Syn. p. 15.

Conferva paradoxa Rotb. Cat, bot. 3, p. 172.

Habitat in sinu Othiniensi certis annis freqvens. Ad rupes maritimas ante ostium sinus Oxefiord Norvegiæe copiose.

DESC. Radix callus exiguus, nigricans. Frondes aggregatæ, subteretes rel potius aliqvantun compressa, spitamæa ad pedalem longitudine et pennx passerinx crassitie, solidx, rigidiuscula, per dichotomias multotics repetitas divisa, implicatc. Anguli dichotomiarum obtusiusculi. Rami diclıotomi, interdun vage ramosi vel secundi, divergentes, curvati, æivales, snbcompressi. Ramuli ultimi paulum attenuati, et lenti subjecti apicibus cernuntur obtusiusculi, et fibris moniliformibus, verticillatim dispositis, obscssi. Hæ fibræ qvo magis ad summitates appropinqvant, eo densiores, non nisi in apicibus ramulorum adsunt. Fructus Semina muda, minutissima, fusca, in maculas subrotundis, frondi hic illic immersas, congesta. Color sordide flarescens. Substantia subcoriacea, lubrica, rigidiuscula. Annua. Estate.

OBS. Descriptionem feci juxta exemplaria Norvegica; si frons fuisset tubulosa, potins ad genus Scytosiphonis esset referenda, scd solida scmper mihi visa est.

\section{T H O R E A.}

Frons teres, solida, lubrica, ramosa, fibris articulatis undiqve obsessa. Fruclus ignolus.

\section{Th. Lehmanni.}

Thorea Lehmanni Fl. dan. T. $\mathbf{r}_{504}$ fig. $\mathbf{r}$.

Habitat in ligno subputrido in paludosis stagnantibus ad lacum Lyngbye Sellandia, ubi hanc speciem singularem Prof. Lehmann invenit.

DESC. Radix callus exiguus, nigricans. Frons teres, filiformis, solida, inarticulata, lubrica, longitudine bipollicaris. Caulis setam porcinam crassitie paulo cxsupcrans, vage ramosus; rami cadem, qva caulis, crassitic, ragi, 
divaricati, interdum secundi, numc approximati, nunc dissiti. Tota frons a basi nsque tibrillosa; fibra similincam longa, lubrica, nitide, patula, undique et nbiqve imbricatim disposita, sub lente pellucida, geniculata, simplices, subulatx, atcnuatx; articulis diametro 4-6plo longioribus, geniculisqre prarum contractis. Color dilute fuscus, viridi tinctus, nitidus. Snbstantia cartilaginea, lubrica, exsiccatx cornca. Ammua. Astate inventa.

\section{A P P E N D I X.}

Sic absoluta Plyycoidatorum rite coguitorum descriptione, restat, ut mentioncm de aliquol injiciam specicbus, qva, licet ab Algolugis (linnceo, Gunnero, Tonningio, Kuenigio, Olafsen, Molnio, 'Zoega, Strömio, Landtio, Espero, Hookero) ut scandinavice afferanur, nililo tamen minns partim ob brevitatem descriptionum, partim ob defectum speciminum et delineationm, inter dubias hodie, a me saltem, referenda sum. Forsan, quod milii in votis est, Algologus quidan, cui plus temporis suppetit et sagacitatis, nonullas carum, aut loca natalia adcundo, ant horbaria, si supersint, inspiciendo, olim extricabit. Sunt igitur ordine alphabetico scquentes, adjectis, qua adsunt, notis et descriptionibus.

1. Furrus abrotanifolius, Lin.

Habital in mari Norvegico; Tonning, Linn. Amocn. Acad. 7, p. 476.

$F$ abrotanifolius, fronde filiformi compressa bipinnati: apicibus vesiculosis dilatati, terminatis, fructifieationibus hine tubcreulatis. - Fucus pinnatus raunis dichotomis, extremitatibus dilatato-vesiculosis. Löfl. it. 174. - eff. Limı. Syst. ed. X]1. 2. P. 716.

2. H'aculcutus, Fsper' 'T. 33 .

Halitat ad oras Norvegix et Srecix; Esper.

Ilanc Alyam a Fuco aculeato Turn. (F. muscoidi Esp.) esse diversan, ex delincatione ab lispero data, eomparatione pattbil; quare ctian Cal. P'of. Mertensins (in Schraderi Journal 1 B. 1801. P. 4i.) at Cel. 'Jurnerus (in Synopsi p. 262.) ut diversan speciem, cam declararunt. Differt imprimis defectu spinularum, 'qrarum in loco ramuli breves patentesqve conspiciuntur.

3. F.albus, Esper Tab. 51 .

Habitat at oras Islandix et Norvegix, Esper.

Omnino diversus a Fuco albo F.l. d. T. 408. (o: F. plicato Turn.); substantian cnim internam esse spongiosan vel porosam, ita .ut frons comprimi possit, 
contendit Esperus. Praterca in aqva facile reviviscit, nec ulla lubricitatis adsunt vestigia; apices sape geniculati; ramuli dissiti, dichotomi, angnlis obtusis, apicibus attenuatis. Color albus, luteo tinetus. Hujus algæ specimina ad Islandiam et Norvegiam lecta ad Esperum misit Chemnitzius, antistcs Hafniensis celcherrimus. - Forsan _Fucus lumbricalis vo confervoides, qui qrandoqve albescit.

4. Fucus Bastera, caule temui, superne ramoso, corpusculis monospermis, ovatis, altcruis. Gmel. Hist. Fuc. p. 166. - Lim. Syst. nat. cdit. XIII. Gmel. 2, I. 1386.

Habitat in mari norvegico prope Nidrosiam; Basteri opusc. subsec. 2, p. $12 \%$ Tab. 12. fig. 1.

OBS. De hac specie dicit Basterus 1. c.: "Planta seminifera ad viginti orgya"rum profunditatem proje Nidrosian sive Dionthemum e mari germanico pe"rita." A Cel. Episcopo Er. Pontoppidano cum Bastero fuit communicata, sed potius ad Zoophyta qram Hydropliyta pertincre mihi videtur.

5. F. cartilagineus, Gum. Fl. norv. 2, p. 108. Tab. 3. fig̀. 5. - Ström Söndm. Fuc. 11. 8. ct Fueus 11. 3. in Act. Hafı. Vol. 10. p. 254. Tab. f. Fig. 3. - König ct Zoega in Flora island. ad fincm itin. Olavs. et Povels. - Land! in Descr. insul. Færoens. - Fucus vindicatus cartilaginens Fl, norv. 2, p. 123. - Ceramium

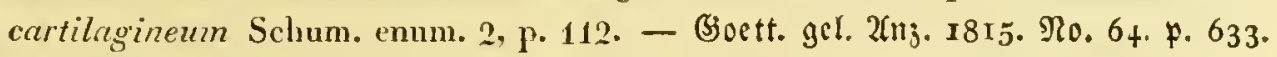

Ilabitat in mari septentrionali ex. gr. ad Finmarkiam passim, Gunnerus. In mari Norv.ad Söndmöer, Ström. - In mari Islandico, König, Zoega, Mohr, Hooker. - Ad insulas Færoenses, Landt. - Ad lapides in mari inter Amagriam et Sellandiam, Schumacher.

OBS. Fucus ille, de cujus ad Norvegiam et Daniam habitatione merito ambigitur, ad Promontorinm bonæ spei, ut satis notum est, lætc crescit et copiose legitur. Cel. Tumerus, auctoritatc Rev. Gunneri et icone hujus algæ in Flora norregica exhibita permolus, plantam Gunneri ad suum Fuc. cartilagineum retulit, neqve immerito; negari enim non potest, iconem illam in algam, de qra loqvimur, bene qradrare; est antcm, qvod miremur, istam plantan, Hcmisplırii anstralis incolam, in mari Finmarkiam alluente provenire. Suspicatur Esperus (Ieon. fuc. 1, p. 15) eam e Capite b. sp. navibus forte eo advectam, seriori tempore ibi esse propagatam; qvæ tamen conjectura non omnia dubia tollit. Cel. Agardhius (Syn. p. 30.) credit, eam non verum esse Fuc. cartilagineum, sed potins ad Fuc. coronipifolium pertinere. Ut autem etiam ego meam qvalemeunque afteram opinionem, credo eqvidem, plantam e regionibus australioribus ad oras Norvegix septentrionales per Oceanum ri llıctum fortc fortuna fuisse delatam; planta cuim, quam icon citata sistit, in apice trita et qrodammodo lacerata videtur, quod ex longa ejus per- 
Occaumm circumvagatione effecum csse colligimus, cangve ob Jauc el alias rationes, ut adventitiam, e eatalogo 'Thalassiophytorum indigenormm esse excludendam opinamur; qvan ficile ctiam fieri potcrat, ut ex commutatione qvadan fortuita schedularum, quas Botanjei plantis singulis adjirere solent, crror pendere possit? Jiucus eartilagineus Gunn. in Fl. norv. interea rite, ut opjunor, determinatus est; cujus rei cansa in eo sine dubio graecuela est, qrod ipse Gunnerus multas Algarum suarum ad Limncem, ut determinarentur, mittere solchat; jpsum enim liev. virum in Fuco cartilagineo determinando alias facile errare protuisse, inde pater, qrod, cun Strömius fincum grendan silji ignotum ad littora Söndnöcx inventum ad Gunnerum, n1 detrminaretur, misisset, hic Strömium literis certiorem fecit, istau algym esse Fucum cartilagincum Lin.; sed in hoc casu vir optimus eravil; nam juxta delincationcm est Furus plumosus. (efr. Act. Hafu. Vol. 10. 1. 256. cun jeone Tah. g. Fig. \%.) - Alera vero alsa, a Rer. Strömio (tam Söndm. Fuc. n. 8. qran Fuc. 11. 3. in Act. Hafu. Vol. 10. p. 254. Tab. f. Fig. 3.) nominc Fuct cartilaginei insignita, juxta iconcm cilatan sine dubio est F'ucus dentatus. Qvan vero plantan sub nomine F'ure carlilaginei allerunt König, Zoegra, Molu, Hooker, Landt, ea neqve hujus loci esse videlur, sed potius ad $F$. coconeum 'T. perelinere censenda est; ex auctorihus laudatis alins, ut videur, alium exscripsit; Könishius igitur est vir princeps, cujus auspiciis ceteri, Thatlassioplyta tunc temporis neglecta mints curantes, nitumlur, et verbis confielume; prodsi igitus ejus berbarium jam supererat, in liqvielum res sjue dubio facile perduci poteral, sed illud luerdsariun jamdurlum periit. - Denirge grod siceo pede, ut dicunt, hoc laco non ommino est pretcrenudum, Cel. Schumathertes in Enum. sua 2, p. 11'? plantan, Ceramium cartilagineum dictan, affere, eamque ad Amagriam inveniri perthibet. Exemplar, frod in Herb. Sehumacheri asscrvalur, revera est l'. cartilagineus 'T'; pace viro optiun rivi dicendum est, tantam inter loce ex cxenplaria Capensia interesse si-

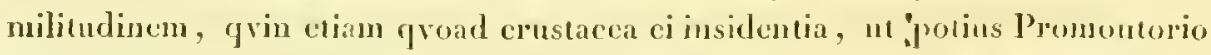
b. sp. qram or: Sellandix lanc algan ortun sumn dejere existincmus; sced ideo non neganns, eam loco indicato fuisse inventam; navihns cnim, qrie ex lndia occidentali huc urebro adveniunt, Fucus natans, bacciferus aliiqve interdum agglutinati insident; tali igitur ratione "Fucum illum cartilagineum ad litora nostra delatum fuisse opinamus.

6. F. rlavatus, Kocnig.

Hahitat in mari Islandico. Kocnig, Zoega, Molı', Hooker.

F. clavatus, dichotomus, tcres, extremitatilus clavatis, apice excavatis. Oeder Enum. 11. 173. - Minimus longitudine podlicis. Kocnis 1. c. 
OBS. Secundum las notas indicatas sine dubio est $F$. py'gmoeus Lightf.; cui etiam ut synonymum adjunxi.

7. Fucus concatcrates, Lin. Tonning.

Habitat in mari Norvegico, T'ouning in Amoen. Acad. \%. p. 476.

$F$. concateratus, fronde filiformi, ramosissima; ramulis dichotomis, resiculis noniliformibus distantibus innatis, foliolis subnlatis. - Frons filiformis, opposite vel alternatim ramosissima, ulimis ramulis expe dichotomis. Vesiculx ovatæ, cauli ramulisque innatx, remote com folio subulato ad latus cujusvis vesiculx. Lin. Syst. nat. ed. XI1. 2, p. $71 \%$

8. F. corneus, König.

Habitat in mari Islandien, Köniqg, Zoega, Mohr, Hooker.

$F$. corneus, virgatus, dichotomus setis æqvalibus. Oed. Enum. n. 169. - Fl. d. T. 3.5s. - König l. c.

OBS. Forsan $F$. aculcatus T., vel etiam, siqvidem FI. d. T. 358. citatur, $F$. flagelliformis.

9. $F$. coronipifolius, König.

Habitat in mari Islandico, König, Zocga, Molnr. Itooker.

$F$. coronipifolius, frondibus eartilagincis, subdiclotomis, canaliculatis, subtus et margine obsitis verrucis seu rumulorum rndimentis confertis; Rajus n. 23. Parvus purpurens v. luteus, a basi usque ad apices ramificationum canaliculatus. Ramifieationes sensim versus apiccm latiores, facie crispa. Verrucæ margiuales in ramulos cylindricos parallelos excrescunt. König et Zoega l. c. OBS. Sccundum has notas est $F$. mamillosus T., ubi ut synonymum attuli.

10. F. discors, Gumnerus, Tonning, Ag. Syn. p. 2.

Habitat in mari norvegico Gunn. Fl. norv. n. 514. - Tonning in Amocn: Acad. $7, \mathrm{p} .476$.

$\boldsymbol{F}$. cliscors, fronde tereti incrmi acnlcatissima, foliis distichis, subpimatis, lineari-lanceolatis, serratis. Lin. Syst. nat. ed. XII. 2, p. 717. - Esper Tab. 26. - Caulis palmaris teres undiqve vestitus ramentis rel aculeis inermibus confertissimis; folia distiche posita, plana, lævia, lincari-lanccolata, scrrata et laxe sxpe pinnata. Lin. l. e.

11. F. ericoides, fronde filiformi ramosissima hirta. Lin. Sp. pl. 1631. - Fl. norv. 851. - Gmel. T. 11. fig. 2. - Retzii Prodr. 1694. - In mari Finmarchiæ ad Vardö ct Hammerfest; Gunnerus.

12. F. foeniculaceus, Gumn., Tomning, Esper.

Habitat in mari norv. Gunn. Fl. norv. 2, p. 685. - Amocn. Acad. 7, p. 476.

In mari Mlcditerraneo, etiam in mari Germanico ct Balthico. Esper ad Tab. 30 . 
Fucus foeniculareus, fronde filiformi ramosissima, vesiculis ovatis terminatis, foliolis multipantitis olutusis apjec fructificantibus. Lin. syst. cd. XII. 2. 1. $71 \%$

Statura Ljehenis Usnere; ramulis copiosissimis capillaribus terminatis vesiculata, sapius prolifera, ultima tcrminata aliggot folielis". apice tubcreulatis. Lin. I. c.

13. $F \cdot$ gremulatus, Ocder.

Ulabitat ad littus Norvegix, Octer Fl. d. Tab. 591.

F. sramuatus, froude filiformi, ramosissima, ramulis acuminatis. vesiculis subrolund is cumulatis, ranis foliisqve acutis omnilus imnalis. Lin. Syst. nat. ad. XII. 2. 1. $71 \%$

OBS. Sccundum Decand. (II. fr.) est Fincus barbatus. Sccundum Agardhium est l'uc. selaginoides vil mucronatus, (Sуn. 1. 2). - Pretcrea apud Lisper. exstat T. 61. huc torsan pertinens. Iuter Fuc. moniliformem Esp. T. 148. at F. granulatum Fl. d. ctiam magna interectere videtur similitudo, sed illum e mari Australi accpit Esperus. - Mertensio est Fucus coneatcnatus L. in statu juniori, cfi. Scluad. Journ. 1. B. 1800. J. 182.

14. F. lanosus, König, Zocga, Gumerus, Molur, Jlookcr.

Habiat in oceano Islandien, König. - Lanx atre instar saxis adnascitur,

Nohr Ilist. nat. Island. p. 242. - In mari Norvegico, Gunnerus, Touning Amoci. Acad. \%. p. $4 \% 6$.

$F$. lanosus, frondibus capillaccis, dichotomis, ramosissimis, scabris, Lin. Syst. nat. cd. XII. - Refert linam atram, palmaris, oculo armato scaber, putuctis subrerticillatis lin. l. c.

UBS. Forsan Mutchinsia fastiggiala $\Lambda \stackrel{\text { g. }}{ }$

15. F. 11. 11. Ström Sïndm. ct in Act. Hafı. 10, ]. 254.

Ilabitat in mari Norregico prope Sündmöer, Strö̈m.

Fucus fronde sessili reniformi, decussatin striata. Siröm l. c.

OBS. Intactam omnino relinquere non possum hane alsam, qva scc. Strum statura gande fore $l:$ sengrinei el prepter colurem anocuissime roscum ol degimtom ramificationem palcherrima; folia ovala, reniformia, simpiticiter costata. Fructus Bacea crigure capilis acicula magnitudine e caule ramisyve: breviter peduncudita. An F. remiformis vol revistatus T.? - Ceterum verla Cel. Strömii, utpote in Algologia parum versati, non nimis sunt urgenda.

16. T.obtusers, Ag. Syn. p. 3.5.

Inalitat in oris Ballusia sccundum Herbariun Cel. Montini.

17. F. psendoceranoides, Esper Tal. 80.

Iabital in mari lstandico tisper.

ґ. psendoceranvides, caulibus ramosis infira terctibus, ghobulis insignilus lateraJilus congestis pellucidis. Syst. nat. col. Xill. (imct. 
OBS. Hxc alga affinis Fuco lumbricali quoad habitum et F. confervoidi quoad fruetum, scd diversa a F. pseudoceranoidi Gmcl. p. 119, qui ad F. mcmbranifolium T. pertinet.

18. Fucus selaginoides, Tonning, Gunncrus, Agardh.

Habitat in mari Norvegico, Tomning in Amocn. Acad. \%, p. 476. - Gunn. Fl. norv. 2, p. 90. - Gmel. Tab. 2, fig. 1. - Ag. Syn. p. 1.

$F$. selaginoides, froude filiformi ramosissima; ramis dichotomis; foliis subulatis altcrnis, basi vesiculosis. Lin. Syst. nat. ed. X11. 2, p. \%1\%.

19. F. spermophorus, Köönis, Tonning, Gunurrus.

Fucus spermophorus Esp. T. 154. - Tnrn. Hist. T. 76. - Fl. norv. 2, p. 26. n. 414 .

Fucus mamillosus Wahlenb. Fl. lapp. 11. 947?

Ceramium spermophorum Roth. Cat. bot. 3, p. 113.

Spherecocrus spermophorus, Ag. Syn. p. 28.

Habitat in mari Islandico, König, Zoega, Mohr, Ilooker. - In mari Norvegico, ex. gr. ad Hammcröe Nordlandice, Gunn. - In mari septentrionali Tonning, Am. Ac. $\%$, p. $4 \%$.

Fucus spermophorus, fronde membranacca dichotoma compressa capillacea. Fructifie. pedunculatis latcralibus, foliis linearibus multifidis. Linu. Syst. nat. ed. X11.

Stipcs palmaris laxns filiformis, compresso-membranaccus, dichotomus in ramos capillares copiosissimos. Pcdunculi laterales, solitarii, fructificatione glohosa, magnitudine seminis Thymi. Ad basin stipitis folia linearia mcmbranaceat canle latiora varie multifida obusa; König. - Lin. 1. c.

OBS. Cum duhium est, hanc plantam, qram descripsit Turnerus, qvamque in mari Indico, Taprobanen alluente, seriori tempore invenit Koenigius, eandem esse ac eam, quam affert Gunnerus, sententix Ccl. Wahlenbergii probabili assentior, Fucum spermophorum Gunn. esse Fucum mamillosum T.; cui etiam ut synonymum cam adjunxi.

20. F'vittatus, Lin., Tonning, Gumnerus.

Habitat in mari Norregico, Tomning Amoen. Acad. $\%$ p. 4\%. - Gunn. If. norv. 2, p. 35. 11. 454 .

F. vittatus, frondibus membranaceis divisis ensiformibus, dentato-erispatis. Lin. Syst. nat. celit. X11. 2, p. T18.

OBS. In lac specie, qræe ad oras Norvegix vix provenit, detcrminanda forsan crravit Cel.'Lommingius, ejusqve determinatione vorlua Rev. Cumneri niti videntur. Habitat antem hre specics, "qra in scriptis Linnaei sub nomine Freci ornati etiam occurrit, ad Promontorium b. sp., unde pulclna specimina vidi, 
etian ad litus America septentrionalis. Qvamnam autem specicm innuerit I'onningins, est dictu difficillimmm. Forsan, si in re tam anbigua conjicere licet, sub nomine $F$. vithati Toun. et Gumn. latet $S$ pherococcus ciliatus, vel Ulva palmata Var. marginifera. Possibile ctian cogitari potest, I'onningio ad manum fuisse verum hujus alga specimen, vi flucuum ab oris America ad littus Norvegice advectunı; sed cavendun est Algologis, ue omnia, Trae inter rejectamenta mas reperiuntur Hydrophyta, pro veris sui literis accolis statim agnosecrent; qrod enim fruetilus nommllis Americanis, qvi qrovis fere anno al littora Norregia et insularum Froensiun rejicinutur, ${ }^{\star}$ ) usu renit, id etiam Thaldssioplytis nomullis acridere posset; qvare laudandat est diligentia Botanicorum, 'qui de late re solliciti, pracautionendye, quan par est, adtribentes, ad singulas $\mathrm{Algas}$ rariores describendas, urum casden radicibus afficas, an inter rejecta fluctuantes inveneriut, annotare dignentur.

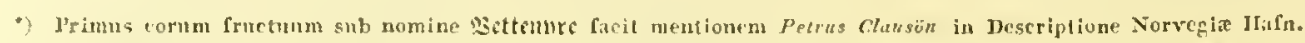

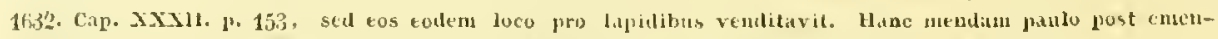

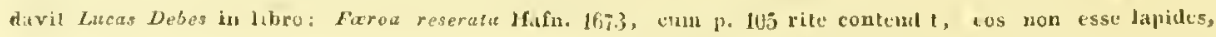
sed fubas ex Indat occidentali mari advectas. Deinle eostledn connemurat Rev. Stroin, in Descr. Sündmör. 1, 1. 138. dicens, se al lillura Norvesiae sappins invenisse fructus Mmose seandentis (nurv. Sob=

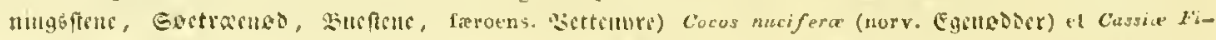

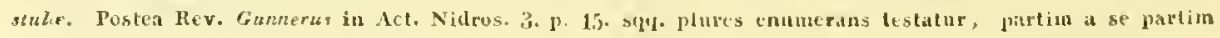
ah aliis id oris Nurvegie inventus esse functis Mhmose seandents, Prscidice erythrine (norv. Drmeficme),

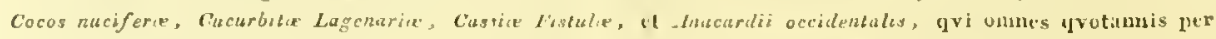

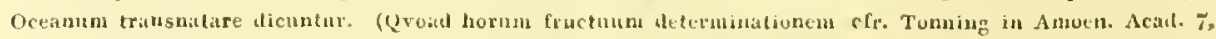
p. 47). Inture non solum illo, scol et nostro tentyore trent: Itstitur enim Cel. Fahlenberg (is Flora

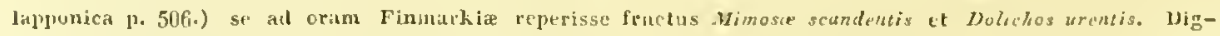

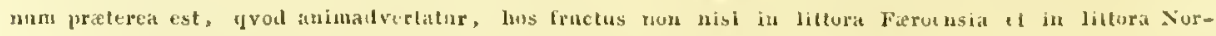

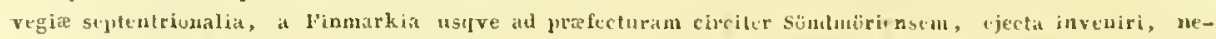

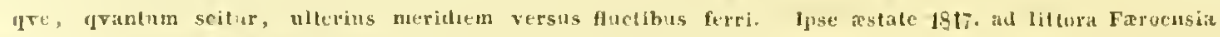

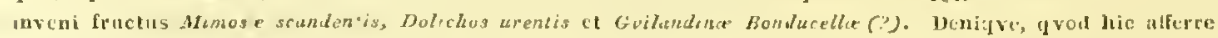

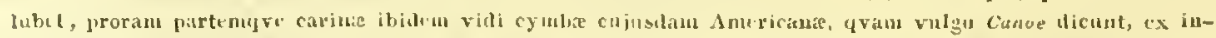

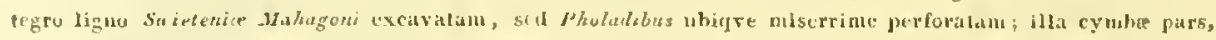

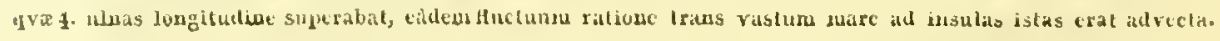




\section{$\begin{array}{lllllllllllll}S & \mathrm{E} & \mathrm{C} & \mathrm{T} & \mathrm{I} & \mathrm{O} & \mathrm{II}\end{array}$ \\ SOLENIA'TA.}

Frous filiformis, tubulosa, continua.

\section{S C Y T O S I P H O N. *)}

Frons teres, tubulosa, continua, ramosa vel simplex, coriaceo-membranacea, æqqalis. Frucus

Semioa nuda, substantiæ frondis innata, solitaria vel congesta.

1. Sc. ramentaceus; fronde terete, filiformi, tubulosa, ramulis patulis sinplicibus confertissimis undiqve obsessa.

Ulva sobolifera Fl. d. T. 556. - Mohr isl. p. 2/9.

Fucus ramentaceus Lin. Sysr, nat. 2, p. 718. - Oeder Fnum. p. rg. - Turn. Hist. T. 149.

- barbatus Fl. norv. 2, p. 129. n. 1007.

- tubulosus Lepech. in nov. Comm. Petrop. pro anmo 1774. Vol. 19, p. 4;6. Tab. 20. Halymenta ramentacea Ag. Syn. p. 37 .

Habitat in scopulis maris Islandici, Oeder. In mari Finmarkia, Hell, Gunnerus. - Apud Reikavik et ad insulam Akarve Islandia, Hooker. - In mari Groenlandico, Herb. O. Fabricii et IVormskioldii.

DESC. Radix callus exiguus, nigricans. Frondes aggregatx. Canlis vel frons primaria simplex, raro divisus, teres, tubulosıs, pahnam et ultra longus, basi tenuitcr altcnuatus, deinde in penux corvinæ crassitiem intumescens, apicem versus itcrum attenuatus. Ramuli (sine ramenta, qvæ totum caulem obsident, et interdum in junioribus speciminibus fere absunt) nunc confertissimi, lrevissimi, lincam circiter longi, horizontales, capillacei, apice acnti, interdum clavati vel emarginati, nunc longiores, versus apicem caulis approximati, pollicem num alterumve longi, teretes, tubulosi, simplices, vel aliis minoribus instrueti, utringqve atcenuati. Fructus Granula minuta per totam frondem sparsa. Color fusco-ruber. Substatia coriacea, membranacea, tenuis; exsiccatæ rigida, tenax.

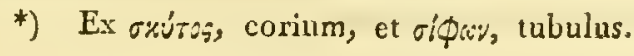


OBS. Finctum arposui ex observatione Cel. Agardhai, nam in speciminibus mihi

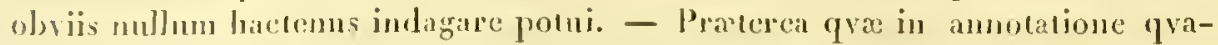
dam, F'uce ramentaceo subjunctâ, genti Danica bliter et injuste objicit opprobria 'Turnerus, hace nodo levis sunt momcnti; viliis neno sine nascitur,

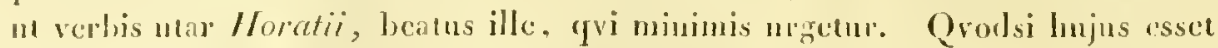
loci, virum gravis sui erroris convincere, non quidem desideranda nobis essent asguncuta; ant, si taglionis jure ntentes versum allatum, vel aljum ejusdem farinx, in cum ipsum, alias mstunatissimm, regererc vellcmus, id ctian ficcile effici poterat; his antem, qrie extrit fucm lujus opcris positi sunt, omnimo superserlemus.

2. Sc.tomentosus; fronde terete, filiformi, tubulosa, rage ranosa; ramis ramulisqve remotis, fibris simplicibus genieulatis dense obsessis.

Scytosiphon comentosus Fl. d. T. 1534. fig. 2.

Conferva villosa Engl. bot. Tab. $5+5$ pro $54^{6}$.

Conferva hispida 'hlore Mag. Enr. an. 5. P. 398. cum icone.

Batrachospermum hispidum Dec. П. Fr. 2, p. 6o. et Syn. p. 12.

Thorea ramosissima Pory in Perl. Nag. 1808. p. 227. Tab. 6. fig. I. et in Ann. Mus. Vol. Xll. 3. 126. Tab. 18. fig. 1. - Ag. Syn. Ineroul. p. XXXVI.

Habitat ad litus Hindsholm Fionia, Hofmann Bang. $-\Lambda$ littus Norvegiae prope Öster Riisöer copiose.

DESC. Rarlix rallus parves, discoidens, rupilans panlo infrit superficiem maris agglutinatus. Frondes gregaria, teretes, filiformes, tululusa, spitlama:a an pedalenn et ultra longitudine, setam porcinam crassitie panto csupurantes, crecta, vageramosic. Canlis aliquot pollices sujpia basin plepumege undus, deinde ramosus. Rami interdum patenti-divergentes vel reflexi, ul plurinum vero basi erecto-patentes, sursum curbati, remoti, saje secumli, apicem versus approximati, aliisque minoribus, temioribus plermmgre alteruis brevilus instructi. Tota frons a basi arl apicen uspre tomento albo unam lineam Jengo dense obsessa, frod micrescopio subjectum e fibris simplicibns arliculatis pellucidis constare cernitur. Fructus ignotus, forsin in fibris vel potius in substantia gramblata qrarendit. Culn caulis nigricans, ramormm olivacens. Substantia subcorianea. mollis: exsicenta subfragilis, sub tente punclata. Clarte ope imprimis, ut suspicor, tomenti arcte adluerct. Anแua. Nestite.

OBS. Fibra incredum ramosx apparent, quales in Chorda Filo \%. ('Jab. 18. 1). 3. 4.) sistuntur. Lurum he fibras pro Conferea pradim parasicica, an pro parte frometis conberantis esscntiali habende sint, non ento constat: milhi

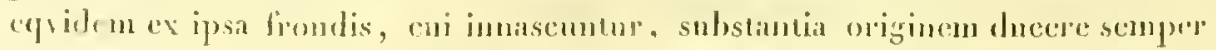
visas sunt. - Conferea hisprida, Thore ad sava fleviorum Grallix inventia est; cetcrum ab hac specie, si quid video, non divcrsa. 
3. Sc. hippuroides; fronde terete, filiformi, tubulosa; ramis alternis, im- 'Tab. 14. plicatis; ramulis brevissimis, horizontuliter divergentibus.

Habitat ad oram Fionize septentrionalem saxis adrascens paulo infra superficiem maris, ubi refluxu rarissime denudatur, qvibusdan in locis freqventissime; interdum in Chordaria flagelliforni parasitice.

DESC. Radix callus parvis, discoidens. Frondes aggregate, tcretes, erceter, spithaman circiter longe, penna passcrina crassitie dimidio minores, requales, ramosissime, implicatie. Rami elongati, alterni, ubiqve erfvales, aliisqre ejusdcm crassitici obsessi, approximati, apicibus ubtusi. Ranuli breves, unam ad quatuor lineas longi. ex fronde liorizontatiter ntringre cxetuntes, ejustem fere ac rami prinarii crassitudinis. Fructus semina nuda oblonga fusca in ipsa frondis substantia dense aggregata. Color fusco-olivacents, exsiccatæ niger. Substantia coriacea, Icnta; cxticcatie flexilis. Mnnua. Decembr. legi.

4. Sc. focniculaceus; fronde terete, filiformi, tubulosa, vage ramosis- Tab. 14. sima; ramis ramulisqre flexuosis, densissime intrieatis, attenuatis, capillaceis.

Scytosiphon foeniculaceus Fl, d. T. I535. Gg. I. - Ag. Disp. p. 25 .

Conferva foeniculacea Huds. p. 594. - Dillen. Tab. 2, fig. 8. - Wills. 4, p. ${ }^{3} \mathrm{~J}_{\text {. }}$

Ceramium inflexum Roth. Cat. bot. 3, p. 131?

Hippuris sstaceus Barrelier Tab. 1123. fig. I.

Fuckes subtilis Turn. Hist. Tab. 23$\}^{\circ}$

- Alagelliformis Jïrg. Alg. Dec. 2, n. 2. (excl. synon.)

Halymenia foeniculacea Ag. Syn. p. 38.

Hutchinsia inflexa Ag. Syn. P. 58.

B) intricatus, fronde subtubulosa, implicata; ramulis minus elongatis brevibusque.

Chordaria flagelliformis y intricata Ag. Syn. p. 13. et Dec. 111. n. 22.

q) membranaceus, fronde tubulosa, majori, membranacea.

Ceramium fubrosum lioth Cat. bot. 2, p. 177? - Schum. enum. 2, p. 11 r.

Habitat ad saxa sinus Othiniensis tempore imprimis vernali copiose, item Scytosiphoni fistuloso parasitice haud raro insidens. Ad oras Bornholmiæ. Ad insulas Færoenses copiose. - In mari Groenlandico copiosissime; Herb. Wormskioldii, Fabricii, Giesexii. - $\beta$. in Chordaria flagelliformi aliisqve ad oras Fioniae et Norvegia legi. - $\gamma$. in mari Groenlandico; Herb. O. Fabricir.

DESC. Radix callus exisuus, expansus, nigricans. Frous tcres. \{u\})ulosa. spithamæa ad nlnarem longiludine, filiformis, sctam porcinam fere crassa, ranosissina, 
intricata; rami vagi, altcrni, munc remoti, numc approxinati, hasi patu]i, apiccm ressus allenuati, capullacei, alisqve minoribus obsossi; ranuli altcrni, sulsscundi, flexuosi, tomuissini. Fuctus Semina uuda solitaria fiusca frondis substantiac lic illic immursa. Colos fusco-olivaccus, interdum dilute lutens aut virescens. Sulistantia coriacea, lenta. Clanta laxe adlixuct. Amma. Tere imprinis legitur.

OBS. Rammlos lujus sprecici fihris goniculatis pellucidis simplicilus nunc d.nsissimis, unne remotius oppositis obsessos, (ut in 'Tab. 14. C. 1. 3. sistmutur) sape olsesrari. Pratexea solatu dignum videtur, jpsos ramos ranulospre interclum praprimis apicem rersus anticulatos conspici, articulis diamulro movioribus, et medio linea transwersali dilutiori notatis. Id autur non nisi pro anomalia gradim habeudum est, sigridem frons alias fere semper inarliculita vel continnat apparel. - Ceraminm inflexmm R., a Cel. Rothio ad littora maris Batthici cirea Fimblimm insulan lectum, ad hanc specicm metuli; restulum cnim jpse liothius, hanc algan in vivo statu simillimam esse suo Ceramio Longissimo (Cigarlina confervoidi mihi), aden ut facile pro cjustem varictate habcri possit, si geniculis evidentissine:(?) precelita non esset. Sed hace geuicula, 11 opinor, non multum ad rem fircint; plures cuim species, qras pleduntre inuticulate sumt. nommugram genicula in ramulis ostemlmut (id prod jam nuper de hac specie amotari, el supra de Gigarlina rividi); prenterea cum fila, teste Rothio, sunt plane opaca, quî fit, ut genicula evidentissine conspiciantur? In C'eramio suo ressyrtoso ct dichotomo Rothius etiam visus est silji videre genicula, qua quiden spmria defuit, sed fila lrarum specicrum longe nnclius corlimu dicuntur. Suspicor igitur, hane Rothï Algam nil aliuel esse, qram So gtos. foeniculaceum, cujus unlulositas in spe-

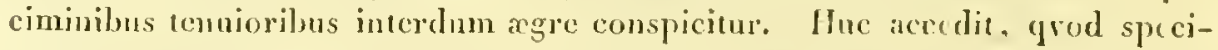
mina, ad litus bornholmia lecta $\cdot 2$ in herbanis $l^{T}$ ahlii et Jofmann Bangii sul, nomine Ceramii inflexi R. asscrvata, in Seyt. foeniculacemm ojtime gra-

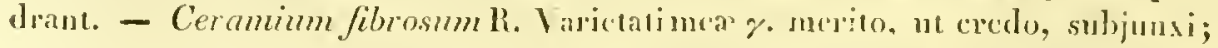
Rothins algam cam inter Fucos, e mari Groculaudico sibi allatos, olservavit: est autcm laxe (alcpe imprimis $\alpha$, nt ex lerbaris, qra citavi, videre contigit), al littori Groculandia frequentissina; capsulas venditatas pro particulis heterogencis potius haberen.

Tab. 15. 5. Sc. compressus; fronde terete filiformi tubulosa ramosa compressa; ramis sparsis simplicibns decumbentibus.

Ulua compressa Lin. - Fl. d. Tab. 1490. fig. 1. - Liglit. p. g6g. - Engl. bot. T. 1-39.

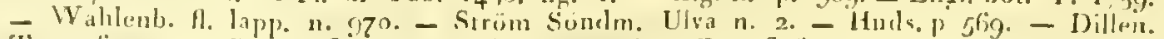

T. 9. lig. 8. et T. 10. fig 8. - With. 4. P. 126. - Dec. A. Ir. 2, P.7.-Ag. Syn. T. 45. Conferva compressa Roıh. Cat. bot. I. p. Itit. - FJ. germ. 3. p. 485.

- crinitr Rotl. Cat. bot. 2. p. igo. - Sclinm. Enum. 2, p. 104.

Tab. 15 B) crispalus, fronde terete tubulosa rugulosa subcompressa decumbente, B. 1-3. ramulos capillares teretes simplices emittente. 
Ule'a prolifera Fl. d. T. ;63. fig. I.

Conferva crinita 2 Koth. Cat. bot. 2, p. 190.

- Jlexuosa Rioth. Cat. bot. 2, p. 188. - Wulf. crypt. n. 13.

r) confervoideus, fronde terete, tubulosa, subsimplici, capillari, articulata, Tab. 15 geniculis Confervam mentientibus.

B. $4-6$.

Conferva percursa Ag. Syn. p. 87.

Habitat $\alpha$. ad littora Dania raro; ad littora Færoensia. - $\beta$. in fossis aqva dulci replctis prope Nebbelnnde Lollandiae copiose, Miiller. Ad littora Groenlandiæ copiose, Herb. O. Fabricii, Wormskioldii, Giesekii. Etiam in rivulo subalpino inter Welbestad et Kirkelöe Færoa; ct ad littora Færoensia copiosissime. $-\gamma$. in fossis aqva submarina stagnante repletis prope Hofmansgave Fioniae, alibique sat freqvens.

DESC. Radix parra, scutata. Frondes polymorplıx; in statu juniori filiformes, tenuissime, subsimplices, flaccide; præterea solitariæ vel sæuius gregarix, palnau vel spithamam longæe, basi atcenuate: in statu vero adultiori tnbulosæ, compresse, pennx passerinæ crassitie, deinde in pennam anserinam ad digitum et ultra intumescentes, ramosæ; rami solitarii, basi attenuati, tenuiores, nume remoli nune approximati, simpliciusculi. Fructus Semina nuda, fusca, globosa, substantix frondis punctatx glomeratim innucrsa. Color saturate riridis, senio pallidior. Substantia membranacea, tenera, subdiapha11a. Amnua. Ristate. Charte laxe adhæret.

OBS. Var. $\beta$, ad insulas Fxroensus copiosissina, magnos ad littora format cæspites, qri e filis majoribus, proliferis, penne passerine crassitie, aliis tenuioribus capillaribus longissimis intricatis immixtis, constant. - Var. $\mathscr{\%}$ lenti maxime angenti subjecta e filis prartim adinstar Confervarum, ubi sunt angustissima, geniculatis, partim linca longitudinali continua, in medio articulorum dilatata, percursis, constare cemitur. Neqve vero ideo ad Conferwee genus annumeranda; hre cnim linca longitudinalis, a Confervis omnino aliena, texture interna Ulvarum plurium respondere videtm; sic v. c. textnram internam UTwae dichotomae e fibris parallelis, ab aliis transversalibus sectis, qvadrata vel rectangula pulchre formantibus constare obserramus; præterea lıane Varietatem ad basin ramosam vidi, e filis tubulosis crassioribus manifeste crumpentem. Qrare, ne cui ob labitum confervoideum fucum faciat, hæc addidi.

6. Sc. erectus; fronde terete, filiformi, tubulosa, ramosissima; ramis ra- Tab. 15. mulisqve densissimis, alternis, patulis, sursum spectantibus.

Habitat in scrobiculis littoreis, aqva marina stagnanti repletis, ante ostium sinus Oxefiord Norvegia. 
DESC. Radic pusilla, scutata, rujilus affica. Frondes gregarix, in aqva crectx vel sursum spectantes, setam porcinam crassa, prolmancpe cireiter longx; rani sparsi., capillares, basi patuli, apicen versus attenuati, debiles, aliisqve uninoribus obsessi. Color lacte viridlis, exsiceata dilutior. Substantia mombranacea, tencra. Anmia. Aestate. Charta adlaxret.

'Tab. 16. \%. Sc. clathralus; froude terete, filiformi, tubulosa, vage ramosa, venoso-clathrata; rantis ramulisqve patenti-divergentibus, decumbentibus.

Gonferva clathrata Roth. Cat. bot. 3, p. 175. - Jürg. Alg. Doc. 2. n. 5. Ulua clathraea Ag. Jisp. p. 23. et Syn. p. 46.

6) uncinatus; ramnlis brevibus, mamilloformibus, horizontaliter patulis. Ulura uncinata Mohr Citt. Alg.

Conferva longissinta Desfont. Fl. Atl. 2, p. 430. (juxta exemplaria missa).

Habitat a. et $\beta$. in sinu Othiniensi saxis adnascens vel libere fluctuans.

DESC. Radix pusilla, seutata, nigricans. Frondes filiformes, palmam circitcr longe, intrieate, setam poreinam lere crassa, sulhequales, a basi useqve vage ramosx; rani alterni, sape secundi, horizontaliter patuli, curvati, hue illuc reflexi, et inde frondi lacies intricata. Fructus Semina nuda, solitaria, oprca, in substantiâ frondlis imprimis clotâ manifesta. Color dilute viriłlis, iutcrdum forsan scuio flavescens. Substantia membranacea, subdiaphana, sub lente reticulata vel fenestrato-venosa. Ammia. Vere el Aestate. Chartie laxe adliaret.

** fronde simplici.

8. Sc. fistulosus; fronde terete, filiformi, tubulosa, simplici, utrinqve attenuata, coriacea.

Scytosiplion fistulosum Ag. Disp. p. 21.

Ulva fistulosa Huds. p. 569. - Engl. Bot. T. 6\{2。 - Wilh. 4, p. 125 .

Conferva Fistula Roth. Cat. bot. 3, p. 169.

Chordaria Filum f. fistulosa Ag. Syn. p. 14.

Habitat ad saxa marina sinus Othiniensis.

DESC. Radix scutata. Frondes aggregatx, tcretes, filiformes, simplices, tubulose, spithameat et ultral longitudine, basi atcentatie, setam porcinam crassx, dcinde sensim in pennx corvinæ crassitudinem intumesecutes, apicem versus iterun attentalta. Fructus non observatus. Color olivacens. Substantia corizeea, lenta, tenax, sub lente punctata vel granulata, granulis subqradratis longitudinaliter dispositis. Annua. Vere ct xstate. Chartio noss adjoxtet.

O3S. Diversus a Chorda Filo videlur partim ob structuram internam, cetcris hujuis generis specriebus commmen, partim ob abscutian fructus illius, Tyo Chorda Filum instructa observatur. 
9. Sc. intestinalis; fronde tubulosa, simplici, anfractuosa et sinuosa, membranacea.

Ulva intestinalis Lin. - Hud. p. 568. - Dillen. T. 9. f. 7. - With. 4, p. 125. - Ag. Disp. p. 23. el Syn. p. 45. - Lam. Thal. p. 65. - Dec. fl. fr: 2, 1. 8. - Strom Sönilm. Ulva n. 1 .

Conferva intestinalis Roll. Cat. bot. 1, p. 159. - Wulf, crypt. p. 13. - Schum. enum. 2 , p. 103 .

Fucus cavus C. Baul. pinn. p. 364 .

Alga ubulosa albida, navibus adharens Petiv. gazoph. Tab. 9. fig. 6.

ß) crispus, fronde compressa, rugosa et crispa.

Ulva intestinalis $\beta$. Roth. Gat. bot. x, p. ${ }^{5} 59$. - Schurn. enum. 2, p. 103. - Ag. $\$$ yn. p. 45.

भ) cornucopice, fronde tubulosa, brevissima, aggregata, superne dilatata, fauce aperta.

Habitat ad littora Dania marina lapidibus adnascens, vulgaris; etian in fossis et stagnis, aqva dulci repletis; et submarinis. - $\beta$. ad littus Torbæk Sellandia. $-\gamma$. ad littora Froensia.

DESC. Radix parva, scutata, saxis agglutinata. Frondes cæespitoso-aggregatæ, pedali et nltra longitudine; in statu juniori tennes, filiformes, dein penuan passerinan crassæ, crectie; in statu adultiori magis tuluulosæ, pennam olorinam ad digitum et ultra crasse, inflate, intestinorum adinstar ineqvaliter sinnosæ, marisqve mou huc illuc fluctuantes. Fructus nondun observatus. Color junioris læte viridis, adultioris flavo-virescens. Substautia membranacea, tenuis, flaccida, sub lente granulis subqradratis et sæpe qraternis notata. Ammua. Vere, rescate. Charte minus adlaxret.

OBS. Ab initio tota hre alga. est filiformis, brevis, tubnlosa, et in eo stadio. ubi maxime gregaria crescit, ramulos simplices ad basin interdumemittens. Varielas y cst membranacea, ad basin filiformis, mox dilatata in tubulum pollicarem apice apertum, qvi semipollicem circiter in diametro tenet; infra intense viridis, apicem versus dilutior, albescens.

10. Sc.verrucosus; fronde terete, filiformi, continua, capillaxi, simpli- Tab. 16. ci, hic illic ob verrucas elevatas nodulosa.

Ceramium vermosun Tioth. Cal. bot. 3. p. 121?

Habitat ad littora Groenlandix; Herb. Wormskioldii.

DESC. Cæspes intricatus, densissimus, ulnaris et ultra amplitudinis "t extensionis, ad litora sape e mari cjectus, supra saturate viridis, infra, sine dubio ob clotionem. alfjicans. Fila tentissima, simplicia, clongata, tubulosa, capilli humani crassitic, aliis crassioribns immixtis, drnse inter se implicata, sub lente continua, punctata, verrucis elevatis nigrescentibus modulbrom adinstar plerumgve obsita. Color filorum viridis, elotorum pcllucidus. Substantia mcmbranacea, tenerrima. 
Tab. 16. 11. Sc. velutinus; fronde terete, filiformi, capillari, simplici, lic illic in membranam dilatata.

Habitat ad saxa rivuli rapidissimi Jeclivia prope littus Öre Österöe Faroense.

DESC. Crspes densissimus, pollicaris et ultra extensionis, saxis adnascers. Fila tcmussima, teretia, filiformia, intricata, pollicem, si extricentur, longa, capillum humanum crassitic aqvania, of gramula qradrata eis dfense inmucrsa faeiem articulatam prese ferentia, interdum sed raro in membraran ul voideam. gramulis qraternis duplici serie notatam, dilatata, vel ita, ut filum ex duobus coalitis constare vileatur. Color iutense viridis. Substantia menbranacea, temuis, mollissima. Anuna. Estate legi.

\section{GAS T RIDIU M. *)}

Frons teres, ubbulosa, continua, ramosa vel simplex. gelalinosa, interdum arricularo-contracta. Fruclus Semina nuda, subscancix ramulorum inmersa.

* fronde ramosa.

'Tab. 1\% sparsis, simpliciusculis, remotiusculis, clongatis.

1. G. filiforme; fronde tereti vel compressa, subæqvali, ramosa; ramis Conferva filiformis Fl, d. Tab. 1480 . fig. 2.

Ulva filiformis Hudson 1. 570. - With. 4, p. 127. - Wahl. 月. Japp. n. 97 t. - Ag. Syn. P. 47.

- purpurascens Engl. bot. Tab. 6亿1.

- compressa $\beta$. purpurea Ag. Syn. p. 45.

B) incrassatum, fronde terete, ramosa; ramis simplicissinis, teretibus, lubricis, apicem versus crassioribus.

Ulva incrassata Fl. d. Tab. 653. - Ag. Syn. P. 47.

Conferia fistulosa Roth. Cat. bot. 3, p. 171. - Wull. crypt. p. 12.

q) spongiforme, fronde terete tubulosa, ramosa, ramis simplicissimis.

Ulva spongiformis Fl. d. Tab. 763. fig. 2. - Ag Syn. p. 47.

d) rugosum, fronde tubulosa, majuscula, rugosa, aqvali; ramis simplicissimis paucissimis.

Tab. 66 \&) flavum, fronde flava.

E. 1 .

*) Ex yxspidor, ventriculus, qroniam tubulus internus est manifcstus, interdum inflatus. 
Habitat $\alpha$. in sinu Othiniensi saxis radice adnascens, sat freqvens. - $\beta$. in $\sin u$ maris prope Laurvig Norvegia raro, Mïller. $-\gamma$. ad oram freti Öresundici raro, Miiller. - $-\delta$. et $\varepsilon$. ad littus Fionize septentrionale le gi.

DESC. Radix parva, scutata, lapidibus agglutinata. Frondes ex cadem basi plurimx, palmares, spithamax, terctes, tubulosa, basi attenuata, pemam passerinam crassa, mox in penne corvinx interdum anscrinx crassitudincm intumescentes, et qro breviores, eo plerunque crassiores. Rami hasi attemuati, patuli, altcrni, deinde elongati, terctes, filiformes, plerumgve simplices, interdum divisi. Frons practerea sinuata, flexuosa, et in adultioribus et senilibus sape hic illic ruguloso-compressa. Fructus Semina muda, subrotunda vel pyriformia, fusca, in maculas substantix frondis galarinosa sparsim immersas congesta. Color fusco-ruber, interdun dilutior. Substantia sub- gclatinosa, lubrica, mollis. Anura. I cre et Astate. Chartæ adlixet.

OBS. Specinima, yræa ad litus maris Codani legi, ramis elongatis, ommino teretibus, rqvalibus, pennam passerinam circiter crassis, Jubriçitatis fere expertibus, et colore dilute rubro, interdum flavo, differunt ab is, qra in sinze Othiniensi occurrunt, qra coloris sunt intensioris, fere brunnei, preterea manifestc lubrica, et qroad periplecriam illis majora, at qvoad longitudinem minora. Ccterum planta, ad provectiorm xtatem perveniens, sensim magis magisque lubrica cvadit, et, granulis maiuris, frons gctatinosa dissolvitur; qvo facto, granula libere inde cxcunt, aliam prolem propagatura; in hoc alultiori statu haxe alga alias Confervas tenuioris substantix, ei immixtas, brevi tempore omnino dcomponit penitusqve sccum dissolvit; tunc etiam tanqram gluten adliberi potest. Substantia sua crassiori et gelatinosa, ut ctiam colore constante, sat superque differt a Scytosiphone compresso, qri fronde gandet membranacea, tenui, viridi, granulis notata, lubricitatisque omnino experte. - Varictas \$, qvan rugosam dixi, ulnarem atlingit longitudincm, digiti crassitudinem, bullosa, flaccida rigosaque sua fronde, ramis paucis aqvalibus, et colore fuscescente facile disccrnitur.

2. G. purpurascens; fronde ramosa; ramis ramulisqve distichis, subop- Tab. 17. positis, ultimis pinnatis; pinnis minutis oppositis.

Ulva purpurascens Huds. p. 569 ?

6) caspitosum, fronde ramosissima; ramis inferne densis, sparsis; summis distichis, oppositis, pinnatis.

Habitat ad littora Færoensia saxis et stipitibus Laminariæ saccharinæe et digitatæe adnascens. $-\beta$. ibidem.

DESC. Radix exigna, nigricans. Frons solitaria vel cxspiloso-gregaria, palmaris, basi attcuata, filiformis, mox penuam passerinam vel corvinam crassa, 
apicem versus iterum attenuata, tubulosa, infcrue plermmye compressa, ramosa. Rami raria longiludinis, hreviores inter longion's dispositi, nunc ap)-

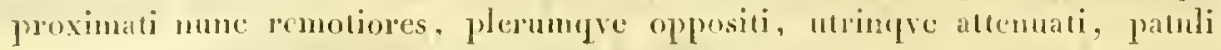
vel divergentes, distichi; ramuli tenuiores, distichi, piunti; pimna ablurevata, ofpositx, lanccolatx. Fructus Capsula urceolata e summis ramulis jumisqve crompentes, Scmina cxigua ovata atropubesecutia iucludentes; reperimutu ctian in diversis speciminibus Semina nudit, summis ramulis imnata. Culor jutense roseus vel ruber. Substantia gelatinosil, lubrica, sub lente mi-

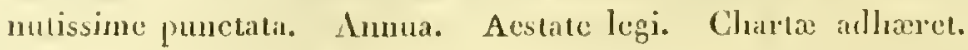

OBS: Caulis vel ramus primarius sirpe comperssus et intus massa gelatinosa allucscente repletus, in rvo stadio, ntrum planta sit tubulosil, neene, agge definitur. Varictas, qra plerumfre cespitose crescit, als ramos sparsos ce densos charta agre adliacet.

'Tab. 17. 3. G. clavellosum; fronde ramosissima; ramis ramulisqve alternis, subdistictis.

Fucns clavellosus Turn. Syn. p. 375. et Hist. Tab. 3n. - Engl. bot. Tab. 1203.

Habitat ad littus Norvegix, Fuco resiculoso insidens; Herbarium Vahlii.

DESC. Rarlis callus exiguns, nigricans. Frons solitaria, teres, tubulosa, palmam el ultä longa, peruam passerinam erissa. Caulis ramis elongatis olositus. Rami plerumque altroni, raro opjositi, minoribus instructi: ranuli breves, simplices rel than divisi, subpimati, non articulalo-contrate. Fructus (sec. 'Tirnerum) Semina nula, subrotunda, mintissina, substantias ranulorm imuncrsa: ediam Ciapsula sessiles spharica, semina inchulentes. Color rubcr, futco linctus. Sulsstantia tenera, subgelatinosa. Ammut. Aestite fert fructum. Chartac adharet.

4. G. kaliforme; fronde ramosissina; ramis ranulisqve subrerticillatis, articulato-contractis.

Fucus kaliformis Linn. Trars. 3. 13. 206. Tab. 18. - Wiul. 4, p. 89. - Turn. Syn. P. 377. et Hist. Tab. 29. - Engl. bot. Tab. Gio. - Lam. Diss. T. 29. - Ner. britt. ed. 2. Tab. is.

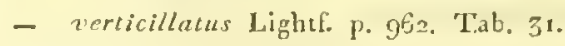

Gigarlina kaliformis Lam. Thal. p. 49.

Ceramium ubulosum Rotl. Cat. bot. 3, p. 124 .

Habitat ante ostium sinus Oxeford Norregia, ubi Cel., IIofman Bang: inter rejectamenta maris unum modo exemplar legit.

DESC. ladis callus parvus, expansus, fibris lorribus saxo afficus. Frons plerumuje: solitaria, tores, tubulosa, paluarm ct uluat longa; caulis pennam passerinan, et infra interdum auscrinam crassitic aqvans, basi altenuatus, hic: illic vage contractus; pani oppositi et alterui, sxpe verticillati, basi angusti, 
apice obtusi, ad constrictiones frondis imprimis dispositi; ramuli simplices, manifeste contracti, adeo ut geniculati videantur, at revera mullis istlmis intus sunt iutcrsepti. Fructus S:mina nuda summis ramulis imnata, et Capsulac spharicx ad ramulos sessiles, congeriem rubram scminum ninutissimorum includentes. Color dilute ruber vel roseus, interdum albicans. Substantia subgelatinosa, tencrrima. Annua. Claarte adheret.

\section{$\star_{*}$ fronde simplici.}

5. G. Opuntia; fronde terete, tubulosa, simplicissina, lanceolata, basi Tab. 18. attenuata, sub lente reticulata.

Habitat ad radices Laminaria saccharinæ, Furcellariæ lumbricalis etc. ad rupes maritimas ante ostim sinus Kalvesund prope Arendal Norvegiae.

DESC. Radix perexigua, nigricaus. Frons plerumqve soregaria, teres, tubulosa, unum ad tres pollices longa, basi insigniter attenuata, setx porcina crassitie, mox iu penna anserinx crassitudinem intunescens, apice obtusa; intcrdun, sed raro, subglobosa, ad magnitudincm mncis Juglaudis intumescens. Fructus Semina nuda, orata, fusca, in maculas exiguas, frondi hic illic immersas oculoqve inermi visibiles, congesta. Color dilnte olivaceus. Substantia membranacea, tenerrina, flaccida, sublente pulchre et subhexagone reticulata. Annua. Acstate. Chartic adhacret.

6. G. lubricum; fronde terete, tubulosa, simplici, tenerrima, oblonga, undulato-sinuosa.

Ulva lubrica Rolh. Cat. bot. I, p. 204. - Lam. Thal. p. 65. - Ag. Syn. p. 4 4.

Habitat in fossis aqva dulci stagnanti repletis prope Hafniam; Prof. Hornemann. - In Holsatia; MIohr (efr. Schrad. Diar. bot. 1 B. 1806. p. 196.)

DESC. Radix parra, scutata, fundo limoso insidens. Cxspites suborbiculares, densissini, spithamam et ultra in diamctro habcntes. Frondes igitur caspitosoaggregatæ, plerumqve oblongx, qratuor ad octo pollices lougx pennamqve passcrinam ad digitum crassa, undulate, rugosæ. levissimo tactu diffluentcs. Fructus Scmina nuda substantix frondiś innata. Color late vel dilute viridis. Substantia membranacea, temuissima, teuerrima, pellucida, maxime lubrica, subgelatinosa, facile disrumpens. Annua. Aestate. Chartx arcie adhæret.

7. G. cylindricum; fronde terete, tubulosa, simpliei, æeqvali, utrinqve obtusata, apice clavata.

L7va cylindrica Wahlent. Fl. lapp. n. 972, T. 30. fig. I. - Ag. Syg. p. 亿4.

Rivularia cylindrica Hooker it. isl. p. 7r. 82. et 27 r. 
Habitat in fluvio rapido prope Reikjavik, in lacu Thingevalle, aliisqve furiis laculusqve Islandiæ copiose, Hooker. - In fluninibus Lapponix magis pacificis lapidibus adnascens, Wahlenberg.

DESC. Radix callus parvus. Frons gregaria, tres pollices ad plures pedes longa, basi ad altitudinem linere supra radiecm attentiata, mox subito obtusata, ipcralis, permam passeriuam et ultra crassa, plerumque ol, tenutatem compressa, apice incrassata, clavatit. Fiructus Scmina nuda, substantia frondis inordinate inmersa. Color dilnte viridis; in statn exsiceato colorem modo virescentem in charta relingyit. Substantia tenerrima, ex, exceptis maculis seminiferis viridibus, tota lyalinat, subgulatinosa, sub lente non reticulata. Anmus. Charte aretissinc adlixet.

OBS. Jutcr hanc et pracedentem magna aflunitas. Discerucnde tancu has species videntur; illa enim, teste Rothio, sub, lente cst reticulata, qradrangulati: hae vero fronde gaudet omnino hyalina, non reticulata, qve pratcrea apice davata est.

'Tab. 18. 8. G.ovale; fronde tubuloso-inflata, ovali, simplici, tenacissima.

Habitat ad infinmm reftexus limitem littoris Færoensis, ut ad Qvivig, Höyvig \&c., rupibus tenaciter adhæerescens.

DESC. Rudix exigua. Firoudes gregaria, ad hasin angustatx, mox in seminis P'isi sativi magnitudinem intumescentes, duas tresve lincas eirciter longx, apjice obtusæ, inturs massa aqrosa vindescente repleta, ideoqre distenta. Fructus incognitus. Color viridis. Substantia membranacra, non gelatimosa, sed pro tenuitate tenacissina, sub lente minutissine punctata. Aestate. Charta non adharet.

OBS. Qvando a rupibus, qribus tenacissime adharen, cultro rel simili qrodam instrumento divelluntur, in aqva din spiraliter torgrentur, adeo ut manibus captaturi facilline clabuntur. Massa interna evacuati, feondes collabuntur, ct sape hyalina apparent. Ad insulas Frocoeses non nisi parva cvadun, sed excmplaria vidi in lecrbario Cid. Íchlii, ex insula St. Cirucis allata, qras ovmm columbinum ınagnitudine exsuperant.

\section{C H O R D A.}

Frons reres, Iubulosa, simplicissima. Semina nuda in muco frondem ambiente nidulantia.

Tab. 18. 1. Ch. Filum; fronde terete, simplicissima, utrinque attenuata, senectute spirali. 
Fucus Filum Lin. - Gmel. p. s3r. - Fl. d. Tab. 821. - Fl. norv. 2, p. 10. - König, Mohr, Landt. $\rightarrow$ Ström Söndm. n. 15. - Horn. I. oec. p. 926. - Turn. Syn. p. 358. et Hist. Tab. 86. - Jürg. Alg. Dec. 3. n. ז.

- Tendo Esper Tab. 22.

Ceramium Filum Roth. Cat. bot. 1, p. 147. - Schum. Enum. 2, p. I11. - Dec. Fl. fr. 2, p. 47 .

Chorda Filum Ner. britt. Introd. p. XXIV. - Lam. Thalass. p. 27.

Chordaria Link. in Sthrad. Diar. bot. 180g. 3 B. 1, p. 8. Tab. 1. fig. 13.

- Filuin Ag. Syn. p. iz.

Flagellaria Filum Ner. britt. ed. 2. Intrad. p. IX.

Fucus angustifolius ligulas referens. C. Bauh. pin. p. 364. - Kyll. Virid. p. 45. n. 7 .

- s. Filum maritimum Germanicum Boccon. Mus. di fisic. p. 271. T. 7.16g. 9. Petiv. gazoph. T. 9r. fig. 5 .

B) inflata, fronde simplicissima, majori, apice inflata.

\%) trichoides, fronde simplicissima, capillari, minuta.

Habitat ad oras Daniæe maritimas vulgaris; $\beta$. et $\gamma$. in sinu Othiniensi.

DESC. Radix callus exiguus, scutiformis. Frondes aggregatæ, teretes, simplicissimæ, mum pedem ad viginti longæe, basi pennam passerinam deinde anserinam crassitic fere xqvantes, apicem versus attcnuatæ, vel in speciminibus vetustis spiraliter tortæ, intus tubulosæ et interdum obsolete geniculatæ, vel dissepimentis, geniculorum adinstar, hic illic interseptæ. Spatium inter genicula diversæ longitudinis, nunc aliqvot lineas, nnnc pollicem longum, vacuum, vel muco interdum repletum; genicula tamen in multis, qvin plurimis nostratinm omnino absunt. Fructus Semina nuda minutissima fusea pyriformia, partibus inferioribus attenuatis totam externam frondis paginam densissime obsidentia. Color fusco-olivacens. Substantia cartilaginea, tenax.

OBS. Chorda a Chordaria partim tubulositate sua, qra maximi habctur momenti, differt, partim, qrod semina Chordce non totam frondis substantian constituunt, sed modo parten ejus exteriorem obsidere videntur. Semina hujus alga observavit et delineavit Cel. Tinkius 1 . e.; eorum etiam obiter meminit Cel. Turnerus in Ilist. Fuc. 2, p. 122. in annot., nbi de Fuco esculento loqvitur; hæc antem semina, si frons eultello leniter sub aqva teratur, facile divelluntur, et sic lenti subjecta in conspeetum observantis veniunt; iisqve seminibus pyriformibus lubrieitas planta, credo, debetur. - Hac porro alga, in aqra fluitans, tomento denso albicante tenuissimo per totam frondem obducta, interelum conspicitur, qrod tamen, plantâ ex aqva extractâ, visum plerumqve fugit; illud tonentum, lenti subjectum, e fibris pellucidis articulatis constare ccrnitur; differunt autem hre fibre ab iis, qve in Fuco vesiculoso aliisqve cernuntur, in quibus fasciculatim congesta e poris clevatis exeunt, in co, qrod in hac specie, ut etiam in Ulva plantaginifolia, Scytos.' tomentoso, foeniculaceo aliisqve, per totam frondem parallele, nt ita dicam, sparguntur. - Deniqve Var. F. ansan Cel. Rothio dedit, hanc speciem intev 
Ceramic sua collocandi; (cfr. Cat. bot. 1, p. 14\%) lanc vero excrescentiam, qra intus ommino racua est, et modo frondis lete cresccntis prolongatio, capsulam nominare, minus apttun vidctur; cst lixe, qvam vocant, capsula tripollicari ar spithamxam longitudine, digiti crassitic, apice nunc rotundata nunc acuminata, intus cara, nec ulla in ca goniculorum arlsuut vestigia. - In Var. \% scmina ejusdem magnitudinis et formæ, ac in $\alpha$, aliqvando obscrvavi.

'Tab. 18. 2. Ch. Lomentaria; fronde terete, simplicissima, breviori, basi attenua9. Bot.t.2g02 ta, dissepimentis angustioribus intersepta.

Habitat in infumo refuxus limite ad littora Faeroensia, ut ad Qvivig, copiose. - Ad Hammerhuus Bornholmix; Prof. Hornemann.

DESC. Radix exigua, rupibus affisa. Frondes maxinc aggregatx, tcretes, simplices, vix palmam longitudine superautes, basi angustatx, sctam porcinam crassa, deinde in penna anscrinic crassiticm intumescentes, apice obtusa, pendulic, disscpimentis, yra frondem lice illic angustiorcm reddunt, manifestis intersepta; spatimm inter Dissepimenta duas lineas ad ungvem lungum. Fructus Scmina nudli, minutissima, subclivata, monilifornia, frondi exteriori insidentia. Color et Substantia ut precedcutis.

Tab. 19. 3. Ch. tomenlosa; fronde tercte, simplicissina, hasi nuda, ceterum tomento lubrico insigniter manifesto undique densissimo obsessa.

Habitat ad rupes maritimas Norvegiae prope Öster - Riisöer copiose, paulo infra superficiem maris; etiam ante ostium sinus Oxefiord Norvegia.

DESC. Radix parva, scutiformis. Frondes ex una hasi plurime, infra filiformes, angustate, deinde prennam passerinam erassitice reprantes, apjecm versus tenuiores, in aqva erecte, perlalem vel paulo ulura attingentes longitudinem, simplicissine, tubulose, ad altitudinem pollicis supra basin semper omnino nude, deinde tomento lubrico tenuissimo flavescente, lincam et ulıa longo, densissimo undiefve el ubiqve obsessit: tomentum sub lente visum c fibris constat simplicibus articulatis; articulis dianctro 2-3plo longioribus, intus gramulis flavescentilus farctis. Fructus Semina muda elliptica fuscal, totam crteriorenn froudis partem constiucutia. Colur fuscus, exsiccata niger. Substantia cartilaginea, tcuas.

OBS. Corpuscula illa clliptica, qre scmina salutavi, e fronde intrrilun sponte exemat, el sic in fibris pendentia capsults latud male mentiuntur. Fibras, qvat tomentum coliciunt, et e fronde ipsa originem ducere sempre mili vise sumt. mungram no: simplices vidi, easqve, si ramosic fuissent, ad Confer-

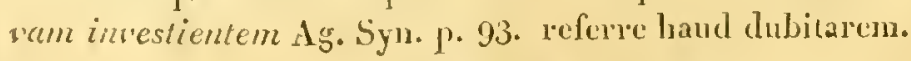




\section{B R Y O P S I S. *)}

Frons teres, tubulosa, subpinnata; granula minulissima in caule et ramis fistulosis nidulantia.

1. Br. Lyngbyei; fronde continua, ramosa; ramis inferioribus sparsis, Tab. 19. summis pimatis oppositis.

Bryopsis Ly"nglyei Fl. d. Tab. 1603.

Habitat ad littus Færoense in infimo refluxus limite, ut ad Qvivig, sed raro.

DESC. Radix callus exigurs, nigricaus. Frondes ex eadem basi plurime, cxspitosæ, tuluulosæ, cylindricæ, continuæ, duos pollices ad palmam longæ, capillares, setam poreinam ad basin crassæ, ramosæ; rami infuriores densi, implicati, sparsi, longiores, subsimplices; superiores omnino distichi, oppositi, pinnati, lineam unam alteramve longi, ita tamen, nt qvo magis ad summitatcm frondis appropinquant, co sint breviores, (unde frondi facies pyramidalis pulehre plumosa) et apice aliis minoribus cadem ratione dispositis obsessi, adeo nt frons interdum sit dıplicato-pimnata. Tota frons intus massâ aqvosâ, granulis minntissimis globosis viridibus immixtis, repleta. Color intense viridis, sed, massa interna evacuata, hyalinus. Substantia membranacca, tenuis, tenax. Annua. Aestate legi. Chartæ bene adlıxret.

OBS. Accedit ad Ulvam plumosam Huds. p. 571. - With. Britt. 4. p. 126. Fucum arbusculam Dec. fl. fr. 2, p. 35. - Poiret Enc. metl. Vol. s, p. 381. - Bryopsir arbusculam Lam. Journ. de Bot. Juin 1809. p. 133. Tab. 1. fig. 1. - sed pinnulis distichis oppositisqve, et caule tereti (non compresso) diflere videtur.

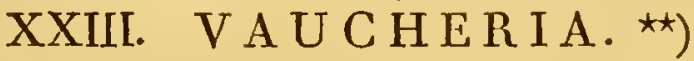

Fila capillaria, continua, plerumque ramosa, massà granulosà intus adspersa. Vesiculæe externze, globosæ.

* vesiculis solitariis.

1. V. dichotoma; filis majusculis, cæspitosis, erectis, apice dichotomo- Tab. 19. ramosis; vesiculis globosis, sessilibus.

Faucheria dichotoma Ag. Syn. p. 47.

Conferva dicholoma Lin. Sp. p. 1635. - Dillw. Tab. 15. - Engl. bot. Tal. $93^{2}$.

Ceramium dicholomum Roth. Cat. bot. 3, p. rrg.

- caspicosum ק. maximum Roth. Cat. bot. 3. p. 120.

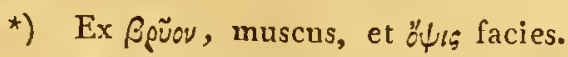

**) Doct. et Summe Rev. Vaucherio, observatori Hydrophytorum Helveticormm accuratissimo, Cel. Decandollius hoc genus dedicavit. 
Tab. 20. B) submarina, flis tenuioribus, decumbentibus, vesiculis lanceolatis ova= tisqve.

Habitat $\alpha_{0}$ in aqva dulci stagnanti in sylva Sorgenfric prope Hafniam, ubi et terram, aqva contiguam, perreptat; etiam in fossis aqva staguanti replctis prope Othiniam et Neoburgum Fionize. - $\beta$. in fossis submarinis prope Hofmansgave Fionize.

DESC. Cespes intricatus, fundun stagui amans et perreptans, pedem et sxpe ulnam in diantetro tcnens, et in loco natali situs omnino nigresecns apparet. Fila e fundo limoso erecta, assurgentia, superfieien aryae non atringcutiat, basi intricata, et, si extricentur, peden unm altcrumve longa, setamqve prorcinanı crassa, adeo ut hæe omnium hujus gencris specicrun sit maxima, basi simplicia, apicen versus dichotoma vel simpliciter ranosa. Vesicula majnsculac, nutlo oculo visibiles, globosa, sessiles, secunda; interelum etian in filis ejusdem cxspitis capsulæ adsunt minores, ovatx, densiores, ad utrunque fili latus sessiles, massa viridi ad dinnidian partem, cetcrâ pellucidì, repletæ. Color filornun viridis, vesicularun intensior. Substantia nembranacca, lenta. Anmua. Vere et xstate. Charte laxe adhacert.

ODS. Apicem fili aliøpando in vesiculan iuflatum, frectumqve massam subgelalinosan cmittere vidi. - Vesicula in Var. F. apicibus intcrdum puncto fusco, operculi instar, notatic erant; preterea inter lumjus fila vesiculas observavi liberas, ex ntroqve fine progerminantes, unde, ut videtur, colligere licet, has vesiculas, licct ex eadem meubrana, 'qvâ ipsum filum, constent, esse corpuscula reproductiva, idcoqve Vaucherio Semina audiunt, Dillwymo Capsulce.

'Ta\}. 20. 2. V. ovata; filis capillaribus, subdichotomis; resiculis pedunculatis, so= litariis, globosis; pedunculis nudis.

Faucheria ovala Dec. fl. fr. 2, p. 65 .

Ectosperma ovata Vauch. p. 25. Tab. 2. fig. 1.

Conferra bursata Müll. Nov. Act. Petr. 3, p. 96. T. 2. fig. 10. - et Berl. Besch. 4, p. 42. fig. $1 \cdot 4$.

Faucheria bursala Ag. Syn. p. 48.

Habitat in fossis aqva dulci stagnante repletis Fionia, v. c. ad Lumbyc.

DESC. Crespes densissinus, intricatus, superficiei aqve innatans, pedali ulnariqve longitudine er latitudine. Fila capillum humanum erassa, palmam pedemrve, si cxtricentur, louga, continna, ut in cctcris lujus gencris specicbus, basi indivisa, apicem versus dichotoma. Pedunculi plerumegre secundi, curvati, qroad longitudinem dianctrun fili 3, lo exsuperantes, apiec vesiculiferi. Yesicula solitarix, glubosa, rarissime ovatie, in apice pedunculi et 
fili terminales. Color viridis, interdum pallide virescens; vesicularum saturatior. Substantia membranacea, tenax. Annua. Primo vere. Chartæ laxe adhæret.

3. V. hamata; filis capillaribus, vage ramosis; vesiculis pedunculatis, Tab. 20. solitariis, globosis; pedunculis hamo reflexo instructis.

Vaucheria hamata Dec. A. fr. 2, p. 63.

Ectosperma hamata Vauch. p. 26. Tab. 2. fig. 2.

Habitat in fossis aqvæ dulcis Fioniæ, v. c. in stagnosis Körnp.

DESC. Cæspcs ut præcedentis. Fila capillo humano tenuiora, apicem rersus imprimis vage ramosa. Peduncnli plerunqve secundi, diametrum fili qvater qrinqviesve longitudine exccdentes, curvati, ad unum latus liamo reflexo sterili instructi, apice rcsicnliferi. Vesiculæ solitaria, globosæ, in apicibus pcdunculorum terminales. Color et Substantia ut præecdentis. Primo vere.

4. V.terrestris; filis capillaribus, ascendentibus, ramosis; ramulis ul- Tab. 21. timis brevibus, secundis, vesiculiferis; vesiculis sessilibus, solitariis, globosis.

Vautcheria terrestris Dec. R. Ir. 2, p. 62. - Ag. Syn. p. 5 r.

Ectosperma terrestris Vauch. p. 27. Tab. 2. fig. j.

Habitat in terrestribus udis, fossisque umbrosis Fioniæ.

DESC. Cæspes intricatus, tcram umbrosam per aliqvot pollices densissimo velamine perreptans. Fila capillum humanum crassitic subæqvantia, erectiuscnla, subdichotoma, ramosa. Ramuli apiccm versus divaricati, patuli, breves, secundi, apice interdum bifurci. Vesicula globose, inter furcas et ad latera ramulornm sessiles, limbo pellucido sæpissime cinctæ. Color viridis. Substantia membranacea, tenax. Annua. Primo vere, etiam autumno.

5. V. Dillwynii; filis capillaribus, flexuosis, ramosis; vesiculis subses- Tab. 21. silibus, solitariis, globosis.

Vaucheria Dillsyynii Fl. d. Tab. r596. fig. x. - Ag. Syn. p. 50.

Conferva frigida Dillw. Tab. 16. - Scluum. Enum. 1, p. 105.

- Dillwynii Web. et Mohr Gross. Conf. Tab. 16.

"Ceramium Dillwy nii Roth. Cat. bot. 3, p. 117.

Riccia arachnoidea Fl. d. Tab. 898. fig. 2.

Habitat in umbrosis terrestribus sat freqvens.

DESC. Cæespes ut præccdentis. Fila intricata, decumbentia, flexuosa. Vesicnlæ slobos , scssiles vel parum pedunculatæ, solitariæ, intcrdom limbo pelluvido cinctæ. Color viridis, vesicularum intensior. 
6. V. granulata; flis nullis, radicibus fibrosis; vesiculis solitariis, globosis, terminalibus.

Ulva granulata Fl. d. Tab. 705. - Linn. sp. 2, p. 1633. - Dillcn. Tab. 10. f. 17. Scureber spicil. f. Lips. p. 1/11.

Linckir granulata Wigg. prim. П. Hols. p. 94. - Schum. Enum. 2, p. 114.

Tremella granulata Huils. 2, p. 5fib. - With. 4, p. 80. - Roth. Fl. Germ. 3. p. 55:. Srue Beitr. 1, p. 312, et Cat. bot. 3, p. 347. - Engl. bot. Tab. 324.

Utua radicate Retzii l'rodr. p. 503. et Act. Holm. 176g. p. 25 r.

Jaucheria radicata Ag. Disp. p. 23. et Syn. p. 52.

Habitat in alnetis, Mieller. - In terrestribus lnunidis argillaceis, fossisqve éxsiccatis.

DESC. Radix fibrosa, fibris ramosis, terram perreptantibus, cidemage immersis, clotis. Frondes supra terram, resicularum instar, aggregatx, globosx, magnitudine seminum Sinapios, aqua vel massa aqvose pellucida replete, extrinsecus laves vel paululum verueosa, vetustate in medio introlabentes. Color virielis. Substantia tenerrima, facile disrumpens. Amma vel potius lebdomalis, brevi cempore apparens, statim evancscens. Autumno observavi cum vesicula ista parve sub pedibus ingredientis lenjtcr crepitabant.

Tab. 21. \%. V. sericea; filis capillaribus, intricatis, dichotomis; vesiculis exiguis, densis, ovatis, breviter pedumculatis.

Habitat in fossis aqva dulci repletis prope Hafniam; Herb. Prof. Hornemanni.

DESC. Cospes intricatus. Fila capillum humanum crassa, dichotoma vel diclıotomo-ramosa, alipgrot polliecs, si extricentur, longa. Vesicula minores, et densiores, qvam in ecteris specibho, solitaria, ad ntrumqve filorum latus sessiles, interdun sccundar, massa viridi ant tote ant ex parte replete. Color crsiccata sordide flavescens. Hanc specien modo siccatam vidi.

'Tab. 21. \&. $V$. clavata; filis capillaribus, apice ramosis; resiculis solitariis, in apicibus ramulorum reflexis clavatis.

V'aucheria clavata Dec. A. fr. 2, p. 64.

Ectosperma clavata Vauch. p. 34. Tab. 3. lig. 10.

Conferva dilatala Roth. Cat. bot. 3, p. 183.

- vesicala Müll. Nova Act. Petrop. III. p. 95. Tab. 2, Gg. 6-9. et Berl, Eeschaef,

4. p. 42. Iab. 3. fig. 5. 6 ?

Ulva Fl. d. Tab. 940.

Habitat in fossis submarinis Fioniæe septentrionalis, ut ad Hofmansgare: 
DESC. Cæespes densissime intricatus, stratum formans ulnare ct ultra supcrficiei xqvæ innatans. Fila capillum humanum crassa, inferne simplicia, ad apicen ramosa. Rami subdichotomi, divaricali, apice reflexi, clavati, vesiculiferi. Vesiculic solitariæ, terminales, apicibus ramulorun incrassatis recurvisque immersæ, ovatæ, minoribns globosis in ubnlis filornm juxta nidulantibus. Color sordide viridis, vesicnlarum intensior. Substantia membranacea, tcnax. Annua. Primo vere et autumno. Charta laxe adliæret.

9. $\quad$. marina; filis capillaribus, ereetis, ramosis; ramis remotiuseulis, Tab. 22. attenuatis; vesienlis ovatis peduneulatisqre.

Habitat ad littus Foroense in infino refluxus limite, ut ad Qvivig, sed raro.

DESC. Cresfes erectus, rmpibus maritimis Jasi affixus, pollicem circiter longus. Fila miuntissima, tubulosa, contimua, capillo humana tenniora, intns massâ viridi granulosû repleta, ramosa. Rami remoti, erecli, apicem versus attenuati. Vesicula laterales, ovatie vel subclavatæ, sursum spectantes, diametrum fili latitudine 2 plo excedentes, atrovirides, brevi tenuiqve peduncnlo fultæ, interdam limbo pellucido cinctx. Color viridis. Substantia membranacca, tenuis. Aestate legi. Chartæa adhæret.

10. $\quad$. pusilla; filis crespitosis, abbreviatis, minutissimis, simplicibus, Tab. 22. continuis, apicem versus inerassatis.

Habitat ad saxa littoris Færoensis in superiori refluxus limite, ut ad Qvalböe Suderöe, et ad Eldevig Österöe, haud freqvens.

DESC. Cespituli aggregati, saxa maritima denso viridiqve velamine obtegentes, lineam unan alteramve longi. Fila ex eadem basi plurima exeuntia, simplicia, flaccida, tubulosa, continua, basi attenuata, apice incrassata et obtusa. Mlassa interna granulosa, viridis, hic illic desinens geniculaqve spur ia menticns. Color viridis. Sulsstantia temuis. Aestatc.

OBS. In fibrica intcrna cum ad præcedentem accedit, primum credidi, cam modo csse stutum ejus juvenilem; sed qrum locis qvidem dissitis eam semper cantem servare staturam pumilam dein obscrvassem, ut proprian speciem eam proponere non dubitavi.

11. $Y$. aqfalica; filis expitosis, liyalinis, minutissimis, simplicibus, 'Tab. 22. apice claratis fuscisqre.

Byssus aqvalica Fl. d. Tab. 896 .

Tlueskimmel Müller in Nor. Act. Hafn. pro anno 1788 . Vol. III. p. 1 5 .

Hakitat arl muscas in aqva emortuas, Mïller. - Ibidem ad Hofmansgave Fionix legit Ilofnamn Bang. - Ad Gasterosteum aculeatum in lacu subalpino prope ivies Österöe Faroa emortumm ipse vidi. 
DESC. Fila ex corpore, cui innascuntur, mndique et radiatim cxcuntia, duas ad tres lineas longa, minutissima, lubrica, albida, adeo ut musca tanqvam ncbulâ circumvoluta in aqva pendere oculo nudo videatur; sub lente fila sunt simplicia, basi attenuata, hyalina, apicem versus clavata granulisqve minutissimis globosis fuscescentibus densissime eompactis intus farcta. Color alljidus, nitens. Substantia membranacea, lubrica. Acstate.

$$
\text { ** vesiculis binis. }
$$

Tab. 22. 12. $\quad V$. scssilis; filis capillaribus, ramosis; vesiculis sessilibus, subbinis; ovatis, cornu intermedio reflexo.

Taucheria sessilis Dec. fl. fr. 2, p. 63. - Engl. bot. Tab. 1765. - Ag. Syn. p. 49. Ectosperma sessilis Vaucl. p. 3r. Tab. 2. fig. 7 .

Habitat in fossis aqva stagnanti repletis prope Hadsmark Fionix.

DESC. Cespes densissimus, intricatus, supcrficiei atrææ innatans, divcrsæ extensionis. Fila capillo humano tenuiora, ramosa, apicen versus dichotoma. Vesicula sessiles, orata, medio puneto saturatiori sape notatx, umnc solitarix, cornibus recurvis cincte, nunc binæ approximate, cornu iutermedio alteram vesicularum amplectente. Color pallide virescens, vesicularum intensior. Substantia membranacea, tencra. Annua. Primo vere. Chartæ laxe alliæerct.

OBS. Vesiculas ab utroqve fine progerminantes inter fila intricala libere natantes tam in hac specie, qram in sequente, ut etiam in $V$. dichotonta, de quâ antea montii pluries olsservavi, omnino ex mente Cel. Vaucherii, accuratissimi observatoris.

Tab. 23. 13. V. geminata; filis capillaribus, dichotomis; vcsiculis binis, globosis, in pedunculo communi cormuto oppositis; cornu intcrmedio recto.

Traucherin geminata Dec. f. fr. 2, p. 62. - Engl. bot. Tab. ${ }^{7} 66$. - Ag. Dec, n. it. et Syn. p. 49.

Ectosperma geminata Vauch. p. 29. Tab. 2. fig. 5.

Habitat in fossis stagnantibus Fionix.

JESC. Cespes densissimus, in superficic aqque strata pedalia et ulnaria intrienta formans. Fila capili hunani crassitic, apieen versus praprimis dichotoma. Pedunculi diametrum fili longitudine 2-3plo exsuperantes, ad latera filorum plerunqre secundi, et inde horizontaliter exeuntes, apice cornu sterili recto subgenieulato terminati. Pedicelli ad latcra pedunculi siti, brevissini, bini, oppositi, apice vesiculiferi. Vesicnlx globosx. Color et Substantia ut pracedentis.

OBS. Vesiculam in peduneulo brevi sotitariam, et in apicc fili recurvi terminalem nomunquam, at raro, vidi. 
14. V. caspitosa; filis capillaribus, crespitosis, dichotomo-ramosis; ra- Tab. 23. mis ultimis horizontalibus, secundis; vesiculiferis; vesiculis binis, sessilibus, terminalibus, cornu intermedio recto.

T'aucheria cospicosa Ag. Syn. p. 49.

Ectosperma caspilosa Vauch. p. 26. Tab. 2. fig. 4.

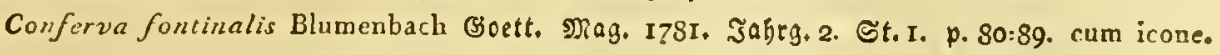

Habitat in terra uda argillacea ad Körup Fioniæ, alıbiqve ad fontes puros leniter flucntes, terram his contiguam udam obtegens, sat vulgaris.

DESC. Cæspes densissimus. Fila capillum humanum crassitie subxqrantia, inferne flexuosa, decumbentia, terramqve sæpe perreptantia, hyalina, superue crecta, dichotoma. Ramuli apicem versus horizontaliter patuli, secundi, apices ramormm semper erecti, resiculiferi. Vesiculæ binæ, globosæ, in apicibus ramulorum opposite terminales. Filum apice acuto recto inter vesiculas paululum plerumqve prolongatur, cornu mentiens. Color cxspitis supremi atroviridis, infini, sabulum perreptantis, sordide luteus vel hyalinus, filorum dilnte viridis, vesicularum saturatior. Substantia menbranacea, subtenax. Annua. Primo vere. Chartæ a sabulo purgata adhæret.

OBS. Ramuli, qvi in extremitatibus steriles sunt, massa intensins viridi farcti sub lente conspicinntur; ex horum apicibus, si cultello vel simili qrodam instrumento tangantur, pollen interdum, fumuli instar, vi emanare observatur. Contendit auctor quidam Gcrmanicus, N.v. Esenbeck, sententiam Mïlleri ct Ingenhousii secutus, hoc pollen esse animalcula infusoria, qvemadmodum Girod-Chantransius voluit, Confervam glomeratam esse Polypun, et granula in articulis sparsa esse orula hujus animalculi. Sic etiam L. C. Trerirames in articulis Conferwa glomeratce aliarumqve omnino, ut affirmat, illasis inmensam Monadum congeriem visus est sibi videre, ( $\mathfrak{c} \mathfrak{\mathfrak { r } .} \mathfrak{B} \mathfrak{B} \mathfrak{b}$. Beitr. zur Raturf. 2 Th. p. 126-141); et Bory de St. Vincent in Conferva scoparia veros se indagasse Polypos eredidit (cfr. Echrad. Journ. 1 S. 1800. p. 445). Cuncte vero illie observationes non extra omnem dubitationis aleam, me judice, jositæ sunt; ego eqridem munqram me tale qvid vidisse ingenue fateor, virosque landatos et celclberrimos fallaciâ opticâ deccptos esse, qvod in rebus tam tenuibus facile tieri potest, eorumqve opiniones parun fundatas ad meras hypotheticas esse relegandas, nò multum abest, qrin credan. - Confervam fontinalem Blum. l. c., assentiente Cel. Rothio (Cat. bot. 3. p. 196), huc retuli; ncqve tamen me fugit, Cal. Molrium ean ad Confervan linosam Dillw. transtulisse. (cfr. Gdrab. ฐ̃ourn. 1 S. 1801. p. 472.)

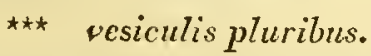

15. V. racemosa; filis capillaribus, dichotomis; resiculis in racemum Tab. 23. pedunculatum congestis. 
Yaucheria raccmosa Dec. A. fr. 2, p. 6r. - Ag. Dec. n. 12. et Syn. p. 50.

Eclosperma raccmosa Vauch. 1. 32. Tab. 3. fig. S.

Habitat in fossis aqva dulci stagnanti repletis ad Lumbye Fionix; etiam in fossis submarinis prope Hofmansgave.

DESC. Cespes dersissime intricatus, superficicm aqve stratis magnis obtegcus. Fila capillum humanum crassit, dichotouti, vel vage ramosa, flexuosa. Pedunculi e filo horizontaliter exeuntes, breves, racemosi. P'edicelli brevissimi. Vesicula qvaternx vel plures congesten, in suo qravis pedicello terminalis. Color sordide viridis, vesicularum intensior. Substantia membranacea, temuis, sublenta. Anuna. Primo vere. Charta line adhaxet.

OBS. Excresccutiam, qram habitaculum Cyclopis Jupule dicit Cel. Taucherius, pluries, non tamen luic specici, sed V auch. dichotome aflixum obscivari. - Pedicellum ultimun semper vesiculiferum, nec ungram sterilem vidi; idcm contra Fancherium, alias cxactissimum, Cel. Agarihius rite monuit.

16. $V$. multicapsularis; filis minutissimis, repentibus, ranosis; ramis erectis, simplicibus, apicem versus incrassatis, vesiculiferis; resiculis spharicis congestis.

Conferva multicapsularis Dillw. Tab. 7r. et Suppl. Tab. D. fig. 4.

Habitat in terrestribus umbrosis limosis ad littus prope Neustalt I lolsatia (ijp. Journ. for ubent. Sitt. Fan 1812); in montosis argillaceis siccis, Dillwyn.

1)ESC. Caspes parrus, ungem circiter latus, intricatus, irregularis, Conferter velutince Dillw. sxpe immixtus. Fila minntissina, flexnosit, stolonum instar repentia, ramosa; rami erecti, interdum lic illie geniculati, simplices rel dichotomi, apicem versus incrassati, el vesiculas solitarias et congestas, splaxricas vel subovatas, granulis cylindraccis oblongo-oratis virescentibus farctas, garentes. Color fusca-olivacens, interdum nisrescens. Sulstantia incmbranacea, tencra. Chirrtx lase adharet.

\section{B A N G I A . *)}

Fila capillaria, continua. Granula elliptico-cylindracea vel globosa inıus congesta.

* simplices.

'I'ab. 24. 1. B. crispa; filis continuis, simplicibus, crispis, gramuliferis; granulis sphrericis, in qvavis serie transversali subternis dispositis.

* Cel. et doct. Hofmann-Bangio, possessori pradii Holmansgave Fionia, indefesso ut naturae totius scrutatori, sic et Algarum felicissimo indagatori, 'pi tractatu sto: De usu Confervarum in oeconomia nature, Hhfuic 1828, eruditorum 
Bangia crispa Fl. dan. Tab. 16ot. fig. 2.

Habitat ad rupes maritimas ante ostium sinus Oxefiord Norvegia, et qvidem, ut Lepas Balanoides, in ipsa aqva superficie vel in summo fluxus limite, ubi rupibus declivibus adhærens a fluctibus marinis semper vexatur.

DESC. Radix minutissima, rnpibus tenacissime adnata. Cæspites per rupes declives penduli, easqge magna extensioue eiugentes, maxime crispi. Fila exspitose aggregata, capilli humani crassitic, pollieari vel bipollicari longitudine, ob undarum vehementiam erispa; sub lente visa simplieissima, continna, tortuosa, hie illie margine paululum contracta, in apicc cxspitis interdum reta, crispationis cxpertia, apicibus nune subclavatis, virideseentibus, nunc simpliciter obtusis, hyalinis, intus transversaliter tri-vel quadripunctata; punctis vel granulis minutissimis, rotundis vel subqvadratis, binis, ternis vel qraternis in qvavis serie transversaliter dispositis, interdum pluribus congestis, ct in filis tenuioribus (nam crassitie diffcrunt) una modo serie dispositis. Color pallide rubens. Substantia membranacea, lenta, tenacissima. Perennis. Acstatc. Cliartæ adhæret. Siccitate non mutatur.

2. B. fusco-purpurea; filis continuis, simplicibus, rectis, inæqvaliter Tab. 24 torulosis, granuliferis; granulis sphæricis, in qravis serie transversali subqvinis dispositis.

Conferva fuscopurpurea. Diliw. Tab. $\mathbf{9 2}^{2 .}$

B) atropurpurea, filis atropurpureis.

Conferva atropurpurea Dillw. Tab. 103. - Roth. Cat. bot. 3, p. 208. Tab. 6? - Wabl. f. lapp. n. 986 .

- trichodes Duclur. Essai p. 39.

Oscillatoria atropurpurea Ag. Syn. Г. rog.

Habitat ad littora Færoensia in summo refluxus limite sæpe denudato. ß. paulo infra snperficiem maris rarius, ut ad Eldevig Österöe.

DESC. Radix minutissima, puuctiformis, saxis declivibus aduata. Crespites penduli. Fila aggregata, duos vel tres pollices longa, capillum humanum erassitie æqvantia, rectiuscula, flaccida, clastica; sub lente inæqvalia, adco ut tenuiora crassioribus sint immixta, hie illic contracta, apieibus obtusa, intus granulosa; granula globosa, in qvavis serie transversali qvaterna, qvina vel plura densissime disposita. Color fuscus, rubro aliqvo tinctus. Substantia membranacea, tenax.

orbi eximie cngnitus est, qui etiam mihi, ad Algologiam animum appellenti, benevolus fuit adjutor et preceptor, hoc genus in grati animi documentum dedicatum volui. 
OBS. Color, in loco natali fuscus vel fuscopurpureus, siccitate in atropurpurenm abit; 'vare Conferwam atropurpuream Dillw., ul ravietaten, hue retuli; radicom tamen fibrosam, yvam suce Conferva allribuit Dilleynius, nunqvam observare mili successit. - Singularis est vis illa, fvam luic speciei competi. 'lastica; si cnim fila in statu madiclo inter manus plus justo extenduntur, vi illa, gra pollent, in statum pristimum ocyus contralruntur.

Tab. 24. 3. B. Laminarice; filis continuis, simplicibus. crespitosis, reqvalibus; gramulis minutissinis, in dnplici serie transversali dispositis.

Habitat in utraqve pagina Laminaria csculenta ad littora Farocnsia, Iand vilgaris.

DESC. Caspituli densi, erceti, abbreviati, lineam unam alteramre longi. Fila in parvis illis caspitulis deuse aggregata, cx una basi plurima, simplieia, capillo humano temiora, irqvalia, interdum apice incrassata et fibrillosa; grannula minutissima, globosa, in duplici seric, genienlum mentiente, intus congesta, et in qravis seric sulugraterna. Color riridis. Substantia tencra.

Tab. 24. 4. B. rntiluns; filis continuis, simplicibus, capillaribus, rectis, granuliferis; granulis cylindraceo-oblongis, parallelis, confertis.

Conferva rutilans Roth. Cat. hot. 3. p. 179. - Jürg. Alg. Dec. x. n. 3.

Habitat in sinu Othiniensi, saxis vel \%ostera marina adnata; Iofmann Bang. Caspitibus Fragilariae nummuloidis variarumqve Confervarmm in aqva submarina immixtam ibidem vidi. - Etian in rivulo, haud procul a mari prope 'Thorshavn Faeroa, inter alias Conferras.

DESC. Crespes oblongus, bi-tripollicaris, flucmans. Fila eapillo humano tcnniora, recta, apicem versus atcentata, interchun bifures. Granula cylinIracea, oblongo-ovata, dianetro sua 4plo longriosia, utringre olutusa, paralJele e longitudinaliter in fili tubulo disposita, nune approximata, nume remotiora, et nounullis clapsis membrana fili hyalina apparet. Colos viridescens vel dilute fuscus, cxsiccate lutcseens, rutilans. '(t quasi vernice obehens, mude nomes. Substantia lubrica, tencra, teras. Anmua. Vere. Chatro adlixet.

Tab. 25. 5. B. micans; filis continuis, simplicibus, minutissimis, granuliferis; granulis cylindraceo-ovatis, sparsis.

Habitat in sinu Othiniensi foliis Ruppixe maritimxe et Zostere marinx innata.

DESC. Fila minutissima, capillo lumano temuiora, lincam fere longa, foliis, quibus parasitice insident, densissinc innata, et inde parallele excuntia. Gra- 
nula xgre conspicua, ovata, cylindracea, longitndinalitcr sparsa. Color albidus, siccitate uitens, micans. Substantia tenera, siccitate fragilis, subcrustacea. Anmua. Aestatc. Cliartæ adliarct.

\section{** ramosce.}

6. B. atrovirens; filis continuis, ramosis, rigidis; ramis vagis, divari- Tab. 25: catis; granulis sphæricis, in qvavis serie transversali subternis dispositis. Conferva atrovirens Dillw. Tab. 25. et Introd. p. 6o. Tab. D. - Wel. et MIolhr Grossbr. Couf. Tab. 25. - Wahl. A. lapp. n. 974. Scytonema atrovirens Ag. Disp. p. 39. et Syn. p. I15. Cornicnlaria pubescens Achar. Syn. Lich. p. 302.

Habitat ad saxa campestria et rupes subalpinas Færoæ copiose; etiam ad officinam ferrariaun Næs Norvegiz.

DESC. Rarlix minutissima. Cæspes intricatus, duos vel tres pollices longus, decumbcns. Fila cespitose aggregata, ad basin ereeta, setam poreinam erassa, deinde decumbentia, teuniora, rigidla, pollicem circiter longa, ramosissima, intrieata, Rami patentes, plerumqre proliferi, apicem versus tenuiores, aliisque minoribus et brevioribus obsessi; ramuli proliferi tennissimi, densi, secundi. Granula interna sphariea, in qravis serie bina vel terna, intervallo inter singulas scries brevissimo. Color cespitis niger, filorum sub lente fuseo-olivaceus. Substautia rigida, tenax. Charte non adhreret, nec siecitate mutatur.

OBS. Amat hace species non solum latera rupium, quæe aqvis rivulorum juxta fluentium irrorantur, sed qroque saxa aridissima subalpina Frrox, qra modo pluvià interdun irrigantur; sed notundum est, insulas Faroenses, ä̈re nehuJoso et vaporibus e mari crebro surgentibus sapissime esse circumfusas; ex illis igitur hre planta, qram nomulli inter Lichenes poumnt, alimentum sibi necessarium haurire existimatur.

7. B. mamillosa; filis continuis, ramosis; ramis alternis, flexuosis, utrin- Tab. 25. qve attenuatis, mamillis abbreviatis obsessis; granulis in qvavis serie transversali subternıs dispositis.

Habitat ad saxa fluvii semper irrigata ad officinam ferrariam Nas Norvegia.

DESC. Fila cxspitosa, aggregata, museis immixta, ereeta vel in saxis abruptis pendula, tres quatuorve lineas longa, setam poreinam fere erassa, ramosa; rami basi patentes, flexuosi, ramulos brevissimos mamillæformes atlutrumqve latus emittentes, utrinqve panlulum attenıati, aliisqve minoribus simplieibus enrvatis obsessi, intus ubiqve granulis transversaliter dispositis, genicula mentientibus, notati; granula in qvavis serie bina vel terna. Color atroviridis, sub lente olivaccus. Substantia tenera, mollis. Annua. Acstate. Clıartæ laxe adhæret. 


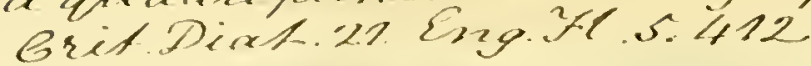

86 SECTIO SECUNDA. BANGIA \& OSCILLATORII.

Tab. 26. 8. B. quadripunctata; filis contimus, ranosis, minutissinis, intricatis, granuliferis; granulis cylindraceo-ovatis, sparsis, vetustate intunescentibus, medio qradripunctatis.

Conferva foetida Dillw. Tab. 104?

Ulia foetida Vauch. p. 2 iq. 'Tab. 17. fig. 13? - Dec. A. fr. 2, p. 5?

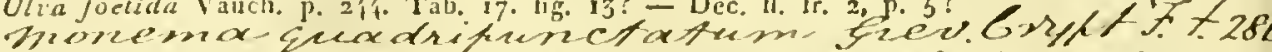

Habitat ad littus Finonix septentrionale Gigartina plicatxe Confervisqve adharescens; in simu Othiniensi ad saxa. - Ad littus Neoburgi et Crucisorx, copiose; Hofmann Bang.

DESC. Caspes dense intricatus, bi-tripollicaris. Fila continua, intricata, flaccida, ramosa, vel dichotomiis quingrics scxicsve repetitas disisa, apice altenuata. Granula in statu juniori cylindracea, oblonga, parallede ct longitudinaliter disposita, minuta; in statu adultiori iutumesecntia, adeo ut totum fili tubulum sungula expleant, nedio qvatuor punctis lutcis stellatim dispositis notata. Color saspitis sordide viridis, vel fuseesccus. Substantia membranaceal tenax. Primo vere et acstate. Chituta adliretet.

OBS. In loco matali hace species primo intuitu Éctocarpum littoralem refert, a qro tamen qroad internam structuram recedit. - Ad Confersan foelitan Dillw. et qroad locum natalem et qvoad cetcras onnes notas prope aceedit; orlorem vero foctidum, cujus meminit Dillwyuius, mcis speciminibus competere non olservavi, 'Trare synonyma dubitanter allegavi. - Denique Confervam fusco-brunneam Jürg. Alg. Dec. 1. 11. 5. ct Glojonema paradoxume Ag. Syı. p. 120. ad hoc genus pertincre cxistino.

\section{O S C ILLA T O R I A.}

Fila continua, membranaceo-herbacra, lubrica, intus lygalina vel striis transversalibus parallelis densis notala.

* aqua dulcis.

* substrato limoso decumbentes.

1. O. limosa; filis simplicibus, cocrulescenti-viridibus, c strato atrovirente, lubrico, densissime compacto, utrinque longissime radiantibus, strictis, rectis.

Oscillacoria limosa Ağ Disp. p. 35. et Dec. 2, 11. 16. et Syn. p. 1n4.

- princeps Vauch. p. 190. Tab. 15. fig. 1. 2.

Conferva limosa Rorb. Cat. bot. 3, p. 197. - Fl. d. Tab. 1549. fig. 3.

- foncinalis Dillw Tab. 64.

- Dillenii Tab. 2. Fig. 5 . 
Habitat in fundo limoso fossarum, piscinarum et rivulorum lente fluentium, impuras aqvas vehentium, demum aqvæ superficiei innatans, sat freqvens.

DESC. Stratum expansum, indeterminatx magnitudinis, palmaris sæpe extensionis, saturate et obseure viride, longissimos radios brevi tempore emittens, substrato limoso superincumbens. Fila simplicia, continua, pollieari fere longitudine, strieta, recta, apice oltusa, oscillantia, citissime in longitudinem exerescentia. Strix transversales distinctx, facile conspicux, densissimæ, parallelar. Interstitia subpellucida, brevissina, cliametro fili $s_{p}$ lo angustiora. Color strati atroviridis, filorum radiantium coerulescens, vel obscure viridis. Vere et aestate, Chartæ arcte adhreet.

OBS. Fila lujus generis continua dici possunt, siqvilem annuli interni transversales, qui tanqram in singulari tubulo interiori densissime compacti sunt, ad ntrumy fe fili marginem spatim pellucidun continum relingvunt. - Ceterum spceics, de qva hie loqvimur, si charte sub aqva imponitur, celcre! incrementum capit, et fila pollicaria et ultra per unain noctem emittere potest; hac fila sub lente mirum in modum oscillant vel sese motitant, idqve in omnes partes et directiones, vix antem singula solitaric, sed una viee duo vel plura invicem hane oseillandi vim exserunt. Cel. Faucherius in ea est opinione, Oscillatorias ob hanc faeultatem ad regutum animale pertinere, qvin chiam dc capitc carum et cauda disserte loqvitur. Cel. Agretllius, qpi fila nommulla vidit in globulos levissime coliærentes abire, eaqre e strato libera motu reptante curvo et lentissino in aqra sese producere, credit, ea in aliis vite temporilous esse vegetabilia, in aliis esse animalia. Ego egvirtem de hac re, qva altioris est indaginis, nullum ferre audeo suffragium. Vidi certe motiunculas istas sub lente maxime angente hand raras; sed inde nil certi concludere liect, siqvidem motns arve mirandi et inexplieabiles in plantis quibusdam phanerogamis, v. e. Hedysaro gyrante, animadvertuntur. Sunt, qvi credant, hane oscillationem luei, yve in fila vim snam exserit, attribui posse; preterca non negandum, nonnullas filorum oscillationes motitationibus aqve, a levissima observatoris respiratione ortis, adscribi deloces q qvod autem per prolongationem fila se motitant, id uulla est oscillatio, serl modo creseentia dicenda. Ceterum non omnibus hujus generis specielous, sed solummodo iis, qve sub prima hac subelivisione contincutur, ista oseillationes competunt, ideoqve Cel. Agardhius Oscillatorias in veras et spurias, qve forsin peculiare genus constitucre possent, rite distinxit.

2. O. nigra; filis simplicibus, griseo-lutescentibus, intricatis, e strato Tab. 26. nigro lubrico longe radiantibus, rigidis, rectis.

Oscillatoria nigra Vauch. p. 192. Tab. 15. fig. 4. - Ag. Dec, 2, n. 18. et Syn. p. ro5. Habitat in rivulis lente fluentibus ad officinam ferrariam Næes Norvegiæ, aqvae superficiei innatans. 
DESC. Stratum expansum, intrieatum, nighescens, lubricum, longe radians, substrato limoso incumbens. Fila pollicem et ulura longa, oculo nudo conspicua, grisco-lutesecutia, recta, rigida, continua, simplicia, oblusa, vivaciter oseillantia, citissime crescentia, radiantia. Strix transversales facile conspicua, atrovirides. Interstitia pellueida, dianctrum fili longitudine fere aqvantia. Acstate. Clarta arcte adlixect, maculan nigreseentem radiantem sistens.

OBS. Hane speciem sub lente vidi momentanco decmsu et horx puncto fila sua celerine et insignites prolongare, oseillantia, idpve nuo obuntu in omnes directiones pendulifurmes et spirales. Interstitia longioria celeri ineremento sine dubio sunt attribuenda. lrorata ocyus reviviscit, nce ullam fere subit mutationcul.

3. O. temuis; fllis simplicibus, dilute viridibus, intricatis, e strato viridi lubrico breviter radiantibus, strictis, rectis.

Oscillatoria teruis Ag. Dec. 2, n. 17. et Syn. p. 105.

- viridis Vauch. P. 195. Tab. 15. fig. 7.

Conferva fontinalis Roth. Cat. bot. 3, p. 195. (excl. syn. Miill.)

- Limosa Dillw. Tab. 20. - Web. \& Mohr Gr. Conf. Tab. 20.

Habitat in fundo fontium vel rivulorum lente fluentium.

- DESC. Stratum expansum, densum, viride, lubrieum, breviter radians, substrato limoso inemmbens. Fila 4-6 lineas longa, temuissima, dilute viridia, simplicia, rectiuscula, lubrica, apice obtusa, oscillantia, radiantia, radiis 2-4 lincas longis. Strix transversales tenuissima, densissimie. Intcrstitia pellucida, lorevissima. Acstate.

OBS. Differt ab Oscillatoria limosa filis multo tenuioribus, colore dilutiori et radiis brcrioribus.

Tab. 26. 4. O. subfusca; filis simplicibus, tenuissimis, hyalinis, e strato compacto lubrico fusco breviter radiantibus, rigidiusculis, rectis.

Oscillatoria subfusca Vauch, p. 193. Tab. 15. fig. 5. - Ag. Disp. p. $3^{5 .}$

- Reizii $\beta$. subfusca Ag. Syn. p. 106.

Conferva velutina Rotb. Cat, bot. 3, p. 199.

f) atra, filis hyalinis, e strato aterrimo nitente velutino lubrico, subtus virente, breviter radiantibus.

Conferva velutina $\beta$. atra Roch. Cat. bot. 3. p. 20o. (excl. syn, Vauch.)

Habitat ad saxa et trabes sub aqva leniter fluente ad officinam ferrariam Nas Norvegix; ad rupes præruptas aqva dulci irrigatas Færoenses. - $\beta$. ad rupes inundatas declives prope Nies Österöe Færox copiose. 
DESC. Stratum expansum, pro loci diversitate diversa cxtcusionis, interdum latissime patens, et per rupes declives rel abruptas pendens plures ulnas in diametro tenens; praterca lubricum, fuscum vel atroviride, breviter radians, substrato limoso tenui superincumbens. Fila minutissima, simplicia, rigidiuscula, recta, dilute viridia vel hyalina. Strix transversales ob tcnuitatem nullie conspiciuntur, ideorve nulla qroqve interstitia apparcnt. Aestate. Chartæadhæret.

5. O. ochacea; flis simplicibus, tenuissimis, flavo-viridibus, stratoqve Tab. 26. crasso ochraceo fragili incumbentibus.

Conferva ochracea Dillw. Tab. 62. - Rnth. Cat. bot. đ, p. 165. - Ag. Disp. p. 54. et Syn. p. 72. - Schum. Enum. 2, p. 105.

Habitat ad ripas lacuum, presertin ad scaturigines martiales prope lacum Fuursöe Scllandix; Schumacher. - Ad fontes martiales Cimbrixe et Fioniæ; Hofmann Bang. - Ad officinam ferrariam Næs Norvegiæ et in insulis Færoensibus.

DESC. Stratum pollicare vel hipollicare, densum, intricatum, substrato incumbens limoso crasso ochraceo perfragili. Fila simplicia, tenuissima, parum curvata, viridescentia, obtusa. Striæ transversales dilute virides, densissimæ, crassiores hic illic tenuioribus immixtx. Interstitia brevissima. Siccata sistit pulverem ochraceum, fragillinum, chartæ non adhærentem. Substratum levissimo tactu vel aqra motu in frustnla vel flocculos facillime secedit.

6. O. Corium; filis simplicibus, lutescentibus, in stratum compactum subcoriaccum fuscum intricatis.

Oscillatoria Corium Ag. Disp. p. 56. et Syn. p. 107.

Habitat ad saxa rivulorum subalpestrium ad officinam ferrarianı Naes Norregix:

DESC. Stratum crpansum, palmari ad pedalcm extcrsione, densissime compactum, semilineam crassum, fuscum, coriaccum, substrato limoso incumbens, vix radians. Fila simplicia, curvata, densissime intricata, tennissima, lutesecntia vel hyalina. Stria transversales ob tenuitatem inconspicux. Acstatc. Chartæ adliæret.

* substrato limoso destituta.

\%. O. torta; filis simplicibus, spiraliter tortis, obscure viridibus, apice clavatis.

Oscillataria torta Ag. Dec. 2, n, 15. et Syn. p. 109.

Habitat in rivulo prope Præstöc Sellandix, Prof. IIornemann. 
DESC. Cospes flucturans vel lapidilus adnascens, hipollicari et ultra lougitudine, atroviride, nullo substrato limeso incumbens. Fila pollicem unum alterumre longa, capillo humano panllo crassiora, lubrica, spiraliter torta, simplicia, ad apices inllatos interdum conjuncta. Surie transversales densie, atro-

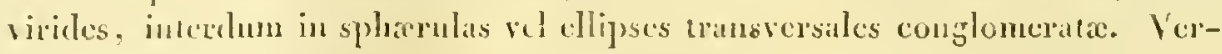
no compure. Chartic adliaret.

S. O. foutinalis; filis simplicibus, temnissimis, subhyalinis, rigidiuscuJis. ercetis, brevibus, cespitem saturate viridem constituentibus.

Oscillatoria fontinalis Ag. Disp. p. 37. et Syn. p. 110.

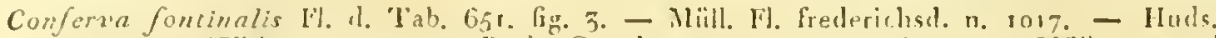
1) 592. - With. 4. 1. 1:!s. - Roth. Cat. bot. 3, 1. 195. (exel. synow. Mliill. qvae ad Fragilarinm pectinalem pertinet). - Schum. Enum. 2, 1'. 10.j.

- minima bj ssi facic Dillenii Tab. 2. fig. 3.

li) ssus minima palustris abscura sic. Michel. nov. pl. gen. Tab. 89. lig. 8.

Habitat ad scaturigines passin, Müller. - Ad saxa in fonte Emilize prope Süclyst: ad plantas aquaticas in rivulo aqvam limpidam vehente ad Lundtofte Scllandice:

DESC. Corspes minutus, saturate pel facte viridis, lubricus, aqva submersus. Fila aggregata, simplicia, 2-3 lineas longa, tenuissima, singula vix oculo muto conspicua, rectit. Stria trinstersales temuissimic, risum fugientes, adco ut fila contimu pellucidarge fere conspicimtur. Color filorum sub lente hyalinns. Acstate. Charta arete adluxect.

9. O. distorta; filis ramosis, coeruleo-viridibus, tennissimis, rigidiusculis, brevibus, cæspitosis.

Oscillatorin distorta Ag Disp. p. 37. et Syn. p. 112.

Conforin distorta Fl. d. Tab. 820. - Dillw. 'Tab. 22. et Introd F. 4r. Suppl. Tab. A. - Web. et Mohr Grossbrit. Cont. T. 22. - Roth. Cat. bot. 3. p. 201.

Habitat in lacu Peblingesöe prope Hafniam raro, Mïller. - In stagnosis Hindsholn Fionia, aqva superficiej immataus, Ilofmann Bang.

DESC. Cospes parvis, prima atate plantis aquaticis putrescentibus adharescens, scminis P'isi satisi maguiludine, it colore arruginoso; deinde in majus volnmen pollicari vel bipollicari longitudine excrescens, plantasegre, qribus antea adhitrehat, relingvens, argae superficici libere imnatat, et colore gande coerulco-vididi. Filit tconissima, ramosa, pollicari circiter longitudine, cat pillo humano tenniora, xqvalia, intricata; rani alterni, remotiusculi, aliisyre minoribus olsessi. Suret transversales tennissine, remotip, sinc ordine disposite. Interstitia nunc opaca, munc medio moniliformia, nunc longiori intervallo ommino pellucida. Color cocruleo-viridis, exsicratie in aruginosntr abit. Substantia tenerrima. Aestate. Charte bene adharet. 
OBS. Spuriam huic speciei Cel. Dilluynius attribuit ramificationem, qvæ ita intelligenda cst: Rami quidem sub lente vcri et alterni videntur, scd diligentius inspecti, tam leviter sibi invicem cohærent, ut potius pro filis diversis, levitcr agglutinatis, qvam pro veris ramis habcri debeant. Illud autem in nostris speciminibus nondum observare contigit.

** aquae salsa.

10. O. majuscula; filis simplieibus, lutescentibus, in cæspitem cylindraceo-oblongum fuscum fluctuantem densissime intricatis.

Conferva majuscula Dillw. Introd. p. 40. el Suppl. Tab. A. - Fl. d. Tab. 1549. fig. I. Oscillntaria majuscula Jürg. Alg. Dec. 4. n. 7.

- $\quad$ cruginosa $\beta$. violacea Ag. Syn. p. 109.

\section{Habitat in sinu Othiniensi, Zosteræ marinæ adhæresccns.}

DESC. Cxspes fluctuans, subrotundus vel oblongus, palmam ad spithamam longus, duos ad tres pollices latus, cylindraccus, apicibus obtusis, fuscus rel nigrescens, dense implicatns, sublubricus, nullo substrato instructus, sed libere fluctuans vol Zosierce marince adhæresccns. Fila simplicia, maxime intricata, si extricentur, aliqvot polliccs longa, capillum humanum crassitie subxqvantia, æqualia, apice obtusa, sub lente lutescentia. Striæ transrcrsales densissinx. Color caspitis fuscus, exsiccate, chartrque imposite, nitens, atro-glaucescens vel chalybæus. Substantia tenera, lubrica. Aestate. Chartæ arcte adhæret.

OBS. Fila spurie ramosa, qrorum mentioncm fecit Cel. Dillwynius non observavi; ceterum juxta cxemplaria ex Anglia nuissa nostra planta in Anglorum optime quadrat.

11. O. cestuarii; filis simplicibus, intricatis, fuseo-viridibus, in stratum Tab. 26. compactum fuscum, late patens, densissime intertextis.

Conferv'n acsintarii Jürg. Alg. Der. 2. n. 8.

B) latevirens, filis simplicibus, rigidis, læete viridibus, in stratum tenue æruginosum dense compactis.

Oscillatoria latevirens Hofmann Bang de usu Conf. p. 23.

- oruginosa Ag. Syn. P. ing.
Conferva stuposa Roth. Cat. bot. 5. p. 20o?

Habitat in æstuariis et vadis sinus Othiniensis, item in fossis submarinis, aqva salsæ contiguis. - $\beta$. supra Confervas aqvæ salsæ, qvas velamine suo ærıginoso obducit, prope Hofmansgave, rarius. Ad mare Balthicum circa Finnbriam insulam, Roth. 
DESC. Stratum expansum, lạtissime patens, uhnali orgyalique estensione, linean unam alceramse crassum, primo vere in fundo rstuarii latens, idcmpse velanuine suo denso tanqram oblegens, deinde a'slivo tempore ct autumo lic illic aq̣a superficici inmatims, magnis loulis instructum, stratoqve limoso snperiucumbens. Fila simplicia, continua, dense intricati, adeo ut cormm longitudo agre dercrmincur, capillum lumanum crassa, fusco-viridia, ubifre arvalia, apice ohusa, non oscillantia vel radiantia. Stria transscrsales facilc conspicux, densissima, crassiones hic illic temnioribns immixta. In-

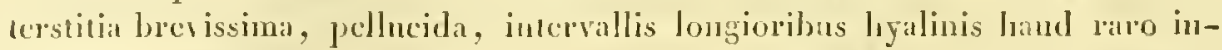
torjectis. Color easpitis fuscus. Substantia tenera. forno tempore ad attumnum. Charte laxe adtaxet.

OBS. Cunferpa stuposa Rolh, vix ab hac specic diversa.

'Tab. 2\% 12. O. ctuthonoplastes; filis simplicibus, viridibus, minutissimis, hyalinis, rigidis, strictis, in ragina subpellucida, lubrica, densissime et parallele inclusis.

Conferwa chthonoplastes FI. d. Tab. 1485.

Oscillatoria cheleonoplastes Hofinann Bang de usu Conferv. p. 89. c. icone.

Glojonema chthonoplastes Ag. Syn. p. 12 .

B) vaginata; filis viridibus, ninutissinis, liyalinis, rigidis, in vagina subpellucicla lubrica inclusis, terramqve perreptantibus.

Oscillatoria vaginata Vauch. p. 200. 'Tab. 15. fig. 13.

Conferva vaginata Dillw. 'Tab. 99. et Introd. p. 40. - Engl. bot. Tab. ז995.

Habitat in vado sabuloso sinus Othiniensis, IIofmann Bang. - Ad littus marinum Hindsholm Fionire passin, et in variis locis sinus Othiniensis, qve parvis funcli elevationibus, badii vel fusci coloris, glabris, lubricis, ab hac planta sabulum subtus perreptante formatis, facile dignoscuntur. - $\beta$. in ripa rivuli prope oficinam ferrariam Nies Norvegiæ, terram lnmidam umbrosam subtus perreptans et e superficic ejusdem hic illic prominens. Ad ripam thermarum prope Reikiavik Islandiae, copiose; Hooker.

DESC. Fila universalia simplicia, continua, tempore vernali silunlum paulo infra superficiom fundi dense pereptantia, plepumpre brevia, scmipollicari ad pollicarem longitudine, setan eqvinam medio crassa, leviter flexuosa, vaginalta, utringre attenuata. In qrolibet filo miversali ope vayine, matticis instar, includuntur siginti ct plura alia, multotics minora et conuiora, oculo mudo inconspicua, in vagina parallele el longitudinaliter disposita, intcrdum

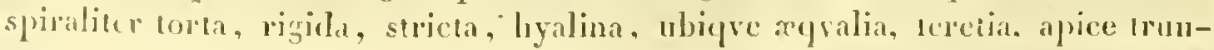
cata. 'Tempore astivos calore solis allicicute, ad superficien soli sabulosi 
proreptant, qram denso exspite, saturate viridi, per plures orgyas obducuut, ct tam lubrican redelunt, ut careat sibi ingressor, nc pedibus titubet atqve cadat: huic lubricitati vagina sine dubio in cansa est. Tere et astate. - Charte, a sabulo purgata, bene adheret.

ODS. Qvam hnic specici dedi diagnosin ab ea, qra in Flora danica cxlibctur, differe comparatione patelst: cum natura vero consentire, obscrvationibus microscopicis constabit. Interdum nulla in filis conspicitur vagina; adest tamen, scd Oscillatorias inlizs communiter pullulantes tam arcte vestiens, ut hanc ob causam vix in eonspectum veniat. Filum universale, si lreditur vel plus justo premitur, in plures lacinias, omnes vaginatas, dividitur' hinc ramosum et intus spiraliter tortum interdum apparet, hinc etian ad apices acuminatum. Est igitur Oscillatoria chthonoplasies tanqvam matrix habenda, in qra Oscillatorix multe, infantum adinstar, invicem gencrantur et crescunt, qrae, cum ad maturitatem pervencrint, aut per apicem ant per latera disrupta vaginte elabuntur. et deinde, sensim sensinqve matris naturam induentes, novam prolem eadem ratione vcrosimiliter progenerant. - Varictas, si locum natalem excipiamus, nullo modo ab a diversa. - Ceterum in textu Flore danica seqveus Cel. Hofmann Bangii de laa planta liabctur observatio, qram hic subjungere liceat: "Nomen hujus speciei e rocabulis gracis $\chi 2 \hat{y}$ e ch $\pi \lambda \dot{\alpha} \sigma$. "Gsi. composuit Cel. Mertens, Prof. Bremensis, obscrvatione mea de hac alga, "qvippe qra fundo maris augendo clevandove inserviat, inductus; filamenta "cuin viscida e substrato singulari, qvale fere in Oscillatoriis I'aucherii re"peritus, qrotannis nascentia, sabulum vi fluctum adrectum retinendo strata "sabulo limoqve altcruantia semper" semperque formant. Scilicet ex co, qrod "dicimus, substrato limus iste procreatur. qui particulis filamentoram putri"dis immixtus strata interdum colorat carnea. Variat ita stratorum copia, ut "ad viginti et qrod excedit numerarim. - Filamentorum structura et a Con"fervis et ab Oscillatoriis diflert; commine tamen cum Oscillatoriis non solum "habet substratum, verum ctiam celcrem crescendi facultatem; portiuncula "cnim hujus algæ, in schedula vel lamina vitica sub acpa expansa, celcre in"crementum capit, ct noya profert fila, qrée ita propullulantia schcdulam co"lore cocruleo obducunt."

13. O. scopulorum; filis simplicibus, viridibus, rigidiusculis, flexuosis, Tab. $2 \%$ ncutis, brevissinis, e caspite denso atroviridi erectis.

Oscillatoria scopulorum $\Lambda$ g. Disp. p. 57. el Syn. p. I1 $\mathrm{x}$.

Conferva scopulorum Web. et Mohr it. svec p. 195. Tab. 5. fig. a. b. - Dillw. Introd. p. 39. Suppl. Tab. A. - Roth. Cal. bot. 3. p. ig1.

Habitat ad saxa marina Hindsholu Fioniae, et ad rupes insularum exteriorm ante ostinm sinus Oxefiord Norvegize, paulo infra superficiem maris, ubi ab undis marinis fere semper inundatur. 
DESC. Ciespes densissinus, scopulis arcte adnatus, atroviriclis, spithamam ad pertem ot ulua in diametro habens, lineam circitcr altus; extra ayvam crustan rimosam nigraun scopulos vesticntem referens. Fila simplicial, lineant id sescrilincom longa, capillo lumano tenuiora, fuscescentia; inqualia, attemuata, apice olstusa. Strie transversales densissime, nigra, crassiores te-

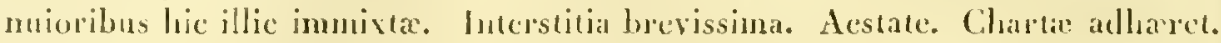

14. O. confervicola; filis simplicibus, aruginosis, rigidiusculis, crectis, attcmuatis, brevissimis, subfasciculatis.

Oscillatoria confervicoln Ag. Disp. p. 37. et Syn. p. tro.

Conferva confervicola Dillw. 'Jub. S. et Introd. P. 39. Suppl. Tab. A. - Web.et Mohr Grosbritt. Conf. Tal. 8. - Roth. Cat, bol. 3, p. 193. - El. d. Tab. 1 is4. Rig. r.

- marina parasitica Scc. Dillenii T'ab. 85. fig. 21.

Habitat in Ceramio rubro aliisqre ad littus I tofmansgare Fionix, non freqrens, IIofmann Licung. - Ad littus 'Torbak Sellandix.

DESC. Fila in cospitulis mimutissimis lincamqve longis aggregata, oumginosa vel glanco-viresecutia, capillo humano truniora, semilineam vel lineam longa, crecta, rigidinscula, simplicia, plerumque vacua ct hyalina. Sura transversales tenuissime, sine ordine disposita, nune remotiones, nune densiores. Interstitia pedlucila. Acstate. Charte adharet.

OBS. In hac sprecie capsulas ilctevit Cel. Mookerus subrotusdas, fuscas, limbo pellucido cinctas, et medio linea pellucidla transversali (ut in capsulis Conferve interrupte lingl. hot. Tab. 1838) notatas, qvarum una in Suppl. 'Tab. $d$. apuel Dillwyinum depicta exstat.

'Tab. 2\% 15. O. zostericola; filis' simplicibus, fuscis, rigidiusculis, crectis, attenuatis, brevissimis, caspitosis.

Oscillatoria zostericola Fl. d. T’ab. 8599 . Cig. 1.

- mucar Ag. Dec. 11. 27. el Syn. p. 11 ?

Habitat ad littus Hofmansgave Fionia, utramqre paginam foliorum Zosterxe marine hic illic dense vesticns.

DESC: Caspituli fuscesceutes. 3 lineas ad pollicum longi. Fila tenuissima, capillo humano multo temiora. lineameque longa, simplicia, crecta, rigidin-

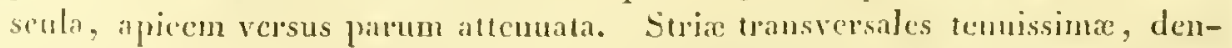

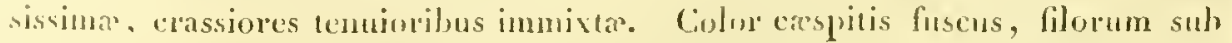
lente fusco-rirescens. Antmmo et hyejwe. Siccatil stratum pulvereum fuscum, foliis Kosterer marince arllaxreseens, sistit.

OBS. Capsulas in hac sperie vidi subrotundas, scssiles vel lorcviter pedunculatas, wi latera filorum sitas, intus dilute fuseats, qrae quidem in Dillwynianas hand male cadunt. Unum antem revera sint capsulx, an heterogencum quid, difficile est dicus. 
$\star \star \star$ suhlerrestres.

16. O. muralis; filis simplicibus, viridibus, rigidiusculis, crassiusculis, flexuoso-curvatis, in caspitem viridem densissime intricatis.

Oscillacoria muralis Ag. Syn. p. 108. - Fl. d. Tab. 1539. fig. 2.

- parietina Vauch. p. 196. Tab. 15. fig. 8.

Conferna muralis Roth. Cat. bot. 3, p. 189. - Dillw. Tab. 7. et Introd. p. 39. - Web. et Mohr Grossbr. Conf. Tab 7. - Jürg. Alg. Dec. 5. n. U.

- frigida Rotl. Cat. bot. 1, p. 166.

Habilat lixe species, inter majores muneranda, ad muros et parictes humidos, terra contignos, et imprimis arl septentrionen vergentes, qros viridibus stratis obducit, vulgaris; etian freqvens in insulis Færoensibus.

DESC. Cespes densus, palmari ad pedalem et ultra extcasionc. Fila capillum

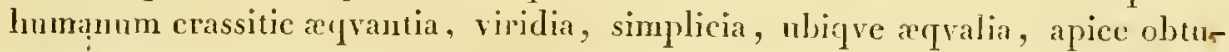
sa, densissime intricata. Strie transversales satis conspicux, densissima. Interstitia brevissima. Interdum in hac specic, ut chiam in ceteris, intervalla vacua longiora conspiciuntur, qve a striis ruptis et confluentibus originem forsau ducunt. Color viridis. Substantia membranacca, tencra, lubricitatis expers. Autumno et hyeme imprimis viget. Charta laxc aclhæret. Siccitate won mutatur.

17. O. autumnalis; filis simplicibus, cinereo-virescentibus, rigidis, rectis, in stratum lubricum nigrum breviter radians dense intertextis.

Oscillatoria autumnalis Ag. Deこ. 4. n. 40. et Syn. p. ro6. (excl. syn. Yauch. et Dilliv.)

Habitat in terra nuda horti botanici Hafniensis, Prof. Hornemann. - Ad Hofmansgave Fioniae, IIofmann Bang.

DESC. Stratum cxpansum, extensione variabile, lubricum, nitcus. nigrnm, brevitcr radians. Fila tenuissima, oculo mudo vix conspicua, simplicia, recta, rigida, densissime intertexta, vix oscillantia. Strie transversales tenuissina. Autumno imprimis. Charte adherct. Forsan modo Tarietas Oscillatorior nigrae, ob locum natalem minor.

18. O. decorticans; filis simplicibus, tenuissimis, cocrulca-virentibus, curvatis, in caspitem viridem densissime intricatis.

Conferva decorticans Dillw. Tab. 26. et Introd. p. 3s. Suppl. Tab. A. - We eb. et Mohr Grossbr. Conf. Tab. 26. (excl. syn. Vauch.)

Habitat ad ligna hnumida; etian ad cortices arborum Fioniæe passim. 
DESC. Cespes densissimus, parvus, mollissiuns, virilis vel glaneesecus. Fila maxime intricata, adco nt eorum longitude determinari negreat, filis Oscillatoria muralis 3 plo tcmuiora, simplicia, ubique xqyalia, non oscillantia vel rarlianlia. Strix transversales tenuissimx, ix conspicua. Interstitia pellucidit, eliancerum fili longitudine sape xegrantia. Acstate. Charta adharet.

OBS. In hac specic Cel. Dillumius capsulas detexit, fusci coloris, sessiles, limbo pellucido cinctas, pro tencritate filorum sat magnas, qvas in Supr. Tab. $d$. delineaulas curavil. Hujusnodi igitur appendienlas, in pluribus luujus generis speciubus inventas, pro capsulis venditare, non plane temerarium aut absomsum videtur.

\section{S C Y TONEMA. *)}

- Tila continua, coriacea, intus striis transversalibus annulatis vel moniliformibus notata.

Tab. 27. 1. Sc.myochrous; filis in cxespitem nigro-fuscum densissine intricatis, inlus transtersaliter annulatis; ramulis geminis, simplicibus, secundis.

Sotonema myochrous Ag. aDisp. p. 38. et Sin. p. 115. - Fl. dan. Tab. 1602, fig. 2. Conferva myochrous Dillw. Tab. 19, et Introd. p. 57. - Web. et Mohr 1. c. Tab. 19.

B) inundatnm, filis tenuioribus, in cespitem purpureo-fuscum intricatis; annulis internis subrotundis; ramulis geminis, secundis.

Scytonema myochrous $\%$ inundatum Ag. Syn. p. 114.

Conforva seriata Wahl. M. lapp. n. 984. Tab. 30. fig. 2.

2) simplex, filis simplicibus, ramos geminos rarissine cmittentibus.

Scytonema myochrous 8. simpicx Ag. Disp. p. 39. et Syn. p. Ir4.

Irabitat $a$ in turfosis et rivulis al officinam ferrariam Nes Norregix, saxis lignisgre inmondatis adnascens; in Groenlandia, IVormstiold; in insulis Færo-ensibus sat vulgaris. - $\beta$. ct $\gamma$, in locis inundatis subalpinis Freroæ.

DESC. Cespes densissimns, intricatus, num ad tres polliecs in diametro habens, lineamcye crassus, nigro-fuscus. mollis, pellicula murince colore laud dissimilis, mole nomen. Filit densissime intricata. curvatit, flexuosa, capillum humanum rrassitic acqrantia, ramosa: rami alterni, ragi; ramuli gemini, sccumeli, simplices, inemsi. Annuli trausversales paralleli, densissimi, olivacco-lutei. Interstitia brevissima, prollucida, lutesccutia. Color cespitis nigro-

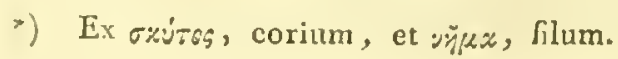


fuscus, filorum sub lente olivacco-lutei. Substantia subcoriacea, tenera, Ienta. Annua. Acstate. Chartæ laxe adhæret.

2. Sc. ocellatum; filis in caspitem nigrescentem densissime intricatis, Tab. 28. tenuissimis, intus moniliformibus, aurantiis; ramulis geminis, secundis, simplicibus.

Conferva ocellata Dillw. Introd. p. 6o. et Suppl. '1'ab. $D$.

Scytonema myochrous $\beta$. ocellatum Ag. Disp. p. 38. et Syn. p. ż弓.

Habitat ad trabes ligneas inundatas ad Næs Norvegiæ, sat vulgaris:

DESC. Antecedentem refert, sed differt 1) filis 3-4plo tenuioribus, et minus flexuosis; 2) intcrná structurâ, qræ aunulis coustat globosis in catenam moniliformem dispositis, totunqve fili spatium occupantibus. Color filorum sub lente olivaceo-luteus, dilutior, qram in præcedente. Chartæ laxe adhærct. Siccitate lıæc, ut præcedens, uon mutatur.

3. Sc. compactum; filis decumbentibus in crespitem nigrescentem densis- Tab. 28: sime intricatis, intus transversaliter annulatis; ramis erectis, dichotomis, strictis, virgatis, fasciculatis; angulıs dichotomiarum acutis.

Scytoncma compactum Ag. Disp. p. 39. et Syn. p. Ir6.

Habitat ad saxa rivulorum et trabcs inundatas ad officinam ferrariam Næs Norvegiæ; imprimis ad trabes inundatas molæ frumentariæ ibidem.

DESC. Cespes nigresecns, pollicem unum alterumve in dianctro tenens, semilineam crassus, coactilis. Fila inferne decumbentia, densissime intricata, apicibus crectis, lincam fere longa, apicem versus ramosissima. Rami dichotomi, crecti, stricti, interdum apicibus curvati, attennati, apice obtusi; anguli di-hotomiarum aciti. Annuli densi, latiusculi, obsoleti, olivaceo-lutei. Interstitia dilute lutea, brevissima. Color cxspitis nigrescens, filorum sub lente olivaceus. Substantia tencrrima, mollissima. Aestate. Chartæ adhrerct.

4. Sc. comoides; filis in cæspitem nigro-ferrugineum intricatis, flexuosis, ramosis; ramis solitariis, remotiusculis, apice attenuatis.

Scylonema camoides $\mathrm{Ag}$. Syn. p. 112.

Couferva comoides Dillw. Tab. 27. et Introd. p. 37. - Web. et Mohr Grosbr. Confo Tab. 27. 
Conferia arancosa Mohr in Schrad. Journ. 1806. 1 L. p. 196.

- rufa Roth. Cas. bot. 3, 3. 280?

Habitat ad littus insule Fimbrix, Rolh. - In Holsatia, Mrohr.

- DESC. Coppes oblongns, nigro-ferrugincus. Fila capillum lunnanum crassitic arvantia, pollicem circiker longa, flaceidla, mollia, flexuosa, rauosia; ranj remoli, soliturii. Annuli distantes, aurantii, moniliformes. Charta adherec. Siccitate uon mutatur.

OBS. Existimat Cel. Dilleyrnius (Iutroul. p. 3\%.), Confertam rufam Roth esse suan Confervan comordem, et ipse Rothius fatetur, coun structurî̀ ct colvice ad plantam Dillwynii accerlere, sed ramulis tamen oppositis difterre. - Qvoad C'onfervam araneosam Mohr, efr. Weber at Molnr Grosshr. Conf. in annotutionc ad Conferwan comoidem Dillw.

Tab. 28. 5. Sc. Bangii; filis simplicibus, ercctis, rigidis, flexuosis, in aculcos crectos fusco-rircscentes densissime contortis.

Scgronema Bangii, Fl. dan. Tah. IGoz. fig. I.

- Hofmazni Ag. Syn. p. 117?

Habitat ad rupes udas umbrosas inter muscos ad officinam ferrariam Nos Norvegix, Hofinann Bang.

DESC. Crspes densissime compacuus, sordide viresens, duos vel tres pollices in diametro habens, pollicem cireiter crassus, muscis ad rupes declives umbrosas inmistus, in superficic aculeos crectos densos, duas tresve lineas longos, apicem versus attunatos, plurinos cmittens. Fila pollicem longa, verticaliter et densissime compacta et tanqram agglutinata, inferne lyalina vel fuscesemtia, superne in aculeos viresecutes contorti, sub lente simplicia, comtinua, rigidiuscula, flexuosa, intus plerumque hyalina, cum veтo parum exsiccata fucrint, catena moniliformis cxigua julchcrima, modium fili percurrens, sape in conspectum renit. Ceterum ammli cl interstitia mulla. Color cespitis fusco-viresecus, filorum sub, lente plernmqve hyaliuns, viridi tinctus. Substautia teucra, lenta, sat tenax. Acstate. Chitrte non adharct. 


\section{N O D U L A R I A.}

Fila continua, simplicia, majuscula, extrinsecus nodulosa. Semina cylindraceo-ovata, in statu adultiori libera, totum fili tubulum replentia.

1. N. fluviatilis; filis subsimplicibus, nodosis; nodulis subternis.

Conferva fluviatilis Lin. Srst. nat. 2, p. 720. - Dillen. Tab. 7. 6g. 47. - Vaill. Paris.

Tab. A. fg. 5. - Hall. Helv. n. 2r22. - Huds. p. 507. - Lightf. p. 985. - Witl. 4. p. 13í - Dillw. Tab. 29. - Web. et Mohr Gr. Conl. T. 29. - Roth, Cac. bot. 5. p. 3of. - Mohr. in Schrad. Journ. 1got. I B. p. 3ı5. Tab. 3. A.

Hippuris exigua fuviatilis \&cc. Pluken. Phyr. Tab. 193. fig. 7. - Petreri gazoph. Tab. roc. fig. 6 .

Lemanea corallina Bory in Berl. Mag. 1 809 . p. 277. et in Ana. du Mus. d'Hist. natur. 1808. Vol. XII. p. 177. Tab. 2r. fig. 2.

- fluviatilis Ag. Dec. n. 36. fig. 2. et Syn. p. 69.

Chantransia fluviatilis Dec. A. fr. 2, p. 50.

Polysperma fluviatilis Vaurh. p. 99. Tab. 1. fig. 4. et Tab. זo. fig. t. 2. 3.

Nodularia Link. in Schrad. Journ. I8०g. p. 9.

B) ramosa, nodis ternis, globosis, insigniter prominentibus.

Tab. 29.

Habitat in amne ad Kongens Möller prope Holbæk, Hofmann Bang. In fluviis et rivulis ad Arendal Norvegiæ vulgaris, saxis semper adnata. - B. ibidem inter ceteras.

DESC. Radix callus parvus, nigricans. Fila ex eadem basi plurima, basi attenuata, palmari et ultra longitudine, sctam porcinam crassitie duplo supcrantia, simplicia, tubulosa, nodis, intcrvallo inter singulos lineari vel bilineari, manifestis instructa. Nodus qvilibet ex duobus vel tribus nodulis subslobosis, elevatis sub lente constare cernitur. Fila, in tenues lamellas transrersaliter secta, intus cara apparent, et in interiori cornm parte fructus in conspectum renit. Fructus in statu juniori Fibræ ramose, articulate vel pulchre moniliformes, pellucida, lateri fili interiori, tam in nodorum yram in cctera cavitatc, ubiqre affixe; in statn vero adultiori Semina soluta, libera, cylindracea, ovata, utrinqve obtusa, oliracea, opaca, ex singulis fibrartum articulis jam dissolutis qravis sine dubio orta, et sic totum fili tubulum dense replentia. Color fusco-viridis, exsiccate nigricans. Substantia subcoriacea, lenta, exsiccatæ fragilis. Annua. Acstatc. Chartæ non adhæret.

OBS. Nomen Lemanece, qrod huic generi attribuit Cel. Bory ob nimiam similitndinem cum nomine Lehmannice (cfr. Sprengelii Eituleitung jur Sintt= níß oer (Sowád) je, cdit. 2. 1817. Tom. 2. P. 1. pag. 458.) nuper constituto, omisi; ejusque loco nomen Nodularice, a Cel. Linkio antea proposilum (cfi. Schrad. Journ. 1809. p. 9.), adoptandum credidi. - Color junioris plante fusco-virilis, adultioris, jam scminiferi, in olivaceun abit. Sunt in statı adulto fila brevia, apice lacerata, flaccida; ad maturitatem enim cum perrencrint, scusim, sensimqre apicem versus dissolvuntur, et matura, qra in iis 
congesta sunt scmina, paulatim ex apice tubuli lacerato liberc exeunt, novam prol'm genitura; ct tantum ahest. ut Cd. Vaucherius, cujus opus, posteqvam delincationern hujus planta ac descriptioncon jamdulum peregissem, primum consulendi data fuit occasio, huic opinioni contridiceret, ut potius omnino assentiatur. Ceterum Cell. Wreber a Mohr in Grosshr. Conferv. n. 29. contendunt, Confervan fluvatilem L. semper lignis inuudatis nee ungvam saxis adfixam esse; omnia vero, qrae ego in locis natalibus vidl specinina, saxis nunquan non adhercbant. - Varictas $\beta$, qram ramosam dixi, partim ramis, partim nodulis insignitcr cminentibus, adco ut globulos fere pedunculatos referant, qrorum terni vel qraterni nodum constituunt, satis, ut opinor, distincta, yvam pro Varictate veuditem. 


\section{$S \begin{array}{llllllll}S & \mathrm{E} & \mathrm{C} & \mathrm{T} & \mathrm{I} & \mathrm{O} & \text { III. }\end{array}$}

\section{STEREOGONATA.}

Frons filiformis, articulata, solida.

\section{L O M E N T A R I A.}

Frons teres, subgelatinosa, articulato-contracta; ramis oppositis verticillatisqre.

\section{L. articulata.}

Fucus articulatzes Lightf. p. 959. - With. 4, p. 9o. - Ner. britt. Tab. 8. - Turn. Syn. p. 383. et Hist. Tab. xo6. - Engl. bot. T'ab, r574. - Sprengel in Berl. Mag. 1809. p. 190. T. 7. fig. 13.

- sericeus Var. Esper. Tab. \$2.

Gigartina articulata Lam. Thal. p. 49.

Ulva articulata Huds. p. $569 .-$ Dec. A. fr. 2, p. 7 .

Ceramium corulosum Roth. Cat. bot. 3, p. 125.

Fucus Moris. III. p. 646. S. r5. Tab. 8. fig. I4.

B) reptans, fronde tenuiori, reptante, Iubrica:

Conferva reptans Roll. Cat, bot. 1, p. 186. Tab. 3. fig. 3. Cat.-bot. 3, p. $251 .-$ Sprengel in Berl. Mag. 1809. p. 187. T.6. fig. 2 ?

Habitat pulchra hæc species ad rupes insularum Freroensium in summo refluxus limite hic et illic copiose. - $\beta$. in mari mediterraneo.

DESC. Radix callus parvus, nigricans, fibras repentes articulatas emittens.

Frondes maxime gregariæ, cæspitosæ, pollicem unum alternmve longæ, hasi attemuatæ, deinde in pennæ passerinæ crassitiem intumeseentcs, nbique per brevia intervalla insigniter contraeta, adeo ut articulatæ appareant; artieuli sie dícti cylindraeci, diametro duplo longiores, ovati vel moniliformes, solidi, massâqque gelatinosî̀ albescente repleti. Frondes a basi usquve ramosissimæ; rami fastigiati, dichotomi, plerumqve vertieillati, aliisque brevioribus eadem ratione dispositis obsessi; ad quamvis fere contractionem, geniculum mentientem, ramuli breves alterni ct oppositi vel vertieillati, nno alterove articulo constructi, emittuntur. Fruetus Semina nuda sparsa oblonga substantie frondis inmersa; Capsulæ eliam seeundum Cel. Turnerum in divcrsis individuis adsunt, ad summitates ranulorum sitæ, exiguæ, urccolati, con- 


\section{SEC'TIO TERTIA. LOMENTARIA \& CLADOSTEPHUS.}

gerien seminum minutissimorum includentes. Color ruber, ranulorum roseus. Substintia membranacea, lubrica, tcucra. Anmua. Aestate. Chartae laxe adhrerct.

OBS. Fructu nullo in excmplaribus ad insulas Faroenses lectis indagato, delincationcm Varietitis fructifere, qve mihi ad manus crat, subjungendam curavi, licet liac Varictas, in mari mediterranco lecta, inter nostras, quantum scio, non nisi peregrina et invectitia laberi debealt.

\section{CLAD O T T PHUS. *)}

Frons teres, articulata, ramosa, setis ad genicula verticillatis obsessa.

Tab. 30. 1. Cl.verlicillatus; fronde ramosa; setis ad genicula verticillatis, simplicibus bifurcisqve.

Cladosteplus verticillatus Ag. Syn. Introu. p. XXV.

Fucus hirsutus Esper Tab. 28. - Fl. norv. 2, p. 25. n. 408. - Lin. Mant. Tab. 1. fig. I. - verticillatus Wulf. crypt. n. I5. Tab. 1.

Conferva Myriophyllum Rosh. Cat. bor. 5, p. 312. Tab. 12, fig. b.

- verticillata Lightf. P. 984. - Huds. p. 653. - Wilh. 4, p. 133. - Dillw. Tab. 55 et Introd. n. 132. - Sclimidel descr. itin. p. 79. Tab. 2.

- Moris. LII. S. 15. Tab. 9. fig. 6. 7.

Ceramium verticillaum Decand. H. fr. 2, p. 39. - Ducluz. Essai p. 49.

Habitat ad littus Fionix septentrionale, saxis in profundo maris adnascens.

DESC. Radix callus exiguns, in exemplaribus majorilons discus cxpansus. Frons solitaria, subdichotoma, tres ad qrattor pollices longa, setim porcinam crassa, ubiguve æequalis, teres, solida, inferne nigricans, opaca, indivisa, deinde ad altitudincm pollicis supra basin ramosa, subdichotoma; rami remoti, vagi; nunc alterni, nunc oppositi; ramuli summi lneves, remotiusculi, noumunquàn secundi, ecteran frondem crassitic aquantes. Tota frous, inlinì partc nudâ exceptâ, setis ad genicula verticillatis obscssa; sctx, in qvovis geniculo dcnx-duodenx disposite, plernmere simplices, interdum tamen apice bifurex, articulis frondis obsoletis 2-3plo longiores, incurve, subliomomallix, apice attenuata, acutx. Articuli canlis ramorumque obsoleti, ob frondem opacan visu diffeiles, ob verticillos tamen cernibiles, breves, diametrun longitudine xepantes; articuli sctarum magis manifesti et sintiliter diametri longitudinc. Fructus nondum observatus. Color fuscus rel fusco-viridis.

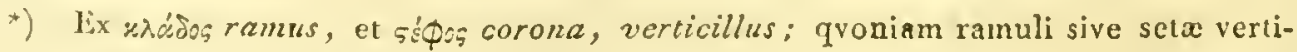
cillatim dispositx sumt. 
Substantia coriacea, lenta, tenax. Annua. Hycme legi. Chartæ non adharet.

OBS. Ad loc genus proterea pertinent Conferva verticillata, ceratophyllum, claveformis, spongiosa Ruth.; Fucus hirsutus Lin. - Fructus secundum Ccl. Agardlium Capsulx.

\section{SPHACELARIA. *)}

Frons teres, articulata, ramosa, disticha. Semina nuda apicibus sphacelatis demum dehiscentibus inclusa; raso Capsulx.

1. Sph. plunnosa; fronde intricata, ramosissima; ramis vagis; ramulis Tab. 30 . summis aggregatis pimatis; pimis oppositis elongatis approximatis patulis strictis; articulis dianetrum longitudine subeqvantibus.

Ceramium pennatum Fl. dan. Tab. 148ı. - Roth. Cat. bot. 3. p. 133? - Ag. Syn. p. 68. Fucus rudis Esper Tab. 27?

B) divaricala, caule breviore robusto; ramis divaricatis, densissimis, im- 'Tab. 30. bricatis.

Habitat ad littus Fioniae septentrionale, Fucis saxisque adnascens, sat frequens. Ad littus Frederitix Cimbrix; Prof. Hornemann. In mari Grocnlandico, Herb. Fabricii. - B. ante ostiun sinus Oxefiord Norvegize.

DESC. Radix callus exiguns. Caulis tcres, nigricans, nudus, opacus, solidus, seta poreinæ crassitie, ubiqre aqralis, flcxilis, qvatuor polliecs ct ultra longus, ramosissimus, intrieatus. Rami vagi, inferiores remoliuscuii, nunc alterni, nune oppositi, apicem versus densiores et sape oppositi ct subverticillati, cjusdem fore longitudinis et crassitiei ac caulis, adco ut tota frons subfastiogiati cradat; ramuli apicem versus approximati vel verticillati, pimnati; pinnæ disticỉæ, oppositx, elongatx, approxinatx, strictx, simplices, capillo humano tenuiores, ob teñuitatem vi fluctuun sape disrupte, ita dispositæ, ut qro magis ad ajicem appropinqvant, co breviores eradant, qvo fit, ut forma pinnarum qroad peripheriam sub lente pyranidalis interdum eonspiciatur, sxpius vero clongato-ovata vel lanccolita. Caulis ramiqve, lenti subjecti, tam obscuri, ut nulla genicula in conspectum veniant; in ramulis vero ct pinnis articuli, diametrum longitudiue subxqvantes, manifeste adsunt.

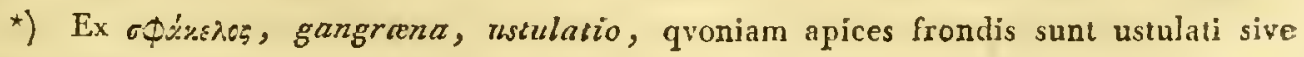
sphacelati. 
A fices pimarun splacelati, scmina nuda rouuda fusca includentes. Color caulis nigricans, opacus; ranulorum pinnarumqre fusco-olivaceus, interdun vilescens. Substantia cartilaginea, lenta, temax. Peremis. Hycme imprimis rejeritul. Charta nou adharet.

OBS. IJac et onnes hajus generis species iroratx ocyus reviviscunt, nec siccilatc mutantur. - Varietas globulos formit libere fluctuantes, in quibus rami, duplo crassiores, qram in $\approx$, sed brevioses, 1110 altcri imbricilim impusito, densissime sunt intricati; pimm oppositx, apice sxpe bifidx; fragrmenta ejusdem ad littora Fionensia clian reperiuntur.

Tab. 31. 2. Sph. disticha; fronde ramosissima; ramis distichis, triplicato-pimatis; ranulis pinnisqve alternis; articulis dianetrum longitudine subxequntibus. Conferva disticha Vahl.

\section{Habitat in mari Norvegico; Herb. Valulii.}

DESC. Radix parva, scutata. Frons setx porcinx ad basin crassitic, Jjpollicari et ultra longitudinc, in ramos inferne vagos diflusa. Rami infernc nudi, deinde bi-triplicato-pimati, distichi, pollicem circiter longi, et qroad peripheriam orati, approximati, alterni. Ramuli crecto-patcutes, alterni, stricti, acuminati; apices ramulorum sphacclati. Tota planta articulata; articuli diaunctrum longitudine xcrvantes, intus striis circiter duabus longitudinalihus notati. Genicula subtilia, opaca. Fructus Sumina nuda in apicibns ranulorum pimnarumqre sphacelatis. Color caulis fusco-olivaceus, ramulorum vircscens. Substantia coriacca, lenta. Chare laxe adharet.

Tab. 31. 3. Sph. scoparia; fronde ramosissima; ramis fasciculatis, subbipinnatis, confertis; pinnis brevibus, alternis, distichis, adpressis, acuminatis ; ar-. ticulis diametrum longitudine sıbreqvantibus.

Conferva scoparia Linn. Syst. nat. 2, p. 720 . Mohr isl. p. $25 \mathrm{o}_{\text {o }}$ - Hudls. P. 505. Lighte. p. 98r. - With. 4, p. 13r. - Dillw. Tab. 52. et Introd. n. 167.

- marina penuata Dillen. Tab. 4. lig. 2\%.

Ceramiun scoparium Rosh. Cat. bot. 3, p. 14t. - Dec. 月. fr. 2, p. 4r.

Fucus scoparia Bauls. pin. p. $3^{66 .}$

- radis Wulf. crypt. $n 3^{6 .}$

Muscus marinus vulgatissimus Lobelii obs. 6.18, 2, et icon, 2, p. 2.49, x.

- - secundus Dodon. pempt. p. 4730.

- $\quad$ - tenui capillo, Joh. Baul. Hist. 3, p. 800.

- - rubens Parkins, theatr. bor. p. 1=96. fig. 3. - Gerard, emac. p. 157r. fig. $2_{0}$ Habitat in rupibus maris Islandici; Molur, Hooker.

DESC. Radix callus exiguus. Frondes cx ead con basi plurimx, cxspitosx, tres ad gratuor pollices longa, teretes, Jasi sctâ porcinâ duplo crissiores, flexiles, in aqra fluctuantes, cxspitcm densum sub aqva formantes, a basi usqre 
ramosissime. Rami alterni, approximati, densissimi, unde plantæ facies penicilliformis. Ramuli fasciculati, densissini, subfastigiati, subbipiunati. Pinnæ alternæ, distichæ, lineam fere longæ, erecto-patentes vel adpressæ, strictx, acuminate, aliisqve minoribus nonnunqquam instructx. Apices ramulorum spluacelati. Color recentis fuseo-olivaceus vel virescens, exsiccatæ fuscus. Substantia cartilaginea, flexilis, exsiccata rigidiuscula. Chartæ non adlırct. Siccitate non nutatur.

4. Sph. pennata; fronde ramosissima, tenui; ranis alternis, subbipin- Tab. 31 . natis; pinnis distichis, alternis oppositisqve; articulis diametrum longitudine subæqvantibus.

Conferva pennata Dillw. Tab. 86. Et Introd. 11. 166. - W. dan. Tab. I486. fig. 2. Hurls. p. 6ó. - With. 4, p. 142. - Wahl. A. lapp. n. 979. - sprengel in Berl. Mág. 1809. p. 187. T. 6. f. I. (excl. syn).

- cirrhosa Rotb. Cat. bot. 3, p. 294 .

Ceramium cirrhosum Ag. Disp. p. 21. et Syr. p. 67.

B) gracilis, fronde minutissima, elongata, ramosa; pinnis horizontaliluus, remotiusculis, elongatis, plerumqve alternatim secundis.

Habitat in Fuco serrato, Gigartina plicata, Laminaria saccharina aliisqre ad littora Daniae vulgaris; ad littus Svinöer prope Lindesnæes Norvegiæe cum capsulis freqventibus legi. In mari Groenlandico; Herb. Fabricii. - ß. ad littus Hofmansgave Fionia.

DESC. Radix exigua, Fucis adnata. Frondes ex eadem basi plurimæ, cæspitosæe, duas lineas ad pollicem longæ, capillo humano tenuiores, ramosæ; rami basi densiores, alterni : ramuli distichi, subpinnati vel potius alternatim secundi; pinne diversa longitudinis, breviores longioribus imnixia, horizontales, remotiuseulx, nuue secundx, munc oppositx, et interdum ita dispositre, ut tres rel qratuor ad umm latus secundx ab aliis ad alterum latus totidem excipiantur, eademqve dispositio itcratâ vice apicen versus pluries repetatur. Apices ramulorun pinnarumqve in hac specic vix sphacelati occurrunt; capsule vero interdum adsuut ovatæ, breviter pedunculatx, medio fuscr, limbo pellucido cinctr, jimnis insidentes. Tota frons articulata; articuli diametro paulo longiores, longitudinaliter striati. Color fusco-olivaceus. Substantia tencra, tenas. Annua. Per totum annum reperitur.

OBS. Cxespites hujus Algx majores, quales Figura Floræ danicæ citata moustrat, in globulos, ovi columbini magnitudine, densissime congesti in sinu Othiniensi inter Algas vel in aqva libere natantes tempore æstivo liand raro observantul:

5. Sph.cospitula; fronde cæspitosa, minutissima, ramosa; ramulis sub- Tab. 32. simplicibus, alternis, elongatis, obtusis. 
Conferza olivacera Dillw. Introd. p. 57. Suppl. Tab. C?

Habitat ad stipitem Jaminariae digitatæe ad littus Freroense rarius. $\Lambda \mathrm{d}$ littus Svinöer Norvegiae in folio Laminaria saccharinic expanso.

1)ESC. Ratlis perexigna. Creppites parvi, lineam cirriter alti, agoregati. Fila ex caden batsi plurinta, caspitosa, erecta, abbreviati, capillo humano temriora, ranosa: rami altermi aliisqve minoribus subsecundis obsessi. Apices splacedati. 'Tota frous articulata: articuli diauctro sesqrilongiores rel candem longituline arqiantes, nullis striis, qrantum sidere licuit, notati. Color viresecns, interelum sordide Jutcus. Sulsstantia tenera. Aumat. Aestate.

6. Spth. reticulata; fronde intricata, minutissima, ranosa; ramis elongatis, apice cirrhorum instar polygonato-flexuosis; articulis diametro brevioribus.

Sphacelaria reticulata Fl. dan. Tab: ‘6oo.

Habitat in Gigartina plicata aliisqre 'Thalassiophytis ad littus Hofmansgave Fionize.

DESC. Caspes nunutus, tres qratuorve lineas longus, implicatus. Fila capillo lumano tcnuiora, scmipollicari, si extriccntur, longitudine, ramose; rami remoti, apice circhorum iustar in polygonos reflexi, pimis brerissimis ex singulis polygonorum angulis externis horizontaliter excuntibus. Apiees ramulorum pimarumquesepe splacediti; pretereacapsulas ovatas pedunculatiasque ad latera ramorum hic illic dispositas oloservari. Tota planta articulata; articuli cliametro breviores, medio opaci; grenicula tenuissima, contracta. Color olivaccus. Substantia tenera. Amna. Hyeme. Clarta non adlierct.

OBS. Forsan modo Varietas Spluacelarice pennatee; quemadmodnm cnim GigarLince purpurascens, si ab aliis 'Thalassiophytis plus justo coasetaum, iisclem tenaciter inhærescens apicibus cirrhosis instructa apparet, sic idem in $S p h a-$ relariom pennalcum cadcre posse opinamnr, a Trât tamen partim apicibus sphacclatis . partim articulis brevioribus nonnihil differre videtur. Gramula lunulata, qve in Delineatione citata frondi hujus speciei agglurinata sistumur, pro particulis heterogeneis, forsan inimalculis mundi invisibilis testaceis, habenda sunt.

'Tab. 32. 7. Sph. spinulosa; fronde ramosissima, implicata, diffusa; ramulis spinulosis, geminis, horizontaliter patulis; articulis diametrum longitudine eeqrantibus.

Iabitat in Gigartina plicata aliisqve algis ad littus Fionixe septentrionalc. Ad ostium sinns Oxcliord Norvegie. 
DESC. Radix pusilla, Thalassiophytis majoribus agglutinata. Frons solitaria, setâ porcinâ tenuior, pollicem circiter longa, a basi usque ramosissima. Rami diffusi, luc illuc divergentes, curvati, patuli; ranuli gemini, raro simplices vel terni, ommino horizontalcs, interdun reflcxi, indivisi, breves, acuminati. Apices summi sphacelati. Fructus Semina nuda fusca in summis ramulorum apicibus sphacelatis nidulantia. Tota alga articulata; articuli diametri longitudine vel pranlo breviores, striis brevibus longitudinalibus densissime compactis, fascian transversalem fuscam referentibus, notati. Genicula tenuissima. Color fusco-olivaceus, exsiccatæ nigricans. Substantia cartilaginea, rigidinscula. Annua. Aestate et hyeme. Chartæ non adhæret.

OBS. Pulchella lıxc species, microscopio subjccta, Prunum spinosam omnino refert. - Fascia fusca, qva sub lente parum augente geniculum nonnunqvan mentiens singulos lujns speciei, aliarumqve ad hoc genus pertinentium, articulos ambit, si lenti maxime augenti subjicitur, e striis plus minus elongatis, interdum in unum corpusculum coalitis, constare cernitur. Striæ istæ longitudinales sine dubio nil aliud sunt, qvam semina nondum matura, qver, cum senina in apice nidulantia ad maturitatem pervenerint, et per apicem delisccntem clapsa fucriut, in corum locum paulatin succedunt, et, ipsis maturis, iterum iterunqqe ab aliis eadem ratione excipiuntur. Neqve hac opinio, qram pluribus olsservationibus fultam in medium profero, temeraria faeile appellanda, neqve ob capsulas, in nonuullis hujus generis speciebus observatas, omnino rejicienda. In Sphacelaria pennata capsulas detexit Borrerus (cfr. Dillw. Introd. p. 8\%), Agardhius item et ego; in Sphacelaria reticulata qroqve adsunt; illæ vero capsulæ non impediunt, qvo minus opjnio, qram protuli, persistat; fructus enim duplex, qvi iu multis Thalassiopliytis obtinet, etiam in lıoc genere assumi potest.

8. Sph. scoparioides; fronde alternatim bipinnata, stricta, erecta; ra- Tab. 32. mis ramulisqve patenti-divergentibus; articulis diametrum longitudme æeqvantibus.

\section{Habitat loco præcedentis.}

DESC. Caulis setam porcinam crassus, semipollicari ad pollicarem longitudine, alternatim duplicato-pinnatus. Rami divaricati, fere horizontales, alterni, rigidi, aliisqve minoribus obsessi; ramuli patuli, alterni, breves, acumiuati. Fructus Semina nuda, rotunda, fusca, limbo pellucido sæpe cincta, apicibus ramulorum sphacelatis immersa. Tota frons articulata; articuli diametri longitudine, striis duabus longitudinalibus notati. Color fusco-olivaceus, exsiccatæ fuscus. Substantia tenera, rigidiuscula. Annua. Hyeme. Chartæ non adliæret.

OBS. Ad hoc genus etiam pertinet Conferta fusca IIuds. p. 602. - With. 4, p. 141. - Dillw. Tab. 95. ct Introd. n. 151. 


\section{H U T C H I N S I A. *)}

Frons teres, articulata, ramosa, rosea; articuli striis vil tubulis pluribus longitadinalibus notali. Frucıs Capsulæe externie vel Tubercula apicibus ramulorum innata.

Tab. 33.

1. II. fasligiuta; fronde dichotomo-ramosissima, fasligiata; articulis diamctro brevioribus, centro punclatis; capsulis ad summos ramulos sessilibus, oratis.

Hulchinsia fastigiata $\Lambda \mathrm{g}$. Syn. p. 53 .

Conferva polymorpha Linn. Syst. nat. 2, p. 721. - Fl. dan. Tab. 305. - Molır isl. p. 250. - Dillen Tab. 6. lig. 35. - Ellis in Pliilos. T'ransact. 5\%, P. 426. TaL. 18. fig. a. A. B. B. - Huds. P. 599. - Lightl. p. 989. - With. 4, p. 138 - Dillw. Tab. 4 . - Engl. bot. Tab. 17G9- Wahl. H. lapp. 1. 976.

- omissa Fl. uorv. 2, p. 116. n. 928. - Strüm Sündm. 1, p. 82.

Ceramiun fastigiatum Roh. Fl. Germ. 5, p. 463. Cat. bot. 3, p. 157. - Sclium. Enum. 2, 1. $110 .-$ - Ag. Disp. p. 20.

- polymorplum Dec. A. fr. 2, P. 45.

Fucus lanosus Lị. Syst. nat. 2, p. 718. - Huds. p. 590. - Will. 4, p. 1:6. - Künig, Zoega, Mohr, Hooker.

- scorpioides Esper Tab. 32.

Muscus coralloides etc. Palmitcs pelagica nigra Pluk. plyt. Tab. 47. fig. 10.

- marinus crispus Barrel. ic. 'Tab. 130x.

- capillaceus multifidus nigger Daul. Pin. p. 363.

Habitat in Halidry nodosa ad littus Freroense copiose; raro Fuco vesicnloso et saxis adnascens. Ad littus Srinöer Norregix. In mari Islandico et Groenlandico.

DESC. Radix callus exiguus. Frondes ex radcm basi plurimx, crspitose, duos tresve pollices longx, sclam porcinam crassa, terctes, solidx, per dichotomias pluries repetitas divise, fastigiatre; ramuli ultimi brevissimi, intcrdum furcati, attonnati. Articuli dianctro dimidio beviores vel candem seqrantes, suriis longitudiualibus quinis et ultra notati; post exsiccationem punctum nigrum in medio cnjusqve articuli in conspectum venit, grod tamen in recentibus exemplaribus scmper abest. Fructus Capsulæ ad latcra ramulorum superiorum sessiles, ovatx, acutx, opacx; in diversis indlividuis ranuli summi intumescentes globulos incluame fuscos limbo jellncirln cinctos. Color atrorubr:scens, adultioris nigresccus, cxsiccatic atcr. Substantia cartilaginea. Charte non adheret.

OBS. Ob froctum rnplicem, qui etiam in Hutchinsia violacen aliisqve hujus gcncris specicbus obscrvatur, Cel. Rolhius, precuntibus Ellisio ct Lightfoo-

*) In honorem Dominx Hulcluins, indefessa Álgarum indagatricis, ad sinum Ban. try Hibernicum olim habitantis, jan vero anno 181 , vita defuncta, ltoc genus Cel. Agardhins constituit. 
tio, de masculis individuis pariter atque frmineis loqvitur; vix recte; cfr. 4ra infra snb Hutch. violacea annotari. - Globnli fusci, sunmis ramulis simplici seric inuati, vix pro suminibus, sed potius pro tuberculis sen congeric scminum, halondi sunt; diffracti cuim in minores particnlas dissolvnntur, iis similes, qui in Gigartina subfusca obserrantur. - Præterca ut co melius perspiciatur, qvo jure Confervam omissam Fl, norv. ad hanc spccicm retulerim, conferantur vcrba Cel. Strömï in Descr. Söndm. 1, p. 82. ad Conferram n. 2, qram Rev. Gunuerus ad suam specicm, ut synonymam, citat. Idcm etiam valet de Conferva seposita Fl. norv., qram ad Ceranium diaplanum, de qro infra, codem jure allegavi.

2. H. Brodicei; fronde ramosissina; ramis primariis inarticulatis; ra- Tab. 33. mulis sparsis, patentibus, fasciculatis, penicillatis, articnlatis; articulis diametro sesqvilongioribus; capsulis oratis, subscssilibus.

Conferva Brodicei Dillw. Tab. ioz. et Introd. n. 153.

Ceramium Brodicci Ag. Disp. p. 20.

- granulatum Ducluzeau Essai p. 72.

Mabitat ad littora Færoensia. Ad littus Svinöer prope Lindesnæes Norvegiæ hic illic copiose; ante ostium sinus Oxefiord Norvegia.

DESC. Radix callus parrus, discoidcus. Frondes ex una basi plnres, cxspitosæ, pedem unum circitcr longæ, basi fili emporetici tentioris' crassitie, apiccm versns altentatæ, capillares, flcruosæ, ramosissimæ. Rami sparsi, patuli, alterni; ramuli breves, setacci, in penicillum fascicnlatum aggregati. Articuli in ramis primariis nulli, ramuli vero articulati; articuli breves, diametrum longitudine æquantes vel eâdem sesqvilongiores, longitudinalitur striati. Fructus Capsulæ ad summos ramulos alternatim sessiles, ovatæ, bres itcr pedunculatæ, tria qratuorve scmina includentes. Color ruber. Substantia cartilaginea, tenera. Chartæ laxe adhæret.

OBS. Hæc alga, qræ inter majores hnjus generis ponenda cst, tuberculis globosis solitariis, in apicibus ramulorum innatis, ctiam instructa reperitur.

3. H. nigrescens; fronde inferne muda, apicem versus ramosissina; ra- Tab. 33. mulis fasciculatis, adpressis; articulis diamctrum longitudine reqvantibus.

Conferva nigrescens Huds. p. 602? - With. 4, p. 541 ?

Habitat ad insulas Færoenses, et ad littus Svinöer Norvegix, saxis adnata.

DESC. Radix callus majusculus, discoideus, niger. Frondes ex cadem basi plurimæ, cæspitosæ, majores minoribus inmixtæ, palmam ad spithamam longa, pennam passerinam inferne crass $x$, apicem versns altenual , teretes, solidæ, ramosissimæ. Rani inferiorcs remoli, breves, spinæeromes, deinde 
longiores, erceti; ramuli brcres, adpressi, fasciculati. Rami primarii obsolete articulati, articulis dianetro brevioribus, 8-10 striatis, striis nou, nisi rani isti premantur, conspicuis; articuli ramulorum diametrum longitudine a'quantes, 3-5 striati, ultimi breviores. Color atrorubescens, exsiccatæ niger. Substantia cartilaginca, lenta, exsiccatic rigidiuscula. Autumno. Chartæe non adhæret.

4. H. alrorubescens; fronde ramosissima; fllo primario inarticulato ; ramulis multifidis, abbreviatis, subpenicillatis; articulis diametrum longitudine subeqrantibus.

Hutchinsia atrormbescens Ag. Syn. p. 58.

Conferva atrorubescens Dillw. Tab. 70. - Wahl. Я. lapp. n. 977.

- nigra Hudsnir P. 595. - Wilh. 4. p. 13r. - Dillw. lntrad. p. 86, n. 162.

Halsitat ad littora Faerocusia et Norregica.

DESC. Radix enigna. Fromles aggregatx, scmipedales, setam porcinam erassæ, apicen versus altcunate. infernc inarticulatx, ranosæ; rani sparsi, clongati; ramuli patentes, approximati, breves, in penicillum difusum fasciculatim congesti. Articuli ramulorum dianetrum longitudine arqvantes. Frnetus Capsula ovata, beviter pedunculatx; preterea Tuberenla splrarica nigrescentia, ramulis summis simplici seric innata. Color rubesccus. Substantia tenera, flaccida. Charte bene adharet.

Táb. 34. 5. II. urceolata; fronde ramosissina, elongata, diffusa; ranulis brevibus, patentibus, sqvarrosis; articulis caulis longis, ramulorum brevibus; capsulis urceolatis, subpedunculatis.

Conferva urcealata Dillw. Intrad. p. 82. Tab. G.

Habitat ad littora Feroensia copiose, Fucis saxisque adnata.

DESC. Radir callus exiguns, nigricans. Frondes aggregatie, perlales et ultra, setam porcinam crassa, ubique aquales, elongate, ramosissimx; rani altcrni, longinsenli, intricati; ramuli breres, patcutes, et in exempliribus fructiferis sqvarrosi. Articuli canlis inferioris longi, ranulorum breviores, diametro 2plo longiores, vel eandem reqvantes, striis Jongiturlinalibus binis notati: illa vero strix in recentibus specininibus cruciatim vel rlomberdaliter disposite sunt. Fructus Capsula breviter pedunculata, ovate, apice attenuate; in statu vero siccato sporangia Splachni urceolati munlantes. Color ruber, exsiceate intensior. Substantia lenta, tencra. Charte non adheret.

Tab. 34. 6. II. byssoides; fronde decomposito-pimnata, ramosissina; ramis ramulisque alternis, patulis, elongatis, pinnatis ; pimis brevibus, approximatis, apice dichotomis, nultifidis; articulis diametro sesqvilongioribus. 
Hutchinsia byssoides Ag. Syn. p. 60.

Fucus byssoides Gooden. et Woodw. in Linn. Transact, 3, p. 229.

Conferva by ssoides Engl. bot. Tab. 517. - Dillw. Tab. 58.

Ceramium molle Roth. Cat. bol. 5, p. 138.

- byssoides Ducluz. Essai p. 66. - Decand. f. fr. 2, p. 40. - Ag. Disp. p. 20.

Habitat in Fuco vesiculoso aliisqre parasitice ante ostium sinus. Oxefiord Norvegize. - Ad littus Hofmansgave Fioniæ, IIofmann Bang.

DESC. Radix parva, seutata. Frons plerumqve solitaria, inferne inartieulata, 3-4 pollices longa, setam eqvinam infra crassa, a basi nsqve ramosissima, flaecida, debilis, apieen versus attenuata. Rami alterni, patuli, elongati, inferne remoti, aliisqve eadem ratione dispositis obsessi; ramuli approximati, horizontaliter patuli, inferiores longiores, deinde apicem versus scusiu breviores, pimisqve brevissimis, c qvovis geniculo alternatim exemtibus. et apice dichotomo-multifidis obsessi. Rami dichotomiarum tenuissimi, longins geniculati, elongati, basi patentes, incurvi, sursum spectantes. Artienli canlis diametro 2-3plo longiores, ramulorum eandem subrqvantes; in statı viro pellueidi, dilute rosei, stria una alterave longiudinali crueiatim pereursi; plantâ vero per aliqvot dies in aqua dulci sine exsieeatione servatâ vel exsiecatầ, artieuli opaeiores evadunt, et strix binæ ternxve luculentius conspiciuntur. Fructus Capsula externa ovatæ ad summos ramulos breviter perluneulate, vel Tubereula interna, fusca, pinnis tunc intumeseentibus infra dichotomias tcnuiores immersa. Color recentis rosens, exsieeatæ fusco-ruber. Substantia tenera, flaccida. Anmua. Autumno et Hyeme fert fructum. Charta arcte arhæret.

7. H. implicata; fronde ramosissima, diffusa, implicata; ramis ramu- Tab. 34. lisqve vagis, divaricatis, æqvalibus, ultimis subsecundis; articulis diametro triplo longioribus.

Habitat in sinu Othiniensi; ad littus Abelöe prope Fioniam, copiose; Hofmann Bang.

DESC. Radix parva. scutata, saxis aduascens. Frons solitaria. ramosissima, diffusa, setx equina crassitie, ubique fere acqualis, elongata, cxs]item formans maxime intricatum, debilem, flaccidum, palinari et ultra extensione. Rami vagi, ut plurimum seemdi, divarieati, reflexi, curvati, aliisqve codem modo dispositis obsessi; ramuli breves, minores majoribus immixti, scemdi vel alternatim secundi, divaricati vel horizontaliter patnli, apieem versus paululum attenuati, apice obtusi. Articnli rami primarii diametro triplo longiores, ramulorum 2plo longiores vel subeqvantes, 2-3 striati. Fruetus noudum observatus. Color fuseo-ruber, exsiceate nigrcscens. Substantia tenera, flaccida. Annua. Hyeme. Chartin non adharet. 
Tab. 35. S. IS. viulccea; fronde ramosissima; ramnlis capillaribus, subfasciculatis, virgatis; articulis diametro sesqvilungioribus; capsulis oratis, subsessilibus.

Hutchinsia violacea Ag. Syn. p. 5í

Ceraminn violaceum Rosh. li. Germ. 5. p. 462. Cat. bot, 1, p. 150. Tab. S. fig. 2. et Car. bot. 3, 1. 150, - Ag. Disp. 1. 20. - Schum. enum. 2, p. 110. - Jürg. Alg. Dec. $3, \mathbf{n}, 4$.

- urccolatum Jürg. Alg. Dec. 4. n. 6. (quoad specimina siccata).

- Sucoides Decand. A. fr. 2, p. 44.

Conferva fucoides Huds. P. Goz. - With. 4, p. 14r. - Dillw. Tab. 75. et Introd, n. 151. H)drobyssus Hetb. Ehrh. (juxta specimina communicata).

Miuscus kyll. Virid. p. 106 . n. 6.

B) allochroa, frònde tenuiori, capillacea, acquali, inferne fusco-rubra; superne rosea.

Ceramium violaceum $\gamma$. Roth. Cat. bot. 3 , p. 152 .

Hutchinsia violacea $\beta$. Ag. Syn. P. 55.

r) squarrosa, fronde aqrali, ramulis brevibus patulis sqvarrosis.

Hutclinsia violacea $\gamma$. squarrosa Ag. Syn. p. 55 .

Habitat ad littora Danize freqrens. -- $\beta$. et $\gamma$. in sinu Othiniensi.

DESC. Radix parra, scutata. Froudes $\mathrm{ex}$ cadcm basi plemuque bine rel ternæ, palmam ad spithaman longa, hasi seta porcinat plus minus crassiores, ct sursum magis magisq̣ve altenuata, debiles, flaccide. Rami altoni infuriores remotiores, superiores densi, apicem versus pluries dichotomi, ramosissimi, tcmuissini. Ramuli alterni, densi, virgati. Articuli varie longitudinis, nunc dianctrun aqvantes, nunc eadem 2-4plo longiores, striis longitudinalibus articulormm inferiormu copiosis, superiormu binis vel ternis. Fractus Capsula solitarie, ad genicula ramulorum exeuntes, brevi pedunculo fultie, stanulis nonnullis oratis fuscis massì mucosît immixlis replele; ctiam 'Tubcrcula vel Globuli fusci apicibus ramulornm innati. Color fusco-ruber, violaccus. Substantia subcartilaginca, tencra, lenta. Annua. Tempore rerniali et astivo fert fructum. Charta adhrert.

OBS. Globuli isti, gvi proprimis tempore rernali summis ramulis inde intumescentibus innati sunt, si difiringuntur, congcriem granulorum minutissimorum includere sub lentc cernuntur; qrare pro tuberculis immersis haberi possumt; occurrunt cliam, 11 jam monni, in Hutchinsia fastigiala, Brodicui, atrorubescente ct byssoide; numquam vero, qrantum scio, in iisclem speciminibus, in qvihns capsule exturue adsunt, sed semper in diversis individuis. Eadem tubercula sine dubio jam observarit Cel. Rothius (cfr. Cat. bot. 3, p. 106. $1.51 .15 \%$ ) qri ca vesiculas muncupat, crelitgre, specimina tali ratione fructifura esse mascula, conceptacula spermatica producentia; de laac autcm opinione aclluc sub judice lis est. Ad littus Torlsek Sellandix ct ad littora 
Norvegix specimina inveni, qræ ad ipsos ramulorum apices corpuscula gerebant oblonga, aggregata, snbliyalina, singula pedunculo tenuissimo longiori suffulta; hæc vero corpuscula (vide Tab. 3.5. A. 3.), qræ etiam in apicibus Hutch. byssoidtis copiose vidi, ad regnum animale sinc dubio pertinentia, hmjus loci non esse videntur; atqve, ni multun fallor, una eademqve sunt, atquve illa, qva Cel. Ellisius in apicibus Conferva polymorpliee (Hutchinsice fastigiata) detexit, et deinde in Phil. Transact. 176\%. Vol. 5\% p. 426. Tab. 18. $b . B$. delineanda curavit, qvaqre codem loco ut fructum Conferve polymorphoe masculum proposuit; hac certe corpuscula in nililo alio a nostris discreparc videntur, qram ut Ellisio fucrint sessilia; scd vidi etian nonuulla. qra ob pedunculum brevissimun subsessilia, et ubi in magna copia aderant omnino sessilia apparchant. - Cetcrum apices ramulorum fibrillis longioribus, ad modum Gigartince subfusca et seqventis specici, obsessos sæpe reperiri, satis notum est.

9. H. fibrillosa; fronde ramosissima; ramis ramulisqve sparsis, ultimis brevibus, multifidis, apicibus protensis, fibrillosis; articulis inferioribus longis, summis brevibus.

Hutchinsia fibrillosa Ag. Syn. p. 57.

Conforva fubritlosa Dillw. Introd. p. 86. Suppl. Tab. G. - Fl. dan. Tab. 5545.

Habitat ad littus Hofmansgave Fionix, ubi llanc speciem legit Prof. Hor-: nemann.

DESC. Radix parva, scutata. Frondes aggregatx, 3-4 pollices longæ, basi setam eqvinam crassæ, sursum attenuatæ, capillares, ramosissimx. Rami ramulique sparsi, diffusi, ultimi hreves, fibrillosi. Fibrillæ in penicillum fasciculatx, dichotomx, remotius geniculatx. Articuli caulis diamctro 4-6plo longiores, ramulorum scsquilougiores, striati. Capsula orata, erectæ, brcvitcr pedunculate. Color ruber. Sulstantia snbeartilaginea, tencra. Annua. Aestatc. Chartæ adhæret.

OBS. An distincta species? Copiose certe ad littus Hofmansgave reperitur; at si habitum ninorcm, diffusum, irregulariter ramosum, atgve apices fibrillosos excipias, in céteris ad pracedenten adco accedit, ut vix ulla nota cssentialis inde crui possi,; et apices fibrillosi, pluribus hujus generis speciehus aliisqve Algis, ut jam antea passim mouui, communes, differentiam specificam sufficienten suppeditare neqveunt.

10. H. lepadicola; fronde repente, radicante, ramosa; ramis remotiu- Tab. 35 . sculis, divaricatis; articulis diametrum longitudine aqvantibus. 


\section{Habitat ad insulas Froenses, testam Lepadis balanoidis perreptans.}

DESC: Frons repens, lije illic radicans af fla raticantia inartieulata, ad basin hulbosa rel in breres lacinias fissa, conpuri. cui inntscuntur, agghulinata cmitlens, setan poreinam crassa polliecmege longa, actralis, vage ramosa; rami

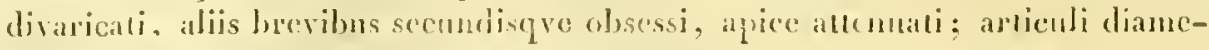
uri longituline, stria nua alterase notali. Fructus non observatus. Color ruber. Substantia tenerat. Chartæ non adlaerct.

Tab. 35. 11. IT. strictcides; fronde ramosissima; filo primario intrticulato; ramis altcrnis, patulis; ramulis virgatis, dichotomis, capillaceis; articulis ramulormm dianctro 2 plo longioribus.

\section{Habitat in profundo ostii sinus Othiniensis, Hofmann Bang.}

DESC. Radis callus parkus, nigrions. Fromdes aggregatre, spithamam ad pedent longa, seta poreina duplo crassiores. icretes, solida, a quales, ranosac: lami inferiores clongati, remoti, nudi, aliistre lnerioribus, alıernis, acqualibus obsessi; superiores al laterat el apices parum attentatos emiltentes vamulos seu fila capillaria, dichotumo-ramosa, capillo lumano pramm crassiora, faseiculation congesta. stricta, articulata: arliculi caulis ramorumqre unlli vel obsoleti, ramulurum dianuetro 2-3plo longiores, in statu recenti eruciatim. in exsiceato longitulinalites striati: strix hine rel ternic. Fructus Capsulic copiose, ex geniculis munulum superiornm cxemutes, solitarix, ovate, sublyyalina, brevissme perlunculate, granula 4 ad 6 ohlonga fusca continentes. Color caulis fusco-ruber, ramulormun dilutc roscus. Substantia canlis cartilaginca, ramulorum mesnbranacea, tenesil. Aestatc. Cilartie adJaret.

12. II. badia; fronde ramosissima, stricta; ramis elongatis, aqvalibus, erectis; ramulis summis abbreviatis, simplicibus, secundis; articulis diametro sub 3 plo longioribus.

Hutchinsia liadia Ag. Syn. p. 56 .

Conferva badia Dilliv. Introd. n. IGr. Suppl. Tab. G.

Habitat ad insulas Ferocnses parum infra summum reflexus limitem rupibus adnata; ad littus Svinöer prope Lindesnaes Norrogiax.

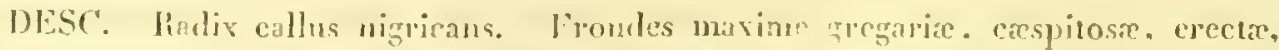

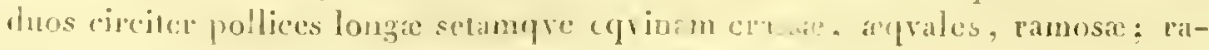

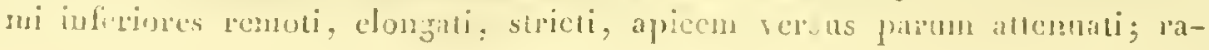


muli superiores abbreviati, subsimplices, approximati, plerunqve sccunrli. Articuli longitudine variant, ad hasin breves, dcin diametro 3-4plo longiores, et iterum in apicibus ramulorum breviores, duabus vel uribus striis longitudiualibus uotati; in statu vero recenti hæ striæ sæpe cruciatim dispositx suut. Fructus latet. Color nigro-rubescens vel atropurpurens. Substantia tencra. Aestate. Charta non bene adliarct.

13. II. stricta; fronde ramosissima, stricta; ramis inferne remotis, su- Tab. 36 . perne approxinatis, fasciculatis, fastigiatis, simplicibus; articulis diametro qvintuplo longioribus.

Hutchinsia stricta Ag. Syn. p. 56.

Ccramium strictum Roth. Cat. bot. 3, p. 130.

Conferva stricta Dillw. Tab. 40. - Wabl. fl. lapp. n. 978.

Habitat in profundo ostii sinus Othiniensis, saxis et stipitibus Fuci vesiculosi adnascens, copiose; ad littus maris Codani rarius. - Ad insulas Færocnses haud freqrens.

DESC. Radix exigua, nigricans. Frondes ex eadem basi plurcs, setam eqvinam crassa, inferiores plerumqre cespitosæ, atrorubentes, repentes, (radicibus ad noodum Callithamnii repentis, ni fallor, interdum instructa), breves, 2 ad 3 lineas longa, obtusx, articulis brevibus, diametro sesquilongioribus, striatis, inter quas alix exsurgunt longiores, duos tresve pollices longa, debiles, flaccide, ramosx, pallide rosce, stricte. Rami alterni, elongati, inferiores remoti, inferne simplices, superne ramosi, rel si velis, dichotomi, superiores cum ramulis densiores. Articuli diametro 5plo longiores, in apicibus ramulorum breviores, striis binis vel ternis cruciatim longitudinalibus pulcherrime picti. Fructus rarissimus; Capsulam semel vidi ovatam sessilem limbo pellucido cinctam ad latus rami supcrioris sitam. Color caspitis rubens, filorum singulorum dilute rosens. Substantia membranacea, tenera. Verc el xstate. Chartæ allowet.

OBS. Substantia tenuiori et colore dilutiori primo intuitu a precedente clistingvitur. - Dissepimenta sive genicula hujus specici, (qvemadnodum etiam Hutchinsice urceolatee, by'ssoidis, strictnidis ct badia, de quibus jam anteá suis locis monui), intus unedio csse perforata, adco ut striis lougitudinalibus, (qras tubulos cylindricos dicit Dillwynius, et canales Agardhius), liber por ca transitus pateat, id cruciata vel rhomboidalis striarnm dispositio, gra in articulum viciuum cadem ratione prolongatur, indigitare videtur. Siccitate non mutatur, nisi qvod strix, qvæ in reccnti teuniores, incurva ct cruciatre apparent, in siccata rectx ct luculentieres in couspectum reniunt. - Fruc- 
tum juxta cxemplar Farocuse, aliqvo teupore siceatum, arposui; in nonmullis certe individuis fiuncusilus coppuscula vidi subrounda nigricantia, pedunculo tennj incurvo suflulta, nume crecta, nunc pendula, rano primario

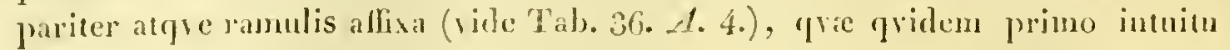

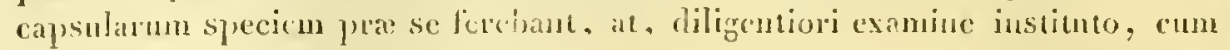

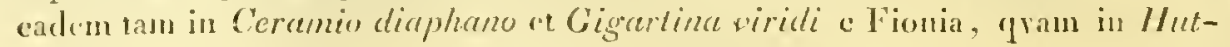
chinsia ureolata c Faroa virlissen, pro heterogencis merito halui; sunt ista corpuscula intus cava, membraù temui, teuaci, opacâ constructit, distenta et sine dubio aëre repleta; crepritant cuim sub pressionc: forsan habitaculum cujustan animaleuli. - Deniqra apices ramulormm hujus specici nonumIvan, at raro, fibrillosi.

Tab. 36. 14. II. Möstingii; fronde ramosissima, rigidiuscula, alternatim bipinnata, disticlı; ramis ramulisqve densis, patulis, strictis, alternis; articulis diametrum longitudine aequantibus.

Habitat clegans haec species ad littus Qvivig Strömöe et ad littus Mölen prope Eide Österöe Tåoa in infino refluxus linite, haud freqvens.

DESC. Radjx exigua, nigricans, pupiluns aggluminata. Froudes gregarix, erectx, vix pollicem louga, setan eqvium ad hasin erassa, sensim attouatie, alternatin bipinnate, distiche; rami singuli ex qrovis artjeulo altermatim exemntes, patuli, stricti, inferiores longiores, apjecm versus breviores, aliisqve minoribus cadem ratione dispositis obsessi; ramuli brevissini, stricti, altcrni, patuli, attennati. Articuli dianetro breviores rel eanden longitudine requantes, in recenti striis cruciatis, in siccatî longitudinalibus, binis ternisve crassioribus pulchre pieti. Fructus latet. Color saturate roseus. Substautia cartilaginea, tencra, rigidiuscula. Acstate. Charta imprimis ob habitum distichum bene adheret.

OBS. Viro excellentissimo JOANNT SIECISMUNDO a MÖSTING, augustissimo Regi a consiliis intimis status, celsissimi ordinis Elephantini cqviti aurato, Dannebrogici magna eruce insignito \&c. \&c. de re litteraria optime merito, cuj ctiam hujns opreris cditio imprimis debctur, hane specicm, summâ, чva par est, revereutiâ dudicayi. 


\section{C E R A M I U M. *)}

Frons teres, articulata, dichotomo-ramosa, rosea; articuli reticulato-venosi vel subdiaphani.

Fructus Capsulæ ramulis brevibus involucratæ.

1. C. elongatum; fronde ramosissima; ramis ramulisque setaceis, elon- Tab. 66 gatis, strictis; articulis diametro dimidio brevioribus, reticulato-venosis.

D. 1 .

Ceranium elongatum Roth. Cat. bot, 3, p. 128. - Ag. Disp. p. 19. - Dec. Я. fr. 2, p. 44. Conferva elongata Huds. p. 599. - With. 4, p. 15i. - Dillw. Tab. 35. et Suppl. Tab. G. - Web. et Mohr Grossbr. Conf. Tab. 33. - Jürg. Alg. Dec. 5. n. 5 .

Hutchinsia elongata Ağ. Syn. p. 54.

Habitat ad littus Fionia septentrionale, saxis, Fucis conchisqve adnascens.

DESC. Rarlix rallus parrus, expansus. Frons plerumqve solitaria, semipedali ad pedalcn longiiudine, setâ porcinâ duplo crassior, tcres, solida, a basi ramosa, subdichotoma; rami altcrni, inferiores remotiores et elongati, supcriores scusim magis magisqre approximati, attennati, setacei, stricti, elongati. Articuli diametro 2plo breviores, subpcllucidi. reticulato-venosi, interdum in ramulis striati. Genicula opaca, venis anastomosantibus notata. Frucus Capsula subrotundx, raccmosæ, vel solitarix ad latera ramulorum summorum sessilcs. Color ruber, subopacns. Substantia cartilaginca, tenacior. Annua. Vere et æstate. Charte non adhæret.

OBS. Articuli ramulorum summorum interdum dianetrum Iongitudíne æqvantes, et longitudinaliter striati apparent, cetcra frondis parte nililomiuns reticulato-venosa. - Fructum, qvem in hac specie nondum vidi, ex observationibus Cell. Dillwynii et Rothii adposui. Dillwynius praterea ramulos obscrvavit racemosos, e geniculis ramorum majorum exeuntes, nunc oppositos, nunc alternos, duas circiter lineas longos, qvorum in apicibus, (ad molum Gigartince sulf(uscae) Tubcrcula, vel, si mavis, Semina subrotunda fusca immersa nidulabantur. Ipse eqvidem tempore vernali ad apices ramulorum observavi corpuscula, capsulas sessiles referentia, filis tenuibus et qridem inarticulatis plerumqve involucrata, nodoqve oculo vix ceruibilia, (cfr. Tab. 66. D. 1). Utrum vero hæ veræ fucrint capsulæ, justa ambigitur; lcviter enim, qvantum videre licuit, frondi adhrebant, et diffracta e fibris concentricis, simplicibus, rectis, moniliformibus, opacis, sub lcnte maximc augente constare ccr-

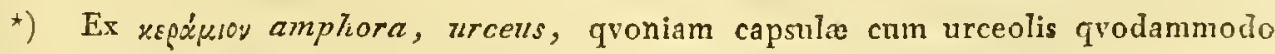
comparari possunt; vel ex xépeś cornu, đquonian substantia frondis est crassiuscula, subcornea vẹl cartilagiuea. 
nchantur; qrare cadcm pro parasitis labens, aul scnus Linckice sub nomine Linckice ceramicolce rolegavi.

'Tab. 36. 2. C. brachygonium; fronde diffusa, vage ramosa; ramis remotiusculis, patulis; ramulis subsimplicibus, strictis, attcnuatis; articulis diametro dinidio brerioribus, reticulato-venosis; verrucis uvaformibus, hemisphacricis, sessilibus pedunculatisqve.

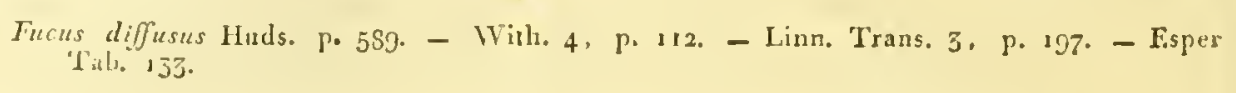

Habitat ad littus Ilofmansgave Fionice saxis adnascens, sat freqventer.

DESC. Radix callus majusculus, discoideus, Jiggricans. Frons solitaria, solidla, cres, palnari ad spithanaam longitudine, basi pennam passerinam crassa, rqvalis, sursum scusim paululum attenuata. Caulis basi flevnosus, inferne ramosus. Liumi vagi, remotiusculi, diflusi, divarieati, caulis fere crassiludine, varic dispositi; ramuli simplices ed apicen versus divaricatim dichotomi, sspe ahterni cl secundi, crecti, strieti, attenuati, sulunlati. Articuli diamctro sua dimidio hrevioles, reticulato-venosi, in caule obsolcti. Finclus (?) 'Tuhereula verrucosa, uricformia, ad apices ramulorum sita, dense aggregata, capituli acicula magnitudine, unde ramulis facies rugosa, sessilia et pedumculita, in quibus tamen diffractis nulla granula ohservavi; forsan ob formam pro verrucis potius labenda. Color ruber, articulis oculo undo conspicuis, exsiccatx nigricans. Substantia cartilaginea, rigicla. Amma. I cre et estate. Charte non atheret.

OBS. Hrec specics, majoribus ammumcranda, siccitate non mutatur, nisi grod colos in uigricantem abit; irrorata cuim ocyus reviviscit, forman pristinam induit, et aqvan, cui inmergitur, in statu tam exsiceato gram recenti colore dilute rubro tingit. - In ubereulis, que dixi, vidi eqvidem puncta fusca, inordinate disposita. quxe tamen pro seminibus vix sumt habenda, sirgvidem ipsa frons, in tenues lanellas secta, puncta cjusdem indolis haud raro ostendit.

Tab. 62

B. 1 .

3. C. rubrum; fronde dichotoma, ramosissima, ramulis apice furcatis; articulis medio pellucidis, reticulato-renosis, ovatis; geniculis contractis; capsulis subglobosis, sessilibus, involucratis.

Ceramiuv , ubrum Ag. Disp. p. 17. el Syn. p. Go.

- virgatum Rotl. Cat. bot. 1, p. I49. Tub. 8. fig. I. - Schum. enum. 2, p. 110. Jürg. Alg. Dec. 2, n. 4 .

- rodulosum Ducluz. Essai p. 6r.

- rongatum lioll. Cat. bot. 2, p. 178. - Decand. A. fr. 2, p. 44. 


\section{SECTIO TERTIA. CERAMUM.}

Conferia rubra Dillw. Tab. 34. et Introd. n. r59. Suppl. Tab. F. - Web. et Molır Gr. Conf. Tab. 34. - Fl. dan. Tab. I482. - Hnds. p. Loo. - Engl. bot. Tab. II66. - flosculosa Ellis in Pliil. Trans. Vol. 57. p. 425. Tab. 18. fig. e. E. - Dillen. Tab.
6. fig. 38.

- nodulosa Liglıt. p. 994. - With. 4. p. ז38.

- diaphana B. atropurpurea Roth. Gat, bor. 2, p. 228.

Fucus Lagasca Clement. p. 3'5.

B) proliferum, ramulis brevibus simplicibus ad omnia genicula verticillatis. Habitat ad littora Daniae vulgaris; ad ora Fionia septentrionalem saxis Fucisqre:adnascens, sat copiose. - B. in sinu Othinicnsi, Hofmann Bung.

DESC. Radix parra, nigricans. Frons plerunque solitaria, basi seta porcina duplo crassior, palmari ad pedalem longitudine, a hasi uscree, si velis, diclotoma, ramosissima, debilis, flaccida. Rami altemi, inferiores remotiores, supcriores magis approximati, tentiores, ramosissimi; ramuli capillares, acmninati, apice furcati, interdum forcipati. Articuli oblongi, teretes, ovati, diamctro aplo longiores, plus minus inflati, ad marginem saturatius colorati, medio pellucidiores, sub lente pulchre reticulati. Genicula plus minus contracta. Eructus Caipsula subglobose, sessiles, solitarir, basi filis dnobus vel tribus apice subincurvis, capsulanı parum superemincntibus involucratæ, scminibus pulpæ gelatinose immixtis repletr. Color saturate rel dilutc ruber, capsularum intensior: planta in Zostera marina cresccus virescit. Substantia subcartilasinca, tencra, cxsiccate tenax. Acstate et antumuo cum firuch legi. Chartæ non adherct. Siccitate arliculi sape altcrnatin compressi.

4. C. secundatum; fronde dichotoma, ramosissima; ramulis ad interiora Tab. 37. dichotomiarum latera omnibus secmdis, distichis, approximatis, apice furcatis; capsulis subglobosis, sessilibus, involucratis.

Habitat ad littora Færocnsia, ut inter Thorshavn et Höyviig alibiqve haud fieqvens.

DESC. Precedentem magnitudine et habitu refert: sed notis allatis, qre in locis natalibus iutlicatis scmper sibi constant, facile distiugvitur. Articuli dianctro 2 plo longiores, sub lente reticufato-renosi; rammli, qui ad intcriora dichotomiarum latera siti sunt, apicem versus dichotomi rel ramosi; interdum, inprimis in individuis froctiferis, in tanta copia adsunt, nt ranuli primarii inde maxime divaricati evadant, et haud raro retrorsum curventur. Fructus et color, "tt precudentis.

5. C. diaphanum; fronde dichotoma, ramosissima; ramulis apice forci- Tab. 37. patis; articulis cylindraceis, hyalinis; geniculis elevatis, turgidis; capsulis sessilibus, involucratis, scminibusque nudis in geniculis sparsis. 
Ceraminn diaphanum Roth. Cat. Lot. 3, p. 154 - Ag. Disp. p. 17. ot Syn. P. 61.

- Jorcipatum $\beta$. glabellum Decaud. 月. fr. 2, p. 4 G.

- elegans Ducluzeau Essai P. 53.

Conferva diaphana Fl. dan. Tah. 958. - Lighef. P.99G. - Wiuh. 4. P. 139. - Wulf. cryp. n. 3s. - Whhl. fl. lapp. n. 975. - Schum. Finum. 2, p. 109. - Roth. Fl. Germ. 3. p. 525. et Car, bot. 2. p. 226. - Dillw. Tab. 38. - Web. et Molır Grosslur. Conf1'ab. 35. - Engl. bot. Tab. $174^{2}$.

- rodulosa Huds. p. Goo.

- glabulosa Rorh. Cat. bot. 2, p. 253.

- moniliformis Roth. Cat. bor. 2, p. 256 .

- elegars Roth. Cat. bot. 1, p. 199. 'Tab. 5. fig. 4.

- seposita Fl. norv. 2, p. 116. n. 929. - Conferra n. 3. Strüm. Sündm. I, p. 83.

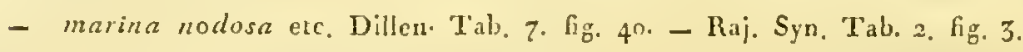

B) hycalinum, fronde dichotona; ramulis fastigiatis, geniculis albidis; articulis longis, aqvose pellucidis, siccitate alternatim compressis.

Ceramium diaphanum $\varepsilon$. hyalinum Rohl. Cat. bot. 5, p. 155.

Conferva fastigiata hoth. Cat. bot. 2, p. 224. - Wulf. crypt. n. 33.

Tab. 37

B. 4 .

r) tenuissimum, fronde dichotoma, tenuissima, eleganti; geniculis crassinseulis roseis; articulis inferioribus hyalinis, diametro 6-8plo longioribus, superioribus brevibus; capsulis sessilibus nudis secundis.

Ceramium diaplanum $\zeta$. tenuissimum Rorb. Cat. bot. 3. P. ${ }_{5} 6$.

Tab. 37.

d) virescens, fronde subdichotoma; ramulis summis ineurvis, forcipatis; articulis apicem versus globosis, insigniter moniliformibus.

Habitat elegans hrec alga ad littora Danix, Norvegixe, Frerox et alibi sat frequens. - B. ad littus 'Torbee Sellandiae. - $\gamma$. ad littora Fionia inter algas majores. - $\delta$. ad littus Qvivig Strömöe Frox, copiose.

DESC. Radis callus parvns, Thalassiophytis majoribus aliisque corporibus marinis tenaciter agghlutinatus. Frondes solitaria vel 'x cadem basi plurima, cxspilosie, duos ad sex polliecs longax, haisi selî porcinâ cluplo crassiones, per dichotomias pluries repetitas divisan, a jicem versus teuniores. Ramuli ultimi apice incurvi, omnes cjusdem fere longitudinis, commiventi-forcipati. Genicula crassiuscula, plus minus derata, lanqvan camosa, sape retieulato-venosa. Articnli cylindracei, geniculis angustiores, diverse longitudinis, diametro sua 2-5pho longiores, pellucidi. Fructus Capsula subglobosa, solitaria, ad laicra ramulorum superiorum sessiles, filis brevilus, tenuibus, tcruis qvinisve 
involucrata. Color nunc saturate, nunc, dilute ruber, scniculorum intensior. Substantia subgelatinosa, flaccida, tcucra. Annua. Vcre et æstate. Chartx laxe adlixet.

OBS. Ad insulas Froenses exemplaria vidi capsulis, at raris, instructa; scd ad littora Daniæ nunquam hanc specicm legi capsulas externas gerentem, at certe capsulas (si ita diccre licet) internas, substantix geniculorum carnosorum, tanqram tubcrcula fusca, immcrsas, qra e geniculis diffractis solutæ sub lente apparebant limbo pcllucido cincte, et singulie quaterna vel qrina semina fusca globosa includentes. Dum lræc scribo, obiter in locum incido, lanc opinionem corroborantem; dicit nempe Cel. Rothius in Nl. germ.! 3, p. 52\% ;de hac specie: "Fructificationum gramula in hac specic geniculis inhærere videntur, qvibens in pluribus hujus gcueris specielons articuli intus adspersi observantur." Idem post Rothium attulit 'L'reviranus (cf. Web. et Mohrii Reue Seitr. zur

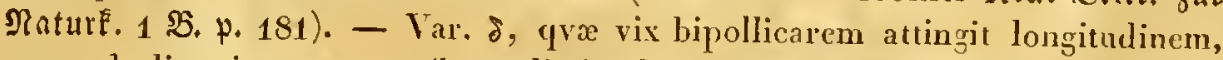
rupes declives in summo refluxus limite densissimis suis caspitibus per plures ulnas obducit. - Deuique de Conferva seposite Fl. uorr. cfr. gqv ad Hutchinsiam fastigiatam antea annotavi.

6. C. ciliatum; fronde tenui, dichotoma, ramosissima; ramulis apice Tab. 37. forcipatis; articulis cylindraceis, hyalinis; geniculis elevatis, ciliis muricatis erectis verticillatim obsessis; capsulis ovatis, sessilibus, involucratis.

Ceramium ciliatum Ducluz. Essai p. 64 .

- forcipatum a. ciliatum Decand. f. fr. 2, p. 46.

Conferva ciliąa Ellis Phil. 'Transact. Vol. 57. p. 426. Tab. 18. fig. h. H. - Huds. p. 599.-

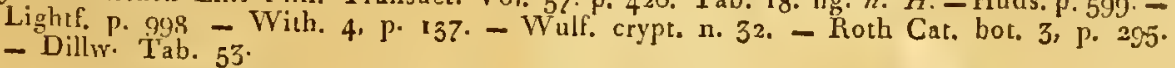

- pilosa Roth Cat. bot. 2, p. 225. Tab. 5. fig. 2.

Habitat ad insulas Færoenses in summo refluxus limite rupibus hic illic dense et copiose adnascens.

DESC. Radix minutissima. Frondès maximc gregarix, ad latera rupium plerumçve pendulx, debiles, pollicem circiter lougæ, setam eqvinam crassx, æqvales, pluries dichotomæ: rami fastigiati, apice forcipati. Articuli diametro plerumqve 2 plo longiores, apicen versus eandem longitudine rquantes, subpellucidi. Genicula saturatius colorata, rosea, turgida et ciliis verticillatis obsessa; cilia erecta sursum spectantia, ad singula genicula 6 vel 8 , lyyalina, abbreviata, singulo ex dnobus vel tribus articulis constante, muricata vel acuminata. Fructus Capsula ovatæ, plerumqve solitariæ, intcrdum binæ ternæve ad lateria ramulorum sumnorum séssilcs, filis brevijus incurvis 
involucratx, intus gramlis pyriformiluns muco inmixtis repletx. Color rosens, capsularum intensior. Substantia subcartilaginea, membranacea, tcnerrima. Acstate. Charta non allheret.

OBS. Fructun, qrem in exemplaribus Feroensibus nusqram vili, ex observatione Cel. Duclusecu adposui. - Color variat, haud raro in pallidum vergens. Ilabitu sno constanter tcnuiori, cilisqge verticillatis a procedente sat superque distiucta. 


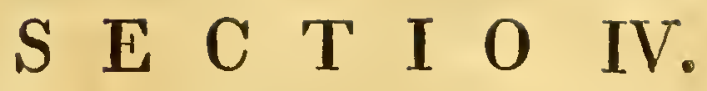 \\ SIPHONIGONATA.}

Frons filiformis, articulata, tubulosa.

\section{C A L L I THAMNION. *)}

Frons teres, articulata, ramosissima, rosea; articuli uno tubulo latiori longitudinali notati. Fructus_Capsulæa ad latera ramulorum subpedunculatæ.

1. C. Arbuscula; fronde ramosissima, caule incrassato cum ramis pri- Tab. 38. mariis inarticulato, inferne denudato, superne ramosissimo; ramulis confertissimis, abbreviatis, multifidis, articulatis; articulis diametrum longitudine aqvantibus.

Conferva Arbuscula Dillw. Tab. 55. et Introd. n. 148. Suppl. Tab. G.

Hutclinsia Arbuscula Ag. Syn. Introd. p. XXVL.

Habitat ad insulas Færoenses in inferiore refluxus limite scopulis adnascens, copiose.

DESC. Radix callns parrus, nigricans. Fronrles ex ma basi plures, maxime gregarix, duos tresve pollices longx, fili emporetici tenuioris crassitie, ramosissimx. Caulis cum ramis primariis teres, solidus, inarticulatus, inferne plerumpre undus, et ramulis confertissimis, tomenti instar, undigre ct nbiqve obsessus, unde frondi toti facies villosa; rami densi, sparsi, inferiores longiores, apicem versus breviores; ramuli confertissimi, lineam fere longi, caulem ramosqve undique et ubiqve densissine vestientes, alterni vel subverticillati, divaricati, multifidi, articulati; articuli dianetro aqvales, nno tubulo subqvadrato repleti. Fructus Capsule minntissima, dianetrum fili longitudine xofvantes, atrorubentes, adlinteriora ramulorum latera secundx, breviter pedunculatx, singulis ex qrovis articulo exemtibns: reperiuntur etian Capsulx majores siliqræformes, vel lanceolatæ, ad ramulorun superiorum

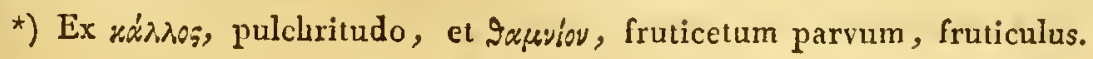


dichotomias plures inviecm dispositx, scmina minutissima rotunda at rorubentia, duplici vel riplici serie disposita, inchudentes. Culor saturate ruber. Substantia corrilaginea. Charte laxe adharet.

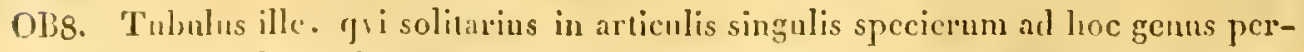
tinculium adest sub nomine utriculi matriralis, grad Cell. Mertensius a Rum.

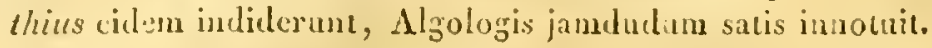

2. C.coccineum; fronde ramosissima; caulc incrassato, inarticulato, hirsuto; ramis alternatim decomposito-pinnatis; pinmlis alternis, fasciculatomultifidis, articulatis; articulis diametrum longitudine subaqrantibus.

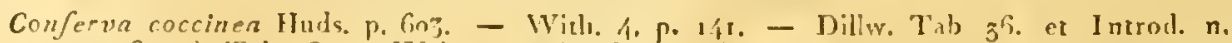
1 i9. Suppl. Tab. C. - Wab. ex Mulur Gr. Con?. Tab. 36. - Engl. bor. Tab. 1055.

Conferva plumosa Ellis Hhil. Trans. Vol. 57, p. 425. Tab. 18. fig. c. C. d. D. - Lightf. p. 996 .

Ccramium hirsutum Roth. Cat. bot. 2, p. 169. Tab. 4. et Cat. bot. 3, p. 137. - Jürg. $\mathrm{Alg}$ Dec. 5. n. 4.

Hutchinsia coccinea Ag. Syn. Introd. p. XXXI.

Muscus Rajus P 79. n. 25. - Plukenet Mhyt. 'Tab. 48. Kg. 2.

ITabitat ad littora insula Helgoland, ubi copiose ejicitur, Jiurgens. - Forsan igitur etiam ad littus Holsatia occidentale.

DESC. Radix parva, scutati. Frondes gregarix, tres pollices ad palmam ct ultra longex, ramosissime: canlis pennam prasscrinam ad basin crassus, leres, inarliculatus, apiecm versus attenualus, filis brevibus arliculatis satpe obsessus, mudc ei facics hirsuta, ramosus; romi tenuiores, vagi, attemuati, altcrni, decomposito-pimati; pinmele disticha, alterna, aliisqueminoribus codem modo dispositis obsessic. Articuli diamctro inquales, urriculati. Fructus Capsulæ solitaris, orala, acuminata, ad hasin yamulorum disposita, congericun seminum contincules: reperiuntur cham Capsule siliqaformes, semina atrorubentia dupljei vel triplici seric dispasita includentes. Color ruber. Substan-

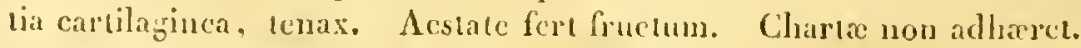

OBS. Ol, canles inarticulatos et quidem solirlos hace et procederns species ad priorem veroun seclioncm; cum dubius hirsitarem, qronan ras poncrem loco, ne numcrus gencrum nimis augerctur, at hoc gomus cas retuli, imprinis ob articulos ramularum unico tanum ululo justructos: non tamen ignorans. eas

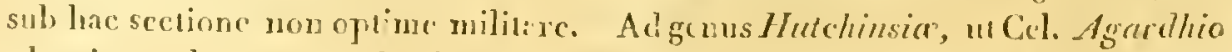
plicuit, rlatx xque claudicant. Forsan norum et peculiare genus meliue constituerent.

Tab. 38. 3. C. fruticulosum; fronde supradecomposito - ramosa; ramulis fasciculatis, fastigiatis, lensissimis, brevibus; articulis dianctro aeqralibus; cap-. sulis globosis, ad ranulorm dichotomias sessilibus. 
Ceramium fruticulosum Roth Cat. bot. 2, p. 183. 3. p. 146.

Conferva fruticulosa Wulf. crypt. n. 30 .

Habitat in oceano Norvegico; Herb. Vahlii.

DESC. Radix callus parvis, expansus. Froudes ex cadem basi plnres, fruticnlum bipollicarcm vel ultra densissimum difinsum referentes, setam eqvinam ad basin crassitic xqrantes, sensim attenuate, a basi at apiecm alternatim ct confertc ramosissime, vel si velis dichotome; anguli, unde cgrediuntar rami, acuti; ramali terminales fisciculati, breves, fastigiati, aprice bifidi. Tota frons articulata; articuli diametrun longitudine xqrantes, uno tubulo latiori rosco repleti. Fructus Capsulx ad ramulorum summorum axillas solitarix, sessiles, ovatx, limbo pellucido sxpe cinctie, granula oblougra fusca inclndentes. Color rosens. Substantia memluranacea, tchuis, tenax. Chartæ adliacert.

4. C. corymbosum; fronde nninutissima, dichotomo-ramosa; ramis al- Tab. 38. ternis, multificlis, fasciculatis, apice bifidis; articulis diametro triplo longioribus; capsulis sparsis, ovatis, breviter pedunculatis.

Conferva corymbosa Engl. bol. Tab. 2352.

Ceramium pedicellatum Fl. dan. Tab. 1596 fig. 2.

B) intricalum, fronde intricata, dichotoma, divaricata; ramulis apicem rersus fasciculatis, fastigiatis.

Habitat elegantissima hæc alga ad littus Fioniæ septentrionale in Zostera marina, Gigartina purpurascente aliisqve parasitica; etiam ad littus Norvegiæ, ut in portu Svinöer prope Lindesnæs et ante ostium sinus Oxefiord. - $\beta$. ad littus Ilofnansgave Fioniae legi.

DESC. Radix callus perexiguus, nigricans. Frons plerumqve solitaria, pollicaris, capillnm humannu crassitie æqvans, diclotomo-ramosissima, diffusa, dubilis, flaccida. Lami patuli, diclotomi, inferne remoti, superne magis approximati, iu sunmitate densissimi; ramuli alterni, patentes, angulis acutiuscnlis, apicem versus attenunti, aliisque minoribus eodem modo colloratis itcrum itcrumqve obsessi; summi ramnli fasciculati, fastigiati, apice bifidi. Articuli dianctro sta 3-4plo longiores, medio aliqvantuhum angustati, rosei. Genicula pellucida. Capsula ad latera ramulorum atropurpurex, limbo pellucido cincte, sine ordine dic illic sparsa, orate, solitarix, interdum opposite linx, lierissime pedunculatie. Color amoene rosens. Substantia membranacea, tenuissima, pro teneritate tenacior. Anuua. Autumno et hyeme cum fructu legi. Chartac arcte adhæret. 
5. C. corcllinum; fronde dichotoma, lubrica; articulis sursum incrassatis, diamctro quadruplo longioribus; capsulis subglobosis, sessilibus.

Conferza corallina Limn. sp. pl. p. r636. - Lighlif. p. 988. - With. 4. p. 136. Landt p. 233. - Mohr isl. p. 250. - Roll Cat. bot. 3, P. 225. - Dillw. Tab. 98. et Introrl. n. r29. - Engl. bot. Tab. 1825.

Conferva corallinoides Linn. sp. pl. ed. 1. p. r166, - Huds. p. 598 .

- geniculata Ellis in Phil. Trans. Vol. 57, p. 425. Tab. 19. fig. $F . f$.

- marina gelacinosa F́c. Dillen. Tab. 6. fig. 36.

Griffuhsia corallina Ag. Syn. Introd. p. XXVIII.

Habitat pulchra hæe planta ad insulas Færocnses; Landt. - Ad Islandiam; Ilolir, Hooker.

DESC. Radix fibrosa. Froudes ex cadem basi plurima, tres pollices ad palmann long̨x, setû porcinâ duplo crassiores vel dimidianı lincan crassæe, per dichotomias octies deciesve rejetitas regulariter divisæe, tenui et pellucidâ membranấ constructix, deloiles, flaccidr; ramuli ultimi simplices, attenuati, obtusi. Arliculi sursum incrassati, subpyriformes, diametro 3-4phlo longiores. Gcuicula pellucida. Fructus Capsulx ad genicula disposítx, sessiles, ovatæ, vel sulrotunda, limbo pellucido cincta, primum foliis tcmuibus lorevibus inarticulatis incurvis olntusis involuctate, serius nude, semina plurima rotunda vel ovata fusca includentes. Interdum excrescentix membranacex gelatinosx, ad genicula hic illic verticillatim dispositx, seminibus immersis, sub lente in conspectum venimut. Color anreo-rulser, splendidus, adultioris dilutior, inferdum viridi tinctus. Substintia gclatinosa, Lubrica. Charte arcte adhæret.

Tab. 39. 6. C. roseum; fronde tenui, alternatim decomposito-pinnata; ramis ramulisqve alternis, patulis, subulatis; articulis dianctro triplo longioribus; capsulis secundis, globosis, subsessilibus.

Ceraminem roseum Rolh. Cal, bot. 2, p. 182. - Ag. Disp. p. 7 et Syn. p. 62. - Jürg. Alg. Dec. 1, n. 9

Conferva rosea Dillw. 'Tab. 17. - Web. et Mohr Gr. Conf. Tab. 17. - Engl.hot. 'Lab. g66.

- purpurascens Huds. p. Goo. - Dillen. Tab. 7. Gig. 41. - With. 4, p. 138. - Engl.
bot. Tab. 2465?

Tab. 39. B) tenue; fronde tenuissina, abbreviata, cæspitosa; ramis ramulisqre alternis; capsulis sccundis, globosis, subsessilibus, numerosis.

Habitat pulchclla hae aIga ad rupes maritimas ante ostium sinus Oxefiord Norvegix. - B. ad scopulos maritimos prescrtim abruptos insularum Farocnsium in summo refluxus limite, copiosissime.

DESC. Radix callus expansus, pusillus, Fuco vesiculoso rupibusque agglutinatus. Frondes ex cadcm basi plures, unum ad tres pollices longx, ct capillum lu- 
manum crassitie xpyantes, apiccm versus sensim attenuata, dcbiles, flaccida, ramosissime. Tota planta, in aqva libcre fluctuans, fasciculum pulclierrimum, subfastigiatum, densissinum, difiusum representat. Rani a Jasi incipientes, alterni, inferiores remotiuscali, superiores magis approximati, divaricati, subulati, aliisqre minoribus eadem ratione dispositis ad summitates usque obsessi. Articnli inferiores dianctro 5-6plo longiores, apiccm versus sub 3 plo longiores, rosei. Genicula pellucida. Fruetus Capsulx secundx, ad interiora ramulorum latera geniculis anucxa, globosa, sessiles vel brevi pedunculo fultx, limbo pellucido cinctx. Color roseus. Substantia membranacea, pro tencritate satis tenax. Charte arctissime adhaect.

OBS. Varictas, si frondem constantcr abbreviatam, duas modo tresve lincas longam, maxime crespitosarn, articulosqve paululum breviores forsan cxcipiamus, in ceteris omnibus, si quid video, adeo cum $\propto$ congruit, ul vix ulla nota, qvâ ab illa rite distingvi potcst, inveniri queat; quare eam merito, ut videtur', huc retuli.

7. C. Plumula; fronde tenui, ramosa, subdichotoma', pinnata; pinnis oppositis, capsuliferis; articulis diametro sesqvilongioribus; capsulis secundis, globosis, pedunculatis.

Conferva Plumula Ellis in Phil, Trans. Vol.57, p, 426.Tab.Is.fig. g. G. -Dillw. Tab. 50.

- Turneri Engl. bol Tab. 1657.

- floccosa Fl. dan. Tab. 828. fig. T.

Ceramium floccosum Roth Cat. bot. 2, p. 185 .

- Plumula Ag. Syn. p. G2.

B) pusilla; fronde'minutissima, pinnata; pinnis pinnulisqve oppositis; arti- Tab. 39. culis dianctro duplo longioribus, pinnarum eandem aqvantibus.

Habitat in sinubus Norvegiæ, raro; Mïller. - $\beta$. ad insulas Froenses in stipite Laminariæ digitatæ inter cæspites Callithamnii Rothii inveni, rarius.

DESC. Frons tcunis, ramosa, vage dichotoma, articulata. Rami ramuliqve alterni, remotinscnli, pinnati. Pinnæ ramnlis breviores, opposite, ex articulortum medio prodeuntes, setaccæ, acuminatæ. Articuli diametro fere duplo longiores, interdum ejusdem longitudine, rosei. Genicula pellncirla. Capsulæ ad interiora pimnaren latcra dispositx, pedunculatæ, solitariæ vel binæ, globosæ, limbo pcllucido cinctæ. Color dilute roscus, pinnarum pallidior. Substantia mcmbranacea, lubrica, tencrima.

OBS. Extra nquam indigesta gelatina, in aqvấ tencrrima Conferva, lrxte rubra, valde ancta magniludine Corallinis affinis conspicitur; Mïller. - Ad Cerctmium Turneri loth. Cat. bot. 3 , p. 127. Tab. 5. (Conferva Turneri Dillw. Tab. 100.) accedit, a qrâ tamen fronde ramosa, majori, subdiclıotoma dif- 
fert. - In: Varictate capsulas minntissimas rarissimas ad basin jimmarnm scmel'vidi.

Tab. 40. 8. C. repens; fronde minutissima, repente, limplexa; ramosa; ramis erectis, ramosis; ramulis subsecundis, oblusis; articulis diametro triplo longioribus; capsulis ad sımmmos ramulos sparsis, ğlobosis, subsessilibus.

Conferva repens Dillw. Tab. ז8. - Weber \& Mohr Gr. Conf. Tab. ss. - Roth Cat. bol. 3, 1. 221. - Ag. 1)isp. 1. 33.

Ccraminu repens Ag. Syn. p. 63.

Tab. 40. B) tenellum; fronde minutissima, repente, ramosa; ramis erectis, simplicibus; articulis diamctro 3-5plo longioribus.

Conferu tenella Dillw. Introd. 11. 12r. Suppl. T'ab. F, - Ag. Disp. p. 33.

Ceramium repens $\beta$, tonellum $\Lambda$ g. Syn. $\beta .63$.

Habitat ad littus Fioniac scptentrionalis in Furcellaria lumbricali aliisqve parasitica, sat freqventer. In Ptilota plumosa ad litus Svinöer prope Lindesnæes Norvegix cum fructu legi. - B. ad littus Hofmansgave Fionia in Furcellaria lumbricali, Gigartina plicata, aliisqve, ut a, parasitica.

DLSC. Crspiles minutissimi, 3-4 lincas longi, iutricati, Mlgam, cujus frondi parasitice insident, densissime olvestientes. Frondes lepente's, capillum lumannu crassa, ramosr ; ranus printurius decumbens, ex singulis fere articu-

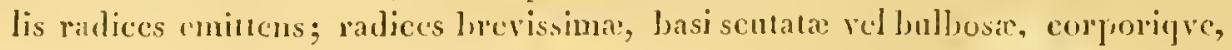
cui imascuntur, trnaciter agghtntuate; ex singulis rami prinarii decumbentis arliculis rant progrediuntur erecti, sursum spectantes, cortumgqe prispee ex codem articulo, ex qro radix, egrediure, ita tamen, ut radix cx uno, rammlusefre cx altero articuli func initium capiat; rami pretcrea $3-4$ lineas longi, capillum lumuanum crassitic acqrantes, ramosi; ranmli altcrui, sxpe secundi, subsimplices, breves, divaricati, apece obtusi. Articuli dianctro sua 3-4plo Inngiores. Gevicula pcllncida. Fructus Capsula minutissimx, ad summitat's ramulorum sparsim disposita, globosa', sessilles vel brevi pedunculo suffulta, saturatius colorate, limbo pellucido cincte. Color saturate rosens. Substantia tenera, lenta. Anuna. Hyeme preprimis reperitur. Autumno cum fructu legi. Charla laxe adharet.

OBS. Si cultello vel simili qrorlam instrmmento rami ab alga , cui insident, dirnlsi lenti subjicimtur, radices cradicata bullose in conspectum veniunt. Exemplaria vidi Conferve cujusdam, ex mari mediterranco allate, fvx aliis algis radice simili bulbosa inharedrar, ramulisque secundis, ramosis a simplicibus instructa : ceterum autem hac nostrâ duplo major, ramulis plurilus apjece, cormum arictis instar, pulchre inflexis, interdum rectis, apice fibrillosis. arliculisqre subopacis, ubulis intense rubris conflucutibus, qrodannodo diversa. 
9. C. Rothii; fronde minutissima, caspitosa, erccta, dichotomo-ramosa; Tab. $\mathbf{4 1 .}$ ranis ramulisqre clongatis, alternis; articulis diamctro duplo longioribus.

Conferva Rothii Turton Syst. of nature 6, j. 1806. (sec. Dillwyn.) - Dillw. Tab. 73. - Jürg. Alg. 1)ec. 2, n. 10.

- wiolacea Roth. Cat. bot. 1, p. 19o. Tab. 4. fig. 1. et Cat. bot. 5, p. 224.

Habitat ad rupes abruptas insularum Færoensinm in smmmo refluxus limite, copiose; imprimis autem ad stipitem Laminarixe digitata, ibidem. - Etiam ad stipitem ejusdem algæe ad littus Svinöer Norvegia, haud copiose.

DESC. Caspites minutissimi, 2-3 lincas alti, masime gregariæ, interdum ad latera rupium glomerulos dnrissimos furmantes; frondes abbreviata, erecta, 2-3 lineas longe, capillo humano tenuiores, ad basin subdichotome, deinde: ramose; rami ramulique alterni, pro tenuitate clongati, remotinseuli. Articuli sxpe minus conspicui, fere conflucutes, plerumgve tamen dianctro 2plo longiores. Fructus latet. Color caspitis fusco rubre, ramorum singulorum rosens. Substantia tencrrima. Perenuis. Charea ob formam cxspiticiom non achserec.

OBS. Iu honorem clarissimi A. G. Rothii, qri serijtis suis studium Algologix, siqvis alins, promovit, lane cleyantem speciem Cell. Turton et Dillwy'n nominaverunt.

10. C. Dawiesii; fronde minutissima, cespitosa; crecta, ramosissima; Tab. 41. ramis ramulisqve alternis, sparsis; articulis diametro duplo longioribus.

Conferva Dawiesii Dillw. Introd. n. 122. Suppl. Tab. $F$.

B) secundatum; fronde minutissima, cxespitosa; ramis alternis, flexuosis; Tab. 41. ramulis numerosis, patentibus, insigniter secundis, abbreviatis.

Habitat ad insulas Freroenses in Ulva palmata, Sphacrococco mamilloso, Conferva tortuosa aliisqve parasitice. - $\beta$. in apicibus Confervæ rupestris, ibidem.

DESC. Frondes minutissima, lincam unam altcramve longæ, capillo humano tenuiores, caspritose, erectr; rami alterni, patentes, aliisqve brevioribus codem modo dispositis olsessi. Articuli dianctrum longitudine xervantes, vel cadem cluplo longiores. Genieula longiora, pellucirla. Fructus secundum Borrerum et Dillaynium Capsule sceundx, ad intcriora ramulorum Latcra sita. Color dilute roseus. Substantia tenerrima. Chartæ vel vitro bene adharet.

OBS. Non multum aljest, qrin varietatem ol, ramulos secundos pro distincta specie habcam; sed ob tenuitatem, nam sis lineam Inngitudine æqvat, lunc cam referre satius duxi. - Rev. 11. Daniesio, qvi plures Confervas ad littora 


\section{0 SECTIO QYARTA. CALLITHANINION \& ECTOCARPUS.}

Anglica lectas cum Dillwynio communicavit, hanc speciem anctor ille celcberrimus delicarit.

'Tab. 41. 11. C. lanugrinosum; filis mimntissinis, abbreviatis, subramosis; ramis simplicibus, erectis, sparsis; articulis rliametro 2plo longioribus.

Conferen lanuginosa Dillw. Tah. 45. et Introd. n. 118.

Habitat ad insulas Feroenses in Hutchinsia urccolata aliisqve parasitice, raro.

DESC. Fila minutissima, capillo fumano tcmiora, lincam longa, càspitosa, e corpore, cui insident, horizontaliter exemtia, crecta, simplicia, vel apice ramosa; rami pauciorus, heves. Articuli diametro 2plo Jonoriores. Genicula pellucila. Frucuslarct. Culor dilute fuscus, rubro tinctus. Substantia tenerima. For'san modo Varictas pracedentis.

Tab. 41. 12. C. floridulum; filis minutissimis, abbreviatis, subranosis; ramis sinplicibus, renotis, apieen versus dispositis; articulis dianetro triplo longioribus.

Conferva floridula Dillw. Introd. n. 124. Suppl. Tals. F.

Habitat in mari Grocnlandico ad basin Conferva rupestris, raro; Herb. Giesekii.

DESC. Crspes minutissimus, unam alteramve lincam longus, ercetus. Fila capillo humino tenuiora, simplicia vel ippice ramosa; rami remoliusculi, patuli, simplices. Articnli diametro 3 plo longiores. Fructus latet. Color recentis roseus, exsiccata pallidior. Substantia tencrrima.

\section{E C T O C A R P U S. *)}

Fila articulata, membranacea, ramosissima, fusca. Fructus Capsulæ ovalæ, siliqureformes rel racemosx, all latera ramulorum subpedunculatx.

Tab. 42. 1. E. littoralis; filis minntissimis, dcnsissimis, ranosissimis; ramis ramulisqve oppositis alternisqve; articulis dianctrum longitudine exquantibus; capsulis globosis, subsessilibus.

Conferva litenalis Linn. sp. pl. p. 1635 - Huds. p. 59\% - Will. 4, p. 130. - Light. p 9-9 - Dillw. Tab. 31. - Web \& Mohr Gr. Conf. 'I'ab. 3ı. - Wahl. 凡. Lapp. n. 9S2. - Conferva n. 1. Strüm. Söndin. I, p. 82.

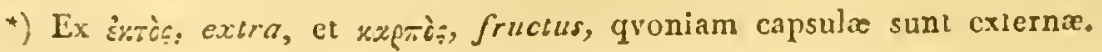


Conferva marina capillacea longa ramosissima Dillen. Tab. 6. fig. ' 9.

Ceramium comentosum Roth. Cat. bot. 3, p. 14́7. - Schum. exum. 2, p. 110. - Fl. dan.

Tab. 1487. fig. 2. - Ag. Disp. p. 18. - Jürg. Alg. Dec. 2, n. 3.

- Lillorale Ag. Syn. p. 65.

- ferrugineum Ag. Disp. p. 18. el Syn. p. 64?

- brachintum Ag. Syn. p. 67?

- purum Roth. Cat. bot. 2, p. 181.

B) major; articulis diametro sesqrilongioribus; capsulis oratis, breviter Tab. 42. pedunculatis.

भ) ruber; articulis diametro æqvalibus, rubris; geniculis pellucidis.

d) protensus; articulis dianetro æqralibus, fuscis; ramulis oppositis alter- Tab. 42. nisqve, ultimis fasciculatis, secundis, protensis.

Habitat $a$ ad littora Daniæ freqrentissime. $-\beta$. in sinu Othiniensi. $-\gamma$. ibidem in Hutchinsia violacea. - $\delta$. ad littora Færoensia copiose.

DESC. Cæspes densissimus, Fuco vesiculoso aliisqve abnndanter affixus, palmam ad spithamam longns, in aqra fluctuans. Fila ex una basi plurima, fasciculatim congesta, ob undarum vehementiam sæpe densissime implexa, ramosissima; rami remotiuseuli, in iisdem individuis nnme alterni nunc oppositi, patuli, apice attenuati, aliisqve minoribus eadem ratione iterum itcrumcre dispositis obsessi. Articuli diametrum longitudine ąrantes, pellucidi, vel massâ dilute fuseâ luteâqve repleti. Genicula lineâ solitâ transversali, interdum annulari, notata. Functus Capsulie globosæ, vel subovatx, viridescentes, ad latera ramorum ramulorumqve sessiles, iuterdum ovatæ, brevissimo pcdunculo fultr; ramuli snmmi massa fusca, grumosa, per dnos tresve articulos nournunqram cincti; vidi etiam in exemplaribus Færocnsibus articulos ramulorum superiorum in globulos fusco-nigros intumescentes. Color plerumqve dilute fuscus, interdum virideseens, fulvo tinetus. Substantia membranaeea, tenera, tenax. Annua. Tempore vernali fort fructum. Chartæ arcte adhæret.

OBS. Ab hae speeic Ceramium ferrugineum et brachiatum Ag. non esse diversa opinor; neqve Ceranium purum Roth., e mari Groculandico acceptun, qvicqram alind credo, qram parvum hujus nostra exemplar clotum. - Varictas $\beta$, fra articulis gandet diametro plerumqre 2plo longioribus, ob capsulas globosas ad hane speciem referenda videtur; est autem paule major, qram $\alpha$, et articulorum longitudo læciori ejus crescentix sine dubio debetur. - Varictas y ab Hutchinssic violacea, cui adlixrebat, colorcm summ purpurcum obtimuerat.

2. E. siliculosus; flis minutissimis, densissimis, ramosissimis; ramis Tab. 43. ramulisqve omnibus alternis; articulis diametro sesqvilongioribus; capsulis lanceolato-acuminatis, pedunculatis. 
Conferva siliculosa Dillw. Introul. n. 112. Suppl. Tab. $E$.

Ceramiam siliculosum Ag. Disp. p. is. et Syn. P. 65.

- confervoides Roth. Cat. bot. 1, p. 151. Tab. 8. fig. 3. ct Cat. bot. 5, p. 148. Schum. coum. 2, p. 109 .

Tab. 43. B) uvaformis; capsulis uvieformibus, grumosis, globosis, ad latera et apices ramulorum sessilibus.

Habitat ad littora Fionensia Fucis adlıerescens, passim; ctiam ad insulas Frerocnscs. - B. adl littus Hofmansgave Fionix.

DESC. Carspes, ul precedentis. Fila elensissina, ramosissima; rami ramulipge

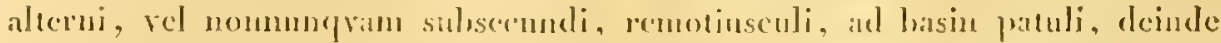

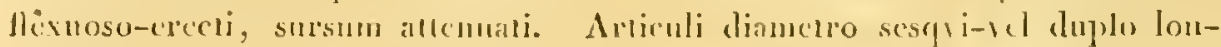
giores, medio gramulis minutissimis sparsis rel congestis untati, "cterum pellucidi. Fructus Cilpsula ad ramulorum latera disposite, siliquxformes, clongato-lanccolatie, acruminata, subincurva, fuscar, opaca, subsecunda, pedunculatic; in excmplanihus liaroomsibus casdem vieli lanecolatas, dilute fuscas. alcornas scrundasque. Color et Substantia, ut pracededulis. Annua. Vere cum fructu legitur. Charte adheret, nee siecitate mulatur.

OBS. Varietas, qram attuli, oh fructum at latera el apices ramulorum sessilem, glolosum, gitumosum, viriedm, punclis viridibus in globulum uvaformem congestis, notilu digुna mihi vidctur'; in cctcris antem a. refert.

Tab. 44. 3. E. tomentosus; filis minutissinis, in funes filiformes densissine contortis, implicatis, ramosissinis; ramis ramulisqve vagis, divaricatis; articulis diametro triplo longioribus; capsulis orato-lanceolatis, pedunculatis.

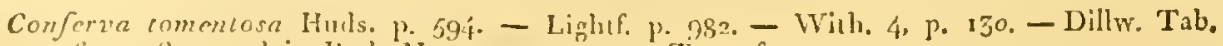

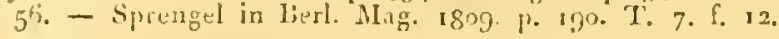

- marina comentosa minus encra ex ferruginca Dilien. Tab. 3. fig. 13.

Ceramium comentosiun Ag. Syn. p. 6í.

- compacimm Piolh. Cat. bot. 5. p. 148.

Muscus marinzs hirsmeus Jlagellis ramosis subviridibus Moris. III. Sect. 15. Tab. 9. fig. 6.

Habitat ad insulas Frerocnses, ut in sinu Qralböe Suderöe, imprimis Himanthalixe lorea allherescens. In simu Sognefiord Norvegix, Prof. C. Smilt. Ad littora maris Balthici circa Fimbriam insulan, Roth.

DESC. Carpes duos tresve pollices longus, sub aqra Alga majori tomentosac plurimos ranos anillenti simillinus: si vero iste caspes exactiori examini subjicium, e filis numerosissimis, in funcs peuna passerinac crassilie densissime compactis ct contortis, constare cernitur. Filit cxtricata minutissima, ca-

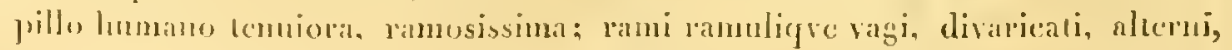

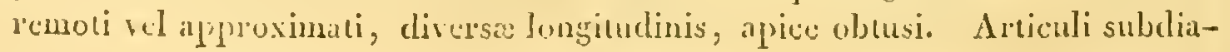


filani vel granulis flavescentibus repleti, diametro 2-3plo longiorcs. Genicula unur pellucida, munc linề solitît transversali notata. Fiructus Capsnla latcrales. snlitarix, sparsin, ad mcdios ranulorm articulos plerumegre dispositic, pedunculate, sublyyalina, oiate, articulo, cui insident, prarum crassiores, corlemule 2-3plo longiores. Color crespitis recentis nigro-fuscus, exsiccati rufo-ferruginens, vel dilute fuscus. Sulstantia sublubrica, nembranacea, tenax, nitoris expers. Aestatc cum fructu legi. Charta adheret.

4. E. densus; filis minutissimis, densissimis, ramosissimis; ramis ramm-- Tab. 44 . lisqve omnibus oppositis, patentibus; articulis diametro duplo longioribus; capsulis globosis, sessilibus.

Ceramium densum Roth. Fl. germ. 3, p. 473. et Cat. bot. 2, p. 179. - Ag. Disp. p. 18. et Syn. P. 6\%. - Mohr in Schrad. Journ. I B. iso6. J. 196.

Habitat in profundo ostii sinus Othiniensis, apicibus ramulorum Desmixe aculeate insidens; item ad insulas Færoenses in eodem Thalassiopliyto parasitice.

DESC. Fasciculus densus, tres qvatuorve lineas longus, lubricus, ramosissinus; rami ramulique remotiusculi, minntissini, capillo Jumano tenuiores, omncs oppositi, basi patentissimi, apicem versns attenuat, acuminati. Articuli pellucidi, rel messa viridescenti fareti, dianetro sun duplo lonģiores. Fructus Capsule virides, minutx, ad latera rimorum ramulorumrige sparsim scssiles, slobosa. Color pallide viridis. Substantia tencrima, lenta, sublubrica. Vere. Charta adliaret.

5. E. chalybeeus; filis minutissinis, confertis, ramosis; ramis ramnlis- Tab. 44. qve strictis, adscendentibus; articulis diametro subtriplo longioribus; capsulis oratis, raccmosis.

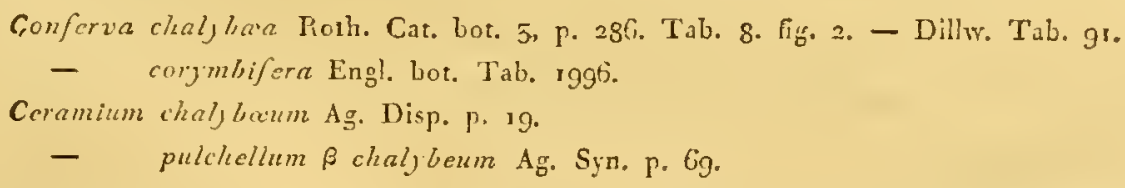

Habitat ad rotas aqraticas mole Lindred Fionia, Hofmann Bang. - Ad molam Bredde Sellandiæe inter Confervam glomeratam cæespitulos legi.

DESC. Cxspes minutus, densus, duas lineas ad ungrem longus. fastigiatus, ramosissimus. Fila tenuissima, capillo humano temiora, conferta, stricta, rage ramosa; rami basi ercelo-patentes. elongati, alterui vel sccundi, stricti, adpressi, superne divisi; lamuli approximati, alterni, breves, simplices, it]ice ol usi. Articuli diametro 3-4́plo longiores. in statu adultiori subojaci. (icsicula ficllucida, tentissima. Fructus Cinpsule ovate, racemosa, ruro soli- 


\section{SECTIO QVARTA. ECTOCARPUS \& BULBOCHATE.}

tariar, c geniculis ıanorum prodeuntes. Color atroviridis vel chalybaus, unde nunen. Substantia membranacea, tenerrima, lenta. Auma. Autumno. Clartax adluaret.

Tab. 41. 6. E. aurens; flis mimutissimis, caspitosis, abbreviatis, ramosis; rannis patentibus, rigidiusculis; articulis diametro sesqvilongioribus; capsulis ovatis, sessilibus.

bj ssus aurca Lin. Syst. nat. 2, p. 72r. - Fl. dan. Tab. 718. fig. x. - Engl. bol. 'Tab. 212. - Huds. p. 606. - Lightf. p. 1002. - Wiilt. 4, p. 144. - Dillen. Tab. x, fig. 16. - Mich. nov, pl. gen. Tab. 8g. lig. 2. - Petiv. gaz. Tab. 15. fig. 3.

Conferva aurea Dilliv. Tab. 35. et Introd. n. 70. Suppl. Tab. C. - Web. et MIohr Gr. Cont. T. 35. - Roth. Cat. bot. 5, p. 217.

- ilicicola Engl. loot. Tab. 1639.

Ccramium aureum Ag. Disp. p. 19. et Sj.n. p. G8.

Habitat in sylva Jredcrichsdalina Sellandiae, Miiller. - Ad muscos in udis Hindsholm Fionia, IIofmann Bang. - Ad rupes, fluviis rivulisqve contiguas, Norregiae et Faroce, sat freqrens.

DESC. Ciespes densissimus, intricatus, diversæ magnitudinis, polliccm et ultra interdum longus latusqve, 2-3 lincas altus. Fila minntissina, lineam nnam ahteramve longa, capillum lumanun crassitic subæqrantia, intricata, vage ranosa; rani alterni, sxpe secundi, patentes, clongati, semoti, aliisqve eadem rationc disprositis rigidlinsculis apice obtnsis olssessi. Articuli diamctro sesquivel duplo longiores, opaci. Gcuicula brevia, pellucida. Cajsula ad latera ramulorm sessiles, globosa vel orata, limbo pellucido cinctx. Color aurantiacus, exsiccat cinerascens, capsularum fusens vel nigricans. Substantia

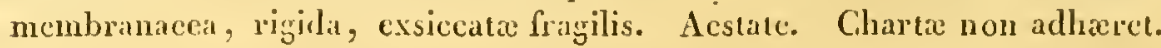

\section{XXXV。B U L B O C H AE TE. *)}

Fila articulata, membranacea, ramosissima, viriclia, setis bulbiferis ad summitates arıiculorum instructa. Fructus Capsula sessiles lateralcs.

Tab. 45. 1. B. setiger't.

Bulliochacte setigera Ag. Syu. p. 7 r.

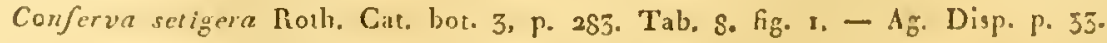

- vivipara Dilliv. Tab. 59. et Introd. n. 86 .

Habilat ad saxa rivulorum prope officinam ferrariam Naes Norvegix, hic illic copiose, Hofmann Bang et ego.

*) Ex Fะ2,G:, bulbus, et \%xity, coma, seta. 
DESC. Radix perpusilla, scutata, saxis aduata. Fila ex una basi cæspituse aggregata, tres lincas ad ungv.m longa, flexuosa, dichotomo-ramosa. Anguli dichotoniarum acuti. Rami ranuliqve interdum altcrnatim sccundi. Setæ, ad genicula vel potius ad summan articulorum partem solitaric annexx, basi bulbosa, adco ut in sua tenuitate petiolos foliorum Robinice pseudo-acacice beuc referant, tenuissimæ, hyalinæ, continux, longitudine fere totius plauta, simplicissime. Articuli dianctro 3-5plo longiores, superne ad insertioncm seta paululum incrassati, granulis sparsis viridescentibus repleti. Geniculit pellucida, brevissima. Fructus Capsule ovate, ad genicula sctarum expertia scssiles, solitarix, limbo pellucido cinctre. Culor pallide viridis. Substantia membranacea, tenerrima. Amma. Aestatc. Charto adhæret, nec siccitate mutatur.

OBS. Capsulas, Dillwynianis omuino similes, in speciminibus Torvegix obserravi.

\section{C O N F ER VA. *)}

Fila articulara, membranacea, simplicia et ramosa, viridia. Granula in articulis hic illic sparsa.

* simplices.

* aqua dulcis.

1. C. brachymelia; filis simplicibus, tenuissimis, cæspitosis, abbreviatis, Tab. 45 . strictis; articulis diametro brevioribus, transversim rectangulatis; geniculis pellucidis.

Habitat ad rotas nquaticas molæ Lindved Fioniæ inter cæspites Confervæ glomeratæ, haud freqvens.

DESC. Fasciculus minutus, 3-4 lineas longus. Fila cjusdem longituctinis, recta, stricta, debilia, capillo humano tenuiora, simplicissima. Articuli diametro breviores, interdum ob massan internam crancscentem pellucidi. Genicula pellucida. Color lete viridis. Substantia tenerrima. Autumuo. Clartie adheret.

OBS. Keftrt quidem Confeream flaccam, de qra infra; sed ob locum watalen. "t propriam specicnı, eam proponere nou dubitavi. Brachymelia, cx Bprxis brevis, et périos membrum, articulus, est breviarticulata.

*) Conferva appellata a conferruminando, Plin. hist. nat. L. 27. c. 8. - Confer. ruminare autem h. J. est aut conglutinare, quoniam Confervæ nonnullæ glutinis instar sunt gelatinosæ, ant, quod melins placet, consuere, qroniam Conferve ob habitum filiformem cum filis, quibus consuitur, comparari possunt. 
Tab. 45. 2. C' compacta; filis simplicilns, tenuissimis, arachnoidcis, sublubricis; articulis dianetro sesquilongioribus, intus qradratis.

Conferva compacia Rollı. Cat. bot. I, p. rzo? - Jïrg. Alg. Dec. 4. n. S.

- zonaia f. tcruior Molur in Scluau. Journ. y B. 1806. p. 196.

Habitat in aqvis stagnantibus Danize tempore vernali sat freqrens. In pratensibus udis gramina interdum obducens. - In Holsatia, Mohr.

DESC. Caspes densissimus, palutinu in dimeno habens, hatud paro latius patcns. F̈̈la densissinc intricata, temissima, simplicia. Arliculi diametro, angrales, rel cầlem sevgrilongiores, intus massî virili gradratâ, tolum fili tubulum replente, nutati. Color viridis. Substantia tonerrima. Charlie adhater.

Tab. 45. 3. C. zonala; filis simplicibus, tenuibus, Inbricis; articulis dianctrum longitudine aqvantibus; granulis in fasciam transversalem coacervatis.

Conferva zonata Wieb. et Mohr iter svec. p. 97. Tab. I, fig. 7. a. b. - Roth. Cat. bot. 3. p. $269 .-$ Dillw. Introd. n. 17. - Ag. disp. p. 29. et Syn. p. 8r.

- lucens Dillw. 'Tab. 4i.

Habitat in lacubus insularum Frerocnsium saxis adfixa, sat freqrens. - In aqris Danixe, raro.

DESC. Caspes fluctuans, nume crechus, nune pendulus, 3 pollices ad palmam longus, Jubricus. Fila simplicia. Icmuia, apiecm versus attemuata, tripollicaria ctultra. secta. Articuli bereses, dianctrun longitudine vix superantes, fascia grann forum sranstersali in modio notali. Fasela tertian articuli partem occupans saturatins virjdis. Gonicula nomnuncyam anumlaria. Color viridis, glancus. Substantia membranacea, tencrat, tenix. Amua. V cre ct astatc. Charte adlierct.

Tab. 45. 4. C. dissiliens; filis simplicibus, temuibus, lubricis, fragilibus; articulis diametro brevioribus, interdum solutis.

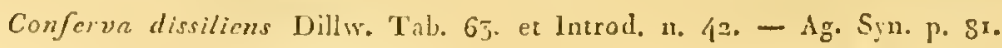

Diatoma?" dissilimns Ağ. Disp. p. 3í.

Ilabitat in fossis Fioniae, ut ad molan Lindved, raro. - Ad ripan Thermarum prope Ricikiavik Islandiae; Hooker.

DESC. Caspes fluctuans.' Fila siricta, rigida, alirgot pollices longa, eapillo lumano tenuioria, fragilia. Articuli diametro dimidio breviores vel candem acgrantes, meelio fascia transversali vel macula ovata saturate viridi notati. Genicula pellucida, interdum solura, adco ut angulo uno alterove solummodo coliercant. Color viridis. Substantia tencra, lubrica. Clarta bene adliacel. 
OBS. In statu siecato tnbuli interni luenlentius apparemt et pulehrius contralıuntur, qram in delineatione, qra juxta exemplar recens leetum exarata est.

5. C. fugacissima; filis simplicibus, tenuissimis, mollibus; articulis dia- Tab. 46. metro sesqvilongioribus, medio granulis fasciatis.

Conferva fugacissima Rolh. Cat. bot. r, p. 176. - Schum. enum. 2, p. 107. - Dillw. Introd. p. 43. Suppl. Tab. $B_{0} \rightarrow$ Ag. Disp. p. 29. et Syn. p. 80.

B) major; filis tenuibus, articulis subqvadratis, geniculis pellucidis.

ү) oscillatorioides; filis tenuissimis, articulis fasciatis, diametro subæqvalibus, geniculis pellucidis.

Conferva oscillacorioides Ag. Disp. p. 29. et Syn. p. 79 .

Habitat in fossis aqvâ dulci stagnanti repletis, passim; in turfosis ad Bagsværd Sellandize - B. in aqvis stagnantibus prope Silkeborg Cimbriæe, Prof. Hornemann et Hofmann $\boldsymbol{B}$ ang. - $\gamma$. in fossis insularum Færoensium.

DESC. Fila tenuissima, in strata fluetuantia, palmari et ultra longitudine, densissime intricata, simplicia, xqvalia. Articuli diametrum longitudine subæqvantes, vel eảdem panlo longiores, pellueidi, vel fascia saturatius colorata, granulis miuntissimis farcti, medio notati. Genicula nunc obscura, nunc pellucida. Color viridis, iuterdum flaveseens. Substantia tenera, mollis. Chartæ adhæret.

OBS. Qvod de fugacitate hujus speeici, charle imposite, Cel. Rothius affert, id non observavi; color yvidem dilutior evadit, sed nullam aliam, quantum vidi, subit mutationem. - Praterea de genieulis, qra iu obscura et pellucida divisi, hoc in antecessnm monendum videtur: Per Genicula obscura (Genicula vera hoth.) intelligo ea, quee solitâ lineâ (ransversali notata sunt, sed per pellucida (Genicula spuria Poth.) ea, qva lincâ istâ destituta sunt, et spatium perbreve pellueidum inter tubulos internos (utriculos matricales Rotl.), qvi artieulos constitnunt, relingrunt; hxe geniculorum dirersa conditio ad species lujus generis suldividendas, ut a Cel. Rothio adhibita fuit, minus certa et apta mili videtur; genieula enim obseura et jellueida in una eademqve specie, qvin etiam in endem individuo, inviecm altermare pluries vidi, cum in aliis filis linea transversalis manifeste eluxit, in aliis autem non item; exempla sint: Conferva ericetorum, fracta, glomerata \&e. In Conferra Lino, cerea, Melagonio \&e. semper, qrantum vidi, genicnla pellueida sibi constant; fieri tamen potest, ut in iis, qvemadmodum in aliis, genieula obsenra appareant, siqvidem Rothius ïsdem genicula vera attribuit. Grnicula igitur vagos modo ad dividendum characteres prestare, eaqve simnleum tubulis, internis, qvi in nna eademqve specie nunc distincti, nune conflnentes apparent, ad species rite disponendas non suficere, cuivis, me judice, patebit. Causam vero lu- 
jus geniculorum altcrnationis Pliysiologis excuticudam relingro; res enim, ut in facto ponuntur, proponere mili suflicit.

Tab. 46. 6. C. Jloccosa; filis simplicibus, tenuissimis, lentis; articulis diametro sub 2plo lonsioribus, macula globosa medio subpellucida notatis.

Conferva floccosa Ag. Disp. p. 29. Dec. 2, n. 13. et Syn. p. 79 .

Prolifera floccosa Vauch. p. xzr. Tab. 14. fig. 3 .

IIabitat in fossis arva dulci repletis, rivulisqve leniter fluentibus.

DESC. Fasciculus sub aqva fluctuans, rcetus, tres pollices et ulua longus. Fila temuissimat. siegula vix oculo nudo conspicua, rectit, sarje intricata, cursum agre seqventia. Articuli diametrum longitudine subervantes, siepe duplo longiores, medio globulo viridescenti notati, cetcrum hyalini; globuli juxta longitulinem articulorm munc approximati, mune remotiusculi, totam fili diametrum occupantes, roundi vel suhovati, nitidi, medio sulprellucidi. Color viridis. Sulstantia tencrima, tenas. Hyeme sub glacie et vere frequentissine; in rivulis Norvegia astate legi. Charta arcte adheret.

OBS. Ab hac longissime recedit Conferre floccosa Fl. dan. Tab. 828. fig. 1. Tra nd Callithamnion Plumulam, de qvo antea, pertinct.

Tab. 46. \%. C. pimctalis; filis simplicibus, tenuissinis, sublubricis, clongatis; articulis dianetro subduplo longioribus; granulis in globulum solitarium denique collapsis.

Conferva punctalis MIïller Nov. Aor. Pets. 1785. p. 8.9. T. x. fig. 1 ? - Dillw. Tab. 5r. et Introd. p. 45.

- breviarticulata Mohr in Schrad. Journ. 1 B. 180r. p. 475.

Habitat in fossis stagnisqve Fionix, raro; in rivulo leniter fluente ad officinam ferrariaun Nas Norvegize.

DESC. Caspes pollicem unum alterumue longus. Fila simplicissima, oculo nuto vix singula conspicua, sub lente tamen filis precedentis 2plo majoria, lubricio Articuli dianctro sesqui-vel aplo lougiores, fascrit transversali viridi. qrie demum in slobulum solitarium collabitur, notati. Color pallide viridis vel flavescens. Charta adharct.

Tab. 46. 8. C. sordida; filis simplicibus, tenuissimis, arachnoideis, tenacibus; articulis subpellucidis, diametro qradruplo longioribus.

Conferva sordida Dillw. T'ab. Go. et Introd. p. 43. - Rath. Cat. bot. I, p. x77. - Jürgz Alg Dec. 3, n. 6.

- bombjeina Ag. Syn. p. 78 .

Muscus Kyll, Virid, p. 106. n. 4. 
B) brunnea; filis tenuissimis, lubricis, hyalinis, in stratum dilute brunneum, aqva supcrficiei innatantenı, densissime intricatis; articulis dianetro 4-5plo longioribus, pellucidis.

子) ztriculata; filis tenuissimis; articulis diametro 3-4plo longioribus; gra- Tab. 46: nulis in globulos oblongos, in qvovis articulo plures, distinctos collapsis; geniculis hic illic contractis.

Habitat in fossis stagnisqve sat freqvens, ut in turfosis ad Bagsværd Sellandiae et Hofmansgave Fioniæ. - $\beta$. in turfosis Geelslyng prope Geelskov Sellandiæ; etiam ad officinam ferrariam Næs Norvegix. - $\gamma$. in stagnis Gravmarken prope Hofmansgave inter cespites Conferve sordidie aliqvando vidi.

DESC. Cæspes densissimus, intricatus, sordide llavescens, pedali ct ultra extensione, crassus, arva superficici innataus. Fila simplicia, capillo humano tenuiora, intricata. Articuli diametro 4-6plo longiores, diaphani vel granulis paucissimis adspersi. Genicula obscura, in statu siccato annularia, parnm contracta. Color caspitis flavo-virescens. Substantia filorum pro teneritate sat tenax. Vere nubis instar plantas aqvaticas infra aqva superficiem circumdans, æstatc cæspitem deusum aqva innatantem formans. Chartæ adhæret.

OBS. Varictas $\hat{\beta}$, qram in fossis turfosis profundis aqve superficiei innatantem inveni, filis gaudet lubricis et maxime intricatis, brevibus, pollicari circiter longitudinc, sub lente omnino hyalina; exsiccata chartan bibulam omnino æmulatur. - Varietas $\gamma$. non magni est nomenti, et sine dubio pro monstrositate fortuita laberi potest.

9. C. alpina; filis simplicibus, tenuissimis, fluctnantibus, rectis, batiis; Tab. $4 \%$. articulis diannetro qvadruplo longioribus.

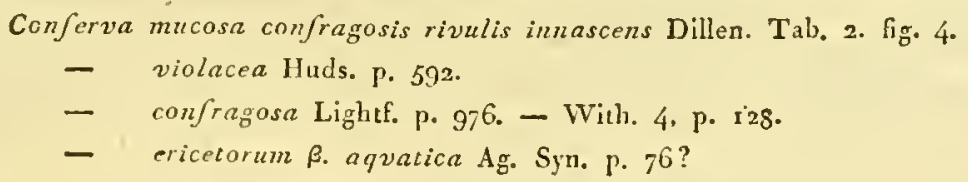

Habitat in lacubus alpinis Freensibus, ut in stagnis rupis Kirkeböefield prope 'Thorshavn, saxis adnata; raro libere fluitans.

DESC. Cespes tres quatuorve pollices longus, saxis lapidibusqve ad ripas lacuum adhærescens, fluctuans. Fila simplicia, capillo humano tenuiora, recta, densissima. Articuli dianetro 4-5plo longiores, rubescentes, medio macula fusca oblonga notati. Genicula obsenra et pellucida. Color crespitis badius vel violacens. Substantia tenerrima. Acstate. Chartæ adhæret. 
OBS. Synonyma, cx Dillenio, Hurlsone et Lightfootio jetita, a Ccl. Dillwy'nio ad suan Confervam decorficuntem referuntur; melius autem, ni multum fallor, ad lane nostram speciem pertinent.

Tab. 47. 10. C. cricelorum; filis simplicibus, tenuissimis, procumbentibus, densissime implexis; articulis diametro sesqrilongioribus.

Conferz's ericetorum lioth. Car. bot. 2, p. 206. 3, p. 213. - Dillw. Tab. 1. et Introd. P. 54. - Wel, \& Molir Gr. Conl I'ab. 1. - Schum. enum. 2, p. 107. - Fl. dan. Tab. 1548. fig. 2. - Ag. Disp. p. 28. et Syll. p. 76.

Habitat in turfosis Daniae, terram Inmidam inprinis in ericelis cæspite suo limoso violaceo obducens, sat vulgaris. Etian in cricetis humidis Fieroa.

DESC. Ciespes diverse magnitudinis et extensimis, palmam "t whlrit longus, terram madidam in locis indicatis obducens et perreptins. Filit naxine inteicata, tcnuissima, recta, simplicia, procumbentia, memhrantî tcnuissimâ constructa. Articuli diametrum longitudine plerumepre subxqvantes, interdun eâtlem sesquilongiores. Genicula ume pellucidla, nunc obsemrit, parum contracta. Color huic, ut praccelcuti, omnino singularis, spardiccus, badlus. Substania tencrrina. Amma. Vore. Cleartx, a sabulo el limo purgata, bene adharet.

OBS. Qvam huic spccici Col. Rothius attributit ramositatem nondum obscrvavi. Differt a precedente partim loco natali, partim articulis brevioribus.

Tab. 4\% 11. C. mucosa; filis simplicibus, tenuissimis, Iubricis, flavescentibus; articulis subtorosis, diametro snbærvalibus.

Conferva mucosa Dillw. lntrod, n. 27. Suppl. Tab. B.

Habitat in aqvis stagnantibus prope Bistrupgaard Sellandix.

DESC. Fasciculus fluctuans, Jubricus. Filat recta, simplicia, capillum luuranum crassa, tres pollices at palman et ultra longa. Articuli diametro eepratles vel sesquilongiores. Geniculiı pellucida. Color crspritis flavesecuti-viridis, filorum sub lente luteus. Substantia tenera, lubrica. Charte arctissime adharet. Articuli exsiccati mungan alternatin compressi.

Tab. 47. 12. C. vesicata; filis simplicibus, tenuibus; articulis hic illic inflatis proliferisqve, diametro sesquilongioribus.

Conferva vesicain Ag. Disp. p. 30. el Syn. p. 83.

- alternain Dillw. Introd. p. 43.

Prolifera vesicaen Vauch. p. 132. 'Fab. 14. fig. 4. (excl. syn. MIïl.) - Fl. dan. Tab. 1483 . fig. 2.

Chantransin vesicala Decand. 1. fr. 2, p. 52. 
B) fuscescens, filis fuscescentibus, articulis hic illic inflatis:

Conferva alternata R. fuscescens Dillw. latrod. p. 43. Supp. Tab. B. = Ag. Syn. p. 83.

ү) breviarliculata, filis viridibus, articulis hic illic toruloso-inflatis proli- Tab. 47. ferisqve, diametro brevioribus.

Habitat in fossis stagnisqve ad preedium Hofmansgave Fionix, Hofmann Bang. Etiam terram udam, aqvae contiguam, nonnunqram obducens. B. ibidem. - $\gamma$. in rivulo Hindsholm Fionix.

DESC. Stratum densum, aqva superficici imnatans. Fila dense intricata, si cxtricentur, simplicia, tenuissima, capillo humano tenuiora, sex ad octo pollices longa. Articuli diamctro sesqvilongiores, vel eandem subeqvantes, hic illic in globulum insiguiter inflati, ramulosqve proliferos temiores breves hic illic emittentes, interdum alternatim viridescentcs et fuscescentes, unde nonen Villwynii. Color crespitis viridis vel glanco-rircscens. Substantia tenera. Annua. Vere. Charte adheret.

13. C. quadrangula; filis simplicibus, tenuibus, intricatis, attenuatis; Tab. 47. articulis diametro æqvalibus; tıbulis internis qradrangulis.

Habitat in sylvaticis umbrosis humidis terram madidam, lignis dejectis putridis inmixtam, obducens, ad Scleidemoe prope officinam ferrariam Nas Norvegize.

DESC. Crespes aliquot polliecs Iongus latusque. Fila simplicia, capillum humanum crassitic subrqrantia, intricata, apicem versus paulo attenuata. Articuli diametrun longitudine xeqvantes, et apice eâdem sesquilongiores. Genicula pellucida et obscura. Color crespitis pallide viridis vel glancescens. Substantia tencrima. Autumno legi. Siccitate non mutatur.

OBS. Articuli, qvi in delineatione sesqvilongiores sistuntur, modo raro, nec nisi apicem versus couspiciebantur; ceteri omnes diametro æxpales. Color glaucescens vel pallidus, loco natali umbroso subcrsiccato sine dubio altribucudus, non magni hubetur momenti.

14. C. capillaris; filis simplicibus, tenuibus, crispatis proliferisqve, im- Tab. 47. plicatis; articulis diametro subduplo longioribus, siccitate alternatim compressis; granulis sparsis vel in globulum oblongum demum collapsis.

Conferva capillaris Lin. Syst. nat. 2, p. 72 r. - Roth. Cat, bot. 3, p. 26r. - Ag. Disp. p. 29. et Syn. p. 81.

- crispa Dillw. Introd. p. 46. Suppl. Tab. E.

Prolifera crispa Vanch. p. 130. Tab. 14. Gig. 2,

Chaneransia crispa Decand. Fl. fr. 2, p. 52. 
Tab. 48. B) lumbricata, filis intricatis, hic illic proliferis, fasciâ fuscâ clevatì, plures articulos occupante, notatis; articulis dianetro sesqvilongioribus.

IIabitat in rivulis fossisqve Dania, passim. - $\beta$. in rivulo ad officinam ferrarian Naes Norvegia.

DESC. Cxspes intricatus, varix longitudinis et extcusionis. Fila simplicia, flexuosa, crispata, laxe intricata, si extricentur, palmari el ulura longitudine, capillum humanum crassitic subæqvantia, ct in V arietate ramulos proliferos, ramo prinario $2 p^{\text {lo }}$ tenuiores, rarissime ennittential, fisciâqve fuseî̀ opacâ, adlinstar cinguli elevati Lumbrici terrestris, duos tıesve articulos hic illic interdum occupante, notata. Articuli diamctro xefrales vel sesquilongiores, granulis rotundis demum in globulum congestis adspersi, et, si sub cxsiccatione nullam patiantur pressionem, plerumpye alternatim compressi. Color viridis. Vere e' xestate. Chartx laxe adhxeret.

Tab. 48. 15. C. rivularis; filis simplicibus, tenuibus, rectis, longissimis, fluctnantibus; articulis dianctro subtriplo longioribus, siccitatc altcrnatim compressis.

Conferva rivularis Lin. Syst. nat. 2, p. 720. - Huds. p. 591. - Light. p.976. - With. 4. p. 127. - Wulf. crypt. n. 17. - Fl. dan. Tab.8sı - Hall. Helv. 11. 215. - Roth. Car. bot. 2, p. 195. 3, p. 263. - Dillw. Tab. 39. el Introd. p. 4r. - Schum. enum. 2, P. 106. - Ag. Disp. J. 29. ce Syn. p. 85.

- fuviatilis sericea vulgaris et fuitans Dillen. T. 2. fig. I.

- funiformis Roth. Cat. bot. 1, P. 169 .

- Plinii Lobelii obs. 654. et icon. 2, p. 257. т. - Parkins. theatr. bot. p. r2Gr. fig. 2. - Gerasd. emac. p. 1570. fig. 11. - Kaj. Syn. p. 5\%. - Gesn. Hist. pl. p. S1.

Prolifern rivularis Vauch. p. т29. Tab. 14. fig. I.

Claneransia rivularis Decand. 1. fr. 2, p. $5 \mathbf{r}$.

Byssus palustris confervoides \&c. Mich. nov. pl. gen. Tab. 89. fig. 7.

E) bipartita, flis simplicibus, longissimis, tenuibus, densissinis; articulis sub 3 plo longioribus; massa interna bipartita.

Conferva bipartita Dillw. Tab. 105. et Introd. 1. 42. - Ag. Disp. p. 29. - Jürg. Alg. Dec. 2, n. 9.

v) mucosa, filis simplicibus, lubricis; articulis diamctro 4plo longioribus, granulis adspersis, lutescentibus.

Conferva rivularis $\%$ mucosa Ag. Syn. p. 86 .

Habitat in amnibus rivulisque Daniae, passin, ut ad 'Torslör prope Frederichshavn Cimbrix; ad molam Bredde Scllandix; in fluviis pacatioribus prope officinam ferrariam Naes Norvegix, eopiose. - $\beta$. in fossis turfosis Geclslyng Sellandiae. - $\gamma$. in rivulo prope Thorshavn Frerox. 
DESC. Crspes longissimus, ulnari orgyaliqve longitudine, sub aqva flnctuans, rectus. Fila simplicissima, tenuia, capilli humani crassitie, in funes plures longissimos dense compacta et sxpe contorta. Articuli diametro 3-4plo et ultra longiores, nunc toti massî viricli granuliferâ sepleti, nunc medio pellucidi ;nterdum in statu adultiori tubuli interni bene conspicui, geniculis pellucidis; genicula alias obscura; ccterum articuli, si fila libere exsiccantur, xqve ac pracedentis, alternatim compressi. Color intense viridis. Substantia pro teneritate sat tenax. Vere et xstate. Chartæ laxe adhæret.

OBS. Ad antecedentem hace species prope accedit; differt tamen qvodammodo filis longioribus rectiorilus fluctuantibus, articulis longioribus et colore saturatiore. - Varietas $\beta$. Lanc nostram in plurimis adeo refert, ut vix inde, si qvid video, scparari qveat. - Varictas \% cespite gaudet spithamro et ultra, fluctuante, lutescente; articulis diametro 3-4plo longioribus, siccitate non alternatim compressis; massa interna intense lutea; chartx arcte adliret. Conferva rivularis Fl. d. Tab. 881, qrae l'amosa ibi sisitur, ex mente Cel. Agardhii ad gems I aucherice pertinet; inferior tamen figura, qvæ simplex et articulata depicta cst, hanc nostram laud male exprimit; dua ista plantx, in uno cespite forte fortuna comnixtæ, Cel. Miillerum, alias oculatissimum, facile persradere potuerint, utramqve ad unam speciem pertincre. - Praterea cum hac, de qua loqvimur, alga per aliqvot dies aliquando in aqva dulci servata esset, interioribus vasis vitrei, in qvo scrvabatur, lateribus punctula qvadam viridia affxa conspiciebantur, 'qvæ, ut crant, microscopio suljjecta e filis brevissimis, articulatis, dilute viridibus, internam hujus algæa fabrican omuino æmulantibus, constare cerncbantur (vide Tab. 48. B. 4); erant igitur pullulagines lujas speciei; ex hac autem observatione seqvitur, ut fila lujus Conferræ statim a prima inde infantia eandem, quam fila deinceps crescendo clongata nunqran non servant, qroal latitudinem habeant mensuram, eandemqve articulorum longitudinem; idem de omnibus Confervis valere opinor; quare Confervam qrandam, cuipiam alii simillimam, ast tenuiorem, pro statu ejus juniori, vel crassiorem pro statu ejusdem adultiori declarare, minus aptum videtur; est hec locutio vaga notio, non admittenda; tenuior vero species, si observatur, pro distincta spccie vel saltem pro Varictatc potins, me judice, habenda est. - Vetcres huic algre (si alias Conferva, cujus Plinius hist. nat. 1. 27. c. 8. meminit, hujus est loci; Ill. Sprengelius Hist. rei herb. P. 1. p. 206. eam at Confervam glomeratam traliit) ossa lumana fracta medendi sanandiqve vim attribnerumt, qvem in finem lane plantam cruribus brachiïse diffractis alligatanı, aqva freqventi irrorandam curarunt; cfr. Plin. l. c. Affirmat etiam nostro temporc Rev. W $\mathrm{W}$ ulfenius, (cfr. Crypt. aqvat. in annotatione sul, Conferva rivulari), se novisse focminam, qva, cum hrachium l,ntyro bulliente adeo combusisset, $\cdot$ ut mulnm inde cutis decoriatum esset, hujus Confervæ fasciculos, expressa prius aqva, lorachio ipsius tamdiu circumligavit, nsqvedum ea medicina deniqve sanatum esset. Sed hac medendi is potius in aqva frigidiori, qvam in ipsa Couferva, forsan qỵarenda est. - In- 
crebuit deniqve hac planta, cum Celcberumus wan Narum cam, utpote qra ad turfam producendam praprimis faceret, in nedium protulit; sed liac hujus viri sententia non nisi ex parte vera est, siquidem non solum Conferwa rimularis v. Marume (qvan noumulli pro Conf. fugarissime Roth habent), sed multe plures Confure ad hane nature operationcu vires suas invicen confernnt. (cfr. Dr. Crome in Hermstadt Archiv der Agriculturchemic 4 B. P. 255. et Hofmsun Bang De usu Confervarum in occon. nat. 1. 11.)

\section{* aque salsce.}

Tab. 48. 16. C. ceranicola; fil ss simplicibus, tenuissimis, rectis; articulis diametro aequalibus, rubris; geniculis pellucidis.

Habitat ad apices Hutchinsiae violacex in sinu Othiniensi, passin.

DESC. Fila caspitosa, agoregati, vix oculo mudo couspicua, abbreviata, linean unan circitcr longa. Articuli dianctrum longitudine sqvantes; tubuli interni subyradrati, rubri. Genicula pellucida, hic illic parun contracta. Hyeme legi.

'Tab. 49. 1\%. C. Racca; filis simplicibns, tenuissimis, minutissimis, faccidis; ar= ticulis diaunctro sul]) revioribus, viridibns; geniculis pellucidis.

Conferva flacca Dillw. Tab. 49. et Introd. p. 53.

Habitat ad littus Fionix septentriouale, apicibus Itutchinsix violacex alia-: rumqre adnascens, raro; ad insulas Froroeuses saxis insidens.

DESC. Fasciculus minutus, tres at pratuor lineas longus. Fila aggregata, simplicia, minutissima, oculo uudo vix conspicua. Articuli dianetro plerumqve dimidio breviores, apjecm versus eadem longiores, massa viridi tänsversim rectangulata notati. Genicula brevia, pellueida. Color viridis. Substantia tencrima. Amma. Vere et estate. Charta arcte adliceret.

Tab. 49. 18. C. implexa; fllis simplicibus, tenussimis, erispato-implexis, mollibus; articulis diametro duplo longioribus.

Conferva implexa Dillw. Introd. p. 46. Suppl. Tab. B.

Bangia viridis Fl. dan. Tab. IGor. fig. I.

Ilahitat in Gigartina plicata ad lithus Hofmansgave Fionix; ante ostium sinus Oxefiord Norvegix, copjose; ad littora Faroensia sat frequens.

OESC. Cespes pollicari arl pelalem et ultra extensione, densissimus, intricatus. lila simplicia, capillo humano tenuiora, maxime implexa, flexuosa, crispa1a, nollia. Arviculi diunctro sesqri-rel 2plo longiores, pellucidi vel massa viridi rectangulata, interdum in globulos collipssa, notati. Genicula obscura, plerungre pellncida. Color viridis vel sordide flarescens. Substantia tencra, tenax. Verce. Charte laxe allixeret. 
19. C. Cortuosa; filis simplicibus, tenuibus, implicatis, rigidiusculis; ar- Tab. 49. ticulis diametro subtriplo longioribus; geniculis pellucidis.

Conferva tortuosa Dillw. Tab. $4^{6 .}$

Habitat ad littora Færoensia, imprimis supra sabulum, qrod in summo refluxus limite saxa maritima hic illic obdncit, haud freqvens; in sinn Qvalböensi alibiqve passim.

DESC. Cxspes tres quatuorve pollices in extensione habens, sabulum in fissuras rupesircs maritimas projectum obdncens ideniqve nonnunqvam perreptans. Fila capillo humano parum crassiora, flexuosa, crispata, simplicia, intricata. Articuli diametro 2-3plo longiores. Color intense viridis. Substantia tenera, tenax. Aestate. Chartæ non adharct.

20. C. hormoides; filis simplicibus, tenuissimis, crspitosis, rectis, pen- Tab. 49. dulis; articulis diametro subrqvalibus, moniliformibus, interdum liyalinis.

Conferva penicilliformis Roth. Cat. bot. 3, p. 271?

Habitat ad littora Færoensia, saxis maritimis in summo refluxus limite adnata, copiose; etiam ad lapides maritimos littoris Hafniensis et ad trabes vallares munimenti 'Trekroner dicti, haud raro.

DESC. Cæespes de saxis declivibus pendulus, duos tresve pollices longitudine xqvaus, sublubricns. Fila capillo humano tenuiora, flaccida, recta vel ob undas irruentes leviter intricata. Articuli diametro xqvalcs vel eadcm parum longiores, moniliformes, globosi vel subovat, interdum ob massan intcrnam cvanescentem hyalini. Genicula contracta, obscura et pellucida. Color saturate viridis. Substantia tenera, sublubrica. Aestate. Chartæ adhæret.

OBS. Articuli noniliformes siccitate in qvadratos formantur, geniculis omnibus pellucidis. Nomen triviale hormoides, ex öpus monile et éioos species compositum, idem est ac moniliformis.

21. C. contorla; filis simplicibus, tenuissimis, crispatis, spiraliter con-Tab. 49. tortis; articulis diametro brevioribuis.

Habitat ad littora Færoensia stipitem !inferiorem Fuci vesiculosi viridi suo crespite parasitice obvesticns.

DESC. Crespes minutus, pollicen circiter longus lineamqve altus. Fila densissime intricata, simplicia, minutissima, flexuosa et spiraliter contorta. Articuli diametro breviores. Genicala subpellucida, brevissinza. Color saturate viridis. Substantia tenerrima. Aestatc. 
'Tał. 50. 22. C. faccicla; filis simplicibus, tenuibus, rectis, in penicillun abbreviatun fasciculatis, flaccidis; articulis diametro xqvalibus; geniculis obscuris.

Conferva flaccida Dillw. Introd. 12. 52. Suppl. T'ab. C.

- Toungana Ag. Syn. p. ss.

Ifahital all littora Ferocnsia et ad litus Srinöer Norvegia, Finco resiculoso insidens, laud raro.

DESC. Fasciculus penicilliformis, duas lincas ad scmipolliccun longus, crectus vel ob flacciditatem pendulus. Fila ex una bisi plurima, casppitusa, aggeregata, simplicia, llaccida, apiecun versus vis altemuata, obusil. Articuli inferjores dianetro dimidio breviores, superiores candem seqrantes, macula fuscescenti medio notati, interdum qraterati. Genicula obscura, post evsiceationem pellucidit. Corlor respitis fusco-viresccus, filorum sub lente dilute fuscus. Substuntiat tenerrima. Aestate. Charte alluxret.

'Tai). 50. 23. C. fucicola; filis simplicibus, tenuibus, cæespitosis, fasciculatis, rectis; articulis diametro iluplo longioribus.

Conferza fucicola Velley Tab. 4. - Mitl. 4, p. 156. - Dilliv. 'Tab. 66. et Inirod. p. 53. - Fl. dan. Tab. X/4א4. fig. 2. - WVall. A. lapp. N.995. - Sprengol in Lerl. Mag. sog. p. 190. 'Tab. 7. fig. I. - Ag. Disp. p. 28. et Syu. p. 75. - Jürg. Alg. Dec. ข. ก. 8 .

- ferruginea Rolh. Cal. bot. 5. 1’.27f. - Schum. enum. 2, p. 107.

- fucarsm Roth. Cat. bol. 3, p. 273? - Schum. enum. 2, p. 1ng.

Habitat in Fuco resiculoso aliisqve Thalassiophytis ad littora Daniac vulgaris.

DESC. Fasciculus penicilliformis. semipollicari en ultra lougitudine, cespitosus. Vila cx cadem radice scututa uigricante numerosissima, fasciculata, simplicia, recta, capillo humano tcumiola, apicen versus pram aucunata, apice obusit. Articuli ad basin diunetro scesgvilongiores, deinde sensim 3-4plo longiores, subpellucidi, granulis minutissmis dilute fuscis inordinate dispositis adsprersi. Genicula obscurat. Color dilute fuscus, fermineus rel flarescens, ersiceate subsplentens. Substantia membrantcea, tenas. Annua. Vere et astate. Charte adharet.

'Tab. 50. 24. C. ulothrix'; filis simplicibus, tenuibus, flexnoso-intricatis, rigidiuseulis; articulis dianetro brevioribus; geniculis pellucidis.

IIabitat in Gigartina plicata aliisqre algis ad littus maris Codani, Fioniam allucute, rarius.

DESC. Carspes parrus. 2-3 lineas longus, intricatus. Fila simplicia, caprillun Iumanum crassitic ectrantia, Ilexuosa, implicata, rigidluscula. Articuli diat- 
metro aqralcs vel dimidio breviorcs. Genicula hrcvissina. pellucida, parum contracta. Color saturate viridis. Substantia rigidiuscula. Vere. Charta. non adhæret.

OBS. Ad seqventem speciem proximc accedit, scd habitu uninori, 3plo tenuiori, crispatione majori et loco natali satis distingritur. A Conferva tortuosa, qram statura paulo exsuperat, articulis differt brevioribus. Ulothrix (cx ojisgs crispus et হọis capillus) qui crispos habet capillos.

25. C. Linum; filis simplicibus, crassiusculis, rigidis, crispatis, laxe im- Tab. 50. plicatis, longissimis; articulis diametro subbrevioribus.

Conferva Linum Fl. dan. Tab. 77 r. fig. 2, - Rotl. Cat. hot. 1, p. 174. 3. p. 257. Jürg. Algt. n. 20. - Schum. entum. 2, p. 107. - Ag. Disp. p. jo. et Syn. p. 34.

- Melagonium Pl. d. Tab. 1485. fig. 8. (excl. syn.)

- capillaris Huds. p. 598. - Lighte. p. 988. - Dillw. Tab. 9. et fntror. P. 47. Weh. et Mohr Gr. Conf. Tab. 9. - With. 4. p. 155. - Dillen. Tab. 5. . . 25. $A$. Pluckenet Phyt. Tab. 84. fig. 9. - Moris. III. S. 15. Tab. 4. fig. 4.

Ceramium I, inum Dec. I. f., 2, p. 47 .

Habitat in sinu Nakskov et Rödbye Lollandia, copiose; Mïller. - In radis simus Othiniensis et fossis ejusdem submarinis, copiose.

DESC. Crespes laxe intricatus, pcdali ct ultra extensione, gyris invicem flexuosis aqve libcre imatans. Fila simplicia, teretia, rigidiuscula, flexuosa, intrieata, si extricentur, uluari et ultra longitudine, setî porcinâ 2 plo crassiora, ubiqqe xqualia. Articuli diametro breviores vel eandem subaqrantes, opaei, siecitate contracti et corrugati. Genicula brevissima, pellucida, interdum hic illic turgida, articulo crassiora, ct tarn opaca, ut oculo inarmato facilc percipiantur. Turgida lıee genicula, microseopio subjecta, e grauulis rotundis vel ovatis, sulsstantia filorum membranacex immersis constare ccrnuntur. Color sordide vel flavo-vircsecns, cxsiccatæ dilutior. Substantia recentis rigidiuscula, fragilis, crsiccata rigiditatis exper's, flaccida, lenta. Amma. Vere et astate. Chartæ non adharet.

26. C. cerea; filis simplicibus, crassiusculis, rigidis, erectis, fluctuanti- Tab. 51. bus; articulis diametro brevioribus.

Conferva cerea Dillw. Tab. so. et Introd. p. 48. - Engl. bot. Tab. 1929.

Habitat in scrobiculis littoralibus, aqra marina stagnanti in summo refluxus limite repletis ad insulas exteriores ante ostium sinus Oxefiord Norvcgiæ.

DESC. Radix callus parvis, sentatus, concolor. Fila ex cadem basi plurima, crespitosa, simplicia, terctia, palmari ad pedalem longitudiue, seta porcina 2plo crassiora, sub aqra fluctuantia, erecta, sursum spectastia. Articuii diametro subaqualcs, breviores longioribus immixti, apicem rersus diametro 21plo longiores. Genienla brevissima, pellucida. Color dilute viridis. Sub- 
stantia recentis rigidiuscula, exsiccatic flacciela. Acstate. Clartic non adhacret.

Tab. 51. 27. C. Melagonium; filis simplicibus, crassiuseulis, rigidis, strictis; ar=ticulis cliametro triplo longioribus, siccitatc alternatim compressis.

Conferva Melagonium Web. \& Molir it. svec. p. 194. Tab. 3. fig. 2. a. b. - Roth. Cat. bol. 3, p. 254 - Dillur. Introd. p. 48 . el Sujpl. Tab. b. - Ag. Disp. p. 30. et Syn. p. 84.

Ilabitat ad saxa in profundo ostii sinus Othiniensis, et ad caules Fucorum ad oram Hofmansgave Fionia, rarius. Ad ostium sinus Oxcfiorl Norvegia. In occano Islandico, Weber ct Mohr. In mari Groenlandico, Wormskiold. Ad insulas Froconses in superiori refluxus limite, ut ad Ridevig, Qvivig, copiose.

DESC. Padix callus parrus, scutatus, niggicans. Fila ex earlem basi plurima, aggregata, raro solituria, simplicia, teretia, erecta, palmani ad spithamxam longitudine, seta porcina 2plo crassiora, rigidiuscula, sursum spectantia, stricta, ap̧ice obtusa. Articuli inferiores interdum diametro xquales, cetcri ad mum onnes 3 plo longiores. et si in exsiccatione nullan fila passa fucrint pressioncm, alternatim compressi. Genicula brevissima, pellucida, parum contracti. Color saturatc virilis. Snbstantia recentis rigida, exsiccatx flaccidior. Anmua. Veré cl xstate. Clutrtx non adhæret.

OBS. Qvando in locis natalibus Frrocnsibus, scroliculis nempe marinis, sub aqra conspicitur, omnino allesecre vel chalybis polita instar fulgere vidctur; extracta vero, hoc fulgore cvanescente, saturatc viridis apparet. - A parcedente differt articulis longioribus, rigiditate majori et colore intensiori. Gramula, qra in articulis contincntnr, and genicula, qua inde ntrinqve nigre-

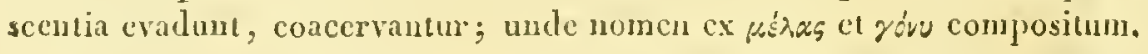

\section{诺米 subterrestres.}

Tab. 4S. 28. C. Pteridis; filis simplicibus, repentibus, acuminatis; articulis longitudinaliter plicatis, diametro triplo longioribus.

Conferta Pteridis Ag. Disp. p. 3r. et Syn. p. $z^{G}$.

Habitat ad radices $P$ teridis aqvilinae vulgaris.

DESC. Fasciculus densus, radicen P'teridis utrinq̣e obvesticus, salulo immixtus. Fila simplicia, intricata, setam equinan crassa, 3-4 lineas longra, apicem versus acuminati. Articuli diametro 3-4plo longiores, linca vel potius plica una altcrave longindinali flexnosa hic illic notati. Ginuicula obscura, interdum annularia, contracta. Color crspitis fusco-ruber, filorum sub lente aureus, rubro tinctus, splendidus. Substantia tencra, exsiccate fragilis. 
Per totum annum et in radicibus plante commenoratæ fere omuibus freqvens. Charte laxe adheret.

OBS. Inter substantiam radicis Pteridis aqvilince, unde succum nutritium basi sna hace planta verosimiliter assumit, atgve internam ipsius algæ structuram, tan qroad colorem quam quoad internam fabricam maxima interest affinitas. Qvare ctiam hanc algam nil aliud esse primum credidi, qvam fibrillas radicis, vel partes eidem sensim sensimqve axtate provectiori avulsas decompositasqve; cum vero lane specicm, qvæ qridem subterranca est, non solum in radice adultiori, sed etiam in juniori provenire, candemqve scmper formam induere observassem, ad sententiam Cel. Agardhï, distinctam hanc algam proponentis, non potui non accedere; analogica algarum subtcrrancarum cxempla insuper prebent Conferwa fodinarum Ag., cryptarum Dillw., Oscillatoria vaginata Vauch., ct forsan plura.

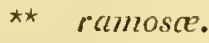

* aquere dulcis.

29. C. pusilla; filis ramosis, minutissimis, fasciculatis; ramis ramulis- Tab. 51. qve alternis, attenuatis; articulis diametro longioribus; geniculis obscuris, parum contractis.

Confcrva pusilla Rolh. Germ. 5, p. 524 ?

- lactea Rorh. Cat. bor. 3, p. 292?

Habitat in rivulo ad molam Lindved Fioniæ Confervæ glomeratæ parasitice insidens; Hofmann Bang.

DESC. Fasciculus mimntus, 3-4 lineas longus, virgatus. Fila minutissima, capillo humano multoties tenuiora, flaccida, ramosissima; rami alterni, superiores approximati, attcmati, subulati, aliisqve minoribus eadem ratione dispositis iterum obsessi. Articuli agre conspicui, in statu filorum subexsiccato qvodammodo in conspectum venientes, ad basin dianetro aquales, deinde aplo et ultra longiores, in apice ob tenuitatem evanescentes, punctulo viridescenti medio notati vel hyalini. Genicula obscura, interdum annnlaria, contracta. Color cæspitis læte viridis. Substantia tencrrima. Antumno. Chartæ adhæret.

30. C. nana; filis ramosis, minutissimis, caspitosis, rubescentibus; ra- Tab. 52. mis alternis, remotis; articulis diametro 2-3plo longioribus; geniculis obscuris.

Conferva nana Dillw. Tab. 30. et Introd. n. I16. - Web. et Molu Gr. Conf. Tab. 30. Habitat in lacu subalpino Vandsdalsvatn dicto prope Qvalböe Suderöe Færoæ, Fontinali antipyreticæ ad ripam habitanti hic illic copiose aduata. 
DESC. Fasciculus mimutissimus, vix semipollicari longitudine, colore suo singuJari facile detegendus. Fila singula riv oculo nudo conspieua, sub lente ramosit; rami alceni, remoti, apieen versus parum allemuati. Articuli di-

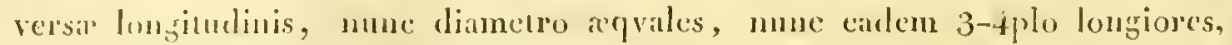
fascia virileseente notali vel hyalini. Color crespitis rubesecns in fulvum vergens, filosum sublente dilute virilis. Substantia tenerrima. Aestate. Chartac allacet, nee siccitate mutatur.

31. C. stellaris; filis ramosis, minutissimis, aeqvalibus, e basi orbiculari parallele exerntibus.

Conferve stellnris Fl. dan. Tab. G6n. fig. x. - Rohl. Cat. Lot. I, p. 163. - Schum. emi1m. 2, p. 105. - Ag. Sy11. p. 32.

- Wilcke Acr. Holm. 17ót p. 264. 'Tab. 8. fig. 2-7. - Naturforsch. VII. p. 189. Tab. 3. fig. 1. 2. 5 .

Habitat ad interiora latera rasorum vitreormm, qure aqva dulei dintius repleta fuerunt, hand freqventer.

DESC. Macula parrae, planx, virides, lincam cirritcr in dianetro habentes, vitri lateri arcte agghlutinate, orlbiculares, margine in stellula forman anguJato, sub lente grumose, mude orimutur fila recta, parallela, lluctumuia, minutissima, pollicem unum alterumve longa, ramosa; rani remoti, alterni. Apliculi dianctro f-5jplo longiores, interdum ob filorum tenuitatcm cvanescentes. Color exspitis viridis, filormn dilutior. Substintia tencrima.

OBS. Hare species, quan locis indicalis tempore vernali et astivo bis vidi, in figuram Flor:s danica optine 'fradrabat, fila modo longiora emittens: rami, imprimis ad apices siti, alterui, nee ut apud /Vilckium oppositi, apparedatut.

Tah. 52. 32. C. lubricu; filis ramosis, minutissinis, lubricis; ramis ramulisqre divaricatis, ragis, approximatis subulatisqve; articulis dianctro 'subluplo longioribus.

Conferva lubrica Dillw. Tab. 57. et Imrod. n. So. - Ag. Syn. p. 9- - Jürg. Alg. Dec. 1. ภ. 10.

- cxigua Dillw. Introd. 11. S-. Suppl. Tab. D?

Draparnaldia tenuis A Dec. 3 , n. 30 .

Habitat in stagnis prope Hofmamsgave Fioniae, saxis adnasecns. - In'rivulo rel amne prope Lundtofte Sellandice ad plantas aqvaticas.

DESC. Caspres densus. pollicen unum alterume longows, lubricus. Fila minutissima, capillo humano muloties temuiorit, debilia, flaccida, sub atpa lluetnantia, apicen rersus altennati, ramosil. Rami vagi, divaricati, nune remotiusculi, mune densi, alterni et oppositi, interdum subredicillati, atlemuati. aliisege minoribus brevioribusqge, eodem modo dispositis, acumina- 
tis, ulsessi. Articuli diametrum longitudine requantes, rel cadem 2-3plo longiores, medio zona viridi notati. Genicula olsscura. Color anocne viridis. Substantia tencrrima, lubrica. Vere el æstate. Chartæ aretc adliæert.

33. C. regagropila; filis e centro communi egressis, globulum consti- 'Tab. 52. tuentibus, ranosissimis; ranis ramulisqve subsecundis, obtusis; articulis diametro triplo longioribus; geniculis pellucidis.

Conferva regagropila Lin. Syst. nat. 2, p. 73t. - Huds. p. 6o4. - With. 4, p. 142. Dixon et Watson in Phil. Trans. Vol. 47. p. 499. - Fl. norv. 2, p. 142. n. rogs. - Engl. bot. Tab. 1577. - Roth. Cat. but. 3. p. 24亿. - Wels. et Molir it. sver. P. zI. Tá. I. fig. 4. a. b. - Dillw. I ab. 87. et lntrod. p. 66. - Ng. Disp. p. 32 . et Syn. p. $9^{2}$.

- Lrevissima Herb. Ehrh. (juxta exempl.)

Marleg Færoensibus.

Habitat in lacubus, passim; Gunnerus. In lacu prope Vay Suderöe Faroze copiosissime, totum fundum lacus, qvantum e ripa videre licuit, globulis suis numerosissinis denso crassoqve velamine nbiqve tegens, etian in ripam ejecta, sed numqvam in aqva superficie natans.

DESC. Globuli sphærici, minores majoribus dense immixti, a scminis Pisi ad Nucis Avellance, interdum. Ireglandis, magnitudinen excrescentes. Fila e centro conımuni progredientia, densissima, capillo lumnano parum crassiora, ramosissima; rami ranuliqve patentes, subsecundi, apicibus oblusi. Articuli diametro sua 2-3plo et ultra longiores, massî viridi in cylindrum collap̧sâ intus fareti. Genicula pellucida, prarum contracta. Color crpitis recentis saturate viridis, exsiccatæ dilutior. Sulsstantia rigidiuscula. Aestate. Charte non adluxret.

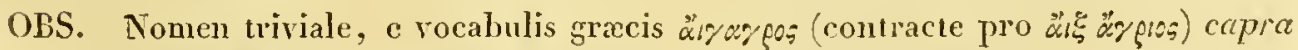
alpina, rupicapra, et mìnos, pileus, tapes spissus e lanu crassa compactus, pila, compositum, proprie denotat pilulas illas villosas, qva in stonachis pecorum qvorundam, cx. gr. Antilopes rupicaprce L. interdum inveniuntur (cfr. Kramer Elcnch. veg. ct anim. Austr. p. 320). sed a pilis, qræ in ufliciuis, ut antidota, sub nomine Bezoar prostant, diverse. Illud agagropila nomen Plarmacopæis olim usitatum ad Conferram nostram, qve pilulas istas refert, denominandam Perillustris Linncens apte adhibuit. - Conferwa vero regagropila, cujus meminit Gouan in Fl. Monspel. p. 460. et Sprengelius in Berl. Mag. 1809. p. 18\%, Ifippe e mari Mediterraneo allata, huc non pertinet, sed ad Conferyam proliferem Roth. referenda videtur. - Conferva agagropilct König, Zocga, Mohr. Hooker, ad Confervent nncialem sinc dubio pertinet; dicit enim Molurius in llist. nat. Island. p. 250, de hac specie: "E filis "tenuissimis, geniculatis, pilie instar intricatis constat; viridis est culoris et "in littus cjecta reperitur." Qvibus notis commotus hanc Königii specicn existimo esse Conferuan uncialem, de qva iufra, cui ctian nt synonymam, at dubitanter, adjungam. 
34. C. crispata; filis ramosis; ramis alternis, remotis; articulis cylindraccis, diametro 6-10plo longioribus, siccitate alternatin compressis.

Conferva crispala Roih. Cat. bot. 1, p. 178. - Schum. ellum. 2, p. ro8. - Dillw. 'Tab. 93. Et Introd. p. 64. - Ag. Disp. p. 3i. - Jïrg. Alg. Dec. 3. n. 9.

- rivularis $\beta$. crispata Ag. Syn. P. 86.

Habitat in aqvis stagnantibus Daniae; rarius. In vasculis aqvaticis, in qvibus in caldariis horti botanici Hafniensis exotica qvædam Nymphæx species servantur, aliqvando vidi.

DESC. Caspes densissimns, interdum late patens, pedali et nltra longitudine. Fila remotissine ramosa, capillum humannm crassa, deusissime implexa. Rami subelichotoni, alterni. Articuli diametro multoties longiores, massa viridi farcti, qra in adultioribus speeiminibus in lincan longitudinalem spiraliter tortam sape collabitur, siceitate alternatin compressi. Genieula obscura. Color saturate viridis. Substantia membranacea, tenax. Aestate. Clarta laxe adhæret.

OBS. Ad Confersam rivularem Varietatis nomine lane speciem pertincre Cel. Agardhius contendit; attames ob ramositatcm suam al, ea separari posse videtur.

Tab. 52. 35. C. fracta; flis ramosissimis, fleruosis; ramis ramulisqve divaricatis, subalternis; articulis diametro 4plo longioribus.

Conferva fracta FI. dun. Tab. 946. - Dillw. Tab. 14: et Introd. p.65. - Web.et Mohr Gr. Conl. Tab. 14. - Rolh. Cat. Lot. 3, p. 250 - Ag. Disp. p. 31. et Syn. p. 88. - Jürg. Alg. Dec. 4. n. 9.

- divaricala Roth. Cat. bot. r, p. 179. - Schum. enum. 2, p. 108.

- z'agaliunda Huds. p. 60I. n. 35. - Lightuf. p. 990. - Dillen. Tab. 5, fig. 52. - Fl. norv. 2, p. 107. - With. 4. p. 139.

B) hirta, geniculis ob Echinellas ei insidentes obsoletis.

Conferva hirta Fì. dan. Tab. 947.

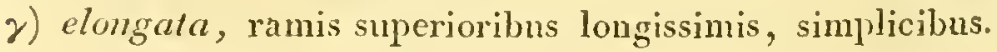

Conferva divaricata $\beta$. clongata Roth. Cati bot. I, p. 13 I.

d) marina, filis crassioribus, viridi-flavescentibus.

Confurva fracla \% marina lioth. Cat. bot. 3, p. 234. - Jürg. Alg. Dec. 1. n. 6.

- refracta Rolb. Cat. bot. 2, p. 193?

Ccramiun vagabundum Roth. Fl. germ. 3, P. 465.

Habitat in fossis stagnisqve Danix, aqva dulci repletis, sat vulgaris. - $\beta$. loens natalis in Flora danica desideratur, attamen certe in aqva dulci inventa: - $\gamma$ in scrohiculis marinis Facoensibus, freqventer. - $\delta$ in sinu Otliziensi. 
DESC. Stratum densissimum, crassius, aepre superficiei innatans. Filn lamosissima, implexa, capillum humanum crissitic expantia, si extricentur, duos ad qratuor pollices longa, æqualia. Rami divaricati, remotiusculi, alcuni, interdum tanen nommulli secumdi, aliisqre eadem ratione pluries ciispositis iterum itcrumeqre olssessi, apicem versus aliqrantum attennati, acnti. Articulorum alii diametro 4-5plo et ultra longiores, alii imprimis ad basin breviores. Genicula plerumqve pellucida. Color sordide viridis, interdum flavescens. Substantia rigidiuscula, exsiccatæe fragilis. Vore ct æstate. Chartæ laxe adhæret.

OBS. Articulos medio iutumescentes, qros Cel. Dillwy'nius delineandos curavit, nondum observavi; corpuscula illa globosa, limbo pellncido cincta, qva pro capsulis venditavit idem auctor, hæe, teste Ruthio, nil alind sunt, qram ovula insecti cujusdam. - Conferwa hirtam Fl. dan. Tab. 947. Junic specici ut varietatem merito adposui; nam ex figura Fl. dau. facile patet, eam, sipvidem Lemna trisulca cespiti cjus immixta est, incolam esse aq̣ra dulcis, et cpramvis unlla in eâ genicula conspiciantur, hoc tamen non magni est momenti; nam 1, tempore veruali fila hujus Conferr a ob massam iuternam densissimam plane opaca et continua, adeo ut nulla genicula appareant, iи conspectum luaud i'aro veniunt, et 2, Vorticellis atqve Echinellis adeo obsessa est, ut, si vel genicula adessent, ab istis parasiticis plane obtegerentur. - Cetcrum de textu Floræ danica, locum natalem omittente, observandum est, inter manuscripta defuncti Mülleri Cel. Vahlium, ejusdem suceessorem, nil qrorl hanc tabulam illustraret, sed modo ipsam æeri incisam reperisse; idem etiam valet de Tabß. 945 et 949, Tvæ meo jurlicio Confervam flavescentem et $V$ aucherian clavatam sistunt. - Varictas $\%$, qræ locis indicatis copiose invenitur, pro distincta specie facile laberi possit; fila enim longissima, recta, æq̣alia, ulnari ct ultra longitudine, simplicissima videntur, articulis dianctro 4-5 longioribus, geniculisqve obscnris; at si deligentius examinautur, videmus, ea afl basin filo majori crassiorifye Conferra nostræe esse annexa; ceterum color cesplitis, radiis solis in scrobiculis tepidis cxpositi, flavescens evadit, elotionis speciem prese ferens. - Tenipore hyemali vidi in Varietatı: $\delta$. corpuscula yrædam parasitica (cfi. Tab. 5?. D. 2.), qra sine dubio sunt ovula insecti cujusdam matrini.

36. C. sericea; filis ramosissimis; ramis inferioribus verticillatis triclıo- 'Tab. 53. tomisqve, superioribus oppositis; ranulis ultimis subsecundis, fasciculatis, confertis; articulis diametro qvintuplo longioribus.

Conferva sericea Fl. dan. Tab. 65r. fig. r. - Wulf. crypt. n. 24. - Ducluz. Ess. p. 45 .

ß) intricuta, filis ramosissimis, maxime intricatis, gyras vcrmictlariter Tab. 53. flexuosas constituentibus.

y) marina, filis ramosissimis, sericeis, rectis. 
Conferva sericea Huds. p. 6ot. - Wills. 4, p. 140. - Dillen. Tab. 5. fig. 53.

Ceranium sericeum Dec. ก. Tr. 2, p. 42.

Habitat $\alpha$. in amme Frederichsdulino Sellindix, haud vulgaris; Miiller. Ad trabes inundatas molarum, ad saxa rivulorum rapide fluentium, sat vulgaris. - ß. ad ripau lacus Fuursöe Sellandia, passim. - $\gamma$. ad littus 'l'orbaek Scllandiae alibiyre.

DESC. Radix parra, sentata, unde oriuntur fila in erspitem spithamaum ot ulIra fasciculation congesta, capillun humanum crassitic fere iequantia, mollia, debilia, flaccida, ramosissima: rami inferiores plerumqre trichotomi, sape rerticillati, interdum alterni, angulo acuto exenutes, patentes, aliistre codeun morlo dispositis pluries obsessi; ramuli ultumi breves, interdum felongati, adpressinsculi, alterni, et sape secundi, remotinsculi. Articuli inferiores diametro sua 3 plo longiores, superiores 5-fiplo longiores. Genicula obsetura, post exsiccationcm noununquan pellucidla. Color late virielis, exsiccata subnitielus, scricens, unde nomen. Substantia membranacea, tenera, tenax. Acstate. Chartie laxe adhiperet.

Tab. 53. 37. C. glomerata; filis ramosissimis; ramis alternis, fasciculatis; ramulis ultimuis brevibus, sccundis; articulis dianctro qvadruplo longioribus.

Conferet glomerata Lin. Syst. nat. 2, p. 721 . - Huts. p. 602. - Lightf. p. 993. - Wull. With. 4. p. 1.10. - Sclum. cnum. 2, p. 108. - Fl. dan. Tab. 651. fig. 2. - Wull.

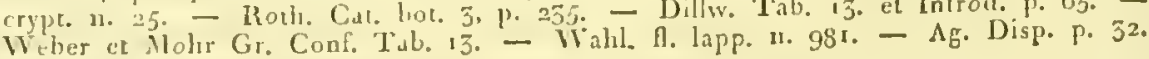
Weber ct 30 . p. 89 .

- minor ramosa Mloris. 11l. Sect. 15. Tub. 4. fig. 2.

- fontinalis ramosissina glomeratim congesta Dillen. Tab. 5. fig. $3^{\mathrm{r}}$.

- cristaca Roth. Cat. bot. 1, p. 195. 2, p. $22 a$.

- vaginata Ducluz. Ess. p. 42.

- canalicularis Girod. Cliantr. Conf. p. 173. Tab. 2.4. fig. 62.

Alga fontalis trichoides Bauh. Pin. 1. 364. - Alga sive Conferva fontalis trichodes Parkins. theatr, bot. p. 126 r. fig. $r$.

Polysperma glomerata Vaucl. p. 99. Tab. 10. fig. 4. 5. (minus apte)

Chantransia glomerata Dec. A. fr. 2, P. $5^{1}$.

Tab. 53. B) macrogony a, filis ramosissimis; ramis alternis, remotis, elongatis; ultimis interdum sccundis; articulis diametro 10plo longioribus.

y) marina, flis ramosissimis, viridibus, crassioribus, ramulis ultimis secundis.

Conferva glomerata $\beta$. marina Roth. Cut. bot. 5, p. 237.

- late virens Dillw. Tab. 48? Engl. bot. Tab. 185 í 
Habitat in amne Frederichsdalino Sellandia, rarius; Miiller. Ad saxa rivulorum, et in aqvis puris rapidius fluentibus Danire, vulgaris. In rivulis Færoensibus. - $\beta$. in rivulis Færoensibus, ut ad Qvalböe Suderöe. $-\gamma$. in sinu Othiniensi et alibi freqvens.

DESC. Radix cxigua, scutata, nigricans. Fila aggregata, tres pollices ad spithaınam longa, capillum humanum crassitic xqvantia, Iluctuantia, conferta, dcbilia, ramosissima, attcnuata. Rami alterni, divaricati, angulo tancn acuto exeuntes, apicem versus fasciculati, virgati. Ramuli snmmi simplices, secundi, e qrovis geniculo singuli excmntes, approsimati, qvo magis ad apicem appropinqvant, co breviores, apice obtusi. Articnli diametro 3-4plo longiores, massa viridi aut toti farcti, aut utriculati. Genicula obscura. Color saturate viridis, interdum dilutior. Substantia nncubranacea, pro teneritatc sat tenax. Aestatc. Chartæ laxe adhæret.

OBS. In hac specie, ut etiam in Zygnemate quinino, in stagnosis Hals prope Hofmansgåve Fionix tcmpore vernali vidi animalculum infusorium, qvod in concha urccolata, bresiter stipitata, non pellucida, fusci vel olivacei coloris habitabat, caput ex orificio conchæ suæ freqrenter et vivaciter exserens (cfir. Tah. 53. B. 3.); in opcre prestantissimo Cel. O.F. Mütleri de animalculis infusoriis cum hanc specicm frustra qræsiverim, opcre pretium habui brevem cjus hoc loce injicere mentionen; cum autem sensu strictiori huc non pertinet, in transitu solummodo hoc dictum esse censeatur.

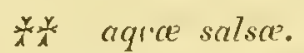

38. C. crystallina; filis ramosissimis, tenubus; ramis subverticillatis vel subdichotonis; ramulis ultimis secundis, solitariis, strictis; articulis subpellucidis, diametro 10plo longioribus.

Conferva crystallina Roth. Cat. bot. 1, p. 196. 3, p. 259. - Ag. Disp. p. 31. et Syn. j. 90.

- pura Roth. Cat. bot. 2, p. 22r. - Wulf. crypt. n. 22.

B) virescens, filis saturatius coloratis.

Conferva crysiallina $\beta$. virescens Roth. Cat. bot 3, p. 239.

Habitat in sinu Othiniensi; Ilofinann Bang. Ad littus Neustadt Holsatiæ, et ad insulam Fimbriam, copiose; Roth. - $\beta$. ad ostium sinus Kalvesund prope Arendial Norvegia Pliycoidatis adhærescens.

DESC. Fasciculus densus, palmari et ultra longitudine. Fila a basi usqve ramosissima, dense implexa, 3-4 pollices longa, capillo humano crassitie arqualia. Ihami inferni subverticillati, hasi patentes. deinde erecti, densi, apicem versus remuliorcs, bini vel terni ex yrovis geniculo exemnes. Ramuli subsccun- 
di. breves, patentes, attenuati, ipsice obtusi. Articuli diametro plerumgre 10plo longiores, massa dilnte virescente e granulis minutissimis constante fareti;

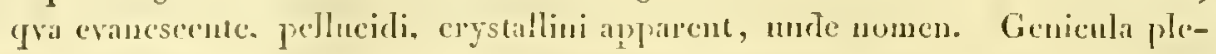

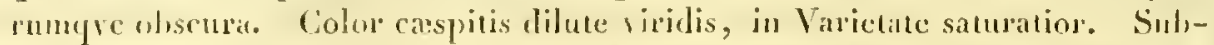
stautiat tencrat, exsiccata subfragilis. Aestate. Charte non adhæret. Siccitatc non mutatur.

Tab. 54. 39. C.rupestris; filis ramosissimis; fasciculatis, virgatis, rigidis, strictis, apice obtusis; ramis subtriclıotomis, alpressis; articulis diametro 4 plo longioribus; geniculis pellucidis.

Conferva rupestris Linn. Syst. nat. 2, p. 72r. - Ifuds. p. Gnr. - With. \&. p. т保Light. ". 994. - Vl. norv. 2, p. 107. T'ab. 3. liq. 3. (figura mala). - til. dan. Tab. 9.48. - Schum. enum. 2, p. 108. - Wult. crypt. n. 2\%. - Rolh Cat. bot. 2, p, 208. 3. 1. 245. - Dillw. Tab. 23. et Intrad. P. 65. - IVeb. et Molir Gr. Conf. "I'ab. 23.

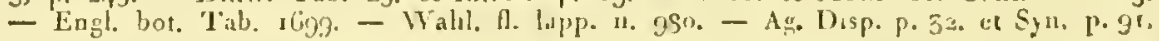

- glarca Roth. Citt. bot. 2, p. 2ng. Tab. 6. (Algan siccatam sistens).

- virgata Roth. Car. bot. 1, 1. 195.

- pellucida Ituls. p. 6or. - With. 4, P. 139. - 1)illı. Tab. 90?

- Dilles. 'l'al). 5. fig. 29. - Pluk. Phỵı. Tab. 192. fig. 6.

Ceramium asperum lioth. Cat. bot. 2, p. 1So. (ex inente Web. \& Mohr).

- rupesere Dec. A. Ir. 2, p. 42.

Fucus seu Alga zulgaris viridis Kịll. Virid. p. 45 n. 6.

B) flexuosa, filis dichotomo-ramosis, rigidiusculis; ramis flexuosis, alternis; ranis subsimplicibus, alternatim secundis, patentibus; articulis diametro sub 3plo longioribus.

Conferm flexinosa Fl. dan. Tab. 882. - Di!lw. Tab. 1o. et Introd. p. 65. - Vieb. et Molir Gr, Conf, Tab. so. - Roth. Cat. bot. 3, p. 234.

Ifabitat ad rupes maritinas Norvegix; Mlïller. Ad littora Danie saxis et

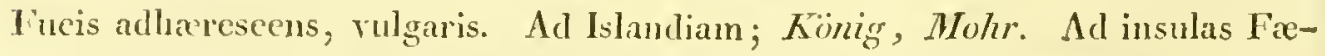
roenses, copiose. - B. ad littus Fionix septentrionale, haud freqvens.

DESC. Radix para, scutata, nigricans, unde oriuntur fasciculi densissini, tactu rigidiensculi. polliconn unum allerumve longi, panosissimi. Fija a basi ad apicrme sujpraccomposito-rannosa, stricta, virgatta, capillo lumano crassiora.

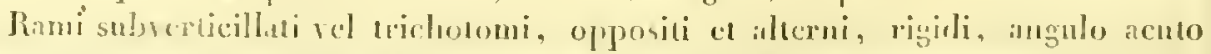

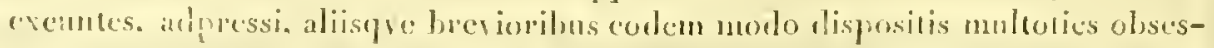

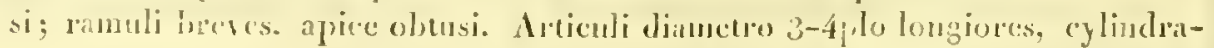

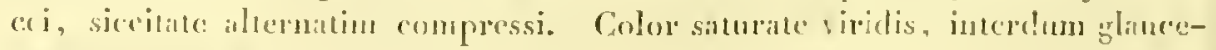
seens. Sulstantia rigielinscula, tenax, lubricititis expers. Annna. Vere et xstatc. Chlartic nun adheret.

OBS. Mel insulas Pactoenses aprecs hujus Conferve interdum fusci vel atrombentis conspiciuntur coloris, qui as parasitis minutis, nempe Callihamnio Da- 
wiesii, Diatomate marino, Fragilaria striatula \&c., tva nonnunqram copiose adsunt, originem ducit. - Varietas $\beta$, a plerisqve pro distincta specie habita, a Cel. Igardhio ad Conferwam fractam refertur; milhi revo ub locum natalem, staturam rigislan crassioremqve, huc pertinere videtur; lıec autem Varictas cum Conferve flexuosc Roth. Cat. bot. 2, p. 188. et Wulf. crypt. 11. 13, qra mihi est Scytosiphon compressus f. crispatus, de quo antea, ue confundatur.

40. C. arcta; filis ramosis, strietis, virgatis; ramis subpatentibus, alternis, ultimis sparsis, adpressis; articulis inferioribus diametrum longitudine agrantilus, superioribus 8-10plo longioribus.

Conferva arcia Dillw. Introd. p. 67. Suppl. Tab. E.

Habitat ad saxá maritima littoris Thorshavn, passinı. Ad littus Norvegix, IIofmanu Bang. Ad trabes vallares munimenti Trekroner prope Hafniam, 1'arius.

DESC. Radix parva, scutata. Fasciculus inde ortus densus, polliccm circiter longus. Fila subdichotoma vel ramosa, cajillum humanum crassitic acjantia, stricta, virgata, Rami angulo acuto excuntes, inordiuate dispositi, remoti, jlerunqve alterni, raro oppositi, subpatentes; ramuli ultimi breves, adpressi, obtusi. Articuli longitudine variabiles, ad basin diametro aqvales, apicen versus ita prolongati, ut ultimi dianetrum 10plo et ultra longitudine superent, subpellucidi, massa interna in cylindrun utriculatum collapsa. Color dilute

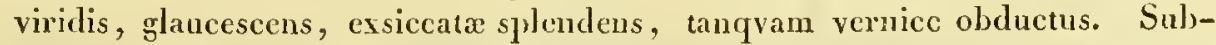
stantia membranacea, tenera, exsiccatæ flaceida. Annua. Vere. Charte laxius adharet. Articuli exsiccati plani, longitudinaliter plicati, ucc alternatim compressi.

41. C. flavescents; filis ramosissimis, subdichotomis, flexuosis; ramis alternis, divaricatis; ranmlis lateralibus brevibus, horizontaliter patulis; articulis eylindraceis, diametro decuplo longioribus.

Conferva favescens Roth. Cat. bot. 2, p. 22\%. 5, 24r. - Schum. enum. 2, p. 108. Dillw. Introd. p. 64. Suppl. Tab. E. - Ag Syn. Introd. p. XXX.

- pennacula Fl. dan. Tab. 245? - Dillw. Introd. p. 64. n. 95.

Habitat in sinu Flenopolitano Holsatize, Herb. Hornemanni. - In aqva bullienti Geyseren Islandia abundanter et luxuriose; Hooker.

DESC. Cxspes densissimus. Fila intricata, minutissima, Ertocarpo littorali 2 plo tcnuiora, palmari et ultra longitudine, subdichotomą, flexuosa, ramosissima. Rani alterni; ramuli breves, horizontaliter exeuntes, parun attenuati, obtusi. Articuli dianctro 8-10plo longiores, granulis oblongis, saturatius coloratis, 
hic illic in lineas flexuosas congestis adspersi. Genicula subpellueida, sape obsenrat. Color sordide llavescens. Aestate. Charta adharet.

OBS. De Fl. d. Tab. 945. nil ecrti diccudum; nam, ut jam antea sul, Conferre fracte monni, nullus locus natalis additus cst. Terosinilitcr tamen, assenticnte Col. Rothio Cat. bot. 2, p. 22.4, hace Tabula nostram plantam sistir; corpora antem parasitica, ei insidentia, procul dulio sunt Echineller fascicrelate.

Tab. 54. 42. C. nigricans; filis dichotomis, rigicliusculis, rectis, densis, reqvalibus; rannis remotis, elongatis; articulis diametro triplo longioribus.

Conferta nigricans Rolh. Cat. bot. 3, p. 277. - Dillw. Introd. p. 63. et Suppl. Tab. E: - Jür. Alg. Dec. 亿. n. 10.

Hubitat in amne prope littus marinum ad Friderichshavn Cimbric; Prof. IIornemalul.

1)ESC. Fila sub aqve superficic cxspitose congesta, setam porcinam crassitie atprantia, palmari ad spidhuaan longitudine, plurics dichotona. Rami chongat, remoti, basi patentes. eqvales, aliisque breviorilus sparsim obsessi. Articuli dianctro 3-4plo longiones, granulis adspersi confertis, yra ad genicula conflucutia articulos modio pellucidiores reddunt; siccitate interdum alternatim compressi. Genicula obscura. Color viridi-nigricans, flavo interdum tinctus, essiccata nigresecus. Substantia menbranacea, tcracior, lnbricitatis expers. Acstate. Charta non allixect.

Tab. 55. 43. C. Wormskioldii; filis ad basin ramosis, rqvalibus, tcunibus; demum simplicibus, crassiusculis, moniliformibus, lubricis, elongatis; articulis cliametro aequalibus, turgidis, ellipticis.

Conferva Hormskioldii Fl. dan. Tab. 1547. - Ag. Syn. P. 85.

Sapangaursak Groenlandis; cfr. O. Fabrää Lexicon groenlandicodanicum. p. 400.

Uncrassib Sarpangei Groenlandis; Ag. Syn. p. S5. secundun Wormskiold.

\section{Habitat ad littora Godthaab Groenlandia; Wrornskiold.}

DESC. Fila cespritose congesta, parallele fluctuantia, ulnari et ultra longitudiue, ad hasin ranosa, tenuia, capilli lumani crassitie, deincle in seta porcina et scusim penua passerina crassitndincm excrescentia, simplicia, apicon versus iterum attenuata. Articuli dianetrom longitndine snberjantes, in filis crassiusenlis insigniter moniliformes, elliptici el rotundi, umrgili: in filis temuiorilus dianctoro sape aplo Iongiores. Genicula contracta, plerumpre pellnridla. Color viridis. Substantia membranacea, tcnerit, lubrica, mollis. Charta adharets

OBS. Ad lintora maris Groculandici, Icstante Col. O. Fubricio, qui hane elemantem speciem jandudum ibi legit, sat vulgaris; a Conferwa Meletgonio, qram 
crassitie reqvat, quin etian excedit, lubrica mollioriqve structura differt; memJrana filorum crassiorum sub lente nee punctata nee reticulata apparet, sed, massa interna glanulosa evanescente, omnino hyalina. Ceterum cum hane specicm contra alios ramosam descripsi, nonere liceat, me speeimina a Cel. II ormskioldio lecta diligentissine inquisivisse, qva cum ad basin ramosa comperissem, meritum, ut vielent, in hae subdivisione huic speciei locum assignavi. - In nomen gröenlandicum, qrod Agardhins secundum // ormskioldium attulit, error sine dubio irrepsit; nam vocabulum. Unerassib et Fabricio et Giesekio erat ignotum.

44. C. obtusangula; filis ramosis, flexuosis, crispis; ramis remotis, sub- Tab. 55 . simplicibus, angulo rotundato exeuntibus; articulis dianetro duplo longioribus; geniculis pellucidis.

Conferva riparia Dillw. Introd. n. Ir. Suppl. 'Tab $E$.

Habitat ad insulas Freroenses, rupibus declivibus maritimis in summo refluxus limite hic illic, ut ad Nas et Qvivig Österöe, copiose adıata; etiam ad rupes maritimas, qve aqva dulci irrorantur, ut ad Nosocomium Arge prope Thorshavn. - Ad littora Groenlandiæ; Herb. Wormskioldii.

DESC. Cxspites per rupes abruptas vel declives penduli, palmari et ultra extensione, flexuosi, bullosi. Fila maxime intrieata, capillum humanum erassitie æefvantia, fragilia, ramosa; rani remoti, divaricati, rel snbdichotomi, angulis dichotomiarum insigniter rotundatis. Articuli diametro 2-3plo longiores. Genicula pellucida, vel ob massam internam eoufluentem inconspicua. Color exspitis viridis vel ob elotionem freqventemn sordide flavescens. Substantia filorum rigidiuscula, fragilis, in articulis faeile secedens, sub cultello crcpitans. Vere et æstate. Chartæ non adhæret.

45. C. ferruginea; filis ramosissimis, minutissimis, flaccidis ; ramis ra- Tab. 55. mulisqve suboppositis; articulis diametro triplo longioribus; geniculis obscuris.

Habitat ad insulas Færoenses, rupibus maritimis abruptis in summo refluxus limite adhærescens, àt ad Næs Österöe et ad Höyvig prope Thorshavn. Etiam ad littus Groenlandix; Herb. IVormskioldii.

DESC. Cxspites per rupes abruptas penduli, strieti, flaccidi, 2-3 polliees longi. Fila reeta, invicem sibi tanqram viscide agylutiuata, ramosissima; rami ramıliqve plerumqve oppositi, interdum alterni, patentcs. Artieuli dianetro 2-4plo longiores, intus linea rufo-fusca vel massa dilutiori repleti. Genienla obsenra. Color fulvescens vel ferruginens. Substantia tencrrima, lenta, viscida. Vere et æstate. Chartæ bene adhæret. 
OBS. In lembrio If ormskioldii groenlandico eandem speciem vili, et in nonunllis cjustem speciminibus globulos fuscos dlijticos in apicibus ramulormu terminales, quales in Tab. 5j. C. 3. depicli sumt, observavi.

Tab. 56. 46. C. lanosa; filis ramosis, tenuissimis, rectis, fasciculatis; ramulis remotis, elongatis; articulis inferioribus diannetro 2plo, summis 5 plo longion-ribus.

Conferva Innosa Roll. Cat. bot. 3. p. 291. Tab. 9. - Dillw. Introd. p. G8. Suppl. Tab. L. - Ag. Syn. p. go.

Habita ad littus Holsatiae; Herb. Hornemanni. - Ad littus 'Torbak Sellandixe, Gigartine subfusce insidens; etian ad munimentum 'Trekroner prope Hafnianı.

DESC. Rerlix perpusilla, seutata. Fasciculus peripheria subrotundus, densissimus, semipollicari longindinc. Fila confertissintil, capillo humano tenuiora, sex at coctu lineas longa, recta, ramosissima; rami romoti, alterni, clongati, simpliecs, apiecen versus parum attentati. Articuli longitudine variabiles: inferioues diamctro 2 plo, superiores 4-5plo longiores, sublyalini, granulis hic illic: arlspersi, nunc fascia transiersali notati, nume utriculati. Genicula obseura. Color flavo-virescens: exsiccala dilutior, nitens. Sulostantia monbranacea. protencritite sat tenax. Anuma. Aestate. Cliarta arcte adlixeret.

Tab. 56. 47. C. uncialis; filis e centro communi egressis, ranosissimis, fasciculatis; faseiculis antice clavatis, rotundatis, semiglobum constiturntibus; ramis remolis, divaricatis, uttimis brevibus subsecundis; articulis dianetro subduplo longioribus.

Conferra uncialis Fl. dan. Tab. 77t, fig. 1.

- regagropila Mohr Hist. nat. Jsl. p. 250? - Künig, Zoegn, llooker.

Habitat ad scopulos insularum exteriorm Norvegia, iisdemgre in ipsa aqua marinæ superficie affixa, ad liftus intes Öster-Riisöer et Arendal sat vulgaris.

DESC. Raulix callus parrus, scutatus, nigricans, subtus rupibus allixus, ex qro fasciculi viginti et pluses progrediuntur, densissime compacti. prollicem fere longi, sursum incrassati et apiec rotusdati, onmes cjusdem longitudinis, qpor fit. ut spluxrulam vel potius hemisplsitrulam, ovo columbino prato majorem, ronstituant. Fasciculi, si extricentur, ex filis unmerosissinis, densissime intricatis, semipollicasi vel pollicari longitudine, capillo hunnano tennioribus, lamosissimis, coustare cermunur' ranni remotinsculi, alterni, patentes, elongati; ramuli breves, subsecumeli, lorizomaliter patuli, curvati, sursum speclantes. Articuli inferiores dianetro 5-6plo longiores, superiores canden plexumçe xquantes, granulis mimutissinis sine ordine dispositis adspersi, Ge- 
nicnla obscura, interdum ob massam internam condensatam minus conspicua. Color viridis, exsiccatæ dilutior. Substantia tencrrima, lenta. Acstatc. Chartx laxe adharet.

OBS. Cespites in loco natali foraminilons cylindricis, qva ab Oniscis atqve aliis animalculis marinis cos inhabitantibus origincm ducunt, tanqqvam pcrforati sæpe conspiciuntur. - De Conferva agagropila Molvr, qvam huic subjunxi, vide qræ ad Confervan aggagropilam antea ammotavi.

48. C. centralis; filis e centro communi egressis, fasciculum planum or- Tab. 56. bicularem constitucntibus, strictis, ramosissimis; ramis ramulisqve sparsis, ultimis secundis, adpressis; articulis diametro subduplo longioribus.

Conferva Hutchinsix Dillw. Tab. Ing. et Introd. p. 65?

Habitat in sinu Othiniensi tempore vernali in vadis sabulosis, aqva deficiente, rclicta, sat vulgaris.

DESC. Fasciculus planus, orbicularis, e centro radians, duos pollices ad palmam in dianctro habcus. Fila e centro communi egressa, numerosissima, recta, interdum flexuosa et intricata, setam eqvinam crassitie fere xqvantia, ramosissima; rami ad basin patentes, nunc remoti, nunc densiores, alterni vel secundi, aliisque eodcm modo dispositis iterum iterumqre obsessi; ramuli ultimi secundi, adpressi, attenuati. Articuli diametro sua 2plo longiores, interdum eandem æqvantes, utriculati, granulis adspersi. Genicula pellucida. Color dilute viridis, exsiccate haud raro flavescens. Substantia membranacea, tencra. Amnua. Primo vere. Chartæ laxe adhæret.

\section{*** subterrestres.}

49. C. muscicola; filis ramosis, repentibus, flexuosis; ramis ramulisqre alternis, divaricatis, acuminatis; articulis diametro subtriplo longioribus.

Conferva muscicula Web. et Mobr It. svec. p. 6o. Tab. 1. fig. 3. a. 6. - Roth. Cat. bot. 3, p. 297. - Aq. S S sil. p. 73.

- castanea Dillw. Tab. 72. et Introd. p. 6r.

Habitat in locis liumidis, umbrosis, muscos perreptans, circa Hafniam ; $\boldsymbol{H}^{\mathrm{T}}$ ber ct Mohr. - Supra muscos ad officinum ferrariam Næs Norvegiæ.

DESC. Fila cxspitosa, repentia, varie flexa, duas tresve lineas longa, capillo humano tenuiora, ramosa. liani ramuliqve altcrni, remotiusculi, horizontaliter patuli, apice acuminati, subulati. Articuli caulis longissimi, ob opacitaten ejusdem vix conspicui, in ramulis evidentiores, subpellucidi, et diaractro 3-4plo longiores. Gcnicula obscura. Color fusco-ferrugincus rel brunneus. Substantia subcartilaginea, membranacea. Acstate. Chartæ non adlixret. 
50. C. Orthotrichi; filis ramosis, cæspitosis, abbreviatis, rigicliusculis; ranis vagis, patcntibus; articulis fere inconspicuis.

Conferva Orthotrichi Dillw. Tab. 89. es Lntrot. n. 81? - Ag. Syn. P. 73?

Habitat supra Orthotrichum striatum prope Rideviga Österöe Færoæ alibiqve, haud freqvens; ctiam ad Svinöer prope Lindesnas Norvegia.

DESC. Caespites minuti, 3-4 lincas hu dianetro labentes, abbreviati, intricati. Fila inter ranulos et folia Orthotriehi deusissime compacta, rigida, fragilia, lincan circiter longa, selam eqvinan crassa, ramosa; rami breves, divaricaii, apice obtusi. Articuli in apice ramulorum interdum conspicui, dianetrum longitudinc subergantes, ceteri ob filorum opacitatcul vel soliditatem inconspicui. Color caspitis firscus, filorum sub lente olivaccus. Substantia cartilaginea, rigida, fragilis. Acstate. Chartæ non adharet.

OBS. Forsan ad tichenes haxe species potius csset referenda, et ex Algarum numero excludenda.

51. C. Acharii; filis ramosis, caspitosis, rigidiusculis, suberectis; ramis brevibus, obtusis; articulis diametro 2-3plo longioribus.

Conferva Acharii Web. et Mohr It. svec, p. 10\%. Tab. 1. fig. 6. a. b. c. - Roll. Cas. bot 3. p. 298. - Dillw. 'I'al. 69. et lintrod. p. 61. - Ag. Syn. p. 74.

Parmelia velutina Ach. Meth. Lich. p. 245.

Habitat in Norvegia; Prof. Hornemann. - In rimis murorim calcariorum sccunchum Acharium; Prof. Agardh.

DESC. Caespes deusissimus, pollicem unum alterumve longns. Fila intricata, fraggilia, ramosa; rami panci, patentes, apice obtusi. Articuli diametro 2-3plo longiores. Gcnicula sulscontracta. Color caspitis virescens, filorum sub Jente firsco-olivaceus.

OBBS. Si locum matalen excipiamus, ad prxcedentem prope accedit; ambigit etianx lare inter Lichenes et Algas.

Tab. 57. 52. C. velutina; filis rumosis, flexuosis, implexis, inferioribus radieantibus, hyalinis, superioribus in stratum velutinum dense intricatis, obtusis; articulis Jongiludine variantibus.

Conferva velutina Dillw. Tab. 77. et Intrud. P. 59. - Engl. bot. Tab. 1556. - Ag. Disp. P. 32. et Syll. P. 94.

- varia Roll. Cat. bor. 3. p. $3^{\text {ris. }}$

Bjssus velutina Lin. Syst. nar. 2, p. 720. - Huds. p. 605. - Light. p. roor. - With.

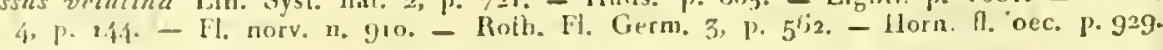

- Dillen. Tab. r. fig. 14. - Mich. Tab. 89. fig. 5. - Hail. Helv. Is. 280 . 
Habitat ad terram nudam sabulosam in sylyestribus ad officinam ferrariam Næes Norvegiae, et alibi sat freqvens. In terra ad Geclskov Sellandiae. In insulis Færoensibus hic illic copiose.

DESC. Crspes densissimus, implicatus, 3-4 pollices longus latusqve, terram sabulosam unbrosam obducens. Fila densissime implexa, inferne terram perreptantia, pellueida vel dilute fusca, hic illic fibrillas radieiformes emittentia, superne in stratum, velutum referens, intricata, vage ramosa; rami altcrni, flexuosi, inferiores remoti, superiores magis approximati; ramuli breves, subsecundi, horizontaliter patuli, incurvi, apice obtusi. Articuli in filo primario nulli, in ramulis summis hic illic adsunt, dianctro 2-6plo longiorcs. Gcnicula pellueida, interdum obscura. Color late vel holosericeo-viridis, velutinus, unde nomcu. Substantia tencrrima, mollis. Acstate. Charț̣ non adhæret.

53. C. umbrosa; filis ramosis, fragilibus, in stratum velutinum implexis; Tab. $5 \%$. ramis erectis, obtusis; articulis diametro subduplo longioribus, in summitate ramulorum inflatis, diametro æqvalibus.

Conferva umbrasa Dillw. Tab. 61. et Introd. n. 76. - Roth. Cat. bot. x, p. 19r. 3, p. 217. - Roth. Fl. Germ. 3, p. 521. - Ag. Syn. p. 94.

- arenaria Roth. Cat. bot. 2, p. 217?

Habitat in insulis Færoensibus ad ripas rivulorum humidas, umbrosas.

DESC. Cæspes densissimus, plures pollices in diametro labens. Fila abbreviata, fragilia, fastigiata, vage ramosa; rami erecti, apicem versus densiores, obtusi. Articuli longitudine variabiles, plerumqve diametro 2-3plo longiores, in summis ramulis haud raro diametro aqvales, inflati, gibli, geniculis contractis. Color saturate viridis, velutinus. Substantia tenerrima, mollis. Aestate. Chartæ non adhæret.

OBS. A pracedente differt filis non radicantibus, articulis hic illic inflatis, et colore saturatiori, qri tamen loco natali forsan debetur.

54. C. Jolithus; flis dichotomo-ramosis, caspitosis, abbreviatis, aurantiis; ramis alternis, patentibus; articulis dianetro sesqvilongioribus.

Conferva Jolithus Ag. Disp. p. 33. ut Syn. p. 75 .

- aurea B. Jolithus Roth. Cat. bot. 3, p. 219 .

Byssus Jolithus Linn. Syst. nat. 3, p. 72t. - Fl. dan. Tab. 899. Gig. 1. - Mohr Hist. nat. Isl. p. 250. - Hudson p. 6o8. - Rotb. Fl. Germ. 3, p. 565. - Starke in Schrad. Journ. 1 B. 1800. p. 340. - Mich. nov. gen. p. 2 ro. Tab. 89. hig. 3.

Lepraria? Jolithus Ach. Meth. Lich. et Prodr. p. x1.

Licken Jolithus With. 4, p. 3. 
Habitat in saxis sylvarum, passim; Mïller. - In Islandia; Molur. - In saxis et rupibus ad oflicinam ferrariam Nies Norvegia.

DESC. Crepes minntus, saxa obtegens. Fila lorerissima, vix semilineam alta, fragilia. ramosa. Artienli dianctro sesyvilongiores. Color exspitis anmlius, sangsincus, exsiccati cincrascedus. Substantia tencrrima, rigida, fragilis. Aestatc.

OBS. Ob odorem violee, qqem in statn recenti sicco et humectato spirat amoc11um, Honch traxit, ex iov, viola, et $7.20 \%$, lapis, compositum. - Ol defectun capsularun, in han: non detectarum, odorem staturamgre minorem ab Ectocurpo aureo, yvem alias refert, nerito distingritur.

Tab. 57. 55. C. odorcula; filis ramosis, cxespitosis, abbreviatis, crectis, fulvis; ramis patentibus, rigidiusculis; articulis dianetro aqvalibus.

Lepra odoratn Wiggers Prim. Al. Hols. p. $9^{6 .}$

Lichen crustaceus, arboribus adnascens suc. Mich. nov. Gen. p. 100. n. 73.

Habitat in Fagis et Betulis prope Vichburg Holsatix; Wiggers. - In cortice fagineo in sylva Lundsgaard Hindsholn Fionix; IIofmann Bang.

DESC. Crespes miuntus, cortici Fagi syloalice aduatus, pulverulentus. Fila rigidinscula, fragilia, vix linean alta. ranosa : rami breves, patentes, alterni

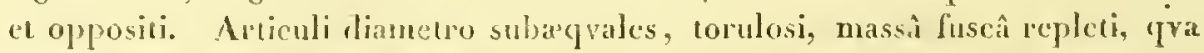
haul raro evaneseconte omuino hyalini. Genicula contractit, pellucida, vel inter articulos hyalinos annularia. Colos cxspitis recentis miniatus, fulvus, in herbario exsiccati cinerens. Substantia rigidinscula, fragilis. Vere. Chartæe $110 n$ adheret.

OBS. Gratum viole hree, aqve ac precelens, spirat odorem, qvem etian post exsiccationem diutius servat; similiter qroqve in statu exsiceato colorem nativum in einereum vel viridescentem mutat; attamen ob locun natilem arboreum, colorem ct articulorum conditionem als câ scparari posse videtur.

56. C. ebenea; filis ramosis, caspitois, brevissimis, crectis, aterrimis; ramis remotis, divergentibus; articulis obscuris, diametrum longitudino eqrantibus.

Conferva ebenea Dilliv. Tab. 10r. ex Introrl. n. 79. - Ag. Syn. p. 74.

- nigra liosh. Cal. bot. 3. p. 299

By.sus nigra Huls. p. GoG. - Lightf. p. 1003. - With. 4, f. 144. - Roth. Fl. germ. 3, p. 5 5.7.

- nigra velutina Hall. Helv. n. 2104.

- petrara nigerrima fibrosa Dillen. T'ab. 1. fig. I8.

- minima saxatilis nigra \&x. Mich. nov. pl. gen. Tab. go. fig. 5 . 
Habitat ad saxa rupestria et supra Jungermannias prope officinam ferrariam Næes Norregia, Hofmann Bang.

DESC. Stratum expansum, variæ amplitudinis, lineam altum, densissimum, pannum velutinum aterrinum referens. Fila minuta, capillo lımano tenıiora, abbreviata, fastigiata, aqvalia, ramosa; rami patentes, vagi, remoti, obtusi. Articuli ob opacitatem filorum rgre conspicui, interdum diametrum longitudine xqvantes apparent, gcuicnlis pellueidis. Color niger, filorum sub lente idem. Substantia rigida, subcartilaginea. Aestate. Chartæ non adhæret.

57. C. melcenc; filis subramosis, caspitosis, intricatis, brevissimis, ri- Tab. $5 \%$. gidis, erectis, aterrimis; ramis ragis, patentibus; articulis diametro 2 plo longioribus, ovatis, moniliformibus.

Habitat in ligno Carpini Betuli subputrido ad Hofmansgave Fioniæe.

DESC. Cxspes variæ atqre indeterminate formæ et extensionis, aliqrot lineas plerumqve diametro tenens, paunum holosericeum nigrum refurens. Fila erecta, vix semilineam longa, densissima, rigida, stricta, frasilia, ramosa; rami vagi, alterni vel secundi, stricti. Articuli diametro 2-3plo longiones, ejusdenn ubiqve longitudinis, ovati, ad utronngre finem acutiusculi, hinc oblongo-moniliformes, ohscuri, nigri. Genicula insigniter contracta. Color aterrimus. Substantia rigida, fragilis. Antumno. Chartæ non adheret.

OBS. Ob fila intricata et fragilia pro certo dicere necrea, sitnc hæe species ramosa an simplex; ramosa tamen patius mihi videbatur.

58. C. atramenti; filis dichotomo-ramosis, minutissimis, decumbenti- Tab. 5\%: bus, in stratum albidmn densissime intertextis; articulis diametro sesqvilongioribus.

B) typhloderma, filis subramosis, in stratum olivaceum densissime implexis; articulis diametro subæqvalibus.

Conferva typlloderma Dillw. Tab. 83. et Inlrod. n. 62.

Habitat in superficie atramenti vulgaris. - $\beta$. supra solutionem Gummi arabici invenit Hofinann Bang.

DESC. Stratum variæ extensionis, lineam erassum, pelliculam albidam superficiei, atramenti, per aliqvad tempus servati, innatans. Fila decumbentia, ararhnoidea, densissime intricata, ramosa; rami renotiores, suldichotomi. Articuli diannetro æqvales, vel earlem 2plo longiores, massa chalybæi intus fareli, ol, filorum tenuilatem sape evanescentes. Gexicula pellucida. Color caspitis albidus. Substantia tenerrima, tcnax. 
OBS. Tarietas, Tram alluli, uon nisi colore, ex massa, cni mascitur, sine dubio orto, neo judicio differt.

59. C.puncliformis; filis ramosissimis, e centro commmi egressis, confertissimis, tenuissimis, brevissimis; articulis diametrum longitudine reqvantibus, moniliformiluts.

Conferra punctiformis Roth. Cat. bot. 3, p. 220.

- mucoroides Ag. Dec. 3, n. 39. cum icone, et in Act. Holm. r81, p. 199?

\section{Habitat in fenestris Nosocomionm Hafniensium; Weber et MTohr.}

DESC. Cosprulu densissmi, puncta in fenestris sparsa, parum elcvata, magnimdine circiter seminis Simapios nigror, constituentes. Fila e centro progredientia, muncrosissina, confertissima, a basi ranosissima, subtorulosa; rami l'amuliqre alteni, interdum secundi, loreves, approximati, erecto-patuli, apice obtusi. Arliculi dianctro apgrales, subrotundi vel ovati, siccitate fere rotundi, et lunc fila moniliformia apparent. Genicula pellucida, contracta. Color atroviridis. Substantia tencrinta.

OBS. Secumdum Cel. Rothium hre, qram nondum vidi, a seqvente longissime recedil, partin colore et temnitatr, partim structurâ filorum, quae articulata conspiciuntur.

60. C. fenestralis; filis ramosissimis, e centro communi egressis, minutissimis, continuis; ramis plerumqve divaricatis, sinuosis, gibbis.

Conferva fencstralis Roth. Cat bot. 3, p. 180. - Schum. enum. 2, p. 106. - Dillw. 'Tab. 91. - Ag. Disp. p. 54. et Syn. p. 25.

Habitat in specularibus Hofmansgave Fioniae et alibi, passim.

DESC. Macula parra, orbiculares, in centro obscuriores, lincan unam alteramve in diametro habentes, vitris fenestrarum soli meridiano expositis rapopibusqve sxpe humectatis in conclasibus. uloi libcr aëris accessus demegatur, agglutinatæ. Fila e centro radicante utrinqve excuntia, mumerosa, repentia, flexuosa, minutissima, vage ramosa; rami divarieati, secundi vel oppositi, intricati, sinnosi. Articnli aut mulli, ant ob filormm teunitaten ineonspicui. Color pallide griseus vel albidus, sub lente hyalinus. Substantia tencrrima. Vere et restate.

61. C. dendritica; filis superne ramosis, e centro communi egressis, nexuosis, minutis, continuis, charta adglutinatis.

Conferva dendritica Ag. Syn. p. $9^{6}$.

Dematium olivaceum Schum. cnum. 2, p. 445. 
Habitat in charta loco humido clauso deposita; Schumacher. - In libris vetustis Hafuix, Prof. Rathke; et Fionia, Hofmann Bang.

DESC. Maculæ parve, planæ, orbiculares, centrifugæ, lineam unam altcramve diametro tenentes, chartis retustis aduatx, jicturam dendriticam exhibentes. Fila tenuissima, flexuosa, inferne unda, superne ramos breves fasciculatos emittentia, tubulosa, continna, vix articulata. Color cxspitis primo fuscoolivaceus, deinde nigrieans. Substantia tcnerrima, mollis. Vere et autumno.

OBS. Auctoritate Ccl. Agardhii hanc speciem in Confervarum phalangem retuli, a qvibus tamen, pariter atque præcedens, in eo reccdit, qrod fila sunt continua, neqve ullis, qrantum videre licuit, articulis predita. Ceterum, si ad Algas ha dux pertincnt, sub Sectione mea secunda post Scytonema peculiare genus forsan melius constituercnt.

\section{A P P E N D I X de dubiis Confervarum speciebus.}

1. C. aggagropila; König, Zoega, Molır, Hooker.

OBS. Hanc spcciem Conferve unciali, ut synonymam, at dubitanter, antea subjunxi; vide etiam qua ad Confervam ágagropilam antea annotavi.

2. C. aeruginosa; König, Zocga, Mohr, Hooker.

Habitat in stagno haud procul a littore marino prope Berufiord Islandix; Mohr.

OBS. Loco natali excepto, de hac specic Cel. $N$. Mohrius nil alind habct, qvam ut sit coloris amocne viridis, unde nibil conjici potest. Vix Conferva aernginosa Huds. p. 595. - Dillen. T.4. f. 20. - Dillw. Introd. p. 67. Stippl. Tab. $\boldsymbol{E}$., qræad littus Fucis adhærere dicitur. An Oscillatoria cestuarii?

3. C. amphibia; Schumachier.

Habitat in fossis, udis et umbrosis locis Sellandie; Schnm. enum 2, p.'104.

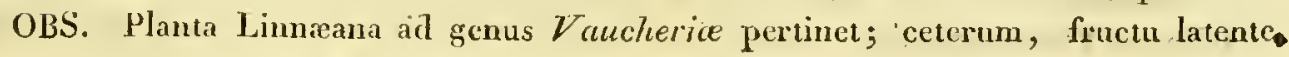
non amplius deteminanda.

4. C. aranensa; Mertens.

Ilabitat in Ilolsatia; D. M. H. Mohr in Schrad. Journ. 1 B. 1806. p. 196.

OBS. Secuudum amotationem W Veberi ct Molurii (in Grossbr. Cunfo ad Tab. 2** Fase. 3. 1. 54.) hace, nusquam descripta, ad Confervam comoidem Dillw. pertinet.

5. C. barbata; König, Zoega, Mohr, Hooker.

Habitat ad littus Islandix. 
OBS. Hac a Künigio ita describitur: "Conferva babata, dichofoma: ranulis suhfistigiatis, obtusis; articulis pellueidis, albis; geniculis purpurasecntibus, barbatis." - Sccundum Retzii Prodr. P. 306 est Conferid polynzorplat fo. barbata. - Etrum vero anctores litudati Confervam barbat in Eugl. bot. T. 1814, an Cercumium diapharum intellexerint, intactum relingvo.

6. C. bullosa; Schumacher.

Habitat in aqvis stagnantibus Scllandix; Schum. cnum. 2, p. 104.

OBS. Ad genus $/$ ancherice pertincre censenda est.

7. C. caralicularis; Landt.

Habitare dicitur in insulis Freroensibus, et ad idem genus, ad qool pracedens, pertinct.

8. C. cancellata; König, Zocga, Molur, llooker.

Habitat ad litus Islandiar.

OBS. Conferwa cancellata Lin. Iluds. est Sertularia spinosa L. efr. Rotl. Cat. bot. 3, p. 281. शcute Bcitr. 1. p. 236. et Dillw. Introd. 1. 32. - An Künigii planta cadem fucrit, iı liqvidum nunqvam perducitur.

9. C. ruf $a$; Roth.

Habitat ad littus insula Fimbrix: Roth. Cat. bot. 3. p. 280.

OBS. De hac specic videsis qra.ad Scytonema comoide, cui dubitanter" adposui, jam paucis monui. An potius Conferva ferruginea (mili)? - Cul. Agardhius ean, ut propriam speciem, cum Cel. Rothio proposuit.

10. C. villosa; Agardl.

Conferva villosa IIuds. p. 603. - With. 4, p. 141. - Dillw. Tab. 3\%. et Introd. n. 134. Suppl. 'Tab. F' - Roth. Cat. bot. 3, p. 314.

Chordaria villosa Ag. Syn. p. 14.

Ilabitat in sinu Codano rarius; Agardh.

OBS. Si frons articulata, qvam ci auctores landati disserte attrilumunt, non;obsta-

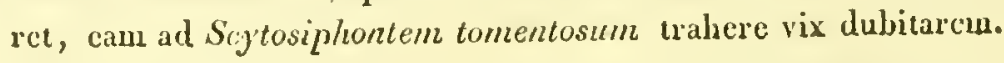




\section{H Y D R O D I C T Y ON. *)}

Fila articulata, membranacea, in formam reticuli piscatorii connexa, viridia. Fructus Embryon, matri simile, in qrovis articulo invaginalum.

\section{H. utriculatum.}

Hydrodictjon utriculatum Roth. Fl. Germ. 3, p. 53r. Cat. bot. 3, p. 322. - Fl. dan. Tab. ${ }^{5} 597 .-$ Ag. Disp. p. 26. et Syn. p. 97. - pentagonum Vauch. p. 88. Tab. 1. fig. 4. et Tab. 9. fig. I.10. - Dec. A. fr. 2,
p. Go.

- majus Rotb. Cat. bot. 2, p. 238.

- tenellum Roth. Cat. bot. 2, p. 239.

Conferva reticulata Lin. Syst. nat. 2, p. 720. - Dilleur. Tab. 4. f. 14. - Petir. gazoph. Tab. 5'. fig. 3 - Guetr. obs. p. 45. - Hall. Helv. n. 2119. - I'luken. Phyt. Tab. 24. f. 2. - Moris. Ill. S. '5. Tab. 4 fig. 4. - Huds. p. 596 - With. 4 , p. 132 - Dillw. Tab. 97. - Engl. bot. Tab. 1687. Musctes aqvaticus tombjcinus retiformis Kyll. Virid. p. 106. n. 1. - Loes. Pruss. p. 173.
Tab. 54.

Habitat singularis hæc species in aqvis Daniæ stagnantibus; Kylling. - In amne prope Næestved copiose; Prof. Hornemann.

DESC. Stratum densum, superficici aqvæ stagnantis vel leniter fluentis innatans; pro xtatis ratione varix longitudinis et extensionis, duos circiter pollices ad pedem longum. Fila tubulosa, capillum humannm crassitic æqvantia, cyliudracea, xqvalia, anastomosantia, vel ad modum reticnli piscatorii singulari ratione combinata, et maculas plerumqve pentagonas, haud raro tetragonas vel hexagonas, constituentia. Fructus Embryon in qrovis articulo insertum sen invaginatum, suls lente conspicuum, matre qvidem multoties minus, at eidem aliàs omnimode simillimum, filisqve reticulatim comnexis instructum; hæc Embrya ex articulis ætate scuili solutis, tanqvam ex matricibus, egressa in matris volumen paulatim excrescunt. Color cæspitis viridis. Substantia membranacea, tenera. Annua. Verc et æstate. Chartæ modo laxe adhæret, nec siccitate mutatur.

OBS. Hæc species Algæ viviparce, ut verbis utar Cel. Rotlï̈, singulare præbet excmplum; hre antem, me judice, non sola; nam Oscillatorice chthonoplastis, rite consideratæ, cadem quadantcnus est ratio.

*) Ex ijap, agva, et Jixivov, rete. 


\section{Z Y GNEMA. *)}

Fila articulata, membranacea, simplicia, viridia, demum per tubulos breves transversales conjugata. Frucus Semina solitaria, singulis articulis post copulationem inclusa.

Tab. 58. 1. Z. genuflexum; filis simplicibus, lubricis, fragilibus, demum hic illic genuflexis copulatisqve; articulis dianetro 4plo longioribus, granulis semirepletis; semine globoso in tubnlo transversali nidulante.

Zygnema gennflexum Ag. Syn. p. 98.

Conferva genuflexa Roth. Cat. bot. 2, p. 199. Cat. bot. 3, p. 268 . - Dec. 月. fr. 2. p. 57. - Dillw. Tab. 6. et Intrnd. p. 5r. Suppl. Tab. C. - Web. et Mohr Gr. Conf. Tab. 6. - Jürg. Alg. Dec. 3, n. 7 .

- fragilis Poth. Cat. bot. 2, p. 204?

- serpentina Müll. Nov. Act. Petrop. 1785. Vol. 3. p. 92. Tab. r. fig. ro. 1. - Dec. ค. fr. $2, p .57$.

- bullosa Herb. Elırl. (cfr. Roth. neue Beitr. I 34. p. 323).

Conjugata angulata Vauch. P. 73. Tab. S. fiğ. 1-9.

- genuflexa Ag. Disp. p. 28 .

Habitat in fossis aqva dulci stagnanti repletis, et in turfosis Danix, freqrens; item in insulis Foroensibus.

DESC. Caspes densus, lubricus, diversæ amplitudinis et extensionis, aqve superficici imatius. Fila simplicia, intrieata, lubrica, fragilia, pollicem unum alterumve longa, capillo humano tenuiora, denum tic illic in anguhum olstusum curvata vel genuflexa. Articuli dianctro sua 4-5 longiores, massa viridi, longitulinaliter rectangulata, ant toti aut ex dimidia parte repleti. 'Tubuli transversales breves, ex angulis uriusqre fili obusis exemtibus, copulatique medio lineâ uransversali notati. Color exspitis recentis dilute viridis, interdum albescens, siccati plerumqve fuseescens. Substantia lubrica, taciu molissima, maxime fragilis. Primo vere ad antumum. Chartac arefe adheret.

OBS. Senina, ryæ in hac specic nondum vidi, ex obserratione Cel. Dillwynie non in articulis, sed in ipsis tubulis transversalibus, line globuloso-inflatis contincntur, solitaria, spherica, saturate viridia. (efr. Dillw. lntrod. p. 18. (t Suppl. Tab. (').

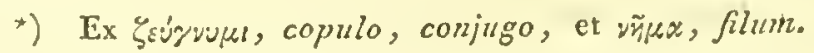


2. Z. compressum; flis simplicibus, lubricis, fragilibus, demum hic il- Tab. 58 . lic curvatis copulatisqve; articulis diametro.3plo longioribus; massa interna compressa.

Conferva serpentina Müller Nov. Act. Petrop. 3, Tab. x. fig. 8 et 9 ?

Conjugata serpentina Vauch. p. 8x. Tab. 8. fig. 1o?

Habitat in aqvis stagnantibus ad officinam ferrariam Næs Norvegiæ, aliis Confervis plerumqve immixtum.

DESC. Nulla fusiori hujus speciei opus est descriptione, cum in plurinis antecedentem refert; differe tamen videtur: 1) filis duplo crassioribus; 2) filis fragilioribus, quippe qvæ in geniculis facile dissiliant; 3) massâ interuâ compressâ, qva, filis cylindraceis in aqva sub lente volutatis, luculenter conspicitur; 4) tubulis transversalibus, qvi medio inflati et opaci cermuntur; utrum vero scmina contineant, ncene, intactum relinqvere cogor; in hac ultima parte antecedentem igitur refert, vel forsan Conferva genuflexa Dillw. Suppl. Tab. C. hue pertinct. Fila præterea uon genuflexa, sed modo flexuoso-curvata sub copulatione in conspectunn veniunt.

3. Z. littoreum; filis simplicibus, lubricitatis expertibus, tenacibus, in- Tab. 59. tricatis; demum hic illic flexuoso-conjugatis; articulis diametro 2plo longiorbus, granulis adspersis.

Conferva riparia Rolh. Cat. bot. 5, p. 2r6? - Jürg. Alg. Dec. 2, n. 7?

Habitat in ripis sabulosis, humidis, umbrosis sinus Othiniensis, ubi ab aqva salsa qvotidie irrigatur, copiosissime, locisqve indicatis fere ubiqve, ut vix ulla species copià majori.

DESC. Cæspes deusus, intricatus, vireseens, ripam humidam umbrosam, aqva marinæ, a qrầ sæpissime inundatur, contiguam, viridi suo velamine dcuse obducens, varix pro loci conditione longitudinis et amplitudinis, palmam plerumqve diametro tenens, sed hand raro latius patens. Fila simplicia, lubricitatis cxpertia, tenacia, capillum humanum erassitie fere xquantia, intricata, et, si extricentur, pollicem unum altcrumve longa, sub eultello crepitantia, demum parum flexuosa et conjugata. Tubuli transvcrsales breves, medio pervii, ex medio articulorum divaricatim exeuntes. Articuli diametro 2plo longiores vel candem aquantes, massâ viridi grauulosâ aut 10tum articuli spatium occupante aut in eylindrum utriculatum collapsê̂ repleti. Genicula obscura. Color sordide viridis, nomumivam flavcseens. Substantia tencra, tenax. Pcr totum annum invenitur; et mense Maii copulatam. vidi. Chartæ laxe adhæret. Siccitate vix mutatur. 
OBS. De observationis mex veritate mullus dubito; singulare igitur lıxe species copulationis inter Confervas marinas prebet exemplum. Corpusenla rectangulata, capsuliformia, ei insidentia interdum, qvæ prima intuitu pro articulis post copulationem avulsis habui, ad Echinellam stipitatem pertincut.

Tab. 59. 4. Z. nitidum; filis simplicibus, lubricis, demum conjugatis; articulis diametrum longitudine subrequantibus, spiris pluribus densis instructis; seminibus ovatis.

Zygnema nitidum Ag. Dec. 3, n. 25. et Syn. p. 38 .

Couferva nitida Fl. dan. Tab. 8ıg. - Dillw. Tab. 4. fig. C. - Web. et Molur Gr. Conf. Tab. 4. fig. $C$.

- jugalis Fl. dan. Tab. 883. - Dec. 月. fro 2, p. 53.

- scalaris Rorh. Car. bot. 2, p. 196. - Schum. enum. 2, p. 106.

- setiformis a. conjugata Roth. Cat. bot. 3, p. 266. - Wulfo crypt. n. 28. - Schum. enun. 2. p. 106.

- multistriata Rolh. Cat. bot. 3, p. $27 \mathrm{1}$.

Conjugata Princeps Vauch. p. 64. Tab. 4. fig. 1-6.

- nilida Ag. Disp. p. 26.

Habitat in fossis aqva dulci stagnanti repletis circa Hafniam et alibi passim: In stagnis Islandix; Hooker. - Item in insulis Færoensibus.

DESC. Cxspes densus, saturate viridis, nitcns, aqvæ superficiei inıatans. Fila simplicia, erassiora, setam eqvinam crassitie requantia, ante copulationem viridia, nitida, lubrica, rigidiuscula, sub copulatione crispata, flexilia, opaca. Articuli diametro aqvales, interdum paulo longiores, spiris pluribus densissimis cruciatis instructi. Tubuli transversales brevissimi, medio linea transversali tenuissima notati. Semina ovata, fusca, in singulis articulis unum. Color saturate viridis, nitidus. Substantia rigida, lubrica, exsiecatæ flexilis. Chartæ ante copulationem laxe adhæret, post eandem, lubricitate amissa, non item.

OBS. Spiræ internæ in massam atrovirenten rel nigricantem, utrienlum matricalem Confervarum quarundam omnino æmulantem, in articulis filorum collapsa vel condensata nommungam eonspiciuntur, qrod Ccl. Faucherius morbum, qro hæc species tanqram laboraret, credidit; idem plıcnomcuon sçgrenti speciei usu interdum reuit.

Tab. 59. 5. 2. deciminum; filis simplicibus, lubricis, demum conjugatis; articulis diametro subtriplo longioribus, spiris duabus laxis instructis. 
Zygnema decimiuum Ag. Syn. p. 99 .

Conferva decimina Müller Nov. Act. Petrop. 1785. Vol. 3, p. 94. Tab. 2, fig. 2. 3.

- nitida Dillw. Tab. 4. fig. A.B. - Web. et Mohr Gr. Conf. Tab. 4. fig. A.B,

- jugalis Dillw. Tab. 5. - Web. et Mohr 1. c. Tab. 5.

- setiformis ß. lubrica Roch. Cat. bol. 3, p. 267.

Conjugata decimina Ag. Disp. p. 26.

\section{Habitat in fossis stagnisqve Daniae sat vulgaris:}

DESC. Cæespes ut præcedentis. Fila 2plo tenniora. Articuli diametro 3-5plo longiores, spiris duabus laxis ornati. Color dilnte viridis, nitens. Substantia lubrica, rigidiuscula. Vere et æstate.

OBS. Hane speciem, qvantum memini, nondum copulatan vidi. - Spiræ illæ dux, qvæ singulos articulos sub lente ornare cernunter, speciem litteræ X. pluries repetitæ præbent, unde Cel. Mïllerus nomen ci indidit.

6. Z. quininum; flis simplicibus, lubricis, demum conjugatis; articulis 'Tab. 59. diametro duplo longioribus, spira unica instructis; seminibus. ovatis.

Zygnema, quininum Ag. Dcc. 3, n. 26. et Syn. p. roo.

Conferva qvinina Müller Nov. Art. Petrop. 3, p. 94. Tab. 2. fig. 4. 5. - Roth. Cat. bot. 3, p. 264. - Wahl. E. lapp. n. 988.

- spiralis Roth. Cat. bot. 2, P. 202. - Dillw. Tab. 3. et Introd. p. 50. Suppl. Tab. C. - Web. et Mobr Gr. Conf. Tab. 3. - Engl. bot, Tab. 1656.

Conjugata quinina Ag. Disp. p. 27.

B) porticale; spirâ in formam porticûs arcuatâ.

Conferv'a porticalis Müller Nov. Act. Petrop. 3, p. 90. Tab. 1. Gg. 2. 3. - Dec. A. fr. 2, p. 53 .

Conjugatio porticalis Vauch. P. 66. Tab. 5. fig. I.

y) longatum; articulis diametro 6plo et ultra longioribus; spiris obtusangulis.

Zygnema longatum Ag. Syn. p. 10r.

Conjugata longata Vauch. p. 7r. Tab. 6. fig. J. (excl. syn. Müll.)

Conferva longata Diliw. Introd. p. 49. - Decand. A. tr. 2, p. 55.

Habitat perelegans hrec species in fossis stagnisqve Daniæe freqvens. - In insulis Færoensibus, sat vulgaris. - In Islandia; Hooker. 
DESC. Crespes densus, intricatus, lubrieus, arpae superficiei imnatans. Fila simplicia, capilli hımani crassitic, longissima, flexuoso-iutricata. Articuli diametro 2-3plo longioles, granula in spiram simplicem disposita contiuentes. Genicula obscura, lincâ solitâ transversali notata, quæ tamcı linca sub copulatione sape evaneseit, in tegumentum semiuis sine dubio abiens. 'Tubuli transversales brevissimi, ex singulis utriusyve copulati fili articulis excuntes, et medio pervii. Semina ovata, rexingre subacuta, fusca vel flavescentia, e granulis utriusqve fili coaceryatis constituta, in alio filorum copulatorum nichlantia, adco nt aliud filum vacum evadat. Color llavo-viridis, sub copulatione sordile vireseens. Substantia primum lubrica, mucosa, deinde post copulationem crispata, fragilis, lnbricitatis cxpers. Aumua. Vere et asstate. Cilarta alharet, post copulatiouen laxius adharet.

OBS. Spira simplex, qrâ gaudent articuli, speciem litterx V. pluries repctita prex se fert, unde nomen Millerianm. Ad hane speciem sine dubio pertinent Conjugata condensata et inflata Vauch. (Zygnema condensatum ct inflatum Ig. $\left._{\text {. }}\right)$ - Caspes lujus specici recens cx ayva extractus, cujus fila spiris suis nitidissimis ommia probe crant ornata, in vase vitreo anjố jurâ repleto per aliqvot dies alinvando servatus fuit, ita tamen, ut soli meridiano in fenestra forte fortuna expositus esset. Aliqvot diebus interjectis, cum fila ad Icutem iterum considerare in uncutem venisset, omuia magnam subiisse mutationem obscrvavi; spira quiden nonnulla in articnlis lic illic remanserant, qvarum ope plantam meam agnoscere ctiannum potui; sed teterum eadem jan crispata, lubricitatis et nitnris expertia, flaccirla, et omnia ferc copulata mirabundus inveni; qvalis nunc fucrit filorum conditio, facilius et mclius, at opinor, ex delincationc accurata (cfr. Tab. 59. D. 3. 4.), qvam ex deseriptione succincta patcbit. Has antem minutias hune in tinem life tetigi, ut, siquis Zygnemata in copulatione videre cuperes, tali modo, idlove facili negotio et sine tadiosa vel sxpe frustranca in fossis stagnisque investigatione, roti compos fieret. Experimentum, tali modo simpliciter institutum, voto cessurum esse, vix est, quod dubitem; calore cnim majori, radiis solis arte quodammorlo immissis effecto, maturitas filorum procul dubio acceleratur. Varietas $\gamma$. vix distincta species; nam in uno eudemgve filo articuli arlmodum variabiles, munc Jreviores, nunc longiores observantur.

Tab. 60. 7. Z. bipunctatum; filis simplicibus, lubricis, demum conjugatis; articulis diametro 2 plo longioribus, bipunctatis, punctis maculas stelliformes refercntibus; seminibus subglobosis.

Conferza bipunctata Rosh. Car. bot. 2, p. 204. Car. bot. 3, p. 267. - Dillw. 'Tab. 3. et Introrl. p. 50 - Web. et Mohr Gr. Conf. Tab. 2. - Wahl. B. Iapp. n. 987. - Engl. bot. Tab. 1516 .

- stellina Müll. Nov. Act. Petrop. 3, p. 93. Tab. 2. fig. 8. - Decand. A. fr. 2, p. 56.

- cruciara Decand. A. fr. 2, p. 56. 
Conjugata stellina Vauch. p. 75. Tah. 7. fig. I.

- cruciara Vauch. p. 76. Tab. 6. fig. 4. et Tab. 7. fig. 2. - Ag. Disp. p. 27. Zygnema crttciatum Ag. Syn. p. 102.

B) gracile; articulis diametro 3-5plo longioribus, globulos binos rotundos Tab. 60 . continentibus.

Conjugata gracilis Vauch. p. 73. Tab. 6. fig. 2. - Ag. Disp. p. 27.

Conferva gracilis Decand. A. fr. 2, p. 55 .

Zygnema gracile Ag. Syn. p. 103.

y) unipunctatum; articulis diametro reqvalibus, globulum unicum conti- Tab. 60 . nentibus.

Habitat in fossis aqva dulci stagnanti repletis Daniæe, haud raro; etiam in insulis Færoensibus. - In Islandia; Hooker. - $\beta$. in aqva stagnanti silvæ Sorgenfrie Sellandiæ legi. $-\gamma$. inter $\alpha$. in fossis prope Hofmansgave Fionix, semel vidi.

DESC. Cæspes intricatus, lubricus, variæ amplitudinis, aqva superficiei innatans. Fila simplicia, lubrica, capillum humanum crassitic fere aqvantia. Articuli diametro 2-3plo longiores, maculas binas stelliformes, radiantes vel angulatas continentes. Genicula obscura. Tubuli transvcrsales, dimidium diametri fili latitndine aqvantes, diametroque sxpe longiorcs, e meelio articulorum cxenntes, medio nunc pcrvii, nunc linea transversali notati. Scmina subglobosa, rnbescentia, totum fili alterius spatiun latiludine occupantia, altero filo evaciuato. Color flavo-virjdis, vel lutescens. Substantia lubrica. Annna. Vere et æstate. Chartæ adhæret.

OBS. Varietas $\beta$. non adeo diversa mihi videtur, ut distinctam speciem efficere possit. Conjugata lutescens Vauch. sine dubio huc etiam pertinet.

8. Z. pectinatum; filis simplicibus, sublubricis; articulis diametro ses- Tab. 60 . quilongioribus, maculas binas transversim oblongas vel tridentatas continentibus.

Zygnema peclinatum Ag. Syn. p. 102.

Conjugata pectinata Vauch. p. 77. Tab. 7. fig. 4. - Ag. Disp. p. 27.

Conferva pectinata Decand. A. fr. 2, p. $5^{6}$.

B) confluens; articulis diametro æqvalibus, maculas binas transversim rect- 'Tab. 60 . angulatas, densas et confluentes continentibus.

Conferva bipunctaca Dillw. Tab. 2. fig. C. - Web. et Mohr Gr, Conf. T. 2. f. C. 
Habitat in fossis Daniæe et insularum Foroensinm, haud ita freqvens. - B. in aqva leniter fluenti ad Hofmansgave Fionia et oflicinam ferrarian Nas Norvegix; item in insulis Frocnsibus legi.

DESC. Crspes et fila ut præcedentis, a qvo tamen differt articulis brevioribus, diametro xqualibus vel sesqvilongioribus, imprimis autem maculis binis internis, qvæ in liae speeie non globosæ, sed transversim oblongæ vel rectangulatx, interdum tridentatæ vel pectinatx conspieiuntur, unde nomen Vaucherianum. Color viridis, vel Hlavescens. Substantia sublubrica. Acstate. Chartx adhacet.

OBS. Hane spceiem nondum ¡̈opulatam vidi; secundum Agardlitum Scmina sphrica in tubulo transversali, adsunt. 


\section{$\begin{array}{llllllll}S & E & C & T & I & O & \text { V. }\end{array}$}

HOMALOGONATA.

Frous filiformis, articulata, plana:

\section{D I A $\mathrm{T}$ O $\mathrm{M}$ A. *}

Fila articulata, plana, simplicia, crystalliformia, immediate copulata, tandem articulis solutis angulo alternatim cohærentibus.

* aque dulcis.

1. D. Swartzii; filis simplicibus, planis, læte viridibus; articulis dia- Tab. 61. metro duplo brevioribus, ad utrumqve marginem bicrenatis, post copulationem angulis alternis colærentibus, solutisqve triangulatis. Diatoma Swartzii Ag. Syn. p. 34. Dec. n. 8. et Syn. p. ris. - Sv. Bor. Tab. 49 r. fig.
1. 2. 3.

Habitat in fossis aqqa dulci stagnanti. repletis in peninsula Hals prope Hofmansgave Fionie, rarius.

DESC. Fila simplicia, capillum hunanum crassitie fere eqrantia, fragilia, lubrica, aqvalia, in fasciculis parvis aqve submersa rel aliis Confervis immixta. Articuli brevissimi, diametro dimidio breviores, medio læte virides, ad utrumqre margincm biercnati, crenis hyalinis, rarius hic illic angulis soluti. Color lacte vel diluce viridis. Aestate.

OBS. In hac specie hoc singulare plimomenon observavi: Fila scilicet, cultello sub lente diffracta rel modo leviter tacta, in geniculis suis a se invicem subito dissiliebant, et articuli singuli dissoluti forman ocyus induebant triangularem, apicibus obtusis. (Videsis Tab. 61. A. 2.3.4.) De veritate hujus Phænomeni flane persvasus, cum in descriptione hujus speciei in Synopsi Cel. Agardhii wil talc commcmoratum inveni, de Synonymo allato aliqvantulum

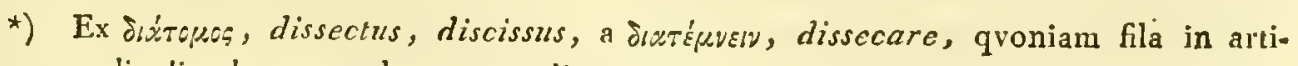
culis dissolvuntur vel tanqvain dissecantur.

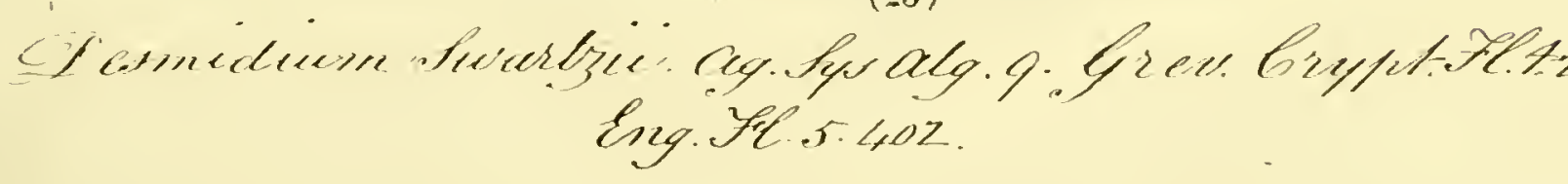


dulito. - Algologi nomulli Anglici lıane speciem cum Conferva dissiliente Dillw. commutant: vidi cnim intce Confervas ex Anglia missas latuc sub nomine Conferve dissilientis Dillw. - Ceternm de singulari hoc genere et menoratu dignissimo, cujus uiginta circiter abhine amnis ne unicam quidem specicm animadrerterant aut curaverant botanici, hoc in miversum de ejus historia paucis monere liceat. Mällerns, in animalculis infusoriis indayandis incristionibus micruscopicis, ut vix ullus alins, ocenpatus, in Noris $\Lambda$ ctis

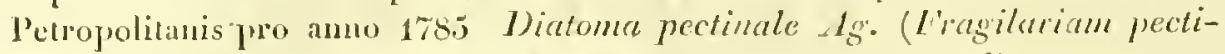
nalem mihi) sub nominc Conferve pectinulis promus orl, crulitorum proposuit et icone illustravit. Rothius, eximnins ille algarum rimator, candem deinde specirm sub nomine Conferve bronchialis desiripsir, a praterea Conferwam flocculosam (Diatoma flocrulosum) adjecit, qram in Cat. bot. 1, Tab. 5. fig. 6. bene delincandam curasit. Decandolle in Flora gallica postlac novum constituit gemus, Diatona nempe, et duas aflert species, Diatoma rigidum (D. arcuatum mihi ?) a flocenlosum (D. marimum mihi). Dillwhruius in opere suo specioso D. flocerulosum el pectinale sub Confervarum nominc exhibuit. Sowerby in English Botany qratuor delineavit Conferras lunc pertinentes, Conferwam Biddulphianan T. 1769, thenike formem 'T'. 1883, obliguatan T. 1859, el striatulam 'T. 1928. - $\Lambda$ pud Agardhium commemorantur Diatona Swartzii, pertinalis, fbocrulusa, fascroulata ot termis. - Ipse infra nommullas Danicas subjungan. Sic igitur factum est, ut illud

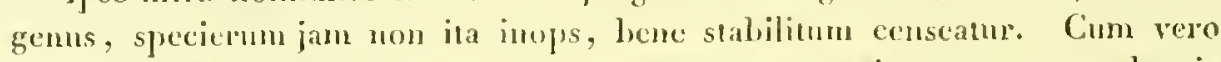
specie's, generi Diutomatis Jaclenus ammmerata, gran i momento qvoad articulorum cohesionen invicen differre milij visa sunt, in duo genera, Diatoma et Fragilariam, easdem distribuere placuit. cxelusât tamen Diatomá fasciculata Ag., qva adeo milhi paradoxa videhatur, ut al Echinellam eam referre satius duxcrim. Omnes autem, qrie ad hoe genus pertinent species, filis gatdent planis, quilus a ceteris Siphonigonatis (Confervoidtis) cylimdraccis reculunt, preterea geniculatis, pullucidis. ct ubi in magna copia adsunt, saxa rivulorum, agra deficiente, rel algas, quibus parasitice insidcm, crustî albissimâ crystalliformi nitente, instar pruina, olducunt. Ad regnum inorganicum fabricâ filorum crystallifurmi accedıun, sed inde diflórunt vi eil, qua juxta opinionem Cid. Agardhii pollum, sese copulandi. A regno animali recedunt, sigridem omni spontanea sese movendi farcultate plane destitunutur. Ad regnum igitur verg tabile potissimum pertincre videntur, et cum Zygnematis quidem ita consentimut, ut sese alipgatmus copulemt, non tamen mediate per tubulos transversales, sed immediate per totas Juorum artienlorum longitudines. qrae sub copulatione arce agglutinantur; fila autem, nbi per aliquod temporis spatium ita inmeliate ronjunctit fucrint, in geniculis tandem dissolvuntur ct angulis alternis in icem modo leviter coharem, in gro stadio ut plurimum observantur. Sic natura. magna rerun mater, in operir bus suis inexhausta. 
2. D. flocculosum; filis simplicibus, planis, hyalinis, linea duplici lon- Tab. 61: gitudinali plerumqve percursis; articulis diametro parum longioribus, transversim striatis, post copulationem alternatim solutis.

Conferva flocculosa Roth. Cat. bot. 1, p. 192. 'Tab. 4. fig. 4. el Tab. 5. fig. 6. Fl. germ. 3. p. 523. - Dillw. Tab. 28 et Introd. P. 52. - Wel. el Mohr Gr. Conf. Tat. 34 et 2S. - Engl. bot. Tab. 176r. - Wahl, Я. lapp. n. 990.

Diatoma flocculosa Ag. Disp. p. 35. el Sy'n. p. 119.

Habitat in stagnis et rivulis Daniæ, non freqvens. In fluviis ad officinam ferrariam Næs Norvegiæ Confervæ floccosæ aliisqve adhærescens, hic illic copiose.

DESC. Cæspes minutus, subhyalinus, adeo ut oculis nudis vix percipiatur, Confervis parasitice adhærescens. Fila minutissima, simplieia, plana, (id qrod, filis sub lente in aqva circumvolutatis, luculenter in conspectum venit), præterea hyalina, vel dilutissime flavescentia. Articuli qvadrati vel diametro parum longiores, transversim striati, striis in medio sape cvanescentibus, et post copulationem soluti, adeo ut angulis alternis modo cohæreant. Color cæspitis dilnte flavescens vel hyalinus. Acstate. Chartæ adliæret.

OBS. In rivulis ad Tres Norvegix Conferva floccosce, rivulari, aliisque adhærens in tanta passim aderat copia, ut saxa rivulorum supra aqvæ superficiem, aqva deficiente, eminentia, radiisque solis exposita et siccata, crusti albâ crystallisante nitente fragili hic illic obducerentur; erat autem hæc crusta, prout lens angens docuit, hujus specici reliqviæ. - Dillwynius fila interdum ramosa pronuntiat; ita etiam videntur; hæe vero ramificatio e filis plus minus copulatis solutisqve pendere rectius sine dubio dicitul.

3. D. tenue: filis simplicibus, planis, minutissimis, rubescentibus fu-Tab. 61 . scisqve; articulis diametro 3 plo longioribus, post copulationem alternatim solutis.

Diatoma cenuis Ag. Der. n. 1o. - Sv. Bot. Tab. 49t. fig. 4. 5.

Conferva flocculosa Fl. dau. Tub. 1487. fig. 1. (excl. syn.)

f) marinum; filis lutescentibus; articulis diametro 3plo longioribus. Tab. 61.

q) elongatum; flis minutissimis, hyalinis; 'articulis diametro 10plo lon- 'Tab. 61. gioribus.

Habitat in lacu Fuursöe Scllandiae et alibi, non freqvens, Confervæ glomerata adhæerens. - $\beta$. in Oscillatoria chthonoplasti Confervisqve marinis in simu Othiniensi, passim. - $\gamma$. in stagnosis Körup Fioniæ, tempore vernali. 
DESC. Fila tenuissima, oculo nurlo inconspicua, rigida, plana, hyalina; deinde, ut pracedentis, immediate copulata, ct alcruatim soluta. Articuli diametro 3-5jplo longiores, angulis alternis coharentes. Verce axstite, sed nulla copia legi.

Tab. 61. 4. D. fenestratum; filis simplicibus, planis, strictis, flavescentibus; arE. 3. ticulis diametro 4plo longioribus, medio fascia granulorum transversali notatis, demum solutis.

Habitat in rivulo leniter flnente ad Nas Norvegia, Confervis immixtum.

DESC. Fila minutissima, simplicia, flavescentia; articuli pellucidi, nullis striis transversalibus, sed linea longitudinali ad marginem utrumuge percursi, e't fascia granulorum circiter trium rotuudorum nedio notati; et ita inmediate copulati, ut sub copulatione linea longitudinalis, trex duos articulos conjunsit, tantumnodo observetur, demun angulis alternatim soluti. Aestate.

$$
\text { ** aquee salsa. }
$$

Tab. 62, 5. D. marimum; filis simplicibus, planis, cespitosis, flavescentibus; articulis diametro sesquilongioribus, transversim granulosis.

Diatoma flocculosum Decand, A. fr. 2, p. 49. et Syn. p. 10?

Hahitat ad littora Feroensia, apicibus Hutchinsiae urceolatæe et Confervae rupestris insidens, passim. Etiam ad littus Svinöer prope Lindesnas Norvegiae.

DESC. Cæspitcs mimut, semilineam alti, fusci, apicibus Confervarum parasitice insidentes. Fila dense agoregata, tenuissima, intricata, simplicia, interdum tamcn ob varian articulorum solutionem ranısa apparentia. Articuli diametro acprales, vel eandem longitudine 2plo superantes, granulis ovatis transversalibus, medio spatium pellucidun relinqrentibus, notati; onnes anguli alternatim soluti. Color ciespitis reccutis fuscus, siccati virescens; filorum sub lente flavus. Aestate. Chartæ laxe adhæret.

OBS. In slatu siccato refert quidem Oscillatoriem Nucorem $A g$; sed sub lentc considerata ab eat longissime recedit; a Diatomate flocculoso partim ab locum natalcm, partim ob structuram internam merito, ut videtur, distingvitur, licet Angli, ut ex speciminibus missis vidi, utramqre speciem identicam lıabeant.

Tab. 62. 6. D. arcuatum; filis simplicibus, planis, arcnatis, flavescentibus; articulis dianetrum longitudine aqvartibus, transrersim striatis, post copulationem subalternatim solutis. 
Diatoma arcuatum Fl. dan. Tab. 1599. fig. 2.

- rigidum Decand. 月. fr. 2, P. 49?

Habitat ad littus Fioniae septentrionale Ceramio rubro et elongato parasitice insidens, hic illic copiose.

DESC. Fila plerumqre solitaria, simplicia, plana, rigida, arcuata, xqvalia, oculo nudo, tançram punctula elongata nitentia, conspicua. Articuli diametro subæqvales, qradrati, striis transversalibus densissimis pulcherrime notati; granulis rotundis pellucidis inter strias collocatis. Color flavescens. Hycme et verc.

OBS. Hanc specicm Algas nominatas tanta interdum copia obvestire vidi, ut istre, cum exsiccatæe fucrint, erustâ albâ pruinosâ obductæ viđlerentur. - De synonymo Decandollii, qrod modo ex coujectura adjcei, aliqvantum dubitatur.

7. D. obliquatum; filis subsimplicibus, planis, cæspitosis, fuscescenti- Tab. 62. bus; articulis diametro sesqvilongioribus, obliqvis, fascia pellucida transversali punctoqve notatis.

Conferva obliqvata Engl. bot. 'Tab. r889? - Dillw. Introd. n. 48.

Habitat ad littora Færoensia apicibus Thalassiophytorum qvorundam, ut Ptilotæ plumosæ, Plocamii coccinei, Delesseriæ alatæ et sinuosæ parasitice insidens, hic illic copiosissime.

DESC. Fila cæspitose congesta, plana, et licet siut minutissima, oculis tamen mudis, ubi copia adsunt, bene conspicna, simplicia, vel ob singularcm articulorem colaxsionem, si mavis, ramosa. Articuli diametro æqvales vel eadem 2 plo longiores, ad utrunqve finem obliqvi, medio fascia pellncida transversali nunc recta nunc obliqva notati, et praterea puneto plerumqve rosaceo medio picti, a faseia usqre transversim striati, angulisqve acutinsculis singulari modo cohærentes, qrod ex delineatione melius, qram cx descriptione patebit. Color recentis dilute fuscus, exsiccati albescens. Aestate.

OBS. Cum TabuIam cx English Botany citatam nondum videre contigit, qratenus hoc synonymum, qrod conjecturâ modo assecutus sum, in mean speciem qvadret, in suspenso relinqvere cogor. Singụlaris certe hæc species est, et utrum ad Diatoma pertincat, necne, adhuc non ecrto constat. In statu siccato, nbi abundanter adfuit, crustam albam in Algis, qvibns insidet, ad modum Diatomatis flocculosi aliorumqve, relinqvit. 
Tab. 62. 8. D. auritum; filis simplicibus, planis, rigidis, flavescentibus; articulis diametro xqualibus, post copulationem alternatim solutis; singulis angulis auritis.

Habitat ad littus Hofmansgare Fionix in Ceramio elongato aliisqre, rarius.

DESC. Ilxc species, qra modo obiter sub lente mihi occurrit, ob cunctos cujusqve articnli angulos paululum protensos vel auritos, digna mili visa est, cujus mentionen facercm. Articuli dianetrum longitudine zqvantes, sub lente flavescentes, et gramulis minutissimis rotundis, nunc cruciatim unuc arcuatim inordinate dispositis adspersi. Hyeme reperi.

\section{F R A GILARIA.}

Fila articulata, plana, simplicia, fragillima, articulis solutis angulo non alteraatim cohærentibus.

Tab. 62. 1. F. fusciata; filis simplicibus, planis, hyalinis; articulis diametro xqvalibus, medio fascia rosacea notatis, post copulationem subaltcruatim solutis.

Habitat in sinu Othiniensi Hutchinsix violaceæ aliisqve insidens, raro.

DESC. Nil nisi frustula hujus speciei hucusqve obvia milui fuerunt. Arliculi qvadrati, cı, fasciâ rosaccầ transversali excẹtâ, omnino hyalini, nullis striis notati. Ilyesne.

Tab. 62. 2. F. latruncularia; filis simplicibus, planis, liyalinis; articulis diametro 2plo longioribus, medio puncto rosaceo qvadrato notatis, post copulationem solutis.

Habitat in Ectocarpo littorali aliisqve in sinu Othiniensi.

DESC. Frustula filorum hactenus modo vidi. Punctum qpadratum rosaccum in medio articulorum transversim vel obliqve positum, toum fili spatium qvoad latitudincm occupans. Articuli cctcrum hyalini, nullis striis notati. Hyeme. 
3. F. unipunctata; filis simplicibus, convexis, crystallinis, fragillimis; Tab. 62 . articulis diametrum longitudine aqvantibus, medio puncto rosaceo notatis.

Habitat ante ostium sinus. Oxefiord Norvegia in Ectocarpo silictloso aliisque, hic illic copiosissime.

DESC. Fila simplicia, utrincre parum convexa, maxime fragilia, adeo nt filum continuum vix in conspectum veniat; articuli vero, facillime secedentes et post dissolutionem in aqva libere fluctnantes, mirum in modum se itcrum citissime agghtutinantes invicen promiscue cohærent, hinc articulorun vicinorum diversa interdum latitudo. Articuli diametro subxqvales, puncto rosaceo medio picti, et striis transversalibus densissimis abruptis vel medio evanescentibus notati, ceterum hyalini. Punctum rosaceum ecntrale nedio ut plurimum pellucidum. Aestate.

ODS. Post exsiccationem, ubi scilicet in copia adest, crusiam albam erystallisantem pruinosam refert, plantæ, cui parasitice insidei, adlıærentem.

4. $F$. striatula; filis simplicibus, planis, flavescentibus; articulis bre- 'Tab. 63 . vissimis, transversin striatis, interdum solutis.

Conferva striatula Engl. bot. Tab. 1928? - Dillw. Introd, n. 45.

Habitat ad littora Færoensia, uł ad Famöjan, Sumböe, Kirkeböe, Eldevig \&c., partim saxis in summo refluxus limite insidens, partim Scytosiphonten intestinalem aliosqre obvestiens; etiam in Laminaria esculenta cum Ectocarpo littorali parasitica.

DESC. Cxspes minutus, lineam ad semipollicem longus, densus, sublubricns, fuscus. Fila simplicia, capillo humano tenniora, plana, id qrod, qvando fila in aqva sub lente volvuntur, bene pereipitur; tunc enin, latere seilicet compresso vel angustato oculis forte obverso, ad alternm finem attennata et nigricantia hand raro videntur. Artienli non bene conspicui, diametro tamen breviores, transversim striati, hie illic in geniculis soluti. Color cespitis recentis fuscus, siccati interdum in viridescentem abiens: filornm sub lentc flavescens. Suhstantia tenerrima, suhlubrica, non multum fragilis. Aestate. Charte bene adharet.

OBS. Primo intuitu fasciculum parvum Ectocarpi littoralis, eni etiam immixta interdum invenitur, simulat, scel sub lente considerata ab co longe diversa cervitur. Ob strias transversales densissimas ad Oscillatorias nonuihil aecedit. - De synonymo allato, cum Tabulam cititam nondum vidi, non ccro constat. 
Tab. 63. 5. F. lineata; filis simplicibus, tenuissimis, fragilibus; articulis diametro subduplo longioribus, linea una alterave tenuissina transversali notatis.

Conferva lineata Dillw. Introd. p. 44. Suppl. Tah. B. - Jürg. Alg. Dec. 5. n. 10.

- moniliformis NIüller Nov. Act. Hohn. 1783. p. 80. Tah. 3. fig. 1-5. - Web. et Mohr Arch. 1, p. 139. Tab. 5. fig. 5. - Fl dan. I ab. 1548. fig. 1. - Ag. Disp. p. 5'. et Syrn. P. 78. - Jürg. Alg. Dec. 1. n. 7 .

- inflexa Roth. Cat. bot, 1, P. 203. - Web. et Mohr Beitr. 1, p. 350.

Habitat ad littora cirea Hafniam; Müller et Moler. In fossis aqra submarina stagnanti repletis ad Hofmansgave Fionix. In sinu Othiniensi; Hofinann Bang.

DESC. Cæspes densus, Ji-tripollicaris. Fila tenuissima, simplicia, plana, capillo humano tenniora, fragillima. Articuli diametro sestri-vel duplo longiores, singnli globulum continentes; globuli totam fili diametrum occupantes, ovati, pellucieli cum opacis mixti, medio linea tenuissima transversali, qra sine dubio geniculum constituit, notati. Color flavescens, post exsiccationem cincrens. Substantia fragillima, siccatæ pulverulenta. Prino vere. Cirarta laxe idlixret.

Tab. 63. 6. F. nummuloides; filis simplicibus, tenuissimis, fragilibus; articulis diametro subrqvalibus, globulos moniliformes, hexagonos vel ellipticos approximatos includentibus.

Conferva numntuloides Dillw. Introd. p. 45. Suppl. Tab. B.

Habitat in fossis submarinis ad Hofmansgave Fionize.

DESC. Stratum fragile, ocluraceum, bi-tripollicare, aqvex superficiei imatans, graminilus sub aqua adlıarescens, Confervisque immivtum. Fila simplicia, tenuissima, fragillina, adeo ut corum longitudo determinari neqveat. Globuli totam fili dianetrum occupantes, moniliformes, approximati, ovati vel elliptici. plerumque hexagoni, pellucidi, nummos aureos hand male reforenıes. Colon filorum sub lente fusco-aureus. Substantia fragilis, exsiccata pulverulenta. Hycme et primo vere. Clarta laxe adharet.

Tab. 63. \%. F. pectinalis; filis simplicibus, planis, rigidis, strictis, fragillimis, attenuatis; articulis diametro 3 plo brevioribus, medio pellucidis, hic illic solutis. 
Conferva pectinalis Müller Nova Act. Petrop. 3, p. 9r. Tab. r. fig. 4-7. - Dillw. Tab. 24. et Introd. p. 51. - Web, et Mohr Gr. Conf. Tab. 24 et 29. - Engl. bot. 'Tab. 1611. - Waht. H. lapp. n. 989.

- Eronchialis Roth. Cat. bot. I, p. 186. Fl. germ. 3, p. $5^{20 .}$

Diatoma pectinalis Ag. Disp. p. 34. et Syn. p. 119. - Fl. dan. Tab. 1598. fig. I.

Habitat arl plantas aqvaticas in rivulis Danix et insularum Færocnsium passim; ad rotas molarmm aqvaticas Confervis adhærescens.

DESC. Fila tenuissima, lyyalina vel dilute viridia, senipollicari circiter longitudine, rigida, apieen versus sensim attenuata. Articuli brevissimi, mudio pellucidi, er internis parietibus fluido viridi interdum repleti, sxpe soluti, adeo 11 angulo solummodo colirreant. Vere ad autumnum. Siecata evadit cinereo-virescens, tanqram vcruice obducta, nitens, fragillima, charta tamen laxe adhærens.

OBS. Frustula filorum fraetorum libere fluctuantia sæpins occurrunt; rarius cæspitosa et integra observantur. - Credunt Cell. IV eber et $M o l v r$, hanc algam et Diatona flocculosum esse nnam eandemqve plantam, contendentes, se sub lente vidisse hane speciem, angnlis solutan, in Diatoma flocculosum abire. Ast in hac observatione sine dubio errarunt; nam inter utrasqre tanta cst structura internæ diversitas, ut aliam in aliam transmutari posse haud facile crederem.

8. F. hyemulis; filis simplicibus, planis, mucilaginosis, fragillimis; ar- Tab. 63. ticulis diametro subbrevioribus, aureis, hic illic solutis.

Conferva hyemalis Roth. Fl. Germ. 3, p. 506. et Cat. bot. 2, p. 205. - Ag. Disp. p. 28. et Syn. p. 78 .

Habitat in rivulis alpinis insularum Færocnsium, nt in rupe Kirkeböe prope Thorshavn, et in rupe, Præstefield dicta, prope Qvalböe Suderöe alibiqve saxis adnata, hic illic copiosissime.

DESC. Cæspites densi, 3-4 pollices longi, sub aqva fluctuantes, nigro-fusci, tactu mollissimi, mucilaginosi. Fila fragillima, capillo lumano tenuiora, iu loco natali 2-4 polliecs longa, sub lente simplicia, plana, sensim attenuata, 
pulcherrime articulata, aurantiaca. Articuli diametro dimidio breviores, interdum eandem reqvantes, punotis aureis notati vel hyalini, facile secedentes. Genicula obscura. Color crspitis recentis fuscus, vel nigro-fuscus, filorum sub) leute anreus; siccati flaveseens. Substantia mollis, sublubrica, fragilis, siccatie pulverulenta. Alensibus xstivis legi. Charte non adlrærct. 


\section{$\begin{array}{llllllll}S & E & C & T & \text { I } & \text { O } & \text { VI. }\end{array}$}

TREMELLOIDA'TA:

Frons vel Massa gelatinosa:

\section{BATR A CHO S PERM UM. *)}

Frons gelatinosa, articulata, ramosa: ramulis ad genicula verticiliatis. Fructus Capsula globosa, intra verticillos sitæ.

1. B. moniliforme; fronde ramosissima, nodulosa; attenuata; ramis al- Tab. 64. ternis, patentibus; ramulis verticillatis, subdichotomis, densissimis; articulis ovato-moniliformibus.

Batrachospermum moniliforme Roth. Fl. Germ. 3, p. 480. Cat. bot. 2, p. 187.3, p. 160. - Vaucl. p. 112. Tal, 1, fig. 5. et Tab. Ir. fig. I et 3. - Ducluz. Essai p. 79. Dec. A. fr. 2, p. 59. - Ag. Disp. p. 40. et Syn. p. 122.

Batrachosperma ludibunda Bory de St. Vincent Ann. Mus. Vol. r2, p. 3 ro.

Conferva gelatinosa Linn. Syst. nat. 2, p. 720. - Huds. P. 597. - Lightf. p. 986. -

With. 4, p. 134. - Engl. hot. Tab. 689. - Dillw. Tab. 32. et Introd. p. 63. Web. et Mohr Gr. Conf, Tab. 32.

Chara gelatinosa Roth. Cat. bot. I, p. 125 .

- batracliosperma Weis pl. crypt. A. Goett. p. 33. Tab. I.

Conferva fontana nodosa \&c. Dillen. Tab. 7. fig. 42. - Hall. Helv. n. 2124.

B) detersum, ramulis detersis.

Batrachospermum moniliforme $\gamma$. detersum Ag. Syn. p. 124.

Ceramium nodulosim Ag. Dec. n. 23.

Conferva nera lluds. p. 597. - With. 4, p. 134. - Eogl. bot. Tab. 6go. - Dillw. Tab, 11. et Suppl. Tab. D. - Web. et Molir Gr. Conf. Tab. I1. - Roth. Cat. boz. 3. p. 3 ก6.

- Dillen. Tab. 7. fig. 46 .

Habitat in rivulis Daniæ saxis adnascens, haud freqvens; ad Norup Fioniæ et Lundtofte Sellandie. In rirulis Norvegiæe freqventius. - $\beta$. ibidem.

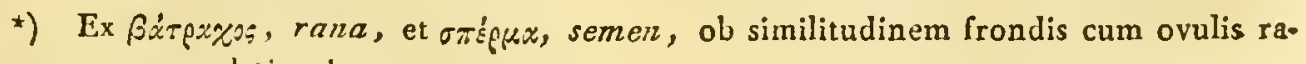
narum gelatinosis. 
DESC. Radix parra, scutata, nigricans. Frondes ex cadem basijplures, quie cx agra extracte massas formant gelatinosas, ovela ranarum referentes, ct tan lubricas, ut c manu captantis dabantur facillime. Caulis 3-4 pollices longus, hasi penuan passerinam interdum crassus, nodulosus, aprecm versus attenuatus, lanosissimus; lami ad basin præprimis approximati, plerumege alterni, rarius oppositi. Noduli glohosi, ad basin distincti, ajicem versus conlluentes, oculo nudo articulos turgidos referentes, sub lente antem e ramulis alybreviatis, fastigiatis, ad genicula filorum et ramorum verticillatim dispositis constantes; ramuli isti preterea diclotomi, articulati, moniliformes. Articuli caulis inferiores dianctro 10plo longiores, respectu nodulorum, ccterum

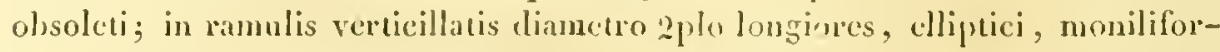
mes, pulcherrimi. Copsulis globosa, atrovirides, vel flavescentes, ad ranulorum axillas dispositx. Color saturate virillis, interdum flavo-viridis. Sulnstantia gelatinosa, lubrica. Annua. Vere el restate. Charta arete adhrecet, nec siccitate unt:atur.

Tab. 64. 2. B. vagum; fronde dichotoma, tereti, eqvali; ramis divaricatis; ramulis verticillatis, dichotomis, densissinns; articulis ovato-moniliformibus.

Batrachospermum vagum Ag. Disp. 1. 41. el Syn. p. 125.

moniliforme o. v'semm Rotl. Cat. bot. 2, P. 187. Fl. germ. 3, P. 483.

Batrachosperma urfosa bory de Si. Vincent Anu. MIus. Vol. 12, P. 327. Tab. 3 I. fig. I. Chara gelacinosa d. vaga Roth. Cat. bot. 1, P. 127.

Conferva gelatinosa \&. Iluds. p. 598. - Wiilt. 4. P. 155. - Walı. A. lapp. n. 975.

- alpina lubrica, filamentis nodosis cocruleis Dillen. 'Tab. 7. fig. 45 ?

Habitat in rivulis turfosis prope officinam ferrariam Næes Norvegia, saxis lignisqve inundatis adhereseens.

DESC. Padix callus criguus, nigricaus. Fronles aggrcgata, minus lulnicx, qram preccelentis, diffusa, tres rel qualuor pollices longxe, scta porcina ?plo crassiores, vage dichotoma, tcretes, ergjalcs, nodulis quvasi obliteratis, conflucutibus, et continuis. Rami clivaricati, dchiles, flaccidi, ob norlulos minns elensos apicilus cocrulescentes. Noduli sive verticilli in canle ramisque majorilus densissini, sub, lente tamen ramuli virticillati, totan frondem qrasi constiluentes, in conspectum reniunt, confertissini, horizontaliter patuli, dichotomi, articulati, fastigiati, adeo ut frons tores evadat; articuli ovatomoniliformes, apice uonuihil incrassiti. Color atroviridis, in apice cocrulescens, siccitate immutabilis. Substantia gelatinosa, lubrica. Acstatc. Chartio aretissimc allowet. 


\section{DR A A R ALDIA. *)}

Frons gelatinosa, articulata, ramosa; ramulis fasciculatis, penicilliformibus. Granulit in articulis hic illic sparsa.

1. D. glomerata; filis ramosissimis; ramulis fasciculatis, multifidis, pe- Tab. 64. nicilliformibus; penicillis subalternis, ovatis, obtusis, patentibus; articulis diametro 2 plo longioribus.

Draparnaldia glomerata Ag. Disp. p. 41. Dec. n. 28. et Syn. p. 124.

- mutabilis Lory Ann. Mus. Vol. 12, p. 402. Tab. 35. lig. 1. a-d.

Batrachospermum glomeratm Vauch. p. 114. Tab. 12. fog. I. - Dec. A. fr. 2, p. 59.

Conferva Chara Roth. Cat. bot. 3, p. 285.

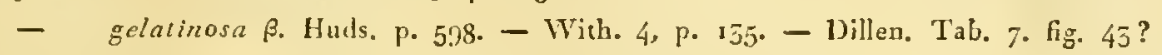

Corallina pingvis ramosa viridis Vaill. Paris. p. 40. Tab. 7. fig. 6.

Habitat in rivulis Danix passim; ad Charlottenlund Sellandia et Norup Fio'niæ. Ad saxa rivulorum Færoensium, ut ad Velbestad, et Qvalböe Suderöe.

DESC. Fasciculus tres ad qratuor pollices longus, oculo nudo mucilaginem viriden referens, et levissimo aqva motu fluctuans. Fila primaria eatpillo humano tenniora, rqvalia, vage ramosa; rami vagi, plerumqve altcrnj; ramuli divaricati, acuti, apicibus hyalinis et sub certa speculi directione protensis, fasciculati, penicillum ovatum patentem viridem constitucntes. Articuli in filis ramisque primariis diametio subduplo longiores, hyalini, medio fascia transversali dilutissime viridi notati; in ramulis diametrum longitudine reqrantes, toti fere viricles. Genicula in filis primariis obscnra, parum contracta. Color viridis. Substantia gelatinosa, lubrica. Annta. Vere et astate. Charı arctissime adharet.

2. D. plumosa; filis ramosissimis; ramulis fasciculatis, multifidis, pcnicilliformibus; penicillis suboppositis, lanceolatis, acutis, erectis; articulis diametro sesqvilongioribus.

Draparnaldia plumosa Ag. Disp. p. 4ã. Dec. n. 29. et Syn. p. 124.

h) pnosa Bory Ann. Nus. Vol. 12, p. 405. Tab. 35. f. 2. a. b. c.

Ratrachospermum plumosum Vauch. p. I15. Tab. II fig. 2. - Dec. I. fr. 2, p. 59.

Conferva mutalilis Roth. Cat. bot. 1, p. 197. Cat. bot. 3, p. 282. Fl. germ. 3, p. 5IS. - Dillw Tab 12. el Introd. P. 63. - Web. et Mohr Gr. Conf. Tab. 12. - Fi. dan. Tab. ${ }_{4} 85$ fig. $\mathbf{x}$.

- Dillen. Tab. 7. fig. 44 .

*) Memoriæe Cel. Draparnaud, eximii algologi Monspesulani, jam vita defuncti, hoc genns a Cel. Bory dedicatum. (efr. Ann. du Mus. d'Histoire naturelle an VI. Vol. XII. p. 399.) 
Tab. 65. B) opposila; ramis inferioribus subverticillatis; penicillis brevibus, patentibus, oppositis; articulis diametro subxqvalibus, lineis binis longitudinalibus notatis.

Habitat in rivulis Danix passim, saxis lignisqve inundatis adnata: Ad Körup et Lumbye Fionix. Ad Öster Riisöer Norvegix. - $\beta$. in rivulo ad Scheidemoe prope officinam ferrariam Nies Norvegia.

DESC. Fasciculus et fila, ut precedentis. Rami vagi, plerumerve oppositi; ramuli acuti, elougati, fasciculati, apiec liyalini, penicillos lanceclatos acutos formantes; uhimus ramulus cetcris multo longior. Articuli ut praccedentis, nisi qrod sunt paulo breriores, diametro subreqvales. Color late viridis. Substantia gelatinosa. Annua. Aestate. Charta arcte adharct.

OBS. Dux illx species, qf $x$ luuic generi annnmcrantur, a se invicem xgre discerunntur, et parum abest, quin cecdam, utramgye non revera esse distinctam, aliam rero sensim in aliam abire. - Varictas $\beta$, qve articulos habet in filo primario nullî fasciầ transversali, sed lincis binis longitudinalibus notatos, diametroqve subxryales, si sempur sibi constaret, melius distingvi posset; scd ex parro fasciculo, qrem loco indicato legi, nil certi concludere licet.

\section{MES O GL O JA. *)}

Frons gelatiuosa, elongata, ramosa; flis ex communi frondis axe exeuntibus, ramosis, articulatis, capsuliferis tarcta.

Tab. 65. 1. M1. vermicularis.

Mesogloja vermicularis Ag. Syn. p. 126 .

Habilat singularis laxe species ad rupes maritimas ante ostium sinus Oxefiord Norvegix inter Phycoidata majora e fundo extracta; Hofinann Bang et ego.

DESC. Frons solitaria, clongata, Julrica, palmam et u!tra longa, pemuam corvinam crassa, teres, solida, seusim atteuuata, rage ramosil; rani diraricati, remoti, subsimplices, minores hevioresque crassioribus immixti. firons diffraeta, lentique subjecta, tota e filis densissime compactis, dichotomis, articulatis, capsuliferis constare conspicitus. Fila illa intra substantiam e com'muni frondis are egressa, totanque frondem constituentia, sunt a basi usque

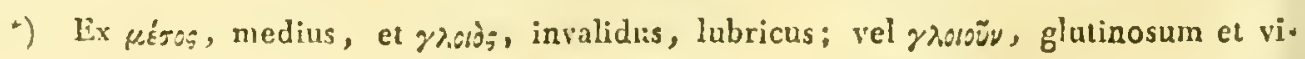
scidum reddere. 
dichotomo-ramosissima; rami inferiores remoti, superiores densi, apiccm versus attenuati, capsuliferi, articulati; articuli inferiores diametro 4-5plo longiores, supcriorcs eandem xqvantes, subpellucidi vel granulis minutissimis fuscis hic illic adspersi. Capsulæa ad axillas dichotomiarum superiorum scssiles, ovatx, fusce, limbo pellucido plerumqve cincte. Color frondis sordide flavesccus vel fuscescens. Substantia gelatinosa, lubrica, debilis, flaccida. Aestate. Siccitate collabitur, ct chartæ arctissime adlhæret.

OBS. Hanc spcciem, ad littus Norvegiæ meridioualis restate 1816 inventam, sub nomine Chatophora capsulifera delineavi et descripsi; cum vero Ccl. Agardhius eandem, ad oras Nordlandixe lectam, sub nomine Mesoglojice vermicularis jam proposuit, nomen auctoris illius celcberrimi merito adoptavi.

\section{C H AE T O P H O R A. *)}

MIassa gelatinosa, elongata vel globosa, filis ramosis articulatis farcta.

* aquae clulcis.

1. Ch. endivicefolia; fronde elongata, planiuscula, solida, palmato-mul- Tab. 65. tifida; ramulis teretiusculis, obtusis; filis intra substantiam ramosissinis; ramulis fastigiatis, patulis.

Chactophora endiviofolia Ag. Syn, p. 42. el Syn. p. 127 .

Rivularia endivicefolia Roth. Cat. bot. 3, p. 334. - Fl. d. Tal. 1488. fig. 2.

- cornu Dame Rotb. Cat. bol. 5, P. 332. et Reue Seitr. 1. p. 261. - Scbum.

Batrachospermum fascicnlatiem Vauch. p. 116. Tab. 13. fig. 1. 2, - Dec. 1. fr. 2, p. 58.

Tremella palmata Hedw. Comm. de Tr. Nos.t. p. 70. Fig. 4-z.

Ulva incrassata Huds. p. 572. - Engl. bot. Tab. 967. - Wilh. 4. p. 124.

Tremella palusiris \&cc. Dillen. Tab. 10. fig. ro. - Hall. Helv. n. 2125.

Fucus fontanus pingvis corniculatus viridis Vaill. bot. paris. p. 56. Tab. 10. fig. 3.

Habitat in rivulis et lacubus Daniæ, saxis lignisqve inundatis adnascens, sat freqvens; ad ripam Fuursöe Sellandia, in turfosis ad Hofinansgave Fionia, et alibi.

DESC. Frons planiuscula, solicla, pollicem nnum alterumve longa, lineam crassa, lobata vel palmato-multifila. Fila iutra substantiam subparallela, ramosa; rami patuli, subsecundi, apicem versus densiores. Articuli inferiores diametro 5 plo longiores, interdum vacui et hyalini, superiores eandem xqrantes. Genicula pellueida. Color dilnte viridis. Substantia gelatinosa. Aunua. Aestatc. Cliartie arcte adhæret.

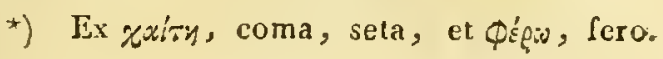


OBS. In fossis turfosis ad Erunclund prope Hafuian hanc specicm insignis ampliundinis, culmis Arundinis Phrasmitis ct Hydrocaris Morsus rance insidentum vidi; crit antem subteres, solida, crassiuscula, 3 prollices longa, polliecmege crassa, papillis vel ramulis abbreviatis crectis utriuque obsessa, saturate viridis; sed structura interna cadem ac unper descripter. Hanc magnitudincon insolitan aqvis puriorilus quietisq̣ve, nbi late crescebat, sinc dubio attribncudim vix and Varietitem, ncdum specicm distinctam, proponcudam suficere credidi. - Cetcrum loc loco moneho, me nomen gencricum Rivularice datâ opcrî omisisse, quippe qvod in Hydropleyta marina leuc pertincntia nominandis nou benc quadrare videretur.

2. Ch. elongata; fronde clongata, subtercti, solida, ramosa, dichotoma; ramis divaricatis; filis extra substantiam longissimis, copiosissimis, intra substantiam diclotomis; ramulis fasciculatis, brevibus, strictis.

Rimularia clongata Roth. Cat. bot. 3. p. 332.

Riccia fluitans Fl. dan. Tab. 275. (sec. Turn.)

Habitat in fossis turfosis prope Nyckiöbing Sellandia, copiosissime; Ocder.

DESC. Frons terctinscula rel subcompressa, polliccm mmum altcrumve longa,

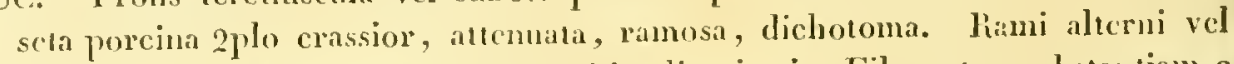
subsecundi, preprimis ad aprecu siti, divaricati. Fila exira substantiam e tota fronde cxemutia, protensa, pollicaria, lyalina, simplicia. Fila intra substantian crassiora, gram in ccteris specicbus, dichotoma, articulata, versus periplucrian froudis fastigiata, ramosa; rami fasciculati, breves, stricti. Color llavescens rel viridesccns. Substantia gelatinosa. llanc specicun nondum vidi; forsan modo varietas pracedentis.

Tab. 65. 3. Ch. elegans; fronde globosa; filis intra substantiam densissinis, dichotomis; ramis divaricatis; ramulis fastigiatis; articulis diametro subduplo longioribus.

Cha:ophora elegans $\mathrm{Ag}$. Disp. p. 42. et Syn. p. 123.

- pisiformis Ag. Disp. p. 4j. et Syn. p. 129 ?

Rivularia pisiformis Rolh. SReue Bcitr. 1, p 272 . Cat. bot. 3, p. 335 .

- elegans Roth. Cat. bot. 3: p. 337. et Reue Bcitr. 1, p. 269.

Batrachosperinum intricatum Vauch. P. 117. Tab. 12, lig. 2. 5. - Decand. A. fr. 2, p. 5 \%.

Conferva globosa gelatinosa Hall. Helv, n. 2110.

Habitat in rivulis Daniae, saxis, conchis, plantisqve aqvaticis adnata, sat freqvens; ut ad ripam lacus Gientofte et Fun'söe Sellandiae. - Etiam in lacu Vandsdalsratn in rupe Qralböefield trans Karagiov Suderöc Færoa, Fontiinali antipyretica adherescens. 
DESC. Frons globosa vel semiglobosa, a seminis Sinapios ad nucis Avellance magnitudinem, solida. Fila intra substantiam e basi cxcentrice exeuntia, granulis. vol vesicis äereis interdum immixtis, tcnuissima, equalia, densissima, articulata, ramosa; rami divaricati, patuli; ramuli breves, fastigiati, intcrdum sccuudi. Articuli diametro 2 plo longiores. Gcnicula pellucida. Color viridis. Substantia gelatinosa, duriuscula, in majoribus individuis mollior. Annua. Aestatc.

OBS. In Gigartina purpurascente ad littus Hofmansgave Fioniæ globulos virides vidi magnitudine seminis Sinapios, gelatinosos, qvi discissi lentique subjecti hanc speciem referebant, crgo a Linckia atra $\beta$, de quâ infra, diversi.

$$
\text { ** aqua salsae. }
$$

4. Ch. marina; fronde globosa, subcoriacea, eava; filis intra substan- Tab. 66. tiam densissimis, dichotomo-ramosis; ramis fastigiatis, apice clavatis.

Nostoc marinum Ag. Disp. p. 45. et Syn. p. 133. Tremella difformis Lin. Syst. nat. 2, P. 714. et Westgoth. Resa p. 193. - Huds. p. 565.
- With. 4, p. 82 .

Habitat ad littus Hindsholm Fioniæ, Gigartinæ plicatæ insidens, hic illic copiose. In sinu Frederitix Cimbriæ; Prof. Hornemann. - In Thalassioplyytis, imprimis in Gelidio pinnatifido ante ostium sinus Oxefiord Norvegiæ, copiose.

DESC. Frons subglobosa, interdum paululum plicata, subcoriacea, intus cava, a semine Pisi ad nucis Avellance magnitudinem variabilis; superficies frondis. lævis. Fila intra substuntian densissime compacta, tenuissima, dichotona, fastigiata, articulara, liyalina, apice clavata, granulifera, fulvo-fusca. Articuli diam tro 3 plo longiores, hyalini. Genicula tenuissima, obscura. Color frondis fulvo-fuscus. Substantia lubrica, subcoriacca, Icnta. Annua. Aeslate. Charta laxe adlixret.

5. Ch. pellita; fronde plana, coriacea, atrorubescenti; filis intra sub- Tab. 66. stantiam subsimplicibus dichotonisqve, parallelis, rectis, moniliformibus.

Habitat ad littus Hindsholm Fionix, saxis ulnam unam alteramve infra maris superficiem demersis, nunqram denudatis, adnata; Hofmann Bang. — Ad insulas Fæeroenses latera rupium declivium in infimo relluxus limite obvestiens, ut ad Qvivig et inter Thorsham et Höyvig.

DESC. Frondes planx, maculas atrorubcntes suborbiculares formantes, pollicem circiter in diametro tenentes, scmiliucam crassa, saxis tota sua fronde arctissime aşglutiuatx, adeo ut non uisi cultelli opc abradi possint. Fila in- 
tra substantiam totam fromlem constiuncutia, in massâ açvos pellucidâ nidulantia, densissima, parallela, reta, simplicia, interdum dichnoma vel apice hifida, actralia, apice parmm atcruata, articulata. Articuli diametro sesquilongiores, rosei, vel moniliformes, hyilini. Color frondis atrorubesceus, filorum sub tente dilute roscus. Substantia coriacea, lubrica. Vere ctastate. Charta adheret. Irrorata ocyus reviviscit, nec siccitate mutatu.

\section{L I N C KIA. *)}

Massa gelatinosa, elongata vel globosa, filis simplicibus, rectis, acuminatis, articulatig vel subcontinuis farcta.

* aquere salsce.

Tab. 66. 1. L. Zosterce; fionde elongata, terete, solida, eqvali; ramis brevibus; patentibus; filis intra substantiam densis, simplicibus, horizontaliter patulis, articulatis; articulis diametro duplo longioribus.

Rivularįa Zosterce Mohr in Web, Ijeitr. Th. 2, p. 367.

Habitat in sinu Flenopolitano; Icrb. Iornemanni. - Ad littus Iolsatize inter Kilian et Eckerufördc; Dr. Muhr. - Ad lituıs maris Corlani, peninsulam Hals prope Hofmansgave Fionize alluentis, basi Gigartina purpurascentis insidens, rarius. - In Zostera marina ad littus Hafniense prope officinam calcariam amicus IIansteen et ego Jegimus.

DESC. Frons teres, solicta, gelatiuosa, scmijollicari lomgiturlinc, ramos breves patentes hic illic emittens. Fila ex communi frondis ase prodemutia, in massâ apvose pelluciclí inclusa, simplicia, hasi non connata, sed singula libere e massa gedatinosa exenutia, horizontalitu pitula, lue illuc incurva, segralia, apicem rersus parmm attenuata. Arriculi dianctro 2 plo longiores, virides, ovati. Genicula pellucida, nom contractis. Color dilnte viridis, sublyalinus. Substantia gelatinosa, lubrica. Vere, Charta arede adhacel.

ORS. Ilabitu quilem arl Rivularian fucirolam Roth. (Calt. Bot. 3, p. 334.), maris mediterranci incolam, accedere videtur: sed fi! is suis intrat substantiam

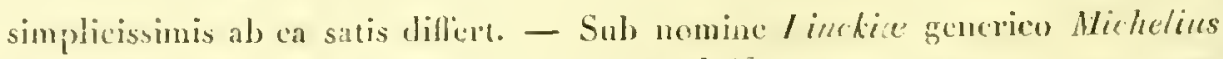

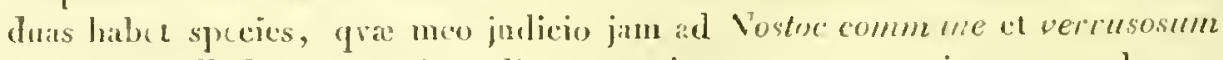
pertincut; illud roo non impedit, qro minus nomen genesicum, grod constituit, retimealur.

*) In animi argnmentum erga Joannem Linchium, Pharmacopamm Lipsiensem prostantissimum, genus aliquod sub hoc nomine Cel. Michelins ulin proposut. 
2. L. ceramicola; fronde minutissima, globosa, punctata; filis intra sub- Tab. 66. stantian subsimplicibus, monilifornibus.

Habitat ad littus Hofmansgave Fioniae in Ceramio elongato, capsulas parvas referens, rarius.

DESC. Frondes globosæ, sessiles, puncta capsuliformia minutissina nigresccutia xmulantes, oculo nudo qvadantenus conspicua, frondi, eui insident, leviter adhærentes, filis minutissimis et qvidem inarticulais interdum involueratx. Primum qvidem, ni fallor, villum densmu caspitosnm referunt, qvi deinde in forman capsulie sensin condensatus conglomerahur: fronrles vero diffracte sub lente e filis exeentricis, rectis, simplicibus, interdum ramosis, moniliformibus, opacis vel pellucidis coustant; intus solidx videntur. Color fuscus. Substantia lubrica. Tempore vernati.

OBS. Capsulas sessiles qridem referunt, sed eum frondi Ceramii elongati solummodo levissimc adhæereant, strueturamyre jan deseriptain sub lente maxime augente prodant, pro prarasitis merito, ut videtur, habui.

3. L. punctiformis; fronde minutissima, subglobosa, adnata; filis ab- Tab. 66 . breviatis, parallelis, rectis, articulatis.

Habitat ad littus Hofmansgare Fioniæe externæ pagina Gastridii filiformis $\varepsilon$ adnata.

DESC. Maculæ minutæ, oblongæ, seminis Papaveris somniferi magnitudine, soliclæ, adnatæ, qræ diffractæ c filis brevibus parallelis flavescentibus sub lente constant; articuli diametro ayvales, inins pumcto notati. Color fuscus, filorum sub lente flaresecns. Substantia prariun lubrica. Yere.

4. L. atra; fronde lemisplæærica, solida, durissina; filis intra substan- Tab. $6 \%$. tiam excentricis, simplicibus, rectis, acuninatis, inferne coadunatis, superne fibrilloso-fissis; articulis inconspicuis.

Rivularia aera lioth. Cal. bot. 3, p. 340. - Ag. Syn. p. 130. - Jürg. Ag. Dec. 4. n. 4. Linckia hemispharica Schum. enum. 2, p. It4.

Tremella hemispharica Lin. Syst. nat. 2, p. 7 r/. et Vestgotb. Resa p 193- - Huds. p. 565. - Lightf. p. 900. - With. 4, p. 81. - Weigel obs. bot. p. 39. Tab. 2. fig. 3. - Roth. Fl. Gurm. 3, p. 550.

- hemisplaarica sparsa Ström Söndm. P. I, p. Iż.

Chacophora atra Ag. Disp. p. 45 .

Batrachospermum hemispharicum Dec. ก. Fr. 2, p. 59r. et Syn. p. Ir.

Fucus Tremella hemispluarica Gmel. Hist. Fuc. P. 225.

B) viridis, fronde globosa, subpellucida, lubrica, solida, viridi; filis in- Tab. $6 \%$. tra suhstantiam simplicibus, rectis, acuminatis. 
Habitat ad littora Daniæ, lapidibus littoreis ab undis marinis humectatis arctissime adnata. - B. ad littus Torbok Sollandiae Gigartina subfusce aliisque Thalassiophytis adhærescens, copiose.

DESC. Frondes globosa vel potius liemisplaxica, magnitudine scminis Sinctpios vel Cannabis, puncta atra referentes, sparsie, solitarix vel plures in unum confluxe, durissimx, arctissims: lapidibus adnata, adeo ut egre inde clidantur, subtus atro-virickes. Fila intra substantian e contro communi frondis excuntia, densissime compactia, stricta, recta, apicem versus attentata, apice fissa, vel in lacinias plures tenuissimas simplices acuminatas alpressas divisa, vix tancen idco ramosa dicenda. Artienli agre observahiles, si adsunt, oblongi, cylindracei. Color frondis externa ater, interne atro-virielis. Substanlia durissima, lubrica. 'Tuto anno. Clsarta ob duritatem non adlıæret, nce siccitate mutatur.

OBS. Qvoad internam falmicam J.inckice durce, qvæ mox scqvitur, admodum similis. Ccl. Moltrius nobis anctor fuit, Jane nostram plantam esse initum Fuci vel Confurre cujustam (cfi. Wuber Beitr. Th. 2, p. 36.5); sed hate opinio nobis, qrorum pracordia ex pejori luto finsit Deus, in incredihilibus putatur. $\rightarrow \mathrm{Va}$ rietas f. est fronde minori, seminis Papaveris vel Sinapios magnitueline, globosa, aggregatit, lubriea, viridi: filit autem intra substantian omnino sunt, ut in e: grare eam pro disersa specie venditate non andeo. Thalassiophytis filitormibus minnribus, ut Gigartince subfuscee, Ceramio rubro aliiseqve ad littus Torloak asstate $\mathbf{1 8 1 5}$ in tanta copia parasitice adherebat, ut globulis suis viridibus frondem corum ad parten fere dimidiam dense obduceret.

\section{** aque dutcis.}

Tab. 6\%. 5. L. nutans; fronde globosa, cava; filis intra substantiam simplicibus, strictis, attenuatis; articulis agre conspicuis.

Tremella natans Hedw. Theor, gener. ed. 2, p. 218. Tab. 35. fig. 7-10. - Rolh. Fl. Germ. 3 , p. $55^{\text {'. }}$

- utriculata Huds. p. 564. - With. 4, p. 8 r.

Rivularia angulosa Roth. Reue şitr. 1, p. 2.3. Cat. bot. 3, p. 340 . - Hooker it. isl. - Ag. Disp. 1. 43. et Syn. 1. 130. (excl. syn. Fl. dan.)

Habitat in fossis turfosis ad Kongsrille prope Frederichsdal Sellandiae inter Lennas trisulcas copiosissine, etiam ad ripan lacus Veilesöe prope Dronninggaard, alibiqve. - In Islandia inter Fontinales sqvanosas et falcatas; Ilooker.

DESC. Frondes globosx, introlum in spcciminibus majoribus globoso-angulosa, cave, a seminis P'isi ad Nueis Auellance magniudium varialjiles, aggregate, majores minoribus immixtx. Fila intta substantiam undeqratge radiatin ex- 
enntia, simplicia, strictissima, recta, raro curvata, apice attenuata, subulata, ad basin limbo longitudinali pellucido instructa, fusca. Articuli regre conspicui, infimus globosus, hyalinus. Color fulvo-fuscus vel olivaceus, raro viridis vel flavescens, exsiccate viridis. Substantia gelatinosa, lubrica. Aunua. Aestate et autumno. Charta arcte adhæret.

6. L. Typnicola; fronde globosa, solida, sublyalina, flavo-viridi, lu- Tab. 67. brica; filis intra substantiam e centro communi exeuntibus, simplicibus, stric-. tis, subulatis; articulis parım conspicuis.

Habitat in paludosis ad lacum Lyngbye Sellandiæ Hypno cuspidato, scorpioidi aliisqre adhæerescens, rarius.

DESC. Frondes globosæ vel hemisphæricx, a scminis Sinapios ad Cannabis magnitndinem, solidx, ad marginem liyalinæ, maxime lubricx. Fila intra substantiam gelatinosam dilute flavescentem simplicia, minus densa, qranı in ceteris speciebus, fulvo-fusca, stricta, acuminata. Articuli agre conspicui, dianctro, qvantum videre licet, subxqvales. Color flavo-vel luteo-viridis, nitcns; exsiccate viridis, radians. Substantia gelatinosa, lubrica. Amuna. Aestate. Charte bene adlixret.

7. L. dur «.; fronde globosa, solida, dura, virili; filis intra substantiam Tab. $6 \%$. excentrice exeuntibus, simplicibus, rectis, infernc coadunatis, superne acuminatis, fissis; articulis inconspicuis.

Rivularia dura Roth. Cat. bot. 3, p. 338. - Fl dan. Tab. I488. fig. I.

Tiemella glolulosa Roth. Fl. Gesm. 3, p. 551. - Hediv. Theor. gen. p. 217. T. 36 .f. ז-6.

- verrucosa Roth. Fl. Germ. 3, p. 554 .

Chatophora tuberculosa Ag. Syn. p. 129?

B) lutescens, fronde hcmisphærica, lutescente.

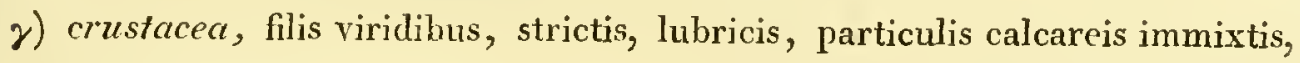
hinc siccitatc crustaceis.

Habitat ad plantas aqvaticas, haud freqrenter; in piscinjs ad Urichsholm Fionia; Prof. Hornemann. Ad radices et culmos Arundinis Phragmitis in lacu Fuursöe Sellandia alibiqve. - $\beta$. ad lapides in ripa lacus Fuursöe, sabulo immixta, copiose. $-\gamma$. ad trabes inundatas prope Bistrupgaard Sellandire, Hofmann Bang.

DESC. Frons capitis acicula magnitudine vel panlo major, globosa, viridis, dura. Fila interna simplicia, confertim et radiatim e centro prodeuntia, stricta, recta, inforne coadunata, apice in lacinias multas subulatas adpressas. divisa. 
Articuli, grantum videre lices, mulli. Sublente sape apparent corpuscula numerosa, filis immixta, nigrescentia, subpllucida. qra qridem subl vesiculas, acire repletas; quando cnim instrumento qrodam frangment vel macex"untur, sub pressione leniter crepitant, adeo ut auribus perejpiatus. Massa gelitinosi, in qra fila niduloutur, sub lente hyalina. Color frondis anome virjdis. Substantia gelatinosa, Jubrica, dura. Ammua. Aestatc. Charta live adharet.

OliS. Virictas 6 . lapides tam lubricos reddit, ut ingredientibus bene cavendum sit, ne pedes vacillent; sabulo intermixta est, et ob locum natalem semiglobosa, sed qroad internam structurim, colore cxecpto, a. omnino refcrt, vesiculisque plerumqve repleta. - Varictas $\gamma$, lineam fere alta, non globosa, sed potitus cespitosa diccula, trabes viridi suo velaninc, qrod siccitate crustaceun evadit, per pollicen et ulura obducit; sed sub lente cjusdem est forma, ac Linchicedura; resicula tanen duriores, calcarea.

\section{NO S T O C. $\left.{ }^{\star}\right)$}

Massa gelatinosa, difformis vel globosa, filis simplicibus, curvalis, moniliformibus farcte.

'Tab. 68. 1. N. commune; fronde difformi, solida, plicata, undulata; filis intra substantiam simplicibus, curratis, moniliformibus.

Nostoc commuze Vauch. p. 222. 'Tab. 16. Gg. 1. - Decand. A. fr. 2, p. J. et Syn. p. 1. Ag. Wisp. P. 44. it Syn. p. 131.

- anlgare Walıl. Al. lapp. n. 992.

- giganteum Mohr in Schrad. Jonrn. I I. 1806 . p. 196.

- ciniflonum Tournel. Hist. П. paris. ed. 2. Vol. 2, p. $4 G_{3}$.

- Paracelsi Geoffr. in Act. Paris. 1708. 12. 293.

Tremella Nostoc Lin. Syst. nat. 2, p. 714. - Fl. dan. Tab. 885. fig. 1. - Molr isl. p. 238 - Dillen. 'Tab. 10. fig. 14 - Hulls. p. 5fit. - Wilı. 4. p. $8^{\text {n. }}$ - Lightif. p. 898. - Engl. bot. Tab. 45x. - Liotl. Fl. Germ. 3, 1. 555. - Hedw. Comm. de 'I's. Nost. Iig. 1. 2. 3 .

- plicata undulata Sirü Sündm. P. T, p. 131.

Fircus Tienella Nostoc Gmel. Hist. Fuc. p. 222.

Muscus fugax membranaceus pingvis Magnol. bot. Monsp. et Hort. Monsp. p. ijg.

Iinchia terrestris \&cc. Nich. nov. pl. gen. p. 126. Tab. 67. fig. ז.

- Nostoc Guett. observ. p. 49. - Roth. Cat. bot. 3. p. 345. - Web. et Mohr Beitr. 2. 1) 359 .

Alcyonidium Nostoc Lam. Thalass. ]. 71.

Coeliflos, Coelifolium V'etcribus.

Skyejald, Troldsmür Danis sulgo.

") Numen apud Paracelsum obvium, originis mili ignotx, forsan alchymisticum. 
B) carneum, fronde difformi, undulata, solida, carnea:

Habitat in umbraculis et alibi autumno vulgaris, Miiller. In granninetis pratensibus Dania, lıaud freqvens. In insulis Færoensibus. In subalpinis Groenlandia, Wormskiold. - - ad rupes Basaltas Færoenses aqva dulci irroratas, ut ad Eldevig Österöe ct Höyvig prope Thorshavn.

DESC. Frondes difformes, sinuosx, plicatx, lobate, 2-3 pollices in dianetro tenentes, 3-6 lineas altx, soliclic. Fila interna simplicia, flexuosa, laxe intricata, moniliformia. Articuli diametro xquales. Color pallide virescens. Substantia gelatinosa, mollis. Annna. Acstate et antumno. Charta adhæret.

OBS. Qvod Cel. Beckmannus, anctoritate Merretti (cfr. Pin. rer. nat. britt. Lond. 166\% p. 219), Persoonii aliorumefve commotus, in Lexicone suo botanico de lac nosna planti in miversum contendit, cam non essc Tremcllam, sed intestina ranarum, qre auscres mandendo comminuerrit et evomuernnt, id assertum minime probamns. Neque melius placuil Lamonrouxius, qvi (Hist. des Polyp. corall. flexibl. Cacn 1816. p. 321.) Lanc specien jnter Polypos referre amat. Massam illam gelatinosam, de qva hic agitur, ad regnum vegctabilc pertinere, non est, qrod dubitemus; sed ab altera parte ctiam cavendum est, ne omnes gelatinas, qrac occurrant, pro algis habeanus; itaque inter veris et falsas distingvendum. - Nostoc giganterm, a Cel. Mohrio inter algas Holsatie l. c. cummeratum, nil aliud qvam magnum lujus algæe exemplar existimo. - Var. $\beta$. mollior est qvam \&, adco ut facillime a se discedat et diffriugatur; siccitate color carneus in virilem vel arujinosum abit.

2. N. verrucusum; fronde subglobosa, subcoriacea, cava, plicata; flis intra substantiam simplicibus, curvatis, moniliformibus.

Nostoc verrucosum Vaucb. p. 225. Tab. 16. Gig. 3. - Decand. 1. fr. 2, p. 4. - Ag. Syn。 p. 132.

Tremella fluviatilis \&c. Dillen. Tab. 10. fig. 16.

verrucosa Lin. Syst. nat. 2, p. 714. - Huds. p. 555. - Lightf, p. 899. -
With. 4. p. 81.

Fucus Tremella verrucosa Gmet. Hist. Fuc. p. 227.

Linckin pulustris \&sc. Mich. nov. pl. gen. p. 126. 'I'ab. 67. fig. 2.

- verrucosa IVigg. prim. A. Holg. p. 44 - Roth. Cat. bot. 3, p. 343.

Habitat ad saxa livulorum Holsatia, Wiggers.

DECC. Froides subglobose vel difforme's, aggregate, a seminis Pisi ad Cerasi magniudinum, juniores solidx, lives, subglobosa, absque simbus vel angulis, op ca, nigrisecutes, adiltiores, massa intema elapsa, magis magisque cave, c loco natali solutx tanquarn vesicula inflax vel inembranæ nlvaformes natuntes, lutco-vircscentes, demum albicantes. Fila interna simplicia, crisp.ta, densissima, moniliformia. Color jumioris atroviridis, uigrescens, 
adultioris Inteo-viresccns. Substantia parum gelatinosa, dura, snbcoriacea. Charta non adharet. Hanc speciem nondum legi.

3. N. muscortum; fronde difformi, papilloso-tuberculata, subcoriacea; filis internis simplicibus, curvatis, moniliformibus.

Nostoc muscorume Ag. Disp. p. 44. et Syn. p. $13^{2}$.

Tremolla intestimalis Fl. dan. Tab. 885. fig. 2 ?

- atrovirens Sclum. enum. 2, P. 43i;?

Habitat in virgultetis rarior, Miiller. - Ad muscos in udis, Agardh.

DESC. Nostoc rommune refert, sed sec. Lgardhium minus est ct durius. Color nigro-virens. Sulstantia subcoriacea.

OBS. Janc specien ipse nondum legi. Ceternm Cel. Agardhius leviter erravit, figuran Flora danica allegatiun bis citans, et ad Ulucem crispam Ag. (U.terrestren mihi) et ad hanc specicm; potius tamen huc pertincere videur.

Tab. 68. 4. N. pruniforme; fronde globosa, solitaria, solida, coriaceo-gelatinosa, levi; filis intra snbstantiam simplicibns, curvatis, moniliformibus.

Nostoc pruniforme Ag. Disp. p. 45. et Syn. p. 134.

Ulva pruniformis Lin. Syst. nat. 2, p. 720. - Huds. p. 572. - With. 4, p. 120. - Weig. obs. bol. p. 40. '1'ib. 2. fig. 4 .

Tromella pruniformis Roh. H. Germ. 3, P. 548 .

linckia pruniformis Wigg. pr. A. Hols. p. 94. - Scbum. enum. 2, p. I14. - Ro1l. Call. bot. 3. P. 343 .

Fucus subglobosus sessilis et mollis Gleditsch Lucubr. P. I.

Habitat in lacubus Daniae plantis aqvaticis adhæreus rel libere natans, non freqventer; in lacu ad Lundelıuus prope Hafniam.

DESC. Frondes globosa, plermugve solitaria, a P'isi ad P'runi maguitulinem, extus coriacce, lacves. intus massa getatinosa. minus dura, farcla. filla interna simplicia, intricata, moniliformia, juxta maryinem densissime compracta, crispatia, medio laxins et minns dense implicata. Color frondis nigrescins, lucem versus subpellucidus, massa interna vitidescens vel aqvose pellucidus. Substantia externa coriacea, internit gुelatinosa. Annua. Aestate. Siccitatc collabitur, ucc charta alliarct.

5. N. 'splucericum; fronde globosa," aggr'cgata, solida, atroviridi, lavi, pisiformi; filis intcrnis simplicibus, curvatis, moniliformibus.

Nostoc splacricum Vauch. p. 223. Lab. 16. fig. 2. - Docand. A. fr. 2, p. 4. - Ag. Syn. 1). 133.

Conferva Pisum Fl. dan. Tab. 660. fig. 2. (excl. syn. Linn.)

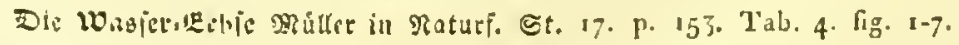

Ula'a pisiformis Huds. p. 572. - Wilh. 4. p. 120.

Linckia granulata Roth. gieue Beitr. 1, p. 297. et Cal. bot. 3, p. 342. 
Habitat ad ripam stagnorum et rivulorum, hic illic copiose, Müller. - In argillaceis inundatis prope Hofmansgave Fionix.

DESC. Frondes globosæ, a seminis Cannabis ad Pisi mag:itudinem, plerumqve aggregatx, solielx, duræe. Fila interna ut præcedentis. Color atroviridis. Substantia duriuscnla, gelatinosa. Autumno. Siccitate corrugatur, nec chartæ adhærct.

6. N. coeruleum; fronde minuta, globosa, solitaria, solida, lævi, coe- Tab. 68: rulea, subpellucida; filis internis simplicibus, curvatis, moniliformibus.

Habitat pulcherrima hæc species in fossis turfosis ad. Viintappergaard prope Gen G. Fl. 7.13 Hafniam, surculis Hypni cuspidati aliorumqve in aqva fluctuantium adhærescens. - In turfosis Stördal Norvegiæ Sommerfeldt legit.

DESC. Frondes globosæ, a capitis acicula ad scminis Cannabis magnitudinem, solidx. Fila intra substantianı ut præcedentium, sed paulo tenuiora et breviora. Color pulcherrimus, pallide coeruleus, nitens. Substantia gelatinosa, maxime lubrica, dura. Annua. Aestate. Chartæ arcte adhæret, puncta coernlea vel æruginosa sistens.

OBS. Color interdum in albidum vergit. - Massa gelatinosa, in qva fila nidulautur, in hac, ut etiam in aliis hujus generis speciebus maceratis vel diffractis, sub lente omnino pellucida et inconspicua apparet; adest tamen, fila invicem continens; nam Kolpodce et alia animalcula infusoria, qræ circa massam huc illuc forte vagantur, fila ante movent, quam ea immcdiate tetigerint.

7. N. Flos aqva; fronde spumea, gelatinosa, lubrica, facile secedente, Tab. 68. coerulea; filis internis simplicibus, curvatis, moniliformibus. Bjssus Flos aqve Linn. Syst. nat. 2, p. $72 \mathrm{r}$. - Huds. p. 604. - Lighte. p. 999. -
With. 4. p. 143 .

Habitat in stagnis Cimbria prope Silkeborg et alibi copiose; Prof. Hornemann et Hofmann Bans. - Ad Hofmansgave Fionia, superficiei aqve dulcis stagnantis copiose innatantem inveni.

DESC. Frons membranam vel spumam gclatinosam, lubricam, captatu difficilem, anoene coeruleam, aqve superficiei innatantem refert. Lenti maxime angenti subjecta fila conspiciuntur simplicia, curvata, pulcherrine flexuosa, et invicem gyrantia, mouiliformia. Articuli diametro xqvales, nonnulli hic illic celcris majores. Color pallide cocruleus. Substantia gelatinosa, lubrica, facillime seccelens. Annua. Vere et æstate. Chartæ arcte adharet et siccata maculas læte cocruleas vel æruginosas cxlibet; siccitate non mutatur. 
OBS. Loco indicato hanc speciem mense Maji 1813 cojiose inveni, posthac frustra ibiden quasitam. An sil Conferva F'los aque Rotlı. Calt. hol. 3, p. 192, Oscillaturia filos aque Ag. Syn. p. 107, justo ambigitur; ille cnim litis incis "t parallelis gautere describuntur, hace rero filis curtatis, implexis inatructat cst.

\section{ALC Y O N IDIUM.}

Massa gelatinosa, elongata, ramosa, vlivarea, iutus collulosa, capsulas solitarias granuliferas incliudens.

1. A. dicophanum; fronde teretiuscula, ramosa; ramis brevibus, acutiusculis.

Alcyonidium diaphanum Lam. Thalass. p. 71. Tab. 6. fig. 4. - Ag. Syn. p. 151.

Slcynnium gefntinosum Linn. Syst. nat. ed. XIIt. 1, P. 391-1 - Fauna svec. n.2228. Lool. dan. T'd,. 14́7. fig. '4? - Lam. Hist. polyp. p. 320.

- ramosum molle Jasteri opusc. subsec. 1. Tab. I. lig. 5. A. B.

- scu Fucus nodusus et spongiosus Ellis Corall. p. 102. 'Tab. 32 fig. d. D.

Ulva diaphana Hluls. p. 570. - Engl bol. Tah. 267. - Mith. 4, p. 121. - Fl. dan. Jab. 1245. - Dec. I1. Ir. 2, p. 6. - Jïrg. Alg. Dec. 5. 11. 5.

Urica marina nodosa Boccnn. mus. di fisica p. 269 cum icnne.

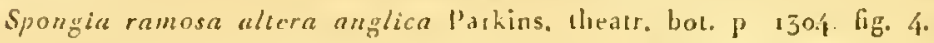

Fucus spongiosus nodosus Gerard. emuc. p. 15:o.

Habitat ad littora maris copiose in insula Föhr, Vahl. - Ad littora sabulosa Cinbriac occidentalia copjose, Prof. MLornemann.

DESC. Frous golatinosa, teretiuscula, solid d, pilmam ad pedem longa, digitum ad corjum crassa, ramosa ; rami vagi, diviricati; ramuli breves, mamillosi, acutiusculi. Frous intcrua collulosa, transvirsim secta cellas hexagonas majuscul:s, yva juvtit peripheriam frondis scusim diminunutur, ostendens; per sectioncm Jo gitudinalem cellac elongure conspiciuntur. Calpsulax (?) majuseulax, saturate flavesecutes vel fuscescentes, in cellas perjplucix copiose disposita, granulis minutis fuscis repletar; in collis interioribus granula solitaria hic illic consputimntur. Color oliviceus, pallidus, diaphatnus, exsiccate nigresecus. Substantia gidatinos: exsiccnta coriacea, dura, subfragilis. Aumua. A estate. Clatrta non adhated, nec post siecalionem in forman pristinam redit.

OBS. An liece speries ad regrnum vegetabile perlincat, non certo constat. Suspicatur Lellisiues l. c., eam nil aliud esse, 'Jvan ovarim animalis cujusdan testacei (le frai de quelque espree nomberuse de poissous à eoquille). (icl. Latmouroxius, qui in libro suo, cui inscribitur: Lissai sur les 'J'halassiophy- 
tes, hanc speciem inter plantas posuit, cum deinde in figuram Zoologix Danicæe P. 4. 'Tab. 147. fig. 1-4. incidisset, scntentiam mutavit, et in Histoire des lolypiers coralligènes flexibles plantun venditatam inter animalia retulit. Neqve negari potest, figuram, qram Cel. O.F. Müllertes in Zoologia Danica l. c. juxta excmplar a Cel. P. C. Abildgaardio ad litus Helgolandia lectum exlribuit, in figuram, quam Cel. Valulius in Flora Danica 'Tab. 1245. proposuit, bene carlerc. Sic regnum animale interdum in vegetabile adco transire videtur, ut tcrminos utriusqve verissimos duterminatu maneat difficillimum. Ego eqvidem, qvi hane speciem nondun in statn recenti vidi, ab omuj pronunciata sententia, ut fas est, lubenter abstineo. Utram vero animalia, qra iu Zoologia Danica depicta exstant, lıanc nostram massam gelatinosam revera inlabitcnt, an alii ci simillima insint, id exactiori inqvisitioni subjici meretur, idcoqve ab industriâ nostratium, cum species memorata ad littora Cinnbrix occielentalia copiose invenitnr, sperandum est, forc, ut iudolem cjus diligentins inspicere suscipiant et explorare dignentur.

2. A. flavescens; fronde subteretiuscula, subramosa; ramis brevibus; olutusis.

Ulva flavescens Huds. p. 570. - With. 4, p. 12r. - Fl. dan. Tab. 12 亿4.

Habitat ad littus maris Germanici prope Thisted Cimbriæ, $V a h l$.

DESC. A priori differt fronde minori, teretiuscula, qra tamen une compressa ct dilatata, nunc margine sinnato-dentata apparet, subramosa; ramis obtusiusculis, colore flavescenti vel fusco-viresccutc. Forsan modo, qura cst scntentia Hudsonis et $V_{\text {ahlii, }}$ varietas præcedentis.

\section{P A L M E L L A. *)}

Massa gelatinosa, sublyalina, granulis solitariis, globosis, farcta.

* aquee dulcis.

1. P. Myosurus; fronde elongata, majuscula, cylindracea, solida, ra- T a b. 68 mosa; ramis tcnuissime ramulosis; granulis intra substantiam minutissimis, globosis, viridibus.

Tremella Myosurus Fl Man. Tah. 1604.

Batrachospermum Ryosurus Ducluzeau Essai p. 76.

- Mlyurus Decand. ก. fr. 2, p. 591. et Syı. p. 12.

*) Ex $\pi \alpha \lambda \mu \partial_{\xi}$, vibratio, tremor; hinc nomen Palmello ad modum Tremello formatum. 
Habitat in rivulo alpino leniter fluente ad rupem Slatteratind prope Eide Österöe Facrox saxis adnata, copiosissime.

DESC. Radix seutata, niggricans, duriusculis. Froudes aggregatx, solidix, masime gelatinose, palman ad pedem Jongx, digitum et ultra crassat, eylindracea, fluctuantes, cursumque aqjae seqventes, apiecm versus attematie, rimosa; rimi sparsi, alterni, clongati, tenuiores, alisquve teunioribus abbreviatisque obsessi. Massa gelatinosa pellucidil, viscosal, sub lente inconspicua, nullo margine apparente, nisi qrod granula intra substantian nidulantia margincm circumscribant: gramula intema glohosa, viridia, in caule ramispre primariis rariora, in ramulis vero imprimis an mangincm densins compacta. Color frondis recentis fusco-olivaceus vel fusco-niger, exsiecata: viridis, gratnulorum recentium et siccatornn virietis. Substintia maxime gedatinosa, et adeo lubriea, ut e naubus captaturi ficilline clabatur. Amnua. Acstate. Chastre arete adheret, et Talco (Nica) imposita post exsiccationem granula interna sub lente bene ostendit.

OBS. In statu recenti odorem tam ingratum spirat, ut exemplaria lujus speciei siceare diffeile sit factu, siqvidem alii homines, qui Algas loujusmodi nou curant, cum odorem regre patiuntur: idem obserravit Cel. Ducluzeau; is hanc specion mense $\Lambda_{\text {jurlis }}$ legrit, rgo mense Augusti; sed alind est clima montiun Gebenu:ntum Gallise, aliud montium frevoensium: is ctiam, cum non nisi ad lentem parum angentem eam consideravit, ob halbitum ad gemus Batrachaspermi retulit: sed melius ad gemus Palmella referri meretur. Color, ul jam monui, in stutu vivo est fusco-olivacens, qvi illis Hydrophytis alpinis Farocusibus, ut Fragilarice hyemali, sinilitcr competit. - Ceterum Tremella nomen, utpote a Mlycologis nomullis usurpatum, in synonymum Palmella mutavi.

Tał. 69. 2. P. hyalina; fronde gelatinosa, cylindracea, subliyalina; granulis internis minutissimis, globosis, viridibus.

Habitat in aqra dulci leniter fluenti prope Thorshavn Faroæ.

DESC. Mlissa gुelatinnsa, cylindracea, solitaria, solida, ayve sujerficici imntaus, pollicen umum altermere longa. Color fere aqrose pellucidus, nisi grod ob granta internat viridia sit virili dilute tinctus. Substantia maxime lubrica. Acstate. Siccitate chiretac adharet.

** aque sulsce.

3. P. froudosa; fronde crespitosa, terete, dichotoma; ramis abbreviatis, trmeatis; terminalibus clavellatis.

- Tremella frondosa Roth. Cat. bot. 5, p. 343. 
Habitat prope Neustadt in Holsatia ad'saxa, ab undis marinis humectata, qvae per ingentes plagas dcnse obclucit; Roth.

DESC. Frondes gelatinosx, aggregatx, erectæ, lineam ad scsquilineam altæ, densie, teretes, dichotomx. Rami alterni vel subsecundi, ultimi subincrassati, opaciores, fuscescentes. Granula intra substantiam exigua, ovata, pellucila. Color sordide vel atro-viridis, subpellucidus. Substantia gelatinosa, tactu duriuscula. Antumno. Charta non adhret ct siccitate corrugatur. Hanc speciom non vidi.

4. P. aclnata; fronde difformi, gelatinosa, rugosa, fusco-flarescente; Tab. 69. granulis internis globosis, fuscis.

Tremella adnata Huds. p. 565. - With. 4, p. 78 ?

Habitat ad rupes maritinas declives Færoenses, inter Thorshavn et Höyvig in superiore refluxus limite, rarior.

DESC. Frons rugosa, pollicem ad palmam extensa, 2-3 lincas crassa, gelatinosa, mollis, fusco-ochiracea, vel fusco-flavescens; granula intra sulstantiam lutescenten minuta, globosa, fusca. Acstate. Chartæ adhæret, crustam fuscescentem sistcns.

5. P. cylindrica; fronde gelatinosa, viridi, subcylindrica; granulis internis minutissimis, solitariis vel submoniliformibus.

Habitat ad littus Ebelöe prope Fioniam saxis adnata, rarius; Hofmann Bang.

DESC. Frous gelatinosa ex substantiis duabus consistit, qrarum exterior colore est saturate viridi, interior dilutiori vel hyalino. Granula intcrna minutissima, globosa, majora minoribns immixta, plerumqve solitaria, scd interdnm ita congesta, at filum submoniliforme abbreviatum amulentur. Color viridis. Substantia gclatinosa. Charte adhieret.

OBS. Hanc specien, anctoritate Cel. Hofmann Bangii introductam, ultcriori Algologorum industrix ct iuquisitioni commendo.

*** subterrestres.

6. P. botryoides; frondibus aggregatis, minutis, globosis, viridibus; granulis internis globosis.

Treinella boiryoides Schreber Spicil. fl. Lips. p, $14^{\mathrm{I}}$.

Byssus botrooides Linn. Syst. nat. 2, p. $72 \mathrm{t}$ - - Dillen. Tab. 1. fig. 5. - Huds. p. 6o8.

- Lighit. F. Ino6. - Fl. dan. Tab. 899. fig. 3. - Mohr isl. p. 250.

Lichen cruslaceus verrucosus viridis Hall. Helv, n, 2089 . 
Lichen borryoides Ach. Lich. prod. p. 10. (excl. syn. Fl. dan.) - With. f. p. 3. - Schum enum. 2, p. 121.

Nostoc botryoides Ag. Syn. p. 135 .

Halitat in peninsula Hals prope Hofmansgave Fionize in terra lumida umbrosa. - In insulis Faroensibus in terra turfosa uda et in Sphagno obtusifolio.

J)ESC. Frondes agrroşatx, cxigux, scmina Papaveris sommiferi magnitudine vix supcrantes, solida, sub lente semipellucidx, granula minutissima globosa inclutentes. Color viridis. Substantia subgclatinosa, carnosa. Vercet astatc legi.

OBS. Intus solidx mihi risa sunt frondes, qrax diffracta lentique subjectx e granulis globosis virdibus constare conspicicbantur, qvare cas ad hoc genus referendas essc credidi; radice minuta, qua corporibus, quibus innascuntur, affixe sunt, eas instructas esse, haud temere suspicor, licet in tanta parvitato nil certi de ca pronunciare andeam.

Tab. 69. 7. P.alpicola; fronde difformi, rugosa, molli, rubra; granulis internis minutis, ovatis, rubris.

Ulua montana Lightf. p. 9:3. - Huds. p. 652. - With. 4. p. 122.

Habitat supra Muscos et Liclienes ad saxa alpina in summitate rupium altissimarum Færoensium, Skiclling, Sncisen et Eilsfield prope Qvivig, haud freyvens.

DESC. Frons gclatinosa, rubra, diformis, mogosa, 2-3 pollices in diamctro tencus, semipollicem circiter crassa, mullis, solicla. Granula intra substantiam ovata vel globosa, atrorubescentia. Color frondis ruber, cxsiceatx intensior. Substintia gclatinosa, mollis, viscosa, exsiccitar coriacca rel crustans atrorubentem relipquens. Acstate. Clasta lixe: adlaret.

ObS. Ccl. Lightfootius, qui in montosis insula Scoticx Shye hane spreicm primus detcxit, dicit, cam Freco palmato esse similcm; ct certe in stalu cxsiccato, si frondem hujus nostre erassiorem excipiamns, frustula ejusdem hene quidem xomulatur; quare ctiam, cum prima vice obvia nilhi fucrit, pro frustulis Fuci ejusdem, ventis et tempestatibus ad summa rupium latera projectis, eam habui; sed cum deinde candem gelatinosam invenissem, sententiam mutavi. Nomine antem Light foolii specifico nti non potui, qroniam nomen, qrod cgo huic speciei imposui, tabula jam antea insenlptum exat, qvam synonymum Light footianum animadverteram. Ldem ctian valet de nuonine Con-. ferie alpina, de qua antea. 
8. P. rupestris; fronde difformi, rugosa, molli, fusco-lutescente; gra- Tab. 69. nulis internis minntissimis, globosis, medio punctulatis.

Tremella juniperina Roth. Car. bot. 3. p. 343 ?

- Sabince Engl. bor. Tab. 7ro?

Habitat ad rupes declives, aqva dulci irroratas, earumqve fissuras ad officinam ferrariam Nas Norvegiæe, lıaud frequens.

DESC. Massa gelatinosa, facile secclens, mollis, pollicem circiter in diametro tenens, difformis, rugosa, subpelhicida, medio crassior et elevata. Granula intra substantiam globosa, nunc solitaria, numc bina vel qratcrua connata, et tuuc ovalia, medio linıâ transversali notata, singula medio punctulo hyalino picta, flavescentia. Color frondis fusco-lutcsccns. Substantia gelatinosa, viscosa, cxsiccatæ collapsa, fragilis. Annna. Acstate. Chartx adhæret.

9. P.rosec ; fronde hemisphærica, carnosa, molli, rosea; granulis internis minutissimis, globosis, subhyalinis.

Lichen roseus Schreb. specil, I Lips. n. Ir5o. - Fl, dan. Tab. 1243. fig. I.

Tubercularia rosea Persoon Syn. meth. fung. 1, p. I14.

Sclerotium persicolor Schum. enum. $2, \mathrm{p} \quad 886$.

Habitat in Lichene stellari saxis adnascenti prope Torbrek Sellandiæe et Hofmansgave Fionia, utroqve in loco haud procul a littore.

DESC. Frondes a scminis Cannabis ad Pisi magnitudinem, solitarix vel aggregate, hemispharicx, molles, caruosa. Granula intra substautiam minutissima, solitaria, globosa, subliyalina. Color extcrior roseus, interior allescens. Substantia carnosa, fragilis, faeile sccudens, molliuscula. Amuna. Hyeme et vere. Siccitate collabitur et chartæ vix adhæret. 


\section{E C H INELLA. *) \\ Massa subgelatinosa, granulis solitariis, cuneatis elongatis jre farcta. \\ * aque dulcis.}

Tab. 69. 1. E. radiosa; fronde gelatinosa, difformi vel cylinılracea, aqrose pellucida; granulis internis solitariis, nunc elongatis medio fasciatis, nunc e centro liyalino radiantibus.

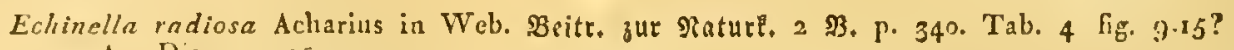
- Ag. Disp. p. 45.

Habitat in fossis aqra dulei stagnanti repletis peninsula Hals prope Hofmansgave Fioniae.

DESC. Massa in aqva fluitans, indeterminatx figurx ex cxtcusionis, pollicem unum itterumve longa, crassa, cylindracea, solida, obtusa. Granula intra sulstantiam solitaria, viridia, nunc elongata, mcdio fasciâ pellucidî̀ notata, nunc rfood periplerian orbienlaria, e centro communi hyalino radiatim exeuntia, singulis radiis apice dilatatis crenatisqve; interdum ctiam alie figura observantur, Color ayvose pellucidus vel dilute viridis. Substantia gelatinosa, viscosa, facile seccdens. Annua. V'ere.

OBS. Primo intuitu hanc massam gelatinosam, qve extcruo habitu ad Palmellam hyalinam antea descriptan acculit, nil aliud esse qram ovulit insecti cujusdan aqvatiei credicli; sêl per tres lecbelomardes et ultra in aqvâ purî̀ rite servata mullim omnino sıbiit mutationem; si esset hıxe massa congeries ovulorum animalculi cujusclam, intra hoc tempus ovulat verosimiliter essent cxclusa; vitellos conim ovulorun ranarum jam intra octo dies vivescere pluries obscrvavi; hinc igitur factun est, ut hauc massam pro distincta specie vegetabili proposnerim; sed cum icon Acharii citata in meam non optine cadit, cumgje Cel. Agardhines Echincllam Acharii pro animali infusorio habet (cfr. Ag. Syn. Lnrod. P. XL.) de synonymo allito nomiliil dubito.

'Tab. 69. 2. E. oblusa; massa difformi, subgclatinosa, fusco-viridi; granulis internis solitariis, rectangulatis, elongatis, ad utrumqve finem obtusis.

Mabitat in rivulo ad Ulrichsholn Fionia filis Conferva glomerata et Vaucheria sessilis densissime adhacrens.

*) Ex Ė\%ัvos, echinı's, qroniam granula interna, acervatim sumta, speciem echini qualemcunque pro se ferunt. 
DESC. Massa subglobosa vel difformis, semipolliccm et ultra in diametro tencus. Granula intra substantiam minuta, solitaria, non colærentia, densissima, clougata, rectangulata, hyalina, medio fascia flavescenti notata, æqvalia, obtusa, truncata. Color fusco-viridis. Substantia parum gelatinosa, exsiccatæ ob granula densiora intcrdum nitens. Autumno. Chartæ adhæret.

3. E. acuta; massa difformi, subgelatinosa, sordide flavescenti; granu- Tab. 69: lis internis solitariis, elongatis, ad utrumqve finem acutis.

Habitat in aqva dulci stagnanti prope Hafniam Confervæ glomeratæ emorture aliisqre parasitice insidens.

DESC. Massa difformis vel subglobosa, magnitudine circiter nucis Juglandis. Granula intra substantiam minuta, solitaria, dense compacta, elongata, hyalina, medio linea transversali tenuissima notata, ad utrum qque finem attenuata, acuta. Color sordide flavescens. Substantia parun gelatinosa, exsiccatæ crustacca. Aestate. Chartæ laxe adhæret.

4. E. olivacea; fronde elongata, cylindracea, obtusa, olivacea; granu- Tab. 70: lis internis solitariis, cuneatis.

Ulva olivacea Fl. dan. Tab. 1429.

f) dilutior, fronde albescente; granulis internis curvatis, lunulatis.

Habitat ad saxa rivuli prope Damsmölle Sellandiæ; Prof. Hornemann. In rivulo prope Charlottenlund Sellandiæe et Norup Fioniæ plantis aqvaticis adhærescens, haud freqvens. - $\beta$. in fossis stagnantibus Körup Fioniæ culmos Potamogetonum amplectens copiosissime.

DESC. Frons gelatinosa, cylindracea, majuscula, palmæ vel spithamæ longitndine, digiti vel carpi crassitie, subhyalina, oblonga , clongata, apice obtusa, culmos plantarum aqvaticarum vel stolones Agrosticlis stoloniferce arcte et longitudinaliter circumdans. Granula intra substantiam gelatinosam nidulantia minutissima, ubiqve densissima, cylindraceo-cuneata, pellucida, medio fascia transversali flavescente notata. Color olivaceus. Substantia gelatinosa, tactu mollis, exsiccatæ collapsa, fragilis. Annua. Vere et æstate legi. Chartæ adhæret.

OBS. Massa ista gelatinosa, pcr plurcs hebdomades in aqra pura rite serrata, eadem permansit, nec ullam omnino subiit mutationcm. - Varietas, qvam primo vere copiosissime vidi, fronde allescente differt et granulis curratis lunulatisqve, interdum binis maculis flavis medio notatis; color autem iste frondis dilutior forsan liycmationi adscribendus est. 
Tab. 70. 5. E. geminata; fronde globosa, fuscescente; filis continuis, intricatis, tenuissimis, apice in bina corpuscula cumeata dilatatis.

Habitat in insulis Faroensibus ad saxa rivulorum subalpestrium prope Argehospital et rupem Skielling, haud freqvens.

DESC. Frons globulum non gelatinosum constituens, sernen Pisi vel nuccm Avellance magnitudine xqvans. Fila intricata, minutissima, continua, pellucida, apice binis raro ternis granulis elavatis euncatis, medio fascia flaveseenti notatis, instructa; hre granula, e filis soluta, omni spoutanco motu destitumtur. Color dilute fusecscens, exsiccate virescens. Substantia tenerrima, subtenax. Aestate. Charta laxe adharet.

** aquae salsce.

Tab. 70. 6. E. fasciculata; filis aggregatis, simplicibus, rigidis, strictis, fastigiatis, continuis, ex basi communi radiatim excuntibus.

Dialoma fasciculata Ag. Disp. p. 35. Dec. n. 9. et Syn. p. 120. - Sv. bot. Tab. $49^{\text {r. }}$ fig. 6. $70^{\circ}$

Fl. dan. Tab. 345. (quoad pilos, qqu in Conferva pennatula, id est, Conferva favescenti adsunt).

Habitat in sinu Othiniensi, Confervis variis et imprimis Ectocarpo littorali parasitice insidens, sat vulgaris. Ante ostium sinus Oxefiord Norvegix.

DESC. Fila brevissima, oculo nudo singula vix conspicua, 3-6 ex uno puncto radiantia, rigida, recta, xeqvalia, vel utrinqve parum attenuata, apice obtusa. Color flaveseens vel hyalinus, crystalliformis, post exsiccationem, ubi fila in copia adfuerunt, albus, nitens. Substantia rigida, fragilis. Per totum annum, imprimis autumno et hyeme.

OBS. Cel. Agardlius, qvi hane speciem ad genus Diatomatis retulit, fila ejusdem articulata describit, qve post copulationem in articulos angulo alterno colierentes solvuntur; vix recte; causa hujus asserti in qvadan Diatomatis specie (Diat. tenui ß.), huic nostræe forte fortüna immixtâ (efr. Sv. Bot. T. 491. fig. 7), sine dubio qvarenda est. Fila autem Echinella fasciculata sub lente maxime angente nulla articulorum vestigia ostendunt, neqve ungram, si qvid vidi, in artieulos alternatim coharentes abeunt; sunt e contrario continua, teretia, tubulosa, id qvod, si alias in re tam tenui sententiam ullan proferre audeamus, ex guttulis, qvæ fila ejus crystallisantibus injecte huc illuc vagantur, conjici potest.

Tab. 70. 7. E. stipilata; flis longitudinaliter aggrcgatis, planis, brevissimis, stipitatis, singulis nedio bipunctatis.

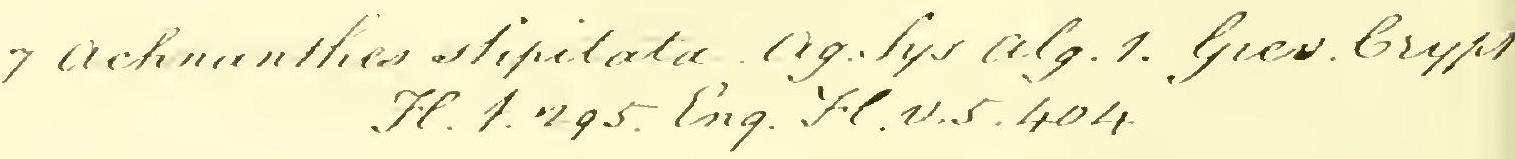


Conferva armillaris Müller Nov. Act. Holm. 1783. p. 80, Tab. 3. fig. 6. 7. - Weber \& Mlohr Arch. I, p. 139.

Habitat ad littus Sellandire, Muiller. - In Hutchinsia violacea, Scytosiphone clathrato aliisqve in sinu Othiniensi, passim.

DESC. Frons, si ita dicere licet, subquadrata, plana, hyalina, rigida, ab altero angulo tenuissime stipitata, ex 3-6 tilis longitudinaliter aggregatis et colærentibus constans; fila ista plana, hyalina, obtusa, interdum transversim striata, medio punctis binis lutescentibus vel aureis notata. Autumno et liyeme inprimis occurrit.

OBS. Confervam armillarem Miill. ad hanc speciem pertinere procul dubio positum existimo; dicit enim, se frustula invenisse, duos ad octo articulos eontinentia, eaqve fuisse pellueida et erystallos concatenatos punetis rosaceis pulcherrime pictos retulisse; qva omnia in hanc nostram bene cadunt.

8. E. paradoxa; filis aggregatis, continuis, rigidis, tenuissimis, ramo-- Tab. 70. sis, apice dilatatis subbinatimqve clavatis.

Habitat in sinu Othiniensi Hutchinsiæ violaceæ parasitice insidens.

DESC. Fila minutissima, microscopica, aggregata, continua, ramosa; apices ramulorum in corpuscula clavæformia dilatati; clavæ istæ terminales cuueatæ, intus punctatic. Color flavescens. Tempore vernali vidi.

9. E. cuneata; granulis minutissimis, aggregatis, cuneiformibus, medio Tab. 70 . fascia flarescenti notatis.

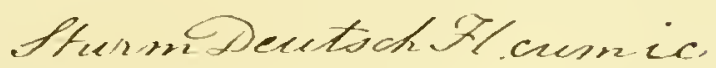

Habitat in sinu Othiniensi Ceramio rubro insidens, rarior.

DESC. Granula vix oculo nudo conspicua, sub lente aggregatim congesta, non colıærentia, cuneata, plana, singula striis binis ternisve longihudinalibus evanidis instructa, medioqve fasciâ granulosâ flavesecnti notata, ceterum hyalina. Hyeme et vere vidi.

OBS. Fieri potest, ut nonnulla species, qvarum sub boc genere mentionem feci, éregno vegetabili, ulteriori carum examine instituto, olim excludantur. Attamen certe non sunt animalia, nam omni spontanco motu penitus carent; sed si qvis nonnullas carum domieilia animalculorum mundi invisibilis esse crederet, non is sum, qui prafracte negarem.

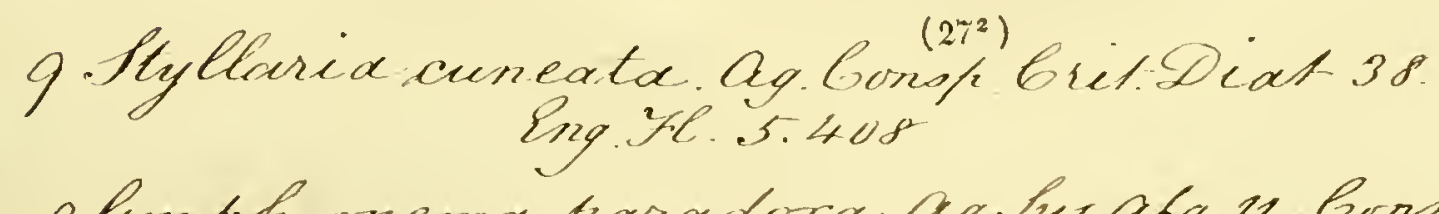




\section{A P P E N D I X.}

Tab. 70. OBS. 1. Glojonema paradoxnm. Ag. Disp. p. 45. et Syn.p. 120. - IIane specicm, qva qviden mihi nondum occurit, juxtit exemplaria siceata, Tra vidi, potius generi Bangice qvam regno animali anmmerandam esse opinor.

Tab. 70. OBS. 2. Pollen Pini sylvestris. Massa flava, mimntissime granulosa, supcrficici maris lacunmqve imnataus ant ad ripas cjecta sub fuem mensis Maji ct ab initio Junii interdum reperitur, qva lenti subjectit e granulis solitariis incurvis val ovatis constant, orculam referentibus, uringve obtusis et nigrescentibus, medio subpellucidis, flavescentibus, reticulatis. Qvid essent hac granula, cum diu laesitarem, tandem essc P'ollen Pini sylestris fuit observatum. Jlanc observasiunculan, licet sensu strictiori hue non pertincat et per se sit levis, onittere tancn nolui, ne aliis, qvibus hec massa obvia fieret, in ejusdem origine et indole diutius justo aqva hacreret. Ante aliqvot annos accidit, quod relatum accepi, ut pluvia sulplurea, qre dicitur, tempore veruali oppidum Hlafine ct loca vicina invaderet, pulverem flavum sccum ferens, emmqve in viis, stagnis tectisqre copiose relingrens; nee dubito, qrin iste pulvis fuerit pollen idem, de qro hic sermo versatur; unde rero in tanta copia venisset, non facile est dictu; forsan e regione Mcgapolitana rel Poncrania, uhi pincta copiosa esse dieuntur, In sinu Codano, procul a littore Siccix, qvoel nobis navigantibus fere recesserat, striam flayam latanyve sub fuem Maji vidi, superficici maris tranquilli per longum tractum innatantem, qva qvidem a nautis pro ovulis pisciun venditata fuit, sed diligentius inspecta pollen nostrum esse apparuit; ventorum igitur ope pollon illud e longiuqvis regionibus per aërem feri ha res in facto posita monstrant. Qvod huic pollini usu venit, id etian scminibus Mnscorum, Fungorum aliorumqve cryptogamorum minutissimis evenirc potest, neqre, me judice, in harum plantarum migratione exponenda opus est, ut ad veterum opinionem de Gencratione sic dicta sequivoca refugiatur. 


\section{O N S P E T U S}

\section{Algarum Floræ danicæ cum nominibus, sub quibus in hoc opere occurrunt.}

\begin{tabular}{|c|c|}
\hline & Nomina Floræ danicæ. \\
\hline 106. & Fucns siliqvosus Oeder. \\
\hline 146. & - nodosus Oed.. \\
\hline 214. & - excisus Oed.... \\
\hline 275. & Riccia fluitans Oed............ \\
\hline 276. & Fucus ramosissimus Oed.... \\
\hline 286. & - spira \\
\hline 349. & - sang \\
\hline 350. & - plum \\
\hline 3.51. & - linearis Oed...... \\
\hline 352. & - alatus Oed...... \\
\hline 353. & - cilianus Oed............ \\
\hline 354. & - pinnatifidus Oed... \\
\hline 355. & - aculcatus Oed........ \\
\hline 356. & Ulva sobolil \\
\hline $35 \%$ & Conferva sqra \\
\hline 358. & - dichotoma Oed.............. \\
\hline 392. & Fucus digita \\
\hline 393. & - fastigiatus Oed.... \\
\hline 394. & 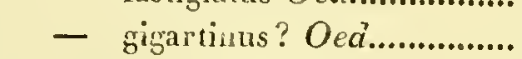 \\
\hline 395. & Confer'va polymorplia Oed......... \\
\hline 408. & 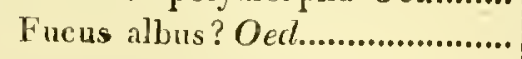 \\
\hline 416. & - sacchiarinus Oed................ \\
\hline $41 \%$ & - esenlentus Oed................... \\
\hline 419. & - furcellatus Oed.................. \\
\hline 420. & - fungularis Oed.................... \\
\hline 591. & - grauulatus Oed................... \\
\hline
\end{tabular}

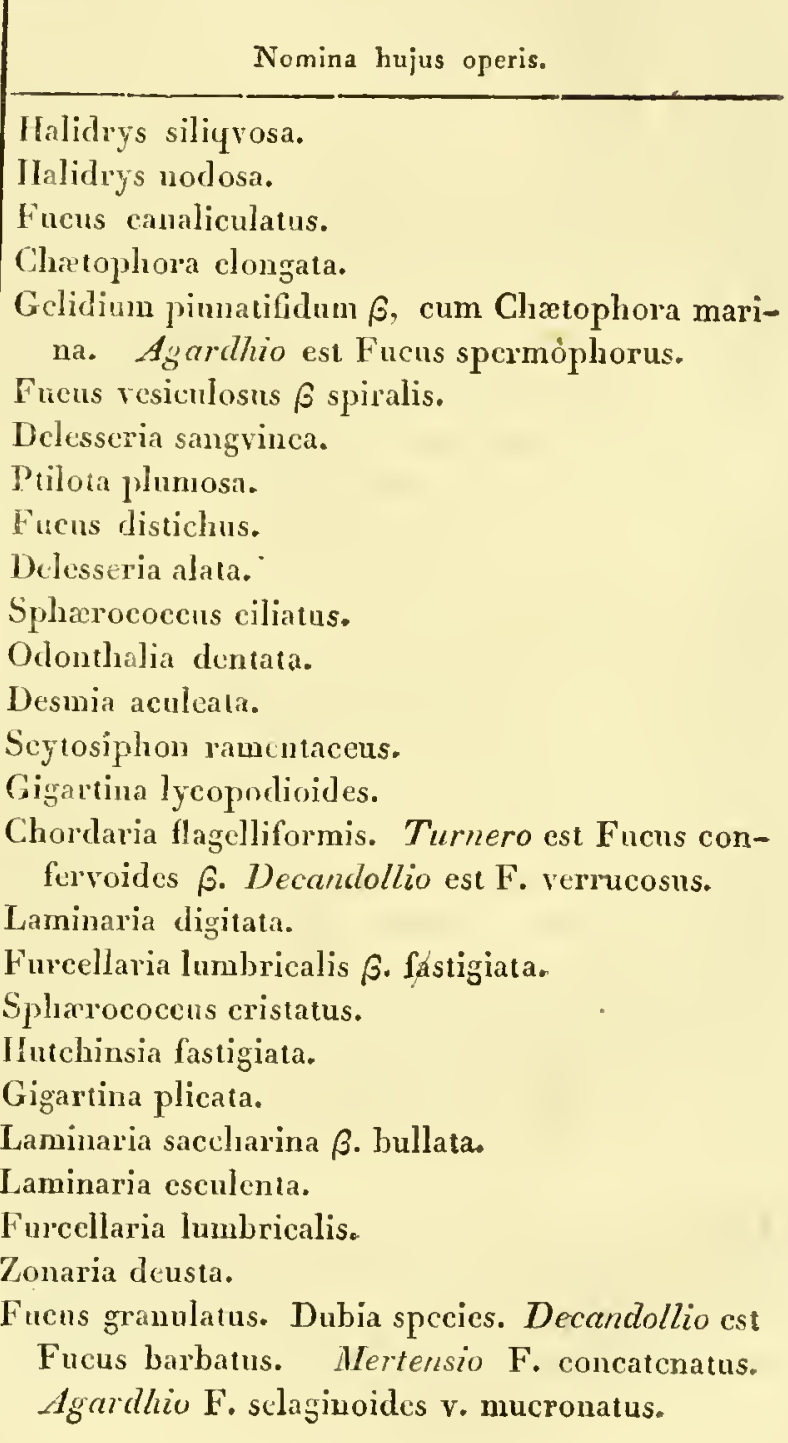




\begin{tabular}{|c|c|c|}
\hline Tab. & Nomina Flora danicre. & Nomina lujus operis. \\
\hline 650. & Fucus llagelliformis Mïller....... & Chordaria flagelliformis. \\
\hline $651,1$. & Conferra sericea $M$................... & Conf \\
\hline-2 & 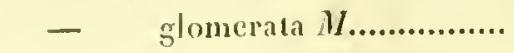 & Conferva glomerata. \\
\hline-3 & - fontinalis $M \ldots . . . . . . . . . .$. & oria fontinalis. \\
\hline 652. & Fucus poscus H....................... & Deless \\
\hline 653. & Ulya incrissata $M . . . . . . . . . . . . . . . . .$. & um filiforme $\beta$ incras. \\
\hline 660.1 . & iris $M \ldots . . . . . . . . . . . . .$. & Confer \\
\hline-2 & - Pisum M.................. & Nostoe sphaxicum. Mohrio est Rivularia elegans $\mathrm{P}$ \\
\hline 70.5. & Ulva granula & mlata. \\
\hline 708. & lus $M \ldots . . . . . . . . . . . . . .$. & Cilio \\
\hline 709. & Is $M . . . . . . . . . . . . . . . .$. & sccus. \\
\hline 710. & - lorens $M$........................ & Itin \\
\hline 718.1. & Byssus atl & Eet \\
\hline 763,1 & Ulva puolifera $M . . . . . . . . . . . .$. & Soytosiphon compressus $\beta$ crisp \\
\hline-2 & - spongi & y spongifo \\
\hline 768 & M..................... & Ulvia \\
\hline 769. & $\div \operatorname{mini}$ & Spharococeus laciniatus. \\
\hline 770. & - bullatus M............. & lisa pro \\
\hline $71,1$. & Conferva uno & cialis. \\
\hline-2. & - Lin! & Conferva Li \\
\hline 819. & - nitis & Zy \\
\hline 820. & - distorta M..... & toria distorta. \\
\hline 821. & Fucus Filum M......................... & a Filum. \\
\hline 826. & - crispatus M.................... & Chondrus crispus $\gamma$ xqrali \\
\hline $8 \% \%$ & - rubcus r. Palnetta $M$........ & Splarecocens membranifolius. \\
\hline $8 \div 8,1$ & Conferva floc & nelumula. \\
\hline 829. & Ulva plicata $M . . . . . . . . . . .$. & Ulra \\
\hline 879.2. & Lichen confunis M......... & Gelidium pygmxum. \\
\hline 881. & Conferva rivularis $M$......... & Confurva rivularis. Aga \\
\hline 852. & 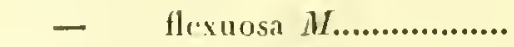 & Conferva rupestris $\beta$ flexuosa. \\
\hline $8 \$ 3$. & - jugalis M.................... & $\mathrm{Zy}_{\mathrm{g}}$ \\
\hline $88.5,1$. & Tremella Nostoc $M . . .$. & Nostoc conun \\
\hline-2 & - inte & Nos \\
\hline $8 \varsigma 6$. & Fuens virilis M......... & $\operatorname{lina} \mathrm{r}$ \\
\hline $88 \%$ & - scorpioides $M . . .$. & $\begin{array}{l}\text { Gigartina confervoides? Agardhio est Sphiero } \\
\text { coccus purpurasecons } \beta \text {. }\end{array}$ \\
\hline 889. & Ulva Linca M... & Ulva Linza. \\
\hline 896. & Byssus aqratica M..... & Vaucheria aqvatica. \\
\hline $898,2$. & Riccia arachuoidea $M . . . . . . .$. & Vaucheria Dillwynii. \\
\hline $\begin{array}{c}899.1 . \\
-\quad 3 .\end{array}$ & 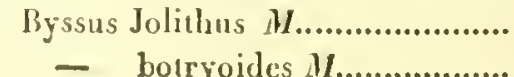 & $\begin{array}{l}\text { Conferva Jolithus. } \\
\text { Palurella botryoide }\end{array}$ \\
\hline
\end{tabular}




\begin{tabular}{|c|c|c|}
\hline Tab. & Nomina Floræ danicæ. & Nomina hujus operis. \\
\hline 945. & Couferva penuatula Miiller....... & Conferva flavescens cum Echinclla fasciculata. \\
\hline 946. & fracta $M \ldots . . . \ldots \ldots \ldots \ldots . . . . .$. & Conferva fracta. \\
\hline $94 \%$ & hirta $M$....................... & Conferva fraeta $\beta$. hirta. \\
\hline 948. & rupestris $11 . . . . . . . . . . . . . . . .$. & Conferva rupestris. \\
\hline 949. & 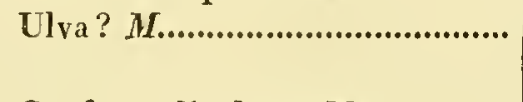 & $\begin{array}{l}\text { Vaueheria clavata. Turnero est Fucus pusillus, } \\
\text { Decandollio Fucus cæespitosus. }\end{array}$ \\
\hline 951. & Conferva diaphana $M$.................. & Ceramium diaphanun. \\
\hline 1065. & Fucus soboliferus $V$ ahl.............. & Ulva sobolifera. \\
\hline 1066. & 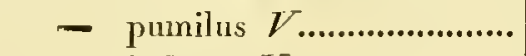 & Chondrus crispus $\varepsilon$. pumilus. \\
\hline $112 \%$ & - inflatus $V$.......................... & Fucns vesiculosus $\gamma$. inflatus. \\
\hline 1128. & - caprinus $V$....................... & Ulva palmata. \\
\hline 1190. & - delicatulus $V$.................... & Ulva palmata $\gamma$. laciniata. \\
\hline $1243,1$. & Lichen roseus $V$.......................... & Palmella rosea. \\
\hline 1244. & 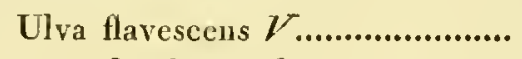 & Aleyonidium flavescens. \\
\hline 1245. & - diaphana $V$........................... & Alcyonidium diaphanum. \\
\hline 1429. & - olivacea Hornemann.......... & Echivella olivacea. \\
\hline 1476. & 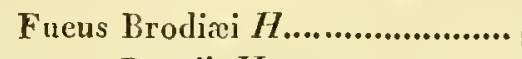 & Spluærococcus Brodiæi. \\
\hline $147 \%$ & 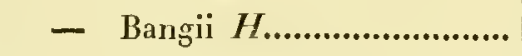 & Cliondrus Bangii. \\
\hline 1478. & - pimatifidus $H$................. & Gelidium pinnatifidım. \\
\hline 1479. & 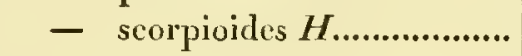 & Cliordaria seorpioides. \\
\hline 1480,1 . & Ulva compressa $H$..................... & Scytosiphon compressus. \\
\hline-2 & Conferva filiformis $H \ldots \ldots . . . . . . . . . .$. & Gastridium filiforme. \\
\hline 1481. & Ceramium pennatum $H$............. & Splacelaria plumosa. \\
\hline 1482. & - virgatum $H \ldots \ldots . . . . . . . .$. & Ceramium rubrum. \\
\hline 1483,1 & Couferva Melagonium $H$........... & Conferva Liuum. \\
\hline-2 & 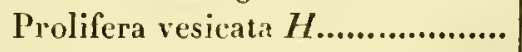 & Conferva vesicata. \\
\hline 1484,1 & Conferva confervieola $H$........... & Oscillatoria confervicola. \\
\hline-2 & fueicola $H \ldots \ldots \ldots \ldots \ldots \ldots . . . .$. & Conferva fucicola. \\
\hline 1485. & clithonoplastes $71 \ldots . . . .$. & Oscilla toria chthonoplastes. \\
\hline $1486,1$. & mutabilis $H \ldots \ldots \ldots \ldots \ldots \ldots . . .$. & Draparnaldia plumosa. \\
\hline-2 & penmata $H \ldots \ldots . . . . . . . . . . . .$. & Spliacelaria pennata. \\
\hline $148 \%, 1$. & floceulosa $H$................. & Diatoma tenue. \\
\hline-2 & Ceramium tomeutosum $H$........... & Eetocarpus littoralis. \\
\hline $1488,1$. & Rivularia dura $H$......................... & Linckia dura. \\
\hline-2 & - cndivixfolia $H$........... & Cliætophora endiviæfolia. \\
\hline 1489. & Ulva furfuraeea $H$....................... & Ulva furfuraeea. \\
\hline 1542. & Fucus Agarum $H$............................ & Laminaria Agarum. \\
\hline 1543. & - subfuscus $H$........................ & Gigartina subfusca. \\
\hline 1544.1. & - rotundus $H$......................... & Furcellaria rotunda. \\
\hline-2 & - lumbriealis fructus $H \ldots \ldots .$. & Furcellariæ lumbricalis fructus. \\
\hline 1545. & Conferva fibrillosa $H$................... & Hutchinsia fibrillosa. \\
\hline
\end{tabular}




\begin{tabular}{|c|c|}
\hline ( & Nomina Flora danicæe. \\
\hline 154 & Ceram. Luberculosum Hornem... \\
\hline $15 \%$ & Conferva Wormskioldii $M$.. \\
\hline $15 \div 8,1$. & - moniliformis $\mathscr{H} .$. \\
\hline-2 & ericetorum $11 \ldots . .$. \\
\hline 1549,1 . & majuscula $H$............ \\
\hline-2 & limosa H............. \\
\hline 1592. & Fucus lignlatus $/ 1 . .$. \\
\hline 1593. & - coccincus $11 \ldots .$. \\
\hline $159+1$. & Thorca Lchmanui $/$........... \\
\hline-2 & Seytosiphon iomentosus $M \ldots$ \\
\hline 1595,1 . & foeniculaccus $H$. \\
\hline - 2. & paradosins $f F . .$. \\
\hline $1.596,1$. & Vaucheria Dillwynii //.......... \\
\hline - 2. & Ceramiun pedicellatum $H$..... \\
\hline $159 \%$ & Hydrodictyon ntriculatum $\mathrm{H}$. \\
\hline $1598,1$. & Diatoma prectinale $\Pi / \ldots$ \\
\hline-2 & - arcuatum $/ / . . . . . . .$. \\
\hline 1599,1 . & Oscillatoria zostericola $H$.. \\
\hline-2 & - muralis $H . \ldots .$. \\
\hline 1600 . & Sphacelaria reticulata $/ / . . .$. \\
\hline $1601,1$. & Bangia viridis $H$.............. \\
\hline - 2. & - crispa H......... \\
\hline $1602,1$. & Scytoncma Bangii H...... \\
\hline-2. & myochurous $/ 1 \ldots$ \\
\hline 1603. & Bryopsis Lyngbyci $/ 1 . . . .$. \\
\hline 1604. & Tremdla Myosurus $H$........... \\
\hline
\end{tabular}

Chordaria Iuberculosa.

Confurva Wormskioldii.

Fragilaria lineata.

Conferva ericelorum.

Oscillatoria majuscula. i

Oscillatoria limosa.

Dosmia ligulata.

Plocimnium coccincum.

Thorea Lehmanni.

Scytosiplion tomentosus.

Scytosiphon foeniculaceus.

Cllordaria paradoxa.

Vaucheria Dillwynii.

Callithamnion corymbosum.

Hydrodictyon itriculatum.

Fragilaria pectinalis.

Diatoma arcuatum.

Oscillaturia zostcricola.

Oscillatoria muralis.

Sphacelaria reticulata.

Conferva implexa.

Bangia crispa.

Scytoncma Bangii.

Scylonema nyochrous:

Bryopsis Lyngbyci.

Palmclla Myosurus.

OBS. Ex hoc igitur conspertu patet in Flora daniea jam contineri 113 distinctas Hydroplyytorum species, is Varietates, et 6 species, quæ dupliciter depictæ sum; item Oederum 26 specics, Müllernm 46, Vah. liun 8. et Hornemannum 52 introducendas curasse. J'reterea notandum est, Confervant hypoidem Fl. dan. Tab. 828. fig. 2. Webero esse Jungermauniam Irichophllam, et Coafervan nidificam Fl. dan. 'Tal). 761. csse Charam intricalam Roth. Cat. bot. 2, p. 125. Ceterum ommes generis (hare spe* cies in Noarum familiam bene recipi posse, eisdemqve, quippe articulatis tubulosisque, locum in Seclione quarla inter Ectocarpum et Bulbochocten aplum assignari, nou multum abest, gvin credam. Ipse Jinneus in primis suis scriptis genus Chare inter Algas posuit. Auduera Chararmm venditatæ ejusdem etiam mihi videntur indolis, ac capsula, qux in Ceramiis, Callithamuits \&. observantur. Hanc autem opinionem, qve, opere jam absoluto, prinum milıi succurrit, peritorum juclicio subjicio. 


\section{A U C T O R E S,}

qvi de Hydrophytis scripserunt, et qrorum plurimi in hoc libro citati sunt.

Achrarus (E.) de Echinella radiosa; in Weler Beitr. zur Naturk. 2 Tls. p. 340.

- Lichenographix Srecicx Prodromus. Lincopia 1'798. 8.

Adasson (M.) Memoire sur un mouvemeut découvert dans une plante appellée Tremelle (Oscill. limosa). Hist. de l'Acad. des Scienc. pro anno 1\%6\% p. 564.

Agardn (C. A.) Dispositio Algarum Svecix. Lundx 1811. 4.

- Algarum Decades I-IV. Lundre 1812. sq. 4.

Syuopsis Algarum Scandinavix, adjecta dispositione universali Algarum. Lundæ $181 \% 8$.

B.

Barrelier (J.) Icones plantarum per Galliam, Itispaniam et Italiam obscrvatarum; opus posthunum, editum cura et studio Ant. de Jussieu. Parisiis 1714. fol.

Bartiolini (Thomæ) Acta merlica et philosoplica Hafniensia. Vol. I-IT. Hafniæ 1673-7\% 4. Basteri (J.) Opuscula subsecivạ, observationes miscellaneas de animalculis et plantis quibusdam marinis \&c. continentia. Tom. 1-2. Haar]eni 1762-65. 4.

B.unnxi (C.) Pinax theatri botanici sire index in Theophrasti, Dioscotidis, Plinii et Botanicorum, qui a seculo scripserunt, opera. Basilex 1623. 4.

Baumixi (J.) Historia plantarcum universalis. Tom. 1-3. Ebrod. 1650. fol.

Beatrais (Palisot) Flore d'Oware et de Benin en Afriquc. Paris 1805. fol.

BLUnexbacir Uelser cinc ungemeine einfaelıe Fortpflanzungsart; in Goett. Mag. 1781. 2 Jahrgang. Erst. St. p. 80.

Boccone Musco di fisica. Venetia 169\%. 4.

Burricuius (OLats) de Alga sarcharifera Corollarium; in Barthol. Act. med. et phil. Hafn Vol. 1. p. 119. ct Vol. 4. p. 159. 
Bonnchus (Olaus) Plantx in planis silicibus cuate. ibid. Vol. 1. p. 118.

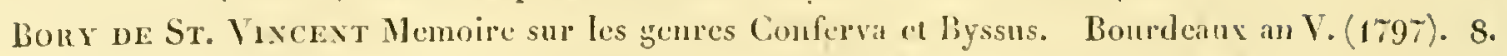
Essais sur les isles fortunées et l'antiqye Mlantide. Paris an X. (1802). 4. Voyage dans les quate principales isles des mers didrique. Vol. 1-3. Paris 1804.8 .

Memoire sur un genre noureau de la cryptogamie afpatiqge nommé Thorea: in Amales du Nuscum dihistoire naturelle; Paris 1808. Vol. XII. p. 126. et in Berl. Mar. naturf. Jiecuude 1808. I' 296.

Memoire sur le gene Lemanca; in Amm. Mus. Vol.'XII. p. 17\% et in Berl. Mag. 1809. p. 254.

Nemoire sur le gुeme Batrachosperma; in Ann. Mus. Vol. Xll. p. 310.

Mlemoire sur le germe Draparnaldia; ihid. Vol. XII. p. 399.

Bose Description d'nne espéce de Conferve, Conferva incrassata. Bullet. philom. 'Jom. I. 3. P. 145 .

Bruckmaxx (F. E.) De lippide violaren sylva Ilereynix. Guelpherbyti 1725. 4.

Buluetix bes Screxces par la socicte philomatique de Paris. Paris 1799-181\% 4.

Buxbats (J. C.) plantarum minus engnitarun Centuria V. Petropoli 17:8. 4.

Cir

C.sMrentrues vicl. Mathiolum.

Garkodor (G.) Memoria sopra il Nostuch. Opuscoli sceli Tomo 1\% p. 36.

Detla crasformatione del Nostoc in Tremella verrucosa \&e. Prato 179\% S.

Cissixi (11.) Doutes sur lorigine et la nature du Nostoc. Bull. philom. 181\% p. 81.

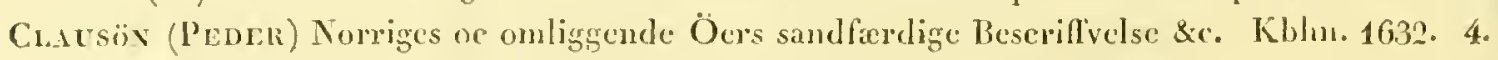

Clenexte (S. R.) Essai sur les varietés dr la vigne, qui vegetent en Andalonsie, traduit de lespragnol par Caumel. Paris 1804. 8. (Accedit appendix de algis llispranicis).

Cucsu (C.) Atrebatis rariornm plantarum historia. Antwerpia: 1601. fol.

Coltoni Observations sur queleques pliénoménes particuliers à une matière verte. Journ. de Pleysique 1791. Tom. 39. p. 169.

Correa de Serra (J.) On the finctification of the submersed alga. Philos. Transact. 1796. p. 494. ct Schrarkers Jomrnal 1500. 2 B. P. 46.5.

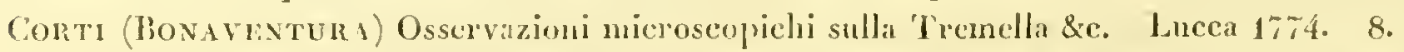
Chone Uelser den Torf und dic Gewïchse, denen er scinc lintstehung verdankt; in lleprmstadt Archiv der Agrienturchemic 4 B. Berlin 1810. J. 258.

D.

Dewes (Lucas) Faror et Farca reserata: det er Ferönis og Faröiske lndbyggeris Beskrifvelse ser. Kiobenh. 16r3. 8.

De Cannolue Flore françoise, on descriptions succinetes de toutes les plantes, qri croissent naturellenemt cu France. Paris 1805. Vol. I-I. S. 
De Candolle Synopsis plantarum in Flora Gallica descriptarum. Paris 1806. 8. - Olservation sur les plantes marines; Bullet. philom. Tom. I. 2, p. 171.

- Extrait d'm rapport sur les Conferves; ibid. Tom. 3.p. 17.

- Note sur la mousse de Corse; ibid. Tom. 3. p. 263.

Desfontarnes (R.) Flora atlantica. Paris an VI. 4.

De Saussure (H. B.) De deux nonvelles éspéces de Tremelles doućes d'un mouvement spontanée; Jouru. de Pliysiqve 1790. Tom. 3\% p. 401.

DrLlenil (J. J.) Historia muscorum. Osonii 1741. 4.

Dillwerv (L. W. British Conferva or coloured figures and descriptions of the britisl plants, referred by Botanists to the genus Confurva. London 1809. 4.

Dioscoridis Libri octo grace et latine. Parisiis 1549. 8.

Dixos (W.) A letter conceruing some vegetable balls (Conferva agagropila); with remarks on them by William Watson; Philos. Transact. Vol. $4 \%$ for the year 1751 and 1752. p. 498.

DoDonæI (R.) Stirpium historix pemptades 6. Antwerpix 1583. fol.

Donati (Vitaliano) Saggio della storia naturale marina dell' Adriatico. Venetia 1750. 4. Essai sur l'histoire naturelle de la mer Adriatique par V. Donati; traduit de l'italien; à la Haye 1753. 4 .

Draparnatd (J. P. R.) Discours sur les moeurs des plantes. Montpellier 1801. 8.

Ducluzeau Essai sur l'histoire naturelle des Conferves des environs de Montpellier. Montpellicr 1805. 8. (Dissert. inangnr.)

E.

Emrinart (Fr.) Plante cryptogame Linn. (exsice.) Dec. 33. fol. Hamnov. 1785-1793.

ElLIS (J.) Essai sur l'histoire naturelle des corallines et d'antres productions marincs \&c.; traduit de l'anglois. a la Haye 1756. 4.

- De sex Confervarum speciebus in Philos. 'Transact. Vol. 5\% p. 426.

Evglisir Botany efi. Smitl.

Esenbeck (C. G. Nres v.) Die Algen des süssen Wassers nach ihren Entwicklungsstufen dargestellı. Wurzburg 1814. 8.

Esper (E. J. C.) Icones Fucorum; Abbildungen der Tange, mit beygefügten systematischen Kemzeichen \&c. Nuimberg $179 \%$ si. 4.

F.

Flora danica, Icones plantarum sponte nasceutium in regnis Danix et Norregix \&ic. editæ als Oedero, Mullero, Vahlio, Horncmanno. Fasc. I-XXVII. Hafuiæ 1z611818. Sol.

Flora norvegica, vide Gunnerum.

Fontana (F.) Sur le Trimella (Cscillatoria limosa); Journ. de Physiqve 1776. Tom. 7, p. 47. Fonsk̉ế (P.) Flora rgyptiaco-arabica \&ce. post mortem auctoris cdidit C. Nicbulırius. Hafnix 1775. 4. 
Fougenoux (A. D.) Sur le varech. Hcmoire de Mead. des Scicnc. de Paris 17i2. P. 2, 1. 55.

G.

Geoffror (C. J.) Observations sur le Nostoch, qui pronsent. que cest veritablement une plantc. Micm. de l'acide des Seicuc. de Paris 1608. 1. 29:3.

Gerarde (Jonx) The Herball or gencral historic of plants cularged by 'Th. Johuson. London 1633. fol. (Citatur Ger. em. o: Gerarde cmaculatus per Johnson; cfi. Mcretti Pin. res. nat. Britl. in prafoltionc).

Gesser (Conn.) Ilistoria plantarum et vires ex Diuscoride, Paulo Aeginctit, 'Theophrasto, Plinio erecentioribus Gracis. Basilea 15t1. S.

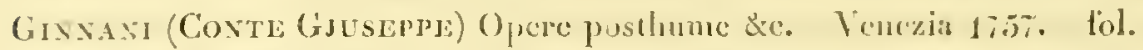

Geron-Cinarraxs Recherehes chimigres et microscopipres sur les Conferves, les Bisses eq les Trenelles. Panris an X. (1402). 4.

- Geographe physigve du Departement du Doubs. Paris 1810. 8.

— Sur lanalyse chimique des Conferves. Bull. philom. Tom. I. 1. p. 59.

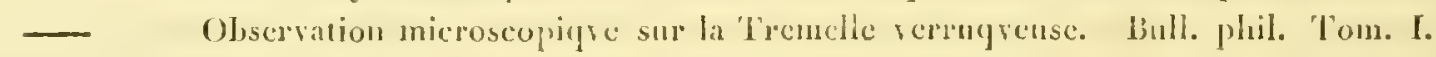
2, p. 43.

Observations sur la nature du Bissus velutina Lin; Mag. cucyclop. Tom. 3. p. 1.5.

Guedrsch (J. G.) Lucubratiunculat de Finco sulggtoloso sessili et molli, (Nostoc pruniformi). Berolini 1.-13. 1 .

Ton der Lingelpflanze oder der so genannen Secpllaume in der Mark Brandenburg (Yost. prmilinence). in scine Plyysic. Bot. Oec. Abhandl. 3 Th. p. 1. Ghene (S. G.) llisturia fucurum. P'elropoli 1768 . 4.

Goonexolgu (S.) et Woomwan (Th. J.) Olsemations on the British Fuci, with particulas descriptions of each species. 'Transact. of the Linn. Soc. Vol. 3, 1) 81.

Goun (1.) Flora Monspeliaca. Lugduni 176.5. 8.

Grateloce (J. P. A. G.) Obscrations sur la constilution de l’élé de 1806 arec un appendix sur les Conferves. Montpellier 1806. 4.

Guetand (J. E.) Observations sur les plantes. Vol. 2. Paris 174\% 8.

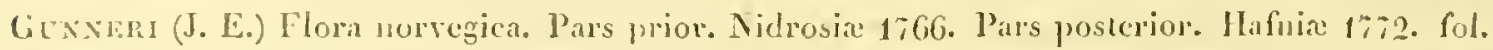

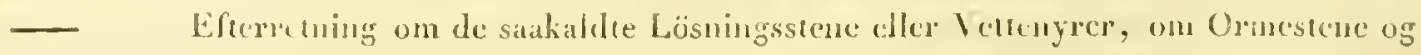
nogle indere udculandslie Fingter, som findes hist og her ved siranden i Norge. Trondhicmske Selsk. Skrift. 3 Deel p. 1.j.

_ Om nogle norske l'lanter. Trondh. Sclsk. Sk. 4 Deel p. St-86.

11.

Ilammerenv (D. A.) Dissertatio inauguralis de Fucolldminthocorto. Erlanga 1792. \&.

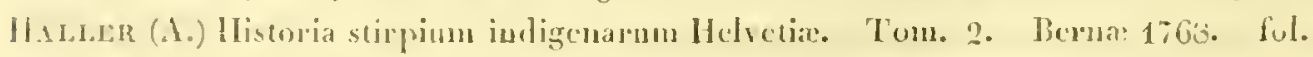

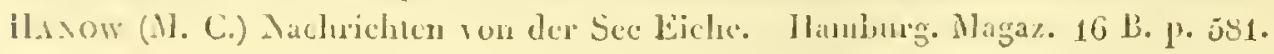


Hedrig (R. A.) Commentatio de Tremella Nostoc. Lipsix 1798. 4.

Hormaxs B.avg (N.) De usn Confervarnm in Occonomia naturæ. Hafnix 1818. 8. HоoкLR (W. J.) Journal of a Tour in lecland in the Summer of 1809. London 1811. 8. Horneraxy (J."W.) Forsög til eu dansk ockonouisk Planteliere. 2Oplag. Khhn. 1806. S. Hunson (G.) Flora anglica. Editio altera. Londini 1iis. s.

I.

Jacevix (N. J.) Collectanea ad Botanicam, Chemiam et Historiam naturalem! spectantia Vol. I-IV. Vindcbone 1786-1796. 4.

Inprate (F.) llistoria raturale \&ce. Nipoli 1599. 4.

Jügens (G. II. B.) Algre aqvatice, quats et in littorn maris Dynastiam Jeveranam el prisian orientalem alluenis rejectas et in harum terrarum aqvis habitantes collegit et exsiecavit. Decades I-1, Jever 1816-1\% fol. (exsice.)

Jissieu (A. L.) Genera plantarum sceundun ordincs naturales disposita. Parisiis 1789. 8. K.

Kivipirof (J. H.) Physicalische Untersuchung des Polizes, welchen die Natur durch Fäuluiss auf einigen Wiesen lierrorgebracht 1752. Erfurt 1753. 4.

Kraner (G. II.) Elenelus regetabilium et animalium per Austriam inferiorem observatornm. liemme 1;56. 8 .

Koglreuter (J. T.) Descriptio Fuei foliacei frondibus fructilicantibus papillatis. Nov. Comm.

Koenig vid. Zoega. Aead. Pctrop. Tom. 11. 1. 4:4.

Ky Lling (P.) Viridarium Danicum, sive catalogus latino-danico-germanicus plantarum indigcnarum in Dania obscrvatarum. Hafuia 1688. 4.

L.

Labillardière (J. J.) Noræ Hollandix plantarum spcrimen. Vol. 1-2. Parisiis 1804-1506. fol. Lanouroux (J. V.) Dissertation sur plusicur's espéces de Fucus. Agen an NiII. (1S65). 4. Éssai sur les genres de la famile des Thalassioghyles nom articulécs. Paris 1813. 4 .

Deseription de denx espéces iuédits de Varees (Fucus flaccidus et ocellatus Lam.) Bullet. philom. Tom. 3, ]. 131 .

Sur le Varee polymorphe. ibid. Tom. 3, p. 194.

Memoire sur trois monveaux gemes de la fanille des Algues marines (Dictyopteris, Amansia, Bryopsis). Journ. de Butaniqve Jain 1809. p. 129.

Memoire snr les Caulerpes, nonvean genre de la famille des Algues marines. Journ. de Botan. Juin 1809. p. 136.

Histoire des Polypiers coralligenes flexibles, vulgairement nonunés Zoeplyytes. Caen 1816. 8.

LANDT (J.) Beskrivclse over Færöcrnc. Kbhn. 1800. 8. 
Lepechin (J.) Qvatnor Fucorum species descripta. Nov. Comm. Acad. Potrop. 17.4. Vol. 19. P. 4.6 .

LigntFoot (J.) Flora scotica, or a systematic arrangement of the native plants of Scothand and we llebrides. London 17\%\% 8 .

Lisk (II. F.) Nova plantarum gencra e classe Lichcnum, Algarum, Fungorum. Schrader Nen's Jomm. fur dic Botim. 1809. 3 B. p. 1.

LinkeI (C.) Systema natura. Lditio Xll. Holmix 1;65. 8.

Amocnitates Academica: Vol. 10. Holmia et Erlangx 1749-1790. 8.

Species plantarum. Edlitio I. Holmix 1753. 8. Editio 4. cura Wilden. Berlin $1797-1805$.

- Flora lappunica. Liditio 2. London 1792. 8.

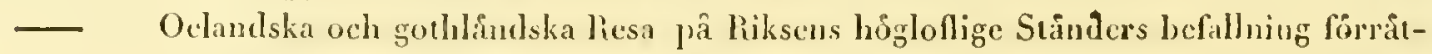
tad in 1741. Stockholm och Upsall 174.5. 8.

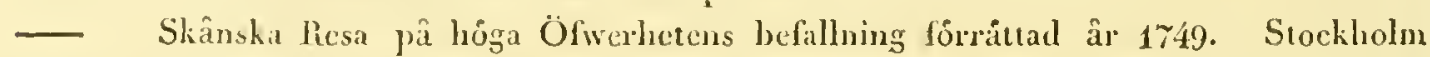
1751. 8 .

- Mantissa plantarnm. Holmix 1767-71. 8.

Lobelir (M.) Plantintum sen stirpium icones. Antwerpia 1581. 4 oblong.

Loeselit (J.) Flora Prussica, sive planta in regno Prussice sponte nascentes; \&c. curante J. Gottsched. Regiomonti 1703. 4.

Luce (D. J. W. L.) Vorlïnfige Bemerkungen ïber den Fuens vesiculosus L. Usteri Annalen der Bot. St. XY. I. 39.

M.

M.igsolu (Petr.) Hortus regius Monspeliensis. Monspelii 169\% 8.

Narsilei (L. F. comte de) llistoire physigue de la mer \&e. Amsterdan 1725. fol. - Edilio Italica, Venezia 1r11. 4.

M.rmtulodes (P. A.) De plantis F pitome novis iconibus (Gesmerianis) descriptionibusque pluribus et accuratioribus locupletata a Joach. Camerario. Francofurti ad Hocuum 1.586. 4 .

Marer (J.) Beolachtungen üher die Befruchtungstheile einer besondern Utva. Naturforscher 17 Siiick p. 165.

Mierse (D.) Beschryving yan cen zonderlinge Zee-plant (Laminaria digitata); implressa cum ejus: 11019 Classe van de Genera plantarun van Limacus opgcheldert. Lcenwarden 1761. 8. P. 135.

Mraxtzintus (C14.) De Coralliis in gemere, Mndrosace, Fucis marinis \&e. inf Miscell. Acad. natur. curios. Dec. 2. an. 3. olss. 21.

Hernettu (Cir.) Pinax recum naturalinm brittanicarnm, continens vegetabilia, animalia ce fossilia. Londini 1667. 8.

Meretens (li. C.) Ueber die Esperschen Fuci. Sehrad. Jonm. 1 B. 1800. p. 170. el ilid. 1801. p. 32. 
Mrcieli (P. A.) Nova plantarum genera juxta Touruefortif methodum disposita. Florentix 1729. 4 .

Moeirning (P. G.) Fucus caule tereti, folio singulari oblongo, marginibns undulatis. (Laminaria saccharina). Act. Acad. Nat. Curios. 1748. Vol. 8. p. 450.

Monr (D. M. H.) Observationes botanici. Kilonia 1803. 8. (Dissert. inangur.)

Ueber Conferva fluviatilis und torulosa R. \&c. Schrad. Journ. 1 B. 1801. p. 313.

- Supplementum Florx Goetting. cryptogamx. ibid. 1801. p. 4\%0.

Schleswig-holsteinische Alggre aqvatice. ihid. 1806. p. 196.

Bemerkungen über die Rothischen Rivnlarien. Weber Beitr. zur Naturk. 2 B. p. 343 .

Monn (N.) Forsö̈.til en Islandsk Naturhistorie. Kiöbenlavn 1786. 8.

Morisox (R.) Plantarum historia universalis Oxoniensis. Oxonii 1660-99. fol.

Mǘl.cR (O. F.) Flora Fridericlısdalina sive methodica descriptio plautarum in agı⿰o Fridericlssdalensi (prope Hafuiam) simulque per regumm Daniæ erescentium. Argentorati $176 \% .8$.

- Von eincr sonderbaren Pflanze (Conferra stellaris). Naturforscher z, Stïck. p. 189.

- Die Wasser-Erbse (Nostoc sphrericum). ibid. 17 St. p. 153.

Von unsichtbaren Wassermoosen (Vanclıeria bursata, clavata). Beschäft. de1* Berlin. Gesellsch. Naturf. Fr. 4 B. P. 42. - Sur la mousse d'eau iuvisible. Journ. de Plyysique, Tome 24. p. 248.

Strand-pånlebandet och Armbandet (Fragilaria lineata et Echinella stipitata) twånne microscopiska Strandwåx ter beskrifne. Srensk Vetensk. Acarl. Handl. 1783. p. 80. - Nachricht von zwey mikroskopischen Strandgewäclisen. Lichtenhergs Magaz. 3 B. 4 St. p. $\% 6$.

De Confersis palustribus oculo nudo invisibilibus. Nova Acta Acad. Petrop. 1785. Vol. III. Hist. p. 89.

N.

Nereis brittanica vid. Stackhouse.

O.

Olafsen (E.) et Povelsen (B.) Physisk og oeconomisk Beskrivelse orer Island. 2 Dele. Kiöbeul. 1772. 4 .

Olvi (G.) Lamarckia, novum plantarum cryptogamarum genus. In ejus Zoologia adriatica p. 255. et in Usteri Annal. 7 Stiick p. 76.

- Memoria soprra ma nuova spezie di Ulva delle Lagune Venete. Saggi dell Acad. di Padova Tomo 3. P. 1. p. 144. 
P.

Parkinsov (J.) Theatrum botanicum, the tlieatel of plants or an Jerball of a large extent \&ec. Lomlon 16i40. fol.

Patli (Biarno) Specimen olservatiomm circa plantarum qrarundam maris Islandici et speciatim $\Lambda l_{g x}$ sacchariferx dicte origincm, partes et usus. Ilatinia 1749. 4. (Disstu. inangur.)

Petivera (J.) Gazoplyy lacium natura el artis \&e. in operibus cjus. Vol. 1-2. London 1\%6\% fol. et scorsim Louclon 1702. fol.

Peyssonel (J. A.) Olservations on the Alga marina latifolia. Philos. Transact. Vol. 50. p. 631 .

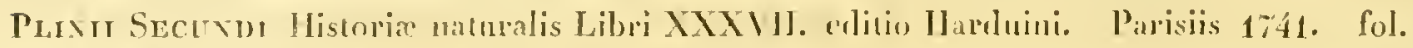

Plukexet (L.) Phytograplia sire stirpium illustrium el minus cognitarm icones. Londini 1691-96. 4 .

Porret De Ulvis at Fucis. Encyclopédic methodique, partic Botanique Tom. 8. Paris 1808. 4 .

Poner, Bemerkungen iibur den Nostoch (c Gallico in Jour. Encyclopcrliqre). Lcipzig. Magaz. 1.83. 1. $4 \% 3$.

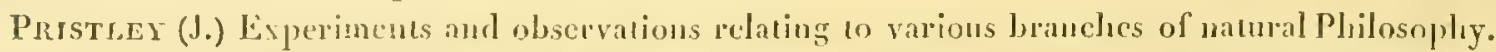
1 bol. London 1799. 2 Vol. Birminglam 178t. 8. (Chi de materia sic dicta viridi, varis Oscillatoriarun at Confervarum non determinandarum specicbus. passin agitur.)

R.

Risus (J.) Syuopsis methodica stippium Britanicarun. Eelitio tertia. Londini 12:4. \&.

Reaumur ( R. A. F.) Description des flents et des graines de divers fincus, ch prelques antres

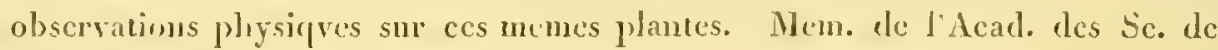
Paris 1711. p. 282. 11 1712. p. 21.

Observations sur la vegetation du Nostoch. ilid. 1222. ip. 165.

Prтzи (A. ...) Flore Scandinavia Prodromus. Liposia 179.5. 8.

Rommen (J. ..) Archiv fur dic Botanik. 3 [3. Leipzig 1796-180\%. 4.

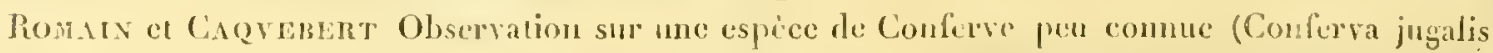
Fl. dan.) Bullet. philom. Tour. 1. 1. p. 69.

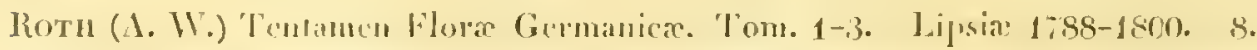

Benerkungen äber das Sudium eler cryptogamischen Wassergewächsc. Hannover 179\% \&.

Catalecta betunica. Tom. 1-3. Lipsias 179\%-1806. S.

Nene Beilrige zur Botanik. \& Th. Frankfurt an Nayn 180?. 8.

Bemestkngen iiher den imeren Ban der Conferven und ilner Vormelurungsart. Selurarl. Journ. 1 B. 1800. P. 62.

De Confervis rerticillatis. ibid. 1 B. 1800. P. 331. 
Rotil (A. W.) Botanische Bemerkungen und Berichtigungen. Leipsig 1807. S. Rurz (Hipp.) De vera Fuci natantis fructificationc commentarius. Madriti 1798. 8. Russelius (Ri.) Dissertation concerning the use of Sea-water in the diseases of the glands. London 1760. 8.

S.

Schade (C.) Beskrivelse over Morsland. Aalborg 1811. 8.

Scherer (J. A.) Observationes ct experimcuta super materia riridi Thermarum Carolinarum et Toeplizensium l'cgni Bohemia. Jacqu in Collcctanca Vol. 1. p. 171. - et gcrmanice in: Abhandlungen der Böhm. Gesellschaft 1\%86. p. 254.

Schmidel (C. C.) Descriptio itineris per llelvetiam, Galliam et Germanix partem anno 177374. instituti. Erlangæ 1794. 4.

Schraders Journal fur die Botanik. Goettingen 1799-1809. 8.

Schrank (F. v. P.) Beschreibung einer Wasserseide. Von Molls Oberdeutsche Beyträge p. 133.

- Ueber die grüne Materie der Aufgüsse. Usteri Annal. 9 St. p. 1.

Schreber (J. C. D.) Spicilegium Floræ Lipsicæ. Lipsiæ 1771. 8.

Schumacher (C. F.) Enumeratio plautarum in partibus Sellandix septentrionalis et orientalis: Partes 2. Hafnia 1801-1803. 8.

SEBA (A.) Locuplctissima rerum naturalium thesauri accurata descriptio ct iconibus artificiosissimis expressio per universam Physiccs Historiam. Vol. I-IV. Amstelodami 1734-1765. fol.

Secondat Une espèce d Ulva, qui croit dans la fontaine bouillante de Daix. Dans ses Observations de Physiqve et d'Ilistoirc naturelle p. 12.

Seetzen (U. J.) Gedanken über den Ursprung der Tremella Nostoch, oder ïber die sogenannten Sternschnupfen. in Lichtenlsergs und Voigts Magazin XI. B. 1796. p. 158. Sexebier (J.) Sur la matière vcrte, on plutôt sur l'espèce de Conferve, qqvi croit dans les vaisseaux plcin d'eau, exposés à l’air. Journ. de Physique Tome 17, p. 209. cfr. etiam Voigts Magazin 2 B. 1800. p. 762.

Sibbaldi (Roв.) Scotia illustrata sive Prodromus Historiæ naturalis \&c. Edinburgi 1694. fol. Slodne (H.) An account of four sorts of strange Bcans, freqvenlly cast on shoar on the Orkncy Isles, with some conjectures about the way of their being bronght thither from Jamaica. Philos. Transact. pro anno 1696. Vol. 19. n. 222. p. 298.

Sмitri (C.) Nogle Reise-Iagttagelser iser over Iisficldene (Gletschere) paa en Fjeldreisc i Norge 1812. i Topographisk-Statist. Samlinger 2 Deels 2 B. Christiania $181 \%$ p. 1-62.

Sxitri (J. E.) Enghlish Botany, or coloured figures of British plants, with their essential cliaracters, synonyms, and places of growth, with occasionel remarks. The figures by James Sowerly. London 1790. sq. 8.

SowEREY vide Smitl. 
Sprengel (Curtii) Epistola ad Willdenowium de Fucis quibusdam et Confervis maris meditcranci. Berl. Magaz. naturf. Fr. 3 Jalırg. 1809. 4. p. 186.

Historia rei licrbarix. 'Tom. 1-2. Amstelodini 1807 et 1808. 8.

SPRINGSFELd Observations snl une plante, gri croit anx environs des eaux chautes de Carlsbarl en loheme, nomméc 'Tremclla thermalis, gelatinosa, reticulata, substantia vesiculosa. llist. de l'Acad. de Berlin, 1752. Tom. VIII. p. 102.

Stacknouse (Jonx) Nereis brittanica, sive Fuci, Ulva et Confervac in insulis Brittanicis crescentes, descriptione latina et anglica, nec non iconibus ad vivun depictis, illustrati. Editio prima. Bathonix 1801. fol. - Editio sccumla. Oxonii 1816. 4 .

- Description of Ulva pmectata. Transact. of the Linn. Soc. Vol. 3, p. 236.

Stancke Uebcr Byssus Jolithus L. in Sclıral. Jourm. 1 B. 1800 . p. 340.

Stepuensen (MJ.) De i Island til Menueskeforle longelige Tangarter. Kongel. Danske Landhuusholdungs Selskubs Skrifter Nye Samling 1 B. Kblın. 1808. p. 48\%

Ström (H.) Plıysisk og occonomisk Beskrivelse over Fogderict Sönlmöer. 2 Dele. Soröe og Kbhn. 1762-1;66. 4 .

_- Beshrivelse over Norske Söc-Væexter. Kiöbcnlı. Vidcısk. Sclsk. Sk. 10 Decl, p. 240. 12 Dccl p. 314 .

— Anmarkuinger til Söndmörs Beskrivelse. Kongl. Norske Vid. Sclsk. Sk. Nye Saml. 1 B. Kbhn. 1784. 4. p. 103.

- Fortegnelse over Norske Söcvester. iljid. 2 B. Klbln. 178s. p. $34 \%$

Svensk Botanik af Palmstruch och Swartz. Audra upplagan. Stockholm 1803-1817. T.

Tabernemontani (J. T.) Eicones plantarum seu stirpium, curante Nic. Basseco typographo. Francof. ad Nlocumm 1590. 4. abl.

Thore (J.) De Conferva hisjuida in Magaz. Encyclop. an V. p. 398.

Essai d'une Chloris du départenent des Laneles. Dax 1803. 8.

Tonnng (1H.) Rariora Norvegix. Amocnit. Acad. Vol. 7 , p. 470.

Tounnefort (J. P.) Ilistoire des plantes. Lelitio altera. Paris 1725. 8.

Trenteponl (J. F.) Anmerkungen ïber cinigge in den ersten Heften der Flora Danica al,gchildete Pflanzen. Roth hotanische Bemerkungen mud Berichtigungen, p. 52.

- Beobachtungen über die Fortpflanzung der Ectospermen des Ilerm Vaucher \&c. ibid. p. 180.

Treviranus (G. R.) Biologie oder Philosophie der lebenden Natur, für Naturforscher und Acrzte, 4 Theilc. Goctlingen 1802-1814. 8.

Trevranus (L. C.) Von Bau der cryptogamischen Wassergewächse. Weber mud Mohrs Beitr. zur Niturk. 1 B. p. 163.

Beobachunngen iblucr die Bewegung eles körnigen Wesens in cinjgen Conferven und cincer Chara. ibid. 2 B. p. 142. 
Turner (Dawson) Synopsis of the british Fuci. Vol. 1-2 London 1802. 8.

- Historia Fucorum. London 180\% sq. Vol. I-III. 4.

- De Ulva furcellata et multifida. Schrad. Journ. 1 B. 1800. p. 300.

- Description of four new species of Fuci. (Fucus ruscifolius, crenulatus, clavellosus, Wigghii). Transact. of the Linn. Soc. Vol. 6. p. 125.

U.

Usteri (P.) Annalen der Botanik; 1-18 Stuck. Zürich 1791-96. 8.

V.

VAHL (M.) Endecl cryptogamiske Planter (Fuci) fra St. Croix. Natur-Hist. Selsk. Sk. 5 Bind 2 Hefte. Kblin. 1802. 8. p. 29.

VaiLLant (S.) Botanicon Parisiense, ou denombrement par ordre alphabetique des plantes, qvi se trouvent aux environs de Paris. Leide et Amsterdam 1726. fol.

Vaucher (J. P.) Histoire des Conferves d'ean douce, contenant leurs différens modes de reproduction et la description de leurs principales espèces \&c. à Genevc an XI1803. 4.

- Memoircs sur les graines des Conferves. Paris 1800. 4. et Bull. philomat. an 9. p. 18.5. et in Journal de Physiqve 1801. Tom. 52. p. 344 .

VELLEY (Th.) Coloured figures of marine plauts, found on the Southern coast of England \&c. Bathonix 1795. fol.

- Remarks on the nature and propagation of marine plants. Transact. of the Lim. Soc. Vol. 5, p. 145 .

Vernisy Nemoire sur le Nostoch. Nouv. Mem. de l'Acad. de Dijon 1784. p. 13.

VILcke (J. C.) On en liten Våxt, som våxer uti Driksglas och hâlles fởr en Sertularia eller Conferva (Conferva stellaris). Act. Holm. 1764. Vol. 25. p. 264.

W.

WAIrLENberg (G.) Flora lapponica, exhibens plantas geographice et botanice consideratas in Laponiis Svecicis. Berolini 1812. 8.

WaLLACE (James) An Account of the islands of Orkney. London 1ro0. 8.

WATSON vid. Dixon.

Weber (F.) et MoHr (D. M. H.) Grossbritauiens Conferven; nach Dillwyn für deutsche Botaniker bearbeitet. Goettingen 1803-1805. 8.

- Beiträge zur Naturkunde 1 Th. Kiel 1801. 2 Th. Kiel 1810. 8.

- Archiv für die systematische Naturgeschichtc. 1 Heft. Lcipsig 1804. \&.

Naturhistorische Reise durch cinen Theil Schwedens. Goettingen 1804. 8.

Weiger. (C.) Olsservationes botanicx. Gryphix 17\%2. 4. (Dissert. inaug.)

WeIs (F. G.) llantx cryptogamicx Floræ Goettingensis. Goettingx 17ro. 8.

Wiggers (F. H.) Primitix Floræ Holsatix. Kilonix 1780. 8. (Dissert. inanguralis, cujus auctorem se profitctur G. H. Weber.) 
Witherivg (W.) An arrangement of British plants, according to the latest improvements of the Linsean System; the third edition. Vol. 1-4. Birmingham 1796. 8.

Woodward (Ti. J.) The history and description of a new species of Fucus (F. subfuscus). Transact. of the Limn. Soc. Yol. 1, p. 131.

- Deseription of two new British Fuci (F. asparagoidcs ct Hypoglossum). ibid. Vol. 2. p. 29. ct P. 321.

- Description of Fucus dasyphyllus, ibid. Vol. 2, p. 239.

- Observations upon the generic character of Ulva, with descriptions of some new Specics. ibid. Vol. 3. p. 46. ct in Schrad. Jouru. 1 St. p. 128.

Wulfex (Xıv.) Cryptogamia aqvatica. Lipsix 1803. 4. - et in Römers Archiv fir dic Botanik 3 B. p. 1.

- Plantie rariores Carinthiacre. Jacqvin Collectanca Vol. 1, p. 351. Vol. 3, p. 146. Vol. 4, p. 342. (ubj de Fucis nomnullis maris Adriatici disserit.)

\section{$\mathrm{Z}$.}

ZoLGA (J.) Flora islandica, (juxta plantas in Islandia a Joh. Gerlı. König lectas claborata) impressa ad finem E. Olavsens et B. Povelsens Reise igjennem 1slaud. Soröe 1779. 4. et cum codem libro germanice verso. Kopenlagen und Leipsig 1775. 4. 


\section{EXPLICATIO TABULARUM.}

\section{I}

monebo, in delineationibus eonficiendis microscopio eomposito bonæ notæ me usum fuisse, chjus ita erant lentes comparatæ, ut qvæ numero jto insignis erat, rem parum angeret, ceteræ gradatim eandem magis magisque amplificarent, adeo ut lens, uumero 1 mo notata, maxime fuerit auctifiea; lentes autem 5. 3. et 1. imprimis adhibui, qvippe maxime distinctivas. Ceterum Lcctores rogatos velim, ut ex seqventi explicatione signo qrodam, qvod cuique placnerit, gradum augmenti unicuique figuræ adauctæ adjicere velint. Tali modo mutua figurarnm relatio, uno tanqvam obtutu ante oculos posita, faeilior reddetur; nam profter spatium, sape nimis arctum, omnes figuras eodem modulo ae pede metiri, fieri non semper potuit. Sic Conferva ulothrix (Tab. 50. C. 2. ad augm. 3.) est triplo minor qram Conferva Linum (Tab. 50. D. 2. qvæ figura ad augmentum 5 exarata est). In seqventibus icitur $11 . m$. cst naturalis magnitudo; 50 : ad lentem 5 , et sic in ceteris.

\section{Tab. I.}

A.1. Particula Fuci vesiculosi..... n.m.

2. Sectio transv. receptaculi parum aucta

3. Tuberculum auctum ...... 5. 5 .

4. Semina cum fibris immixtis..... 3 .

B.1. Particula F'uci serrati . . . . . n.m.

2. Semina eum fibris ......... 3 .

3. Semina immatura ........ 3 .

4. Eadem............. 1.

C.1. Particula Fuci distichi . . . . . n.m.

2. Semina ............. 3 .

D.1. Particula Fuci canaliculati .... n.m.

2. Semina............ 5.

3. Semen cum fibris ramosis..... 3 .

$$
\text { Tab. } 2 .
$$

A.1. Particula Delesserice sangvinece . . n.m.

2. Foliolum radicale scminiferum. . 5 .
$B .1$. Folium Delesser. sinuose fructifer. n.m.

2. Partic. cjus ......... 5. 5 .

3. Semina. ............ 3 .

4. Folium Varictatis fo. quercifolice . n.m.

5. Semina............. 3 .

6. Folium Varietatis $\gamma$. ciliatce . . . n.m.

7. Cilium uberculiferum ...... 5.

8. Semina tuberculi ........ 3 .

C.1. Partic. Delesseria alatce. . . . . 11.m.

2. Partic. ejnsd. seminiferr ..... 5 .

3. Partic. frond. angustioris capsulifere $\quad \therefore$

4. Tubereulum .......... 5.

5. Semina tubercnli ........ 3 .

Tab. 3 .

A.1. Partic. Odonthalice dentatce . . . n.m.

2. Siliqva axillares......... 5.

B.1. Partic.SpharococciBrodicei c Norv. n.m. 
B.2. Eadem e Fionia ......... 11.m.

3. Fila tuberculi moniliformia .... 3 .

4. Eadem maxime ancta ....... 1 .

C.1. Partic. Sphaerococci membranifolii n.m.

2. Tuberculum pednnculatum .... 5.

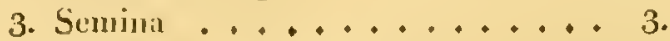

4. Eadem ............. 1 .

D.1. Particula Chondri Bangii . . . . . 5.

2. Scmina ............ 2 .

\section{Tab. 4 .}

A.1. Pars Spharococci laciniati. . . . 1n.m.

2. Seminat e tuberculo ...... 3 .

3. Eadem . . . . . . . . . . 1. 1 .

B.1. Partic. Splacerococci ciliati. . . . 11.m.

2. Eadcm aucta .......... 5.

3. Scmina e tubcrcnlo difliacto .... 3 .

4. Eadem cuprea ........... 1.

C.1. Sphrerococcus ciliat. $\beta$. fuscus... n.m.

2. Tubereulum .......... 5 .

3. Semina ............. 1 .

D.1. Pars Sphcerococci cristati ... n.m.

2. Particula frondis ....... 5.

3. Sectio transvers. tuberculi .... 3 .

4. Somina ........... 3.

5. Eadem .............. 1 .

\section{Tab. 5 .}

A.1. Pars frondis Chondri crispi ... n.m.

2. Semina tuberculi liemispherici... 3 .

3. Eadem ............. 1.

B. 1. Chondlus crispus \%. cequalis.... n.m.

2. Sectio transvers. tuberculi ....5.

3. Scmina .............. 1.

C.1. Spluerococcus mamillosus..... n.m.

2. Sectio transvers. tuberculi .... 5 .

3. Seminat ............. 1 .

4. Nlia sectio transv. tubcrculi ... 5.

D.1. Koncria deusta saxo insidens ... n.m.

2. 3. Massa interna ancta....... 2.

E. Partic. I.amin. saccharince ancta ... 4.

1.1. Ulva Fascia fo temuior e Norvegia, n.m.

2. Partic. cjustcun ........ 3 .

3. Partic. Ulpa l'ascice e marillafnicnsi 3.
Tab. 6.

A.1. Ulıa plantagrinif. in Zost. mar . 11.nn.

2. Parlic. frondis aucta ....... 2 .

3. Semina............ 2 .

B. 1. Ejustem Varietas $\beta$. tenuior . . . n.m.

2. Singula frons ......... n.m.

3. Eadem aucta......... 3 .

C. 1. Ul'a dichotoma e Norv...... n.m.

2. Partic. frond. aucta ex ins. St. Crucis 3.

3. Eadem e Norvegia ....... 3 .

D. Partic. frond. Ulva miniate .... 1 .

$E$. Partic. frond. Ulva terrestris ... 1.

\section{Tab. 7 .}

A.1. Ulwa rubescens ......... n.m.

2. Partic frond. aucta ...... 3 .

B. Partic. Desmice lignlatce...... n.m.

C. 1. Pars Desmice Hornemanni ... n.m.

2. Ramulus auctus ........5.

\section{Tab. 8 .}

A.1. Himanthalia lorea infans .... n.m.

2. Eaden provectiori xtate ..... n.m.

3. Eadem frondes cmitcons ..... n.n1.

4. Semina cum fibris........ 3 .

D. 1. Ramms Halidry's nodose. . . . 11.m.

2. Tuberculum e recept. communi . . 5 .

3. Semina cum fibris........ 3 .

4. Semina post siceationem dissoluta 3.

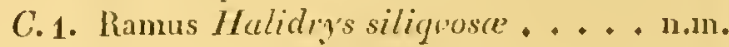

2. Sectio transversalis receptaculi . . 5 .

3. Senriua cum fibris........ 3 .

4. Fibra ramosa ......... 3 .

\section{Tab. 9 .}

A.1. Partic. Ptilote plumusce ..... n.m.

2. Ramulus Varict. capsulifera ... 5.

3. Alins ramulus capsuliferus .... 5 .

B. 1. Partic. Plocantii coccinei..... n.m.

2. Apex ramuli cum sem. internis... 5 .

3. Ramulus capsuliferus ...... 5 .

4. Semina capsula ........ 3 .

C. 1. Pars Gelidii pirnatyidi....... 11.n.

2. Apex ramuli cum sem. immersis. 5 . 
C.3. Scmen magis anctum ...... 3 .

4. Idem post siccat. dissolutum .... 3 .

\section{Tab. Io.}

A.1. RamusGigart.subfusce tcmp.luyem. n.m.

2. Partic. cuns tuberc. internis ... 5.

3. Tubercula ........... 1 .

B.1. Ramus ejusd. tenjpore vern. . . . n.m.

2. Partic. ejusden capsulifera .... 5 .

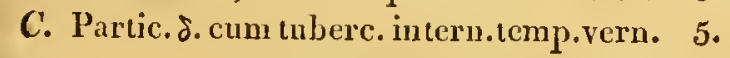

\section{Tab. I I.}

A.1. Ramus Gigart. subf.usca fibrillosus et cum corpusculis heterogeneis . . 3.

2. Corpusculum lieterogeneum .... 1 .

3. Fibrillæ . . . . . . . . 2.

B.1. Ramulus Gig.subf. ß. cum verrucis . 5 .

2. Verruca transversaliter secta ... 3 .

C.1. Partic. Gigart. Griffithsice . . . . n.m.

2. Tuberculum frondem amplectens . 5.

3. Semina ............. 3 .

D.1. Partic. Gigartince Fabriciande. . n.m.

2. Rámulus auctus . . . . . 5 .

\section{Tab. 12.}

A.1. Pars Gigartince lubricce ..... n.m.

2. Ramulus fructiferus ....... 5 .

B.1. Partic.Gigart,putpurasc.y.rostratce n,m.

2. Ramulus ejusdem ......... 5 .

3. Tuberculum diffractum . . . . 5. 5 .

4. Semina ............ 3 .

C.1. Parlic, Gigart. purp. ¿. virese. . . 11.m.

2. Ramulus fructifcrus . . . . . 5 .

3. Tuberculum diffractum ..... 3 .

4. Semina . . . . . . . . . . 1 .

\section{Tab. 13.}

A.1. Pars Chordarice scorpioidis . . . n.m,

2. Sectio frondis transversalis . . . 5.

3. Eadem longitudinalis ...... 5 .

4. Semina in Tuberce et fronde .... 2 .

B.1. Chordaria flagelliformis, . . . . n,m.

2. Sectio frondis transversalis .... 3 .

3. Sumina cuncata ......... 1.
C.1. Chordaria thizodes ....... n.m

2. Eadem aucta ......... 5 .

D.1. Thorea Lelmanni . . . . . . . n,m

2. Fibrillæ ........... 1 .

Tab. I4.

A.1. Pars Chordarice paradoxce. . . . n,m。

2. Apex ramuli ........... 3 .

3. Partic, froud. infer, fructiferæ... 2.

B.1. Scytosiphon hippuroides ...... n.m,

2. Sectio transv, frond, inferioris . . . 3 .

3. Eadem frondis superioris . . . . . 3.

C.1. Ramulus Scytos. foeniculacei ... 3.

2. Scmen in substantia frondis .... 1 .

3. Ramulus ejusd. fibrillosus et articul, 3 .

\section{Tab. I5.}

1.1. Scytosiphon compressus e Færoa . n.m.

2. Partic. frondis seminifera ..... 1 .

B.1. Varietas 3. crispata ........ n.m.

2. Ramulus cjusdem ........ 5.

3. Partic frondis seminiferx .... 1.

4. Varictas $\gamma$. confervoidea ..... 3 .

5. Fila cjusdem aucta ....... 1 .

6. Alia ancta ............ 1 .

C. 1. Scytosiphon erectus ........ n.m,

2. Ramulus ............. 5 .

3. Partic frondis..........1.

Tab. 16.

A.1. Ramulus $S_{c y t o s}$ clathrati $\ldots \ldots .5$.

2. Varictas $\beta$. uncinata ....... 5 .

3. Parlic. Varietatis ......... 1.

4. Ramulns clotus seminiferus..... 3 .

D.1. S ytosiphon verrucosus. . . . . n.m.

2. Fila ejusdem.......... 3 .

3. Eadem . . . . . . . . . . 1.

C.1. Scytos, velutinus ad saxum..... n,m.

2. Fila cjusdem aucta ....... 3 .

3. Eadem ............. 1.

Tab. I7.

A.1. Gastridium filiforme. . . . . . n.m.

2. Partic. frondis seminifuræ .... 5.

3. Semina. . . . . . . . . . 34 
B.1. Gustrid. purpurascens ad saxum . 11,m.

2. Liamulus capsuliferus ...... 5 .

3. Semina expsula ........ 3 .

4. Apex ramuli seminiferi ..... 5 .

5. Semina ejustem ......... 3.

C. 1. Gristriel. clavellosum in Fuco vesic. n.m.

2. liamulus ............ 5 .

\section{Tab. Is.}

A.1-3. Gastridium Opuntia ...... n.m.

4. Iflon fructifarum ........ n.m.

5. Partic. frondis seminifera .... 2 .

B.1. Gastridium ovale ad saxum ... n.m.

2. Partic frondis ......... 3 .

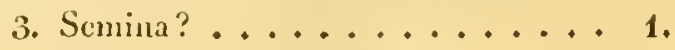

C. 1. Fructus Chorda Fili . . . . . . 3.

2. Idem ............. 1 .

D.1.2. Chorda Filum \% trichoides . . n.m.

3. Ramulus cum fibrillis ...... 5 .

4. Fibrilla.............. 2 .

E.1. Chorda lomentaria. . . . . . n.m.

2. Semina frondi exterius insidentia . 1.

\section{Tab. Ig.}

A.1. Chorda tomentosa ......... n.m.

2. Sectio frondis transversalis .... 5 .

3. Somina............. 2 .

4. Filum e tonento c.scm. adharentib. 2.

B. 1. Bryopsis lyngyei ad saxum ... n.m.

2. Ramulus .......... 5 .

3. Particula ramuli ......... 1.

C. 1. Partic. Faucherise dichotoma. . + n,m.

2. Ramus vesiculiferus........ 5.

3. Ramus ex codem cespitc . ... 5.

4. Aper ramuli vesiculiferus. ..... 3 .

\section{Tab. 20.}

A.1. Yanch. dichotonna $\beta$. submarina. . n.m. 2-3. Eaden ........... 5 .

4. Vesicula progerminans ...... 3.

B. 1. Taucheria ovata ......... nom.

2. Filum auctum .......... 5 .

3. Idcm .............. 3 .

C. 1. Vaucheria tiamala ........ 11, m,
C:2. Ramulus ............ 5 .

3. Idem ............. 3 .

\section{Tab. 2 I.}

A. Faucheria terrestris ........ 5 .

B. Taucheria sericea ......... 3 .

C. Taucheria Dillwynii........ 5.

D. Yrucheria cluvata ........ 5 .

\section{Tab. 22.}

A.1. Taucheria marina ad saxum ... 11,nı.

2. Ramulus ........... 3 .

B.1. Tancheria pusilla ad saxum ... n.um.

2. Caspes ejusdcur......... 3.

C. 1. Vaucheria aquatica ........ 3 .

2. Eaden ............. 1 .

D.1. Taucheria sessilis ........ 5 .

2. Vesicula progerminans ...... 5 .

\section{Tab. 23.}

A.1. Partic. Trucheria geminatce ...n.m.

2. Filum anctum ......... 5 .

3. Fíla aucta ........... 3 .

4. Vesicula progerminaus ..... 5.

B.1. Trucheria cospitosa ....... 1,m,

2. Fila vesicrilifera ......... 5.

3. Ramulus granula emittens .... 5.

C.1. Faurheria raccmosa ....... 11.11,

2. Filnur auctum ......... 5 .

3. Ideu cum corpusculis lucterogencis 3.

\section{Tab. 24.}

A.1. Caespes Bangice crispae ad rupen n.m.

2. Fila cjustcm .......... 2.

B.1. Bangia Laminarice in Laniu, escul, n.n.

2. Caspes ejustem ........ $5_{+}$

3. Fila aucta ........... 3 .

4. Partic. fili ........... 1 .

C. 1. Bangia fuscopurpurea ad saxum . n.m.

2. Fila aucla ............ 3.

3. Filum maxinc anctum ...... 1 .

D.1. Bangia rutilans in Zost. marina. $11 . \mathrm{m}$.

2. Fila aucta ........... 3 .

3. Filuın ............ 1 . 
Tab. 25.

A.1. Bangia micans in Ruppia marit. . n.m.

2. Fila ejusdem ....... 5 .

3. Eadem. . . . . . . ... 3.

B.1. Bangic atrovirens ad saxum. ... n.m.

2. Particula froudis ....... 3 .

C.1. Bangia mamillose ad saxum ... n.m.

2. Partic. frondis . ...... 3 .

3. Eadem . . . . . . . . . 1.

\section{Tab. 26.}

A.1. Partic. Bangice quadripunctatce + 11.m.

2. Ramulus auctus ...... 5 .

3. Idem........... 2 .

4. Fila xtate provecta....... 1 .

B.1. Oscillatoria nigra . . . . . n.m.

2. Fila aucta ........ 2 .

3. Eadem ........... 1 .

C.1. Oscillatoria ochracen ... . . n.m.

2. Fila in substrato limoso $\ldots \ldots 3$.

3. Eadem . . . . . . . . 1 .

D.1. Oscillatoria subfusca . . . . . n.m.

2. Fila ejus aucta ....... 2 .

3. Eadem ............ 1 .

E.1. Oscillatoric cestuarii ...... n.m.

2. Fila $\ldots \ldots \ldots \ldots \ldots . . .$.

3. Eadem ............. 1 .

Tab. 27.

A.1. Filum Oscillat. chthonopl. . . . . n.m.

2. Fila vaginata $\ldots \ldots \ldots \ldots 3$.

3-4. Eadem ............ 1 .

B.1. Oscillatoric scopulorum ad saxum n.m.

2. Cæspes auctus ....... 5 .

3. Filum ejusdem ........ 2.

C.1. Oscillat. zostericola in Zosto mar, n.m.

2-3. Fila aucta ......... 1 .

D.1. a. Scytonema myochr, in ligu, demers, n.n.

b. Filum ramosum c crespitc .... n.m.

2. Idem auctum ........ 5 .

3. Particula fili ......... 2 .

Tab. 28.

A.1. Partic. Scyton. ocellati . . . . n.m.

2. Partic, frondis cxtricata.... n.m.
A.3. Ramulus auctus . . . . . . 2 .

4. Particula filorum ....... 1.

B.1. Scytonenac compactum ad saxum - n.m.

2. Partic. cæspitis ....... n.tn.

3. Ramulns auctus........ 5 .

4. Idem ............. 1 .

5. Ramulus ex cæspite minore .... 2 .

6. Particula ejusdem ....... 1 .

C.1. Scytonema Bangii inter muscos . n.m.

2. Aculei frondis crecti ..... 5 .

3. Fila ex aculcis extricata ..... 1 .

\section{Tab. 2g.}

A.1. Nodularia fluviatilis . . . . . n.m:

2. Filum anctum ........ 5 .

3. Sectio fili transversalis ...... 2 .

4. Fibre in cavitate nodulorum ... 2 .

B.1. Eadem planta senili ætate $\ldots$. n.m.

2. Pars fili inferior ....... 5 .

3. Partic. fili cum granulis internis .. 3.

4. Sectio fili transversalis ....... 3.

C. 1. Varictas $\gamma$. ramosa . . . . . . n.m.

2. Partic. frondis ancta ..... 5 .

\section{Tab. 30 .}

A.1. Pars Lomentarice articulatce . . . n.m.

2. Varietas G. reptans. . . . . n.m.

3. Ranulus Varietatis fructiferæ ... 5 .

4. Scmina ............ 3.

B.1. Cladostephus verticillatus .... n.m.

2. Ramulus cum setis verticillatis... 5 .

3. Setæ ............ 3.

C.1. Sphacelaria plumosa e Fionia ... n.m.

2. Pinnula cjusdem ...... 3 .

3. Varietas f. divaricata c Norvcg. . n.m.

4. Ranulus ejus........ 5 .

\section{Tab. 3r.}

A.1. Partic. Sphacelaria distichce ... n.m.

2. Ramulus anctus ....... 4 .

3. Apex ramuli sphacelatus...... 1 .

b. Ramulus Sphacelarice scoparice .. 5 .

C.1. Partic. Sphacelariac pennatce e Norv. n.m.

2. llamulus capsuliferus...... 3 .

3. $\mathrm{Idcm}$..............

(30) 


\section{Tab. 32.}

A.1. Spharel.caspilula in slip.Lam.digit. n.m.

2. Frondes e lixion........ 3.

3. Exelem in Lamin. sacch. e Norveg. 3.

B.1. Sphacelaria spinulusa. . . . n.m.

2. Particula frondis ....... 5 .

C.1. Sphacelaria scoparioides .... n.m.

2. Eadcm aucta ....... 5 .

\section{Tab. 33.}

A.1. Partic. Hutchinsice fastigiatce . . n.m.

2. Ramulus capsuliferus. . . . . 5 .

3. Ramulus uberculiferus. . . . 5 .

B.1. Hutchinsia Brodicei....... n..n.

2. Ramulus capsuliferus ...... 3 .

3. Ramus primarius inarticulatus . . 3.

C.1. Hutchinsia nigrescens. . . . . 11.m.

2. Ramulus capsuliferus...... 3.

\section{Tab. 34.}

A.1. Mulchinsia urceolata ...... n.m.

2. Ramulus capsuliferus recens ... 3 .

3. Idem post siccationem..... 3 . . . .

B.1. Hutchinsia byssoilles f Fionia . . n.m.

2. Ramulus tuberculiferus .... 5 .

C. Eadem species e Norvegia .... 3 .

D.1. Hulchinsia implicatu ...... n.m.

2. Eadem ancta

\section{Tab. 35 .}

4.1. Ramulus Hutrhins. violac. ubereulif. 3.

2. Idem adultiori xelate ...... 3 .

3. Alius ramus cum corpuse. heterogen. 3. B. 1.2. Eadem species capsulifura . . 3.

C. 1. Mutehins. lepadicola in Lep. Ballan. n.m. 2.3. Ramulus radicans anctus.... 5.

D.1. Par's Hulchinsice strictoiles. . . u.m.

2. Ramus primarius inarticulatus ... 5.

3. Idem apiccin ressus ..... 5 .

4. Inferior ramuli pars ...... 5 .

5. Ramulus capsuliferus ..... 5.

\section{Tab. 36.}

1.1. Partic. Huldhinsice strictae .... u.m.

2. Ramulus anctus rececus..... 3 .
3. Corpuscula heterogonea : . : : : 3.

4. Vesicula heterogonea ...... 3.

5. Ramulus post siccat. c. capsula e Freroa 3.

B.1. Mutchinsia Mistingii . . . . . N.m.

2. liamulus auctus........ 3 . . . . . . . .

C.1. Ceranium!brachy'sonimm .... n.m.

2. Superior rani pars renoso-reticulati 5.

3. Ejusdem pars inferior ...... 5 .

\section{Tab. 37.}

A.1. Ceramium secundatum c. fructu . n.1n.

2. Iten stcrile .......... 11.1n.

3. Aper ramuli c. caps. inolucratia . 5.

4. Scrnina ........... 3.

B.1. Ritmulns Ceramii diaphani . . . 5.

2. Tubercula seminiferit e geniculis . 2.

3. Ranulus capsuliferus ..... 5 .

4. Ramulus Varict. $\gamma$. ternussimu'. . 3.

C. Ramulus Varict. S. viresc. E Froa - 5.

D. Cercmiun riliatum anctum ... 5 .

\section{Tab. 3S.}

A.1. Cullithamnion Arbuscula .... n.m.

2. Famulus capsuliferus...... 3 .

3. Ramus primarius inarliculatus . . 3.

4. Parlic. frondis excmpl. ex Anglia . 5.

5. Cajosula cjusden ....... 5.

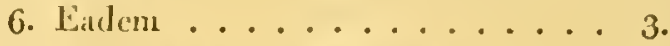

B.1. Callithammion fruticulosum . . . n.m.

2. Ramus ramuliqve capsulifuri ... 5 .

3. Ciapsulat seminifera ...... 3 .

4. Scuina capsulx ....... 1.

C. 1. Callithann. corymbos. in Zost. nuar. u.m.

2. Particula frondis capsulifera... 3.

3. Eudem .......... 1 .

\section{Tab. 39.}

1.1. Partic. frondis Callithammii rosei . n.m.

2. Rianuluscarjesulifirus...... 5 .

3. Ramns prinasuius ....... 5 .

B.1. Collith. roseum $\beta$. tenue ad saxum n.m.

2. Ilcun cxtricatum ....... n.m.

3. Ramulus capsuliferus...... 3 .

C. 1. Callith. Mlumula p. pusilla.... n.m.

2. 1dem anctum ......... 3 . 


\section{Tab. 40.}

A.1. Callith, repens in Furcell. Inmbric, n.m.

2. Sectio transv,tuberculi siliqveformis 5.

3. Semen post siccat, dissolutum ... 3 .

4. Semen recens .......... 3 .

5. Partic. Callith. repentis in Furcell. 5.

6. Fila cjusdem cum tubulis internis . 1.

7. Filun cum tubulis internis confluent. 1.

$B$, Eadcm specics capsulifera c Norveg. 3.

C. Varietas $\beta$. tenella c, radicibus .. 3 .

\section{Tab. $4 \mathrm{r}$.}

A.1. Callithannion Rothii ad saxum . . n.m.

2. Idcm divulsum . . . . . . n.m.

3. Ramulus anctus ........ 3 .

4. Idem ............. 1.

5. Partic ramuli ......... 1.

B.1. Callith, Dawiesii in Conf, tortnosa 3.

2. Idem in Loment, articulata lectum . 3.

3. Ramulus ............ 1.

4. Variet, $\beta$. secundatce inConf,rupestri n.m.

5. Dartic frondis ......... 5 .

6. Ramulus ........... 1.

C. Callith.Lanaginosum in 3utch,stricta 3.

D.1. Callith florideslum e Groenlandia 3.

2. Ramulus ........... 1 .

\section{Tab. 42 .}

A. Ectocarpus littoralis capsulifcrus 2.

E.1. Idem cum capsulis scssilibus . . . 3 .

2. Var. S. major c. fi. ....... 3 .

C. 1. Var. .. protensa e Frroa ..... 3.

2. Eadem c. articulis gibbis c Færoa - 3.

\section{Tab. 43.}

A. Ectocarpus littoralis $\gamma$ ruber .. 3 .

B. Lriocarpus siliculosus c. fr, c F Froa 3 .

C.1. Idem cum fr. c Fionia ....... 3 .

2. Idem cum fiuctu noudum maturo 3.

3. Fructus maxime auctus...... 1.

D.1. Varietas cjus $\beta$, uvoeformis .... 4.

2. Ladem ma jis aucta. . . . . . 3 .

\section{Tab. 44.}

A.1. Ectocarp, fomentos.inllimanth,lorea n.m,

2. Partic, crespitis funiformis ... 3 .

3. Fila capsulifera ancta....... 1.

B.1. Ectocarp. densus in Desmia aculcata u.m,

2. Fila cjusdcm (c. ft. ?) ..... 3 .

C.1. Ectocarpus clualybaus. . . . . n.m.

2. Ramulus auctus ......... 3 .

3.4. Idem c. fi. magis auctus .... 1 .

D.1. Ectocarpus aureus ad saxum ... n, n,

2. Ramulus capsulifurus . . . . . 3 .

3. Idem ............. 1 .

\section{Tab. 45 .}

A.1. Bulbochoete setigera ....... n.m.

2. Ramulus cum setis ....... 5 .

3 Idem cum capsulis ........ 2 .

4. Sctæ bulbiferæ ......... 1.

B.1. Conf.brachymelia in frust, rotx mol, n,m.

2. Fila............ 3 .

3. Eadem ............. 1. C.1. Pars cæsp. Conferra compacta. . n.m.

2. Filum anctum ........ 2 .

3. Idem magis auctum ....... 1.

4. Idem in statu siccato ...... 1 .

D.1. Cxspes Conf. zonatee ad saxum ... n,m,

2. Fila aucta.......... 3 .

3. Filum ............. 1.

E.1. Pars cxsp, Conf, dissilientis.... n.m.

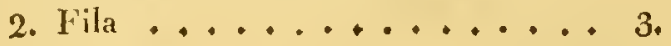

3. Eadem ............ 1.

Tab. 46.

A.1. Fila Conf. fngacissimae e Norveg. 3.

2. Eadem ........... 1 .

3. Eadcm in statu siccato ...... 1 .

4. Eadem species e Sullandia ..... 1.

5. Alia judidem ......... 1.

6. Eadem in statu siccato...... 1 .

\%. Varictas f. major e Silkeborg . . 3 .

8. Eadem valde ancta ....... 1 .

9. Eadem in statu siccato....... 1 .

10. Varietas \% oscillatorioides e Firoa 1. 
B.1. Cespes Conferve floccosce .... n.m.

2. Fila cjus aucta .............. 3 .

3. Eadem e lionia .......... 1 .

4. Eaclen e Norregia .......... 1 .

C.1. Fila Conf. punctalis aucta .... 2.

2. Eaden ............. 1.

D.1. Fili Confcree sordida ....... 3 .

2. Eadem c Fionia .......... 1.

3. Eaclem e Norregia . . . . . . . . 1.

4. Eadem in statu siccato...... 1 .

5. Varictas $\gamma$.utriculata e Fionia ... 1 . Tab. 47.

A.1. Cospes Conf. alpince in saxo.... n.m.

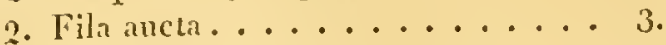

3. Eadcm .............. 1.

B.1. Fila Conf. ericetorum aucta .... 3 .

2. Eadem magis aucta ....... 1 .

C.1. Fila Conf. mucosce........ 3 .

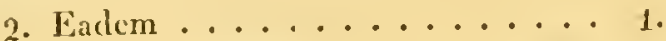

D.1. Fila Conf. vesicate ....... 3.

2. Ejusd. Varictas \% breviarticulate . 3.

E.1. Crespes Conf. quedrangule .... H.m.

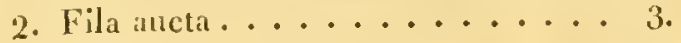

3. Eadcu ................. 1 .

F.1. Fila Conf. capillaris ....... 2 .

2. Filum cjusd. magis auctum .... 1 .

3. Idem in statu siccato . . . . . . 1.

\section{Tab. 48.}

A.1. Part.Cersp.Conf.copill.B.lumbricate n.m.

2. Fila cjuscl. ancta ......... 2.

3. Filun magis auctum....... 1 .

4. Idem in statu siccato....... 1.

B.1. Fila Conf. rivularis e Norregia . 3.

2. Eadem in statu siccato. . . . . 3 .

3. Fila valde ancla .......... 1.

4. Prima filorum initia ....... 3.

5. Fila cjusd. specici e Sellindia .... 3 .

6. Filun magis auctum ....... 1 .

־. Eartem species e Freroa . . . . . 3.

8. Eaclem valde aucta ........ 1 .

C. Filit Conf. P'teridis ancta ....... 5 .

1).1. FilaConf.ceramicol. in lhutch.violac. 3.

2. Eadem maxime aucta ...... 1.

\section{Tab. 49.}

A.1. Conf. flacca in Gigall. subfnsca .. n.m.

2. Eadlen saxo irsidens.......

3. Filum auctum ..................

4. Fila magis ancla ......... 1 .

B.1. Conf. implexa in Gigart. plicata . nim.

2. Fila aucta........... 2.

3-4. Farlem valde anctil ...... 1 .

5. Eirlem in statu siceato ...... 1 .

C. 1. Caspes Conf. Lurtuosa ...... nisn.

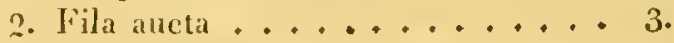

D.1. Conferva hormoides in saxo ... n.m.

2-3. Fila ancla .......... 3.

4. Eadem ............ 1 .

L.1. Conf.rontortain stipite Fuci vesicul. n.m.

2. Filum auctum .......... 3.

3 . Idem .............. 1 .

\section{Tab. 50.}

A.1. Conf. flaccida in Fuco vesiculoso , n.m.

2. Ciespitulus auctus ....... 3 .

3. Filat singula maxine aucta .... 1 .

D.1. Cunf. fucicola in Fuco vesicul. . 11.m.

2. Císpitulus autetus ....... 3 .

3. Púlicula fli ............ 1 .

4. Ciespes cjust. speciei in Lost.marina n.m.

5. Filum auctum .......... 3 .

C.1. Conf. ulothrix in Gigart, plicata . 11,m.

2. Filum auclum .......... 3 .

D.1. Conferva Linum ......... n.in.

2. Fila cjusdem ancta........ 5 .

\section{Tab. $5 \mathrm{r}$.}

A.1. Conferva cerca in saxo...... $11 . \mathrm{m}$,

2. Fili inferior pars ....... 5 .

3. Ejusdom superior ........5. 5 .

4. A pex fili .......... 5 .

B.1. Conferva Melagonimu in saxo..., n,m.

2. Filum auctum ......... 5 .

c.1. Conferva pusilla in Cionf. glomerata $n_{1} m$.

2. Ramulns aucus .......... 3 .

3. Idcm valdc auctus ......... 1 . 


\section{Tab. 52.}

A.1. Conf, nana in Foutinali antipyr. . . n,m.

2. Ramulus auctus......... 3 .

3. Fila magis aucta ........ 1 .

4. Eadem in statu siccato ...... 1.

B.1. Conferva lubrica in saxo ..... n.m.

2. Plamulus ............ 2 .

3. Idem ............. 1 .

C.1. Conferva agagropila ...... n.m.

2. Ramulus ............. 3 .

D.1. Conferva fracta aucta ...... 3

2. Var. ঠे. marina c. corpusc, heterogen. 3.

Tab. 53.

A.1, Conferva sericea ancta ..... 5 .

2. Ejusd. Var. F. intricatc ..... 5 .

3. Ramulus Varictatis . . . . . . 3 .

B.1. Conferva glomerata aucta ..... 3 .

2. Diatoma tenue parasiticc insidens . 3.

3. Animalculum infusorium..... 3 .

C.1. Conf. glomerata 3. macrogonya . . n,m.

2. Ramuli inferior pars ....... 3.

3. Ejusdem superior pars...... 3 .

\section{Tab. 54 .}

A.1. Conf. crystallina f. virescens.... n.m.

2. Ramulus auctus ......... 3 .

3. Particula samuli ........ 2 .

B. Ramulus Conf. rupestris e Froa 5.

C. 1. Conferva nigricans ....... n.m.

2. Eadem aucta ........ 5 .

3. Partic. fili siccati ........ 5 .

\section{Tab. 55 .}

A.1. Cxspitulus Conf. IVormskioldii , n,m.

2. Ramulus e crespitc extricatus ... n.m.

3. Fili tenuioris inferior pars .... 3 .

4. Aper ejusclem ......... 3.

5. Particula fili crassioris ..... 5 .

B.1. Conf. obtusangula ad saxum . . . n.m.

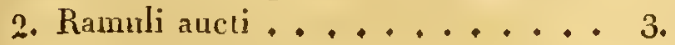

3. Filım magis auctum ....... 1.

4. Idem post siccatiouem ....... 1 .
C. 1. Conf. ferruginece saxo adırata ... $11, \mathrm{~m}$.

2. Ramuli aucti ......... 3 .

3. Fila apice globulifera e Grocnlandia 3.

4. Partic. fili valde aucta ...... 1.

\section{Tab. 56.}

A.1. Conf. lanosa in Gigart, subfusca . n, m,

2. Ramulus auctus ......... 3 .

3. Ejusdcm inferior pars ....... 1.

4. Idem apicen versus ....... 1 .

B.1. Conferva uncialis ........ n.m,

2. Ramulus auctus ....... 4.

3. Idem valde auctus ....... 1 .

4. Filum in statu siccato ...... 1 .

C. 1. Conferra centralis ........ n.m,

2. Ramulus .......... 5 .

\section{Tab. 57 .}

A.1. Caspes Conf. vclutince in terra .. n.m.

2. Raunulus auctus......... 1 .

3. Ejusdem inferior pars ..... 1.

B.1. Partic. cæsp. Conf. umbrosa . . . nn,

2. Ramulus auctus . ....... 3 .

3. Particula ramuli ........ 2.

C. 1. Fila Conf. atranenti aucta .... 3 .

2. Eadem ............ 1.

D.1. Conf. odorata in cortice fagineo... $11, \mathrm{~m}$.

2. Fila aucta .............. 3 .

3.4. Eaden maxinic aucta ..... 1 .

E.1. Conf. melcena in ligno subputricio $n \mathrm{~m}$ 。

2. Fila ejusclem aucta ........ 3 .

3. Eadem ............. 1.

\section{Tab. 58 .}

A.1. Pars cesp. Hydrodiclyi utriculati, n,m,

2. Partic. frondis retiformis . . . . 3.

3. Articuli Embryona includcntes. . 1.

B.1. Fila $Z_{y}$ gruematis geruflexi aucta . 3.

2. Eadem copulata ........ 3. 3 .

3. Eadcm masime aucta ...... 1 .

C. 1. Fila Zygnematis compressi aucta . n.m.

2. Eadem in copulationse ..... 3.

3. Eadent magis aucta........ 2.

4. Articuli hyalini soluti ...... 2 . 
C. 5. Scclio fili transfers, imaginaria .. 2.

6. Filum fragile maxime auctum ... 1 .

\section{Tab. 59 .}

A.1. Corspes Zygnematis littorei .... n.m.

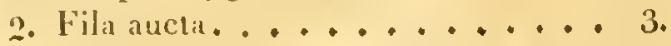

3-4. Eadcm . . . . . . . . . . 1 .

5-7. Echinella stipitata parasiticc insid. 1. B.1. Filnm Zygnematis nitidi anclum . 3.

2. Fila cjusdem copulata ...... 3 .

3. Eatcun ............. 1.

C. 1. Fila Zygnematis decimini ancta.. 3.

2. Filun valde anctum ...... 1 .

D.1. Filum Zygnematis quinini anctum 3.

2. delen maxime anctum ...... 1 .

3. Fila ejus sub copulatione. .... 3 .

4. Filum copulatum valde anctum .. 1 .

\section{Tab. 60.}

A.1. Fila Zygnomatis bipunctati aucta . 2. 2-3. Eielem copulata . . . . . . 2.

4. Particula fili non copulati ..... 1 .

B.1. Var. G. gracilis aucta ....... 3 .

2. Eardem masine ancta ...... 1.

3. Var.y.unipuncteta inter Zyğn.bipunct.3.

4. Earlen valde ancta........ 1.

C.1. Fila 'Zygnematis pectinati c Norveg. 3.

2. Earlem E Fionia ....... 3.

3. Filum maxime auctum ..... 1 .

4. Var. (j. confluens antia....... 3 .

5. Ladem maxime aucta ........ 1.

\section{Tab. 6r.}

A.1. Filit Diatomatis Swartzii ancta . . 3.

2. Articuli soluti ancii ...... 3 .

3. Tïla maxime aucta ....... 1 .

4. Articuli soluti valde ancti .... 1,

5. Filum in statu siccato ..... 2 .

B. 1. Crespes Diat.flocrul in Confofloccosa n.m.

2. Filum Coufure floccos $\ldots . .2$.

3. Fila cjusdem maxime ancta .... 1 .

4. Fila ipsius Diatomatis flocculosi .. 2.

5. Articuli alternatin cohrerentes . . 1 .

C. 1.2. Fila Diat, tenuts in Conf. glomerata 3.
D.1. Diat.tenue ß. marin. in Oscill. chthon. 3.

2. Jdem maxime anctum ....... 1 .

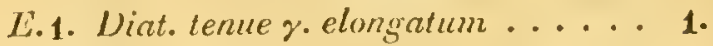

2. Artiruli ejusclem soluti . . . . . 1.

3. Diatona fenestratum auctum.... 2.

\section{Tab. 62.}

A.1. Diatona marinum in Hutch. urccol. n.m.

2. Idem auctum.......... 3 .

3. Articuli alteruatim cohrerentes ... 1.

Z 1. Diatona arcuatum in Ceram. rubro 3.

2. Arliculi soluti .......... 1 .

C. 1. Diatona obliquatum in Ceram. rulsro 3.

2. Hem majus ce froprentius..... 3.

D. Diatoma auritum .......... 1.

E. Frustula Fragilarice fasciata. .... 1 .

F. Parlic. Fragilarice latruncularice .. 1.

G. Fragilaria unipunctata e Norres. . . 2.

\section{Tab. 63.}

A.1. Casp. Trag. striatulue inLamin.cscul. n.m.

2. Fila ejusdern ancta ....... 3 .

3. Partic. fili maxime aucti ...... 1 .

B.1. Fila Fragilarice lineata aucta ... 3 .

2-3. Eadem maxime ancta........ 1 .

C.1. Fila L'ragil. munumuloidis aucta .. 3 .

2. Earlem. . . . . . . . . . . 1 .

D.1. Filum Fragilarice pectinalis anctum 2.

2. Idun.............. 1.

E.1. Caspes Fragil. hyernalis in saxo. . n.m.

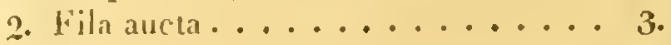

3. Eadem in statu siecato ...... 3 .

4. Filum maxine anctum ...... 1 .

5. Fila alius raspjitis aucta ..... 3 .

6. Eadem valde aucta ......... 1.

\section{Tab. 6/4.}

A.1. Partic. Eatrachosp. moniliformis . n.m.

2. Thanns auctus. . . . . . . 5 .

3. Lamulus everticillis ce capsula ... 1 .

D.1. Parlic. Extradho p. ragi ...... n.m.

2. liamus aucus......... 5 .

3-4. Ramuli rerticilluti. . . . . . . 2 . 
C.1. Ramus Draparn. glomeratoe auctus 3.

2. Particula penieilli........ 1 .

\section{Tab. 65 .}

A.1. Ramus Draparn. plumosa f. auctus 3.

2. Partieula rami primarii ..... 3 .

B.1. Mesogloja vernuicularis. . . . . . n.m.

2. Pamulns capsuliferus e massa gelat. 2.

C. 1. Chactoph. endiviaef. in ligno demerso n.m.

2. Particula frondis ancta ..... 3 .

3. Filum internum maxime anctum .. 1 .

D.1. Chatophora elegans in saxo .... n.m.

2. Fila interna aucta ........ 3 .

3. Eadcm ............. 1.

\section{Tab. 66.}

A.1. Chatophoramarina in Gigart.plicata n.m. 2-3. Particulæ frondis extricata... 1 .

B.1. Chaetophora pellita in saxo..... 11.m.

2. Fila interna aucta ....... 3 .

3. Filum valcle auctum....... 1.

C. 1. Linckia Zosterce in Zost. mariıa. . n.m.

2. Particula frondis aucta ..... 5 .

3. Eadem magis aucta ...... 2 .

4. Filum maxime auctum...... 1.

D.1. Linck. ceramic. inCeram. elong. aueta 5.

2-3. Fila c froude capsuliformi ... 2.

4. Eadem e froude villosa ..... 2.

E.1. Linck. punctiformis in Gastrid. filif.s. s.m.

2. Fila ejusdem aucta....... 2 .

3. Eadem value aueta........ 1.

\section{Tab. 67.}

A.1. Linck.natans in stolon.A grost.stolon. n.m.

2. Eaden coloris viridis ....... n.m.

3. Partic. frondis ancta ....... 3 .

4. Fila interna maxime aucta .... 1.

B.1. Linck. hypricola in Hypuoscorpioidi n.m.

2. Partic. froudis aueta ...... 3 .

3. Fila interna........... 1.

C. 1. Linckia dura in rad. Arund. Plıragm. n.m.

2. Particula froudis aucta..... 3 .

3. Fila iuterna cum vesiculis...... 1 .

4. Varietas f. lutescens ancta .... 3 .
D.1. Linekia atra in Fuco vesienloso .. n.m.

2. Eadem in saxo ........ n.m.

3. Seetio frondis transversalis .... 3 .

4. Fila interna valde aneta ...... 1 .

5. Varictas $\beta$. viridis in Gigart. subfusca n.m.

6. Eadem aucta .......... 3 .

7. Fila interna $\ldots \ldots \ldots \ldots \ldots 1$.

\section{Tab. 68.}

A.1. Nostoc pruniforme ........ n1.m.

2. Fila interna.......... 3 .

3. Eadem moniliformia....... 1 .

B.1. Nostoc coeruleum inIlypuo scorpioidi n.m.

2. Fila interna.......... 3 .

3. Eadem ............ 1 .

C.1. Nostoc commune. . . . . . . 11.11.

2. Fila interna.......... 3 .

3. Eadem ............... 1.

D.1. Particula Nostoc Flos aquae .... n.m.

2. Fila interna........... 3 .

3. Eudem ............. 1.

E.1. Partic. frond. Palmellce Myosuri . num.

2. Eadem aucta .......... 3 .

3. Ramulus maxime auctus ...... 1.

\section{Tab. 69 .}

A.1. Palmella adnata ......... n.m.

2. Particula frondis ancta ...... 3 .

3. Eadem............... 1 .

B.1. Palmella alpicola inter muscos ... n.m.

2. Particula frondis ancta ...... 3 .

C. 1. Palmella hyalina .......... n,m.

2. Particula frondis........ 3 .

3. Eadenn .............. 1.

D.1. Palnuella rupestris ad rupen udam n.m.

2. Particula frondis......... 2 .

3. Grasula interna .......... 1.

4. Eadem in statu subsiccato ..... 1.

E.1. Echinella radiosa. . . . . . . . n.m.

2-3. Granula varia interna ...... 3.

$F$.1. Partic. frondis Echinellce obtusae . n.m.

2. Granula aucta in Vancherix spceic . 3.

3. Earlem maxime aueta ........ 1 .

G.1. Pastic. Echin. acutce in Conf.g lomcs. n.m. 
G.2. Granula interna elongata ...... 3 .

3. Eadem valde aucta......... 1 .

\section{Tab. 70 .}

A. Eclinn. fasciculata in Hurch. violacca . 3. B.1. Echin. stipitata in Scytos. clathrato 3.

2. Eadem maxime ancta........ 1 .

3. Alia specinina solnta ....... 3 .

4. Aliud specimerı .......... 3 .

5. Idem valde auctum ........ 1 .

C. 1. Echir.olivacea in stolon.Agrost.stol. n.m.

2. Granula intcrua aucta. ...... 3 .
C.3. Eadem maxime aucta........ 1.

4. Granula lumulata Varictatis f..... 1.

D.1. Echinella geminuta in saxo..... n.m.

2. Fila interna apice clavata ..... 3.

E.1. Echinclla paradoxa in llutch. viol. 3.

2. Ramulus maxime anctus ...... 1 .

F.1. Eihinella cuneata in Ceram. rubro 3.

2. Eadem valde aucta ........ 1.

G.1. Glojonema paradoxum post siccation. 3 .

2. Articuli ejusdem dissoluti ..... 3.

H.1. Pollen l'ini sylvestris auctnm . . . 3.

2. Idem maxime auctum....... 1.

\section{ADDENDA ET CORRIGENDA.}

Pag. 5 Lin. 5 a basi: reperitur lege reperi.

- 6 - 14. n. 393. $\operatorname{leg}$ n. 939.

- 7 - 10. post costata arlde rosea.

- 9 - 13. Ad Odonthatiam dentatam ut synon. addatur: Fucus cartilagineus \&c: Ström Söndh. 11. 8. el Art. Hafn. Vol. 10. p. 254. Tab. $f$. Fig. 3.

- 13 - 6. Ad Sphurorocrum ciliatum ut synon. addatur: Fucus dichotomus Lepechin Nov. Comment. Petrop. \ol. 19. p. 479. Tal. 22.

- 21 - 5 a basi: Ad Laminariam saccharinam ut synon. addatur: Fucus caule terete \&c. Nochring in Act. Acad. nat. curios. 174s. Vol. 8. p. 450. Tals. 9. Fig. 1. 2 .

- 25 - s. Ad Vlvam palmatam ut synon. addatur: Fucus foliaccus Ström Nor. Act. soc. litt. norr. P. 2. p. 3i\% lig. 4.

- 33 - 31. filis lege fibris.

- 39 - 29. subtilis lege subtile.

- 39 - ult. cincimms crines lege rincinni. crimes.

- 40 - 12. Ad Geliclium pinnatifidum ul synon. addatur: Fuctus pinnatifidus Ström Nor. Act. soc. litt. norv. T'. 2. p. 3ts. fiv. 1.

- 60 - 31. Hi fructus (Y ettengrer dieti) chian in littore maris Dencaledonii et in Crcadibus inscnimur: efr. Sibbaldi Scot. illust. P. 2. 1. 5.5. et Jam. Wallace Account of the isl. of Orkney j. 36, ubi sub nomine l'kascolorum Holncanorum lirevitur commenorantur.

- 72 - 21. vindescente lege viridescente.

- 72 - 28. Myalina lege hyclina.

- 86 - 5. 'Tab. 1\% Jig. 13. lege Tab. 1\%. fig. 3.

- 98 - 16. Ad Scyton. Bang. ut synon. addatur: Oscill. Friesii As Syn. 1. 107?

- 102 - 14. Ad Cíndostephimn verticillatum ut synon. addatur: Fucus Biyum Ström Nov. Act. soc. litt. norv. P. 2. p. 34́s. tig. 2.

-153 - 13. Conferva hirtam lege Confervam hirtam. 


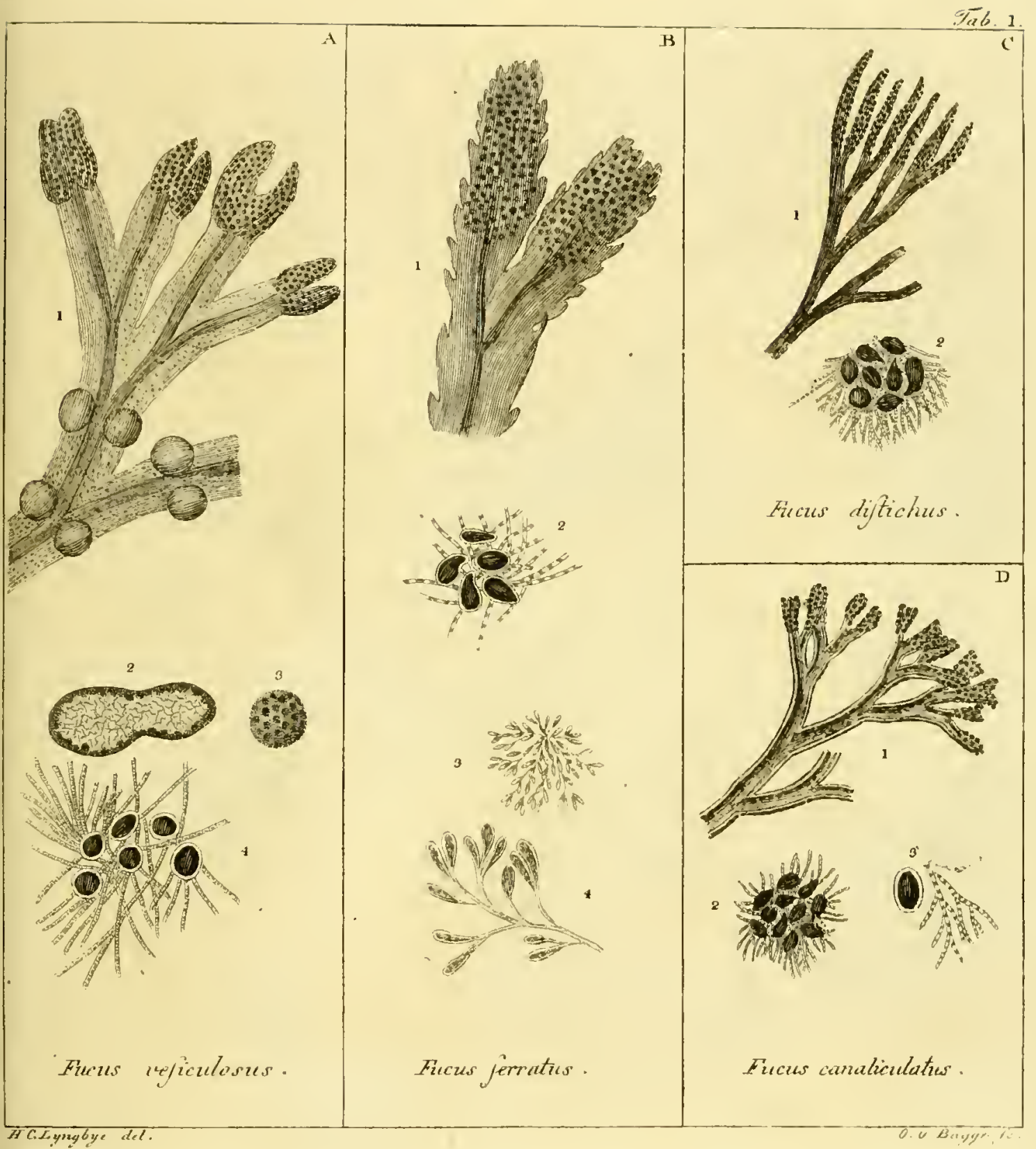


Tab. 2

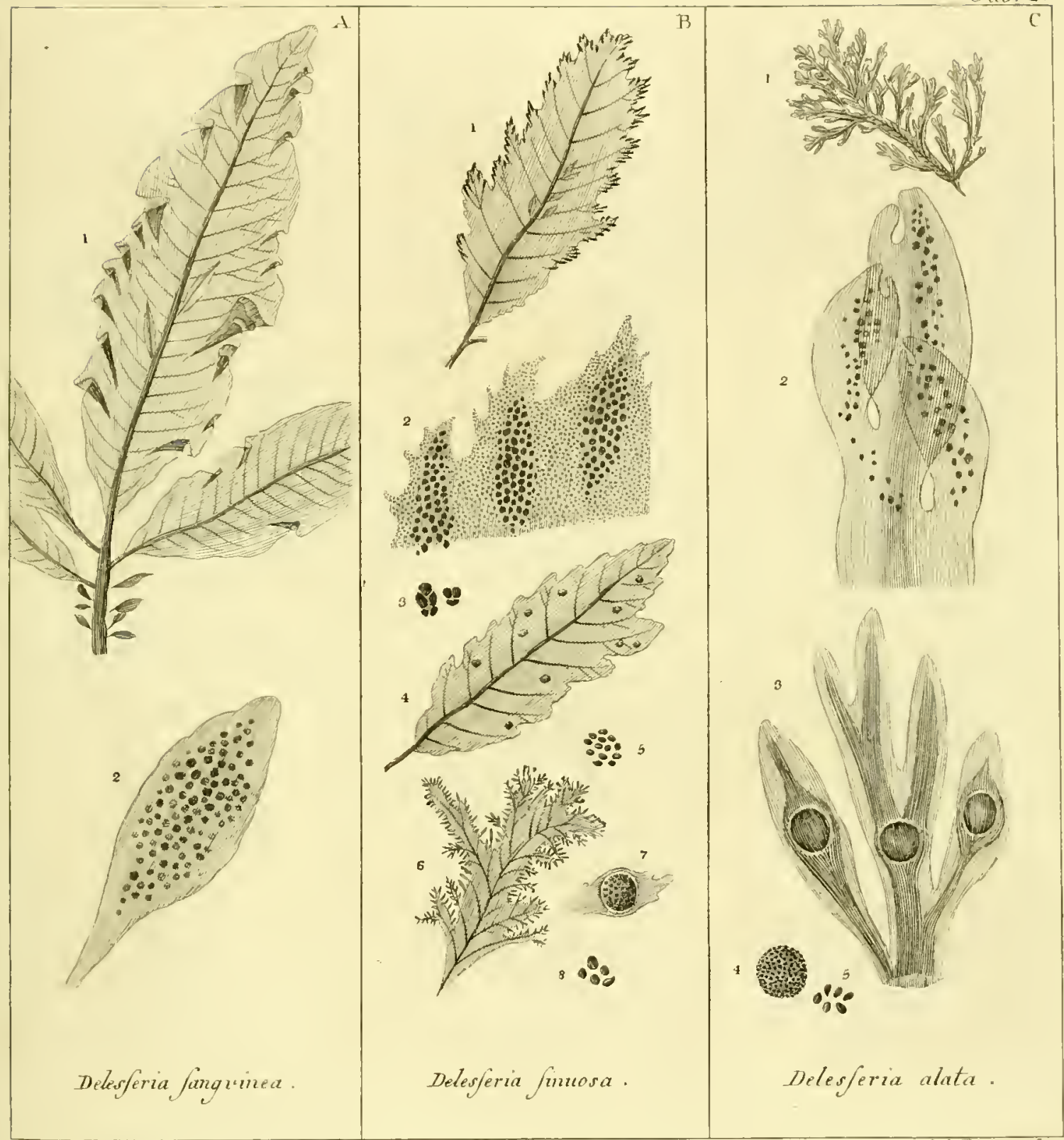





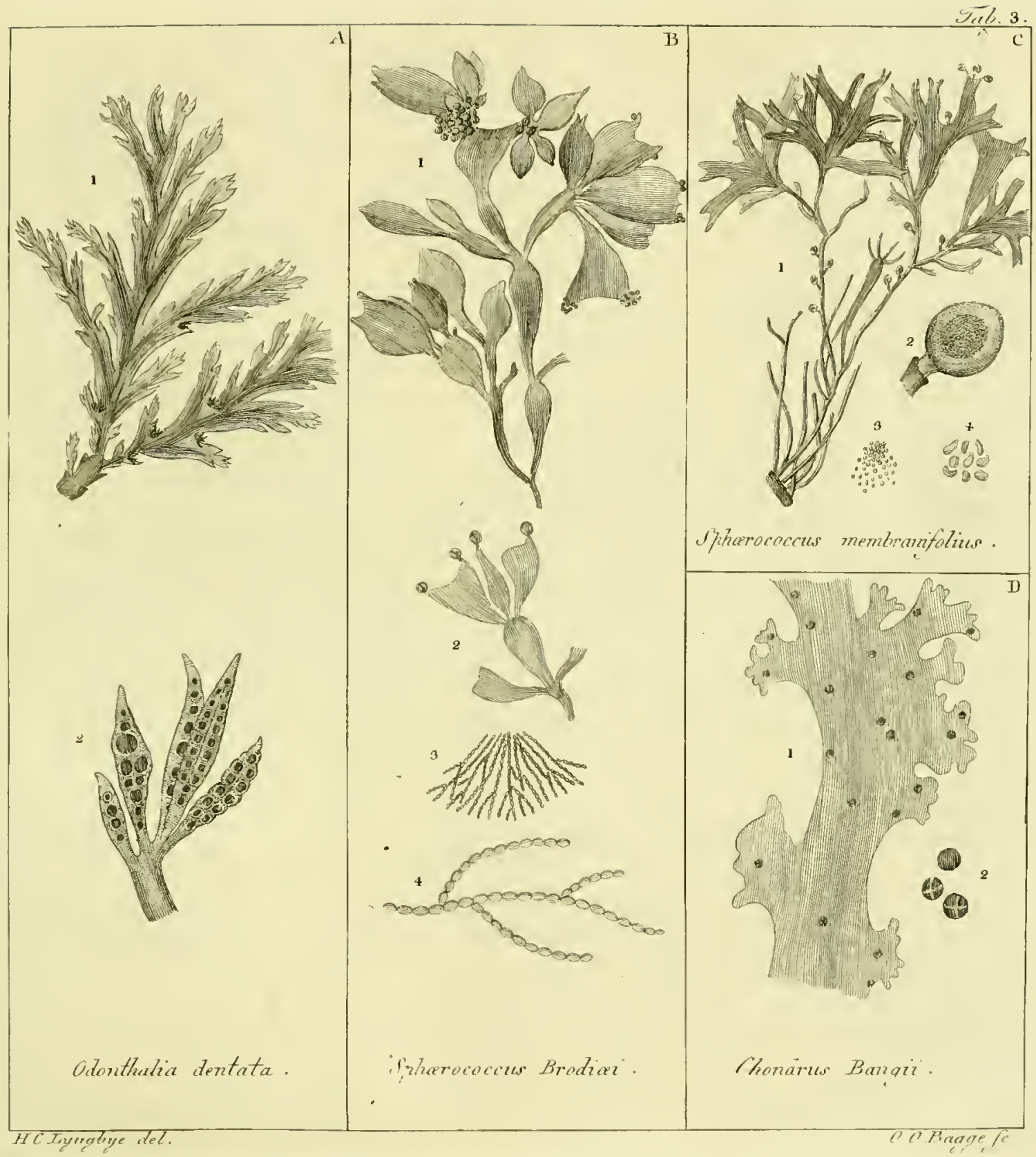





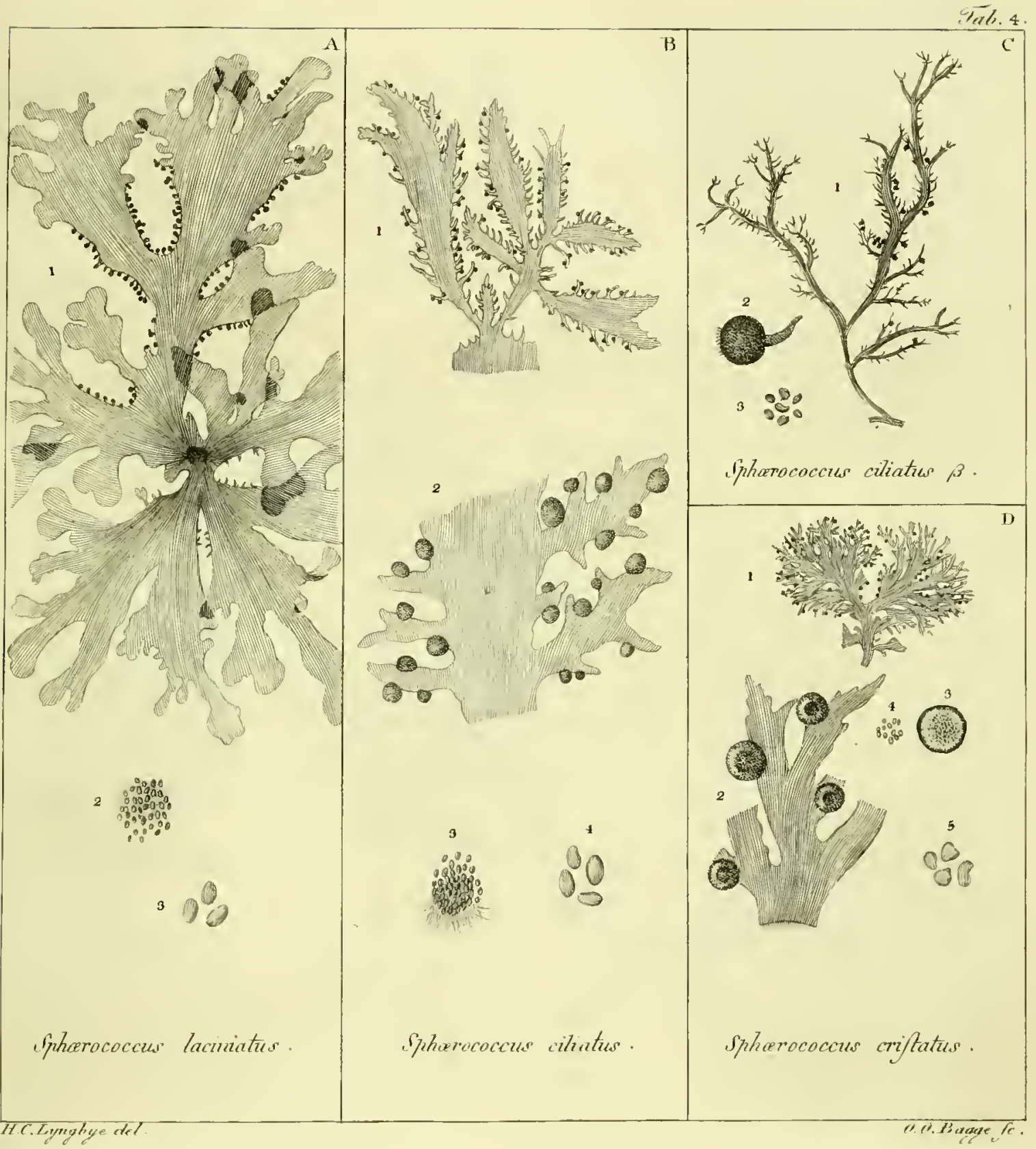





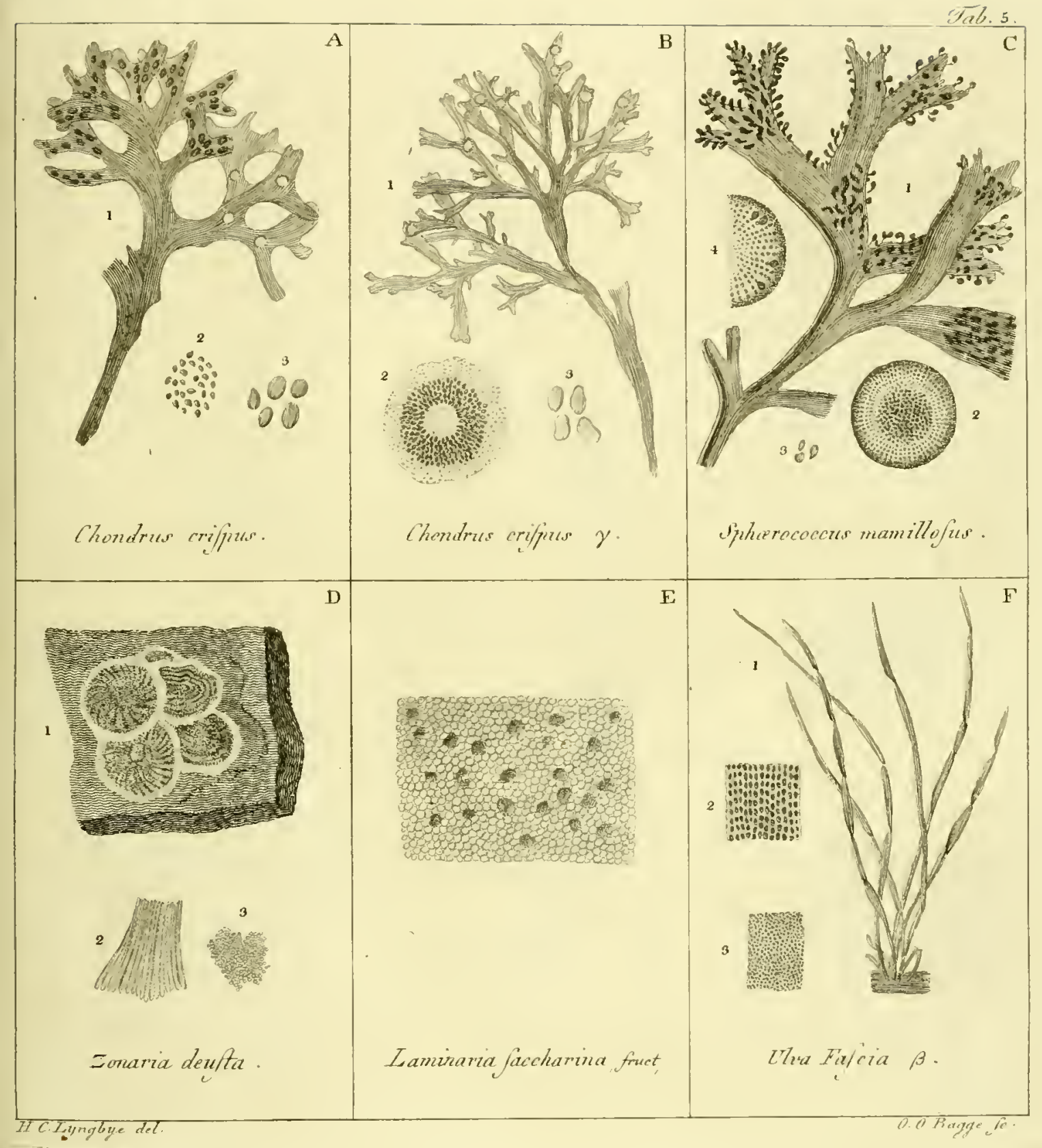





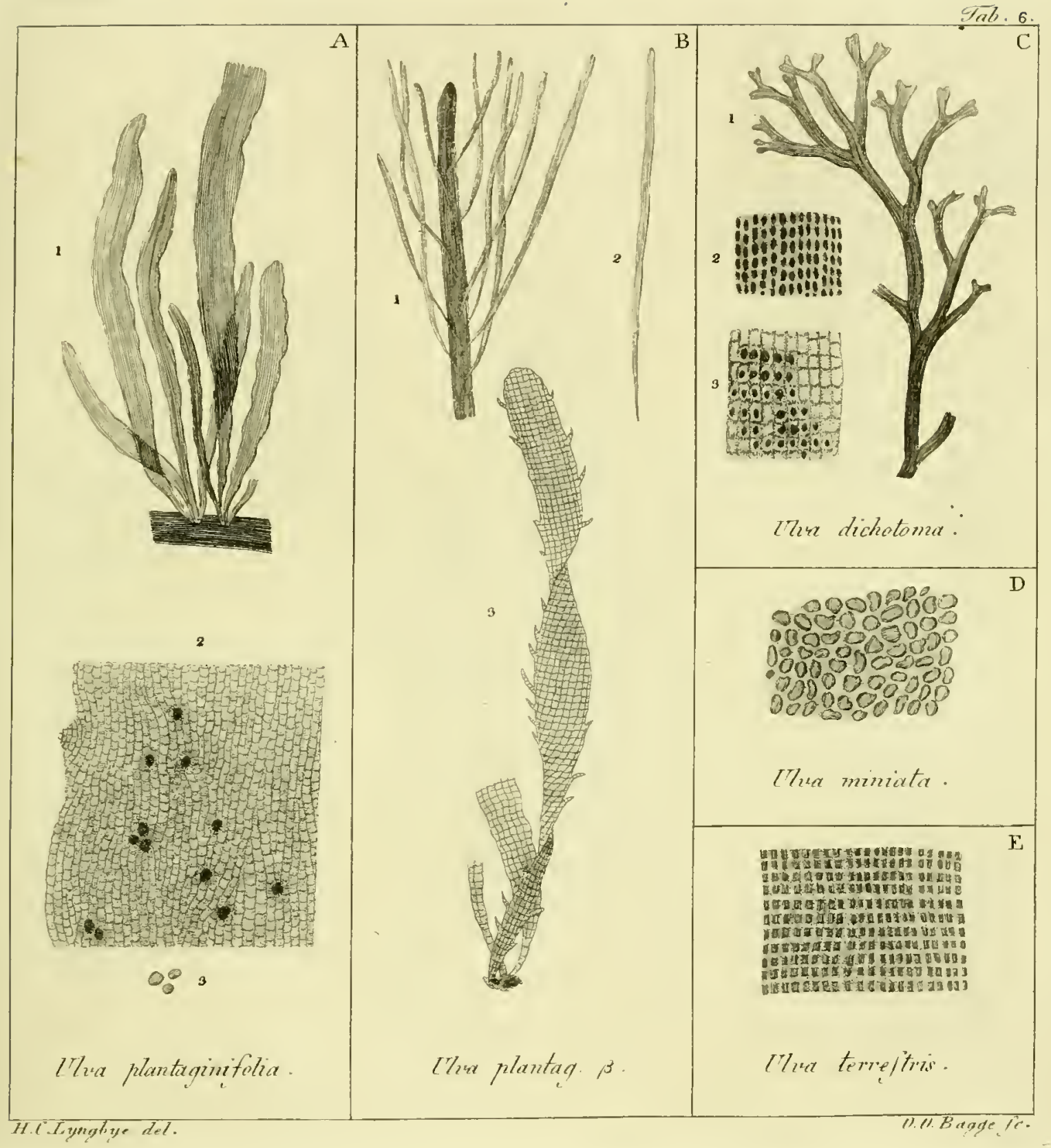



Fab. 7.

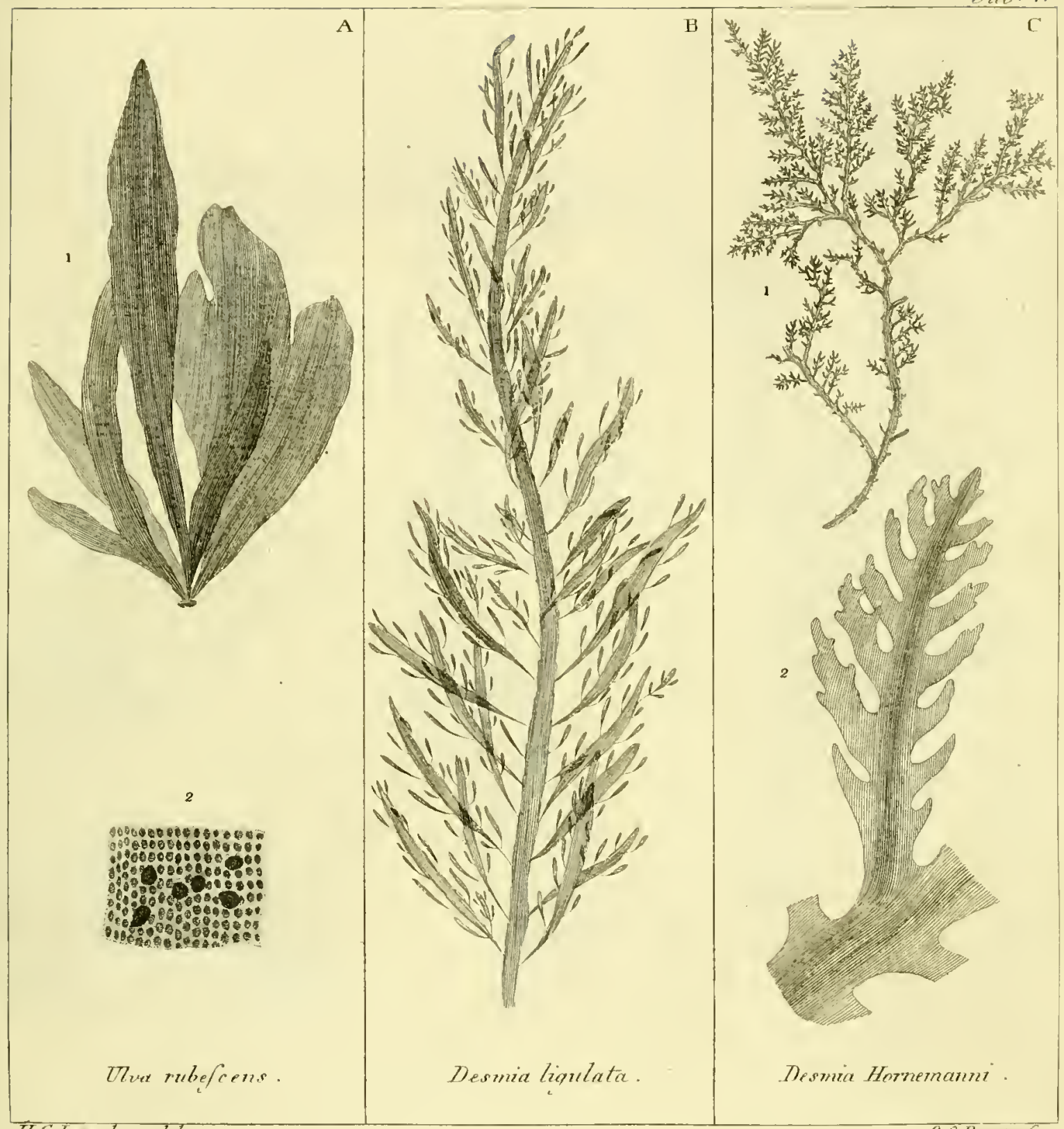

II. C. Lyingbige del. 
$\checkmark$ 


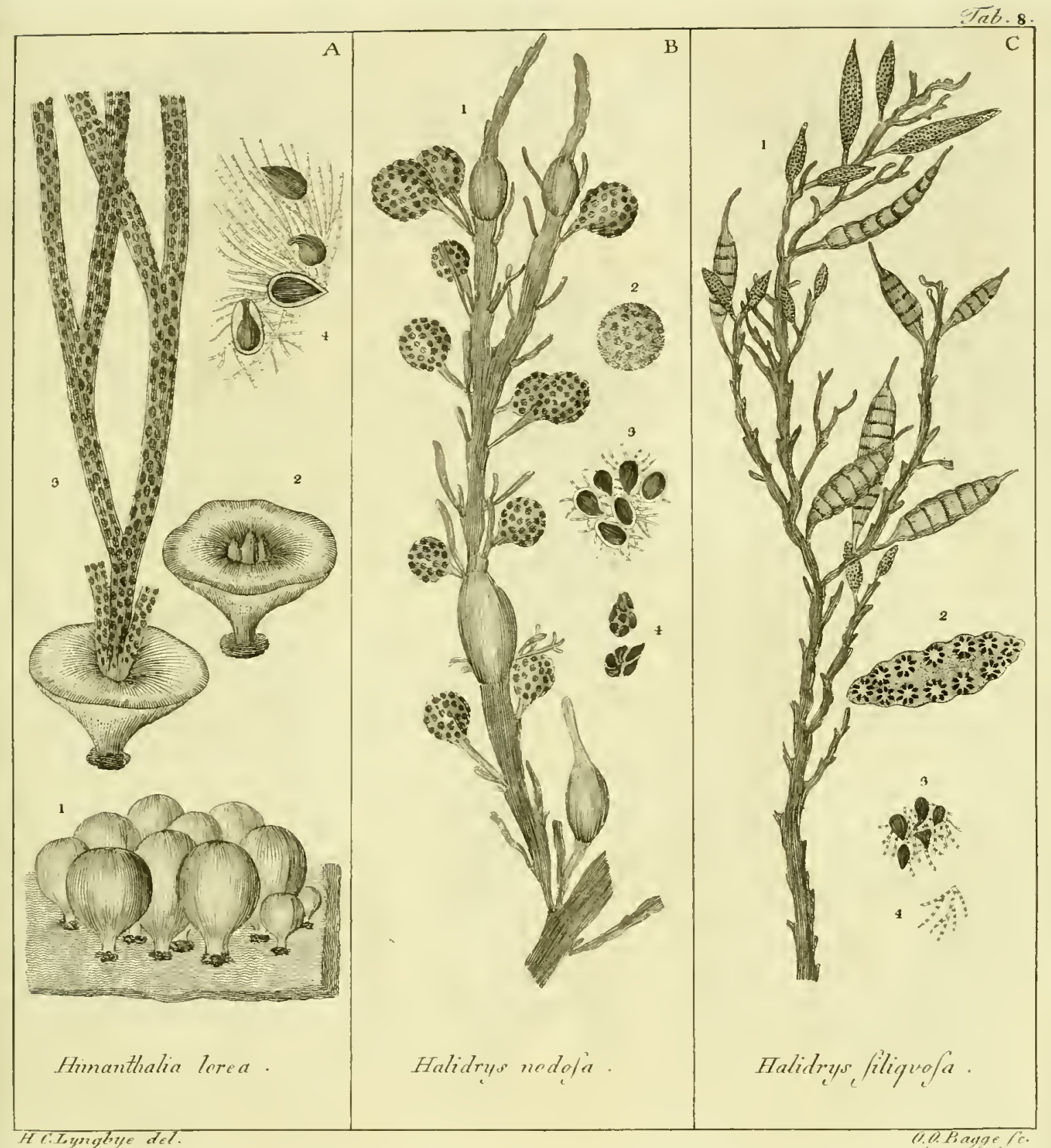



A vil $x^{2}$

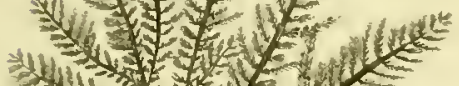
$-3 y 36$ * $y^{2}, y^{2}$

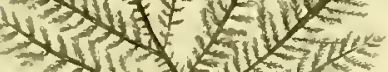
$313 x+4 y$ thy

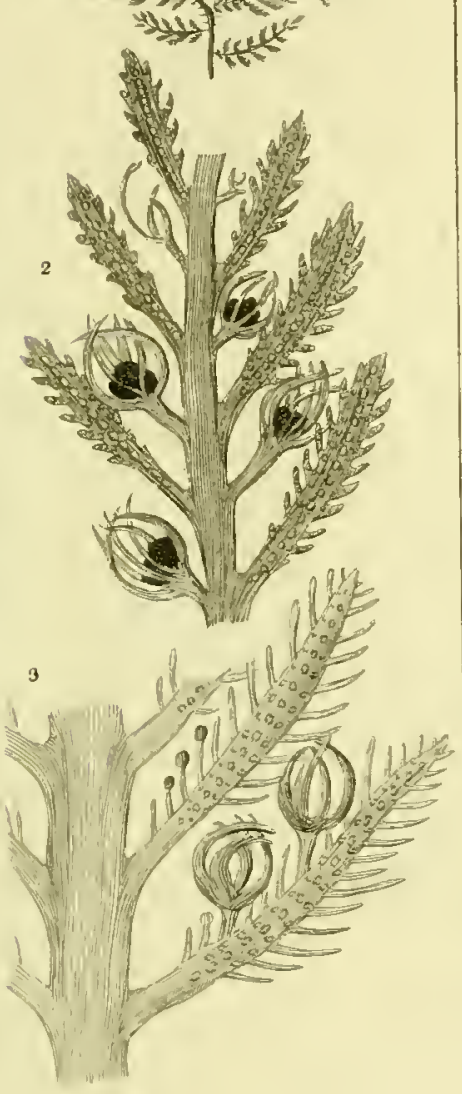

Ptilota plumeja
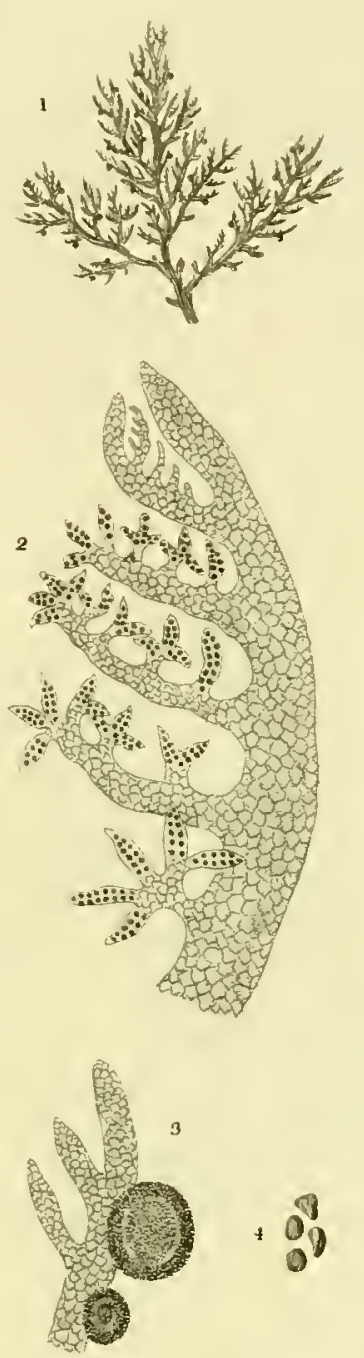

Plocamium corcineum.
B

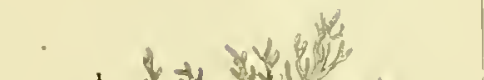

1 to 310

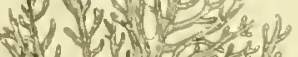

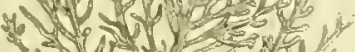

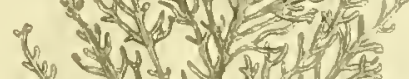

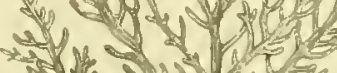
*

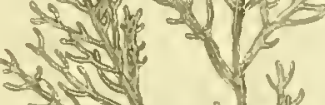
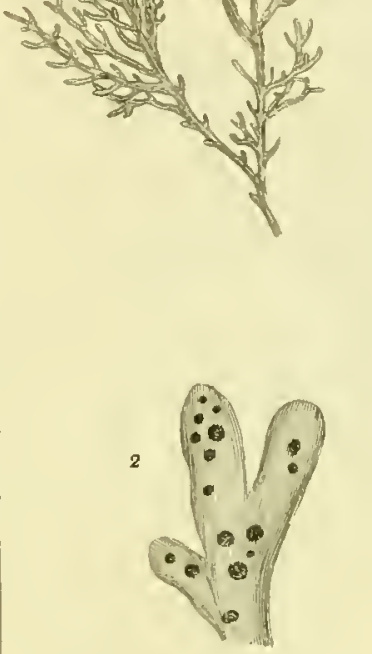

3

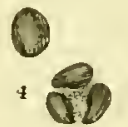

Gelidum pumatifidum. 

Tab. 10

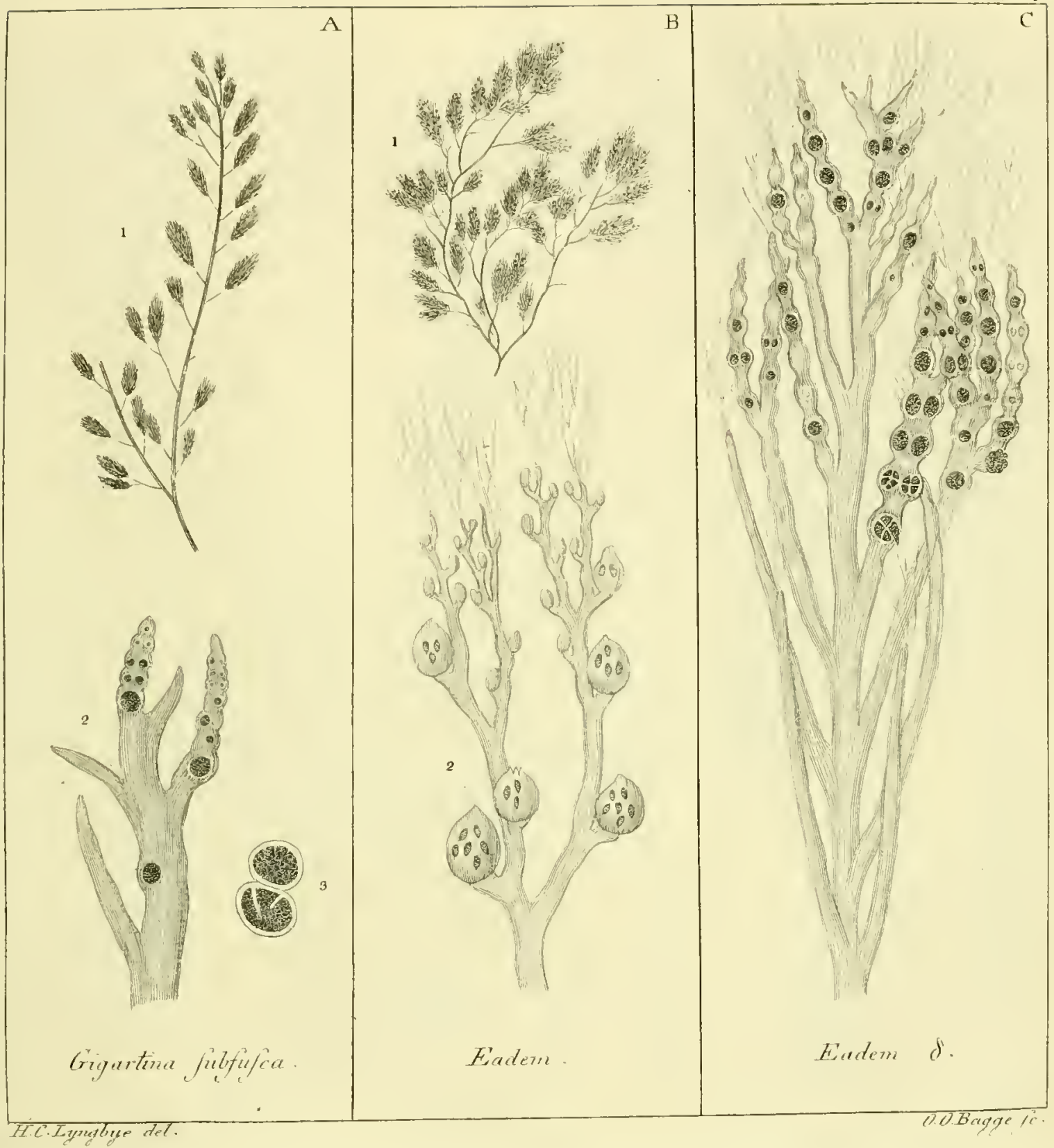





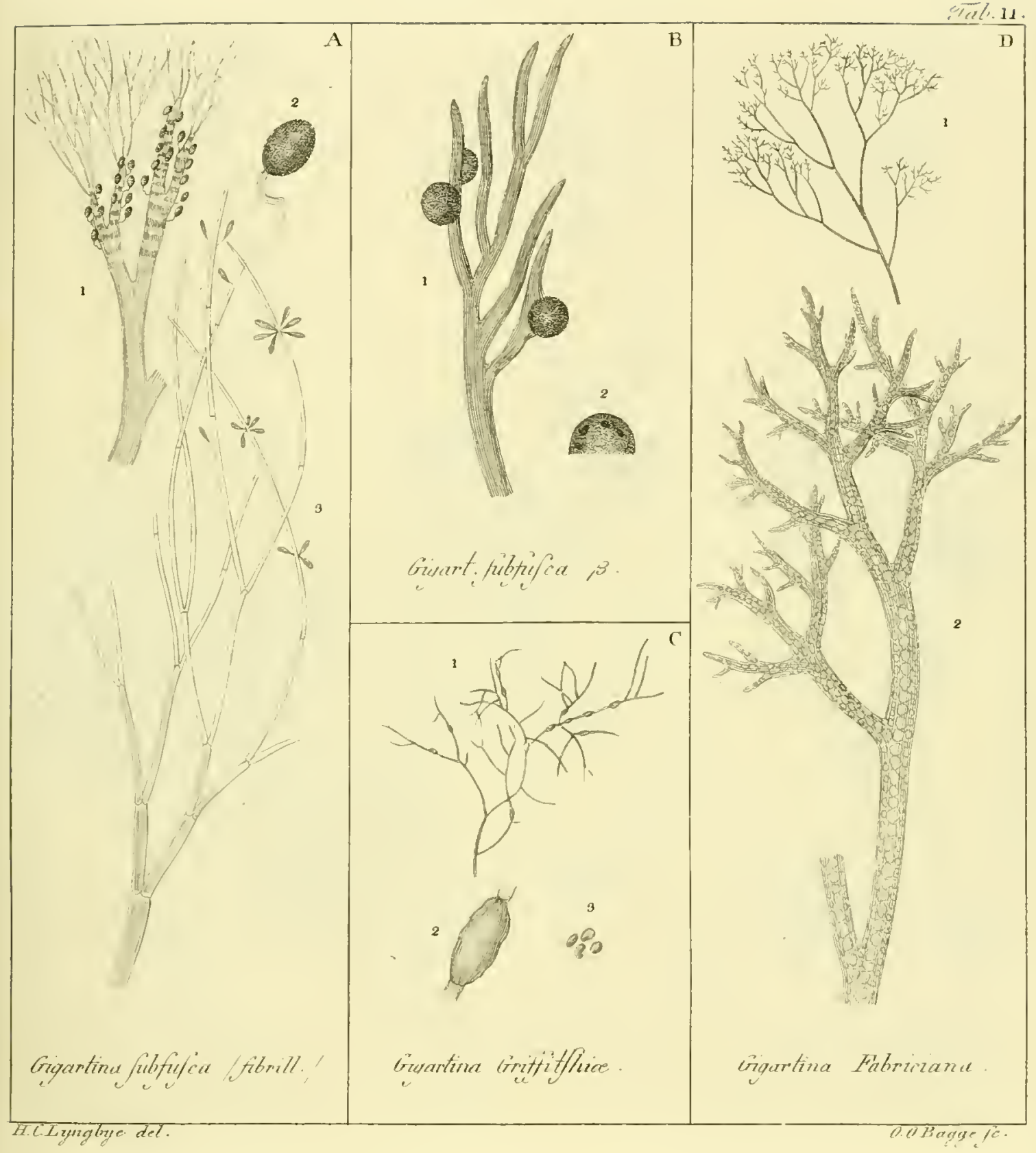




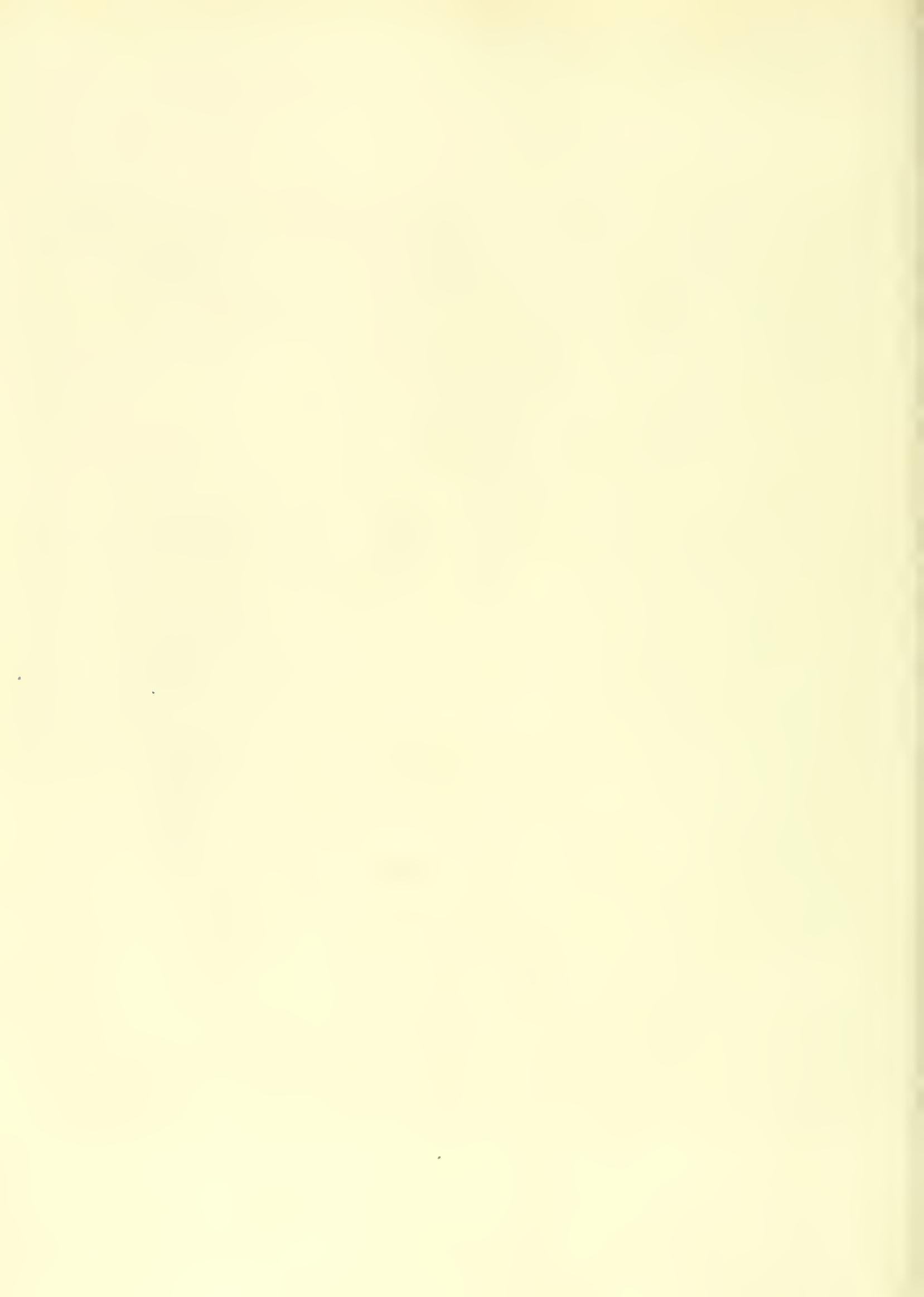




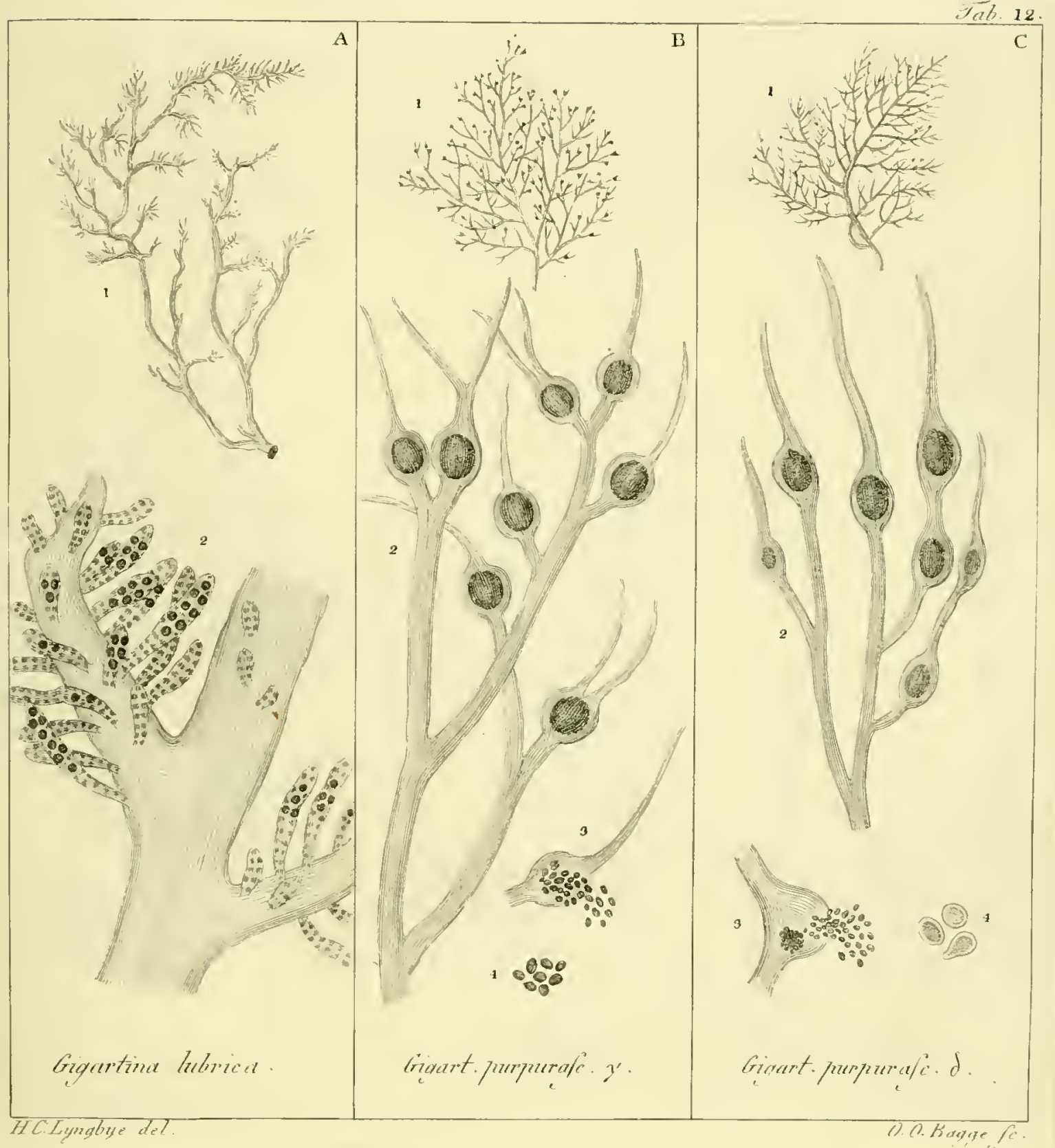


. 


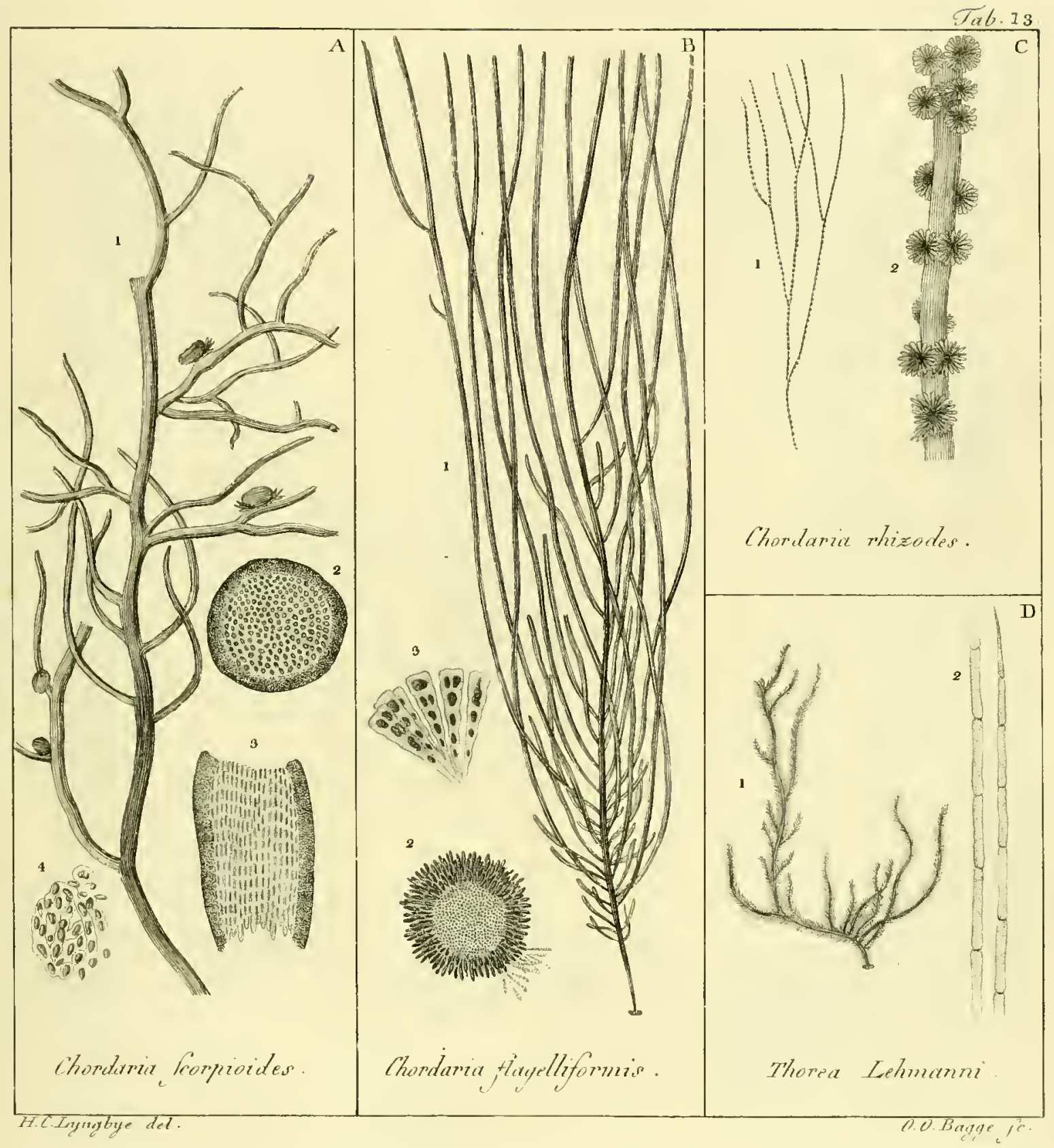


, 


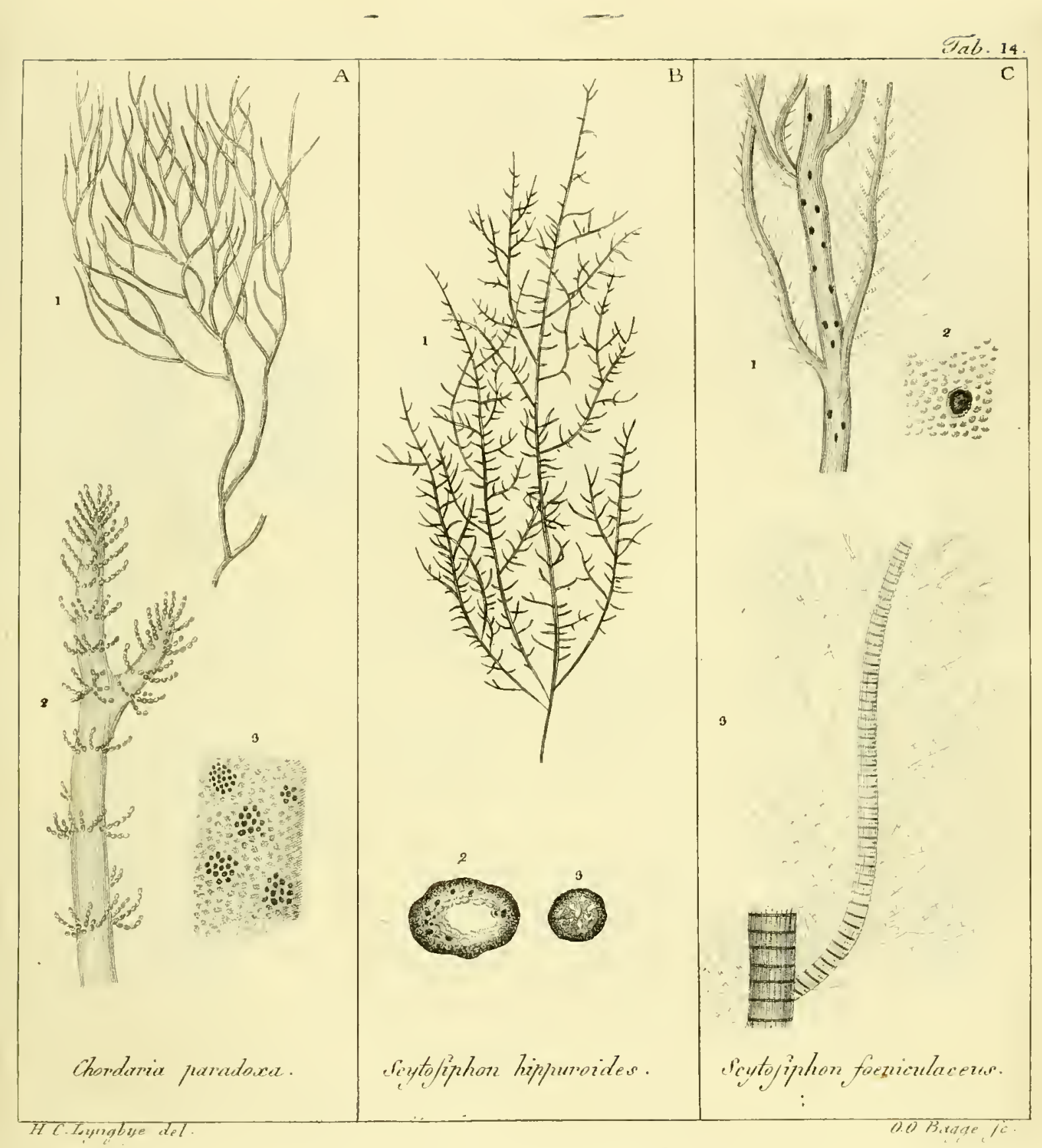




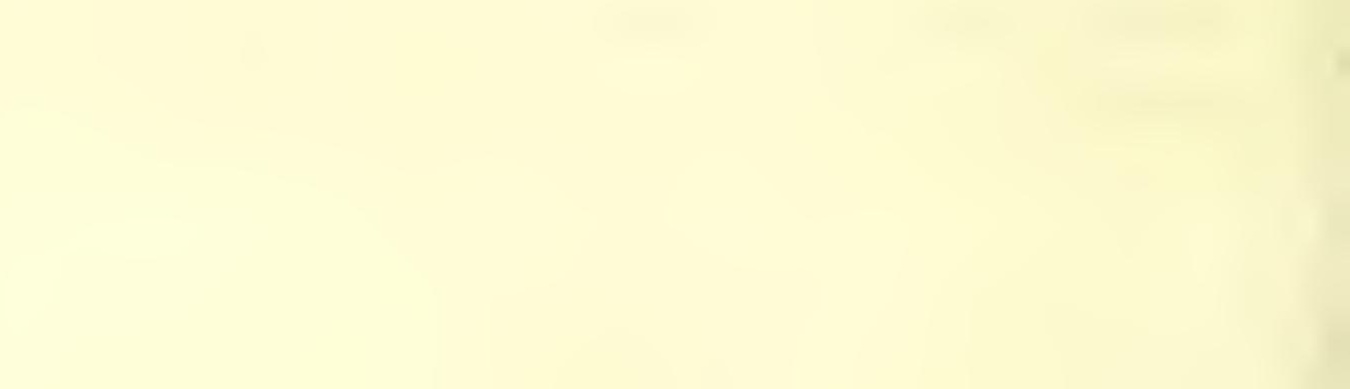


$\pi / 2 b \cdot 15$

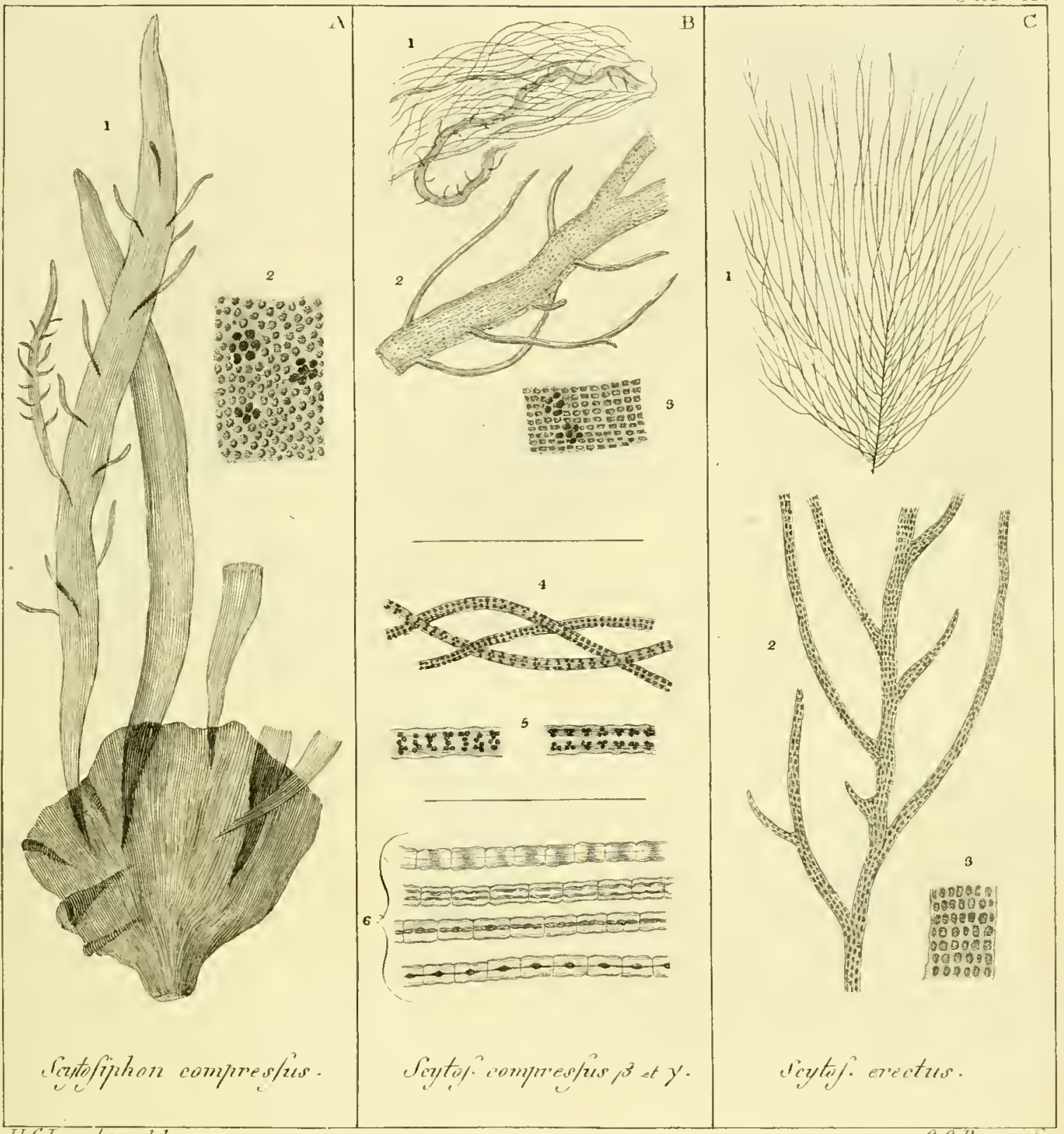

II. C.Lyng bye del. 


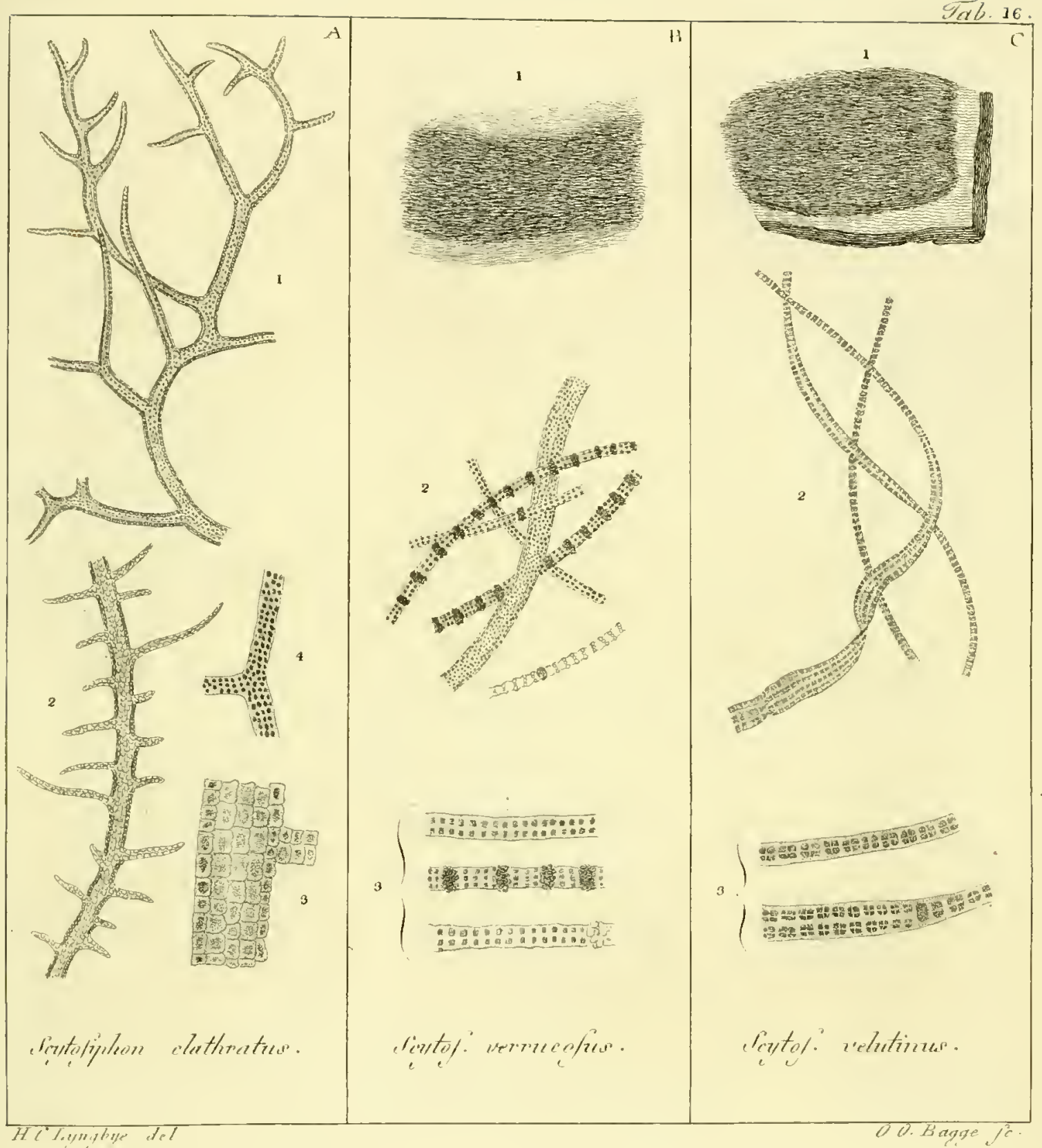





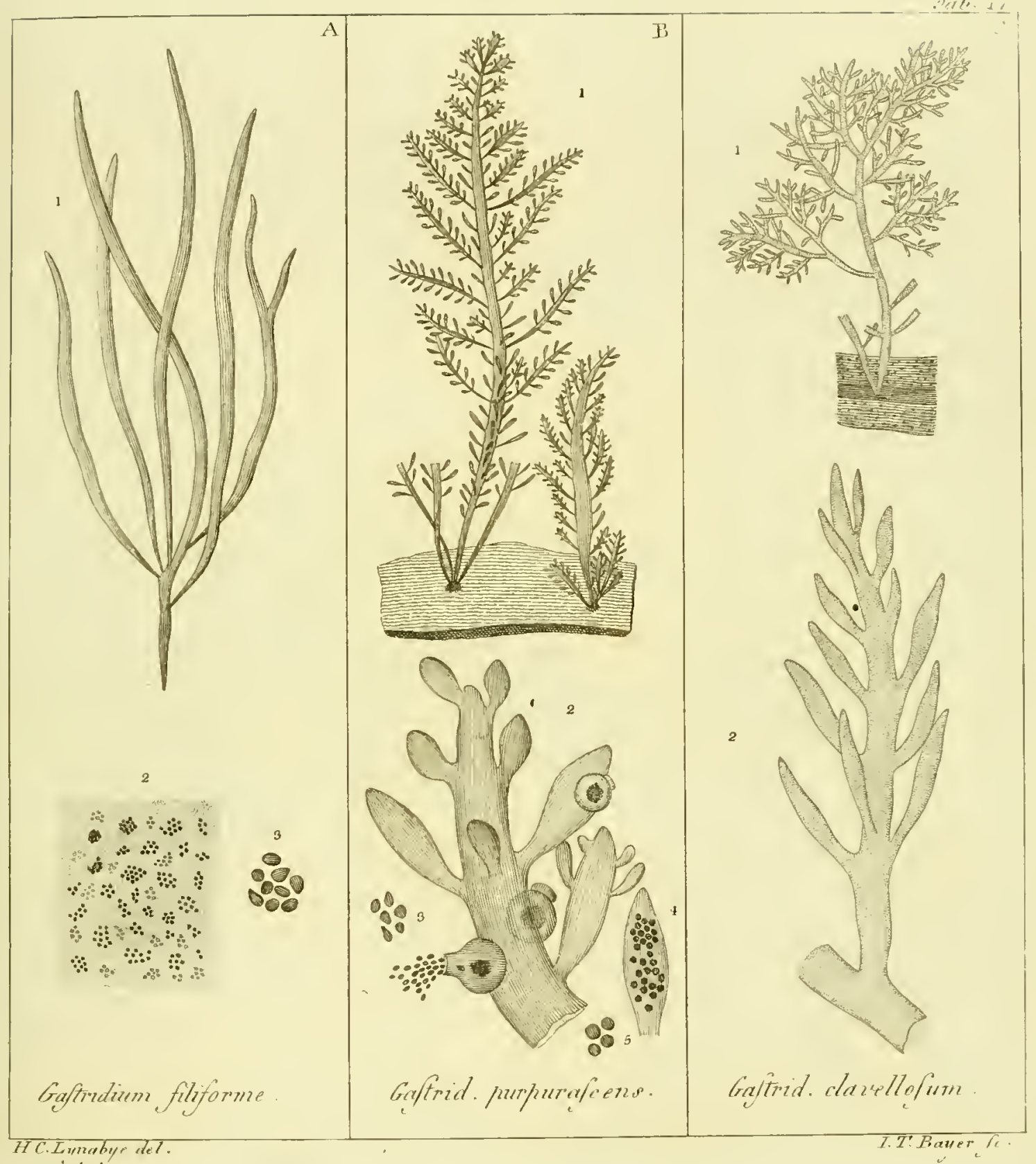





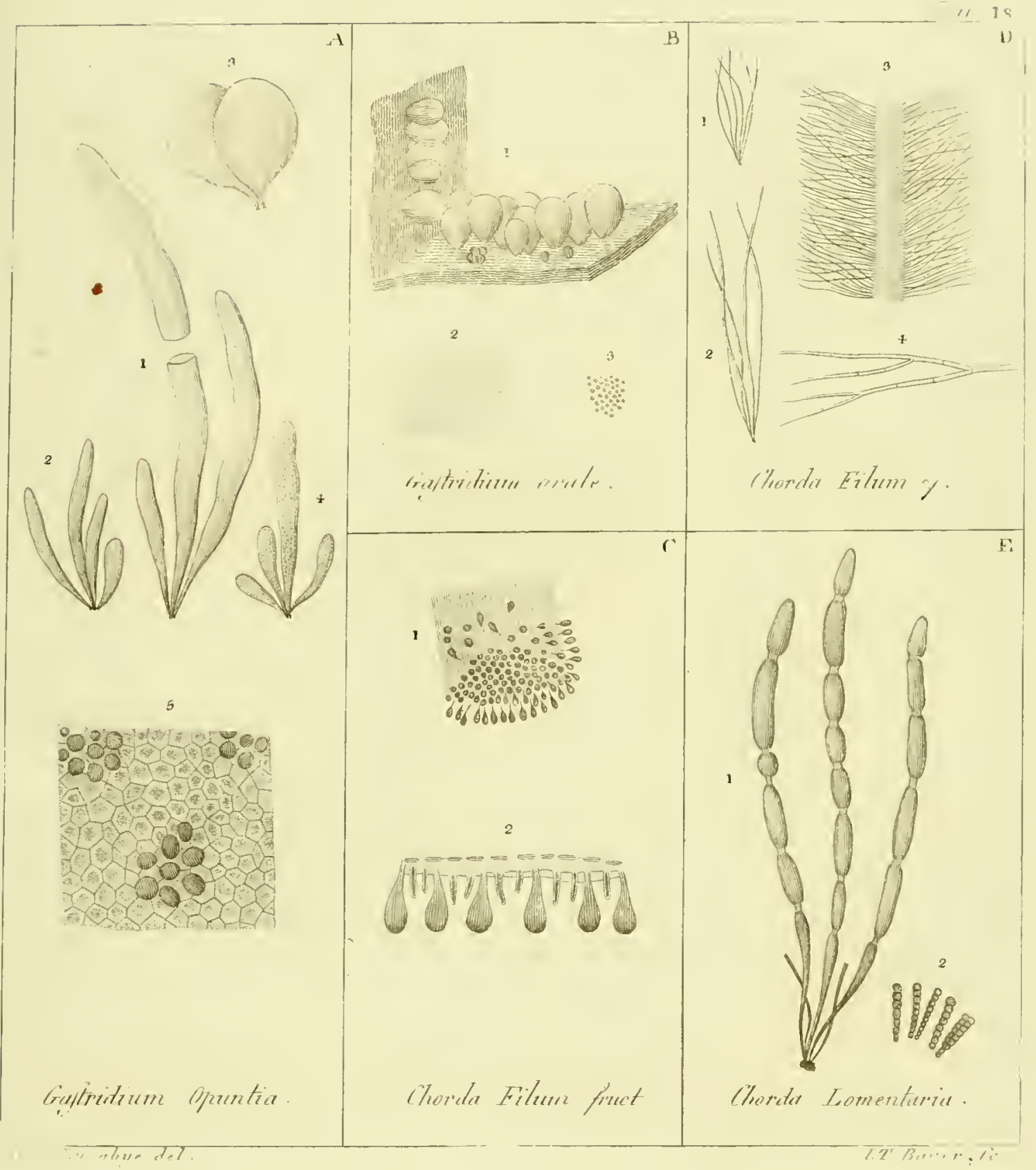




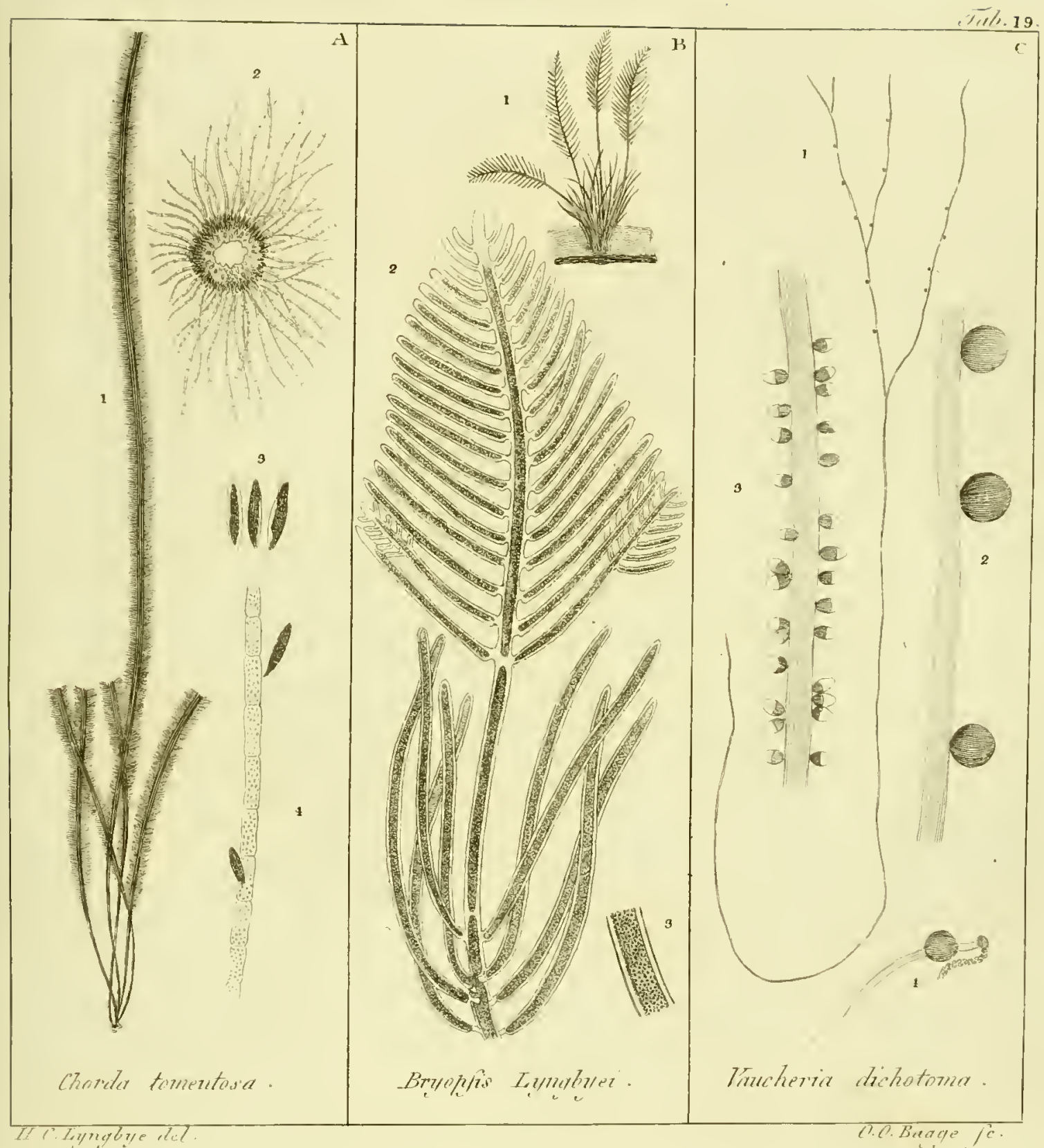




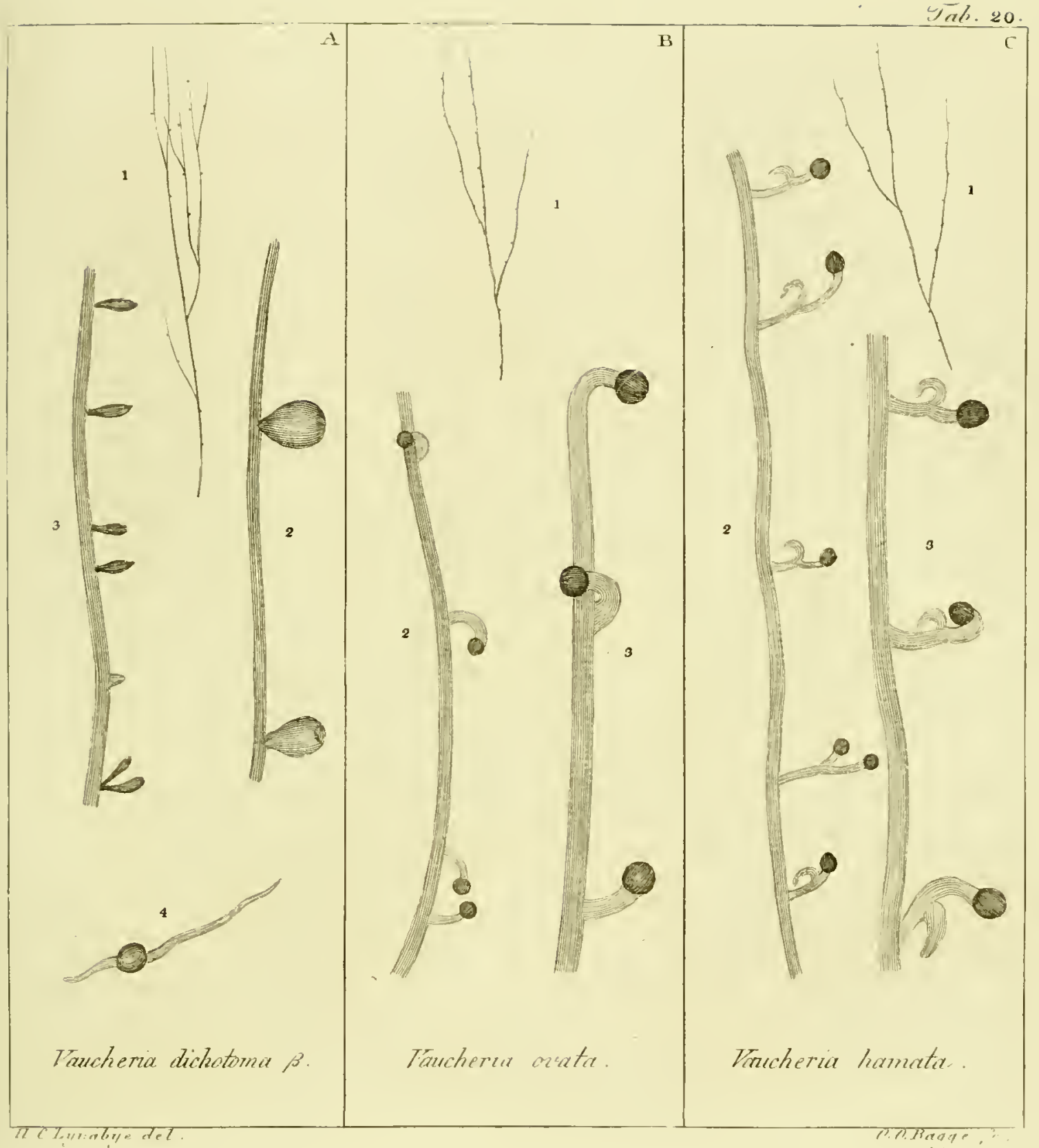



Tab.

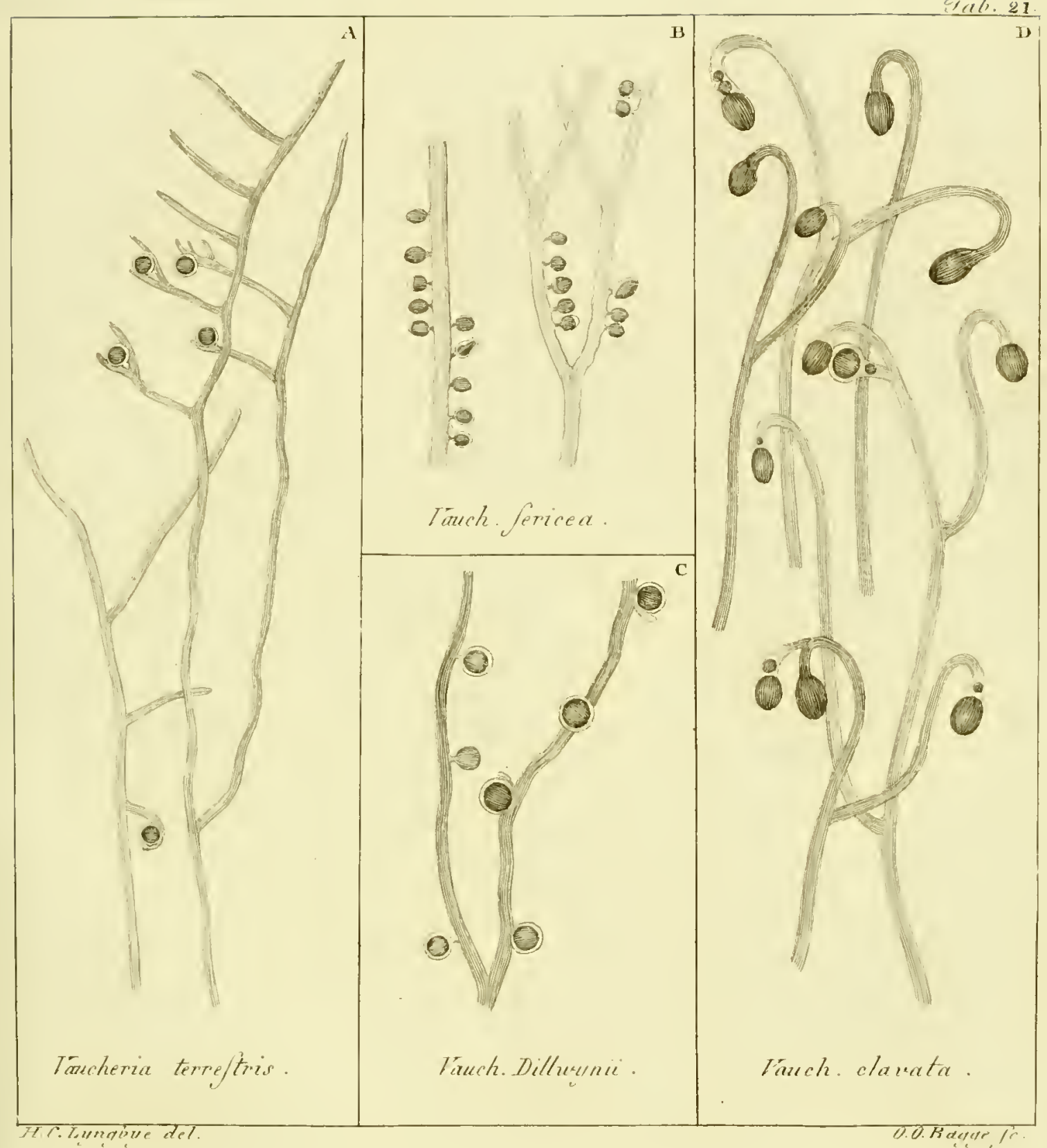


पinl. 2

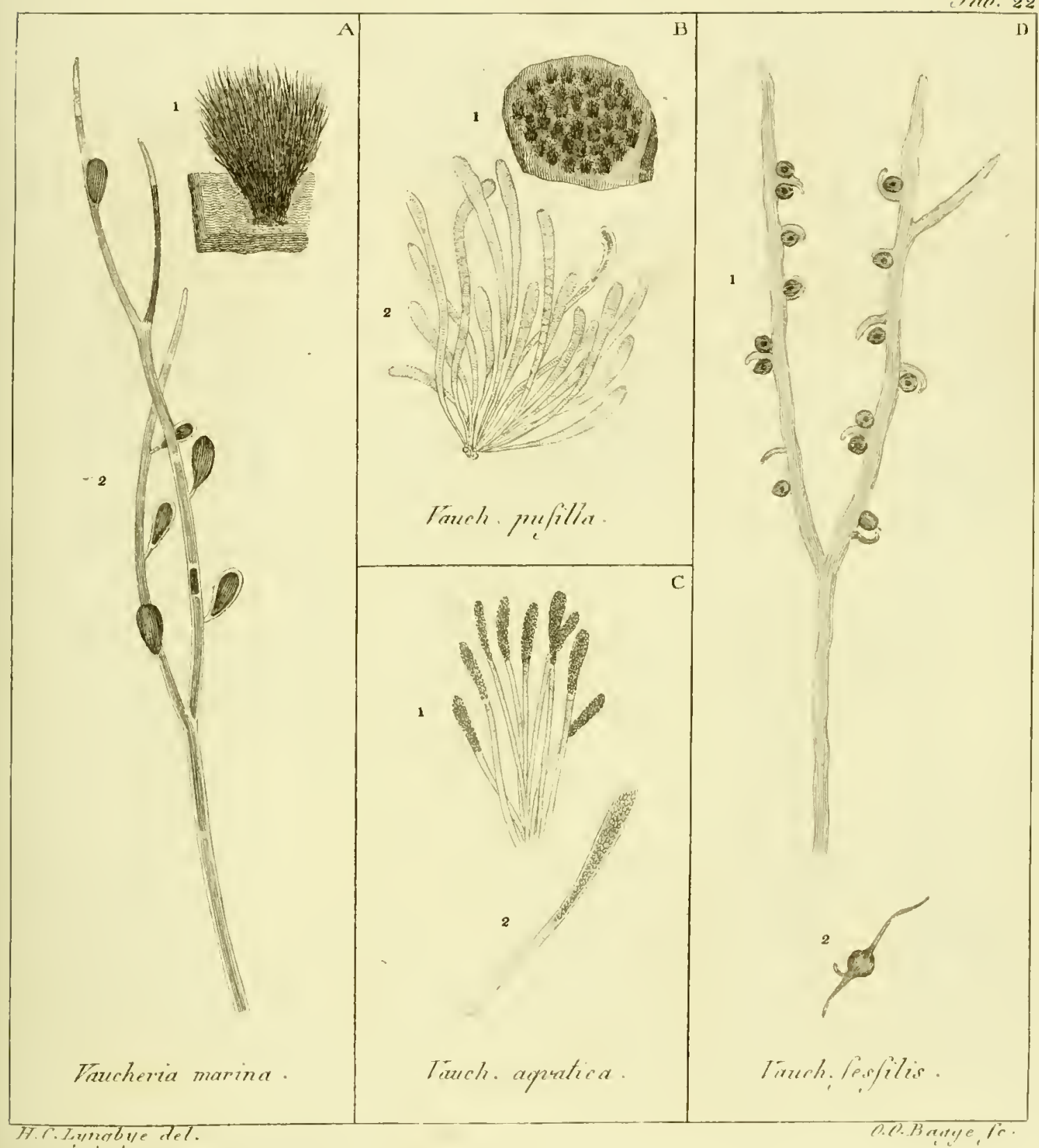





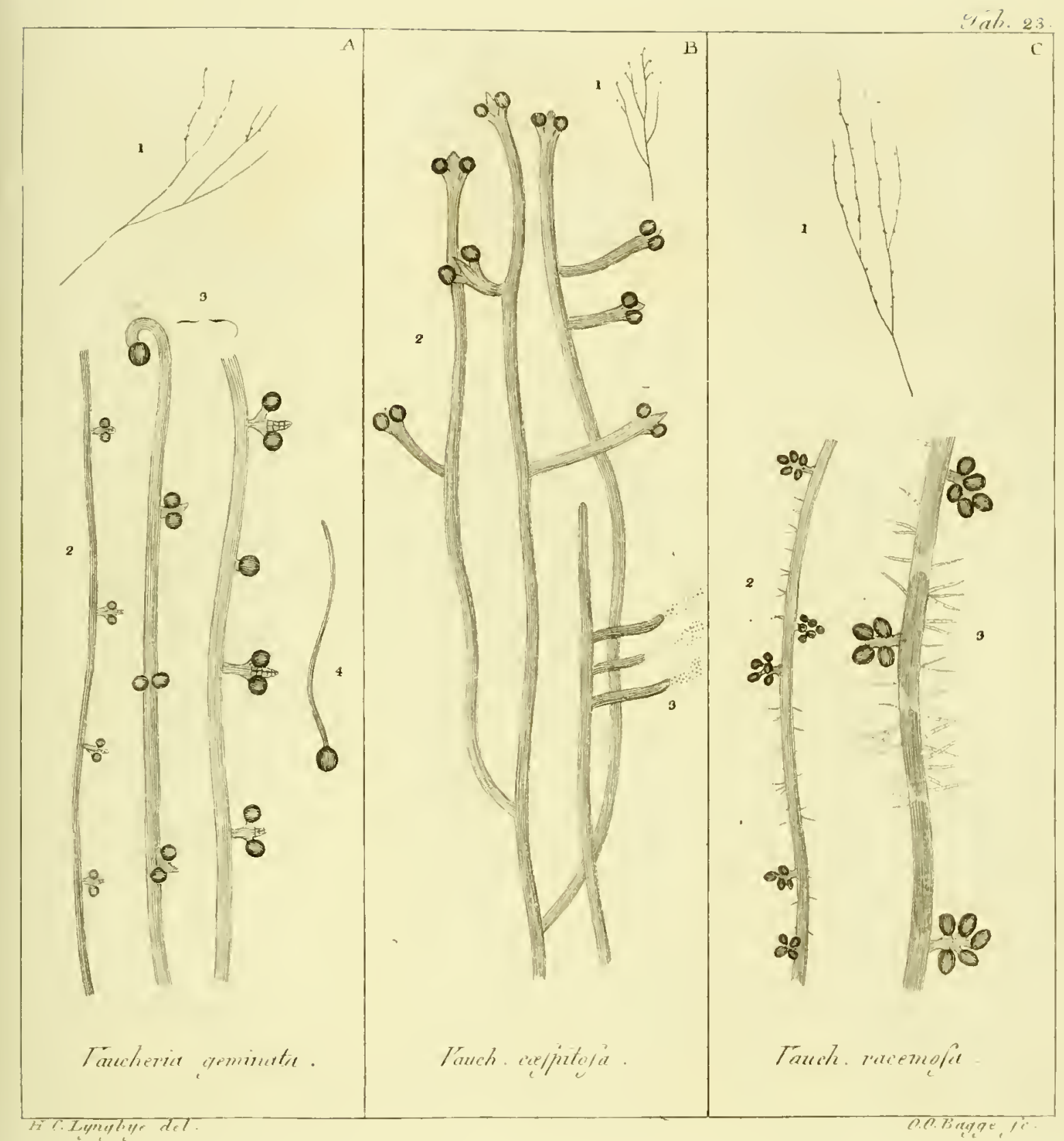





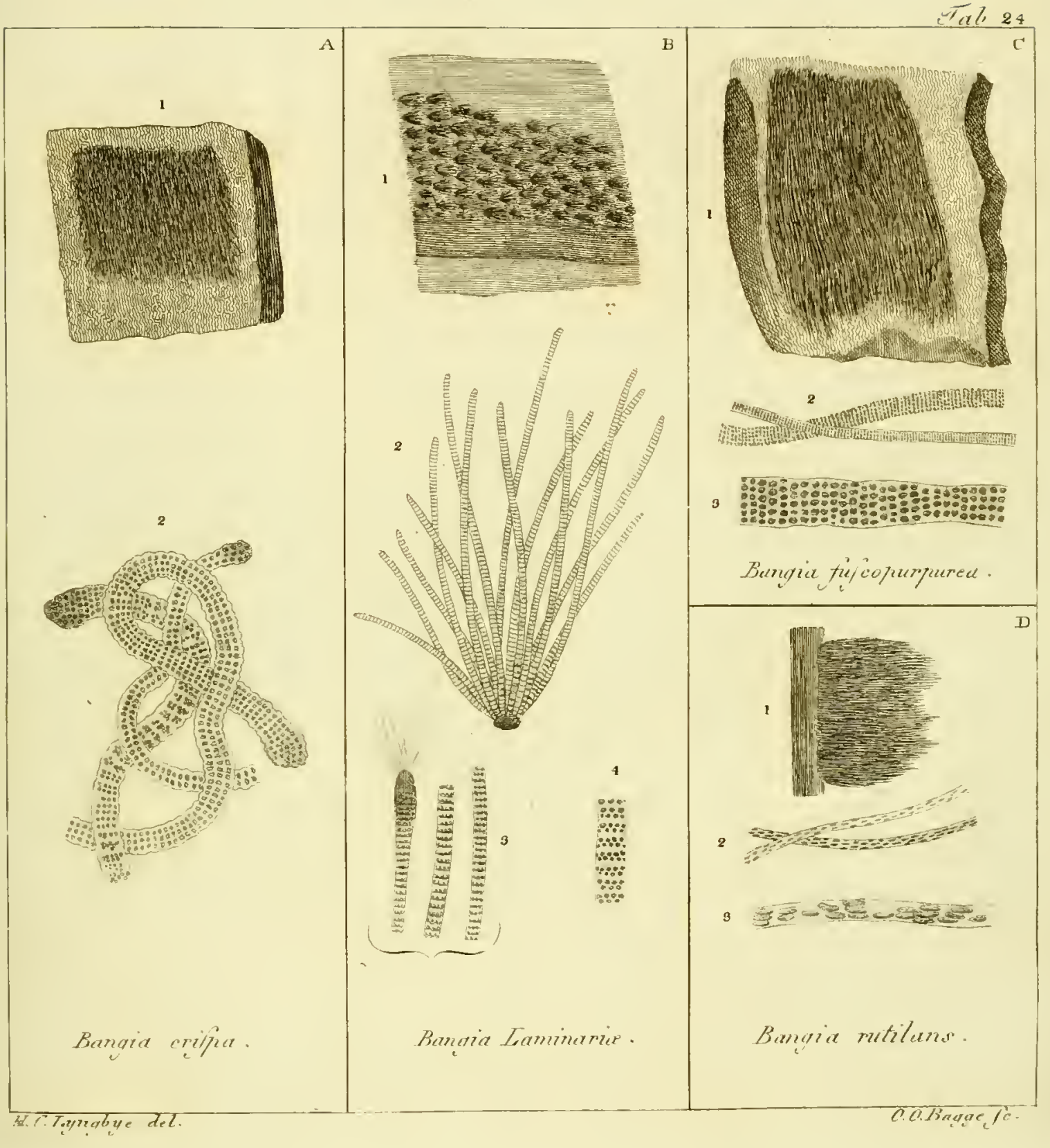


ज्ञाl.

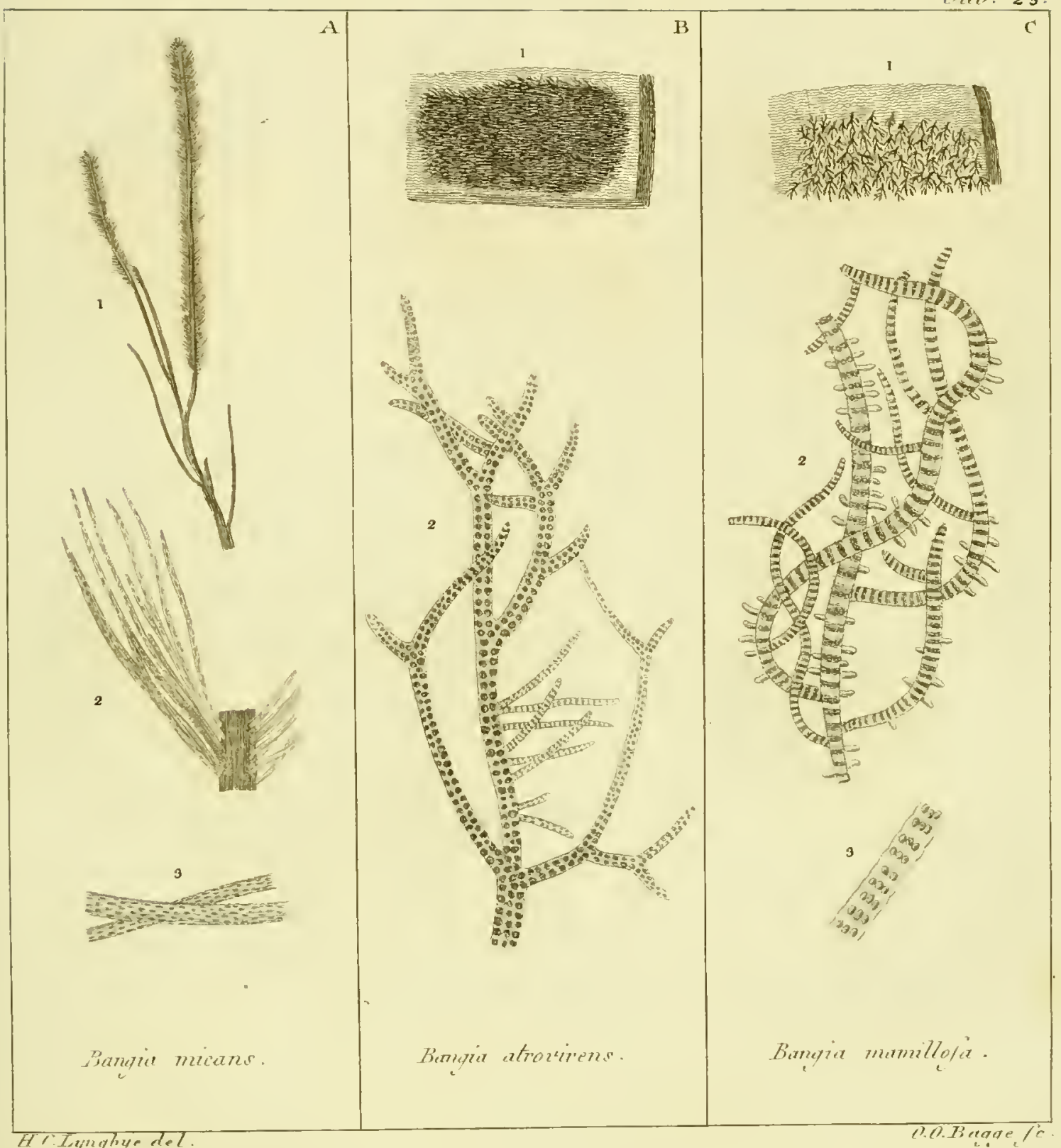




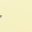


पell. 26

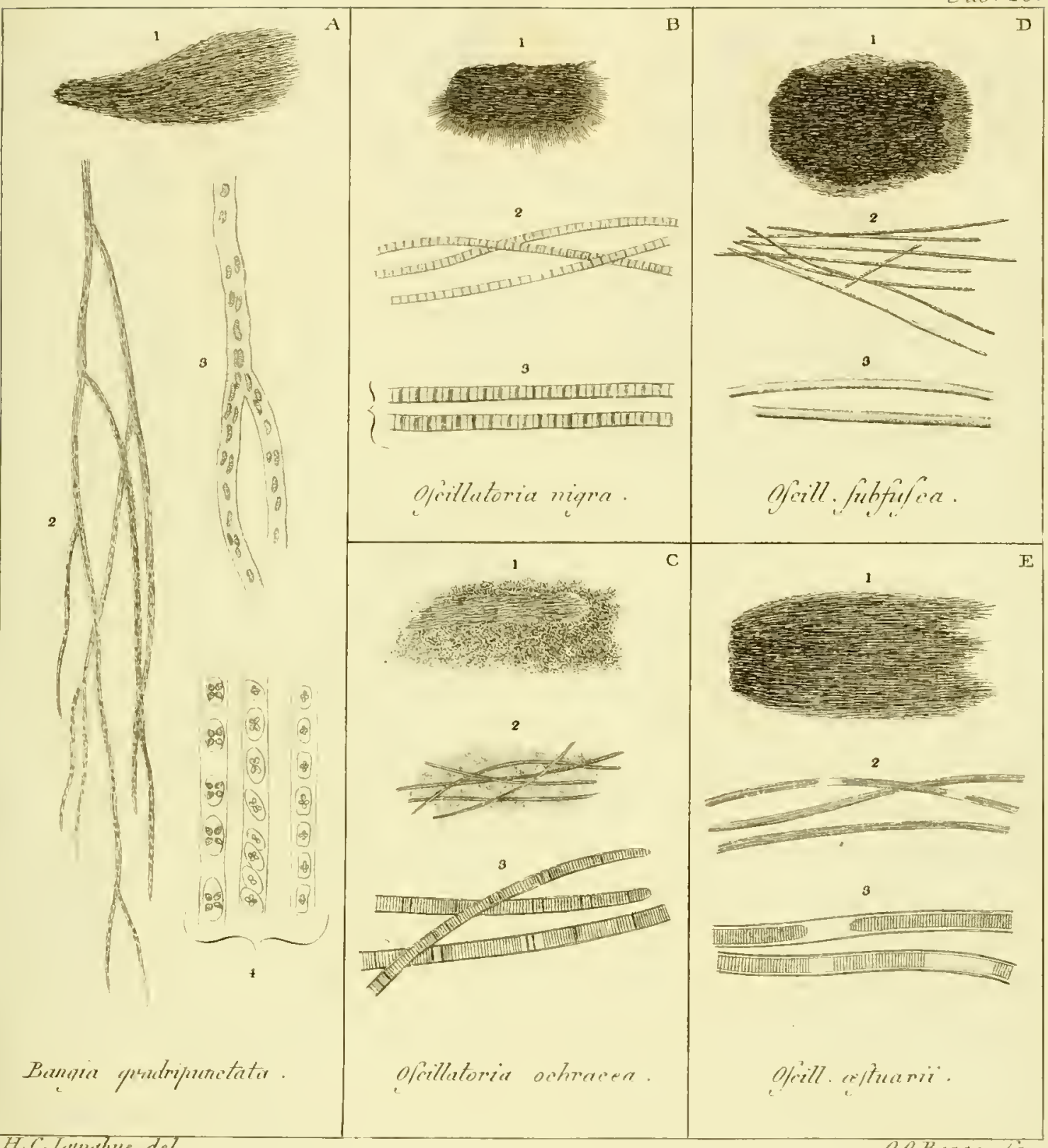

H. C. lumblue del 



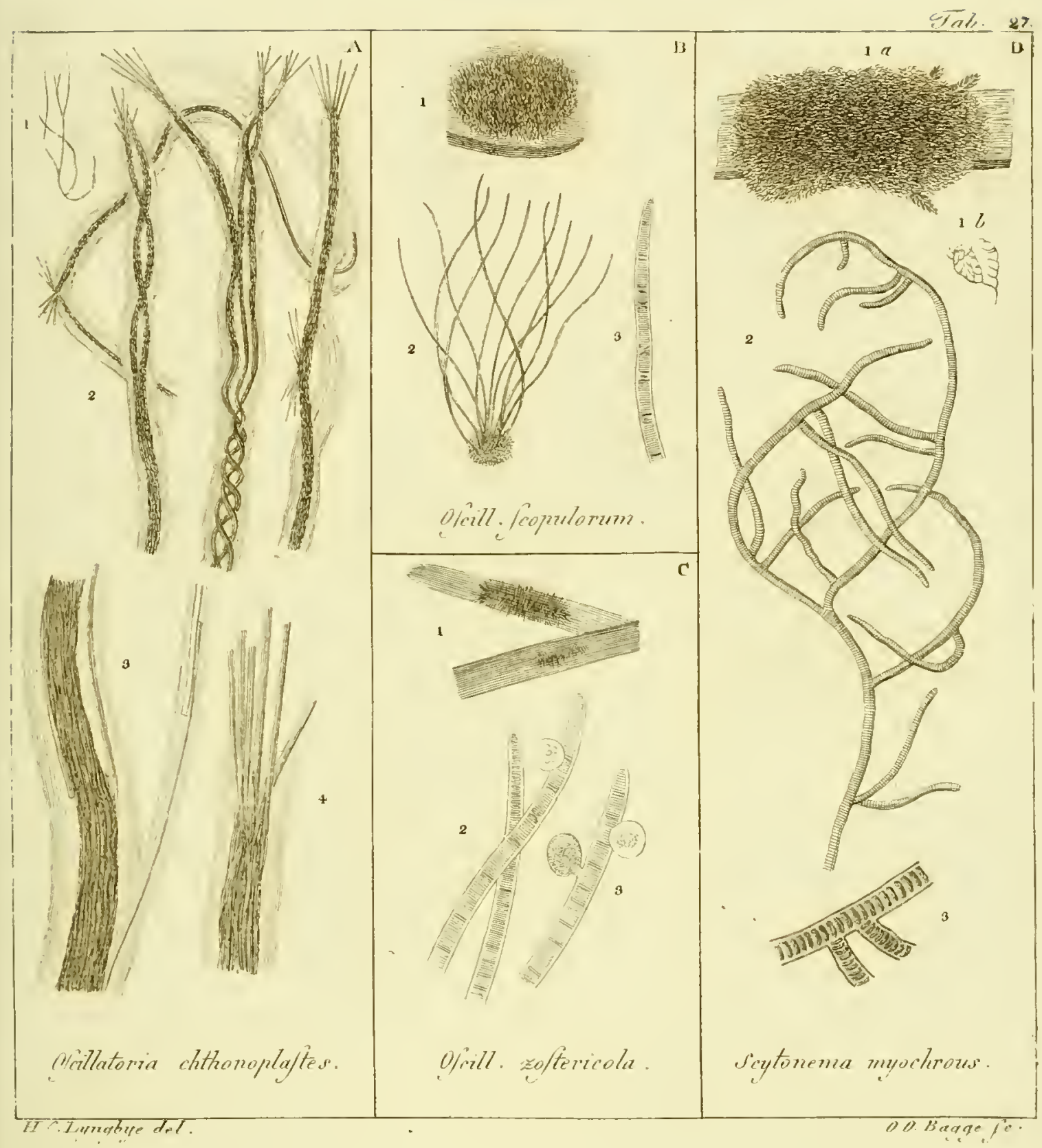




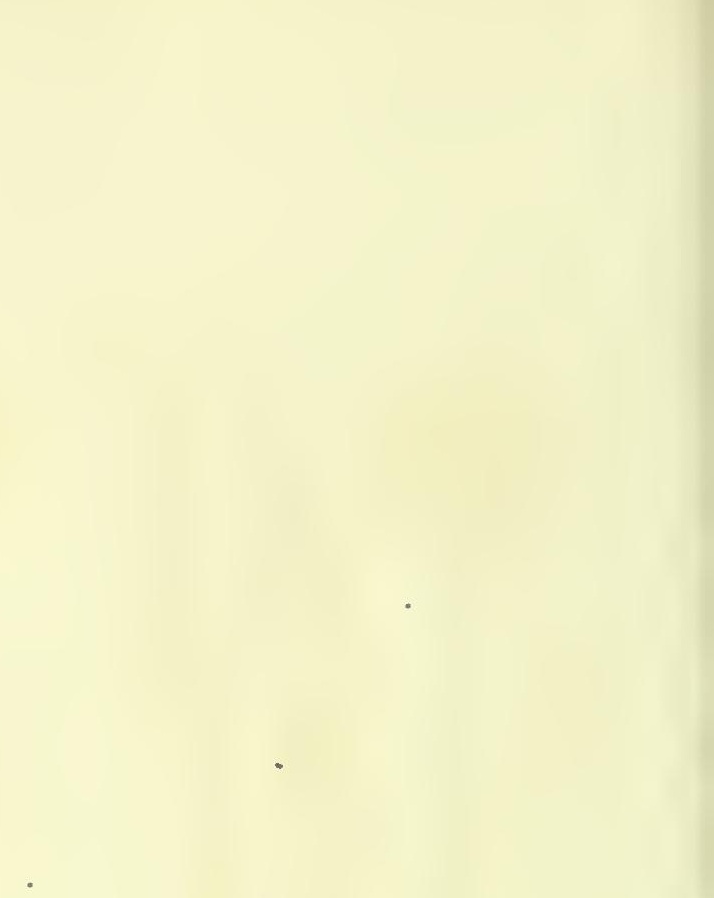


"Irt \&8

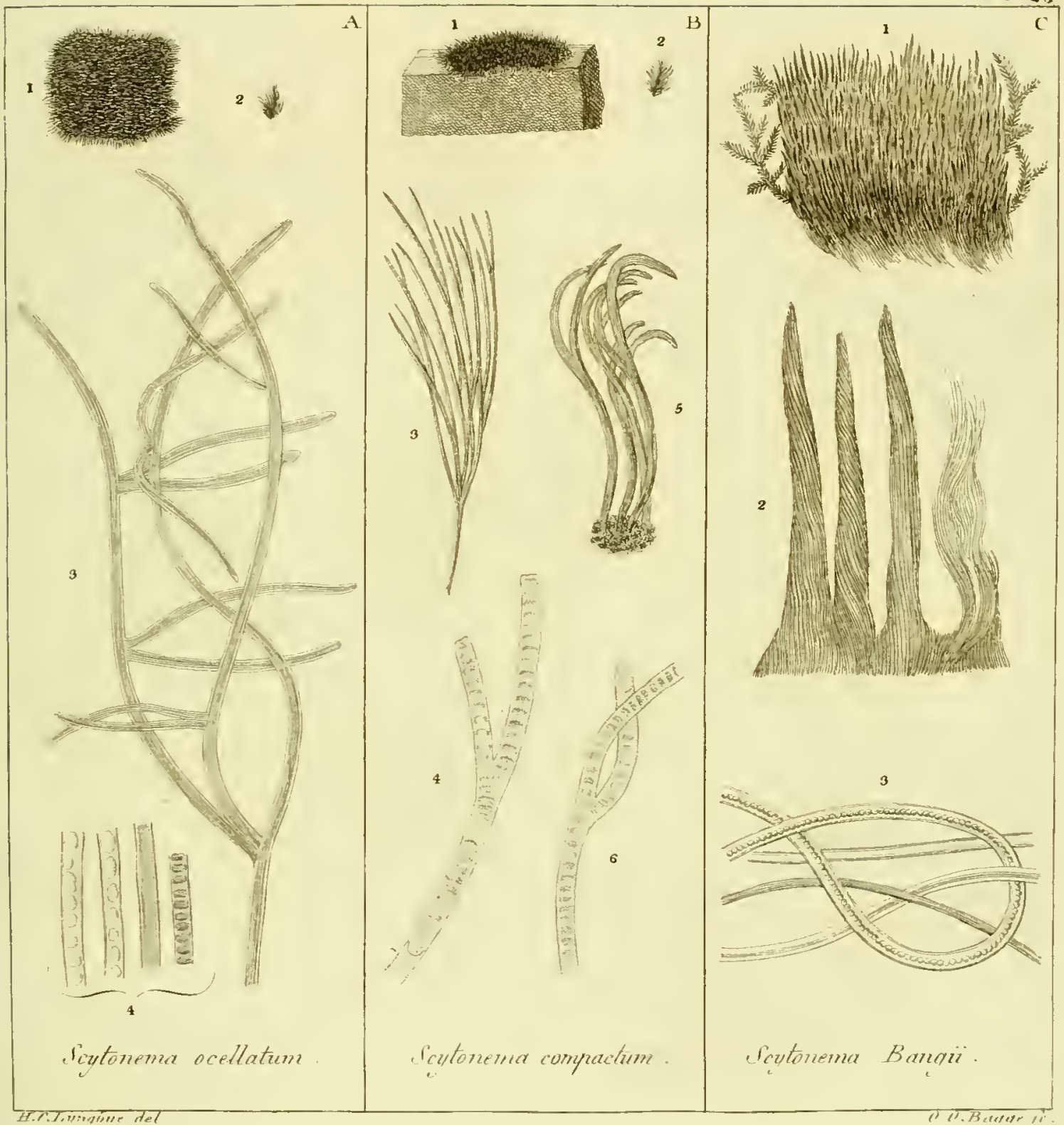






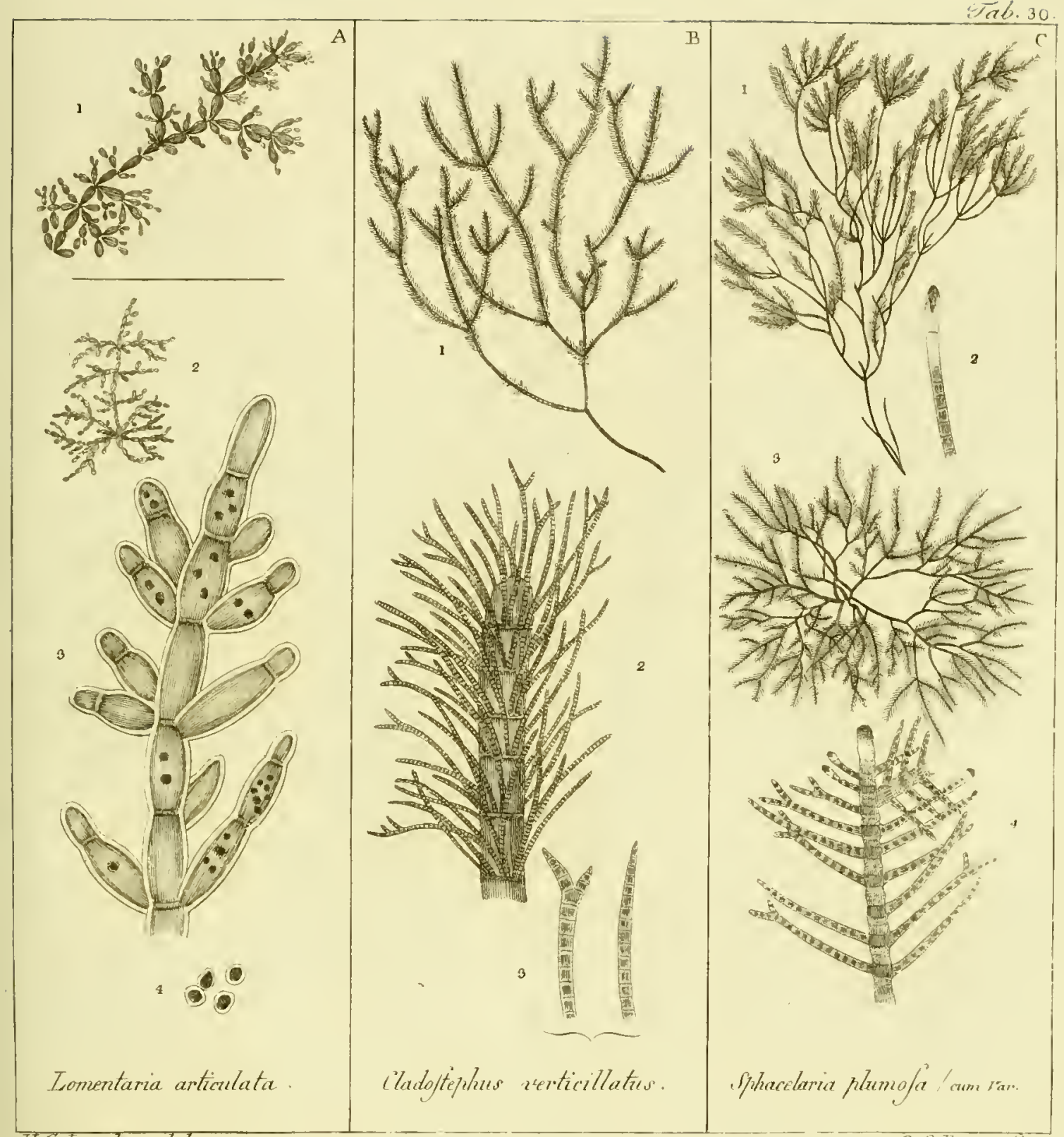





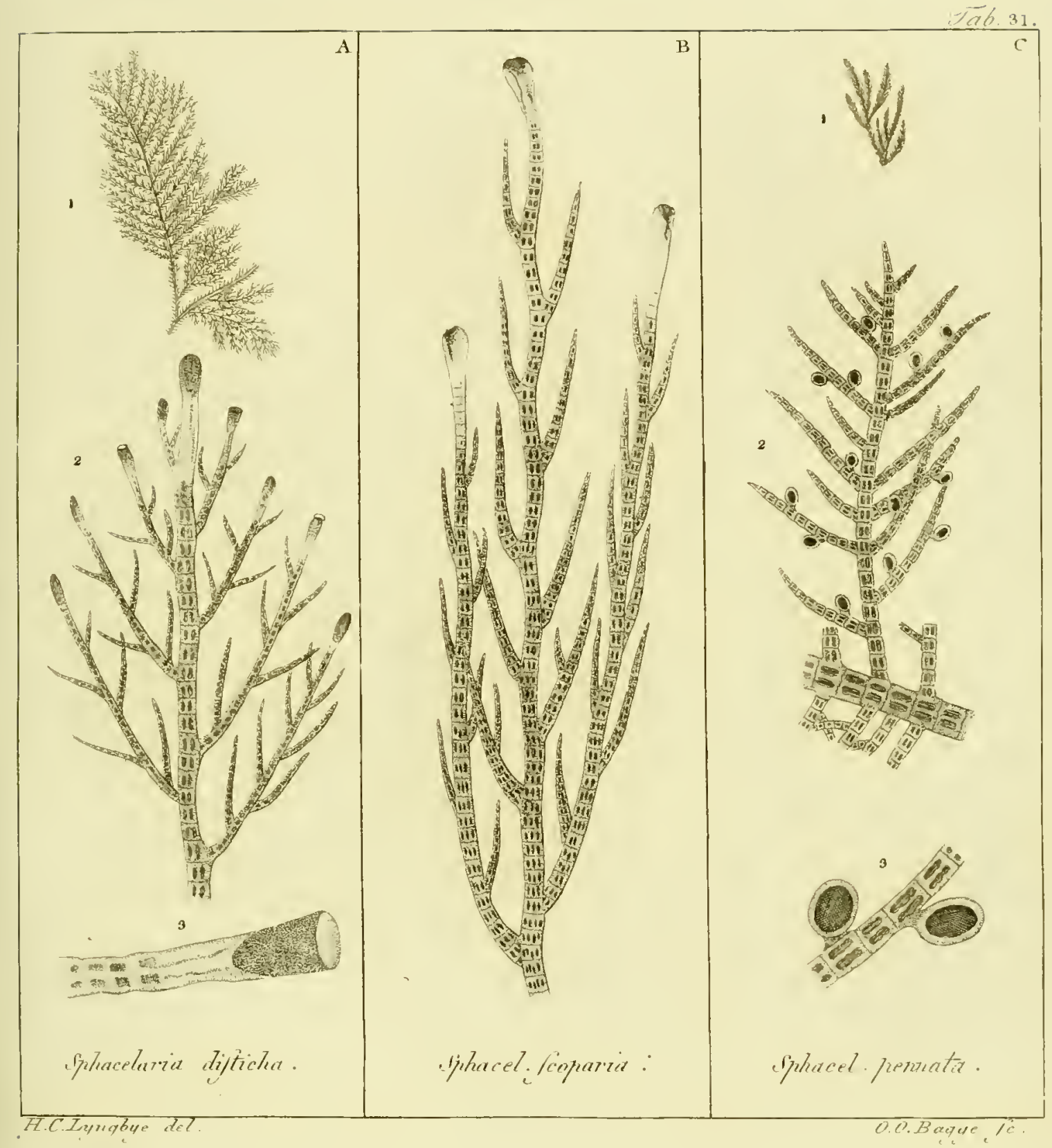





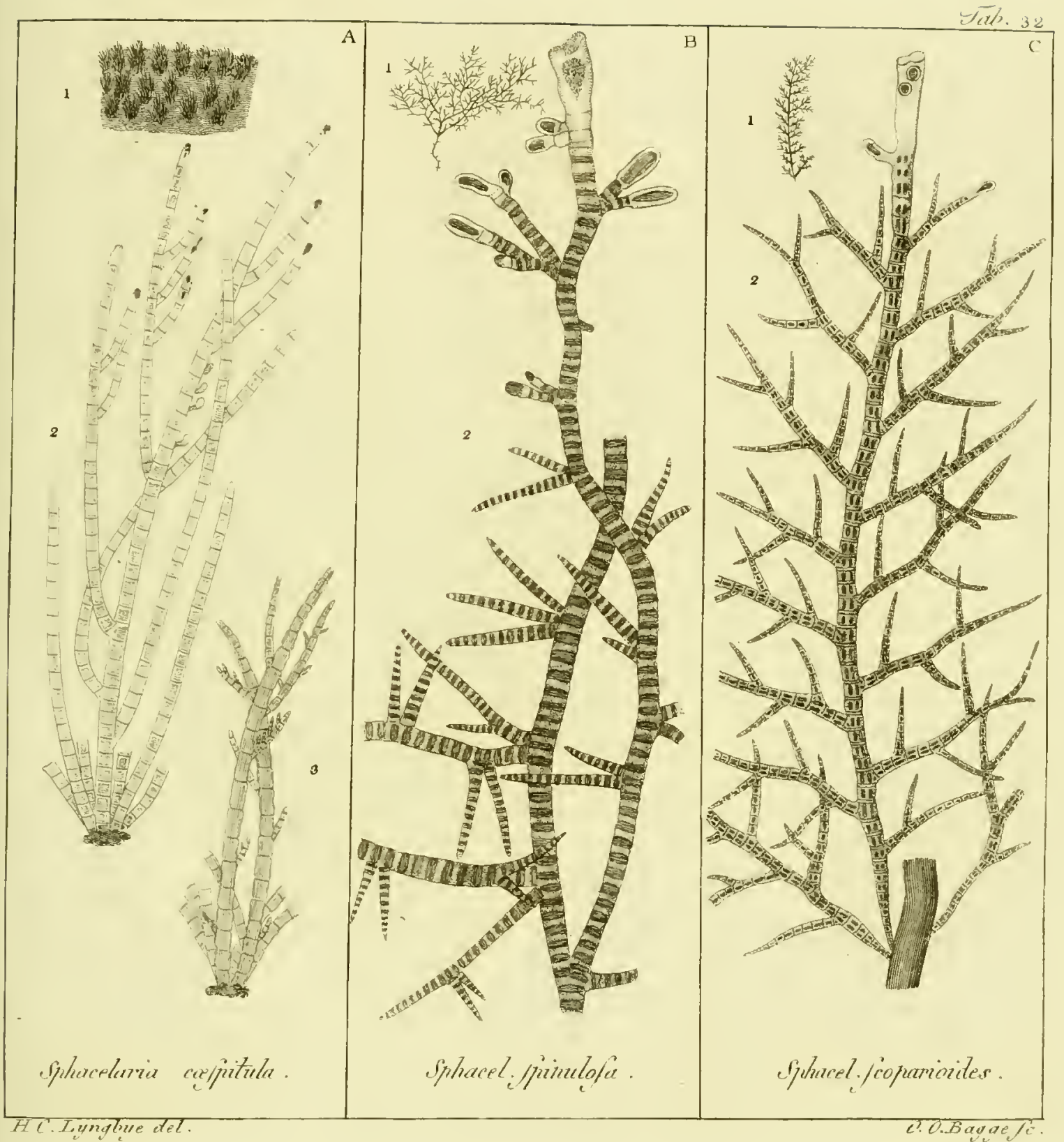





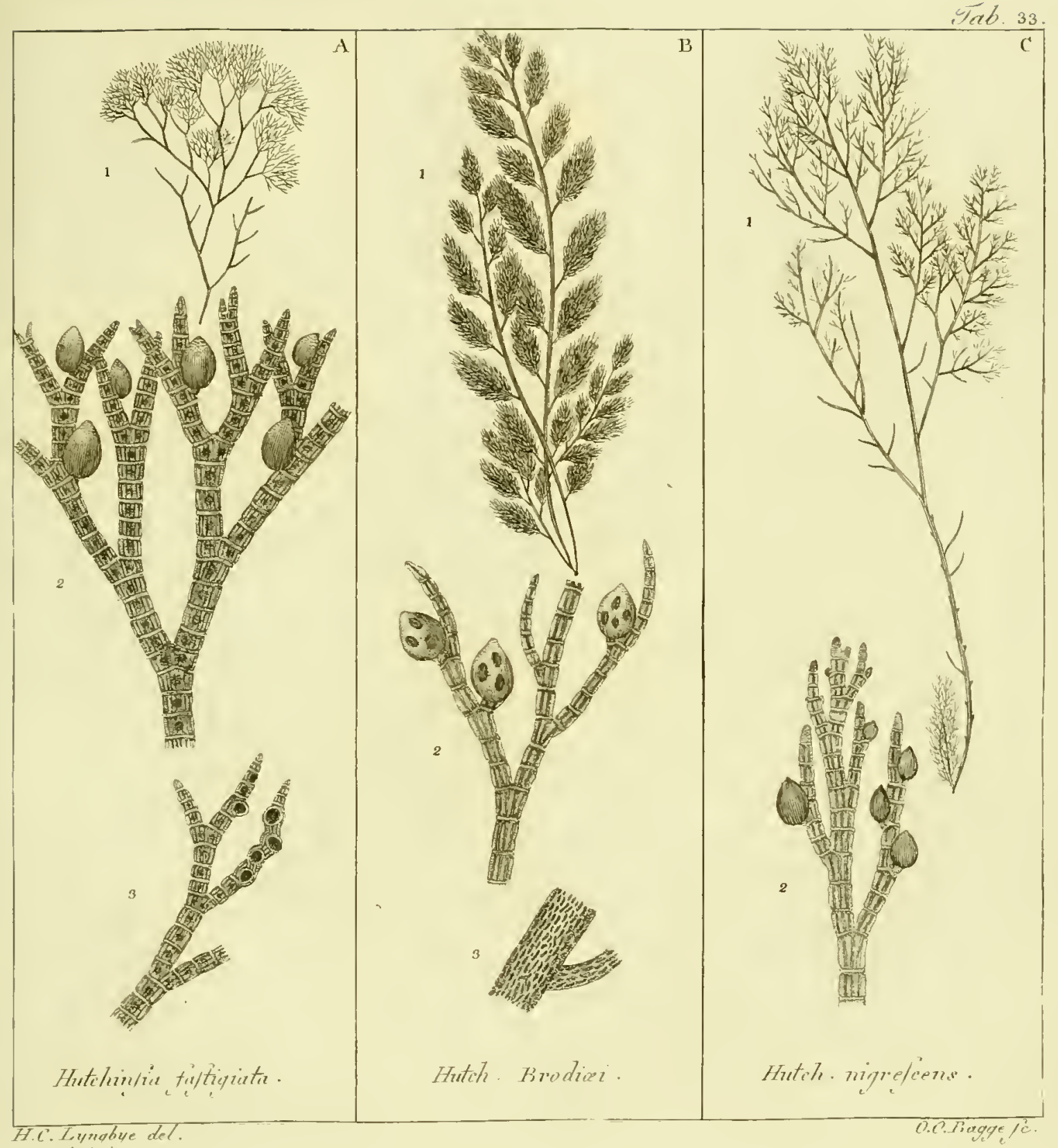


T.11. 34

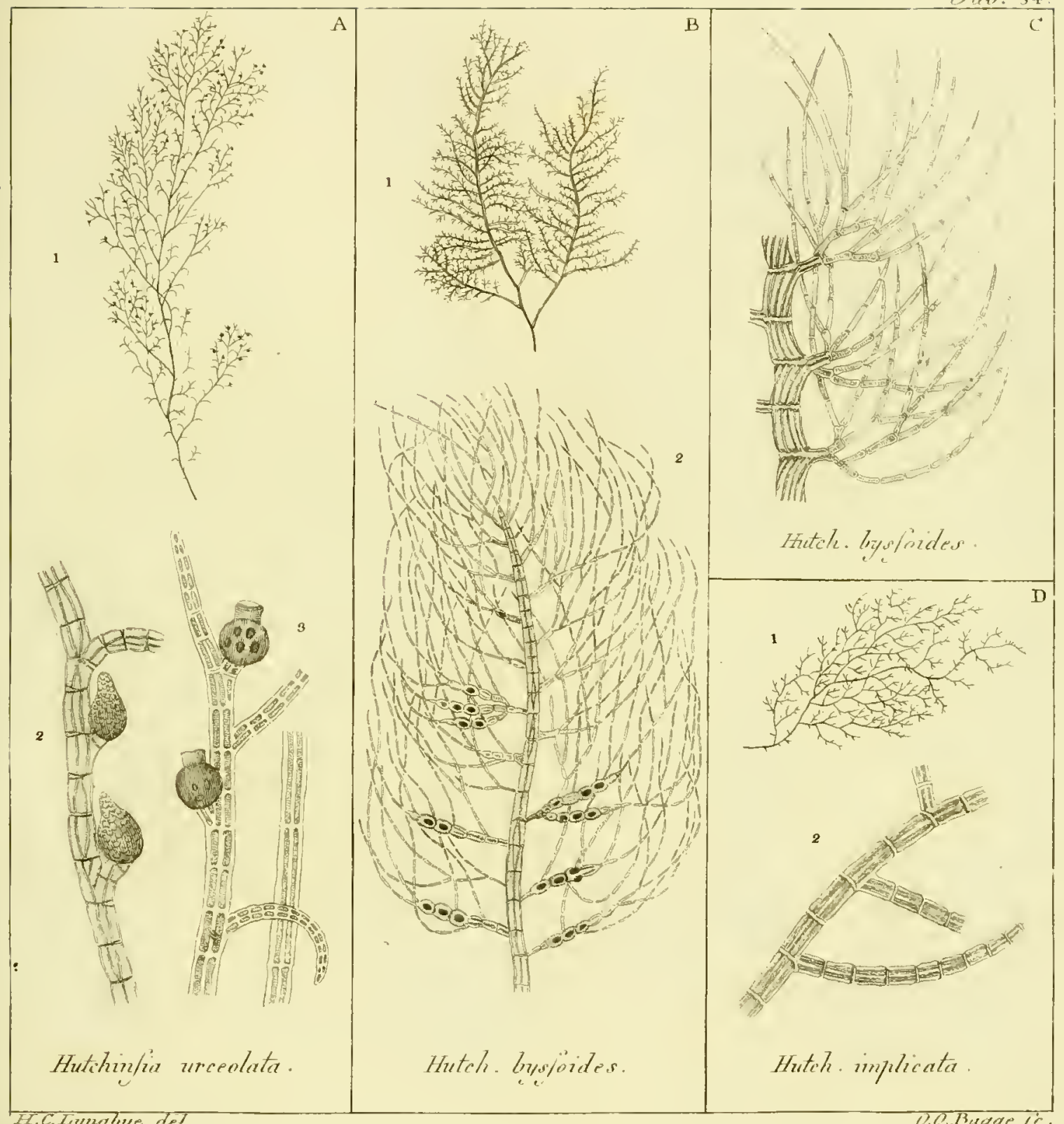


Ted. 35

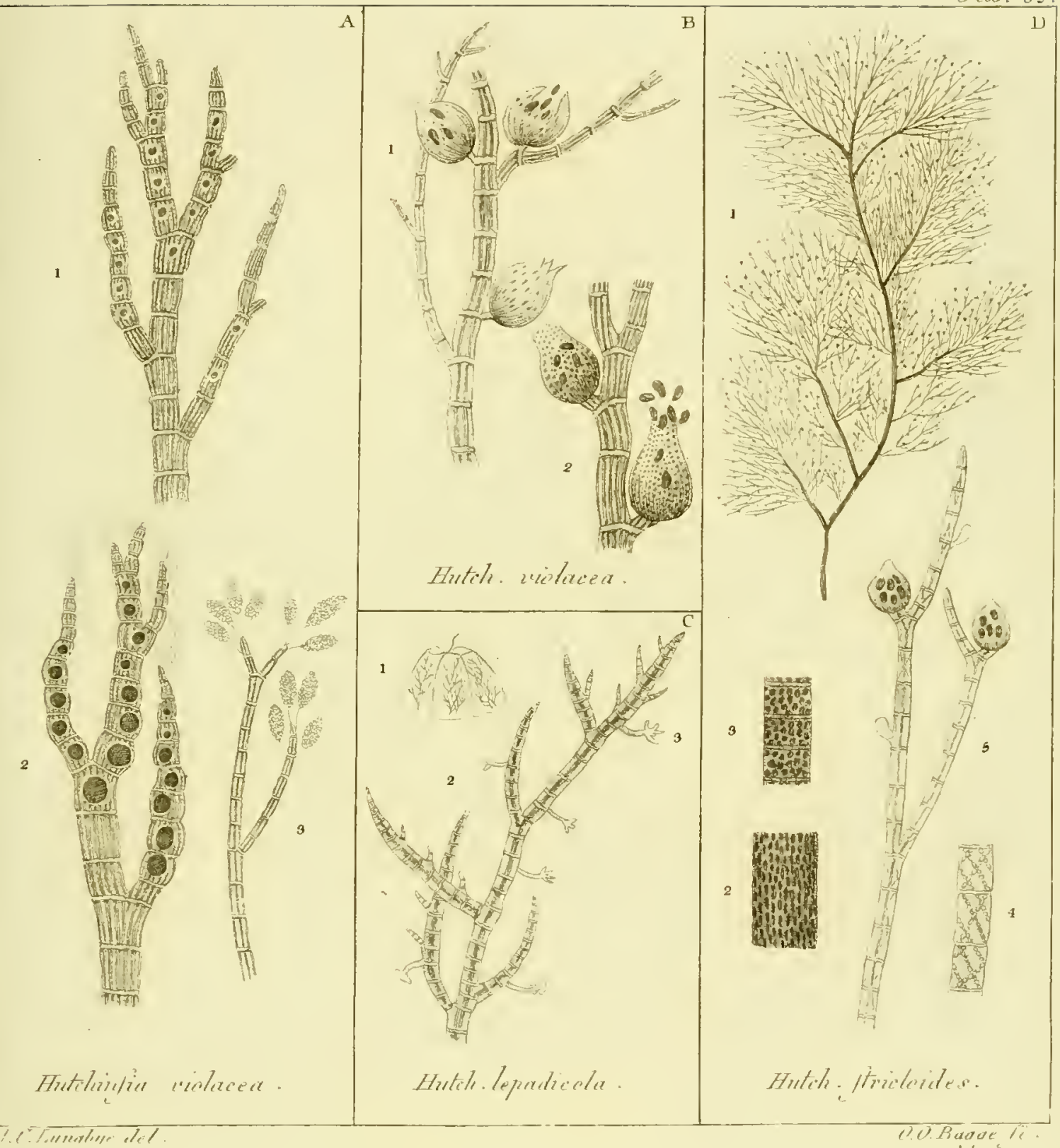





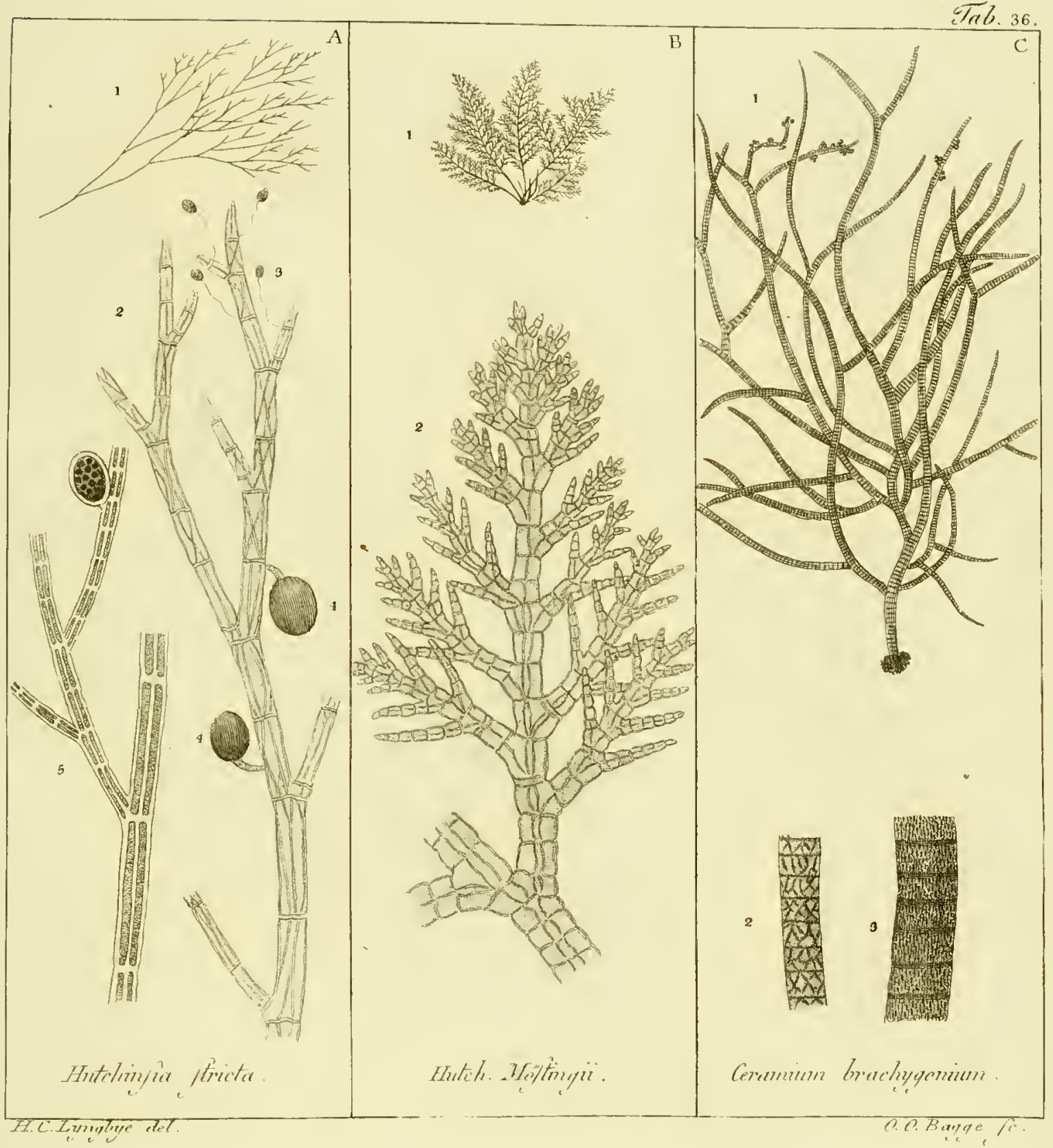





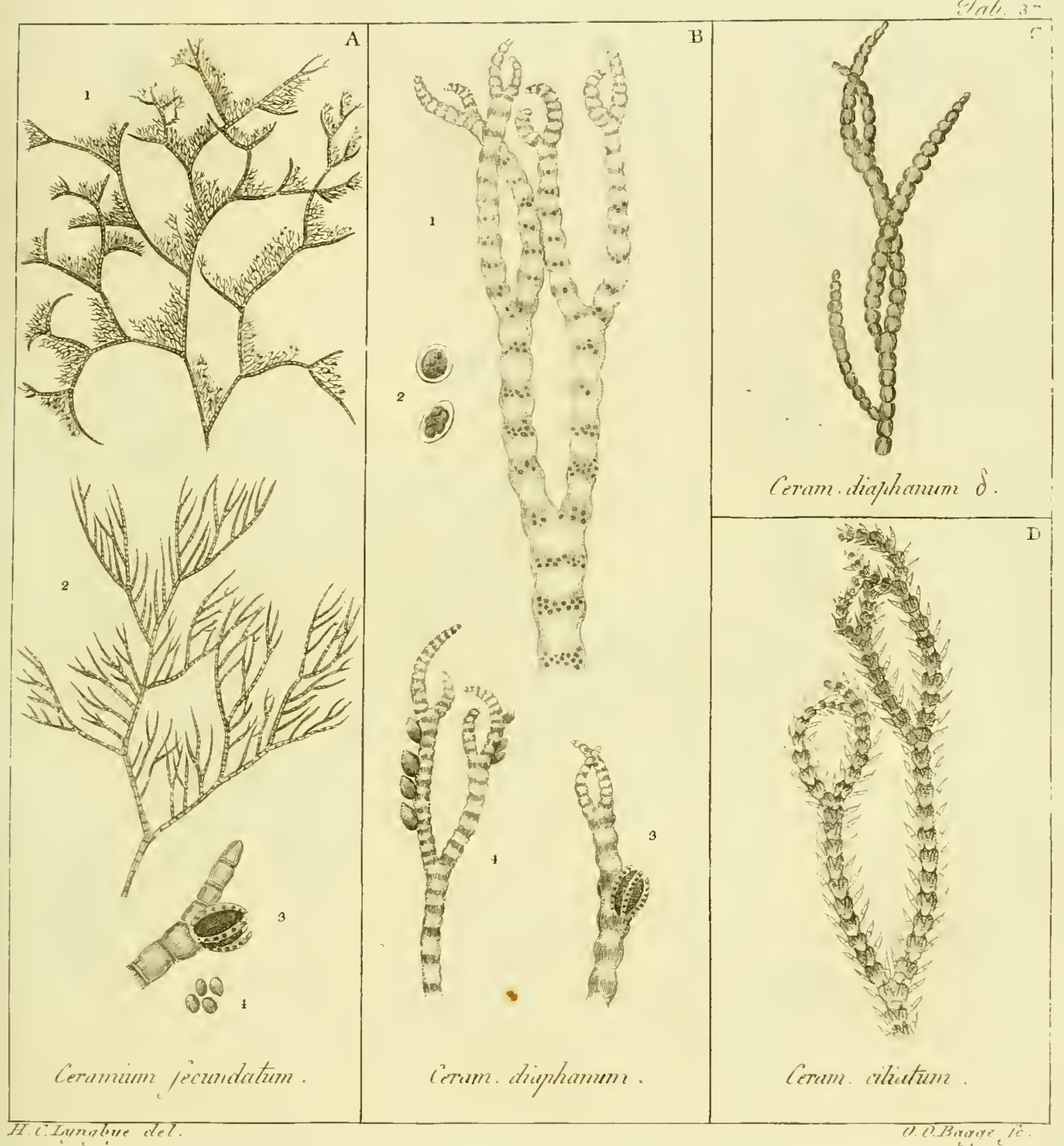


Fale 38

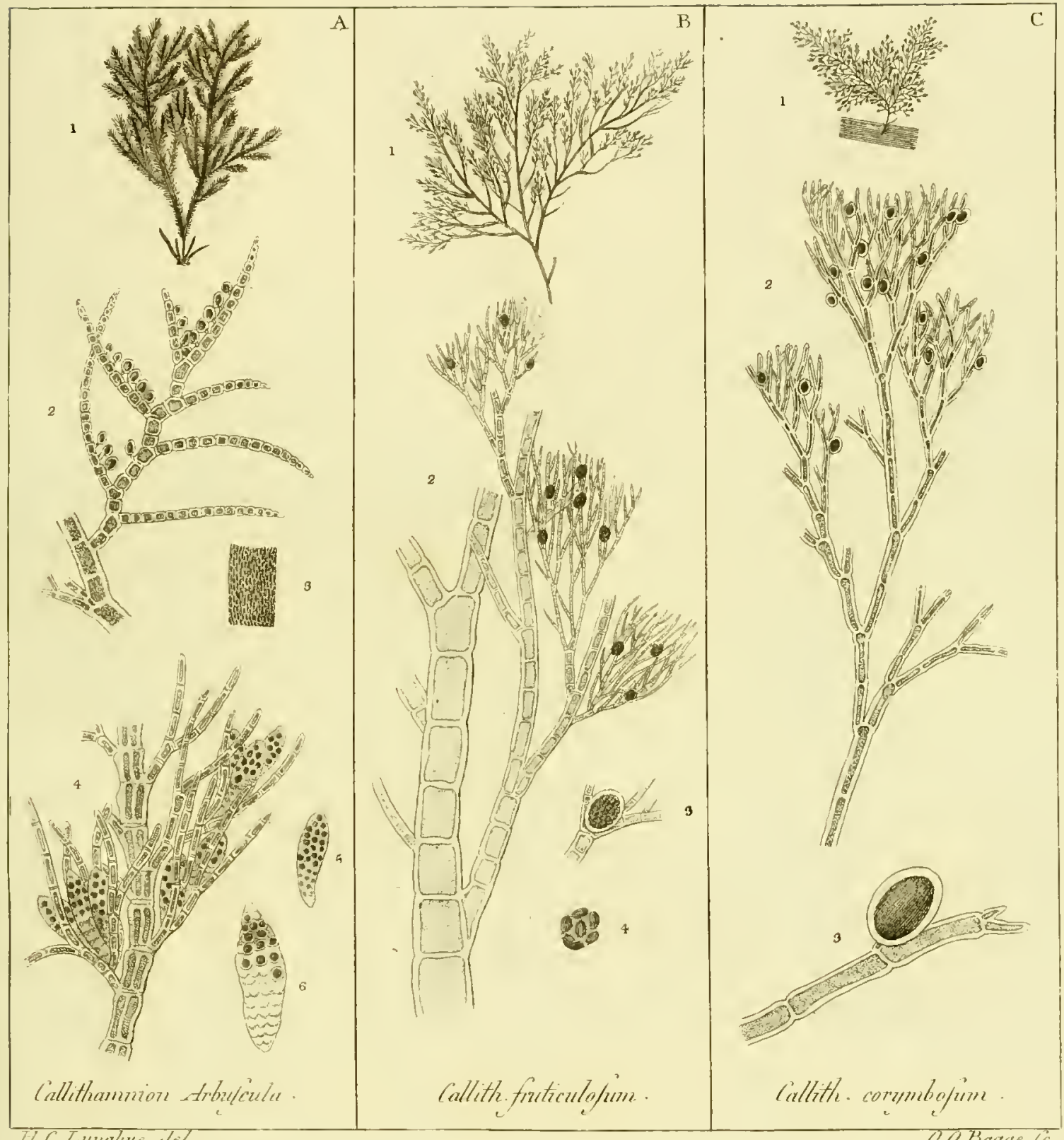





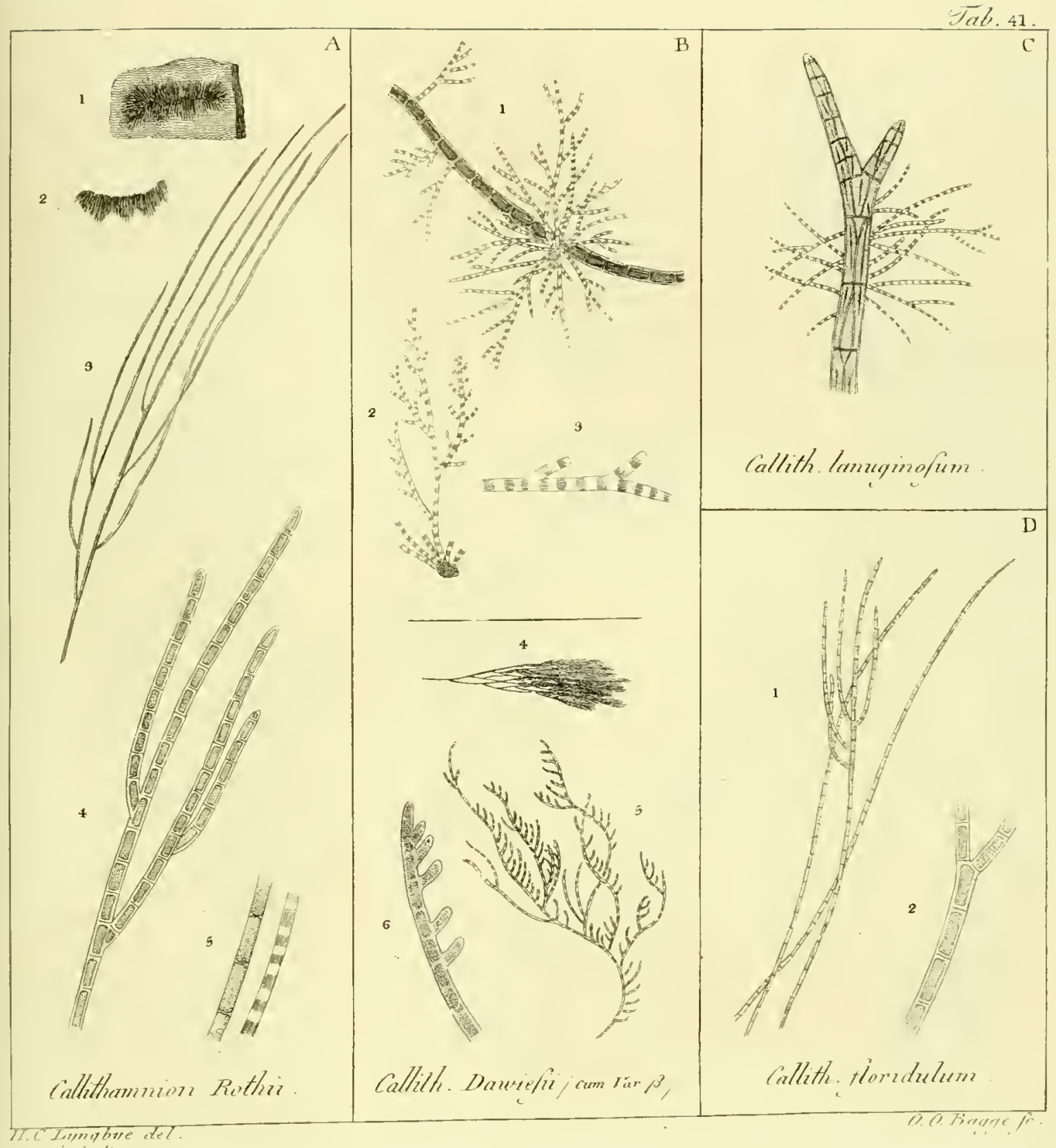


- 
cint. 42

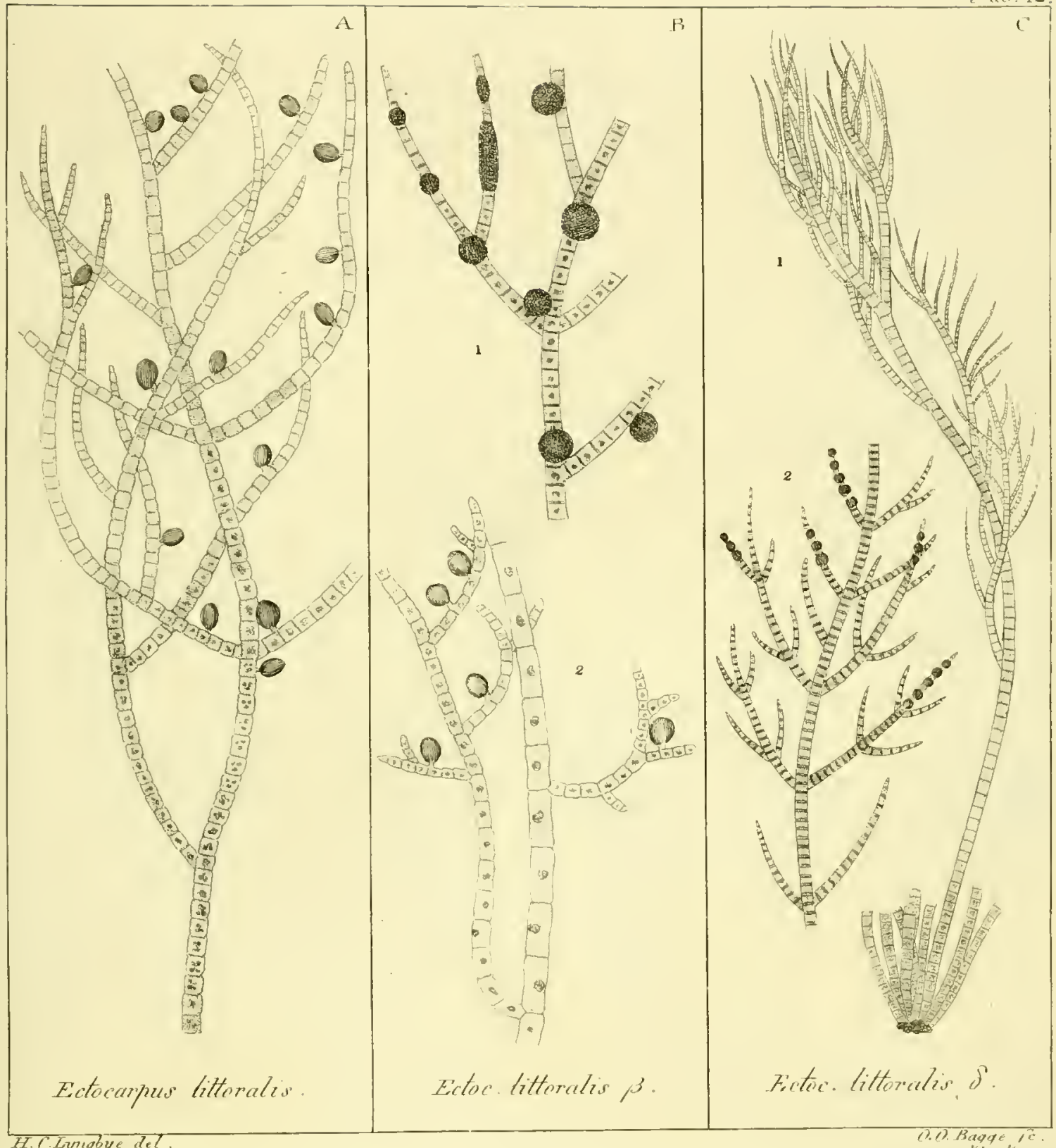



Tab. 43

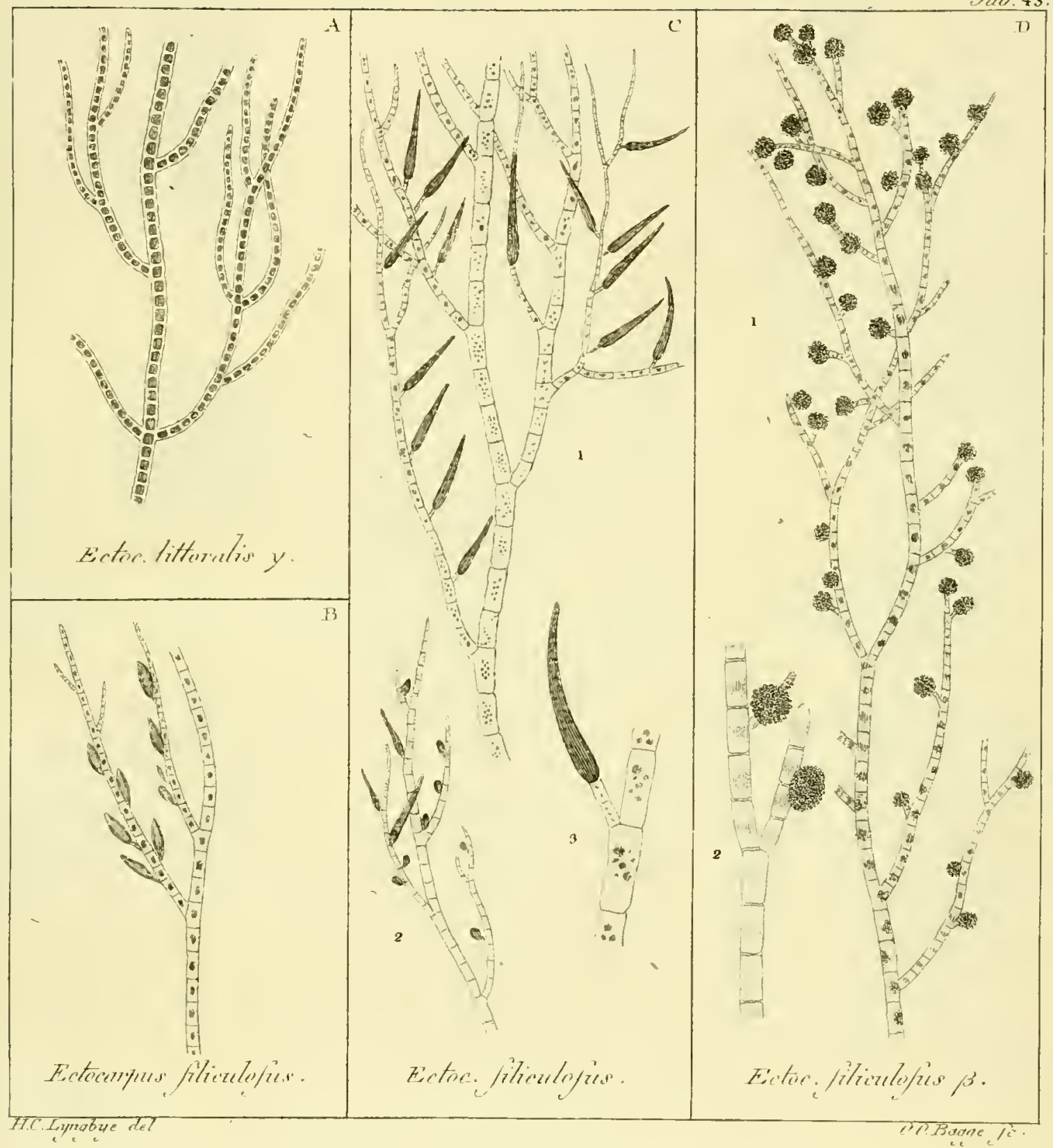



Tal. 44
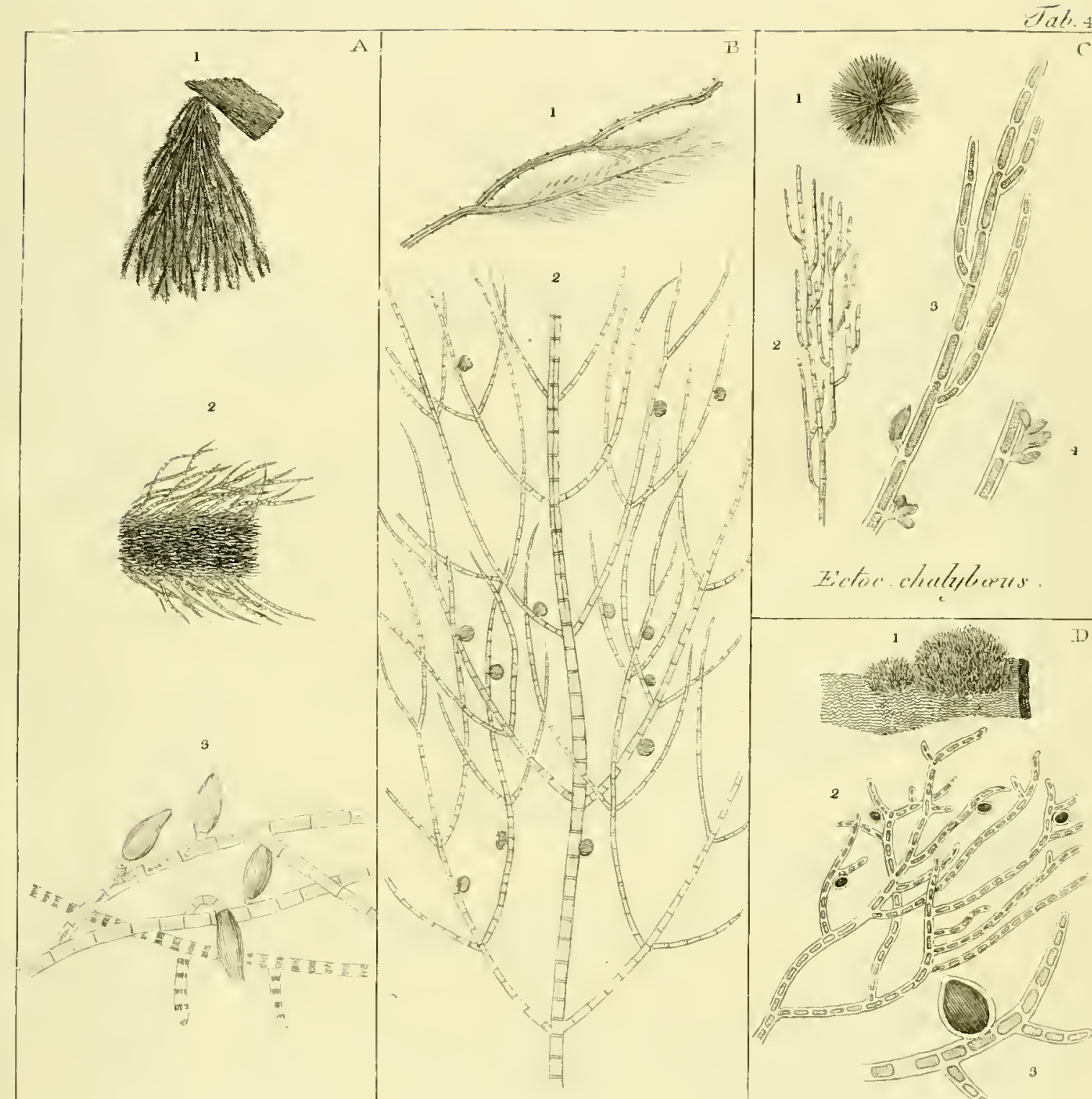

Eietoe chatuluerzy.

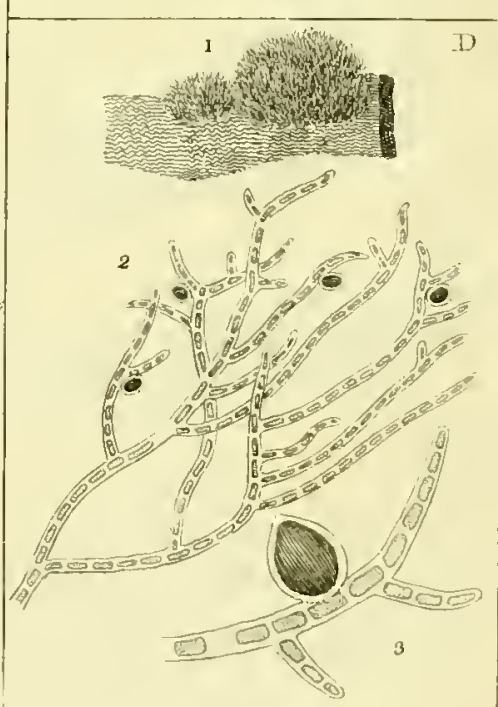

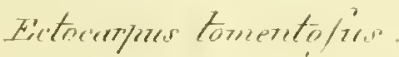

Binter derifrion.

Fintor currean.. 


$$
\text { - }
$$




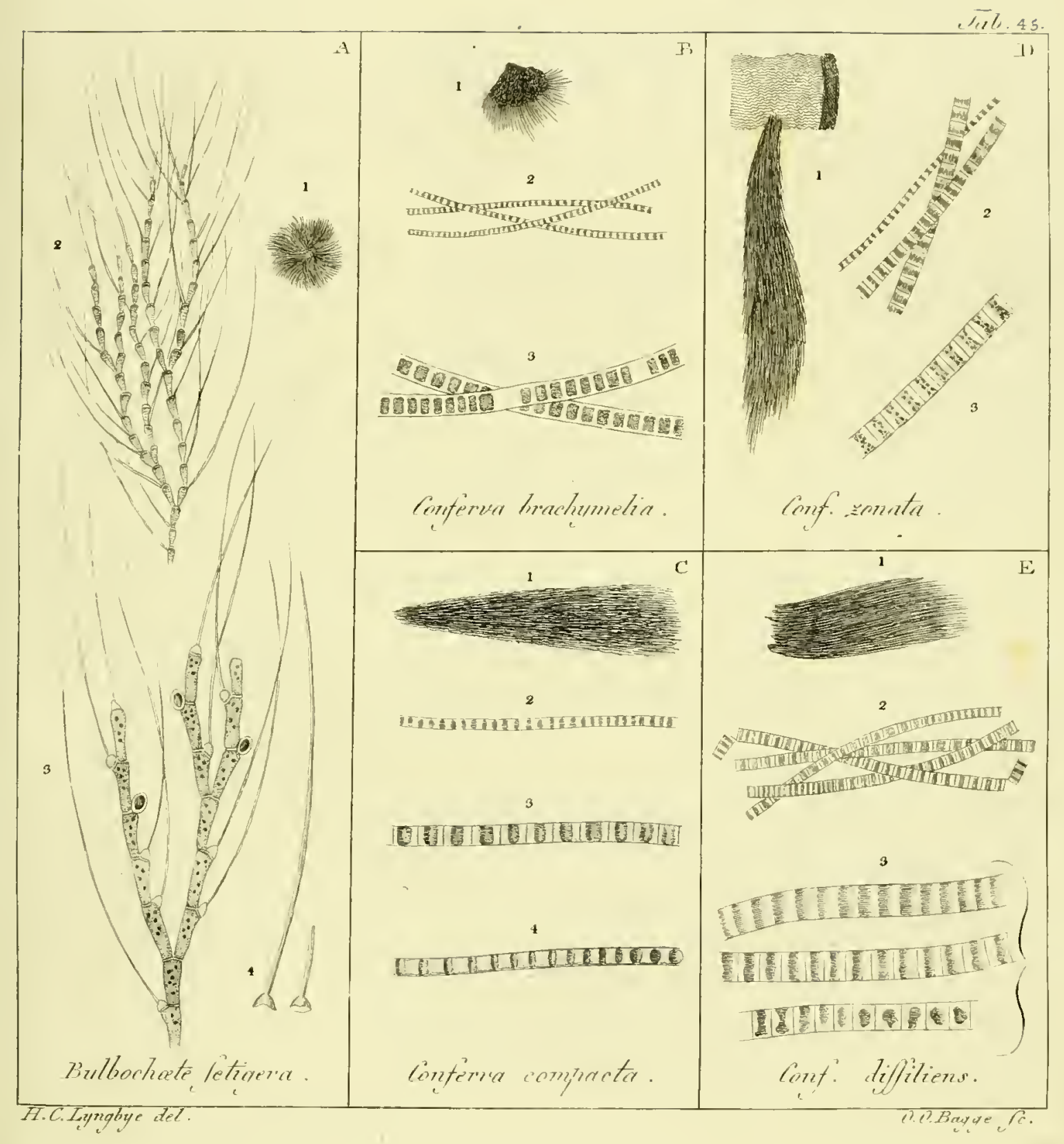




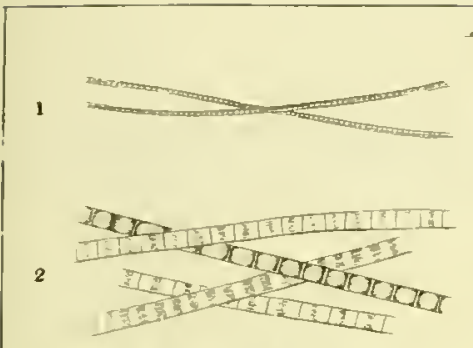

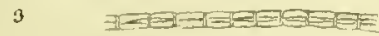

00000000100

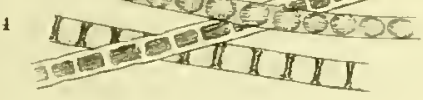

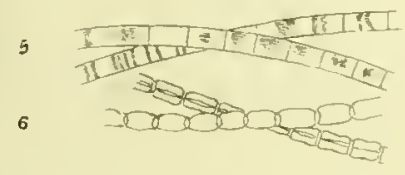

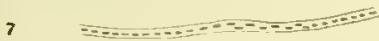

1 360

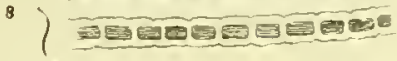

1 jeseserese

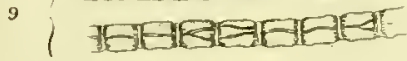

पive

10

$$
\text { 118 }
$$

Conferen, finacishmen.

\section{A}

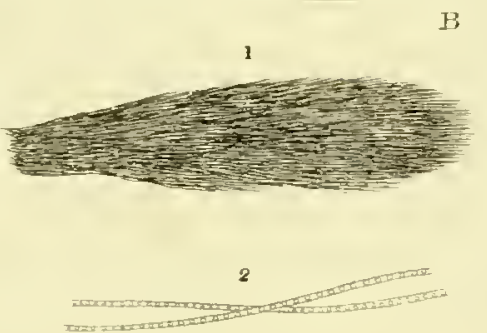

3

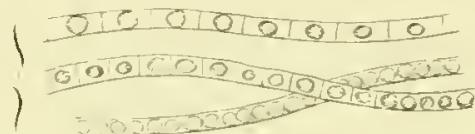

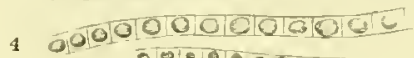
-T0.0.0.

imef ifleceolie

C

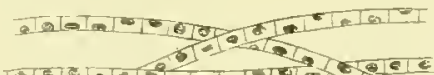

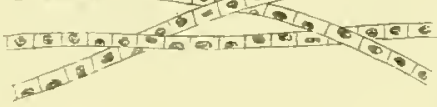

2

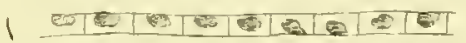

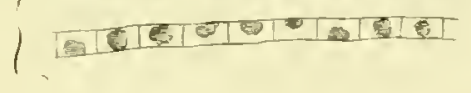

Cont. puenctetis.

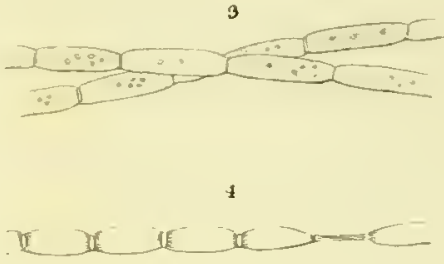

Teals.46

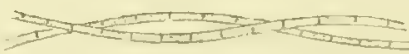

2
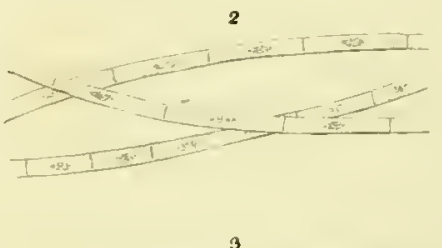

5

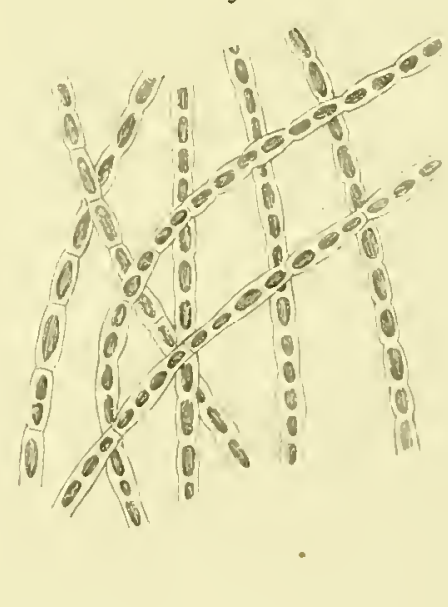

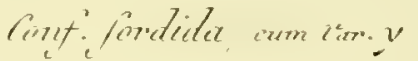




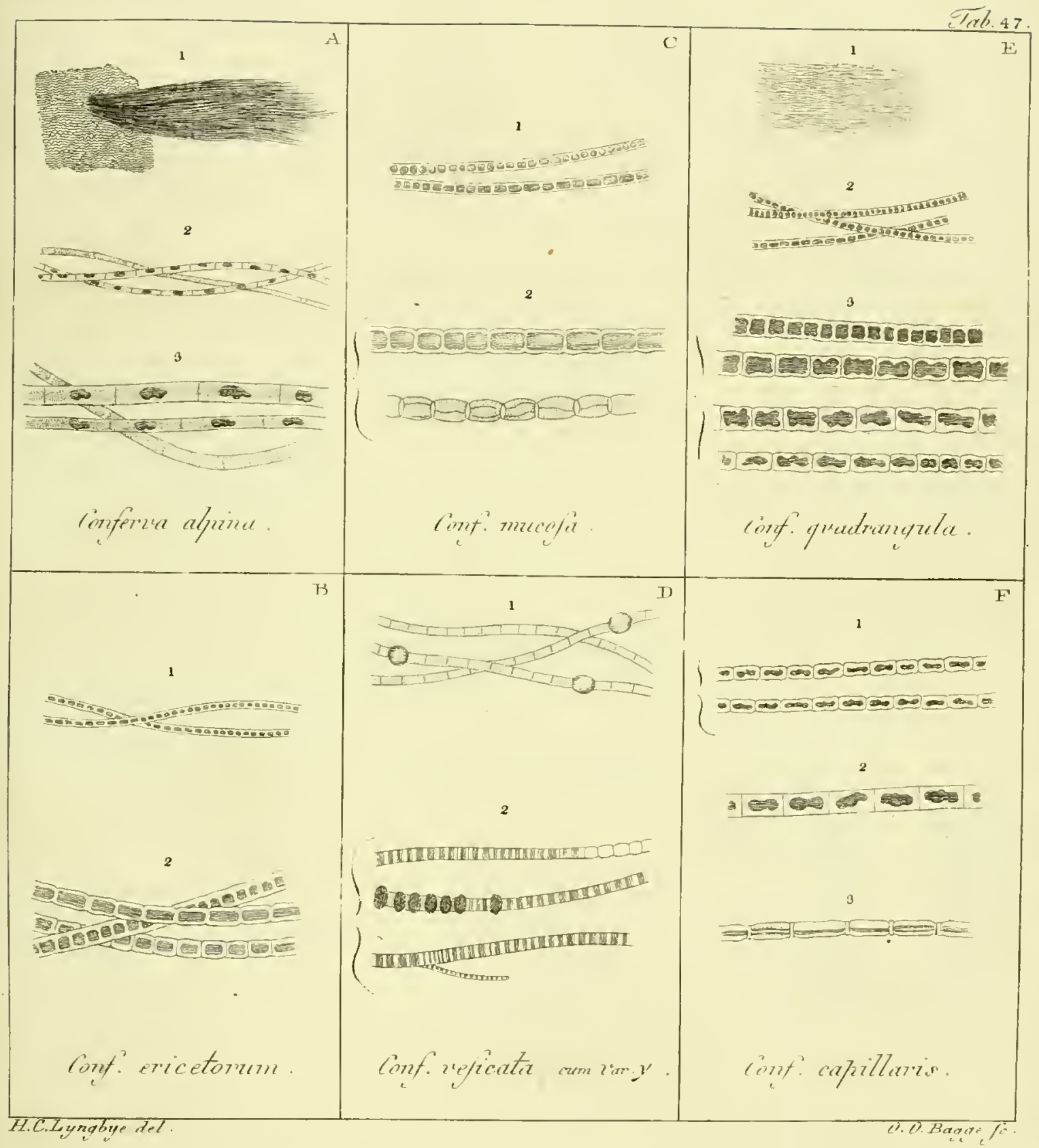




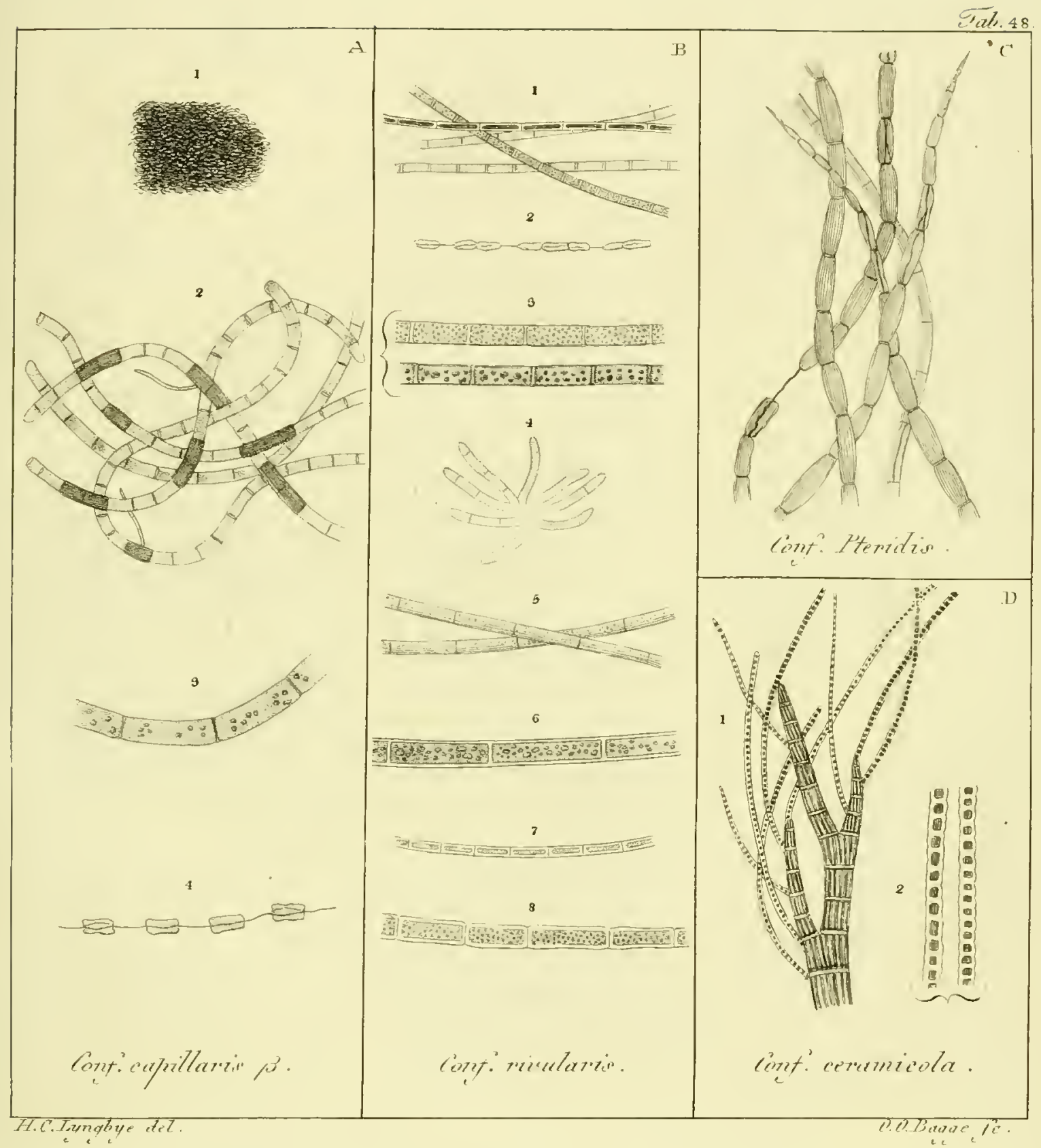




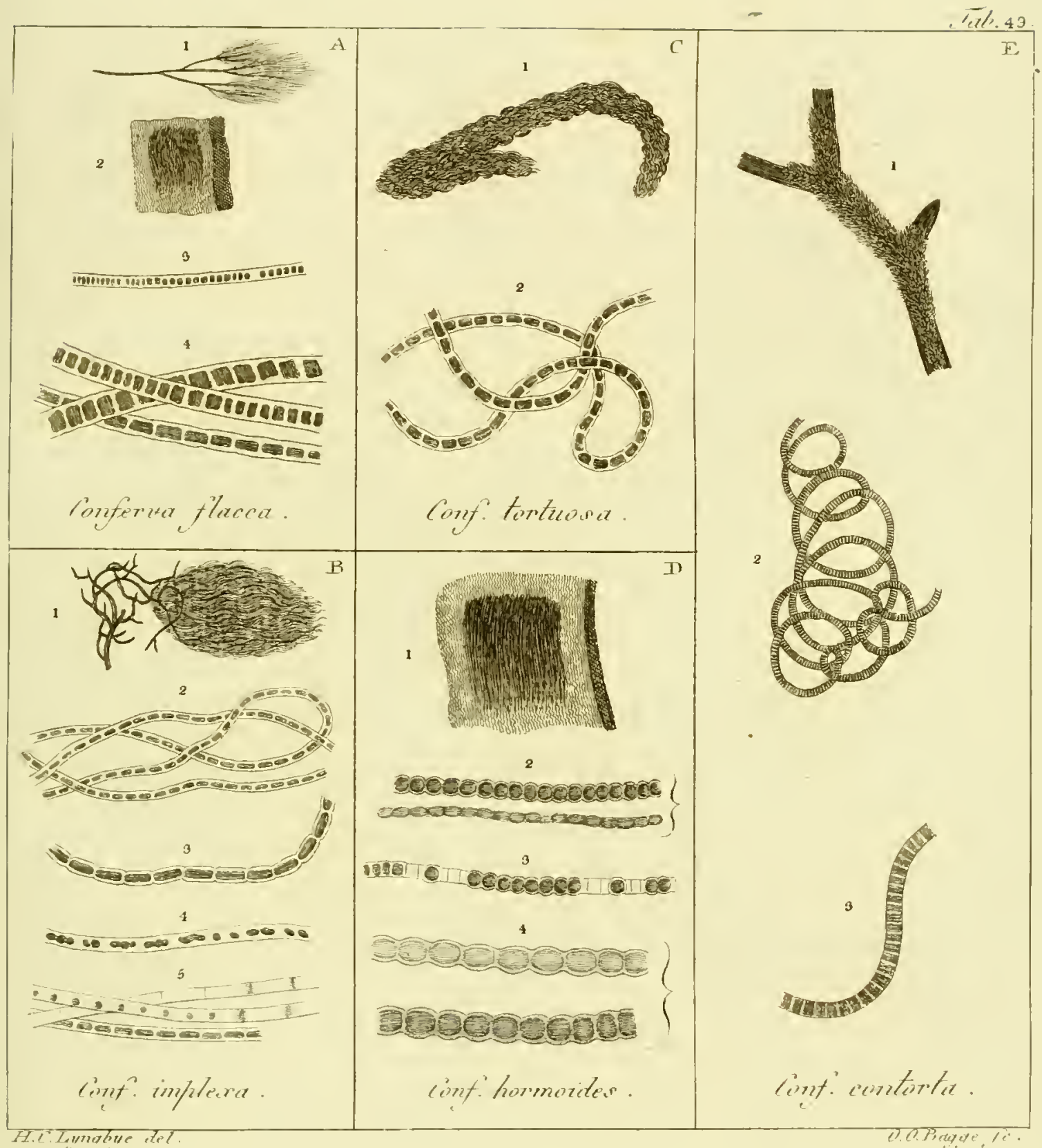



lecí. 50

1
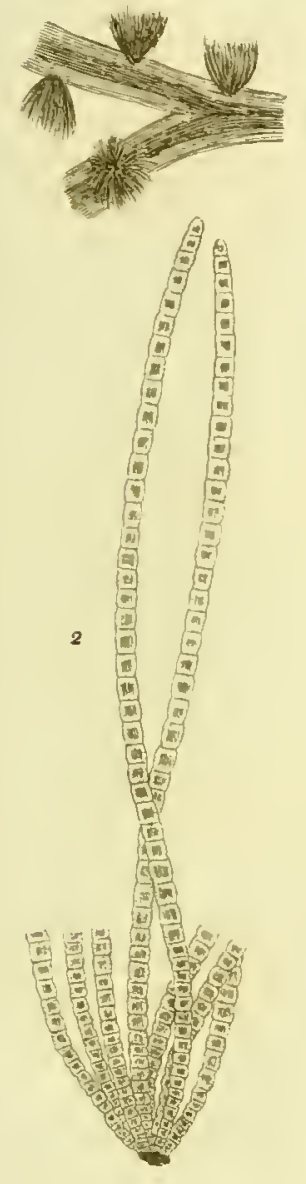

3

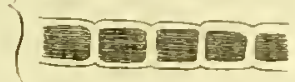

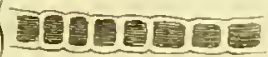

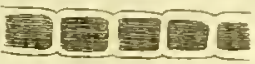

Confermy flaccidix

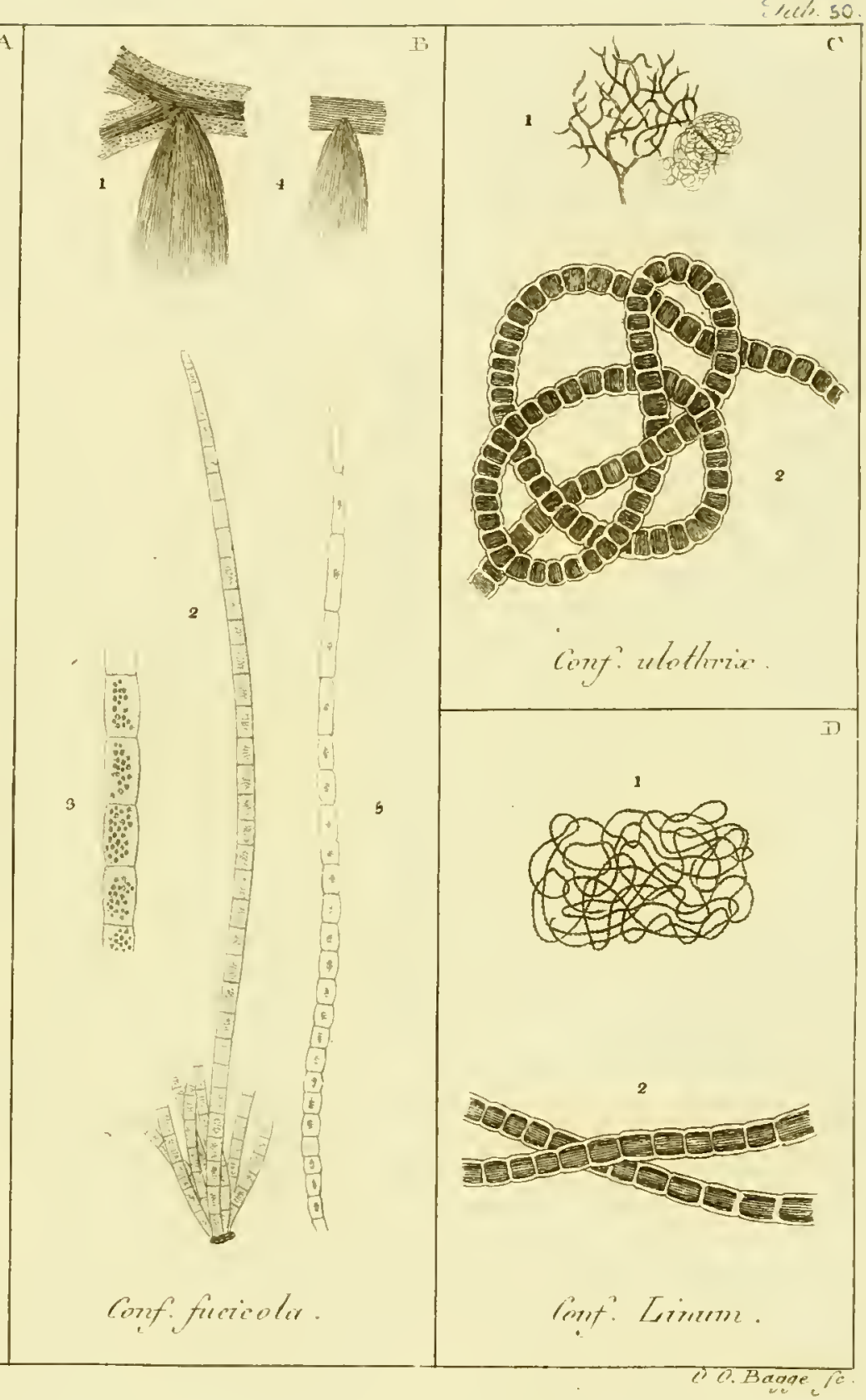





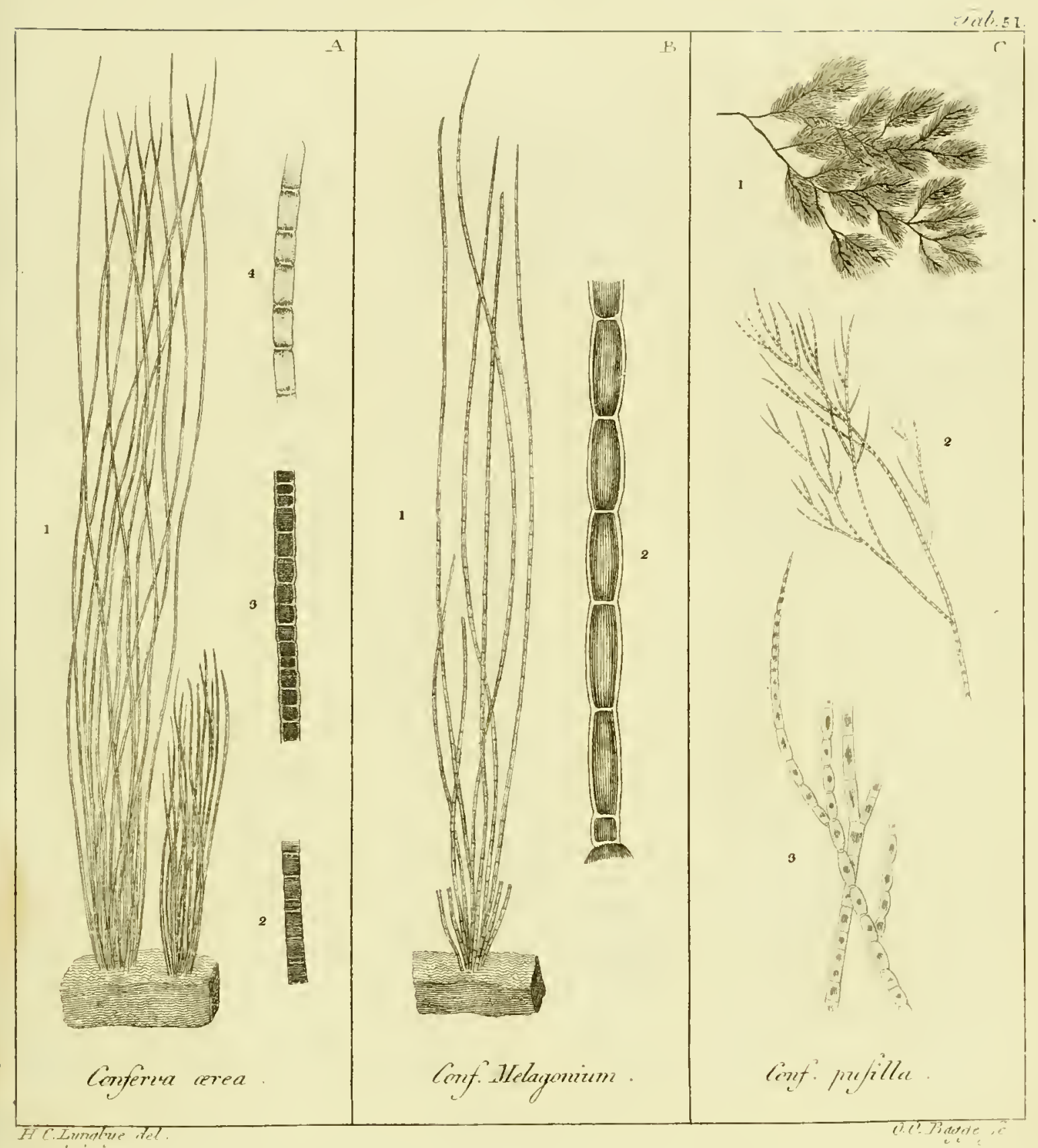





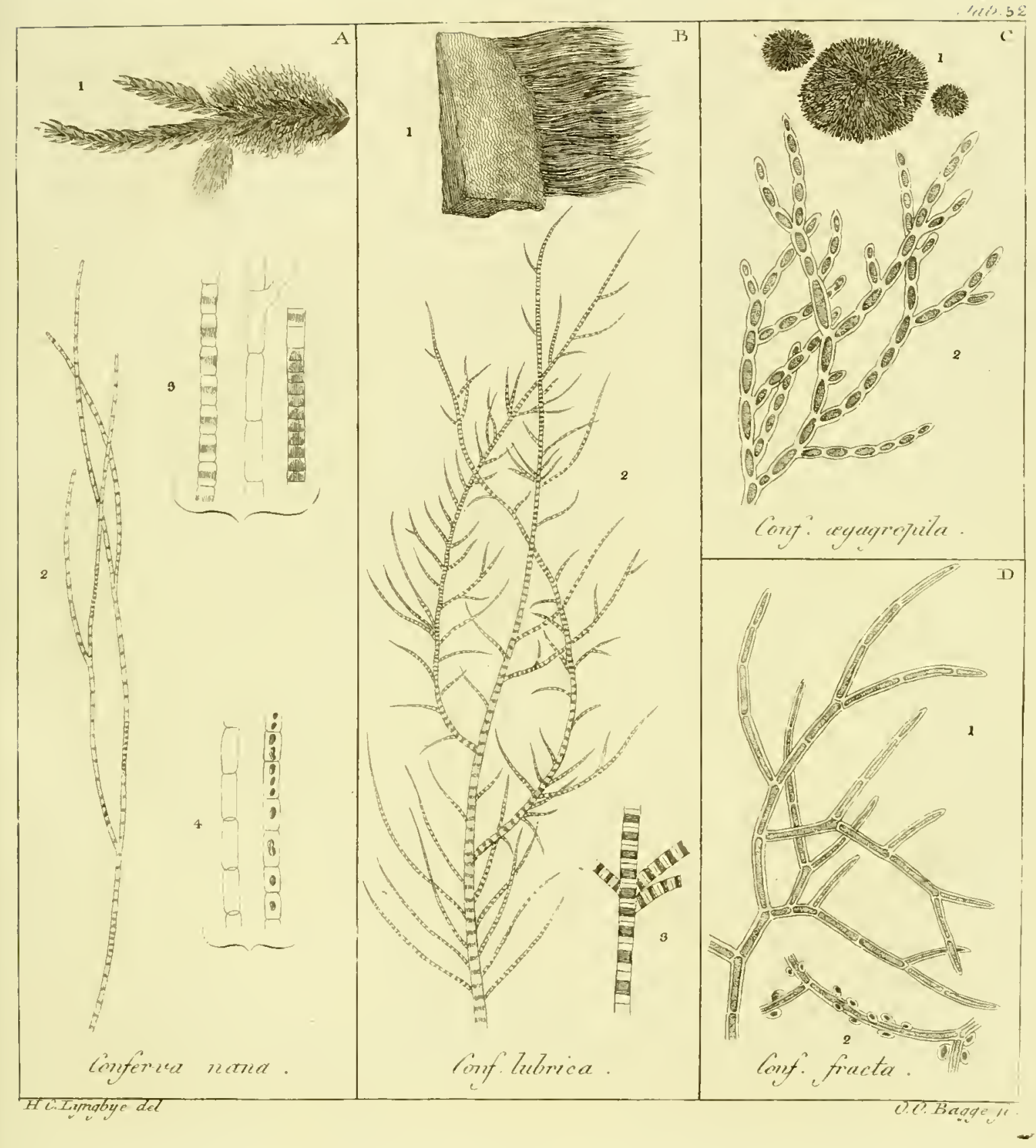



बत्यl. 53

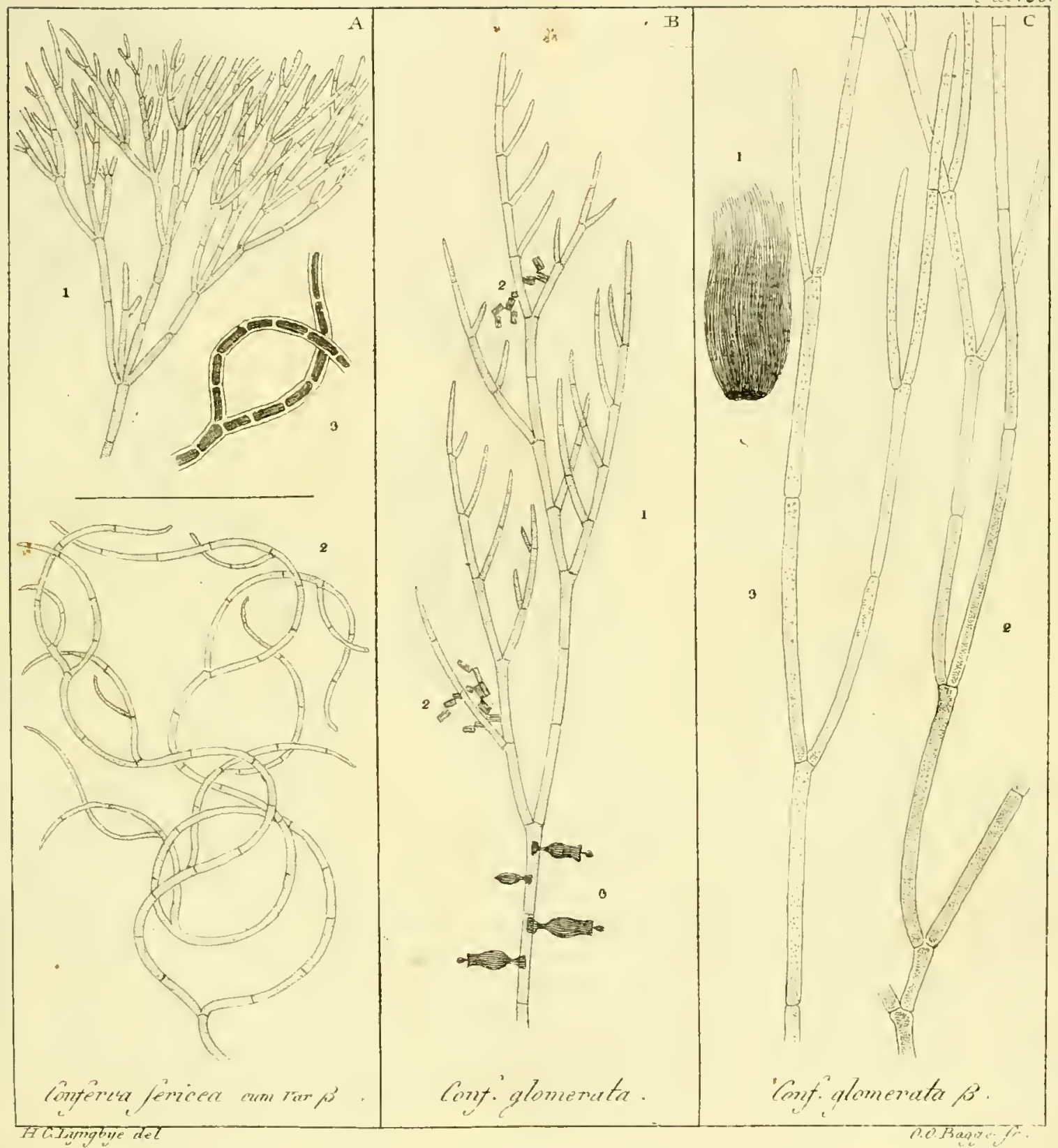


$\checkmark$ 
Tat. 54

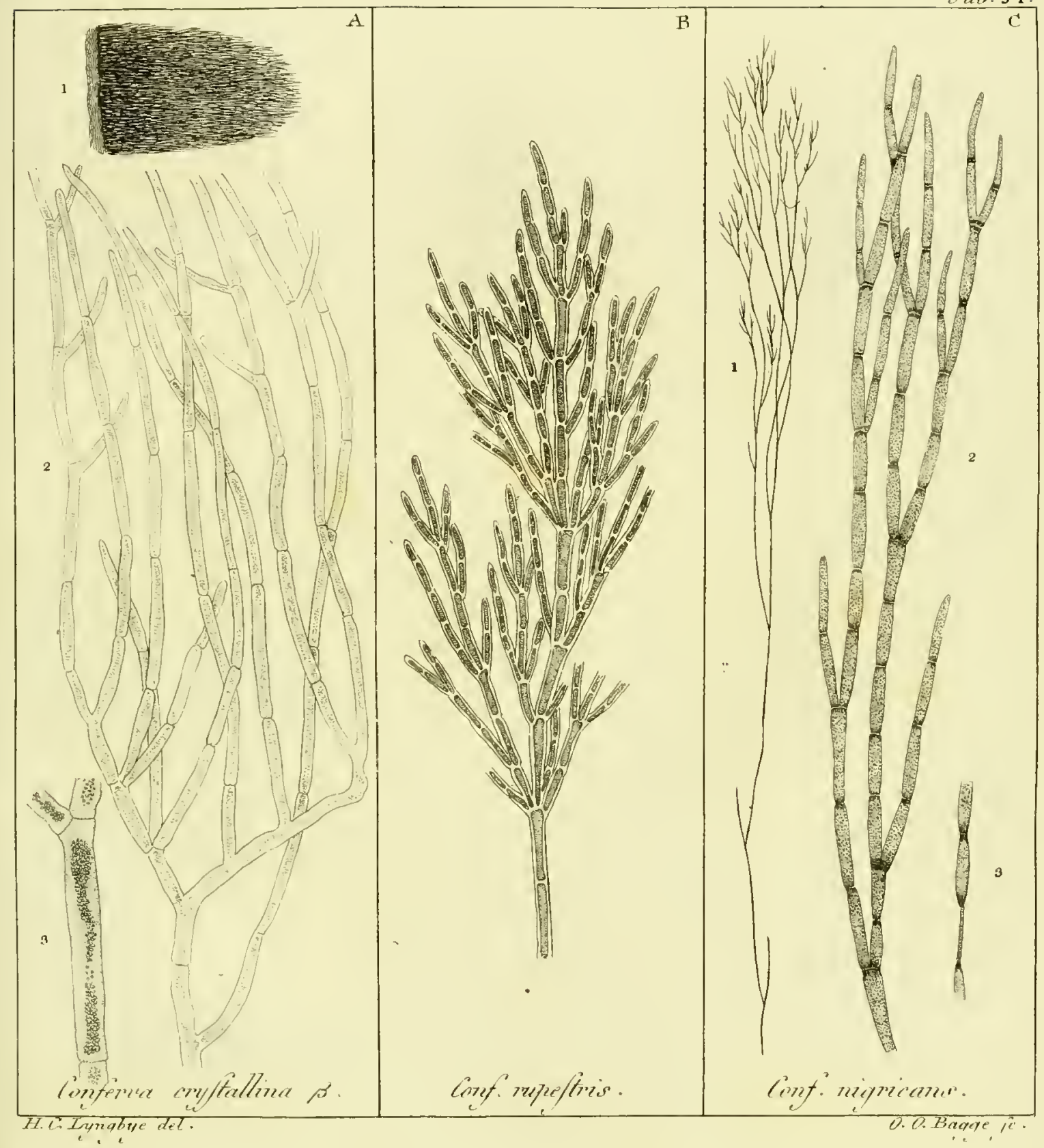



ate. 55.

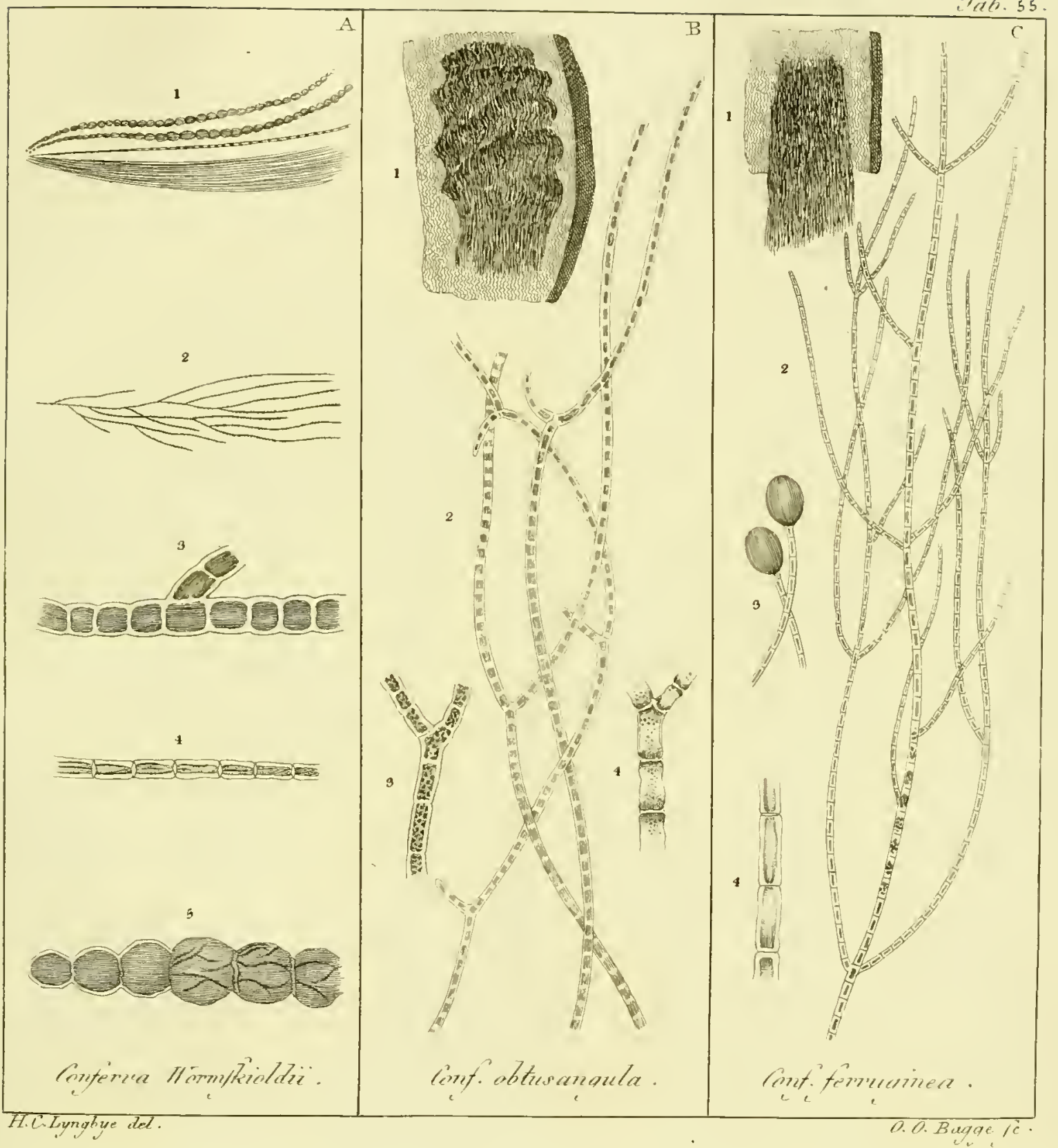



Tab. 56.

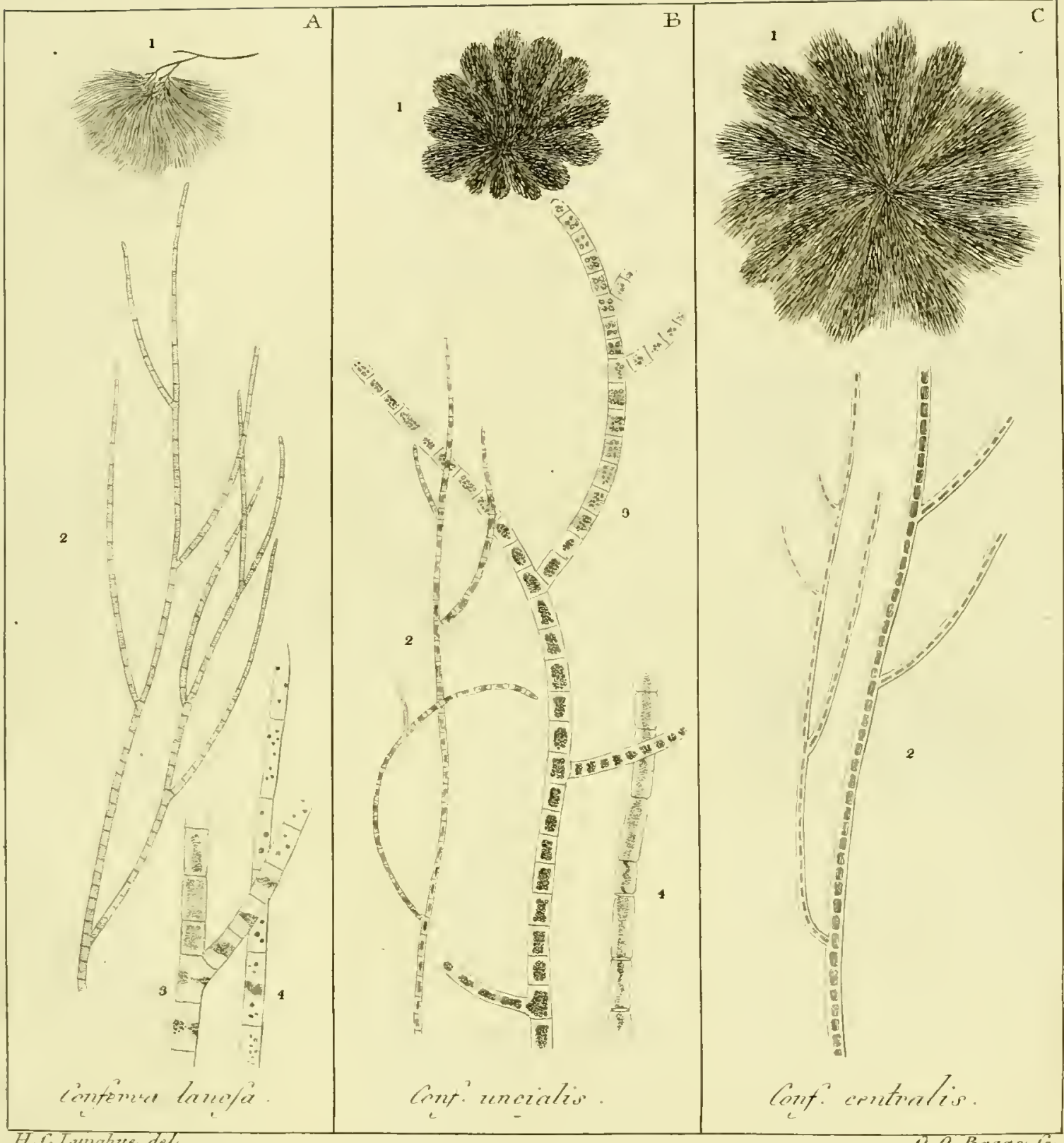

H.C. Lumabue dex. 

Tab. 57

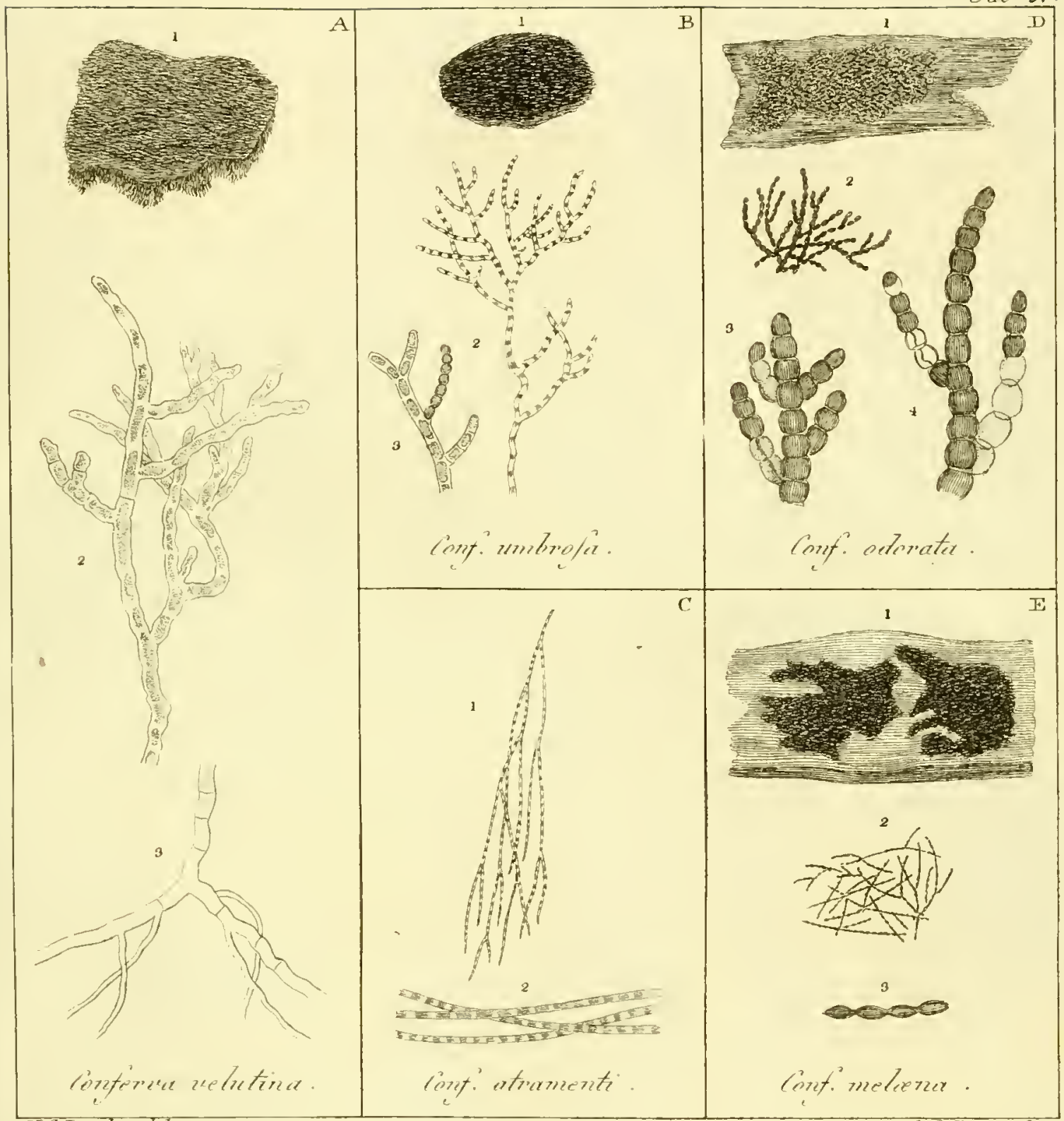

H.C.Iynsbye del. 
$$
\text { . }
$$ 
Tab. 58.

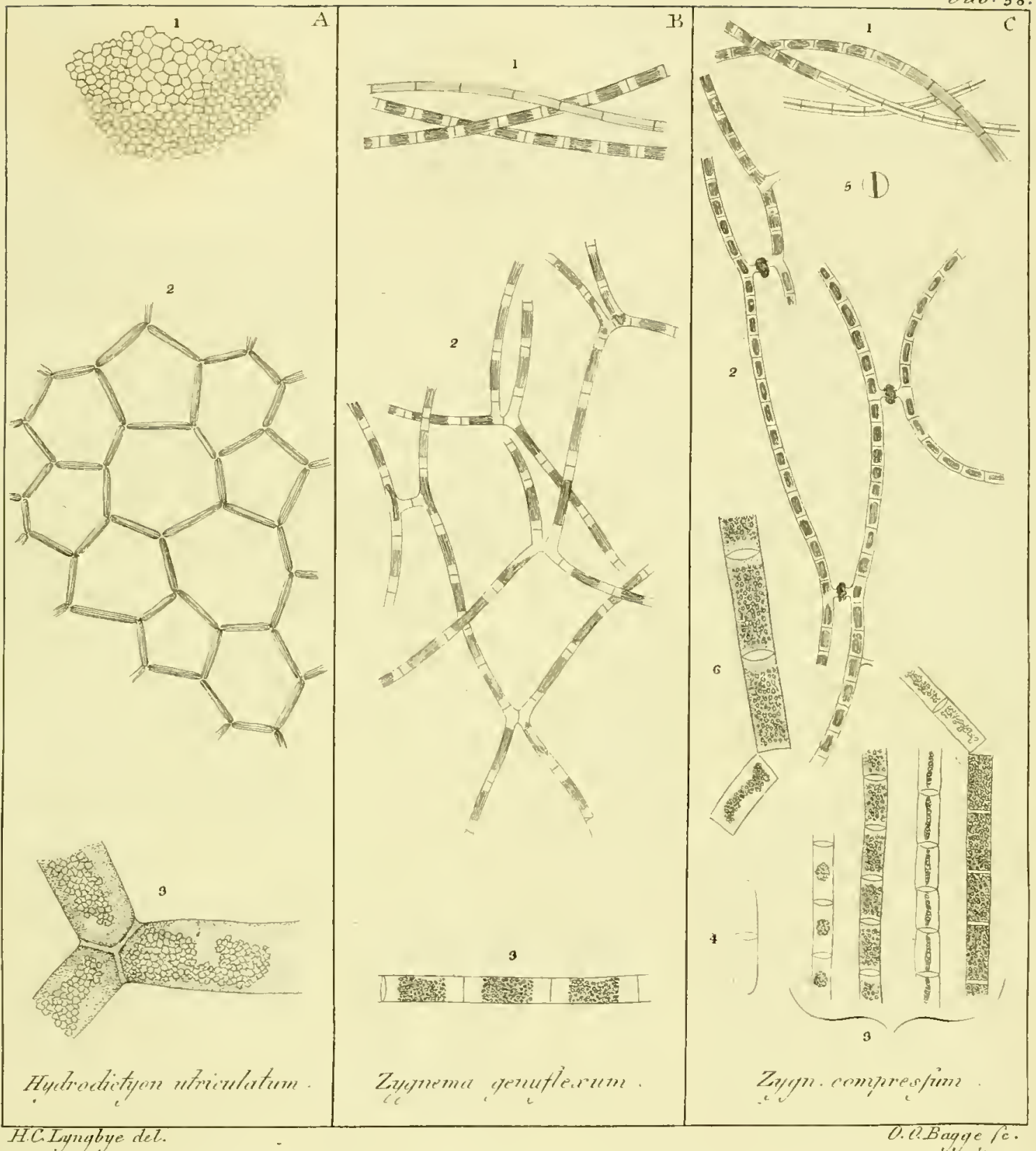



Tab. 59 .

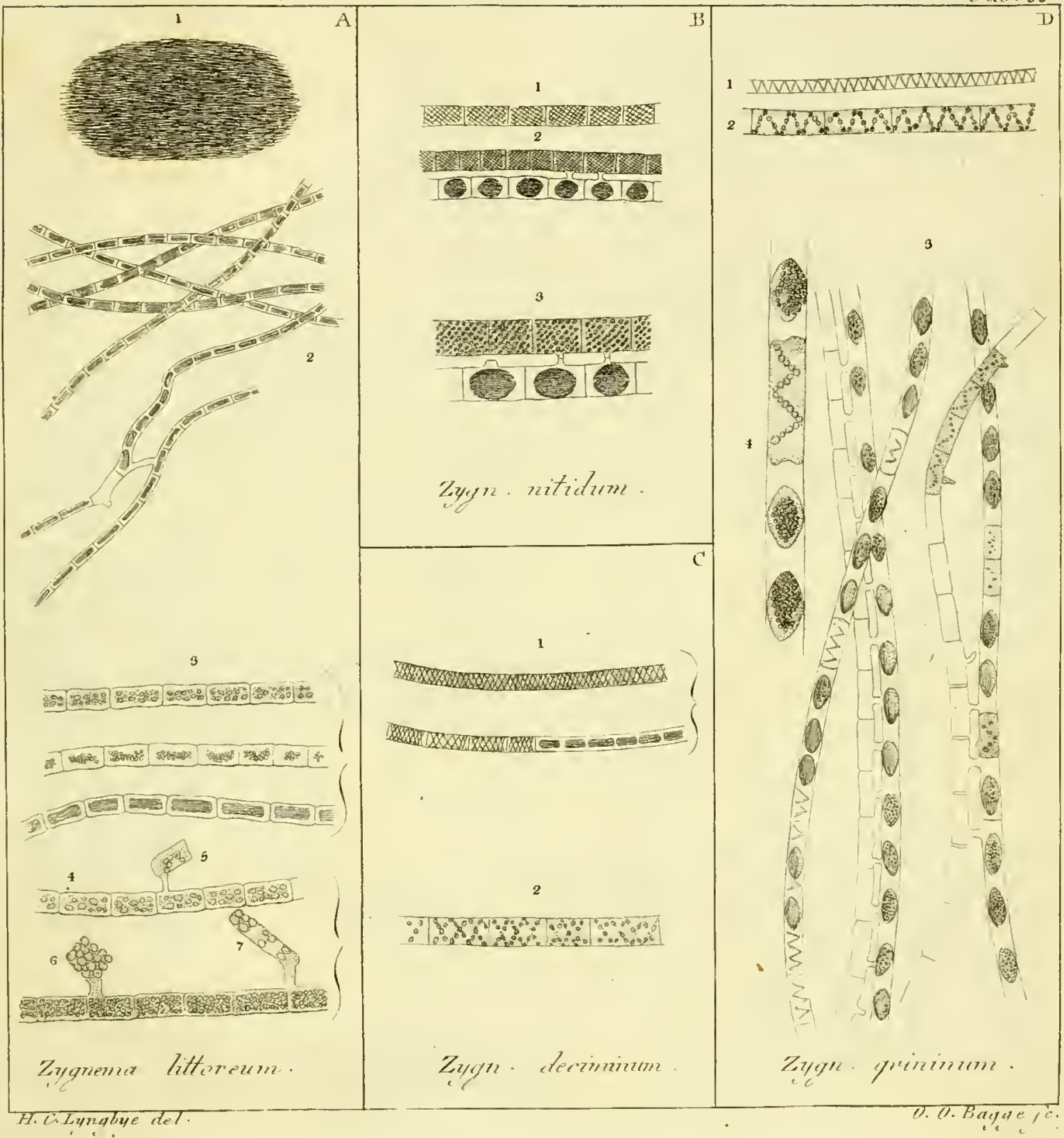


$\checkmark$ 
Tab. 60

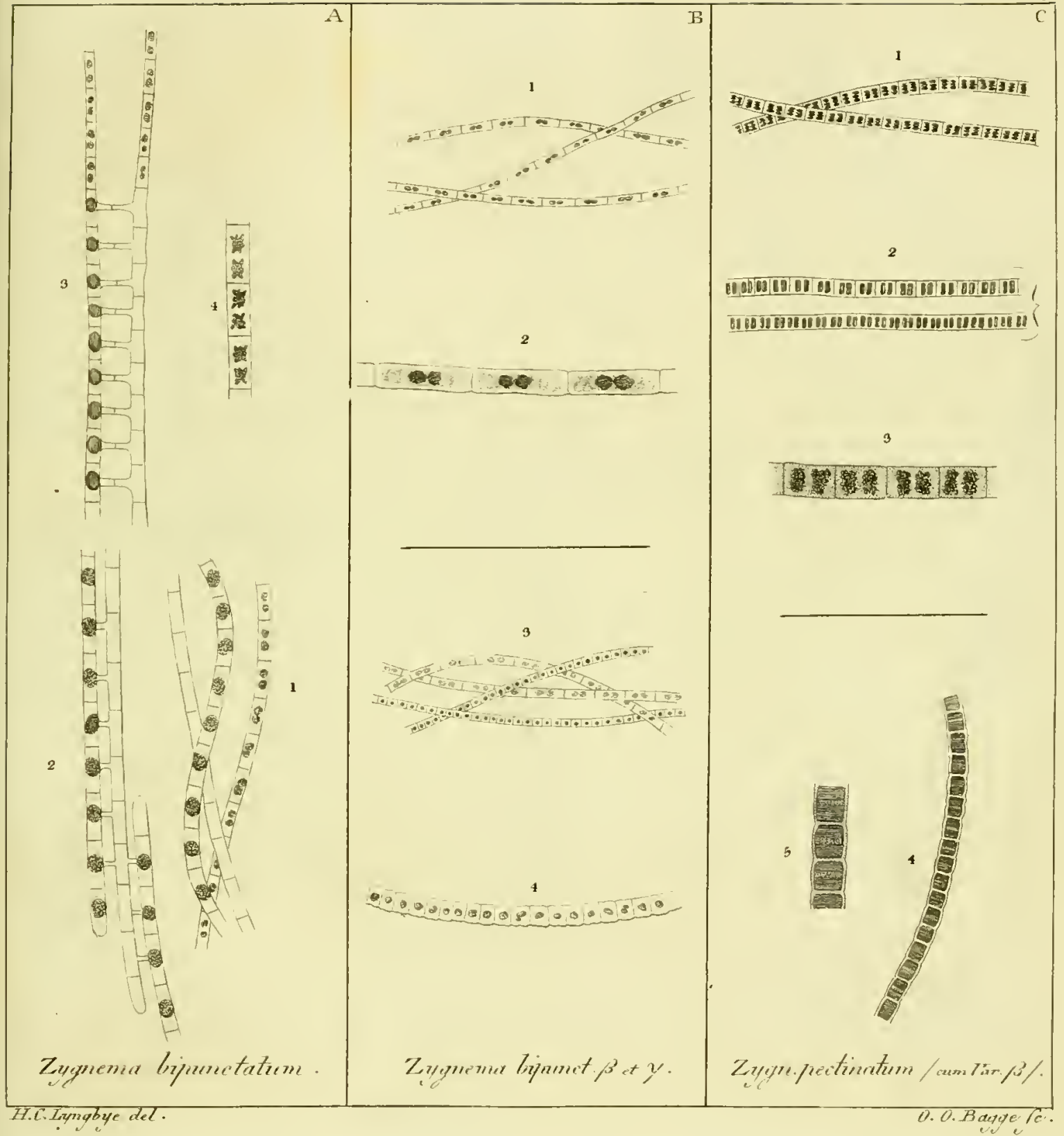





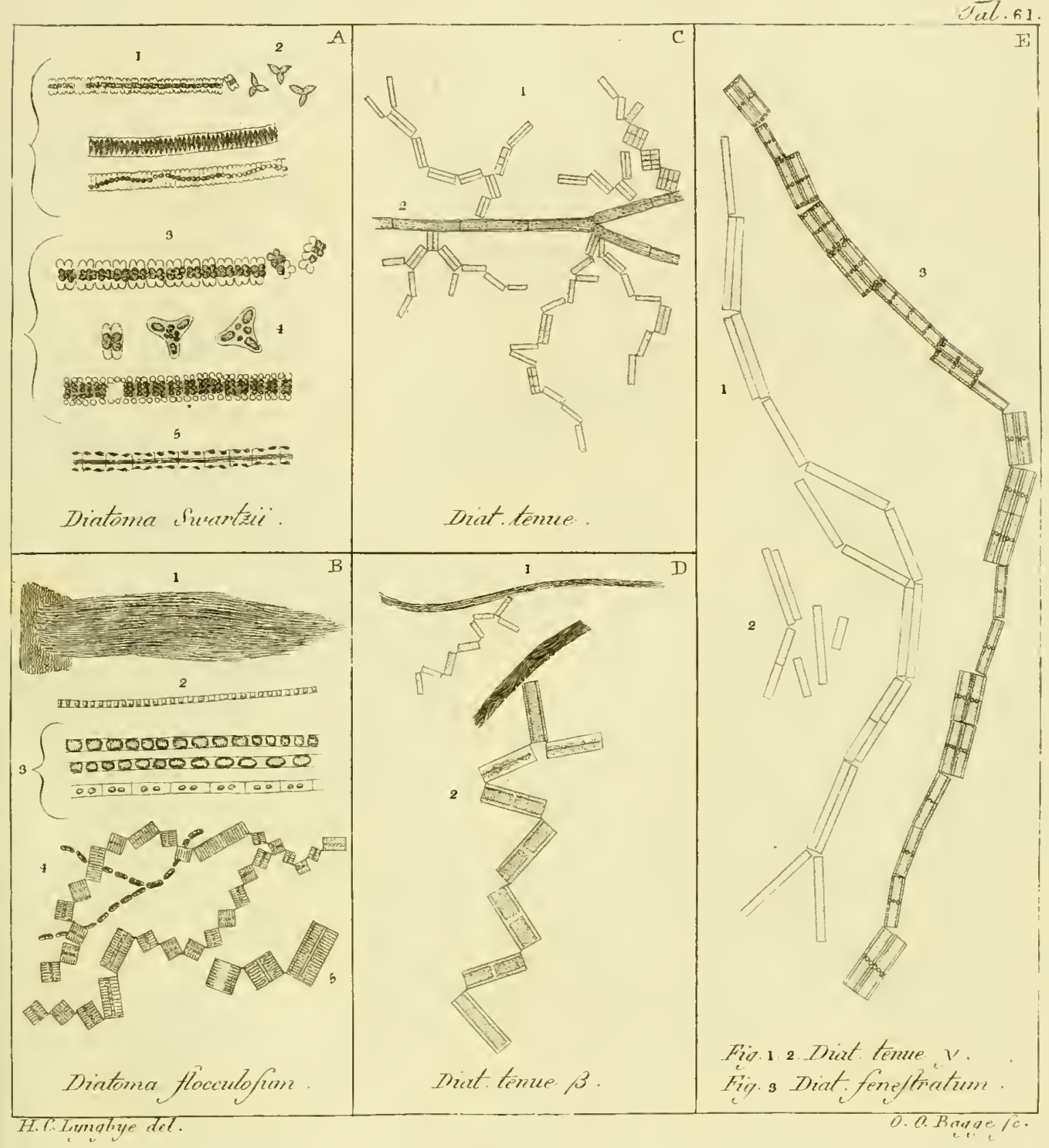


Tai. 62
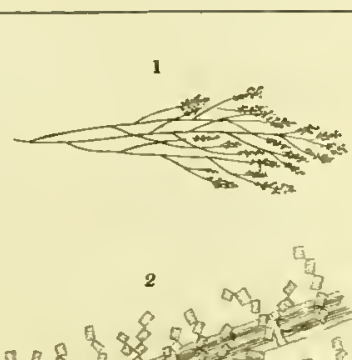

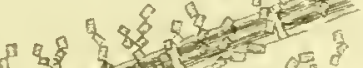

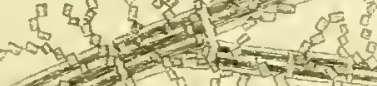

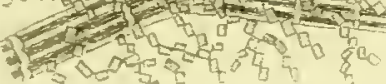

g $=60$

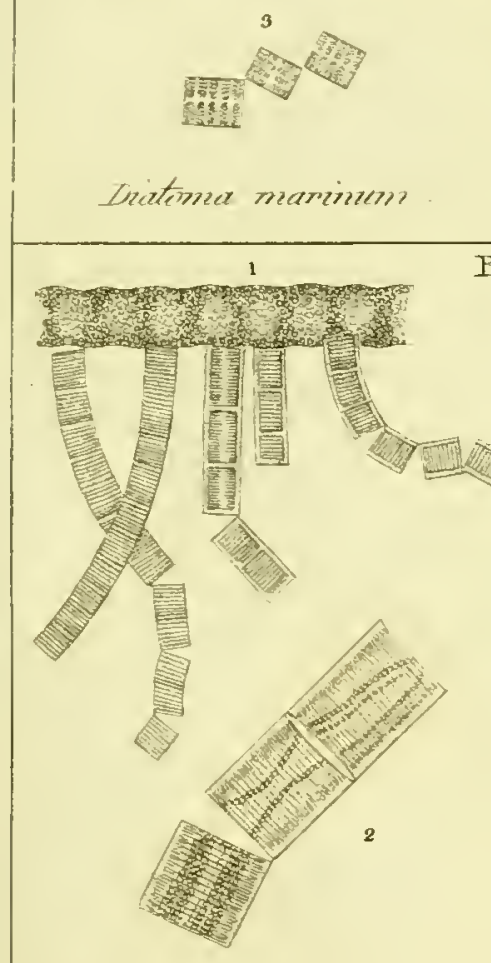

Diatoma arcuatum .
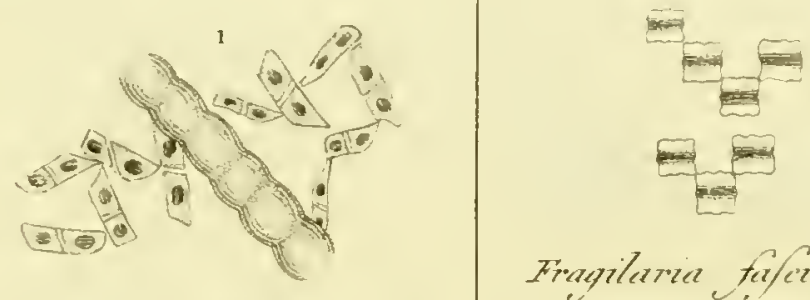

Fragilaria fifcrate
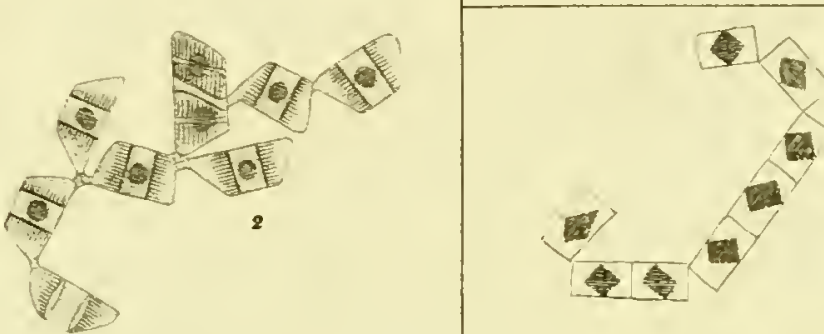

Frad latrumcularia

Drat obfiguatume

I

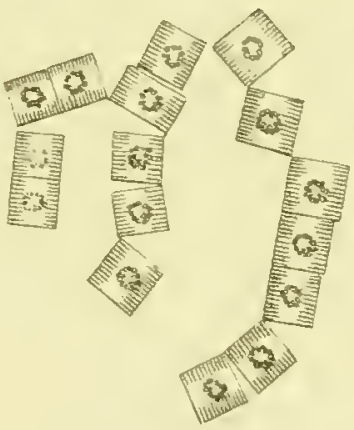

Diat arentume.

Fraq. unipunctate. 

सत̄te.63.

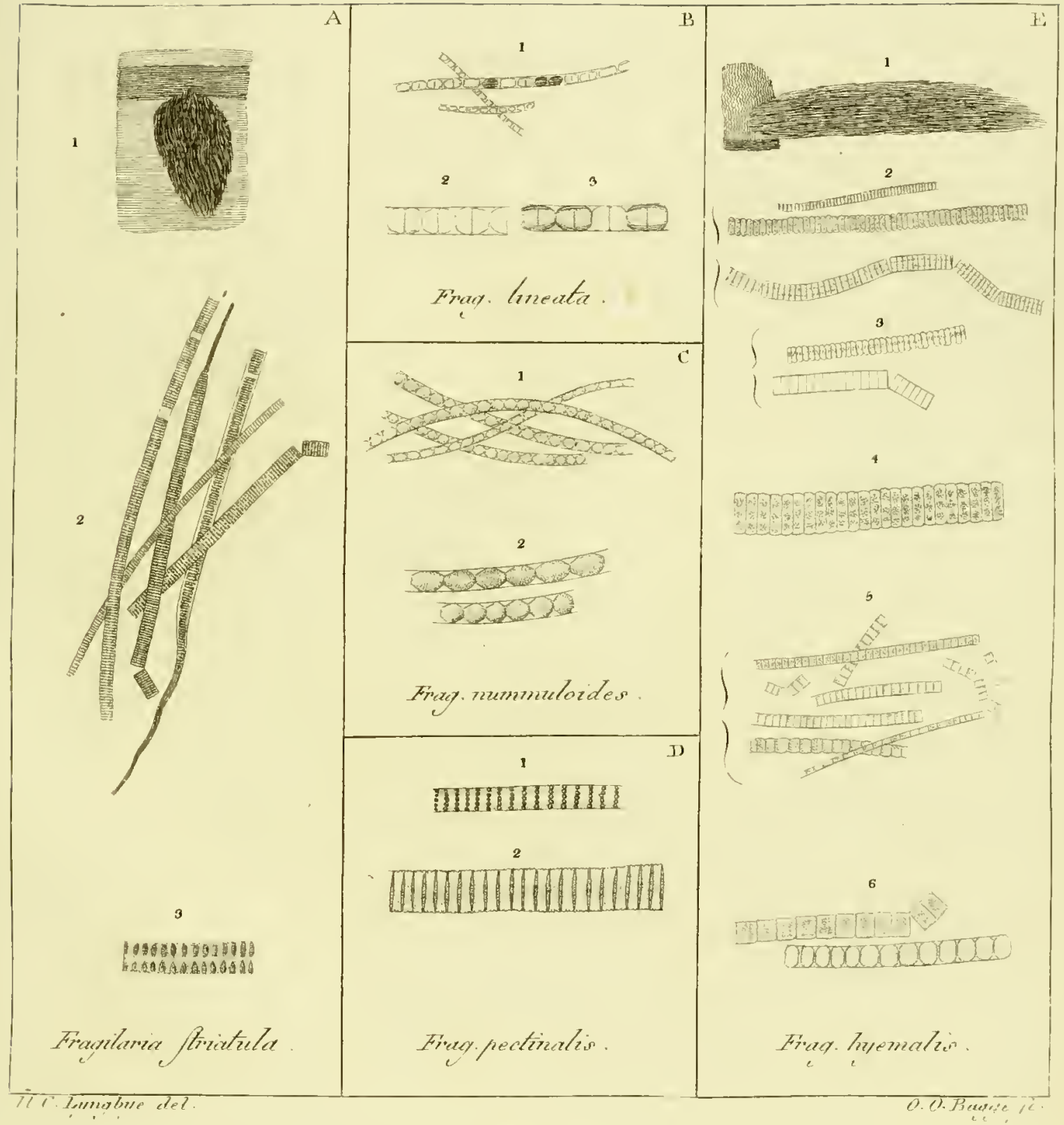




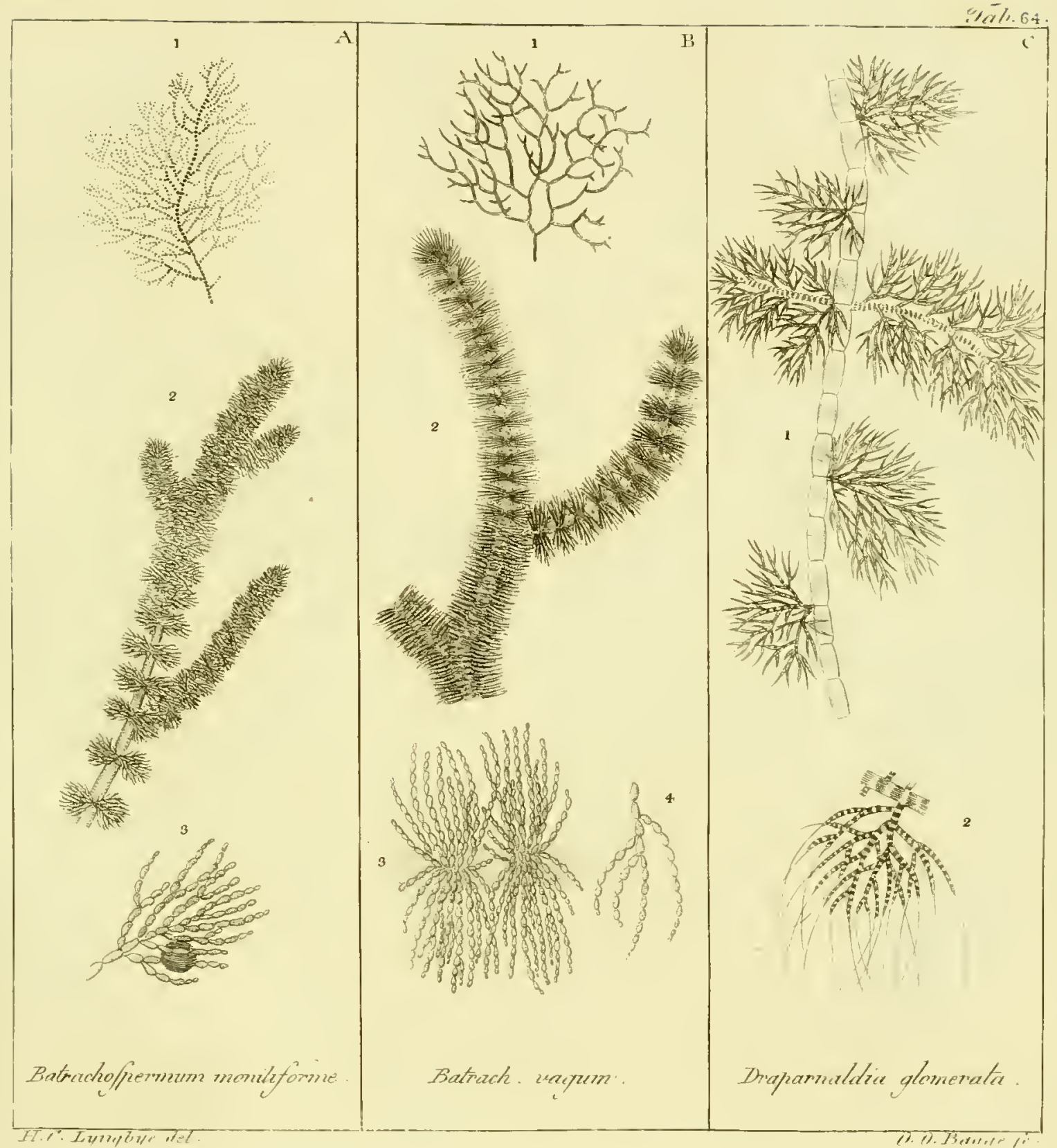




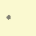


$406.6=$

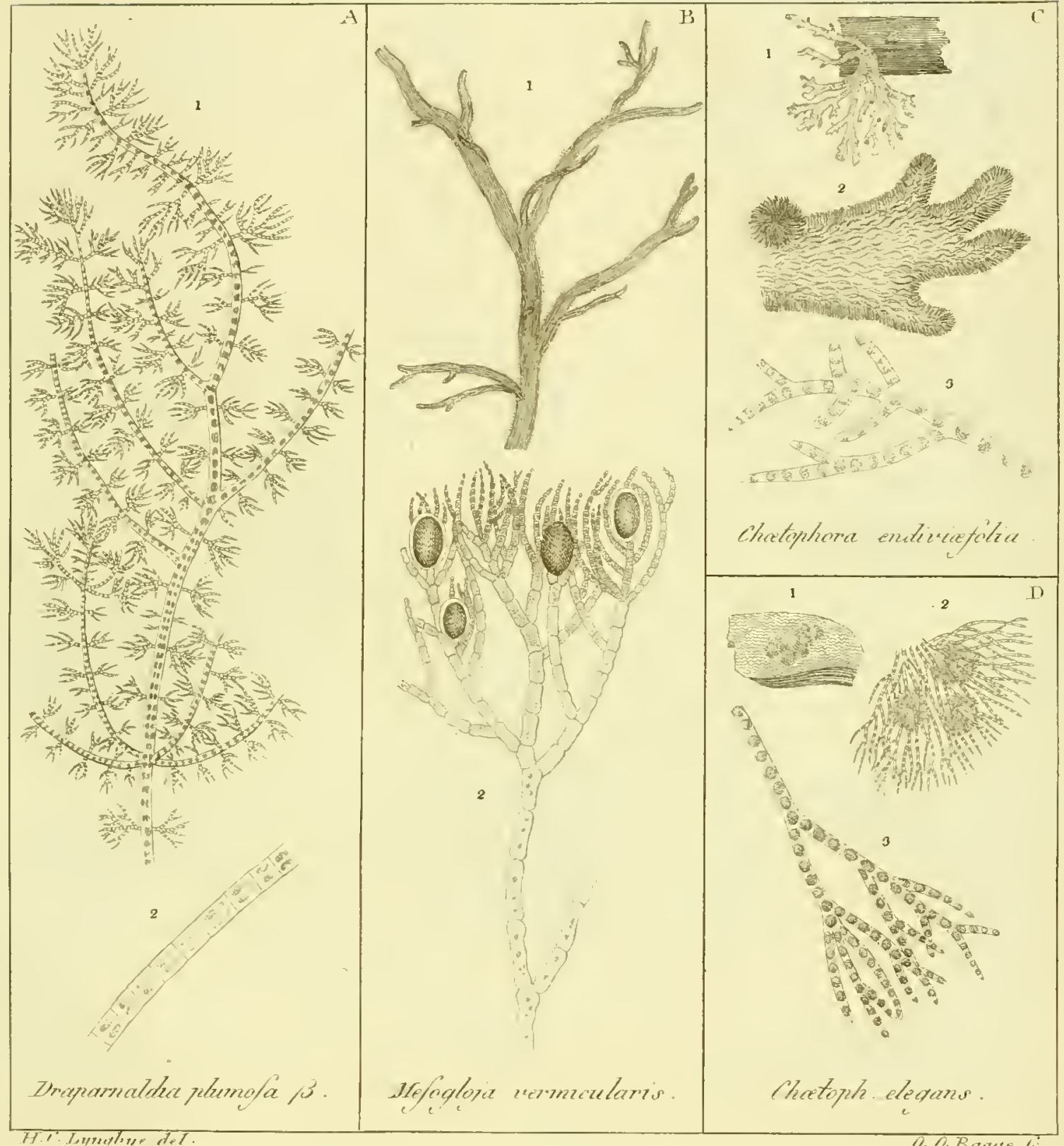

O. O. Bavere 

"xinlers.

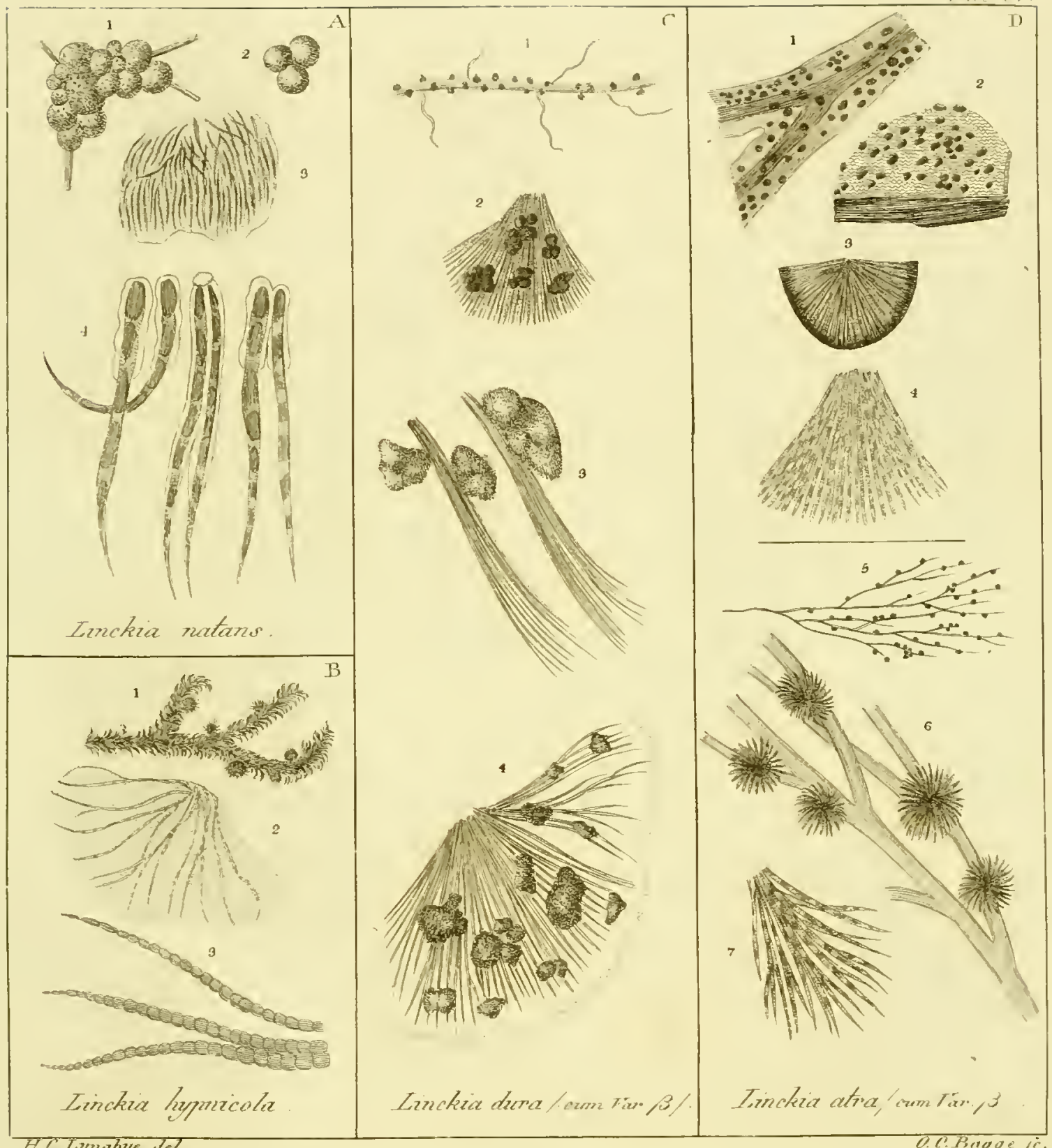





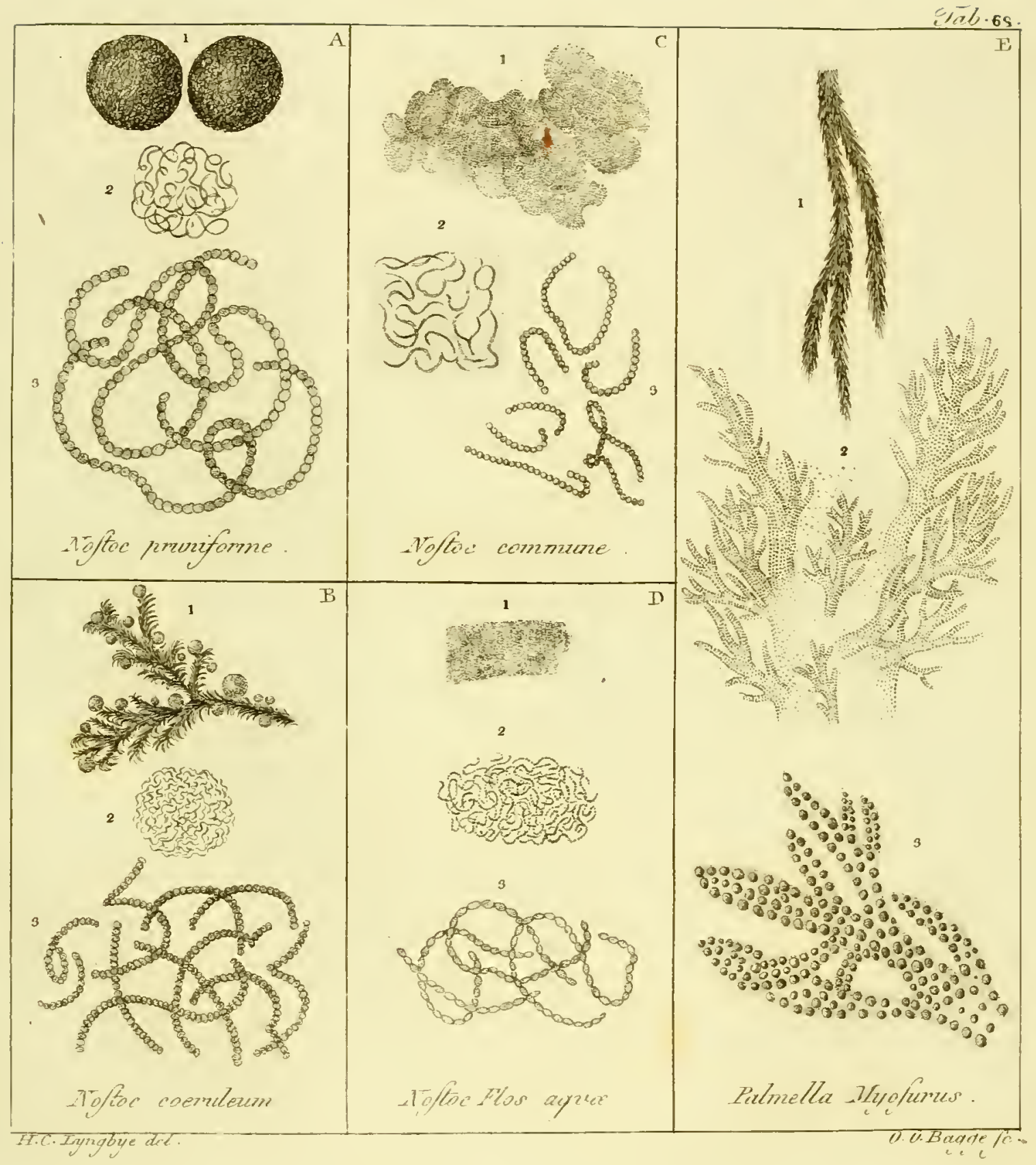


ind. 69

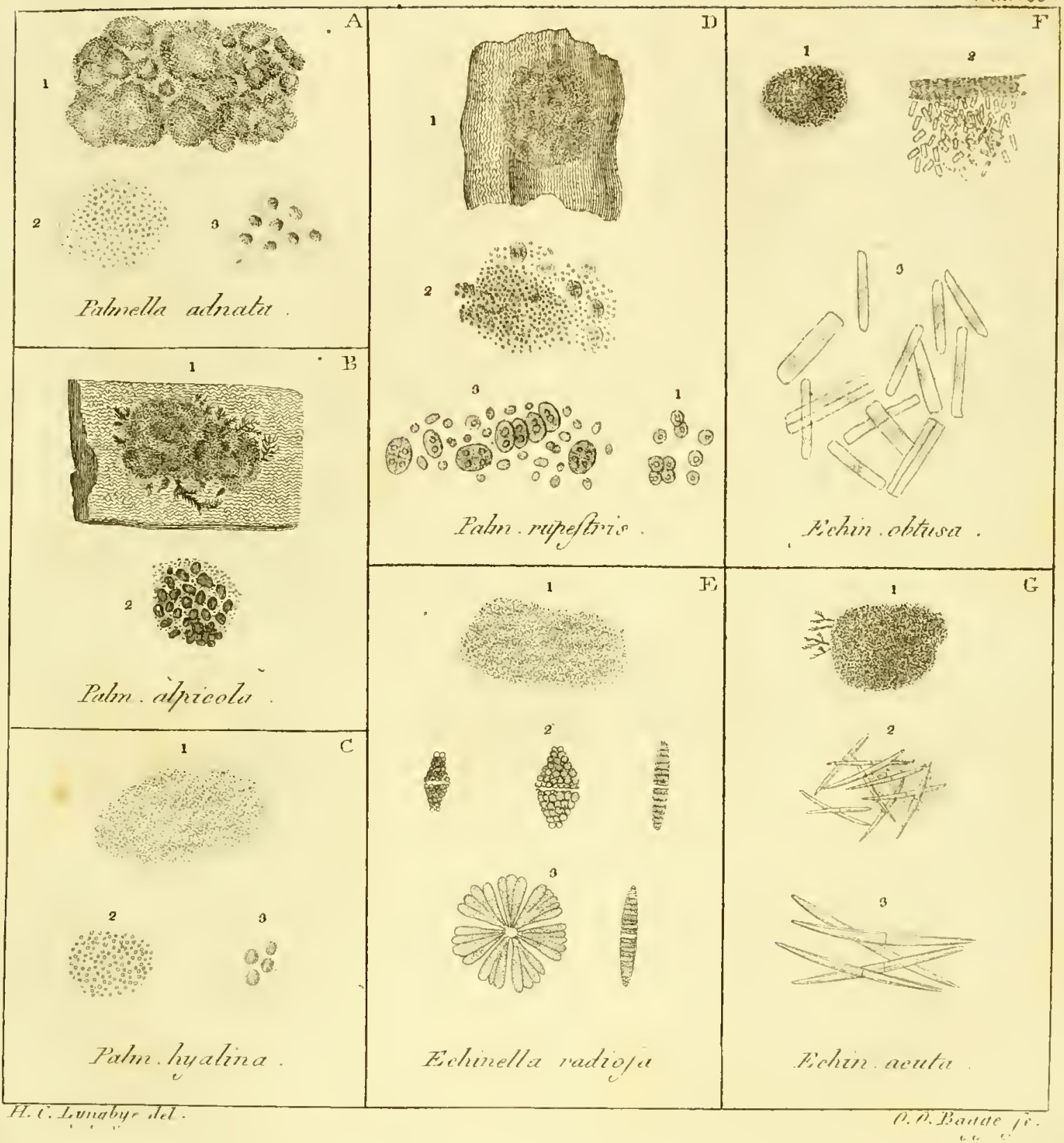



anb. 70

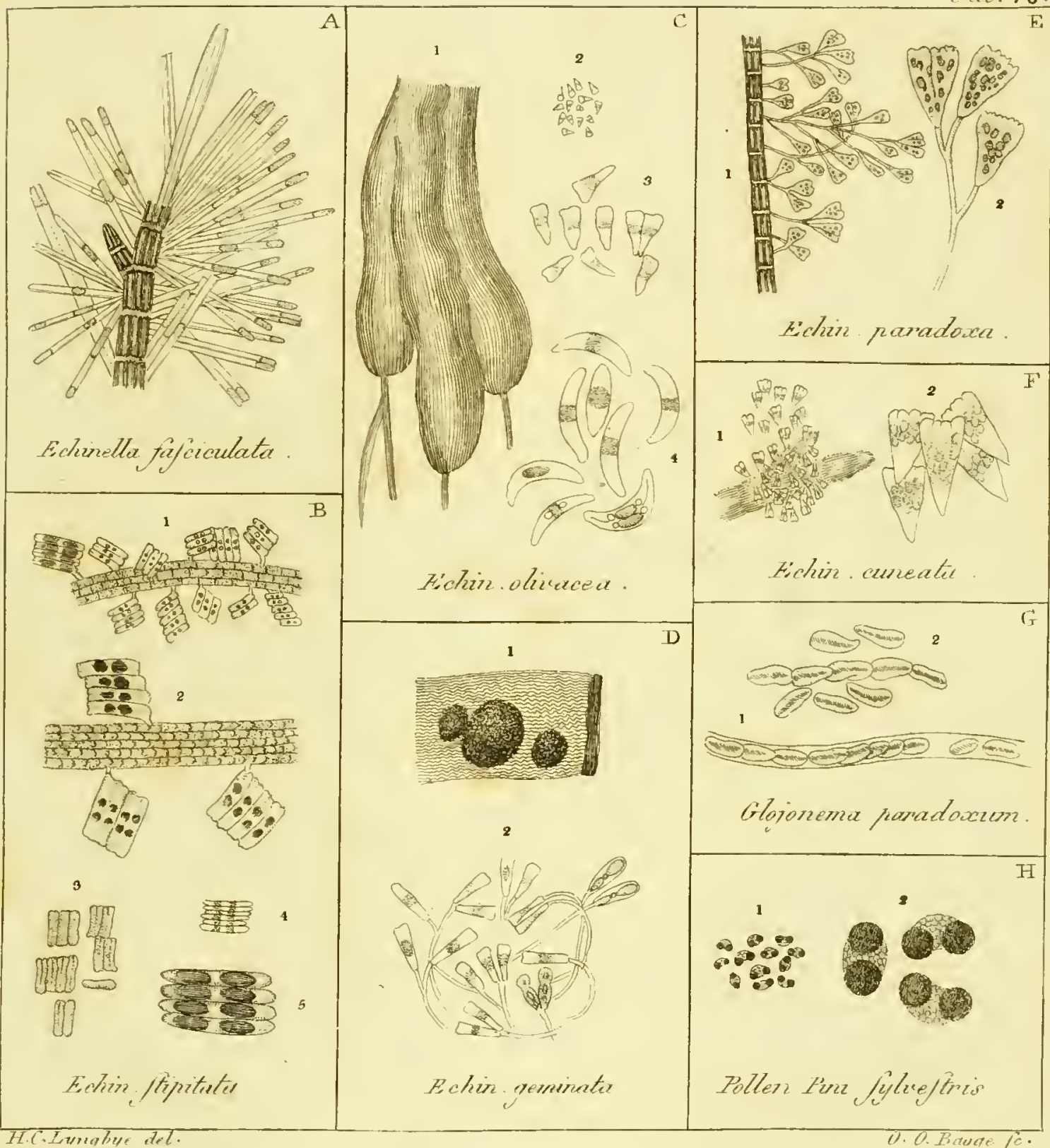




\section{N D E X}

\section{specierum et synonymorum.}

alaria 23

\section{(Litteræ cursivæ synonyma, numeri paginas indicant).}

Alcyonidium

diaphanum 202.

flavesceny 203.

Nostoc Lam. I98.

Alcyonitum

gelatinosum Lin. 202. ramosum \&c. Bast. 202. Alga scu Fucus \&c. Ell. 202.

fontalis \&uc. Bauh. 154. saccharifera Borrich. 22, 25. cubulosa \&c. Petiv. 67. vulgaris wiridis $K_{y} l l . \quad{ }_{5} 6$. Anacardium occidentale 60. Animalculum infusorium 155.

Bangia

atrovirens 85 .

crispa 82 .

fuscopurpurea 83.

- $\beta$. atropurpurea 83.

Laminarix 84. mamillosa 85 .

micans 34 .

qvadripunctata 86.

rucilans 84 .

viridis Fl. dan. I44.

Batrachosperma

ludibunda Bory 18?.

turfosa Pory I88.

Batracliospermum

fasciculatum Iauch. 19I. glomeraiun I'auch. 189. Gemispharicnin Dec. 195. hispidum Dec. 62.

intricatun J'auch. 192. moniliforme 187 .

- $\beta$. detersum 187 .

- d. vagum R. I88. Myosurus Ducl. 203. Afyurus Dec. 203 . plumosum Fauch. 189.
Batrachospermum vagum I 88 . Bryon Lactuca folio Lob. 30. Bryopsis

arbuscula Lam. 75.

Lynghypi 75 .

Buestcue 6o.

Jiulbochære secigera I34. Byssus

aqvatica Fl. d. 79.

antea Lin. I34.

botryoides lim. 205.

Flos aquo Lin. 20I.

Jolitleus Lin. 163.

minima \&c. Micle. 90.

minima \&ec. Mich. I64.

nigra Sce. Hall. I64.

nigre Huds. I64.

palustris \&ic. Nich. I 42 . petroe sc. Dillen. I64. zelutina Lin. 162.

Callithamnion

Arbuscula 123.

cocrineum I24.

coralliuum 126.

corymlosum 125.

- $\beta$. intricatum I25.

Daviesii I29.

- B. secundatum 129.

floridulunı 130.

fruerculosunı 124.

lanuginosum I30.

Plumila I27.

- $\beta$. puarlia I27.

rcpens 128.

- 3. tcuellum 128.

roseum 126.

- $\beta$. tenue 126.

Rothii 129.

Cassia Fisiula 60.

Ceranium

asperum R. I56.
Ceramium

aureum Ag. 134 .

brachiatum Ag I3I.

brachygonium II8.

Brodicei Ag. 109.

byssoides Ducl. III.

caespilosim R. 64.

P. maximum R. 75 .

cartilngineum Sclum. $55 \cdot 56$.

clealy brum Ag. 133 .

ciliatum I2I.

cirrlusum Ag. I05.

compactum $R$. I32.

conferzoides R. I32.

densum R. I33.

diaphanum II9.

- $\beta$. hyalinum I20.

- $\gamma$. tenuissimum I20.

- j. virescens 120.

dichoconum R. 75 .

Dilliwnii R. 7 .

elegans Ducl. 120.

elongatum IIT.

elongatum R. II8.

fastiginum R. IOS.

ferrugineum Ag. 131 .

fibrosum R. 63.64.

Filum R. 73.

floccosum R. I 27.

forcipalum a. Jec. I2I.

- $\quad$ 3. Dec. 120.

fruliculosum $R$. 125 .

jucoides Dec. II 2 .

gigartinume R. $4 \mathbf{I}$ granulatum Ducl. Io9.

hirsulum $R$. 124.

incurvum Dec. 45.

inflexum $R \quad 6364$.

Jinum Dec. I 77 .

litiorale Ag. I3I.

longissimum R. $43 \cdot 64$.

longissimum Schum. $5 \mathrm{I}$.

(3i) 
Ceramium

molle R. III.

nodulosum Ag. I87.

nodulosnm Ducl. IIS.

pedicellatum lil d. 125.

pennalum Fl. al. 103.

plicalum R. 42.

Plocaminm li. 39.

plunuosum li. 38 .

l'umula Ag. $_{\text {lu }} 127^{\circ}$.

poljmarphum ljec. 108.

pulchcll. B. claty baum Ag. 133.

purum Il. 131 .

repens $\lambda_{\text {rg. }} \mathrm{I} 28$.

- B. cencllun Sg. 123.

$105 \mathrm{c} n \mathrm{~m}$ R. 126.

¿ubrum 118.

- B. poliferm IIg.

rupesire /)a. 156.

scoparium /l. I04.

securidatum 119.

sericeam Jlec. I5t.

siliculosmm $A$ s. 132.

spermophorum R. 59.

serictume R. II 5

comencosum At. 132.

conetilosum li. $13 \mathrm{I}$.

cormoswm Bucl. 47.

cormlosmu R. IOI.

tuberculosum Fl. It. 52.

inbulosum li. 70.

Turneri R. I27.

urceolatum Jïrg. II2.

2ngalindum R. I52.

2errucosum R. 67.

nerticillatum Dec. $\mathbf{0} 02$.

violaceum li. 112.

virgatum R. 118.

Frilfenii R. 43.

Chatopliora

alre Ag. 195.

capsuliferu I9I.

elegans 192

clurgata I92.

entivitelia 191 .

marina 40. I93.

membranifolii IJ.

norlulosa Ag 52 .

jellita 19. 193

pisiformis 1 ig. 192.

rulira Ag. $5 \mathrm{I}$.

iuberculosa Ag. 197.

Chaniransia

crispa Dec. ItI.

fluviatilis lJec. 99.

glouerata Dec. 154 .

rivularis $D_{\varepsilon^{\prime} C}$ I $\$ 2$.

Chara resicala Dec Ifo.

batrachosperma IItis 187. getalinosa R 187

- o. vaga K. 188.

intricala 1 . 216.

Chondria pinnalifida $\mathrm{Ag}$. 40

Chundrus

bangii 17.
Chondrus

Bangii $\beta$. tenuior $I ?$.

crispus 15.

- $\quad \beta$. stellatus 15.

- $\gamma$. regualis 15.

- d. liliformis 16 .

- E. pumilus I6.

- ऊ. uncurvatus I6.

laceratus 18. $\%$. Incinatus 16 .

norvegicus 16 .

rubens I8.

Chorda

$$
\text { Filım } 72 .
$$

- f. inflatit 73 .

- \% trichoides 73

Lomentaria 74 .

tomentosa 74 .

Chordaria

Filum Ag. 73 .

- p. fisiulosa Ag. 66.

nagullitormis $5 \mathrm{I}$.

- \% intricata sog. 63.

multifirla $5 \mathrm{I}$.

paradoxa 53 .

rhizodes 52 .

- B. paradoxa Ag. 53.

rolund $\Omega$ s. 49.

scorpioides 50 .

tuberculosa 52.

villosa $A$. 168 .

riridis $A_{\text {gy. }} 44$.

Cladostephus verucillatus I02.

Cocos nucifera 60.

Coeliflas 198 .

Coelifoliunz I98.

Conferva

Acharii 162.

acgagropila $\mathbf{1 5} \mathbf{I}$.

acgagropila Gouct $15 \mathrm{I}$.

aegagropila Künin 151. I67.

acgagropila Wohr I6o.

aegagropila spreng. I5I.

a $\in$ rea 147 .

acruginosa könig 167 .

aestuarii Jürg. 91 .

alpina 139. 206

alpina 太.c. Dillen. IsS.

allernala billw. If0.

amplibia Sclsum. I67.

araneosa Mohr 98.167.

arbuscula Dillw. 123.

arcia 157.

arenatin li. 163.

armillaris Whll. $21 \mathrm{I}$.

atra Huds. 187.

atramenti 165.

- $\beta$ typhiloderma 165.

atropupuren billw. 83.

atrorulescens Dillw. IIO:

atrovirens Jillw. 85.

auren Dillw. 134.

- f. Jolichus R. 163.

badia Dillw. IIt

barloata Fingl. bot. I63.

barbata Küniğ 167.
Conferva

Biddulphinn Engl. Hol, 178.

bipartita Dillw: 142.

bipunctata Dillw. 175.

bipunctala R. 1 ?4.

Lombycina Ag. 138 .

brachymelia 135 .

breviarticulata wohr 133.

brevissima Ehrh. I5I.

Brodiari Dillw. 109.

bronchialis R. $185^{\circ}$

lumllosa E\%rh. 170.

bullosa Schum. I68.

bursain diüll. 76.

by ssoides Jillw. IIJ.

ianalicular is Chantr. 154.

canaliculuris Lande 168 .

cancellatu Künig 168.

cancellata lin. 168.

cajillaris $1+I$.

- $\beta$ lumbricata I 42 .

capillaris Dillw. I 47 .

caslanen Dillw. $16 \mathrm{I}$.

centralis I6I.

ceramicola I4t.

Ceratoph, llum R. Jo3.

clealybera R. I33.

Chara li. 189.

chthonoplaste's Fl. d. 92 .

ciliata Ell. $12 \mathrm{I}$.

cirrlosa R. 105.

clathrata R. 66.

claveformis R. 103.

coccinea Huds. 124.

comoilles Dillw. 97.

compicia 136

compressa il. 64 .

confervicola Dillw. 94.

confragosa l.ighte. 139.

contoria 145

coralline billw. 126

corallinoides Huds. 126 .

corymbifera Engl. bat. 133.

corjunbosa Engl. bot. 125.

crinita R. 64.

- \& R. 65.

crispa Dillw. I4I.

crispata 152.

cristata R. 154 .

cruciata Dec. 174.

cryplarum Dillw. 149.

r.rystallina 155.

- $\beta$. virtscens I55.

curea Jillw. 146.

Dawiesii Dillw. 129.

decimina Wirll. 173.

decorticans llillw. 95.

dendrilica 166.

diaphana li. d. 120.

- B. atropurp. K. II9.

dichocoma I\%. d. 5 I.

dichocoma Lin. 75 .

dilatata K. 78.

Dilliwnii itcl, \& Mohr. 77.

dissiliurns 136 .

dissiliens Dillu. I78. 


\section{Conferva}

disticha F"ahl I04. distorta Fl. d. 90 .

divaricata $R$. I52. - B. elongala $R, 152$.

ebenea 164 .

elegans $R_{4}$ I2O.

elongata Huds, II7*

ericetorum I 40 .

- B. aqvatica Ag. I39.

exigua Dillw. I50.

fastigiata $R$, I20.

tenesiralis 166.

ferruginea 159. 168 .

ferruginea $R, 146$.

fibrillosa F\%, dan. II3.

filiformis $\mathrm{Fl}$, dan. 68.

Fistula R. 66.

flacca I4t.

flaccida $1+6$.

flasescens 157 .

Alexuosa $1 \%$ d. 156 .

Alexuosa $R, 65$.

floccosa 138 .

floccosa 11. $d, 127$.

flocculosa Fl, d. 179.

flocculosa $R$, 179 .

floridula Dillw' 130.

Flos aqva $R_{+} 202$.

flosculosa Ell. I19.

Aluriatilis Lin, 99.

fluviatilis \&c, Dillen. 142.

fodirnarum Ag. I49.

foeniculacen Huds, 63.

foetida Dillw. 86.

Jontana \&r. Dillen. IS7.

fontinalis Blum. 8I.

fontinalis \&c. Dillen, 154 .

fontinalis Dillw". 86.

fontinalis $F l_{*} d_{*}, 90_{*}$

fontinalis $R+88$.

fracta 152 .

- $\beta$. hirta 152.

- \%. elongata 152 .

- J. marina 152 .

fragilis $R_{+}+17^{\circ}$.

frigida Dillw. 77.

frigida $R .95$.

frulicnlosa iWulf, 125 .

fucicola 31,146 .

fucoides Huds, 112 .

fucornm $R_{+} \mathrm{I} 46$.

fusca Huds. 107.

fuscobrunnea Jïrg. 86.

fuscopurpurea Dillw. 83.

fugacissima 137 .

- B. major 137.

- $\gamma_{+}$oscillatorioides I37.

funiformis $R$, I42.

gelatinosa Lin. 187.

gelatinosa $\beta$. Huds, I 89 .

J. Huds, 188 .

geniculata Ell. 126.

genuflexa $R_{*}$ I 70.

glanca $R+156$.

globosa \&c, Hall, 192.
Conferva

globulosa $R_{+}+120$.

glomerata I5t.

- P. mderogonya 154.

- $\gamma$ marina I5t.

glomerata Clantr. 8I.

glamerata Trevir. 8I.

hiven Fl, d. I52.

lispida Thore 62.

hormoides 145.

Hutchinsia Uillw. 16I.

Hydrobyssus Ehrh, II2,

hjemalis $R$. I85.

hyproides Fl. d. 216.

ilicicola Engl, bot. I3t.

implexa 144.

inflexa $R_{+} \mathrm{I} 84$.

incerrupta Eingl, bot. 94.

intestinnlis $R .67$.

investiens Ag. 74.

Jolithus 163 .

jugalis Dillw. 173.

jugalis Fl. d. 172 .

laclea R. I49.

latevirens Dillw. I54.

lanosa 160.

Ianuginosa Dillw. I30.

limosa Dillw'. 88.

limosa $R .86$.

lineata Dillw. I84.

Linum 147.

littoralis Lin. I30.

longata Dillw. 173+

longissima Desfont. 66.

Jubrica 150 .

lucens Dillw. 136.

majuscula Dillw. 91.

marina \& ${ }^{2}$ Dillen, 94, IO4. I 20.

melæna 165 . $126+13 I+132$.

Melagonimm 148 .

Melagonilum Fl. d. I47.

minima \&e. Dillen, 90.

mireor ramosa Moris, 154.

moniliformis Müll. I84.

moniliformis $R, 120$.

mucoroides $A g$, 166.

mucosa 140.

mucosa \&r. Dillen, I39.

multicapsularis Dillw. 82 .

multistriata $R_{4} 172$.

muralis $R_{*} 95$.

muscicola $\mathrm{T} 6 \mathrm{~T}$.

mutabilis $R, 189$.

Myoclerous Dillw. 96 .

MIjiopleyllum $R_{+} 102$.

nana 149 .

nidifica $\mathrm{Fl}$. d. 216.

nigra Dillw. IIO.

nigra R. I6.4.

nigrescens Huds. 109.

nigricans 158.

nilidre Dillu. 173.

nilida Fl. d. I72.

modulosa Huds. I20.

nodulosn Lighif. II9.
Conferva

nummuloides 7)illw. I84. obliquatr Ensl, bot. 181.

obuusangula 159.

occllata Dillw. 97.

orhracea Dillw. 89.

odorata 164.

olivacer Dillw. 106.

omissa Fl, norr. 108.

Orhatrichi 162.

oscillatorioides Ag. 137 .

paradoxa. $R_{4} 53$.

pectinalis Mull 185 .

pectinata Der. 175.

pellucida Huds. 156 .

penicilliformis $R$. 145 .

penmata Dillsi. 105.

penuatuta Fl. d. $157+210$.

percursa Ag. 65.

pilosa R. I2I.

Pisum Fo, d, 200.

Plinii Lobel. I42.

plumosa Ell. I 24 .

Plumula Dillw. 127.

polymorpha Ell. II3.

polymorplia Lin. Ios.

- e. barbata Retz. I63.

porticalis Mïll. $\mathbf{1 7 3}$.

Pteridis 14 S.

punctalis 138.

punctiformis 166 .

pura $R+155$.

purpurascens Huds, 126.

pusilla I 49.

qvadrangula $14 \mathrm{I}$.

quinina Mäll, 173.

refracia R. 152.

repens Dillw. Ieg.

reptans $R$. IOI.

reticulala Lin, I69.

riparia Dillw" 159.

riparia $R, \mathbf{I} \mathbf{I}$.

rivularis $I+2$.

- $\beta$. bipartita If2.

- $\beta_{+}$crispala Ag. 152.

- $\gamma$. mucosa I42,

rosea Dillw. 126.

Potlii Dillsi. I29.

rubra Dillw. II9.

rufa R. 98. 168 .

rupestris 156 .

- $\beta$. Ilexuosa I56.

ruilans $R$. 84 .

scalaris $R, 172$.

scoparia Bory SI.

scoparia Lin. I04.

scopulormm $\mathrm{H}^{\circ}$. ct $\mathrm{M}_{+} 93$.

seposita Fl norv, $\mathrm{I} 20$.

seriala IVahl. 96.

sericea 153 .

- P. intricata I53.

- $\gamma$. matina 153.

sericea Huds, I54.

serpentina Miull. I70. I7I.

setiformis a comjugnia $R, I-2$.

- $\beta$. lubrica R. 173 . 


\section{Conferva}

setigera $\pi, 134$.

silirulosu Dillw, I32.

sordiela 133.

- B. brunnea 139.

- $\gamma$. unirulata i39.

spiralis 11,173 .

spongiosa 11.103.

squarrosa Fl. $d .45$.

stillaris 150 .

stelluris irilcke 150 .

stellina Miill. 174.

striamla Engl. 60t. 183.

strica lillw. II5.

sisposa R, 91.

exniajormis lingl, bot. 178 .

icnella Dillti', ins.

tomentosa Hids, I32.

rortuosil 145.

trichodes Jucl. 83.

Turneri Dillw. 127.

Turneri Innd, bot, 127.

typhloderma Dillw. 165.

iulothrix I 46 .

umbrosa 163.

uncialis 151.160 .

"recolaca Dilln. I10,

vagaluada Huds, 152 +

vaginuta Dillw, 92.

vaginata 1ucl. 154.

varia $R, 162$.

veluina 162 ,

velutina $R, 88$.

- B. atra $R_{\text {. } 88 .}$

2'erticillatn Lighty. I02.

vesicata 140,

- $\beta$. fuscescens I4I.

- $\gamma$. breviarriculata I4I.

vesiruta Mïll, 78 .

villosa Dillw. 168.

villosa Engl. hot, 62.

jiolacea Huds. 139.

violaces R. 129.

virgata $R, 156$.

vivipara Dillw. 134.

Wormskioldii 158 .

Youngana A $\mathrm{B}$. 14 .

Zunata 136.

Conjugata

- B. tenuior Mohr. I36.

angulaia Trauch. 170 .

condcrsala $J^{\prime}$. I74.

rruciata $T^{\circ}$. 175.

decimina 19.173.

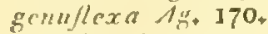

gracilis I'. 175.

inflata l: 174 .

Longaba I'. 173.

lutescens $\%$. 175 .

nitida $A_{5} .172$.

pectinata 1.175 .

porticalis $I$. 173 .

l'rinceps $I^{\prime}, 172$.

quinina Ag. 173 .

serpentina $I$. I7I.

sellina $J .175$.
Corallina pingvis \&c. I'aill. I89. Corniculuria pubescens dch. 85.

Cucushilu lagemaria 60.

Cyclops Lupulu I'auch, 82,

Delesseria

alata 8.20.

- $\beta$. angustifulia 8 .

Brodiai Lam, II.

coccinea slg. 39.

denlate lant 9 .

sangvineal $7+$

simuosa 7 .

- B. quercifolia 8.

- $\gamma$, ciliata 8

Dernatium olivaceum Schum, I66.

Desmarestive

aculenia L.am. 34 .

ligulata lem. 34.

vilidis lam, 44.

Desmia

acileata 34 .

Hornemanui 35.

ligulata 33 .

Diatoma

arcuatum 180.

aturitum 182.

dissilirns Ag. $\mathbf{I} 36$.

fasciculata Ag̈. $178,210$.

lenestratum 180 .

Jlocculosa Ag. 179.

llocrulosum 179.

flocculosum Dec, ISO.

marimom 180.

objiqvacum I8I.

pectinalis $4 \mathrm{~g} .185$.

rigidim Dec, 181.

Swarkii 177.

tenue 179.

- ק. marinum 179.

- $\gamma$ e elongatun 179.

tenuis As. 179 .

Dolickos urens 60 .

Dracontium periusum 24.

Diaparmaldia

glomerata 189 .

lejpnosa Bory 189.

mulabilis Lury 189.

plumosa 189.

- $\beta$. opposita 190,

tcnuis Ag. 150 .

Echinella

acuta 209.

cuncata $2 \mathrm{II}$.

lascirulata 210.

geminata 210.

olsusa 208.

olivacea 209.

- B. llivtior 209.

paradoxa $2 I$.

radiosa 208 .

stipitata 172. 210.

Ectocarpus

aureus 134.

chalvbaus 133 .

densus 133 .

litcoralis I30.
Ectocarpus

litcoralis $\beta$, major 131 .

- $\%$ rulier 131 .

silirulocus I ${ }^{2} I$.

- $\beta$, uvielormis 132,

inmentosus 132.

Eclosperina

crspitosa F"ach. 8I.

clavalu 5.78.

grminaln $t^{\prime} .80$.

hamata 5.77 .

ovain 7.76 .

racemosa $/ .82$.

se'ssilis $r^{\prime} .80$.

terrestis : 77 .

Eganüd 60.

Filum maritimum Boce. 73.

Flugellaria Filum Ner, bi bu, 73.

llueshimmel Mïll. 79 .

Frilgilaria

liscidta I82.

hyemalis $\mathbf{1} 85$.

latruncularta I 82 .

lineati 184 .

nummuloides I84.

pectiustis 184.

striatula 183 .

Fucus unipunctata I83.

abrotamifolius Lin, 54 .

acerosus Eisp. 43.

acicularis Ksp. 46.

aruleatus Esp. 54. aculeatus $F \%$ d. 34.

Agarum Cin. 24 .

alnius lim. 8.

albus Fisp. 54 .

allius Hi. d. 42.

alvcolalus Lisv. I4.

angustifolins Baul +73 .

Arbor Ulajs. 20.

arluascula liec. 75.

articulatus lishlf. IOI.

asplenioides $T \cdot 38$.

bacciferus $T .56$.

ballhicus $\mathrm{Ag} \mathrm{3}$.

Bangii Fl, d. 17 .

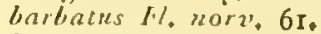

barlontus Lin. 58.

Bastera Gm. 55.

lifidus Huds. 12.

bifurcalus Gurn, 20.

Brodici T. 11.

lirunm Strüm. 240.

buillosses T. 21 .

bullatus Fl. d. 25 .

b) ssoides Good, II I.

canalirulatus 6 .

camaliculaus Esp. 3I.

capillacrus Esp. 46.

caprinus Fl. d. 25.

caprinus Gum!. 49.

carnosus Esp. 20.

cartilagincus Gunn, 55 . 
Fucus

cartilnginesus Oed. 39.

cartilaginens Strïm, 240 .

cartilaginous 7.35 .

caule ierere \&". Noehr. 240.

cavis Bauh. 67.

ceranoides 5.

ceranoides Gm, r5.

- 8. Gm. I4.

ceranoides lin. 5 .

ceranoides Wahit. 6 .

ciliatus Gm, I2.

cilintus $T .13$.

Clathrus Esp+ 24.

clavalus Kön. 4I. 56 .

clavellosus $T+7 \mathrm{O}$.

coccineus $T+39$.

- $\beta$, pusillus Wah. 14.

concalcuatus $1 . i n+57+58+$

confervoides $T, 43$.

contorius Esp+34.

corallicus Fl, d. 46.

corneus $K \ddot{0} n_{+} 57$.

coronipifolius hön+ I4+57+

corjmbijer Wrulf, 40 .

corymbiferus Esp, 40 ,

crenatus Gm+7.

crinitus $T$. $\mathbf{1} 3$.

crispatus Fl, $d_{+} \mathrm{I}_{5}$

crispatus Lin. I8.

crispatus Ner, britt, I2,

crispus Esp. 12.

crispus Aer. brit. I5.

crispus Lin, 15+

cristatus Lin, I3. I4,

- $\gamma$ articulatus $T$. I4.

cristulatus Mert. I4.

dentatus Lin, 9. 56 .

dichotomus Lepech, 240 .

diffusus Huds. II8,

digitatus Iin. 20.

discors Gnnn. 57.

distichus 6 .

distichus Esp. 5.

divaricntus Lin. 3 .

dulc is $G m+26$.

edulis $T, 26$.

elongatus Gm. 36.

clongatus Gunr, 43 .

epiphyllus $\mathrm{Fl}_{+} \mathrm{d}_{*} \mathrm{IB}$.

ericoides Gunn. 57.

esculeatus Lin. 23 .

excisus Lin, 6.

Fascia Fl. d. 28 .

fastigialus Lin, 49.

fastigiatus Ner, britt. 49.

filiformis Gm, 6.

flliformis Huds, 16 .

Filum Lin. 73.

finbriatus Gm, 23.

Jlagelliformis Jürg. 63 .

flagelliformis T, $5 \mathrm{I}$.

foeniculaceus Gunn. 57 .

foliaccus Scröm 240.

fontaules \&ic, Vaill. I9I.

fungularis Oed. I9.
Fucus

furcellntus Lin. 49 .

furcellatus Moler. 49.

gigartinus $F l, d$. I3. 14 ,

gigarlinus Lill. $4 \mathbf{1}+$

granulatus $1 \%$ d. 58 ,

Griffuhsice T. 43 .

herbaceus Huds, 34 .

hirsutus Esp. 102,

hirsulus Lin. 103.

holosetnceus Gm. I3.

Hornemeanni Mert. 35 .

hyperboreus Gunn. 20.

incurzus Huds. 45.

inflatus Lin, 3 .

kaliformis $T+7 \mathrm{o}_{+}$

laceratus $G_{m}$, I8,

lacinintus $\mathrm{Gn}, 18$.

laciaialus $T$, 12.

Lactuca Esp. 26.

lanceolatus Retz. I8.

Lagasca Clem, II9.

lanosus Kön. 58.

lanosus Lin. IOS.

ligulatus Gm. I3.

ligulatus Lightf. 34 .

linearis Fl. d. 6 .

longissimnes $\mathrm{Gm}$. 43 .

longissimus lWulf. 43 .

lorcus Fl. d. 36.

lumbricalis 7 ? 49 .

l) copodioides Lin+ 45 .

mamillaris Esp. 3 .

znamillosus T, I4, 59.

membranifolius lam. II,

membrauifolius T. 10.

miniatus $F l_{\text {. }} d, 12$.

nuz cronalus $T .58$.

muscoides Lin+ 34 ,

natans $T, 56$.

nodosus $\mathrm{Lin} .37$.

norvegicus $T$. 16.

obuzisus Ag. 58.

Oederi Esp. 4I.

Oederi Gunn 40.

ornatus L. 59.

ovinus Gunn, 25 .

palmatus $G m_{+} 2 \mathrm{I}$.

palinatus $T+25$.

- B. Lightf. 26.

Palmettr Gm. IO.

Palnetia $T$. I2.

- B. Lani. I2.

- Tar. Esp. 7.

pectinalus Gunn, 38 .

Phyllitis T. 23.

pinastroides T. 45.

pinaacifidus Fl. d. 9.

pinnatifidus Gm. 40.

pinnatifidus Ström. 240.

pinnatifidus T. 40.

- \%. T. 40.

pinnatus Gulnn, 23.

pisilllatus Gm. 4I.

plicalus Esp. 43.

plicalus $T_{4} 42$.
Fucus

Plocamiam Gm. 39.

plumosus tin. 38.

polymorpluus Lam. I5.

- l'ar. Lam. 16.

polyscides Ner. britt, 2I.

procerrimus Esp. 43.

prolifer Lighif. I8.

pseudocernoides Iss. 58.

pseudoceranoides Gnz. 59.

ptilotus Gunn. 38.

pumilus Esp. 41.

pumilus Fl. d. 16+27.

purpurascens $T+46$.

pusillus Esp. I6.

py gmestes lighlif. 4I.

Qvercus mariun Gn. 3.

radialus Ner. britt. 49.

ramentaceus $T$. $6 \mathrm{I}$,

reniformis $T$. 58 .

raseus $F l, d$. 7 .

rotundus Esp. 6.

rotundus $T .49$.

rubers Esp. 25.

rubens Fl, d+ 10.

rubens Ner. britt, 7.

rubens Lin. 18.

rudis Esp. 103.

rudis livulf, I04.

saccharinus $\mathrm{Fl}$. d. 22 .

sacclearinus Jin, $2 \mathrm{I}$.

sangvineus Iin. 7 .

scoparia Bauh, IO4.

scorpioides Esp. I08.

scorpioides Fl. d, 43, 50,

seloginoides Lin. 58. 59.

sericeus I'ar, Esp. IOI.

serratus 5 .

secacens Wulf. 47 .

siliqvosus lin. 37 .

sinuosus Lin, 7 .

- r. Wahl. 8.

soboliferus $\mathrm{Fl}+\mathrm{d}+27+28$.

spermophorus Kün+ I4 • 59. spiralis Esp. 3*

spiralis Lin. 3.

spongiosus sec. Gerard, 202,

stellatus Ner, britl, 15.

subfuscus 7 , 47*

subolobosus \&ac, Gled, 200.

sulitilis T. 63 .

Tendo Esp. 73.

Tremella hemisph. Gm. I95.

- Nostoc Gm. I98.

- unbilic. Gin. 28.

- verrucosa Gm. I99.

tabulosus Lepech, 6I,

uniformis Esp. 43.

zesneoides Oed. 34 .

varialilis Good, 47 .

zerrucosus Ner, brill. 43 .

verticillatus lighef. 70 .

zerticillatus IVulf, I02,

vesiculosus 3 .

- $\beta_{+}$spiralis 3 .

- $\gamma$, inllatus 3 . 
Fucus

vesiculosus o. acutus 3 .

- $\varepsilon$. subecosiatus 3 .

vindicnus curt, Gumm, 55 .

viridis $1 . l, d .+4$.

villatis Tonn, 59.

Furcellaria

lumbricalis 48 .

- B. fastugiara 49.

b copodioide's $A$. 45 .

- rolunda 49.

Gasıridium

clivellosum 70 .

cylindricum 71 .

filiforme 68.

- B. incrassarum 68.

- \%. spongiforme 68.

- 8 , rugasum 68.

- $\varepsilon$, favuu 68.

haliforne 70 ,

Jubricum 7I.

Opuntia 71 .

ovale 72.

purpuriscens 69.

Gelidium

- B. caspitosum 69.

gigartinum 4 .

pinudtifium 40.

- $\beta$. angusım 40.

pygmaum $4 \mathrm{I}$.

Geniculn

oliscura I37.

Gigartina

pellucida 137 .

arliculata Lam. rox.

confervoiles 43 .

- P. procerrima 43.

- $\%$ plirata 43.

Fabriciana 48 .

Ingellifornits Lam, 5I,

Griffitlisia 43 .

kaliformis lam. 70.

lubica 45.

lycoporliniles 45.

pinastroides 45 .

pisillata Lam. t1.

plicara 42.

- P. simplicior 42.

- \% telunior 42.

purpurascens 46 .

- P. cirshosal 40 .

- \% rustrita 46.

- D. virescens 46 .

pjomrear lam. 41.

subfusca 47.

- P. racmosa 47.

- $\because$ tenuior 47 .

- Raccida 47.

riridis 44 .

Glojonema

chilionoplastes Ag. 92.

paradoxum to. 86. 212 .

Griffillesire corallina Ag. 126.

Givinuliua Bonduccella 60.
Haliders

nódosa 37.

- $\beta$. minor 37.

siliquos.d 37 .

- P. denudata 37.

Halymenir joeniculaceu $/ g .63$.

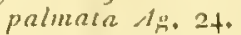

- ¿. simplex Ao. 25.

ramentacen $A g .6 \mathrm{I}$.

sobolifern $A g$. 27.

Hezly sarum ayrans 87.

Hlimantlualia lurea 19, 36.

Hippuris

cxigun \&cc. Pluk. 99.

setaceas Barrel. 63.

Hutchinsia

Aliusrula Ag. 123.

alrorubescens IIO.

budial II 4 .

lirolliei 109.

byssoides ilo.

cocrinea $A_{5}+124$.

elungnin $A g$. II

fastifiala Iog.

librillosa 113

implicata III,

inflexa Ay 63 .

lepadic ola II 3 .

Müstingii I 6 .

nigrescens I09.

stricta II5.

strictoides IIf.

urceolata I IO.

violicea II2.

- P. alluchroa II2.

- $\gamma$. squirrosa 112.

Hydrodictwou

majus K. 169.

peungonum t'nuch. 169.

cenclimi B. I 60 .

utriculatum 160.

Jungernanuia trichophylla 216.

Kolpoda 20I,

Laminaria

Agarum 24

bulluesa 20 .

digitata 20,

esculentit 23.

Fascilt dy. 28.

liguluen $\operatorname{Sg} .34$.

Phyllitis 23.

plameginca Ag. 3 I.

saccliaina $2 I$.

- P, bullata 2I.

- $\%$. latissima 22.

Lemanea

corallinu Bory 99.

fluviulilis Ag. 99 .

Lepra odoratn Wigu I64.

Leprariu Jolichas Acli. 163.

lichen

botrjoiles Ach. 206.

confinis Fl. d. $4 \mathrm{I}$.
Kichen

crustaceus sc. Hall. 205. crusterceus \&c. Mich. I6t Jolichus II ith, 163.

marinus Tabsru. 30 roseus $1 \%$, d. 207.

Jichinu PJ gnare As. AI.

Linckia

alra I95.

- $\beta$. viridis 195.

crrauicola 118.195.

dura 19 ?

- $\beta$. lutescens $197^{\circ}$

- $\%$ crustacea 107.

gramulata R. 200.

sraunlata THign. 78 .

hemispherica Schum. 195. Jiypuicola 197.

natans 196.

Nostoc R, 198.

pulustris \&re, Mich, I00.

pruniformis Wign, 200.

punctiformis 195.

ierrestris \&ec. Mich. I98.

verrucosa 1 igg. I99.

Zostera I04.

Lomentaria

articulata $10 \mathrm{I}$.

- B. icptans Ior.

Lüsningssiene 60.

Marleg $15 \mathrm{I}$.

Materia viridis Pristl. 224.

Mesogloja vermicularis 190 .

Mimesn seandens 60.

Muscus

aqualicus \&ce, Kyll. 169. cupillaceus \&ir. Bauh. I08. coinlloides \&c, J'luk. Io8. fugax \&c, Magnol, ig8. mariuks biarr. 108. marimus \&c. Banh. 104. marinus \&. Dodon. 104. mariuns \&e, lobel. Io4. marinus sc. Matrleiol. 30. mariuns \&s. Moris, I32. marius \&c. Mark. IO4.

Nodularia Auviatilis 99.

Nostoc

lotigoides $1 \mathrm{~g} .206$.

ciniflonum 'Tourn, 198.

coeruleum 20 r.

commune I98.

- $\beta$. carneum Igo.

Flos aqvae 201.

giganleum Mokr I08.

inurimum Ag. 193.

muscorum 200.

Paracelsi Geoffr. I98.

pruniforine 200.

splisericum 200.

verrucosum I99.

vulgare IValel. I98.

Odonthalia dentata 9. 
Ormestene 60.

Oscillatoria cerkginosa $A g .9 x$.

- B. violacea Ag. 9I. aestuarii $9 \mathrm{I}$.

- $\beta$. lotevirens 9J. Rtropurpurea Ag. 83 . autumnalis 95 . cbllionoplastes 92,169 . - $\beta$, vaginata 92, confervicola 94. Corium 89. decorticans 95. distorta 90.

Flos aqua Ag. 202.

fontinalis 90 .

Friesii Ag. 240.

laelevirens Hofin, $B, 9 \mathrm{r}$.

limosa 86.

majuscula $9 I_{+}$

mucor $A_{g} .94$.

muralis 95 .

nigra 87.

ochracea 89.

parietina Yauch, 95.

Princeps Trach. 86 .

Retzii $\beta$ sub/usca Ag* 88 . scopulomin 93 .

subfusca 88 .

- B. atra 88.

tenuis 88 .

torta 89.

vaginata Trach, 92.

viridis I'auch. 88 .

Zostericola 94.

PaImella

adnata 205 .

alpicola 206.

batryoides 205 .

cylindrica 205.

frondasa 204.

hyalina 204 .

Myosurus 203.

rosea 207.

rupestris 207 .

Parmelia velutina Ach, 162.

Pli) codendron 20.

Piscidia eryihrina 60 .

Plocamium

coccineum 39.

- $\beta$ subtile 39.

plumosum Lam. 38 .

vulgare Lam+ 39 .

Pallen Pini sjlvesiris 212.

Polysperma

fluviacilis Trauch, 99. glomerata Yauch. 154.

Prolifera

crispa T'ancli. I4I.

floccosa $V^{\prime}$ I38.

rivularis $T$. 142 .

Ptilota resicata $Y .140$.

plumosa 38 .

- $\quad$. asplenioides 38 .
Riccin

arachnoidea Fl. d. 77.

fluilans Fl. d. 192.

Rhizomorpha $5 \mathrm{I}$.

Rivularia

angulosa R. I96.

atra R. 195.

cornu Daince R. I9I.

cylindrica Hook. $7 \mathrm{I}$.

dura R. 197

elegars $R .192$.

elongata R. 192.

endiviafolia li. I9I.

fircicola R. I94.

multifida W. et M. $5 \mathrm{I}$.

pisiformis R. I92.

Zosterce Moler I94.

Rytiplulea pinasiroides Ag. 45 .

Sapangaursak I 58.

Saul (Söl) 25

Sclerotinm persicolor Sclum. 207.

Scyconema

atrovirens $A g .85$.

bangii 98 .

comoides 97 .

compactum 97.

Ho/manni Ä. 9S.

myoclirous 96 .

- $\beta$. inundatum 96.

- $\%$ simplex 96.

orellatum 97.

Scytosiphon

clatliratus 66.

- $\beta$. uncinatus 66.

compressus 64 .

- P. crispatus 64.

- $\gamma$. contervoideus 65 .

erectus $6 \tilde{5}$.

fistulosus 66 .

foeniculaceus 63 .

- $\beta$. intricalus 63.

- $\gamma$. membranaceus 63.

hippuroides 63 .

intestinalis 67 .

- $\beta$ crispus 67 .

- $\gamma$. cornucopiæ 67.

paradoxus Fl. d. 53 .

ramentaceus 61 .

tomentosus 62 .

velutinus 68 .

verrucosus 67 .

Sertularin spinosa Lin. 168.

Shyefald I 98.

Sütrcenüd 60 .

Sphacelaria

crespitula IO5. $_{5}$

disticha 104.

pennata 105 .

- P. gracilis 105.

plumosa I03

- $\beta$. divaricata 103.

reticulata 106 .

scoparia jo4.

scoparioides 107.

spinulosi 106.

Spleceria specics 49 .
Spliarococcus

bangii $A g .17$.

Brodixei II.

ciliatus 12.

- $\beta$. fuscus 13.

confervoides Afr. 43 .

coronipifolius Alg. 35 .

crispus Ag. I5.

cristatus 13.

- P. angustatus 13.

dentalus Ag. 9 .

Jaciniatus 12.

mamillosus 14.

membranifolius so.

- $\beta$. stellatus 10.

- $\%$ angustilulius Io.

morvegicus $A g .16$.

Jalmeta $1 x$.

- bifidus 12.

plicalus $A, \pi .42$.

purpurascens $A g+46$.

rubens Ag. 18.

spermophorus Ag. 59.

subfuscus Ag. 47 .

Sponoia ramosa \&e. Park, 202. Sporochuus aculeatus A A . Stereocnulon confine Aik, $4 \mathrm{I}$. Siwietenia Malnagoni Lin. 60 .

Tetraspora I.ink, 33 .

Thorea

Lehmanni 53.

ramosissima Bary 62.

Tremella

adnain Huds, 205.

nirovirens Schum, 200.

botryoides Schreb. 205.

difformis lin. J93.

fluviatilis \&c, Dillen. 199.

frondosa R. 204.

globulosa R. 197.

granulata Huds, 78.

Hemispharica Lin. 195.

intestinalis $\mathrm{F} . d_{*} 200$.

juniperina R, 207.

Mjosurns Fl, d. 203.

natans Hedis. 196.

Nostoc Lin. I98.

palmate Hedw' J9r.

palustris \&c. Dillen. I9I.

plicata \&ic. Strüm I98.

pruniformis R, 200 ,

Sabina Engl, bot. 207.

utriculata Hids, 196.

verrucosa Lin, 199.

verrucosa $R, 197$.

Troldsmör 198.

Tubercularia rosea Pers. 207.

Ulvả

articulatn Huds, ror.

bullosa Dec. $2 \mathrm{I}$

caprina Gunn. 25+

ciliata Dec. 13.

clailurata Ag. 66.

compressa lin, 64. 
Ulva

compressa B. purpurea Ag, 68 . crispa Dce. 15.

crispa Lighly. 32 .

cylindrica iVahl. $7 \mathrm{I}$.

delicacula Gurn. 25.

diaplana Huds. 202.

dichotoma 3 I.

digilala $D_{e \cdot c} 20$.

edulis 26.

Fascia 28.

fuliformis Huds. 68.

fisiulosa Huds 66.

flavescens Huds. 203.

foetida l'auch. 86.

furfuracea 32.

granulate $\%$ d. 78 .

incrassata Dec. 45.

intestinalis Lin. 67.

- B. R. 67.

Lactuca 30 .

- $\beta$. contorta 30.

- \%. Huds. 32 .

lanceolata Auct. 32 .

latissima lin. 22.

Linza 32.

longissima Fl. norv. 2I, lubrica R. ZI.

maxima fl. Horw. 22.

mesenteriformis $R .22$.

miniata 29.

montana Lighte. 206. olivacea Fl. d. 209. palmata 24.

- $\beta$. marginifera 25.

- $\gamma$. laciniata 25.

- $\delta$. simplex 25 .
Ulva

Plyllitis Dec. 23.

pisiformis Huds. 200,

plantaginifolia $3 \mathrm{I}$.

- $\beta$. temuior 31 .

plicata 30.

plumosa Huds. 75.

prolifera Fl. d. 65.

pruniformis Gunn. 36.

pruniformis Lirt. 200.

purpurascens Engl. Lot. 68.

purpurascens Huds. 69. purpurea 29.

- B. elongata 29.

- B. miniala As. 29.

$-\gamma$. unbilicalis $A_{0} .28$.

radicala Retz. 78.

reticulata Forsk. 24.

rubescens 27.

rubra Huds. $5 \mathrm{I}$.

saccharina Dec. 21.

sobolifera 27.

terrestris 32 .

$n$ mbilicalis 28 .

- B. purpuren FVal. 29.

uncinata Mlohr 66.

Uncrassil Sarpangei 158.

Urtica marina \&c. Bocc. 202.

Uiriculus matricalis 124.137.

Vaucheria

aquatica 79.

bursata dig. 76 .

crespitosa 8I.

clavata 78.

dichotoma 75 .

- B. submarina 76 .
Vaucheria

Dillwynii 77 .

geminata 80.

granulata 78 .

liamata 77 .

marina 79.

multicapsularis 82 .

ovata 76.

pusillat 79 .

racemosa $8 \mathbf{r}$.

radicata $1 \mathrm{~g}$. 78 .

sericea 78 .

sessilis 80 .

terrestris $7 ?$.

l'etteryre 60. 240.

Wasscr-Erlse Müll. 200.

Zonaria deusta 19.

Zygnema

bipunctatum 174.

- B. gracile I75.

- $\gamma$. unipunctatum 175 .

compressum 171 .

condensatum Ag. 174 .

cruciatum Ag. 175.

deciminum 172 .

genuflexum 170.

gracile Ag. 175.

inflatum $\mathrm{Ag}$. 174 .

littorcum I?I.

longatum Ag. 173.

nitidum $I_{72}$

pectinatum 175 .

- $\beta$. confluens 175. quininum 173 .

- $\beta$. porticale I73.

- $\gamma$. longatum 173 . 




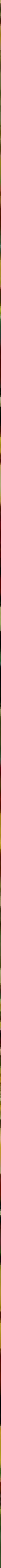



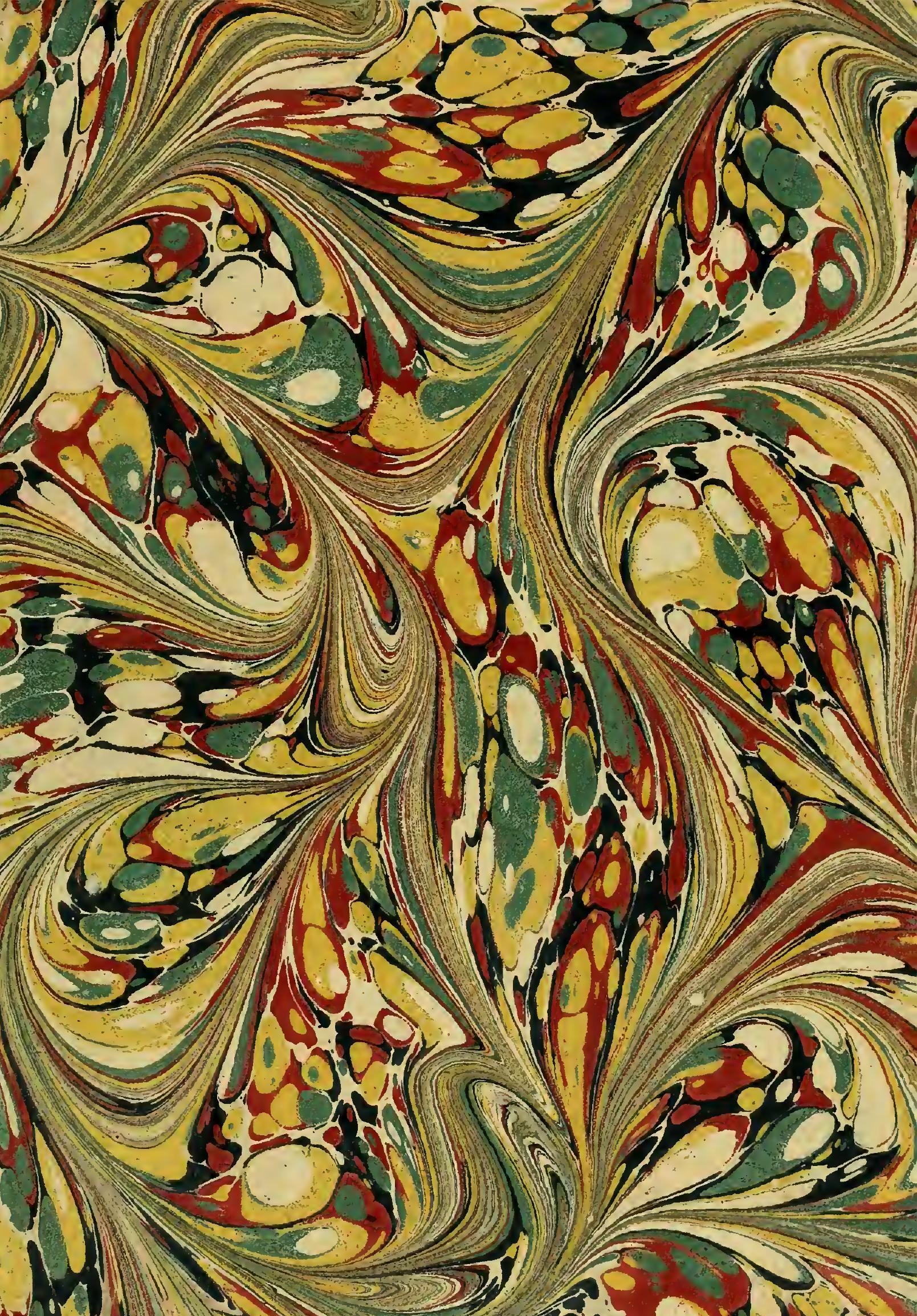
